\title{
Site Characterization Handbook
}

June 1988

\section{National Low-Level \\ Waste Management Program \\ EG\&G Idaho, Inc. Idaho Falls, Idaho 83415}

Work performed by

Golder Associates, Inc.

Redmond, Washington

and

Roy F. Weston, Inc.

Seattle, Washington

Prepared for EG\&G Idaho, Inc.

and the Department of Energy

Under DOE contract No. C-86-131159

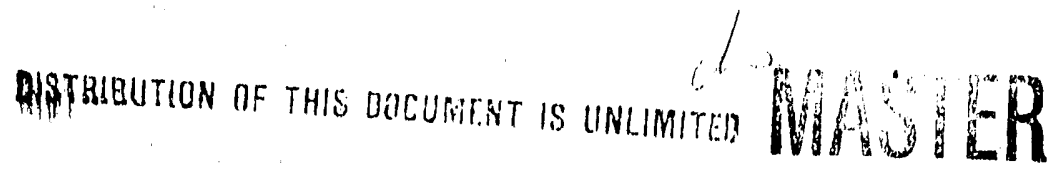




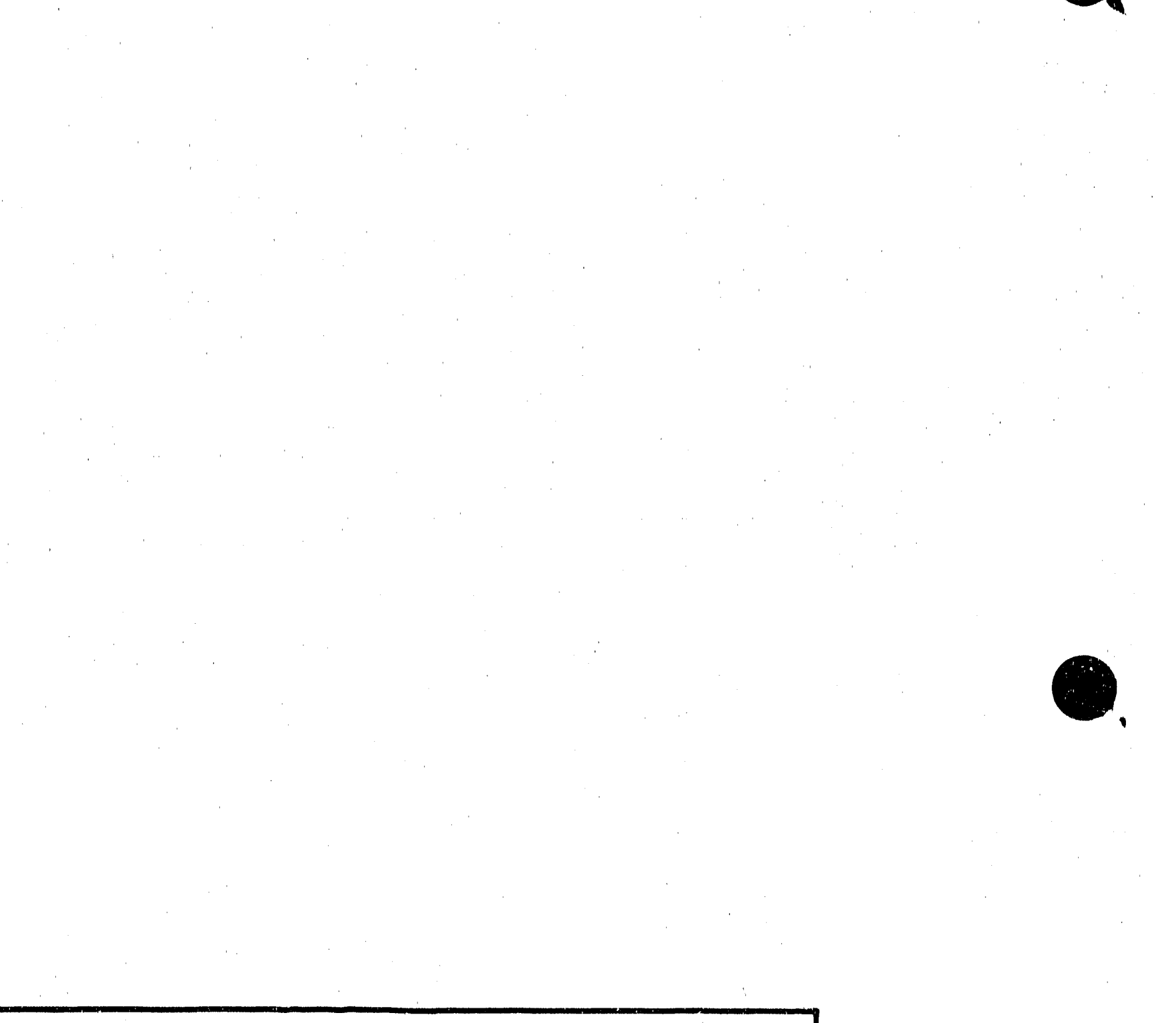

\section{DISCLAIMER}

This book was prepared as an account of work sponsored by an agency of the United States Government. Neither the United States Government nor any agency thereot, nor any of their employees, makes any warranty, express or implied, or assumes any legal liability or responsibility for the accuracy, completeness, or usefuiness of any information, apparatus, product or process disclosed, or represents that its use would not infringe privately owned rights. References herein to any specific commercial product, process, or service by trade name, trademark, manufacturer, of otherwise, does not necessarily constitute or imply its endorsement, ecommendation, or favoring by the United States Government or any agency thereof. The views and opinions of authors expressed herein do not necessarily state or reflect those of the United States Government or any agency thereof. 


\section{CONTENTS}

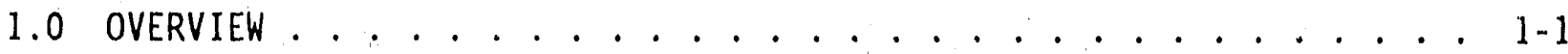

1.1 Introduction ....................1

1.2 Objective . . . . . . . . . . . . . . . . . . . . 1-2

1.3 Handbook Organization ................ 1-2

2.0 OBJECTIVES OF SITE CHARACTERIZATION . . . . . . . . . . . 2-1

3.0 SITE CHARACTERIZATION PROGRAM PLANNING ............. 3-1

3.1 Technical Planning . . . . . . . . . . . . . . 3-1

3.2 Project Management . . ............... . . 3-1

3.2.1 Work Scope Development . . . . . . . . . . . . 3-2

3.2.2 Establish Schedule .............. 3-6

3.2.3 Budgeting................ . . 3-11

3.2.4 Development of Project Controls . ......... 3-13

3.3 Characterization Strategies ............. 3-14

3.3.1 Early Verification of Parameters Important to Licensing 3-15

3.3.2 Focusing on Fatal Flaws ............ 3-15

3.3.3 Characterizing Multiple Sites ........... 3-15

3.3.4 Dividing the Program into Phases ......... . 3-16

3.3.5 Anticipating Potential Delays . . . . . . . . . 3-16

3.3.6 Preparing Specifications for Data Requirements . . . 3-16

3.3.7 Institutional Interfaces ............ 3-16

4.0 TECHNICAL DATA REQUIREMENTS AND ACTIVITIES

FOR SITE CHARACTERIZATION .................. 4-1

4.1 Introduction . . . . . . . . . . . . . . . . . . 4-1

4.2 Summary of Requirements and Activities
by Data Type . . . . . . . . . . . . . . 4-3

4.2.1 Geology .. . . . . . . . . . . . . . . 4-3

4.2.2 Ground-Water Hydrology ............. 4-. 4

4.2.3 Surface-Water Hydrology .............. . 4-6

4.2.4 Geochemistry/Hydrochemistry .. . . . . . . . . . 4-8

4.2.5 Water Resources .................. 4-9

4.2.6 Geologic/Timber/Agricultural Resources ....... . 4-10

4.2.7 Geotechnical Investigation ............. 4-11

4.2.8 Geography .. . . . . . . . . . . . . . 4-12

4.2.9 Demography .................. 4-13

4.2.10 Land Use ...................... 4-14

4.2.11 Meteorology ... . . . . . . . . . . . . . 4-14

4.2.12 Air Quality . . . . . . . . . . . . . . . 4-15

4.2.13 Radiological Assessment ............. . 4-16

4.2.14 Ecology................... . . 4-17

4.2.15 Socioeconomics . . . . . . . . . . . . . 4-18

4.2.16 Cultural Resources .. . . . . . . . . . . . 4-19

4.2.17 Transportation ............... . 4-19

4.2.18 Aesthetics ................. 4-20 
5.0 QUALITY ASSURANCE AND QUALITY CONTROL CONSIDERATIONS . . . . . . 5-1

5.1 Introduction and Definition of Quality Terminology . . . . . 5-1

5.2 Regulatory Background ................. 5-1

5.3 Basic QA Program Requirements . . . . . . . . . . . 5-1

5.3.1 Organization .............. . 5-2

5.3.2 QA Program .. . . . . . . . . . . . . 5-2

5.3.3 Design Controls ............... 5-3

5.3.4 Procurement Document Control . . . . . . . . . . 5-3

5.3.5 Instruction, Procedures, and Drawings ....... 5-3

5.3.6 Document Control ................ 5-4

5.3.7 Control of Purchased Material, Equipment and Services . 5-4

5.3.8 Identification and Control of Materials, Parts, and Components .............. . 5-4

5.3.9 Control of Processes ............. . 5-4

5.3.10 Inspection . . . . . . . . . . . . . . 5-5

5.3.11 Test Control . . . . . . . . . . . . . . . . . 5-5

5.3.12 Control of Measuring and Test Equipment . . . . . . 5-6

5.3.13 Handling, Storage, and Shipping........ . 5-6

5.3.14 Inspection, Test, and Operating Status . . . . . . 5-6

5.3.15 Nonconforming Materials, Parts, or Components . . . . 5-6

5.3.16 Corrective Action ..... . . . . . . . . . . 5-7

5.3.17 Quality Assurance Records . . . . . . . . . . . . . . . 5-7

5.3.18 Audits, Surveillance and Managerial Controls . . . . 5-7

5.4 Qualification of Data ........... . . . . . .

5.4.1 Review and Qualification of Published Data . . . 5-8

5.4.2 Gathering and Qualification of New Data...... . 5-8

6.0 REFERENCES CITED .................... 6-1 


\section{APPENDICES}

APPENDIX A Technical Parameters/Data Requirements Matrices

APPENDIX B Technical Activities/Study Methods Tables

APPENDIX $C$ Phasing of Site Characterization Activities

APPENDIX D Federal Data Sources 


\section{FIGURES}

1 Example of a General Site Characterization

Program Schedule Based on a Phased Approach .............. 3-3

2. Example of Work Breakdown Structure (WBS)

for Site Charaiterization .......................... 3-5

3 Site Characterization Logic Diagram ................. 3-7

4 Example of a Gantt Chart Showing Typical Tasks

Relevant to Ground-Water Model Development .............. 3-9

5 Example of a Dependency Diagram Showing

Activities Relevant to Ground-Water Model

Development

6 Example of a Critical Path Diagram Showing

Activities Relevant to Ground-Water Model

Development 


\subsection{OVERVIEW}

\subsection{Introduction}

The Low-Level Radioactive Waste Policy Amendments Act of 1985 (the Act) requires the Department of Energy (DOE) to provide technical assistance to "...those compact regions, host States and nonmember states determined by the Secretary to require assistance" in fulfilling their responsibility under the Act. I In accordance with the requirements of the Act, the "Site Characterization Handbook" was developed to assist host States in developing and implementing comprehensive site characterization programs to support the licensing of low-level radioactive waste (LLW) disposal facllities.

Site characterization is part of a continuum of activities to select a preferred site for licensing. It is preceded by efforts to select one or more candidate sites for detailed investigation. Those efforts are generally expected to rely on existing data, paper studies, and limited onsite reconnaissance work, as discussed in DOE/LLW-64T, Site Selection HandbookWorkshop on Site Selection for Low-Level Radioactive Waste Disposal acilities. ${ }^{2}$ Detailed investigations will then be conducted at each candidate site during site characterization to verify site conditions, to support or confirm the selection of a preferred site for licensing, and to provide information required for licensing of a disposal facility at that site. The precise point on the continuum where site characterization officially begins may vary from one State's approach to another's, as discussed in Section 3.3. However, a common assumption under all approaches is that it cannot begin in earnest until site access has been granted and a reasonable degree of community willingness to let characterization commence has been achieved.

Site characterization activities comprise one of the most important steps in preparing a disposal facility license application and are critical elements in the schedule to meet the following milestones set forth in the Act:

January 1, 1990

- Complete license application Filed, or

- State certifies to the NRC that it will provide for LLW storage, disposal, or management, and describes actions to be taken.

January 1, 1992

- Complete licerse application filed.

This Handbook discusses both management and technical elements that should be considered in developing a comprehensive site characterization program. Management elements typical of any project of a comparable magnitude and complexity are combined with a discussion of strategies specific to site characterization. Information specific to the technical elements involved in site characterization is based on guidance published by the Nuclear Regulatory 
Commission (NRC) with respect to licensing requirements for LLW disposal facilities.

The Handbook is intended to supplement the site Characterization Field Manual for Near Surface Geologic Disposal of Low-Level Radioactive Waste ${ }^{3}$, prepared for the National Low-Level Waste Management Program by the University of Arizona, to reflect the large body of regulatory guidance issued by the U.S. Nuclear Regulatory Commission since the publication of that manual.

\subsection{Objective}

The objective of this Handbook is to provide a reference for both NRC Agreement States and non-Agreement States for use in developing a comprehensive site characterization program that meets the specific objectives of the State and/or site developer/licensee. Each site characterization program will vary depending on the objectives, licensing requirements, schedules/budgets, physical characteristics of the site, proposed facility design, and the specific concerns raised by government agencies and the public. Therefore, the Handbook is not a prescriptive guide to site characterization.

\subsection{Handbook Organization}

The following four sections of the Handbook discuss objectives of a site characterization program, management planning and technical strategies, a summary of data required to support the license application and activities for collecting the necessary data, and elements of a quality assurance/quality control program.

Appendix A describes the technical data types and parameters necessary during site characterization that were identified as a result of an analysis of the NRC LLW disposal regulatory requirements and guidance. This appendix consists of eighteen matrices based on the major disciplines or data types involved in a site characterization program. Each matrix contains quotations from NRC guidance documents relevant to each specific data type. Each data type is further divided into a number of specific elements or technical parameters that are fully described on the matrix attachments. The technical parameters that are explicitly or implicitly referenced in the NRC guidance documents are identified. These matrices can be used to help identify the data and analyses required to comply with requirements for the Safety Analysis Report (SAR) and Environmental Report (ER), which together comprise the facility license application.

Appendix $B$ consists of eighteen tables that are also broken down into the technical parameters for each data type. For each technical parameter, ihe tables identify technical activities and study methods that can be used to collect and/or analyze the required data, typical formats or types of data, sources for acquiring data, and selected references that provide detailed information related to the required technical activities and study methods. 
Appendix $C$ describes typical field activities that can be carried out during a three-phased site characterization program designed to increase the level of detail and confidence in a site. Appendix D lists the addresses for the Federal data sources included in Appendix B. 


\subsection{OBJECTIVES OF SITE CHARACTERIZATION}

A site characterization program is one of the primary components in the development of a license application for a LLW disposal facility. Site characterization is defined by the NRC as:

"...the program of investigations and tests, both in the field and laboratory, undertaken to define the site characteristics affecting the isolation of the low-level radioactive wastes, the long-term stabllity of the disposal syte, and the interactions between the disposal site and its surrouridings."

The NRC states that the overall objective of site characterization is:

"...to investigate the characteristics of the preferred disposal site to the extent needed to 1) support a license application and environmental report, and 2) permit an independent evaluation of the proposed nearsurface disposal facility by the staff. "4

The NRC further states that:

"Specific objectives of site characterization are to develop the technical information needed for:

1. Demonstration that the performance objectives and the minimum technical requirements on site suitability will be net;

2. Evaluation of the ability of the site characteristics to contribute to isolation of the low-level radioactive wastes;

3. Design of the near-surface disposal facility;

4. Identification of interactions between the site characteristics and the low-level radioactive waste and waste containers;

5. Establishment of data collection points and a baseline of data for some portions of the site monitoring program; and

6. Identification of potential environmental impicts resulting from construction, operation, and closure of the near-surface disposal facility."

States that have achleved Agreement State status with the NRC may have developed technical objectives that are specific to their state regulatory requirements. It is assumed, however, for the purposes of this document, that since Agreement State regulations are based on Title 10 Code of Federal Regulations Part 61 (10 CFR 61), "Licensing Requirements for Land Disposal of Radioactive Waste," 5 the technical objectives of the Agreement States are comparable to those contained in that regulation. 


\subsection{SITE CHARACTERIZATION PROGRAM PLANNING}

As stated in Section 2, one overall objective of site characterization is to provide the information necessary to develop the Safety Analysis Report and Environmental Report, which together comprise the facilicy license application. Considering that these reports will be reviewed within the context of 10 CFR 61 or State regulations equivalent to this Federal regulation, 10 CFR 61 has been used in this handbook to establish the specific technical requirements for site characterization. These requirements are addressed in Appendix A.

With the regulatory requirements as a guide, the technical elements of a site characterization plan may be defined. Once defined, the various elements can be managed according to typical project management concepts and consistent with factors that may be unique to a particular State's iicensing program. Regardless of variations between programs, all site characterization plans should consider certain strategies to ensure achieving the technical and management objectives of the programs. The following sections address these topics under the following headings: Technical Planning, Project Management, and Characterization Strategies. Taken together these topics comprise the primary bases for planning and managing a site characterization program.

\subsection{Technical Planning}

Eighteer technical data types are identified in Appendix $A$ as relevant to determining whether a site ineets the requirements of 10 CFR 61 . By analyzing each of these eighteen data types for the technical parameters that are necessary to ensure site performance, it is possible to determine which technical activities/study methods (Appendix B) may be performed to characterize the site. These technical activities, specified in terms of compliance with regulatory requirements and with associated confidence levels, define the technical plan objectives of the characterization program. The technical requirements (Appendix $A$ ) and the types of technical activities/study methods that can be used to collect and analyze the required data (Appendix B) are summarized in Section 4.

\subsection{Project Management}

After the objectives of the project have been defined, the activities necessary to meet these objectives must be divided into their component parts (tasks) and organized into a logical and systematic framework. This is the task of project management, which integrates technical requirements, schedule constraints, and budgetary considerations. The following discussion provides a generalized guide to the steps in creating a site characterization plan and managing the site characterization process.

There are four basic steps required for creating a site characterization plan: 1) developing a work scope, 2) establishing a schedule, 3) developing a budget, and 4) developing project controls. 


\subsubsection{Work Scope Development}

The first step in site characterization planning is the development of the work scope. The work scope is a management document that defines the full range of tasks for characterization and organizes them into a framework for planning, monitoring, and controlling the work. The four elements of a work scope are: 1) identifying project constraints, 2) identifying tasks and milestones, 3) organizing the tasks, and 4) developing task descriptions. Portions of the work scope, such as the task descriptions, can be incorporated into the Site Characterization Plan (SCP), which is a separate document recommended by the NRC as a working program guide for their review and comment.

3.2.1.1 Identifying Project Constraints. Based on technical, schedule, and financial requirements, characterization programs may have constraints that should be evaluated during the development of the work scope. An example of a technical constraint could be site subsurface conditions that preclude or limit the use of certain exploratory techniques. Overall schedule objectives (e.g., final date for a complete license application) can produce constraints on the length and scope of the characterization program. In addition, the costs of characterization studies can constrain the number of sites that can receive a complete field investigation.

3.2.1.2 Identifying Tasks and Milestones. The development of the work scope begins with the identification of:

- all tasks required to collect, analyze, and present data in support of interim reports and the license application

- all logistical tasks required to support the field studies (permits, access, etc.)

o all important optional program activities (communication with outside groups)

- all milestones for deliverable products and decision points.

Identification of technical tasks will be derived primarily from NRC or State regulatory requirements. The task list on Figure 1 , based on NRC requirements, shows technical and logistical task, that are typical of a site characterization program. Further breakdown of these tasks into subtasks of subsequent levels of detail will depend upon specific objectives of the site characterization program and conditions at the sites. This list was developed for use in the project management examples which follow. 


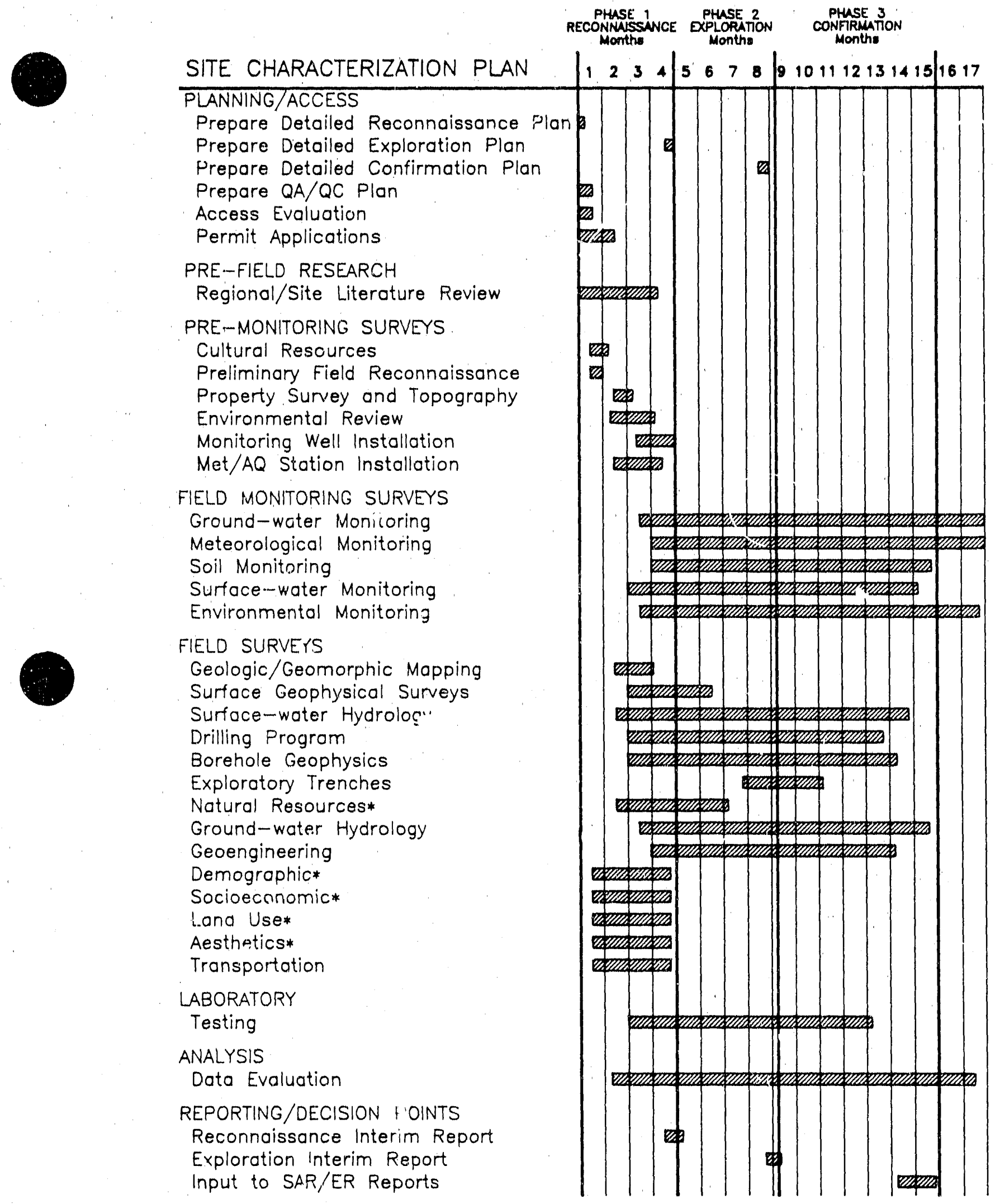

* Tasks that can be performed in one or more phases, depending on local or site-specific conditions.

Figure 1. Example of a general site characterization program schedule based on a phased approach. 
3.2.1.3 Organizing the Tasks. There are numerous ways to effectively organize tasks based on the complexity of the project, the technical objectives, and the technical requirements. For example, depending on the specific requirements, a project can be organized by development phase, by departmental responsibility, or by cost account. Techniques such as work breakdown structure (WBS) permit such flexibility in organizing project tasks and are commonly employed for large investigations. The WBS provides a visual breakdown of the tasks identified in the workscope and provides a system for organizing tasks into subsequent levels of detail. Figure 2 shows a partial WBS based on the task list used in Figure 1. The advantage of the WBS is that it permits the project tasks to be defined in terms of the project priorities and at the appropriate level of detail.

Because characterization focuses on confirming a suitable site using progressively detailed investigations, one of the most direct methods of organizing site characterization tasks is by development phases. Figure 1 shows one example of how phases can be useful for dividing the characterization program into levels of detail such as Reconnaissance, Exploration, and Confirmation phases. In this example, phases are defined by certain decision points or milestones (interim reports) that reflect an increasing level of knowledge and confidence in the site. The sequence of typical activities within each of these phases is described further in Appendix $C$. The utility of each phase is discussed below.

- Phase 1, Reconnaissance, is designed to quickly and economically assess the site for fatal flaw characteristics that would disqualify a site, to develop the basic parameters for the geologic model, to begin the hydrologic and meteorologic characterization and monitoring program, and, if necessary, to permit the identification of a smaller area for the later investigation phases. Phase 1 also develops an extensive data base on the site and region from published and unpublished sources. The combined results of Phase 1 become the bas is for planning the details for Phase 2 activities.

- Phase 2, Exploration, will only proceed if the site has no obvious fatal flaws. Phase 2 comprises a more comprehensive subsurface investigation designed to expand the understanding of the geologic and hydrologic activities, focus on investigating anomalous conditions revealed in Phase 1, add to the density of subsurface investigation in a selected area of the site (identifying and partially investigating a facility location), and conducting field and laboratory testing.

0 Phase 3, Confirmation, completes the field investigation program by increasing the density of subsurface information (especially at a facility location), performing the analytical and rumerical modeling, and completing the testing required to determine site parameters important to analyzing site performance objectives. Phase 3 also establishes the requirements for long-term monitoring for the hydrologic program. Phase 3 usually concludes with the preparation of technical reports for input to design and licensing documents. 


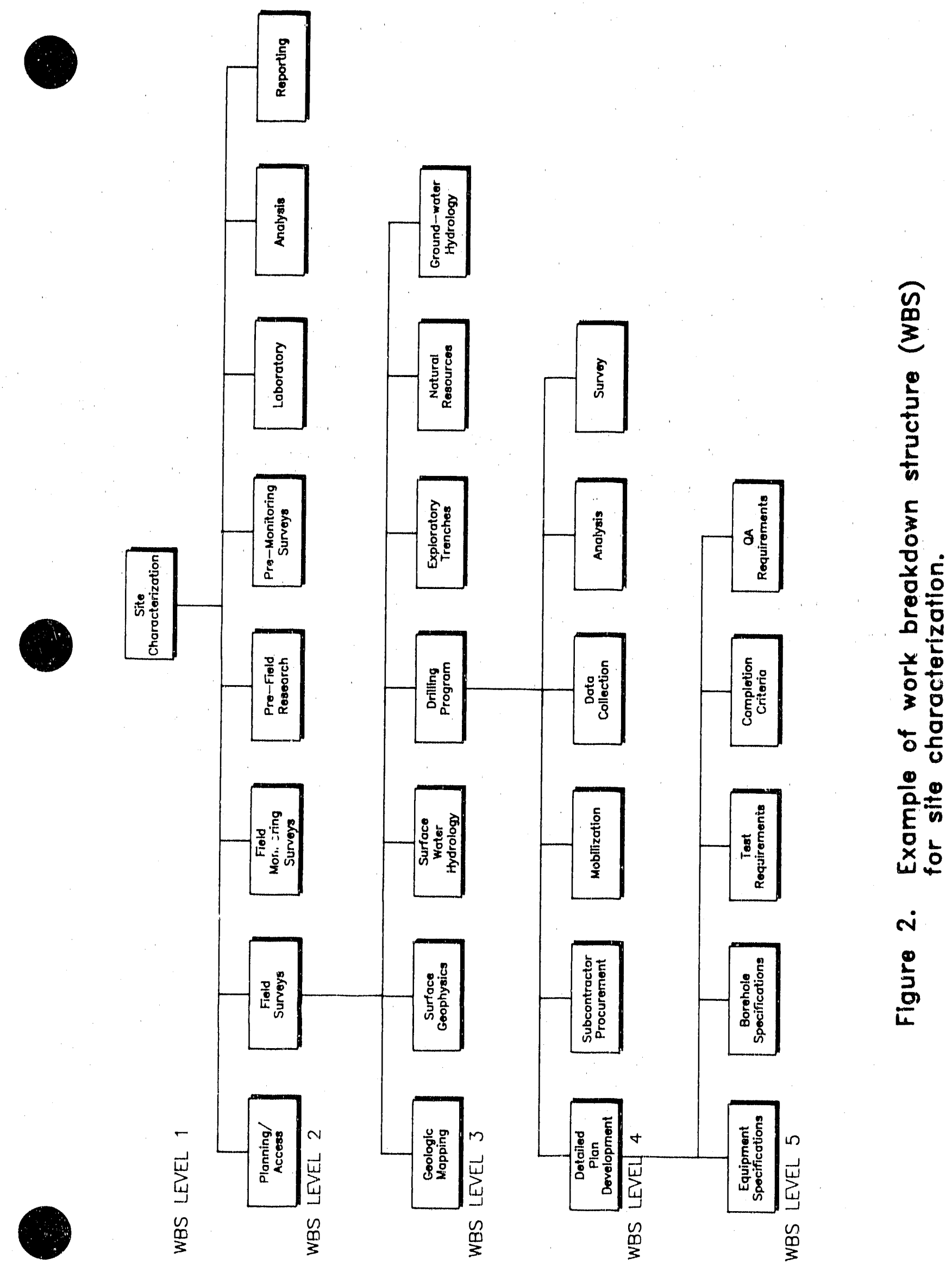


3.2.1.4 Developing Task Descriptions. Each of the tasks defined in the workscope should be fully described. Ty, ically, this information will be incorporated into a site characterization plan (SCP) which will be a working program guide. The content of the SCP and the format of the descriptions may vary, but the tajk descriptions should generaliy include the following:

- technical discussions of the task scope and objectives (including end products, such as data reports, decisions, etc.)

- applicable data bases, tests, and regulatory criteria

0 accuracy and precision requirements

0 use of computer models

- data management and presentation requirements

o equipment requirements.

\subsubsection{Esizblish Schedule}

The second step in the planning process is the development of the program schedule. Scheduling places the detailed tasks into their proper timeframe. The objective of proper scheduling is to develop a realistic, acceptable fit between the time requirements for completion of technical tasks and the constraints imposed by the project milestones.

The development of the program schedule is done by developing logic diagrams, determining dependency relationships, estimating task durations, determining critical path relations, and tailoring the schedule to time constraints.

3.2.2.1 Preparing Logic Diagrams. Logic diagrams define the overall processes that will be followed by the characterization program and outline the flow of information that will be used in the decision points or milestones. Logic diagrams are not mandatory, but they are a useful technique for clearly laying out the project objectives and processes. Figure 3 shows a logic diagram for the example characterization program used in this handbook.

3.2.2.2 Determining Dependency Relationships. After the overall logic of the program has been defined, each of the tasks must be analyzed in terms of its relationship with the other tasks. Clear relationships and dependencies must be identified between tasks, such as:

0 what must irecede each task

o what must follow each task

o what can occur parallel with each task. 


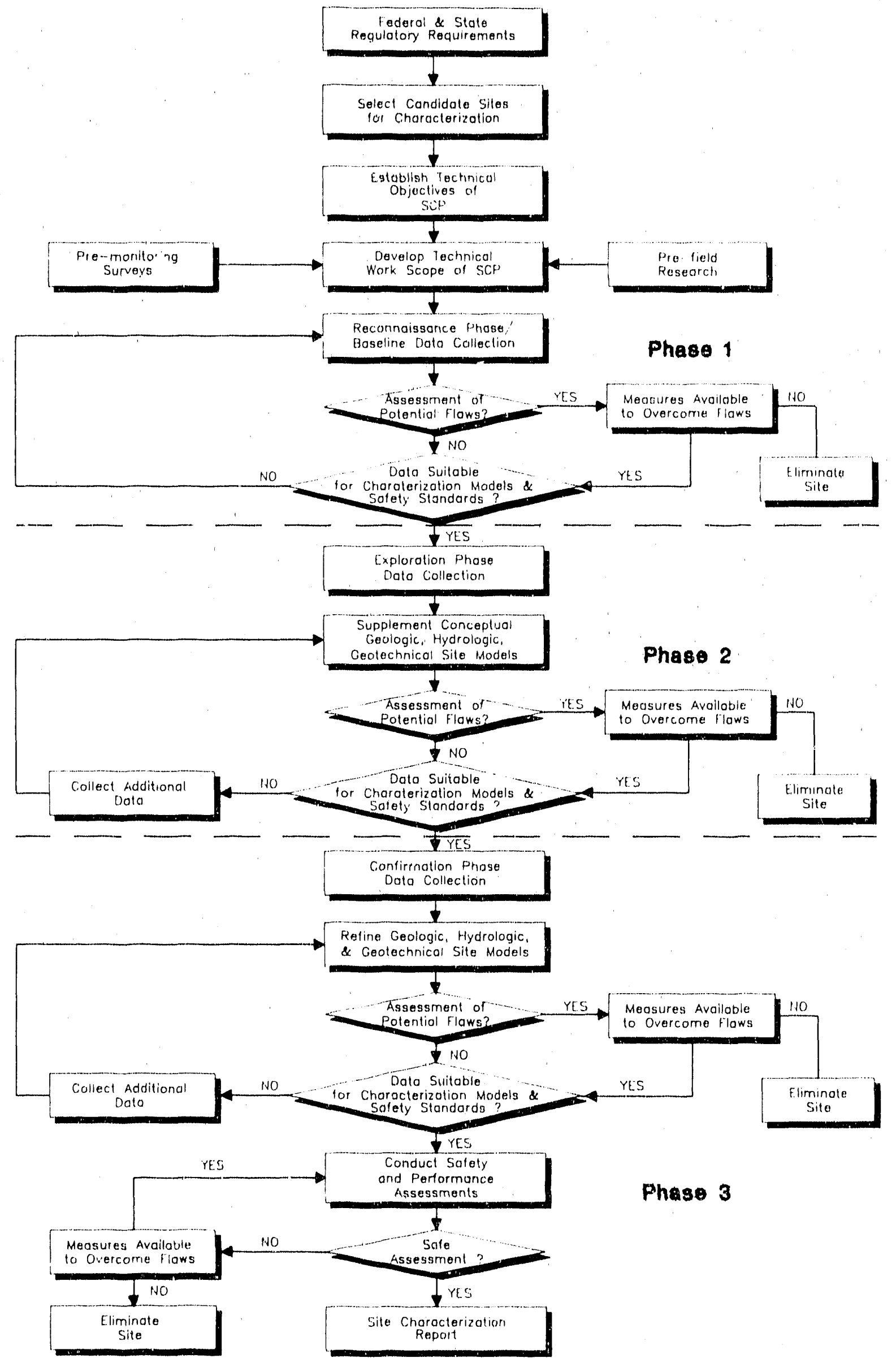

Figure 3. Site characterization logic diagram. 
Figures 4 and 5 are examples of graphical depictions of the dependency relationships between selected tasks in support of the development of a ground-water model. Figure 4 shows the task start and end dates, the overall task duration, and the tasks that are critical to meeting the schedule. Figure 5 shows the interdependency of these tasks, which is prerequisite to determining critical path relations. As shown in Figure 5, field activities such as geologic mapping, surface geophysics, and monitoring well installation cannot begin until all prerequisite pre-field activities have been carried out; however, activities such as field research are independent of the prefield surveys, and can be ongoing during both pre-field and field activities, as demonstrated in Figure 4.

3.2.2.3 Estimating Durations. The duration of each task should be established independently of other tasks so that a realistic estimate can be made. The task duration should include consideration of the planning, data collection, and technical analysis/reporting requirements. Durations may also depend upon resource usage assumptions (i.e., two people for one week). Assumptions should always be documented.

3.2.2.4 Determining Critical Path Relations. After the logical dependencies of the tasks and the estimated durations have been determined, the tasks can be arranged into a preliminary schedule and compared with the program milestones and overall time constraints. Ranges of estimated start and stop dates (earliest and latest) are determined for each task, and the maximum and minimum durations are calculated. The critical path of the program is the path through the dependency diagram along which the cumulative project duration is the longest. The tasks that control the schedule are the critical tasks because a delay in any of them not only affects completion of all tasks that follow, but also affects completion of the project as a whole. critical path calculations are commonly developed mathematically using project management computer programs.

In a few instances, such as the requirements for ground-water and meteorological monitoring, the data gathering for the baseline studies requires a one-year minimum. This long lead time may nearly equal the time required for the entire site characterization investigation. Therefore, the tasks prerequisite to actual monitoring, such as well drilling, logging, and installation of equipment, may represent a special critical path relationship to the program, and the start of these activities should have a very high priority in the schedule.

Scheduling of characterization studies at multiple sites can place additional constraints on the critical path, especially if there are: 1) limited resources with which to complete the multiple investigations, or 2) very close schedules between the completion dates for the sites. 


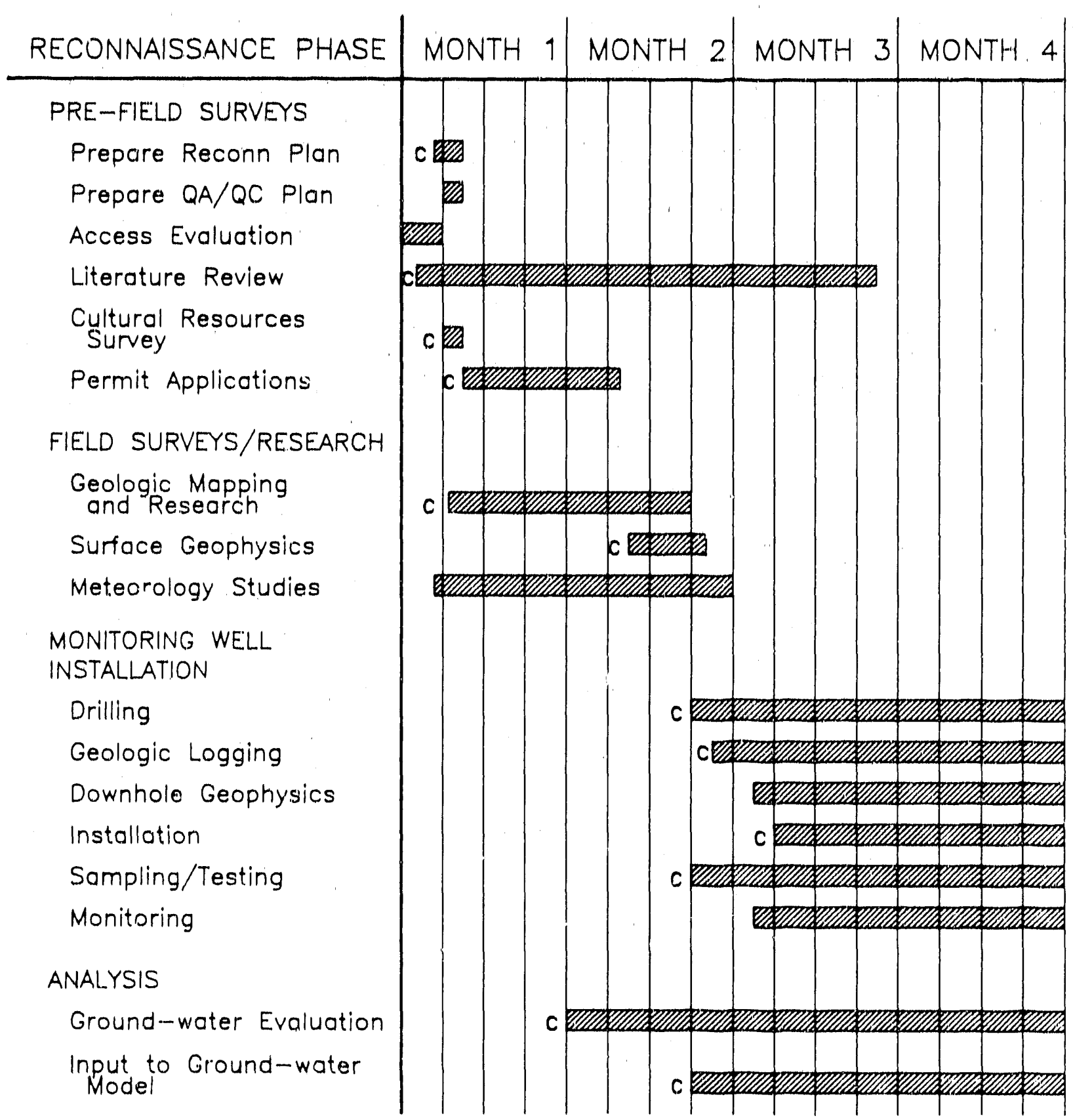

Notes: 1. C identifies the activity as critical to meeting the schedule.

2. See Figure 1 for complete site characterization schedule

Figure 4. Example of a Gantt chart showing typical tasks relevant to ground-water model development. 
PRE-FIELD SURVEYS

Prepare Reconn Plan

Prepare QA/QC Plan

Access Evaluation

Literature Review

Cultural Resources

Permit Applications

FIELD SURVEYS/RESEARCH

Geologic Mapping

Surface Geophysics/

Geochemistry

Meteorology Studies

MONITORING WELL

INSTALLATION

Drilling

Geologic Logging

Downhole Geophysics

Installation

Sampling/Testing

Monitoring

ANALYSIS

Ground-water Evaluation

Input to Ground-water Model

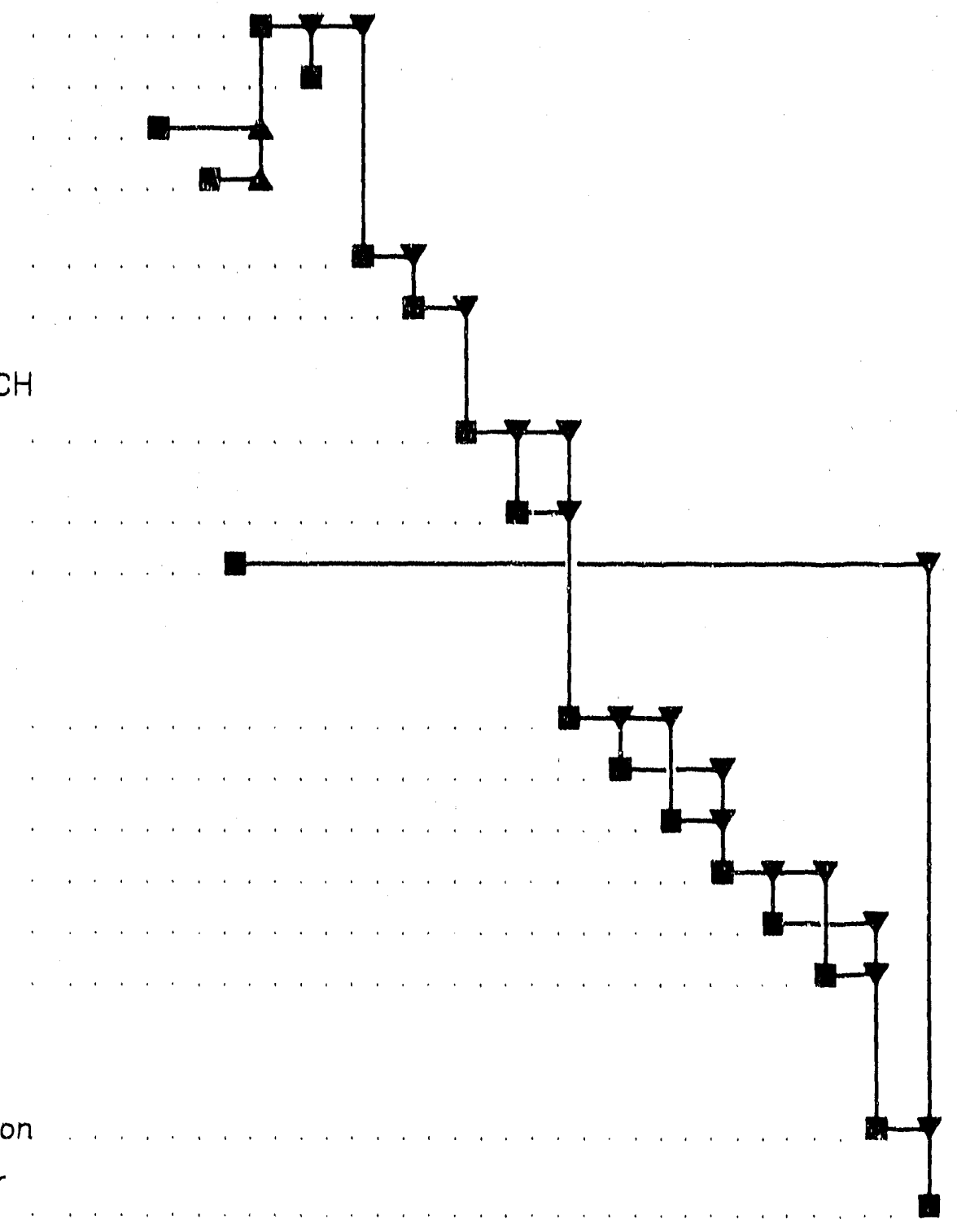

EXPIANATION

$\nabla$ - Direction of dependence

- - Source or destination of dependency

- Dependency connection

Figure 5. Example of a dependency dlagram showing activities relevant to ground-water model development. 
Figure 6 shows an example of the critical path for the typical tasks supporting the development of the ground-water mode1. This is an example of one of the several types of computer-generated diagrams that can be used to show critical path relationships. It is important to note that the critical path tasks may change as the program progresses.

3.2.2.5 falloring the Schedule to Overall Time Constraints. Commonly, preliminary schedules do not satisfy the overall time constraints of the program. This requites reanalyzing the time requitrements and dependency relationships of all tasks and evaluating alternate schemes for saving time. The most commonly used techniques for shortening the schedule are the following:

- adding more resources to certain critical path activities; for example, more drill rigs and staff may be added to the drilling task to complete it sooner

- conducting more tasks simultaneously

o reducing or delaying the amount of information required at a selected milestone."

\section{2 .3 Budgeting}

The third step in site characterization planning is the development of the budget. Estimates of costs for the proposed program are closely related to the detalls of the work scope, schedule, number of sites urider consideration, amount of avallable resources, and the site characterisitics. The elements that must be considered in developing and reviewing a budget include allocating adequate resources, optinizing the cost effectiveness of the field program, and checking the costs for realism.

3.2.3.1 Allocating Resources. The 1ist of resources required for site characterization will depend on the exact nature of the program; however, the typical requirements for the examples in this handbook may include the following:

- Personnel - this category will include the professional staff for conducting the surveys and analysis of the data, in addition to the support staff required for logistical and legal activities, public relations, obtaining right-of-way, laboratory analyses, and general labor activities.

- Equipment subcontractors - this category will include spectalized services for drflling, geophysical surveys, trenching, road butlaing, and special laboratory analys is. 


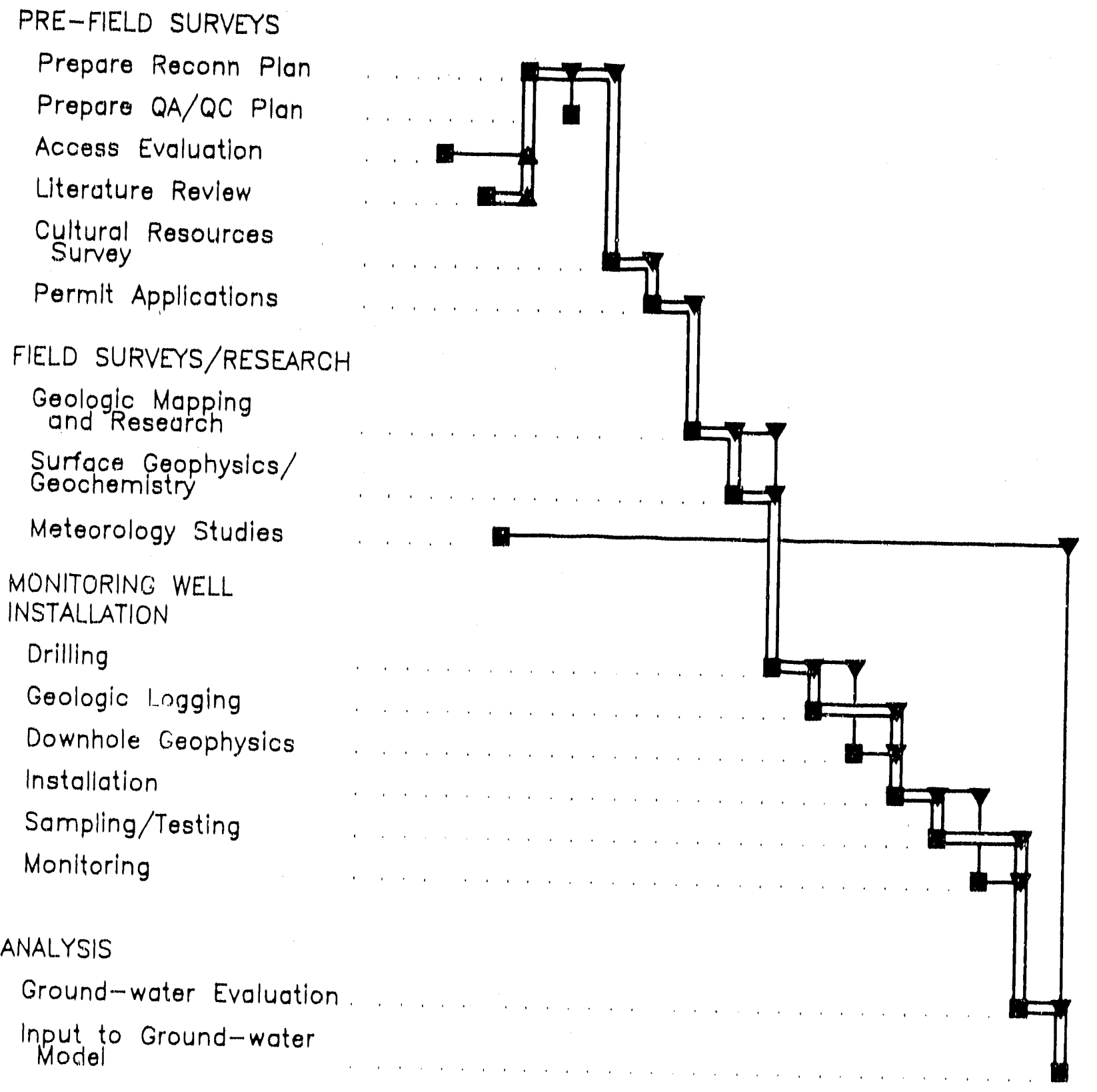

\section{EXPLANATION}

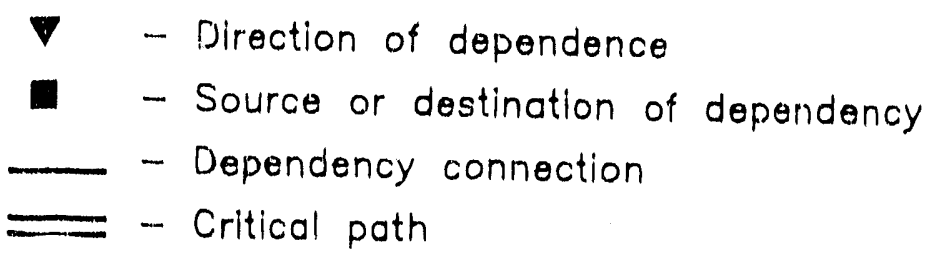

Flgure 6. Example of a critical path diagram showing activities relevant to ground-water model development. 
- Capital Purchases - long-term monttoring systems will probably be the largest capital equipment expenditure for the site characterization program. These will include systems for collecting meteorological, ground-water, surface-water, and geochemical/hydrochemical data.

- Expenses - direct expenses for program expenditures and purchases may be large (e.g., travel expenses, per diem, etc.), depending on the proximity of the work force to the site and the amount of support for the work force during site characterization studies.

3.2.3.2 Optimizing the Cost Effectiveness of the Field Program. Certain field investigations, such as drilling programs, will be used by a number of different disciplines as important sources of site specific data. As a result, field investigations must be carefully planned to 1) collect the data required for all appropriate disciplines and 2) maximize the use of all planned field investigations (borings, etc.), as potential sources of data for any appropriate discipline. The objective is to optimize the investigation costs by maximizing the yield of data from all the planned field investigative techniques (drllling, geophysics, trenching, etc.).

3.2.3.3 Checking Costs for Realism. Budgets for characterization studies are often complex and may have been developed by different groups using various costing assumptions. As a result, budgets that are submitted for review should be closely checked for the realism of the cost estimates. The most effective technique for determining realism is to obtain independent opintons from reliable sources. Potential sources may incilude State agencies familiar with costs and time requirements for performing the activities, private consultants or organizations, professional associations that publish salary data bases and price ranges for professional services, and comparisons of competitive proposals.

\subsubsection{Development of Project Controls}

The fourth step in site characterization planning is the development of project controls. After the baseline costs and schedule are established, a system must be organized to track and report the appropriate information about cost and progress on a periodic and timely basis. The updated cost and schedule information is used to evaluate the progress of the project and to determine any necessary adjustments to the level of effort.

3.2.4.1 Orqanizing Program Control. Control of the charactertzation program relies on the periodic and timely receipt of accurate information by the managers relevant to the technical progress and associated costs of the investigation. Since the most accurate cost/progress information is available from the personnel and contractors carrying out the work, a system must be organized that quickly gathers actual and accrued costs, preferably directly from the field. To maintain control, the frequency of reporting from the fleld to the program manager can vary from every day during times of intense 
activity to about every week during relatively slow perlods. The field reports are usually summarized by the program manager on a weekly or monthly basis tnto a more conctse document for distribution to the client or other interested groups.

3.2.4.2 Iracking Progress. Tracking of cost and schedule is a regular and frequent function of project control. Tracking the progress of the program cost and schedule requires that:

o there are master baseltne budgets and schedules for compartson, and

- the tasks contain the type of work that can be measured in terms of the amount of progress (for example, drilling can be broken down into how may feet per day are expected).

In instances where the task may contain the type of work that cannot be readily measured (e.g., researching baseline data), qualitiative estimates of completion are often used. As stated in 3.2.5.1, the frequency of task tracking will vary depending on the nature of the task 11.e., a task on the critical path might require more aitention) and the revel of effort being expended (i.e., more expensive tasks can overrun the budget within short pertods).

3.2.4.3 Evaluating/Adjusting the Schedule. As the field investigation progresses, the cost and schedule should be evaluated against the original program plan and adjustments should be made either to maintain the budget or to preserve the schedule. The tracking information can be compared to the haseline data and evaluated in terms of:

- the actual costs for a task compared to the scheduled costs for the same performance period

o the actual progress for a task compared to the scheduled progress for the same performance period

o the schedule and cost comparisons are evaluated to determine if the progress has been in proportion to the cost and the technical plan

0 the managers must then make estimates of the level of effort to complete each task.

The level of effort for any task can then be adjusted to either step up the schedule or meet the budget.

\subsection{Characterization Strategies}

In implementing a site characterization program, there are a number of strategies that should be considered to ensure the achievement of the technical and management goals of the program. The following section 
describes some of those strategies. The potential contribution of each should be analyzed early in the program and should be implemented at the appropriate time.

\subsubsection{Early Verffication of Parameters Important to Licensing}

Any evaluation made during the site selection process that may have a critical influence on licensing should be confirmed with a high degree of confidence as early as posstble in the characterization program. This may entail collecting certain site-specific (in particular, subsurface) data early in the profect. Under certain State approaches, such early data collection activities may be zn essential part of selecting the sites to be subjected to a full site investigation, particularly if existing data for critical parameters are either lacking or highly uncertain. Other State anoroaches may use the early vertfication strategy to narrow the number of sites for which the remaining characterizat ion ctudies will be completed and to "bank" the other sites. This latter approach may be necessary where limited financial resources require focussing on the most promising sites.

\subsubsection{Focusing on Fatal Flaws}

Because site characterization is time consuming and expensive, the technical investigation should focus as early as possible on revealing any "fatal flaws" (i.e., conditions that would prohibit licensing of a disposal faclitty at that site). This will minimize the amount of time lost and money wasted if it is necessary to start over with another site. Initial fatal flaw studies could be part of the selection of one or more candidate sites for characterization under some state approaches, whereas in other State approaches the early phases of characterization would immediately investigate any potential problems revealed during the selection process, preliminary research, or ground reconnaissance tasks. The studies to be performed will vary depending on the characteristics of the site. Moreover, it will be important throughout the site characterization program to be alert for potential fatal flaws, to quickly investigate any that are identified, and to anticipate how to respond if any of these are determined to be significant problems.

\subsubsection{Characterizing Multiple Sites}

To maximize the chances of finding at least one lifensable site within an established time period, many states are planning to characterize several sites. In some cases, this means full characterization of more than one site to support the final selection of a preferred site for licensing and to provide a reserve of alternative or backup sites. In other cases, only limited investigations of sites other than the initially preferred site will be carried out under the assumption that this preferred site will most likely prove to be licensable. However, even in this latter case, each of the alternative sites should have 1) a baseline monitoring program underway to avoid restarting the long lead time activities, and 2) some minimum level of 
site-specific information on which to characterize them and confirm their priority status.

\subsubsection{Dividing the Program into Phases}

It may be useful to divide the site characterization program into phases or to otherwise identify milestones for major deciston points regarding the technical suitability of the site. Several important purposes for developing phases and/or milestones are to: 1) force an integration of the technical data at various stages of the characterization program, 2) develop preliminary conclusions on the outcome and trends of the technical program, 3) assess the level of confidence in site sultability consistent with the completeness of the program, and 4) search for fatal flaws. The number of divisions or milestones within the program can be tallored to the individual site investigation. This type of strategy is discussed further in Section 3.2.1.3.

\subsubsection{Anticipating Potential Delays}

Potential delays should be evaluated for all significant tasks, and contingency plans should be developed to ensure that tasks progress on schedule. Examples of tasks or data that may be subject to delays include: 1) field input parameters to site computer models, 2) site permits and access, and 3 ) baseline monttoring of ground water and meteorology.

\subsubsection{Preparing Specifications for Data Requirements}

Prior to starting the investigation, each of the tasks should be evaluated to determine how much data needs to be collected. Each of the technical activities should be analyzed relevant to:

0 the amount of data required from each field technique

0 the accuracy and precision requirements

0 the required confidence level.

This planning will establish the specifications of the field data requirements and will minimize the possibility of gathering too little or too much data.

\subsubsection{Institutional interfaces}

An effective site characterization program should include coordination with the NRC or Agreement State regulatory agency by means of regularly scheduled briefings, informal communications, and requests for informal guidance. Depending on the nature of a specific State's LLW siting legislation and site-specific conditions, it may also be necessary and/or prudent to involve various Federal, State, and local resource management agencies in the site characterization planning process. In addition, 
effective involvement of the public in the overall site development process will play a critical role in the success of the effort. 


\subsection{TECHNICAL DATA REQUIREMENTS AND ACTIVITIES FOR SITE CHARACTERIZATION}

\subsection{Introduction}

The Nuclear Regulatory Commission or designated State licensing authority has the respansibility for the licensing and regulation of commercial L.LW facilities, and for ensuring that these facilities comply with the National Environmental Policy Act (NEPA) of 1909, in accordance with Title 10 Code of Federal Regulations Part 51.6 In order to provide assistance to the States in planning and carrying out their site characterization programs and in meeting the regulatory requi ements, the NRC has issued several guidance documents that contain interpretations of the regulations, recommendations as to specific types of site characterization activities that may be needed at proposed sites, and guidance as to the information that should be included in the SAR and ER, which comprise the 1 icense application. It is desirable for both project management and technical staff involved in site chracterization to be cognizant of the technical guidance provided by the NRC a.d to maintain communication with NRC policy and technical staff.

Appendix A matrices cite specific NRC regulatory guidance statements relevant to eighteen technical disciplines or data types that are involved in characterizing a LLW site, including:

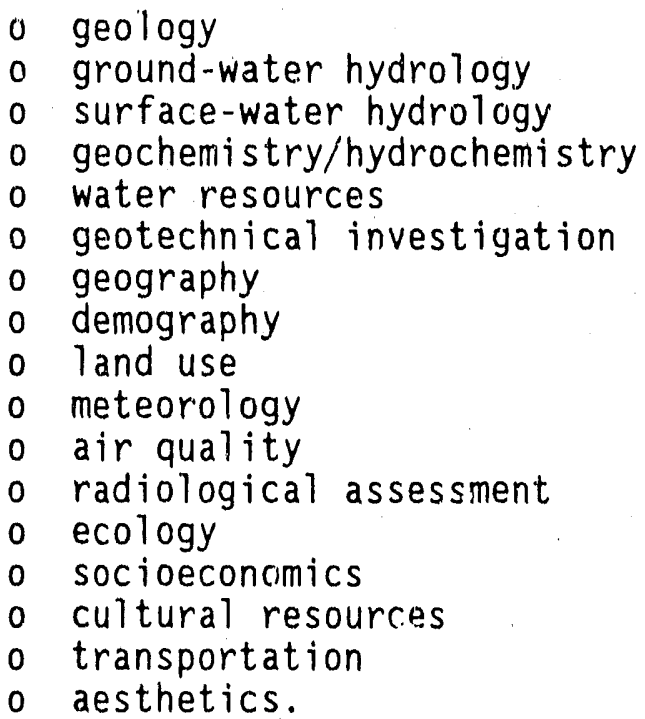

Each data type is further divided into specific technical parameters that must be addressed in licensing documentation. The determination of the technical parameters was based on an interpretation of NRC guidance contained in the following documents:

- NUREG-0902, "Site Suitability, Selection, and Characterization"4

- NRC Draft "Technical Position Paper, Environmental Monitoring of LowLevel Waste Disposal Facilities"' 
- NUREG-1199, "Standard Format and Content - Safety Analys is Report"8

- NUREG-1200, "Standard Review Plan - Safety Analysis Report"9

- NUREG-1300, "Environmental Standard Review PIan - Environmental Report"10.

It should be noted that revisions to NUREG-1199 and NUREG-1200, published early in 1988, were not available at the time Appendix $A$ was written. However, the changes in these new documents address only near-surface trench disposal, specifically those alternative concepts that incorporate structures constructed of comentitious materials with earthen covers; consequently, they do not affect the scope of information included in Appendix A.

Technical parameters are described in an attachment to each Appendix $A$ matrix; these descriptions include the data required by the NRC for each parameter. The matrices list the parameters that are explicitiy or implicitly treated in each NRC guidance statement. This Appendix should be used for guidance and reference in preparing a site characterization plan to ensure that the plan addresses all required parameters. A review of Appendix $A$ will also aid in understanding the uses to which the site characterization data are to be put and, thus, the quality and extent of data required.

Appendix $B$ tables list the technical activities and study methods that can be used to collect data specific to each technical parameter. The tables also identify the sources of data, the forms in which data are obtained and/or displayed, and references for additional information on technical activities pertinent to data collection and analysis. These tables describe standard site characterization activities that apply to regions with widely varying geological, hydrogeological, and environmental characteristics. It will be necessary to tailor these activities to each specific geographic region when preparing an actual site characterization plan. The information in Appendix $B$ provides guidance that can be used in preparing and assessing the adequacy of site characterization plans and in performing periodic evaluations of the adequacy of interim characterization results.

Section 4.2 provides a general overview of the regulatory requirements and technical activities that must be carried out during site characterization. Its purpose is to condense the information provided in the appendices for each of the eighteen data types in order to provide an overall understanding of the major components of a site characterization program. Appendices $A$ and $B$ are intended to provide specific guidance for technical planners and project managers duri y the initial planning stages of the site characterization program and as iork proceeds and program plans require updating or revision.

Section 4.2 also discusses guidance from the NRC as to the extent of the area to be characterized and the map scales to be used for specific data types. However, neither Section 4.2 nor Appendices A and B provide guidance on the level of effort needed to adequately characterize a site. The actual level of effort will be determined by the complexity of characteristics at a 
particular site, the number of sites being characterized, and the management strategies being used.

\subsection{Summary of Requirements and Activities by Data Type}

\subsubsection{Geology}

4.2.1.1 Iechnical Requirements. The NRC regulatory requirements and guidance with respect to geology are directed toward providing assurance that the site geology can be adequately characterized, that the natural processes affecting the site occur at consistent and definable rates, and that the site will be geomorphically and tectonically stable for a period of 500 years. The seven parameters specific to geology identified in Appendix $A$ are geomorphology, stratigraphy, lithology, structure, tectonics, seismology, and geologic hazards.

4.2.1.2 Data Needs and Collection Methods. The technical activities and study methods that address these seven parameters include review and tabulation of existing geologic data; surface and trench geologic mapping and sampling; borehole logging and sampling; surface and borehole geophysics; geomorphic analysis; seismic hazard analysis of tectonic structures and provinces to within 200 miles of the site; analysis of samples collected during the surface and subsurface studies; and detailed mapping, sampling, testing, and analysis in areas having potential geologic complexities. Surface mapping of the site geology should be on a scale consistent with the site topographic maps discussed in Section 4.2.3.2, and terminology used should be consistent with the accepted usage of the State geological survey or the U.S. Geological Survey. 4 The nature and depth (degree of detail) of specific geologic investigations will depend upon the types of geologic, geomorphic, and tectonic environments at and near the site.

4.2.1.3 Data Evaluation and Reporting. Raw geologic data required in the SAR or ER include: a site topographic map; geophysical and geologic borehole logs; test pit or trench logs; petrographic data; soil and rock descriptions; age determinations; results of laboratory analyses; earthquake maps and lists of historical earthquakes within 200 miles of the site with a magnitude of 3 or more or a modified Mercalli intensity (MMI) of IV or more; 8 large-scale maps showing all earthquakes within 50 and 5 miles of the site; ${ }^{9}$ maps of geologic structures and tectonic provinces within 200 miles of the site $;^{8}$ and where applicable, geodetic monitoring data.

Data interpretation and analysis will be required for: the preparation of surface geologic maps, isopach maps, and geologic cross sections, which provide the basis for a conceptual geological model of the site; the analysis of landforms for evidence of destructive geomorphic processes, subsidence, or collapse, and the determination of the nature and rates of these processes; 
the determination of the relationship between regional and site physiography and structural geology; the development of stratigraphic sections and the determination of the geologic history of the site area; the evaluation of structural features for evidence of potential deformation that may affect the site, and the determination of the nature and rates of this deformation; the identification of geologic and structural features that will affect or be affected by the disposal site; the determination of unrelieved stresses in bedrock and their potential for creep and rebound effects; the determiiation of the geologic and structural history of tectonic structures in the site and region; the determination of the tectonic provinces within 200 miles of the site; the evaluation of the relationship between seismicity and geologic and tectonic features, and the determination of the earthquake-generating potential of active structures; the determination of the design earthquake, horizontal ground acceleration, seisinic wave transmission characteristics, and settlement and liquefaction potential at the site; the determination of the potential for volcanic activity; the identification of potential geologic hazards; the prediction of the rate and extent of changes in geologic processes during a 500-year period; the description of the paleontologic resources that could be affected by the site; and the description of site soil conditions.

\subsubsection{Ground-Water Hydrology}

4.2.2.1 Technical Requirements. The NRC regulatory requirements and guidance with respect to ground-water hydrology are directed toward providing assurance that the site is hydrologically simple, that the site can provide sufficient depth to the water table so that ground-water intrusion into the waste will not occur or, if disposal is below the water table, that molecular diffusion is the predominant means of radionuclide movement and the rate of movement will result in performance objectives being met. The guidance is also concerned with providing assurance that in no case will waste disposal occur within the zone marked by fluctuations of the water table, that the hydrogeologic unit used for disposal will not discharge ground water to the surface within the disposal unit, and that the ground-water regime will not be adversely affected by the site. The fourteen parameters specific to groundwater hydrology identified in Appendix $A$ are moisture potential, moisture content, hydraulic conductivity, porosity (total and effective), geometry, boundary conditions, and hydrogeologic modeling for unsaturated flow, and hydrautic head, hydraulic conductivity, porosity (total and effective), specific storage, geometry, boundary conditions, and hydrogeologic modeling for saturated flow.

4.2.2.2 Data Needs and Collection Methods. The technical activities and study methods that address these fourteen parameters include: review and tabulation of existing ground-water data; field hydrologic testing; borehole geophysical logging; minimum one-year monitoring of soil-moisture content, water-table fluctuations, hydraulic head, and ground-water quality; laboratory testing; inventorying ground-water users; and investigating the subsurface to identify and sample all significant hydrogeologic units. 
The radius of ground-water studies during site characterization should depend on the types of aquifers underly ig the site. The NRC recommends that shallow, unconfined (water table) aquife, s may require a study area radius on the order of several kilometers to encompass the ground-water flow system and off-sitis ground-water users, whereas confined (artesian) aquifers may require a study area radius on the order of several tens of kilometers. 4 In either case, the NRC staff anticipates that the off-site data can be obtained by review of available reconnaissance-level information. All significant hydrogeologic units underlying the site should be identified to a depth on the order of 30 meter's below the level of waste disposal. 4 Ground-water monitoring wells should be located so that they continue to provide usable data during site operation, closure, and long-term care. In addition to wells downgradient of the site, upgradient wells should be installed to detect changes in background levels during later phases of facility operation. The NRC recommends that the head and moisture content be measured for a minimum period of one year and compared to historic records of precjpitation, moisture content, and water levels in the same or similar aquifers. ${ }^{\text {The frequency of }}$ measurement of head and moisture content during monitoring should reflect the mode of recharge of the hydrogeologic unit, with more frequent (weekly) measurements in unconfined units responding to precipitation events and less frequent (monthiy) measurements in confined units not directly responding to precipitation events. 4 The data collection points for moisture content and head measurements (above and below the water table) should be appropriately located in three dimensions within the separate hydrogeologic units to establish the boundary conditions for modeling. 4 The nature of specific ground-water investigations will depend upon the physical and hydrological characteristics of the site and surrounding area.

4.2.2.3 Data Evaluation and Reporting. Raw ground-water hydrology data required in the SAR or ER include: detailed descriptions of all monitoring wells; descriptions of all aquifer tests and tabulated test data; descriptions of laboratory analys is techniques and tabulated results; descriptions of data and methods used for determining the principal hydraulic characteristics for each hydrogeologic unit and for determining radionuclide transport characteristics of each unit; descriptions of input parameters for hydrologic models and the transport analysis; historic and seasonal records of precipitation, moisture content, and water levels; and ground-water user inventory data.

Data interpretation and analys is will be required for: the determination of the site water budget; the identification of hydrogeologic units and the description of their areal extent and properties; the determination of interrelationships between ground-water and surface-water systems; the identification of recharge and discharge areas; the description of all potentially affected aquifer systems and unsaturated zones, and the spatial and stratigraphic distribution of their hydrologic parameters; the description of the occurrence and movement of water in the unsaturated and saturated zones; the development of numerical and conceptual models of the ground-water system in the saturated and unsaturated zones; the description of the conceptual model of the ground-water flow system in relationship to the 
planned engineering Jesign; the description of all possible graund-water pathways to the accessible environiment; the description of the ground-water flow system and parameters used in the contaminant transport analyses; the calculation of the ground-water travel time downgradient from the site; and the qualitative and quantitative descriptions of the impact of the site on the ground-water system.

Ground-water user data can be obtained from the water resources studies in Section 4.2.5, and the geologic studies in Section 4.2.1 can provide input data to the identification and description of hydrogeologic units. Information on annual precipitation and evapotranspiration rates required for the ground-water flow model can be obtained from the meteo.ology studies in Section 4.2.11.

\subsubsection{Surface-Water Hydrology}

4.2.3.1 Technical Requirements. The NRC regulatory requirements and guidance with respect to surface-water hydrology are directed toward providing assurance that the site will be generally well drained and free of areas of flooding or frequent ponding, that upstream drainage areas will be minimized to decrease the amount of runoff that could erode or inundate the site, and that surface-water systems will not be adversely affected by the site. The fifteen parameters specific to surface-water hydrology identified in Appendix A are hydrologic system, water users, flood studies, drought studies, precipitation, infiltration, runoff, discharge, channel characteristics, stage, flow velocity, erosion, sedimentation, hydrologic and hydraulic modeling, and site surface-water impact.

4.2.3.2 Data Needs and Collection Methods. The technical activities and study methods that address these fifteen parameters include: review and tabulation of existing surface-water data, including water users, historic flood and drought data, and rainfall and snowfall record summaries; identification and description of the natural and man-made components of the surface-water system; field measurement of runoff, infiltration rates, and charinel characteristics of drainage systems crossing the site; installation of Parshall flumes and sediment samplers, where appropriate, to determine the rate of erosion; inventorying surface-water users; and monitoring surface-water flow and temperature for a minimum of one year.

The NRC recommends that surface-water site characterization studies should include not only the site but also the upstream drainage area contributing flow across the site and the downstream drainage area to a distance of approximately 10 kilometers. ${ }^{4}$ The NRC suggests that topographic maps of the upstream drainage areas should be at a scale on the order of $1: 2,400$, whereas $1: 24,000$ - or 1:62,500-scale maps will be acceptable for downstream areas. ${ }^{4}$ The inventory of existing surface-water users and municipal supplies should extend approximately 10 kilometers downstream. ${ }^{4}$ The nature of sicific surface-water investigations will depend upon the physical and hydrological characteristics of the site and surrounding area. 
4.2.3.3 Data Evaluation and Reperting. Raw surface-water hydrology data requitred in the SAR or ER include: water resource maps; hydrographs; stream records; data on historical flood events; topographtc maps showing natural drainages, surface gradients, and man-made features; descriptions of surface-water bodies and extsting and proposed water control structures and diverstons in the site and surrounding areas; aerlal photography showing drainage areas and areas of flooding; flood-frequency distributions and floodplain descriptions for affected streams; flow duration data; maximum, average-maximum, average, average-minimum, and minimum monthly temperatures and flow of affected water bodies; historical prectpttation and drought data; surface-water-user inventory data; results of laboratory analyses; input parameters for models and the transport analysis; and detalled computations that provide the bases for the design of protective features.

Data interpretation and analysis will be required for: the determination of the interrelationship of natural and man-made components of the surface-water system; the description of the surface.water flow system and its relationship to the planned engtneered design, and parameters used in the contaminant transport analyses; the evaluation of the flooding potential of the site and surrounding area, including the delineation of the 100-year floodplain, flood-flow frequencles, and the Probable Maximum Flood (PMF); the evaluation of the ability of the site to withstand floods; the estimation of arosion and sedimentation characteristics of the site; the determination of the Probable Maximum Precipitation (PMP) and precipitation characteristics that will contribute to the flooding and erosion studies; the determination of the infiltration rate at the site; the estimation of runoff, stage, flow velocity, and discharge at the site; the determination of channe 1 characteristics; the demonstration that upstream drainage areas have been or will be minimized to decrease runoff; the computation of water-surface profiles and flood velocities for revised flow regimes created by geomorphic changes; the description of surface-water pathways; the numerical and analytical hydrologic and hydraulic modeling of surface-water flow and transport; the evaluation of radionuclide migration; the determination of the effects of dam fallures, including analytical hydraulic fallure models; quantitative and qualitative descriptions of ground-water-surface-water interactions; the preparation of hydrologic evaluations and design detalls of the site flood control system; and the qualitative and quantitative descriptions of the impact of the site on the surface-water system.

The extent of the 100-year floodplain should be defined based on Executive Order 11988, "Floodplain Management". 11 Guidance for determining flood-flow frequencies can be obtained in the U.S. Water Resources Cquncil Bulletin 17-B, "Guidelines for Determining Flood Flow Frequency, "12 and guidance for determining the PMF and PMP can be obtained in NRC Regulatory Guide 1.59, "Design Basis Floods for Nuclear Power Plants". 13

Ground-water studies in Section 4.2 .2 can provide data on ground-water baseflow contributions to stream flow. Activities described for the geotechnical investigation in Section 4.2.7 can provide input data on soll erodibility. Surface-water-user data can be obtained from the water resources 
studies in Section 4.2.5, geomorphtc data can be obtained from the geologic. studies in section 4.2.1, and temperature data can be obtalned from the geochemistry/hydrochemtstry studies in Section 4.?.4.

\subsubsection{Geochemistry/Hydrochemistry}

4.2.4.1 Iechntcal Requtrements. The NRC regulatory requitrements and guidance with respect to geochemistry/hydrochemistry are directed toward providing assurarice that background chemistry data is collected to permit monitoring of key indicators of water quality anc any leachate migration, and to identify parameters that may affect transport of the waste leachates. The twelve parameters specific to geochemistry/hydrocheinistry identifled in Appendix A are water quality, lon-exchange capacity, organic content, Eh-pH, distribution coefficient, temperature, radiometric dating, isotope content, soll mineralogy and mineral solubllity, hydrodynamic dispersion coeffictent, geochemical model, and transport analysts.

4.2.4.2 Data Needs and Collection Methods. The technical activities and study methods that address these twelve parameters include: review and tabulation of existing geochemistry/hydrochemistry data; collection of background ground-water, surface-water, and soll samples in the fleld; chemical analysis, age dating, and experimental testing of field samples; monitoring of surface and ground-water chemistry at least quarterly for a minimum 1-year period; performance of laboratory simulations of field conditions; performance of fleld tracer tests; performance of fleld measurements of temperature and Eh-pH; and performance of modeling and transport analysis.

Ground-water monttoring wells should be located so that they continue to provide usable data during site operation, closure, and long-term care. The NRC recommends that, in addition to wells downgradient of the site, upgradient wells should be installed to defect changes in background levels subsequent to initial site characterization. Surface-water sampling locations should be selected upgradient, adjacent, and downgradient of the site in all subwatersheds to which the site may contribute. Nearby impoundments and surface-water drinking sources should be included in the sampling program. The NRC suggests that effort should be made to sample ephemeral water courses during runoff perlods, and samples should be taken following extreme hydrologic events. Sediment sample locations should be approximately the same as the surface-water samples. Preoperational soll samples should be taken from surficial solls as well as at depths that reflect the site stratigraphy. ${ }^{7}$ Soll samples should be collected at various points and depths in the cross section of the sediment proftle; samples from a discrete cross section may be aggregated for radiological and chemical analysis. 7 The nature of specific geochemistry/hydrochemistry investigations will depend upon the geologic and hydrogeologic characteristics of the site, particularly the location of the water table and surface-water system relative to the waste emplacement zone, and the composition of the waste. 
4.2.4.3 Data Evaluatton and Reporting. Raw geochemtstry/hydrochemistry data required in the SAR or ER include a complete set of site-spectfic surface-water, ground-water, sot1, and rock chemlstry data, and the mean, range, and temporal and spatial vartations in parameters as applicable; and descriptions and tabulations of regtonal water quality data.

Data interpretation and analys is will be requitred for: the determination of the coefficlent of dispersion, including distribution coeffictents, for radionucildes in the ground-water-soll system; the evaluation of the anticlpated chariges in water chemtstry for ground. and surface-water systems that may be affected by the site; the calculation of radionucilde concentrations; the performance of a contaminant transport analysis; the development of conceptual and numertcal geochemical models; the description of preexisting contaminated environments, and sources of contamination that may affect local water quality or site monitoring, construction, or operation; the determination of geochemical interactions between solls and water th the vadose and saturated zones; the description and analysis of surface-water pathways to demonstrate that potentlal radiological and nonradtological effluent concentrations will be within acceptable limits; arid the determination of surface-water bodies and users that would be affected by changes in water quality caused by the site.

Acttrittes described for geology, ground- and surface-water hydrology, and radiological assessment in Sections 4.2.1, 4.2.2, 4.2.3, and 4.2.13, respectively, can provide input data to the geochemlstry/hydrochemistry studies, particularly the contaminant transport analysis.

\subsubsection{Water Resources}

4.2.5.1 Techntcal Requtrements. NRC regulatory requirements and guidance with respect to water resources are directed toward avoidance of any inadvertent intruston into the site, avoldance of water resource development activities at and near the site that would compromise, either directly or indirectly, the safety of the site, and assurance that the proposed site will have no adverse effect on the explottation of water resources. The seven parameters spectfic to ground-water resources identifled in Appendix $A$ are past and present ground-water usage, past and present surface-water usage, ground-water discharge points, projected surface-water usage, projected ground-water usage, water rights and legal summarles, and site water resource impact.

4.2.5.2 Data Needs and Collection Methods. The technical activities and study methods that address these sever parameters include: review and tabulation of existing water resource data; performance of a ground-water-user inventory within approximately 2 kilometers of the site and a surface-water-user inventory in the vicinity of the site and within approximately $10 \mathrm{ki}$ lometers downstream of the site, including location, type, and amount of use; ${ }^{4}$ comptlation of a summary of statutory and other legal 
restrictions related to water use; and compllation of geographlc, demographic, and economic information to determine future water usage. The nature of specific water resources investigations will depend upon the hydrologic, geologtc, demographtc, and geographic condttions at and near the stte.

4.2.5.3 Data Evaluation and Reporting. Raw water resource data required in the SAR or ER include past and present surface- and ground-water-user inventory data and a summary of water rights and legal restrtctions.

Data interpretation and analysis will be requited for: the determination of projected surface- and ground-water usage; the preparation of a quantitative and qualttative descriptions of the direct and indirec effects of water use on site sultablitty; and the detarmination of the impact of the stte on water usage.

Geographtc and demographtc studtes described in Sections 4.2.8 and 4.2.9, respectively, can provide input data for the determination of projected water usage. The ground-water and surface-water hydrology studies described in Sections 4.2 .2 and 4.2 .3 , respectively, can provide data on surface-water features and the ground water flow regime for input to the analysis of the effects of water resource exploitation.

\subsubsection{Geologic/Timber/Agricultural Resources}

4.2.6.1 Technical Requirements. The NRC regulatory requilrements and gufdance with respect to geologic, timber, and agricultural resources are directed toward avoldance of any inadvertent intrusion into the site, avoldance resource development activities at and near the site that would compromise, efther directly or indirectly, the safety of the site, and assurance that the proposed stte will have no adverse effect on the exploitation of known resources. The nine parameters specific to natural resources identified in Appendix $A$ are past and present resource data, mineral rights/lease data, borehole/well data, potentlal resource location, resource quality and quantity, resource value, direct effects of exploitation, indirect effects of exploitation, and natural resources impact.

4.2.6.2 Data Needs and Collection Methods. The technical activities and study methods that address these nine parameters include review and tabulation of existing geologic, timber, and agricultural resource data, collection of lease and well data, evaluatior of samples collected and analyzed during the surface and subsurface geologic field studies for tndications of geologic resource potential, and detalled mapping, sampling, testing, and analysis in areas identffied as having geologic resource potential. The types of geologic resources to be investigated and the nature of specific investigations will depend upon the types of geologic environments at and near the site that could serve as potential resource hosts. The NRC has not specified a radius for the geologic resource evaluation; the area evaluated wt11 depend upon the types of 
resources existing or expected to exist at and near the site and their potential for impacting site sultablitty.

4.2.6.3 Data Evaluation and Reporting. Raw geologic, timber, and agricultural resource data required in the SAR or ER include: past and present resource locations, types, and commodities; quantitative data and extraction methods for active or previously active mines; quantity, quallty, production data, and harvesting methods for timber and agricultural resources; the location, ownership, and types of exploration activity carried out on mining claims and mineral leases; and the location, current activity, depth, diameter, completion practices, and geophysical logs of exploration boreholes and geothermal, brine, and hydrocarbon wells.

Data interpretation and analysis will be required for: the determination of the location of potential resources; the determination of resource qualtty, quantity, and value; the estimation of projected resource use; the classification of mineral resources using the U.S. Geological Survey and U.S. Bureau of Mines classificiation system; 14 the assessinent of current and potential exploration and extraction methods at and near the site to determine the potential direct and indirect effects of exploration and explotiation on site sultability; and the evaluation of the effects of the proposed site on the exploftation of known resources.

Land use studies descrlbed in Section 4.2 .10 will provide data on timber and agricultural resources at and near the site.

\subsubsection{Geotechnical Investigation}

4.2.7.1 Techntcal Requirements. The NRC regulatory requitrements and guidance with respect to the geotechnical investigation are directed toward providing data for major design-related analyses, such as slope stabllity, cover integrity, erosion, compaction characteristics for backfill materials, foundation analyses, gradations for proposed filler matertals, and possible interactions between the sult and waste containers. The five parameter's specific to the geotechnical investigation identified in Appendix $A$ are soil classification, engineering properties, engineering units, ground-water conditions, and engineering analysis.

4.2.7.2 Data Needs and Collection Methods. The specific technical activities and study methods that address these five parameters include field testing, collection of samples from borings, test pits, and trenches, and laboratory testing of samples to classify solls and to determine the engineering properties of the soll matertals.

Regulatory Gulde 1.132, "Site investigations for Foundations of Nuclear Power Plants", 15 should be uscid as a general guide in developing the geotechnical fleld investigation program. Testing of soll and rock parameter's should be in accordance with the general gutdance of Regulatory Guide 1.138, 
"Laboratory Investigatjons of Solls for Englneering Analysis and Design of Nuclear Power Plants". 16 The nature of specific geotechnical investigations will depend upon the stratigraphy, slope characteristics, and soll conditions at the site, and the proposed site design and operations.

4.2.7.3 Data Evaluation and Reporting. Raw geotechnical data required in the SAR or ER include: borehole, test pit, and trench logs; fleld and laboratory test data; and plans showing grades, slopes, and locattons of test pits and boreholes.

Data interpretation will be required to perform the engineering analysts that develops geotechnical recommendations for siope stability, settlement/subsidence, 1 iquefaction potential, freeze/thaw potential, active and passive earth pressures, bearing capacity, long and short-term control of surface runoff, and fill-placement procedures. Development of plans showing cross sections and proposed borrow area 1 imits will also require data analysis and synthesis.

Activities described for ground-water and surface-water hydrology in Sections 4.2 .2 and 4.2.3, respectively, can provide information on the groundand surface-water conditions at the stte. Activities described for geology in Section 4.2.1 can provide information on potential future geologic events.

\subsubsection{Geography}

4.2.8.1 Techinical Requirements. The term "geography" is used herein to refer collectiveiy to the several ttems necessary to describe the location and physical and jurisdictional setting of the proposed site. NRC regulatory requirements and guidance specify that both highly site-specific, as well as local and regional descriptions be provided. The six parameters specific to geography identified in Appendix $A$ are geographic location, political subdivision, nearby features, site area, topography, and site ownership.

4.2.8.2 Data Needs and Collection Methods. The technical activities and study methods that address these six parameters include identification and mapping of site ownership/control boundaries, political units such as county and city boundaries, prominent local features such as rivers and lakes and their drainage basins, site topography, and major highways and other prominent man-made features. Geographic data necessary to satisfy NRC requirements and guidance can primarily be obtained from existing map sources, but there is also the need to conduct field surveys to establish properly referenced geodetic control points. The latter are fundamental to the correct spatial referencing of much of the remaining geographic data.

4.2.8.3 Data Evaluation and Reporting. The format for reporting these data consists of at least two map series, one to describe site features to a radius of $10 \mathrm{~km}$ from the site at a relatively large scale, and another to 
display the broader geographlc context (1.e., to a radius of approximately 50 $\mathrm{km}$ from the site) at a smaller scale. 10 Both map series can be prepared to serve as "base maps" for display of other spatially-orlented data types (e.g., demography, land use). These relatively siraightforward geographic data do not require a signiffcant degree of evaluation, although it is 1ikely that the degree of detall (e.g., the types of highways and roads to be shown) may need to be carefully considered.

\subsubsection{Demography}

4.2.9.1 Technical Requirements. Demographic data required to fulf 111 NRC 1icensing requirements and regulatory guidance consist of the geographic distributions and sizes of hoth existing and projected human populations within designated distances from the site. The purpose of this information is to provide data for analyzing the potential health and safety impacts of factlity development and operation on existing and future populations and the potential for future intrusion into the disposed waste. The five parameters specific to demography identified in Appendix $A$ are population centers, population density, residence inventory, transient population, and projected population.

4.2.9.2 Data Needs and Collection Methods. The technical activities and study methods that address these five parameters include collection of current and historic decennial or other appropriate census records, estimates or formal projections of population, records or estimates of transient population use, and associated geographic information such as census tract boundaries, population center boundaries, and the locations of individual housing units in the vicinity of the site. These data may be collected from the U.S. Census Bureau, State demographer's office, regional and local planning agencies, and through direct field counts and estimates. The residence inventory should be conducted within approximately $2 \mathrm{~km}$ of the site and population centers should be identified within radial distances of $2 \mathrm{~km}, 10 \mathrm{~km}$, and $50 \mathrm{~km}$ from the site. ${ }^{4}$ Population densities within $10 \mathrm{~km}$ of the site should be calculated.

4.2.9.3 Data Evaluation and Reporting. Reporting of demographic information makes extensive use of tabular and graphic portrayals of data; population density is commonly portrayed in mapped form. Evaluation of most census data is a relatively standard process of complling and desegregating population figures according to appropriate spatial units (e.g., Minor Civil Division) and calculating population densities on the basis of persons per unit area. Population projections should generally be evaluated by examining the underlying assumptions and the projection methodology used; this analysis may indicate a need for modification of the assumptions or methodology to meet the specific informational requirements for low-level waste disposal itcensing. 


\subsubsection{Land Use}

4.2.10.1 Technical Requirements. The NRC guidance pertaining to the topic of land use is primarily oriented to identifying and evaluating land uses, facilities, or activities that could adversely affect the ability of the site to meet performance objectives or significantly mask the environmental monitoring program. This applies to a wide variety of existing and potential 1and uses. However, the regulatory guidance is also concerned with potential impacts of the LLW facility on existing and potential surrounding land uses, so the land use characterization must be comprehensive. The ten parameters specific to land use identified in Appendix $A$ are residential 1 and use, industrial iand use, agricultural land use, recreational land use, specialuse areas, zoning restrictions, local land-use plans, land ownership patterns, USDA land use classification, and utility land uses.

4.2.10.2 Data Needs and Collection Methods. The technical activities and study methods that address these ten parameters include collection of data on the locations and designations of lands classified according to: standard land use classifications such as residential, industrial, agricultural and recreational; special uses such as military bases; zoning restrictions; local or regional land use plans; USDA land capability, particularly prime or unique farmlands; and utility uses or rights-of-way. Along with the data on land use and zoning designations, information on the restrictions or permissible uses that accompany each designation should be obtained.

The 1 and use survey should include 1 and use patterns within a radius of approximately $10 \mathrm{~km}$ from the site. ${ }^{4}$ Collection of such data typically encompasses existing sources, such as planning and zoning authorities, aerial photo interpretation and direct field observations, and compilation of historic records and discussions with knowledgeable agency personnel and the public.

4.2.10.3 Data Evaluation and Reporting. Compilation of 1 and use data from existing sources and original data collection utilizes both tabular summaries and maps. It is often appropriate to standardize multiple, separate land use data sets using a recognized land use classification system, such as the hierarchical method employed by the USGS. Although reporting of historic and current land use is generally not difficult, projecting future trends, particulariy in areas experiencing unstable economies or major shifts in population, may require considerabiy more professional judgement and is subject to qualifying assumptions.

\subsubsection{Meteorology}

4.2.11.1 Technical Requirements. The focus of the NRC regulatory requirements and guidance with respect to meteorology is to establish baseline information on meteorologic conditions to determine the site's water budget, 
to define design loads arid operating bases, to evaluate the airborne release pathway, and to assess the frequency, probability, and potential consequences of severe meteorological events. The ten parameters specific to meteorology identified in Appendix $A$ are wind speed and direction, atmospheric pressure, precipitation, pan evaporation, humidity/dew-point/wet-bulb, air and soil temperatures, frost penetration, snow cover, solar radiation, and severe weather.

4.2.11.2 Data Needs and Collection Methods. The technical activities and study methods that address these ten parameters include both the compilation of existing historical records and the establishment of an on-site monitoring program. In most cases, historical records will serve to characterize regional meteorological conditions over time and to provide perspective for on-site measurements, but will not substitute for on-site monitoring. The NRC anticipates that a minimum record of one year of sitespecific meteorological data will be collected during site characterization. ${ }^{4}$ The monitoring activities include continuous and periodic measurements using instrumentation mounted on meteorological towers and in selected surface and subsurface locations. Meteorological data collection is especially amenable to digital data acquisition system, which can facilitate data management and analys is functions.

4.2.11.3 Data Evaluation and Reporting. The meteorological data base for site characterization is formulated by preparing tabular summaries of data collected on-site, backed up by historical records obtained from existing sources. These summaries provide hourly, daily, monthiy, or seasonal averages, depending on the specific parameter. These summaries are reported individually in the SAR and ER to meet NRC regulatory guidance, and are also provided as input to other data types (e.g., hydrology, air quality) as required.

\subsubsection{Air Quality}

4.2.12.1 Technical Requirements. The focus of NRC regulatory requirements and guidance with respect to air quality is to define a baseline (pre-existing background conditions) for assessing the potential environmental impacts of releases of nonradiologic pollutants from disposal facility operations. The five parameters specific to air quality identified in Appendix $A$ are pollutant type, pollutant concentrations, regional classification, air quality control region, and air quality ceilings.

4.2.12.2 Data Needs and Collection Methods. The technical activities and study methods that address these five parameters include the compilation of existing data, as well as collection of new data on-site. Existing data sources will generally be sufficient for characterization of existing eniissions sources and the geographic designations of air quality status in the site region. The measurement of air quality parameters should provide at 
least a one-year record of site-specific information. 4 On-site monitoring using continuous and 24-hour integrated sampling techniques is necessary for characterization of pollutant types and concentrations in the local vicinity.

4.2.12.3 Data Evaluation and Reporting. The nonradiologic air quality data base for site characterization is compiled as tabular summaries of existing data and newly collected data summarized by hourly, daily, quarterly, or annual averages, as appropriate. The regional and local air quality designations (e.g., attainment status) are displayed on regional and local base maps. These data are used to evaluate the potential for contaminants to be dispersed to the disposal site from nearby industrial or agriculture sources, as well as to assess the potential impacts of proposed onsite facilities (e.g., incineration) or activities affecting local and regional air quality (e.g., truck traffic raising fugitive dust).

\subsubsection{Radiological Assessment}

4.2.13.1 Technical Requirements. NRC regulatory requirements and guidance with respect to radiological assessment focus on establishing preexisting background concentrations of radioactive constituents at the site to form a baseline from which to identify any releases during disposal operations or following site closure. The ten parameters specific to radiological assessment identified in Appendix $A$ address the media to be monitored, and include direct gamma radiation, airborne radionuclides, soil, surface water, ground water, sediments, flora, fauna, and food.

4.2.13.2 Data Needs and Collection Methods. It has been assumed that sites selected for characterization will not be in close proximity to facilities or areas in which detailed radiological monitoring programs have already been performed (e.g., nuclear reactor sites), as that would violate the NRC's site selection guidance to avoid areas where nearby facilities or activities may tend to mask the LLW site's environmental monitoring program. Therefore, it is generally unlikely that detailed radiological baseline data exist. Thus, the compilation of radiological data will generally require a monitoring program consisting of aerial and ground-based surveys, and periodic and continuous sampling. Radiological measurements should provide at least a one-year record of site-specific information; additional pre-operational monitoring through construction may be necessary to establish a complete baseline for the operational environmental monitoring program. Radiological monitoring is performed both as a stand-alone task, using equipment such as airborne scintillation detection devices and ground-based dosimeters, as well as in conjunction with monitoring programs for other data parameters, such as surface- and ground-water quality.

4.2.13.3 Data Evaluation and Reporting. Data obtained in the radiological monitoring program are compiled and reported in tabular formats supported by maps of sampling grid locations. Interpretation of certain 
sampling data yields isometric contour maps showing radionuclide presence, location, and activity levels.

\subsubsection{Ecology}

4.2.14.1 Technical Requirements. NRC regulatory requirements and guidance with respect to ecology are directed toward defining the baseline terrestrial and aquatic characteristics of the site to support environmental impact assessments and mitigation planning. Important concerns include abundance and characteristics of species, importance of the species, seasonal and migratory patterns, offsite conditions, and existing natural and humaninduced effects. The ten parameters specific to ecology identified in Appendix $A$ are terrestrial fauna species, terrestrial flora species, aquatic species, livestock, food chain, migratory species, game animals, habitat, threatened and endangered species, and disease vectors and pests.

4.2.14.2 Data Needs and Collection Methods. The technical activities and study methods necessary to address these ten parameters include the compilation of existing data from agency sources, followed by onsite investigations at several levels of intensity. The ecological survey should ancompass a radius on the order of $5 \mathrm{~km}$ from the disposal site for major vegetation types and commercially or recreationally important vertebrate species. 4 other important vertebrate species should be identified within a radius of $25 \mathrm{~km}$. Sampling should be conducted for a minimum period of one year on a quarterly basis to determine seasonal variations of species. 4 site reconnaissance surveys (including aerial photography) are used to confirm information obtained from existing sources, to determine species and habitat conditions, and to select sites and techniques for more intensive investigation as necessary. These investigations include such methods as mark and recapture studies to determine species population densities and site usage, detailed surveys following grid transects for quantitative estimates of population and habitat conditions, and sampling and analysis of vegetation in monitored plots for characterization of conditions slich as the presence of contaminants. Many of the characterization methods for the ecological data parameters are inter-related and should be planned and executed in an integrated manner.

4.2.14.3 Data Evaluation and Reporting. The ecological data collected for site characterization consist of species lists, maps, tabular summaries, and narratives, backed up by field notes and analytical data. Evaluation of these data is necessary to characterize the terrestrial and aquatic systems of the site itself and in surrounding areas, which might be affected by site construction and operation. The baseline ecological conditions can be assessed in terms of the overall health of the ecosystem, the importance of the habitat to the resident and migratory species, the ability of the ecosystem to accommodate site development, and the potentiar effects of ecological conditions on site operations. The latter should specifically address the pattern of vegetational succession that would occur if the site 
were left undisturbed and unmanaged. This is useful information for characterizing surface hydrological conditions and erosion potential, as well as for planning and evaluating facility operational and performance characteristics. It should be recognized that stte characterization may need to address the role and effects of long-term ecological conditions and processes as an integral part of the geohydrologic environment that surrounds and affects the LLW facility. The ecological baseline also provides an important starting point for mitigation planning related to specific site development features or operations.

\subsubsection{Soctoeconomics}

4.2.15.1 Technical Requirements. The NRC regulatory guidance regarding the wide variety of topics encompassed under the term socioeconomics is directed toward developing the data necessary to conduct a comprehensive analysis of the potential effects of the proposed facility on local and regional economics, public services, and quality of life indicators. The focus of the analysis is on the ability of local communities to accommodate a significant construction project and long-term operation of a radioactive waste management facility. The six parameters specific to socioeconomics identified in Appendix $A$ are labor force, housing, health and public safety systems, education systems, tax base, and sociocultural characteristics.

4.2.15.2 Data Needs and Collection Methods. A variety of data, some of which are related to the geography, demography, land use, transportation and aesthetics studies, are required for socioeconomic characterization. These include the size, composition and availability of the local labor force; the types, amounts, age, condition and availability of existing and projected housing; the capacity and capabilities of health and public safety systems to meet the needs of the labor force; the capacity and availability of educational institutions; the taxing jurisdictions, tax structures and revenues that may be affected; and various indicators of sociocultural characteristics, such as cultural values and family stability. These data are generally obtained through a combination of accessing existing public agency data sources and conducting direct surveys and interviews of local residents, community leaders, and professionals. The region for which socioeconomic data are collected should include the county in which the site is located and those portions of surrounding counties and urbanized areas (generally up to $40 \mathrm{~km}$ ) from which the work force would be drawn or whose community services would be affected by in-migration of workers.

4.2.15.3 Data Evaluation and Reporting. Depending on the complexity of the socioeconomic characteristics of the $10 \mathrm{cal}$ area and region surrounding the site, as well as the nature of significant socioeconomic concerns that have been raised, evaluations of the data obtained may vary from qualitative and quantitative analyses supported by tabular data summaries to complex socioeconomic impact assessment modeling. If modeling is used, the site characterization report would describe the quality of input data and 
assumptions used, data processing methods, and the sensitivity of the model results to any qualffications regarding the data or assumptions used.

\subsubsection{Cultural Resources}

4.2.16.1 Technical Requirements. NRC regulatory guidance with respect to cultural resources is directed toward identifying the potential for encountering sites, butldings, structures, or objects of historical, archeological, architectural, scenic, cultural, or landmark significance during disposal factlity construction, operation, or closure to support environmental impact assessments. The three parameters specific to cultural resources identified in Appendix A are historic places, archaeologic sites, and other cultural resources.

4.2.16.2 Data Needs and Collection Methods. The cultural resources survey should be performed to a radius of approximately $10 \mathrm{~km}$ from the site. The location of historic structures and archaeological sites should be identified through consultation with Federal and State historic preservation agencies, literature review, field reconnaissance, and limited surface testing if necessary. It is especially important in this discipline area to maintain a close working relationship with appropriate agency personnel (e.g., the State Historic Preservation officer) in all data collection activitios in order to ensure compliance with the standards and procedures that have been established for cultural resource preservation.

4.2.16.3 Data Evaluation and Reporting. The principal emphas is of the regulatory guidance on this topic is the determination of the significance of any identified cultural resources and the potential for any such resources to be found or affected during facility development. Explicit criteria have been established, for example, for evaluating the potential of a cultural site to be included on the National Register of Historic Places. Reporting on the findings of the cultural resources investigations in the documents resulting from site characterization may require special consideration for confidentiality to protect any identified sites from unauthorized intrusion. As with data collection and evaluation, reporting should also be closely coordinated with the responsible agencies.

\subsubsection{Transportation}

4.2.17.1 Technical Requirements. The emphasis of the NRC regulatory guidance with respect to transportation is to identify transportation modes, routes, and systems that will be used to ship wastes to the disposal facility to assess carrying capacity and condition, modifications affecting traffic flow, and potential radiation exposures to the general population along waste transport routes. The six parameters specific to transportation identified in 
Appendix A are major highways, local highways and roads, navigable waterways, rallroads, rights-of-way, and public transportation.

4.2.17.2 Data Needs and Collection Methods. Data collection for the transportation characterization can be coordinated with the collection of land use and demographic information. This will provide the locations and routes of local and regional transportation facilities and systems, as well as population counts along the projected waste transport routes. Data on the carrying capacities, condltions, restrictions, and planned modiffcations to local and regional transportation systems are generally obtained from the appropriate agencies (e.g., State and Federal departments of transportation), carriers/operators (e.g., railroad companies), and local planning agencies. Accident data pertaining to specific roads and highways may be maintained by local law enforcement agencies.

4.2.17.3 Data Evaluation and Reporting. Much transportation data can be summarized in narrative, tabular, and map formats that require little interpretation or analysis. Modifications to existing transportation systems to be imposed by a LLW disposal facility, either physically or in terms of traffic volumes or routing restrictions, may require traffic engineering or other types of transportation planning analyses. Analysis of accident scenarios and statistics along with populations resident along transport routes provides the data necessary to support subsequent dose calculations for potential accidents resulting in release of radioactive materials.

\subsubsection{Aesthetics}

4.2.18.1 Technical Requirements. NRC regulatory requirements and guidance with respect to aesthetics are directed toward assessing the impacts of disposal facility construction and operation on the visual quality of the area and on terrestrial biota that are sensitive to noise to support environmental impact assessments and mitigation planning. The two parameters specific to aesthetics identified in Appendix $A$ are visual resources and noise.

4.2.18.2 Data Needs and Collection Methods. Collection of data pertaining to visual resources typically focuses on two general data categories: 1) physical conditions contributing to the quality of visual resources, such as topography, vegetation and land uses that are characterized using factors such as landform diversity, man-made alterations, and the scale of scenic vistas; and 2) visual sensitivity, or the ability of a visual resource to accommodate modification, that is characterized by measuring the number and frequency of viewers (e.g., highway travelers), the relative scenic importance of an area, and other indicators. For sites located within or adjacent to public lands, these characterizations may have been performed by the land management agency (e.g., U.S. Forest Service). If not, visual resource characterization methodologies developed by such agencies may be 
applicable. The other princtpal component of the aesthetics characterization, ambient noise, is measured using standard noise monitoring equipment placed to develop a proftle of amblent notse levels on the site and its environs.

4.2.18.3 Data Evaluation and Reporting. Reporting on the aesthetics characterizations involves both narrative descriptions and maps depicting "viewshed" boundaries and other visual resource parameters. Photo documentation of viewsheds is also essential. The amblent noise characterizations also generally utilize maps of the site area depicting sources, receptors, and noise levels. A significant degree of subjectivity and judgment is inherent in evaluation of data collected to characterize the aesthetics of a project area. This is one reason to utilize methods such as the U.S. Forest Service Visual Resource Management System, which tend to provide standardization and objectivity to the analysis process. It may be useful to establish technical linkages among the land use, socioeconomics, and aesthetics evaluation for both technical effictency as well as to incorporate the concerns and values of local residents. 


\subsection{QUALITY ASSURANCE AND QUALITY CONTROL CONSIDERATIONS}

\subsection{Introduction and Defintition of Qualtty Terminology}

As applied to the development of LLW disposal factlities, quality Assurance (QA) may be constdered to be all of those planned, systemattc activities necessary to provide adequate assurance that the facility will perform satisfactorily throughout its operational lifetime. QA is generally considered to include quality control (QC), which refers to those specific methodologies used to provide control or measurement of performance within given limits or specified criteria. The goal of a $Q A / Q C$ program during the LLW site characterization process should be to assure the technical suitability and defensibllity of the site, to assure that the data obtained during site characterization is adequate to support the facllity design process, and to establish the management controls and feedback systems that will assure consistently accaptable facility performance through its operational iffetime and closure.

\subsection{Regulatory Background}

QA/QC program requirements for LLW facllttles originate in

10 CFR $61.12(\mathrm{~J})$, which requites that the applicant describe the QA/QC program in effect throughout the ilfetime of the facility. Lifetime facility phases include:

- Determination of natural disposal stte characteristics

0 Design and construction of the factlity

- Facflity operation

- Facility closure.

The QA program requirements that are discussed in Section 5.3 relate to all phases of the faclitity's Iffetime; however, those aspects pertinent to site characterization are emphasized.

\subsection{Basic $Q A$ Program Requirements}

The NRC has recently published NUREG-1293, "Quajity Assurance Guidelines for Low-Level Radioactive Waste Disposal Facility, "17 which provides guidance to license applicants in meeting the $Q A / Q C$ program requirements of 10 CFR $61.12(\mathrm{j})$. At the time of preparation of this handbook, the document is in draft form, subject to public comment. The quality program criteria presented in NUREG-1293 are simflar to those contained with in 10 CFR 50, Appendix B, "Quality Assurance Criteria for Nuclear Power Plants and Fuel Reprocessing Plants." 18 The NRC has accepted these criteria as basic to any QA program, and has taflored the concepts to fit the requirements of LLW disposal facility development. The individual criterta discussed below comprise the elements of 
the $Q A$ program that will be required by the State agency, private developer, or subcontractor with primary responsiblitties for site characterization activity.

\subsubsection{Organization}

The applicant will be responstble for the development and matntenance of a QA program. The organization of the QA program must be clearly defined in terms of the authority and responsibllities of those individuals and organizations performing QA functions. The primary functions under the $Q A$ program are (a) maintenance of the QA program and systematic assurance of continued program effectiveness, and (b) verification of correct technical performance by review, inspection, auditing, or other means. The applicant may subcontract portions of the implementation and development, but must remain responstbie for overall effectiveness and must be capable of independentiy assessing the adequacy of a contractor's performance. Sufficlent organizational independence and authority must be provided to ensure that the individuals and organtzations performing $Q A$ functions for site characterization can effectively identify quality problems; inttlate, provide, or require solutions to such problems; and control further activities until any qualtty problems are resolved.

\subsubsection{QA Program}

The $Q A$ program should be established at the earliest practicable time, tdeally, before any technical data are gathered. It should be flexible in structure to permit expansion and modiflcation as site characterization progresses. NRC will require that all site characterization or preliminary destgn data be obtained under program controls or be vertfied and qualified by established $Q A$ procedures prior to use. It is prudent for the applicant to establish the $Q A$ program elements concerned with the review and qualification of published data and the gathering and qualification of new data as early as possible in the site characterization process. This is particularly important because the design, and consequently the ultimate safety, of the facility will be based on site characterlzation data. The early establishment of a QA program will not only preclude unnecessary and potentially costly reverification of data, but will also provide defensible documentation of the process. Section 5.4 discusses items that must be considered in the qualification of publtshed and gathered data.

Al1 elements of the QA program should be documented by written policies, procedures, and/or instructions. The program should provide for conducting all activities affecting quality in controlled conditions, and should address special controls, processes, equipment, and personnel skill levels, where required, to attain the desired level of quality. The program must provide means of veriffcation by inspections, tests, or other methods, and should provide for the training and qualification of all personnel performing activities affecting quality. The applicant should regularly examine the overall effectiveness of the $Q A$ program. Management of other participating (or subcontracted) organizations should similarly perform a periodic review of 
the portions of the QA program for which they share responstbility for effect tveness.

It will be particularly important in the design of a $Q A$ program to provide a means for evaluating site charactertzation activities and controlling the extent and level of application of QA program elements. The NRC has made it clear in NUREG.1293 that the relationship of all activities to the performance objectives of 10 CFR 61.12. (J) must be identifled. All QA program controls should be applied at a level commensurate with the type, complexity, and criticality of the activity; when a direct relationship to performance has been identifled, the full range of avallable controls must be considered, or other mearis provided to properly control the activity.

\subsubsection{Destan Controls}

The QA program should provide the means for ensuring that the regulatory requirements of 10 CFR 6!l that govern the developmerit of the design and safe operation of the disposal factlity are properly transferred to the specifications, drawings, procedures, and instructions that define the construction of the facility. Because the data resulting from the site charactertzation process have a major role in the development of the disposal facllity design, they must be subjected to controlled $Q A$ review and approval processes. All changes to design-supporting recommendations resulting from site characterization must be submitted to the same controlled review processes utilized for the original documerit. If contractors are used for portions of the sitie characterization activity, the applicant must ensure that appropriate review processes and interface controls exist to control development of the recommendations from site characterization.

\subsubsection{Procurement Document Control}

During site characterization, procurement of ttems such as computer software, data base information, field equipment, and laboratory equipment may be required. Varfous types of contractor services are also likely to be needed. The QA program should provide review procedures to ensure that all applicable $Q A$, regulatory, and design requirements are included in procurement documents. Revisions to procurement documents must undergo the same review and approval cycle as imposed for the original, and approprtate elements of the QA program should be passed on to contractors or their subtler suppliters. Procurement documents should specifically define acceptance requirements, describe rionconformance reporting and handiing requirements, define contractor documentation and records retention responsibilities, and allow for applicant access for purposes of inspection or audit.

\subsubsection{Instruction, Procedures, and Drawings}

A11 activities affectirig quality, including the QA program elements discussed here, must be implemented and controlled by means of procedures, instructions, drawings, specifications, or other controllable documents. When 
approprtate for the affected activity, documents must incilude adequate qualttative or quantitative acceptance or completion criteria in order to facllitate performance verffication. In site characterlzation, this applies to techntcal procedures for fleld and laboratory investigations, verffication of computer software, review of reports, reduction of fleld data, and other activities.

\subsubsection{Document Control}

The QA program should control the review, issuance, and revision of the documents discussed in 5.3.5. Procedures for document control must ensure that documents are distributed to approprtate personnel and locations, and that only current revistons of documents are used.

\subsubsection{Control of Purchased Materfal, Equlpment and Servicas}

Matertals, services, and supplies will need to be purchased during site characterization, as described in Section 5.3.4. The QA program must provide for the evaluation and selection of suppliers and consultants, and must address the inspection or evaluation of purchased materlal, equipment, and services. The means selected must provide a checkpoint prior to the acceptance and use of the materlals or equipment, or in the case of services, provide a means of evaluating the quality of the service provided on at least a pertodic basts. The evaluation techntques may include source inspection, survelllance inspection, recelving inspection, acceptance testing, software verfficatior and validation, technical review, auditing, or other methods. Procedures should address each potential method of evaluation, and should discuss the documentation of the acceptance or rejection of the evaluated item or service.

\subsubsection{Identification and Control of Matorials, Parts, and Components}

The QA program should address identification and control requirements for purchased equipment, parts, and fabricated assemblies or subassemblies. In site characterization, these ttems may include field and laboratory test equipment used in site studies, computers or software. Item identification should be untque, maintained by physical marking or by traceable records. Identification requirements may also be interpreted to apply to physical samples such as core samples or samples for hydrologic or geochemical testing performed during site characterization.

\subsubsection{Control of Processes}

All processes that affect the quality of ttems or services must be controlled through the use of procedures, drawings, instructions, or other appropriate means as discussed in 5.3.5 above. During site characterization it will be parifcularly important to invoke appropriate controls over those processes that have a direct relationship to the collection, accuracy, 
adequacy, arid compllation of stte data. Such activities may tnclude sampling, laboratory analysis, and modeling.

Certain processes may be considered "spectal" and, in addition to the controls just mentloned, will require qualification of personnel, equipment, and procedures prior to actual project use as a means of controlling the quality of the ttem or service subsequently produced. NUREG-1293 does not spectfically define the types of processes requiring qualffication, but such considerations are tradltionally confined to processes such as welding, heat treating, and nondestructive testing, for which it is necessary to demonstrate that a particular combination of personal skill, procedures, and equipment will produce acceptable results in actual practice.

Because such special processes are generally related to facllity construction, it is unlikely that they will be used in the site characterization phase. However, if these or other such processes are identified in the future, procedures must be developed that control the qualification of personnel, equipment, and procedures in accordance with established codes, standards, or other requirements. Special process qualification activities must be completed prior to the actual use of the process.

\section{3 .10 Inspection}

The QA program should provide procedures for inspection of activities affecting the quality of the results of stte characterization. Procedures should define the qualification requirements for inspectors, and specifically require their independence from the activity being inspected. Direct inspection methods are assumed to be most applicable during site characterization; such methods include receiving inspection, in-process inspection, and survelllance inspection. Recelving inspection is performed as a means of controlling purchased ttems or materials, and ensures that only items in compliance with thetr procurement requirements are accepted for use or further processing. In-process inspection is performed at scheduled hold or check points for site characterization activities documented in plans, procedures, or other documents; in such cases, inspection will be required before the activity can proceed. Survelllance inspections are overchecks of selected ttems, processes, or procedures that are performed to ensure continued performance in compliance with specified requirements.

\subsubsection{Test Control}

All testing and analytical procedures used during site characterization should assure that the test prerequisites have been met, testing is performed under sultably controlled conditions, supporting instrumentation is both adequate and accurate, acceptance or completion criterla are provided, inspection hold points are established where appropriate, and adequate means of documenting and evaluating the test results are provided. 


\section{3 .12 Control of Measuring and Test Equipment}

The QA program should provide a system of callbration and maintenance for measuring and test equipment that w111 ensure the accuracy of the results of all site characterization. This system should apply to all activities involving sampling, data collection, fleld verffication, or laboratory analysis. Responsiblitties for the malntenance of the system should be clearly defined. The system should requlre traceabllity of callbrations to nationally recognized measurement standards, provide for positive identffication of measuring and test equipment to callbration and maintenance records, and provide a means of controlled issue and recall of equipment to ensure that only properly serviced and calibrated equipment is utilized.

\subsubsection{Handling, Storage, and Shipping}

The QA program should provide measures for controlling the handing, storage, and shipment of materials and equipment. The roquirement extends in particular to the handling of samples, which must be protected from degradation, detertoration, physical damage, and loss of identification. The maintenance of sample identification and preservation of in-situ characteristics, to the fullest extent possible, may be critical to the success of an investigation. Sampling procedures must properly address such considerations, and personnel must be trained to the procedure requirements.

\subsubsection{Inspection. Test, and Operating Status}

The QA program should provide the means of indicating the inspection status of procured materfals and equipirent to preclude the use of uninspected or refected materials or ttems. Inspection status of tests or in-process inspections must also be determinable in order to preclude missing test steps, double inspections, or the potential invalidation of test results. Test equipment operating status must be clearly visible to preclude invalidation of results due to unauthorized movement or adjustment of test equipment.

\subsubsection{Nonconforming Materials, Parts, or Components}

The $Q A$ program should contain procedures for documenting and resolving nonconformances observed during recelving or in-process inspections that may be conducted during site characterizatior. Means must be provided for identification of nonconforming materials or ttems and segregation from accepted ttems wherever possible. Procedures must provide a systematic means for obtaining proper problem disposition; correcting the discrepancy by reanalysis, retesting, repair, rework, or returning to the supplier; and taking appropriate corrective action to reduce or preclude the possibility of similar discrepancies. Procedures must define the authority required to resolve nonconformances and provide for the complete documentation of the resolution processes. 


\subsubsection{Corrective Action}

The QA program, in particular the inspection, nonconformance control and auditing portions, should provide the means for identifying and ensuring the prompt correction of conditions adverse to quality. The correction of a nonconforming condition is not considered complete without considering the basic or root causes of the nonconformance and taking appropriate corrective action to address those causes. The corrective actions taken as a result of nonconformances are effectiveness indicators that must be reported in a timely manner to levels of management that have overall program responsibilities.

\subsubsection{Quality Assurance Records}

The QA program should provide for the maintenance of records that furnish documentary evidence of quality during site characterization. Records should be retained from receiving inspections, sampling, tests, in-process inspections, surveillances, audits, work performance monitoring, training, reviews, material analyses, and radiation exposure pathway evaluations. Personnel qualification records, special process procedure qualification, and special process equipment qualifications should be retained whenever special processes are used. The applicant must assign responsibilities for records retention and establish procedures for records identification, access control, protection, retrieval, and storage.

\subsubsection{Audits, Surveillance and Managerial Controls}

The QA program should provide for a system of planned and periodic surveillances and audits during site characterization. Surveillance, as discussed in Section 5.3.10, may be considered to be a type of inspection; it requires overchecks of selected items, processes, or procedures to ensure continued performance in compliance with established requirements. Auditing is a planned and documented investigation performed in accordance with written procedures or checklists for the purposes of verification, by examination of objective evidence, that applicable elements of the $Q A$ program have been developed, documented, and effectively implemented. Surveillance is directed towards a specific ongoing activity; auditing is used to examine the full scope of $Q A$ program applicability, and relies in a large part on objective evidence and formal investigative techniques. Auditors must be properly trained, qualified, and independent from the activity being audited; audit results must be reviewed by management responsible for the area audited and corrective action taken where required, as described in Section 5.3.16.

\subsection{Qualification of Data}

Controls over the data collected during site characterization and used for the design of a disposal facility will be critical to successful licensing. All data used in the license application, whether it is preexisting, published or newly gathered, must be qualified under a QA program meeting the requirements discussed in Section 5.3. 


\subsubsection{Review and Qualification of Published Data}

Existing data collected during site characterization may be utilized, provided that they are examined and qualified. The examination and qualification of data must be documented and supporied by formal review processes to support licensing. Qualification may be accomplished by technical review, peer review, qualification testing, software validation and verification, literature search/review, or other means, singly or in combination. Qualification techniques should be selected based on their appropriateness for the type of data that are being reviewed or examined. Each technique should be controlled by procedures and should provide the criteria for the examination, qualificatior.s of the examiner or reviewer, and documentation of the review or decision process.

\subsubsection{Gathering and Qualification of New Data}

The process of gathering new data will involve many elements of the applicant's QA program; effective procedures in the following areas will be particularly crucial in the data-gathering process:

- Training and qualification of technical, testing, and irspection personnel

- Controlled test procedure development and test control

0 Calibration and maintenance of measuring and test equipment

- Literature search and review

- Computer software validation, verification, and control

- Technical and peer review.

New data that may have been gathered when $Q A$ program controls were not in effect may be acceptable for use if qualified through one or more of the techniques discussed in 5.4.1. 


\subsection{REFERENCES CITED}

1. Low-Level Radioactive Waste Policy Amendments Act of 1985 , Public Law No. 99-240, 99. Stat. 1842, 1986.

2. U.S. Department of Energy, Site Selection Handbook; Workshop on Site Selection for Low-Level Radioactive Waste Disposal Facilities, National Low-Level Waste Management Program, prepared for EG\&G Idaho, Inc., and the U.S. Department of Energy, DOE/LLW-64T, 1987.

3. University of Arizona, Site Characterization Field Manual for Near Surface Geologic Disposal of Low-Level Radioactive Waste, U.S. Department of Energy Report DE FG07 871D 12514, 1985.

4. D. Seifken et al., Site Suitability, Selection, and Characterization, NUREG-0902, Branch Technical Position - Low-Level Waste Licensing Branch, Office of Nuclear Material Safety and Safeguards, 1982.

5. U.S. Nuclear Regulatory Commission, Licensing Requirements for Land Disposal of Radioactive Waste, Title 10 Code of Federal Regulations Part 61 (10 CFR 61), 1987.

6. U.S. Nuclear Regulatory Commission, Environmental Protection Regulations for Domestic Licensing and Related Requlatory Functions, Title 10 Code of Federal Regulations Part 51 (10 CFR 51), 1987.

7. U.S. Nuclear Regulatory Commission, Technical Position Paper, Environmental Monitoring of Low-Level Waste Disposal Facilities, Working Draft, Division of Waste Management, 1986.

8. U.S. Nuclear Regulatory Commission, Standard Format and Content of a License Application for a Low-Level Radioactive Waste Disposal Facility: Safety Analys is Report, NUREG-1199, Office of Nuclear Material Safety and Safeguards, 1987.

9. U.S. Nuclear Regulatory Commission, Standard Review Plan for the Review of a License Application for a Low-Level Radioactive Waste Disposal Facility; Safety Analys is Report, NUREG-1200, Office of Nuclear Material Safety and Safeguards, 1987.

10. U.S. Nuclear Regulatory Commission, Environmental Standard Review of Plan for the Review of a License Application for a Low-Level Radioactive Waste Disposal Facility; Environmental Report, NUREG-1300, Office of Nuclear Material Safety and Safeguards, 1987.

11. Executive Order 11988, "Floodplain Management", Federal Register, 42, 101, Wednesday, May 25, 1977.

12. U.S. Water Resources Council, Guidelines for Determining Flood Flow Frequency, Bulletin 17-B, Washington, D.C., 1981. 
13. U.S. Nuclear Regulatory Commission, Design Basis Floods for Nuclear Power Plants, Regulatory Guide 1.59, 1977.

14. U.S. Geological Survey and U. S. Bureau of Mines, Principles of a Resource/Reserve Classification for Minerals, U.S.G.S. Circular 831, 1980.

15. U.S. Nuclear Regulatory Commission, Site Investigations for Foundations of Nuclear Power Plants, Regulatory Guide 1.132, 1979.

16. U.S. Nuclear Regulatory Commission, Laboratory Investigations of Soils for Engineering Analys is and Design of Nuclear Power Plants, Regulatory Guide $1.138,1978$.

17. U.S. Nuclear Regulatory Commission, Quality Assurance Guidelines for a Low-Level Radioactive Waste Disposal Facility, NUREG-1293, Low-Level Waste Licensing Branch (draft), 1987.

18. U.S. Nuclear Regulatory Commission, Quality Assurance Criteria for Nuclear Power Plants and Fuel Reprocessing Plants, Title 10 Code of Federal Regulations Part 50 (10 CFR 50), Appendix B, 1987. 


\section{APPENDIX A}

TECHNICAL PARAMETERS/

DATA REQUIREMENTS MATRICES 
Eighteen matrices have been developed for specific technical disciplines or data types that are involved in characterizing a LLW disposal site for licensing by the NRC. These data types include geology, ground-water hydrology, surface-water hydrology, geochemistry/hydrochemistry, water resources, geologic/timber/agricultural resources, geotechnical investigation, geography, demography, land use, meteorology, air quality, radiological assessment, ecology, soctoeconomics, cultural resources, transportation and aesthetics.

Each matrix cites those sections of the NRC regulations and guidance documents that are pertinent to the data types. The NRC documents include:

- 10 CFR 61, NRC Licensing Requirements for Land Disposal Radioactive Waste

- 10 CFR 51, NRC Environmental Protection Regulations for Domestic Licensing and Related Regulatory Functions ${ }^{2}$

- NUREG-0902, NRC Branch Technical Position on Site Suitability, Selection, and Characterization ${ }^{3}$

- NRC Draft Technical Position on Environmental Monttoring of LLW Disposal Facilities"

0 NUREG-1199, Standard Format and Content - Safety Analys is Report 5

- NUREG-1200, Standard Review Plan - Safety Analysis Report6

- NUREG-1300, Environmental Standard Review Plan - Environmental Report.9

Revisions to NUREG-1199 and NUREG-1200, published early in 1988, were not available at the time Appendix $A$ was written. However, the changes in these new documents address only near-surface trench disposal, specifically those alternative concepts that incorporate structures constructed of cementitious materials with earthen covers; consequently they do not affect the scope of information included in this appendix.

The contents of Regulatory Guide 4.18, "Standard Format and Content of Environmental Reports for Near-Surface Disposal of Radioactive Waste, " 8 were considered by the NRC in the preparation of NUREG-1300. However, the overall data and information requirements of NUREG-1300 are not necessarily consistent with the guidance provided in Regulatory Guide 4.18. Until the NRC prepares a revised version of Regulatory Guide 4.18, the NRC has stated that review procedures outlined in NUREG-1300 will be followed. For this reason, Regulatory Guide 4.18 has not been included in the Appendix A matrices; however, this document should be reviewed when the revised version is published by the NRC. 
For each of the above NRC documents (exclusive of the Part 51 and 61 regulations), the guldance for licensing documentation pertaining to the relevant data type is summarized in the matrix using etther direct quotations or paraphrased statements. Direct quotations are enclosed by quotation marks and paraphrased passages are enclosed by brackets.

All technical parameters determined to be necessary to complete the site characterization 1 icensing documentation for each data type are 1 isted across the top of the matrix. These technical parameters are described in attachments accompanying each matrix. An " $x$ " on the matrix indicates that the parameter is specificaliy required to address the NRC guidance statement on the left site of the matrix. A " + " on the matrix indicates that the parameter was interpreted to be implicitly required by the NRC guidance statement.

The purpose of these matrices is to provide guidance to technical planners and program managers as to the types of data that are necessary to comply with NRC licensing requirements and technical guidance. They can be used during the initial planning stages of the site characterization program and as work proceeds and program plans require updating or revision. The data types and parameters identified in this handbook are based on interpretations of NRC regulations and guidance. Individual states may find that other data types or parameters may better address their specific needs in complying with their State's licensing requirements. 


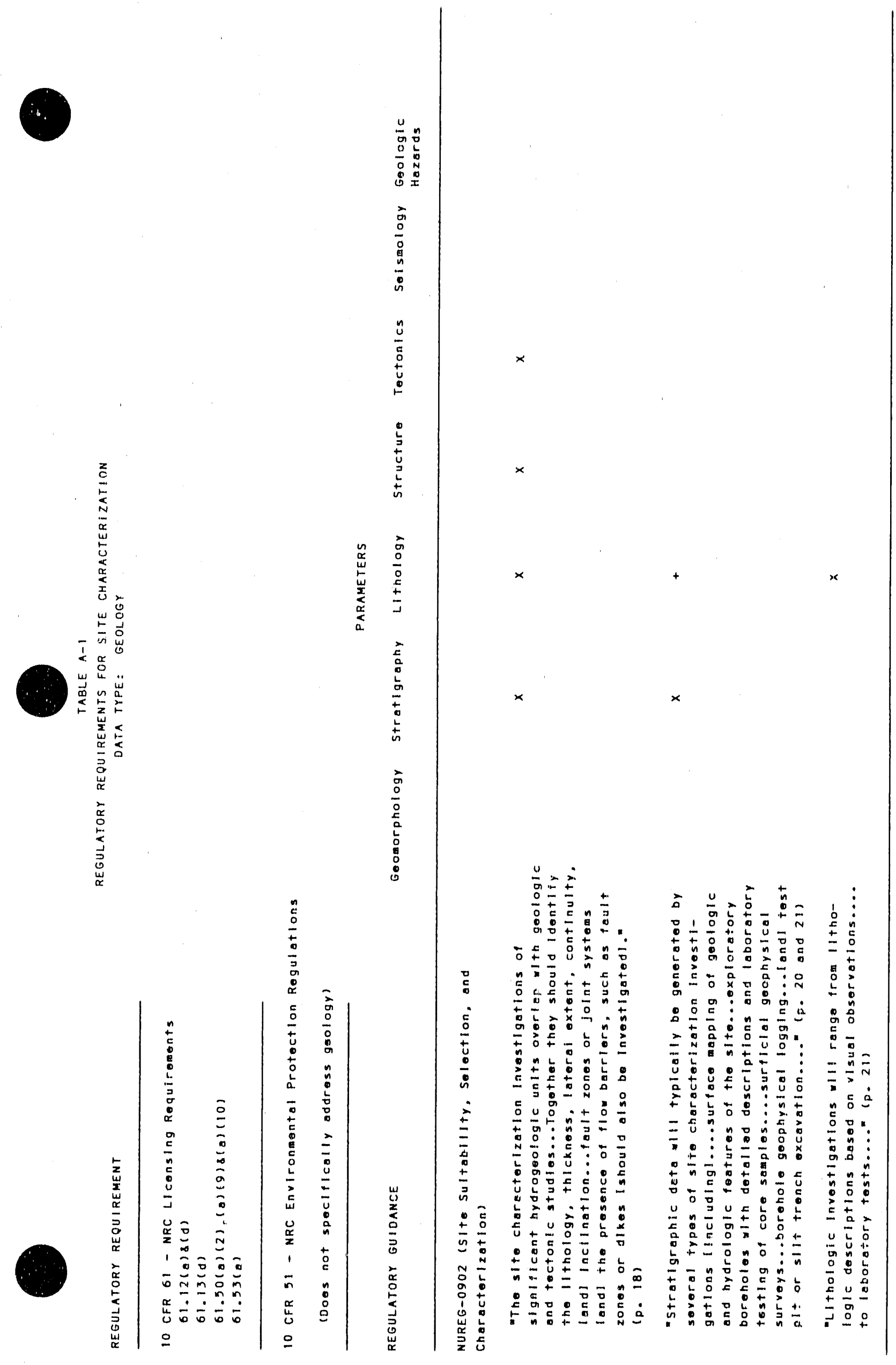




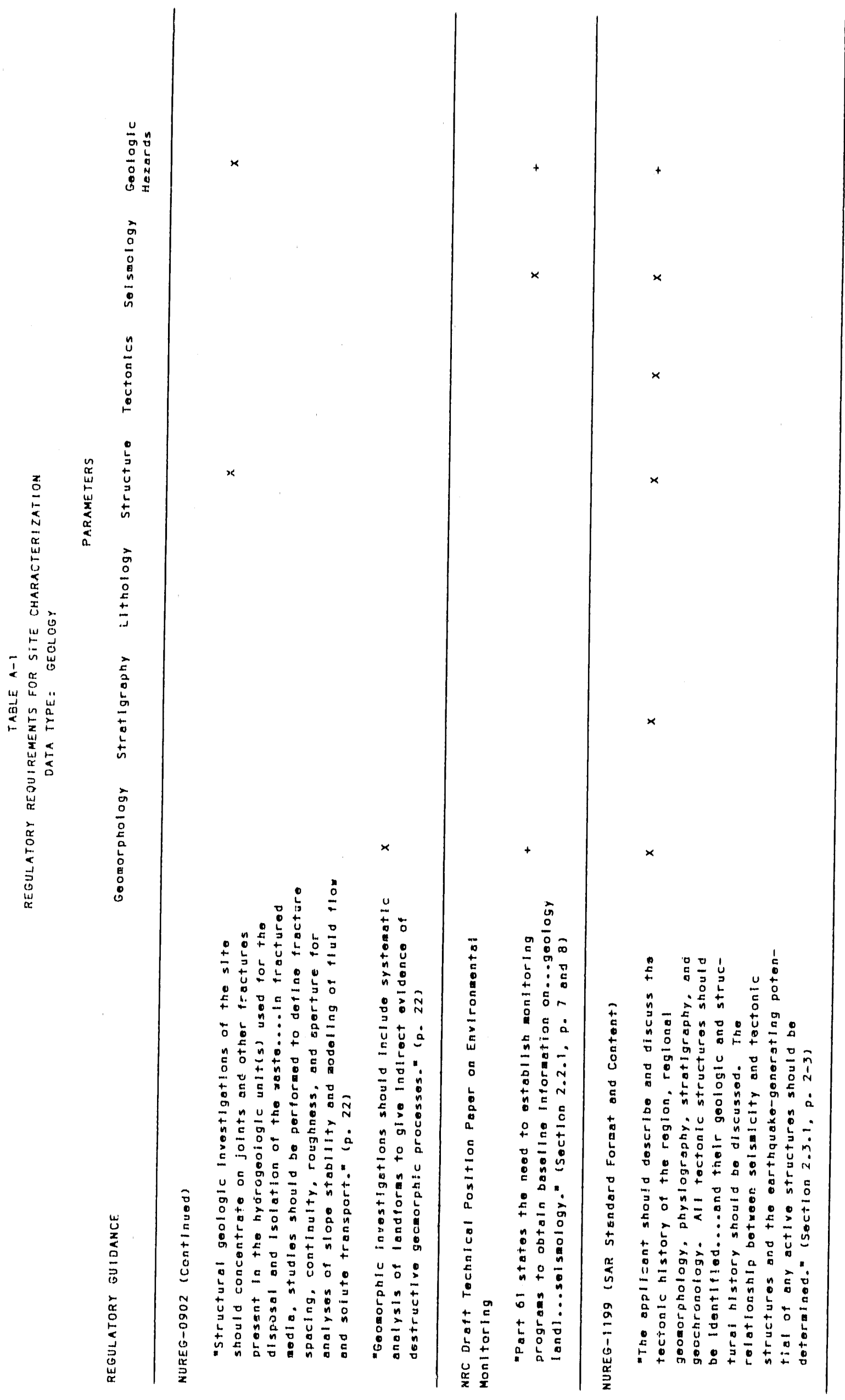




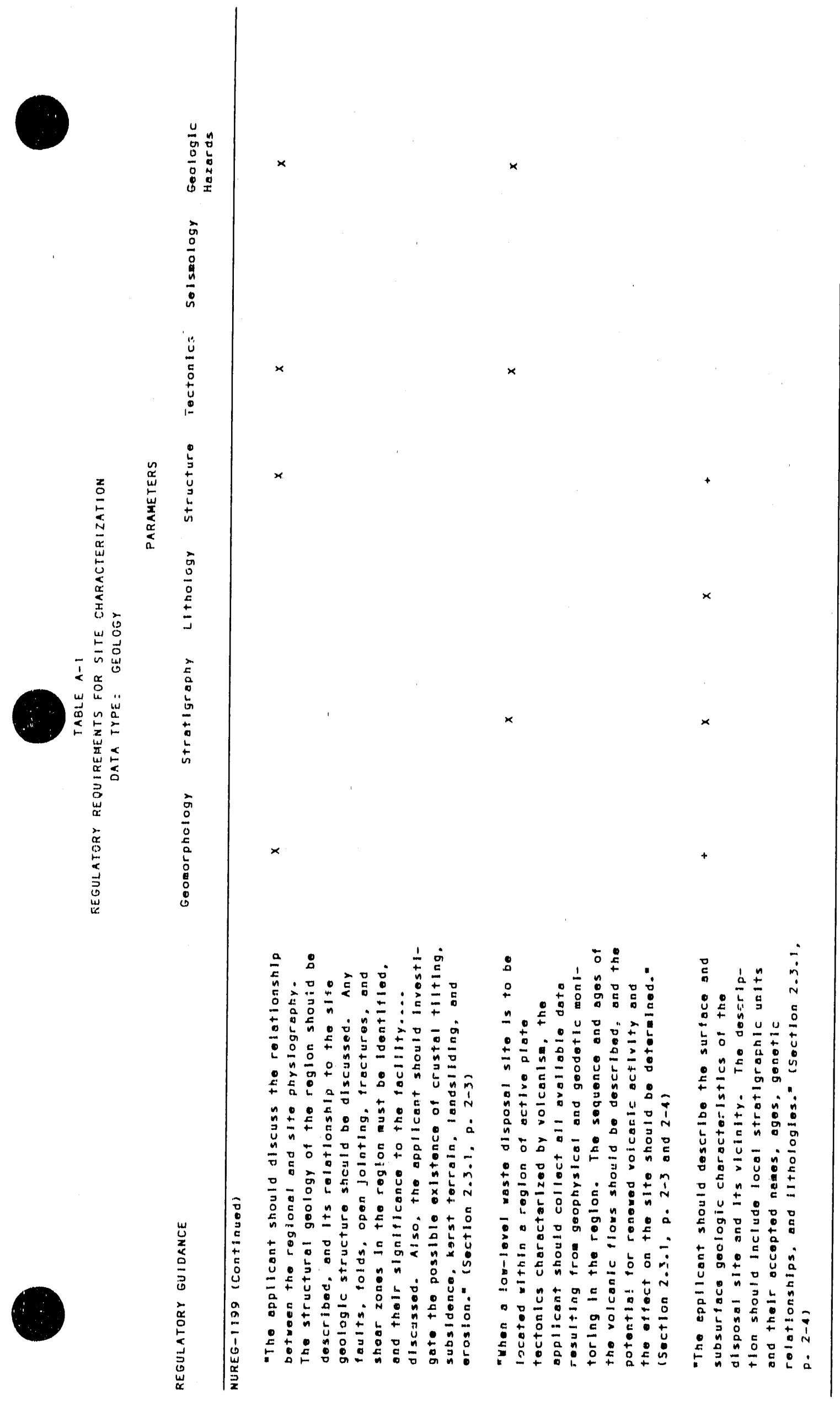




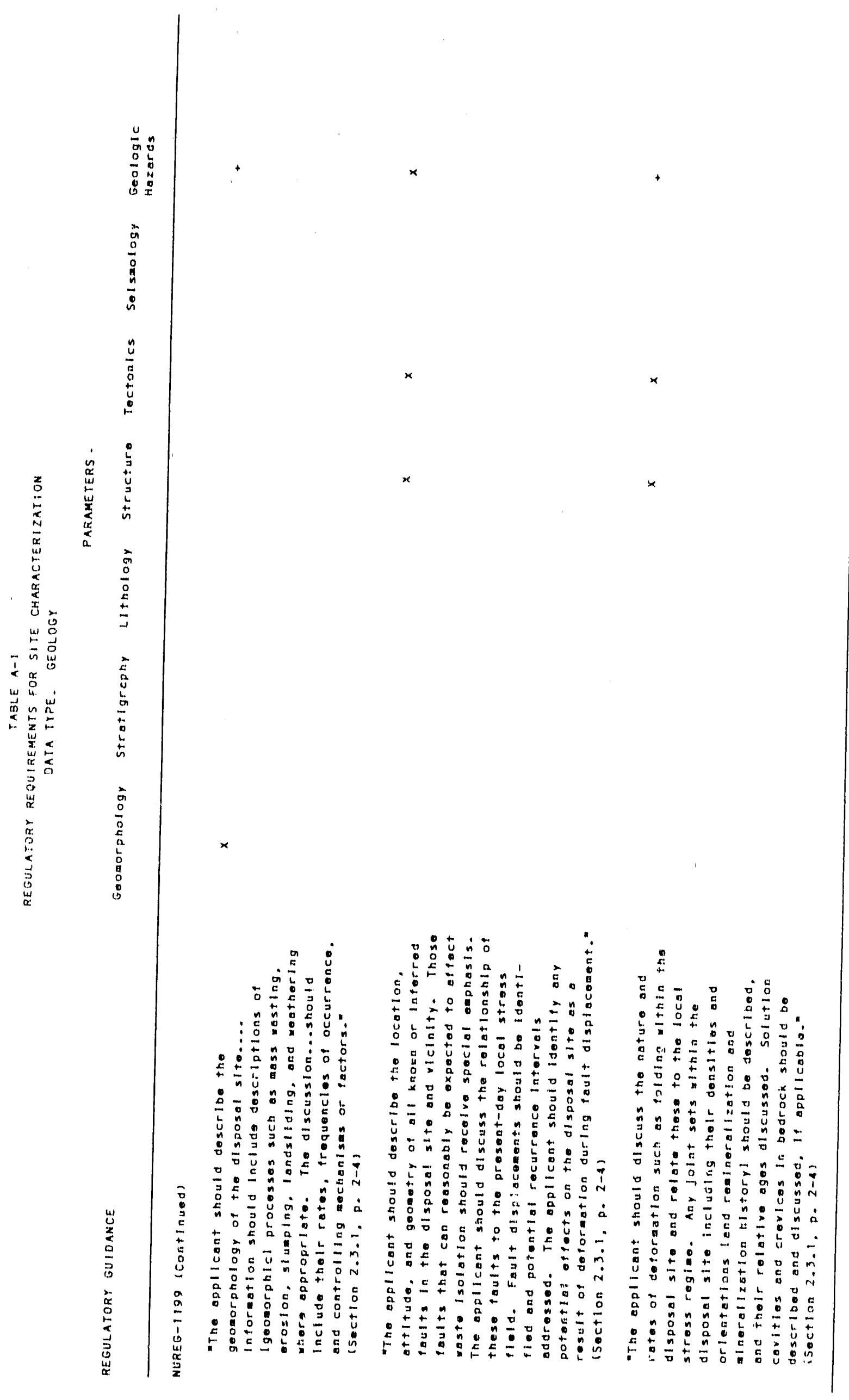




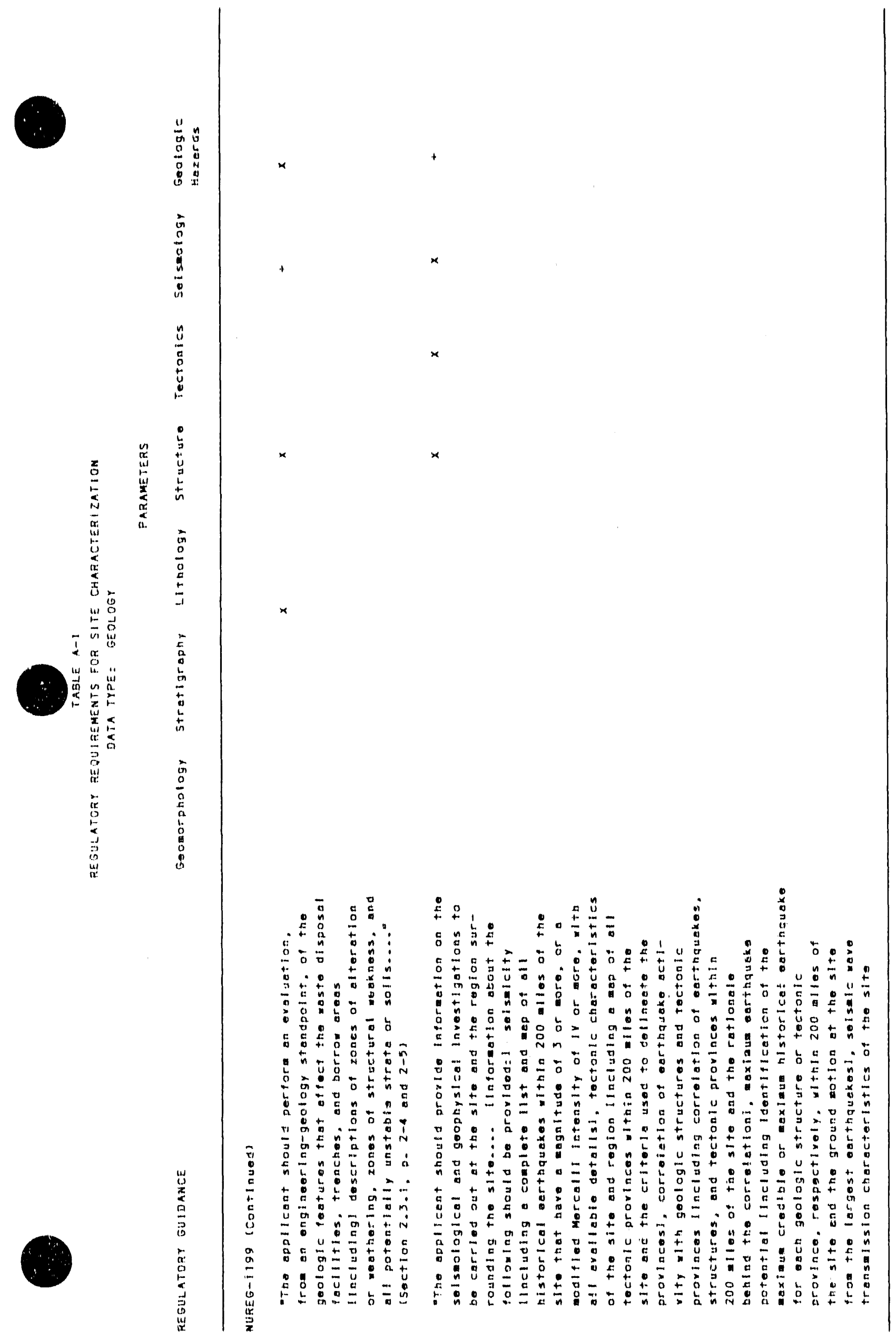




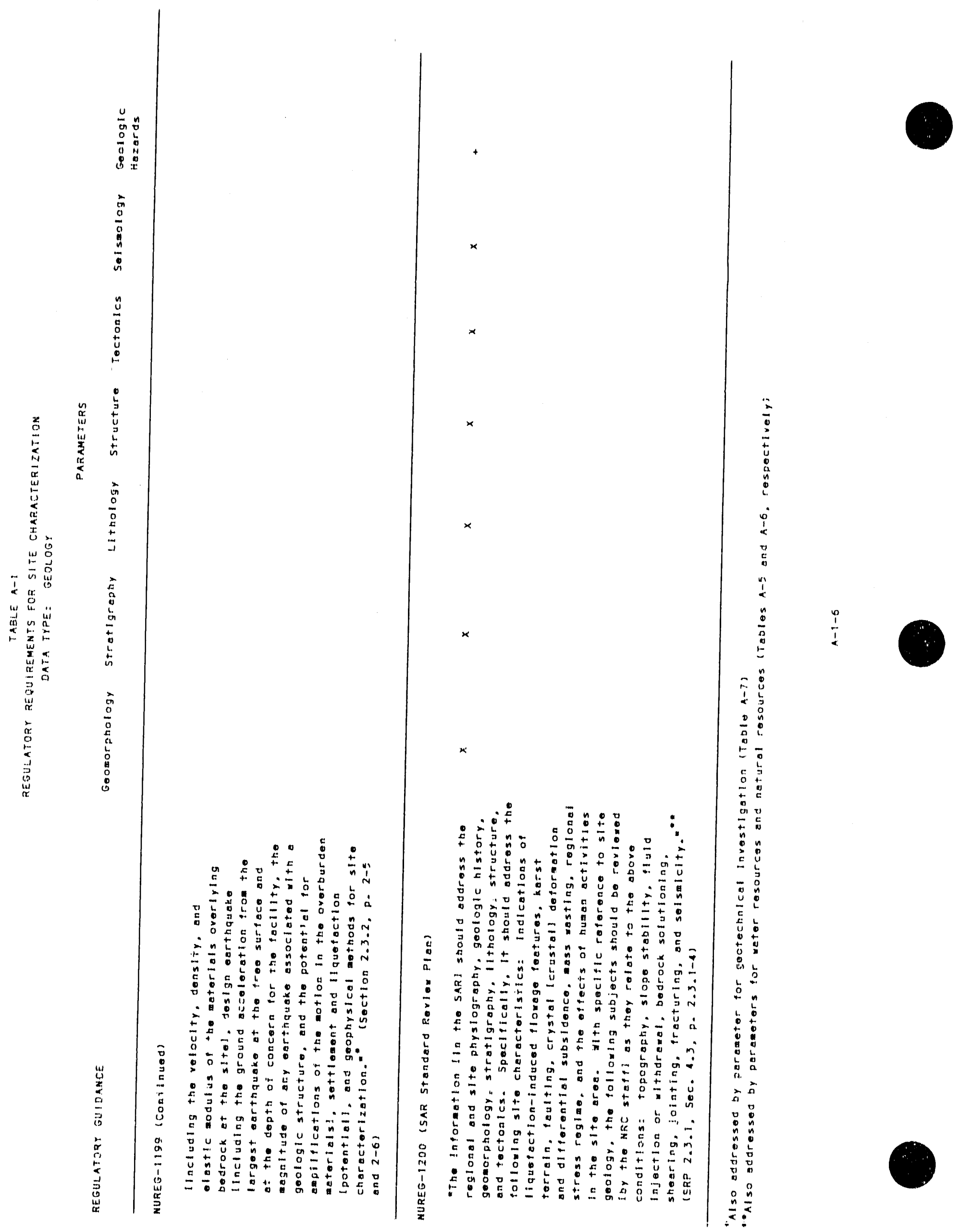




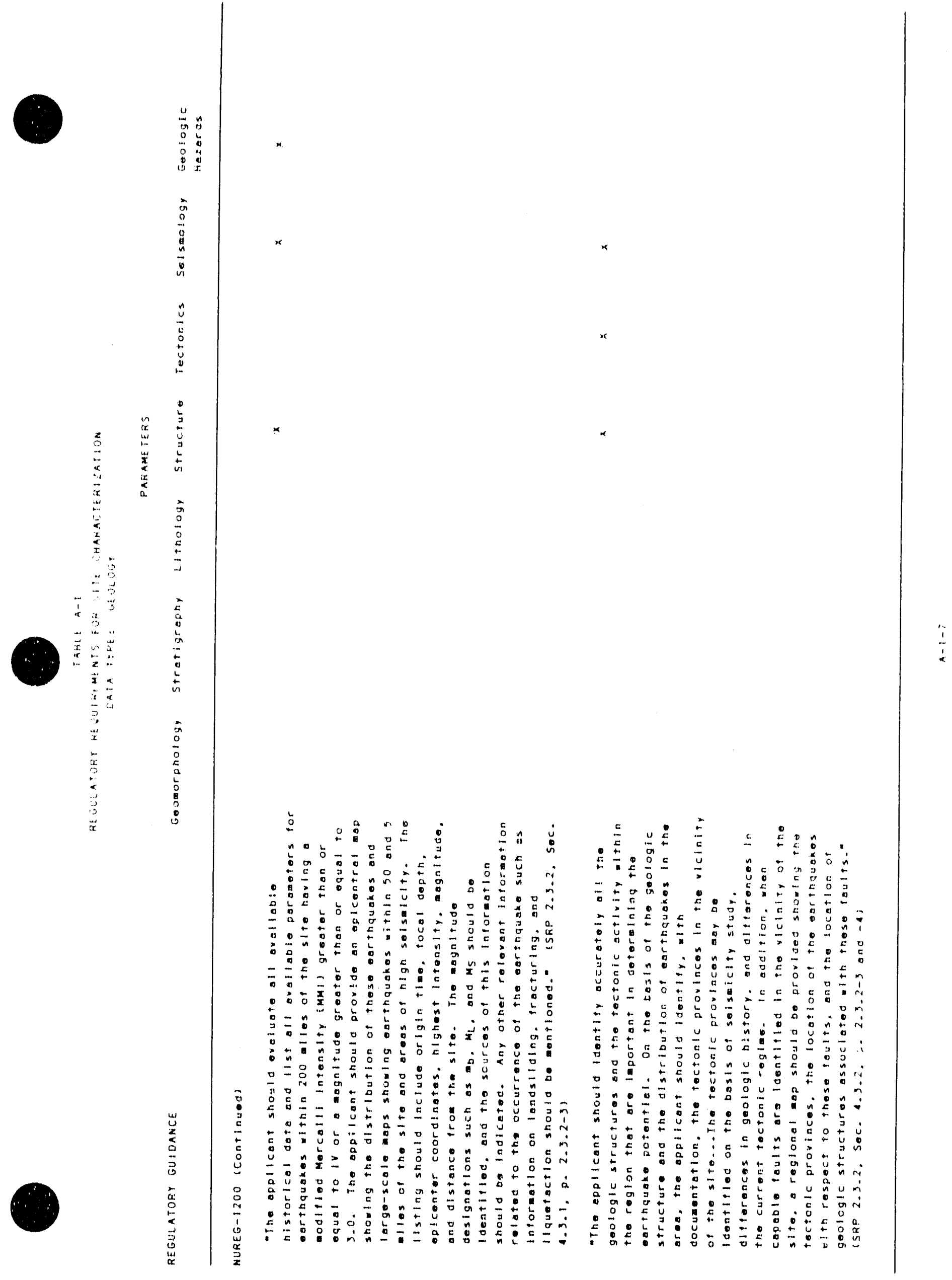




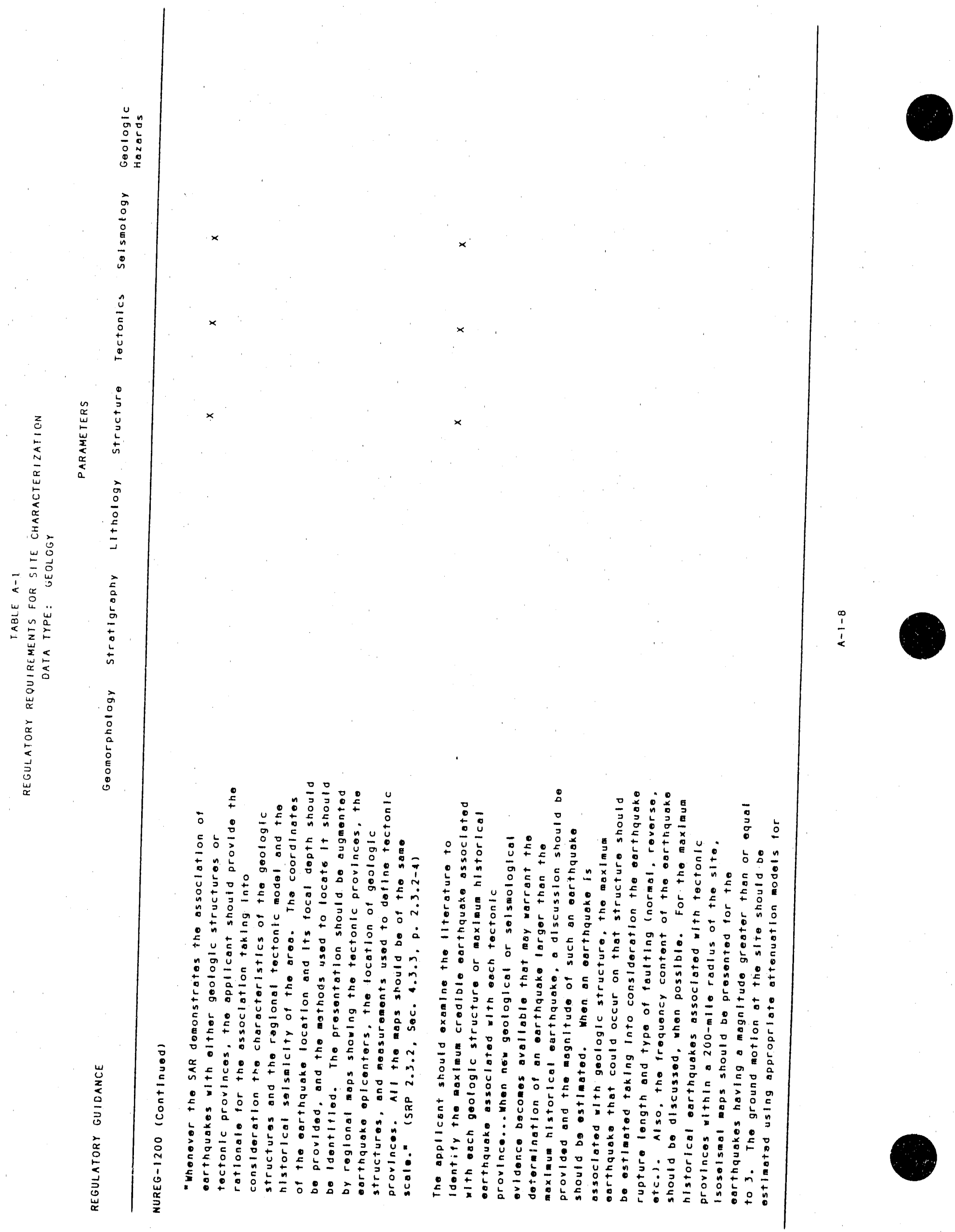




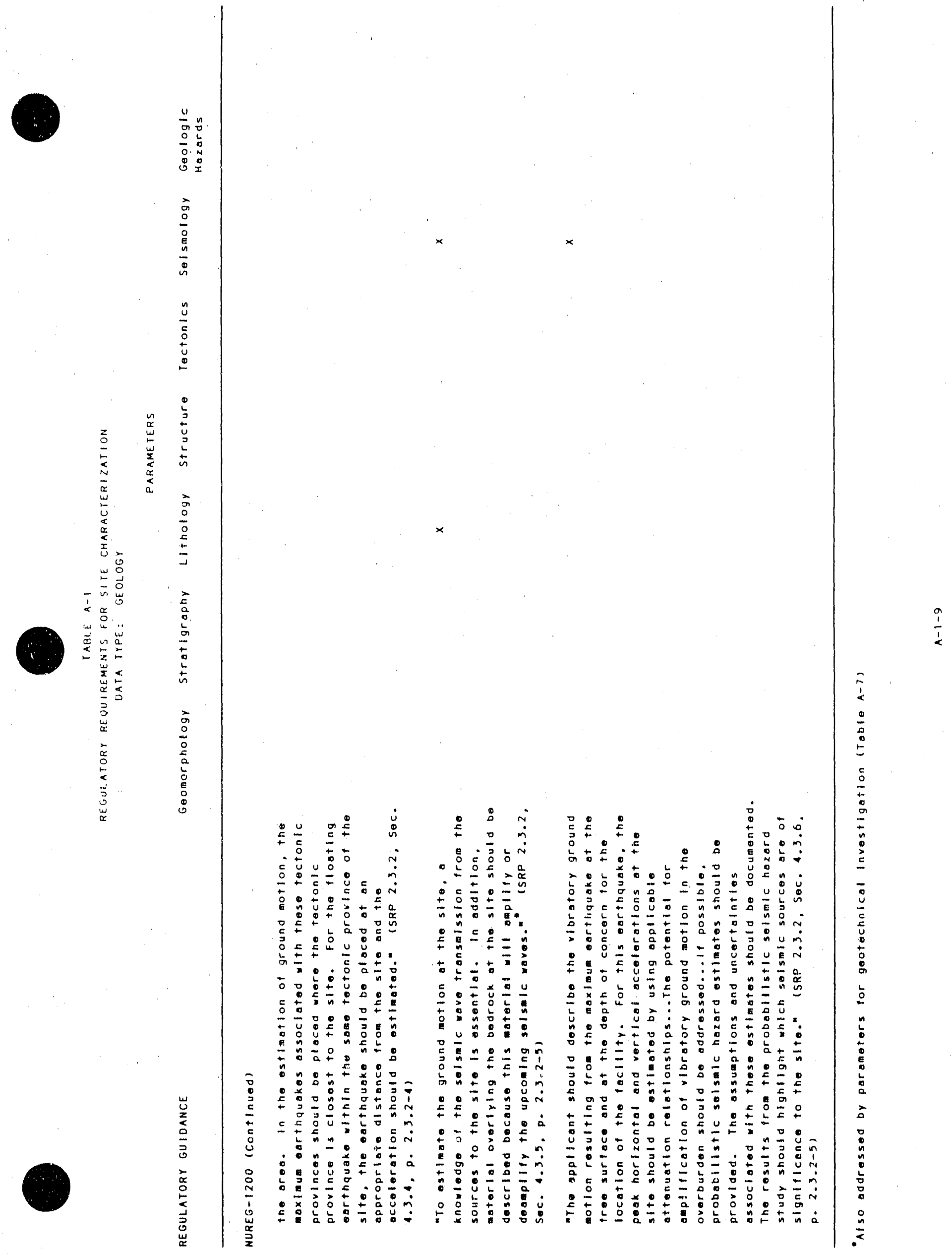




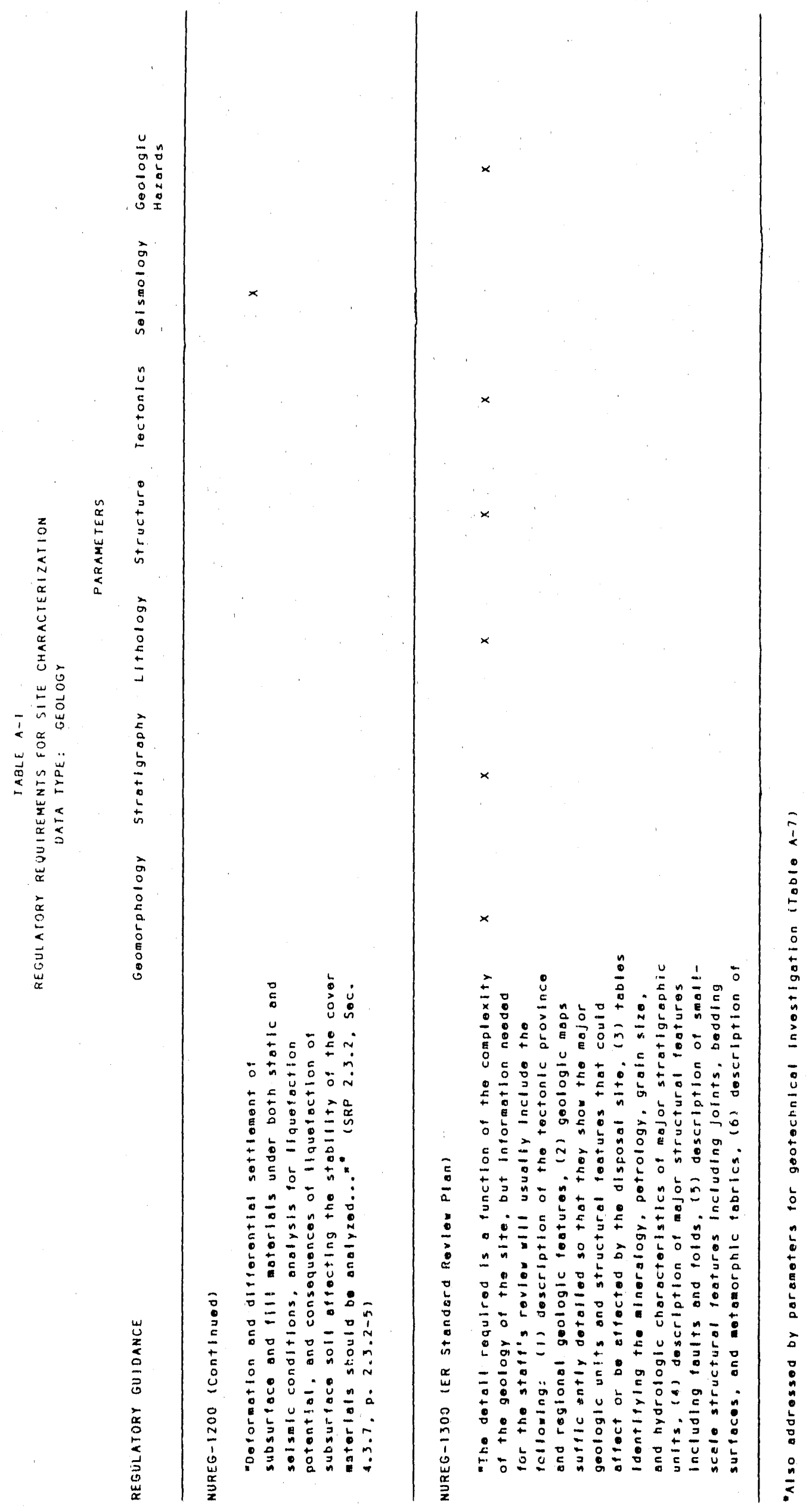




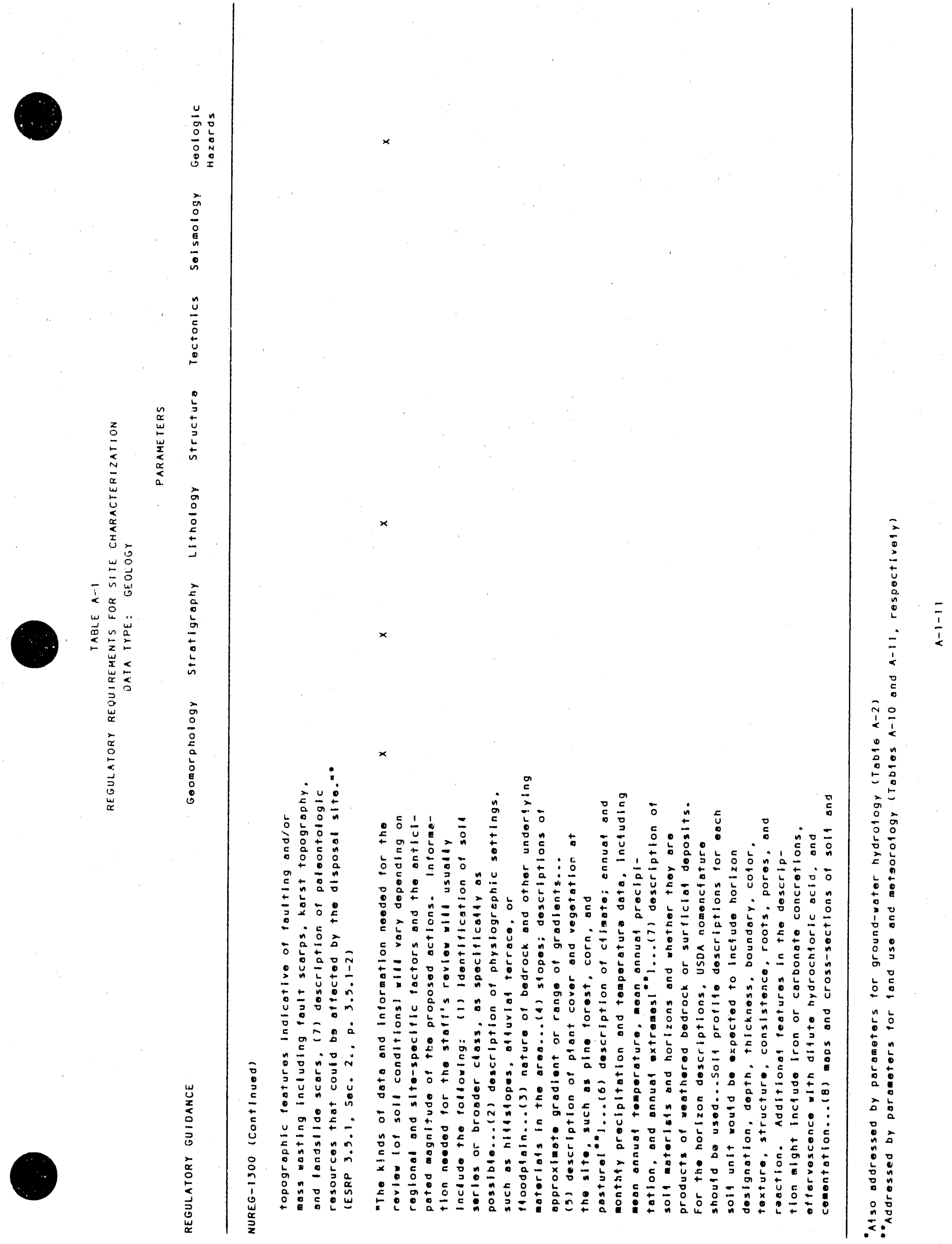



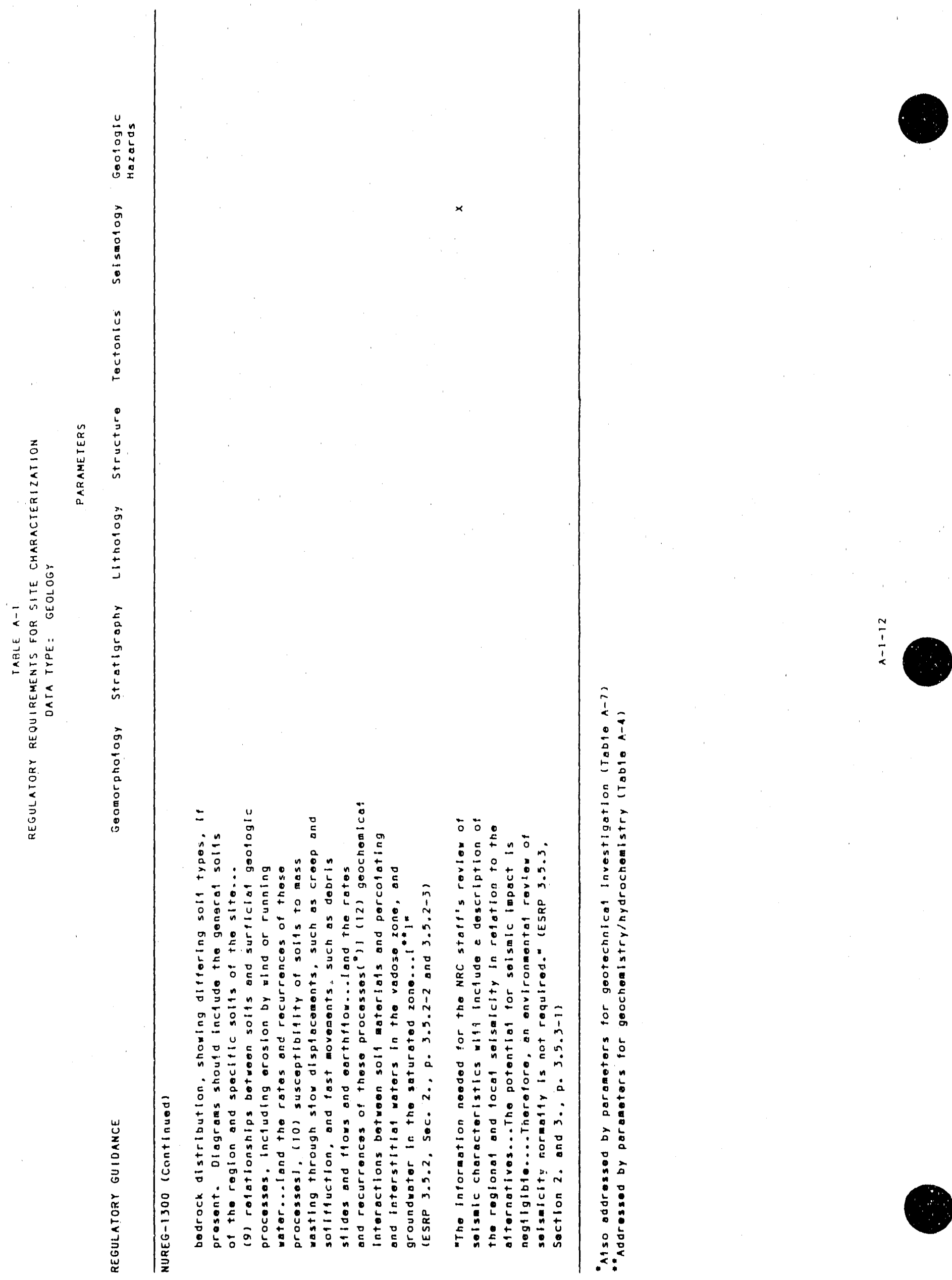
TABLE A-1

PARAMETER DESCRIPTIONS - GEOLOGY

Geomorphology: The characteristics, origin, and development of the regional and site landforms, their relationships to underlying structures, and the history of geologic changes as recorded by these surface features.

Topography, slopes, drainage basis, stream channels, mass wasting, weathering, and erosion, and the rate, frequencies, and controliting mechanisms of these processes are included in this parameter.

Stratigraphy: The classification, correlation, and interpretation of surficial and Quaternary deposits and underlying rocks. Stratigraphy is concerned with accepted unit names, genetic relationships, depositional environment, areal extent, unit depth, thickness, geometry, vertical and lateral extent and variations, heterogeneity, paleontology, age (geochronology), and the geologic history of the site area.

Lithology: The description of surficial and Quaternary deposits and underlying rocks based on visual and laboratory characteristics. Information such as the gross lithology, lithologic trends, color, mineralogy, grain-size distribution, texture/fabric, primary and sedimentary structures, facies changes and relationships, lithologic contacts, cementation, alteration, metamorphic grade, weathering, type of clay, inclusions, degree of devitrification of volcanic rocks, organic content, carbonate content, and natural radioactivity is part of a complete lithologic description.

Structure: The characteristics, origin, and development of the faults, folds, joints, solution cavities or crevices, and other discontinuities or zones of weakness within the region and site. This includes their location, orientation, relative position, length, spacing/density, relative age, aperture or infilling, roughness, mineralization history, type of structure, displacement history or deformation rate, potential recurrence intervals, relationship of structures to present-day local stress field, and capability or activity.

Iectonics: The large-scale structure of the Earth's crust and the nature and rates of the processes responsible for these structures. This parameter includes the tectonic provinces within 200 miles of the site and their history, uplift, subsidence, tilting, folding, faulting, nature of volcanism and volcanic history, the regional and local stress regime, and the potential for unrelieved stresses to produce creep and rebound within the time frame of interest (500 years).

Seismology: The study of earthquakes and their relationship to the tectonics and structure of an area by both natural and artificially generated seismic waves. This includes determining, within a 200 -mile radius of site: the historical seismicity of magnitude 3 or greater, or of modified Mercalli intensity IV or greater, with all available details; the earthquake recurrence intervals; the correlation of earthquakes with structures or tectonic provinces and rationale; the maximum earthquake potential of each geologic structure or tectonic province, its frequency content, and the resulting 
ground motion at the site; and the design earthquake and accelerations at the site developed, if possible, from probabilistic seismic hazard estimates. The seismic wave transmission characteristics of the site, including velocities, bulk densities, and the shear and elastic moduli, and historical and potential fault rupture, seismically-induced hillslope fallure, and liquefaction or settlement are also included in this parameter.

Geologic Hazards: The potential natural or man-induced hazards that could present a risk or potential dariger to the site or to life. Evaluation of fault displacement, seismicity, slope fallures, landslides, renewed volcanism, subsidence, collapse, liquefaction, karst terrain, flooding, expanding clays and other unstable elements in near-surface stratigraphic units and soils, and corrosivity of soils should be part of the site geologic hazards assessment. 


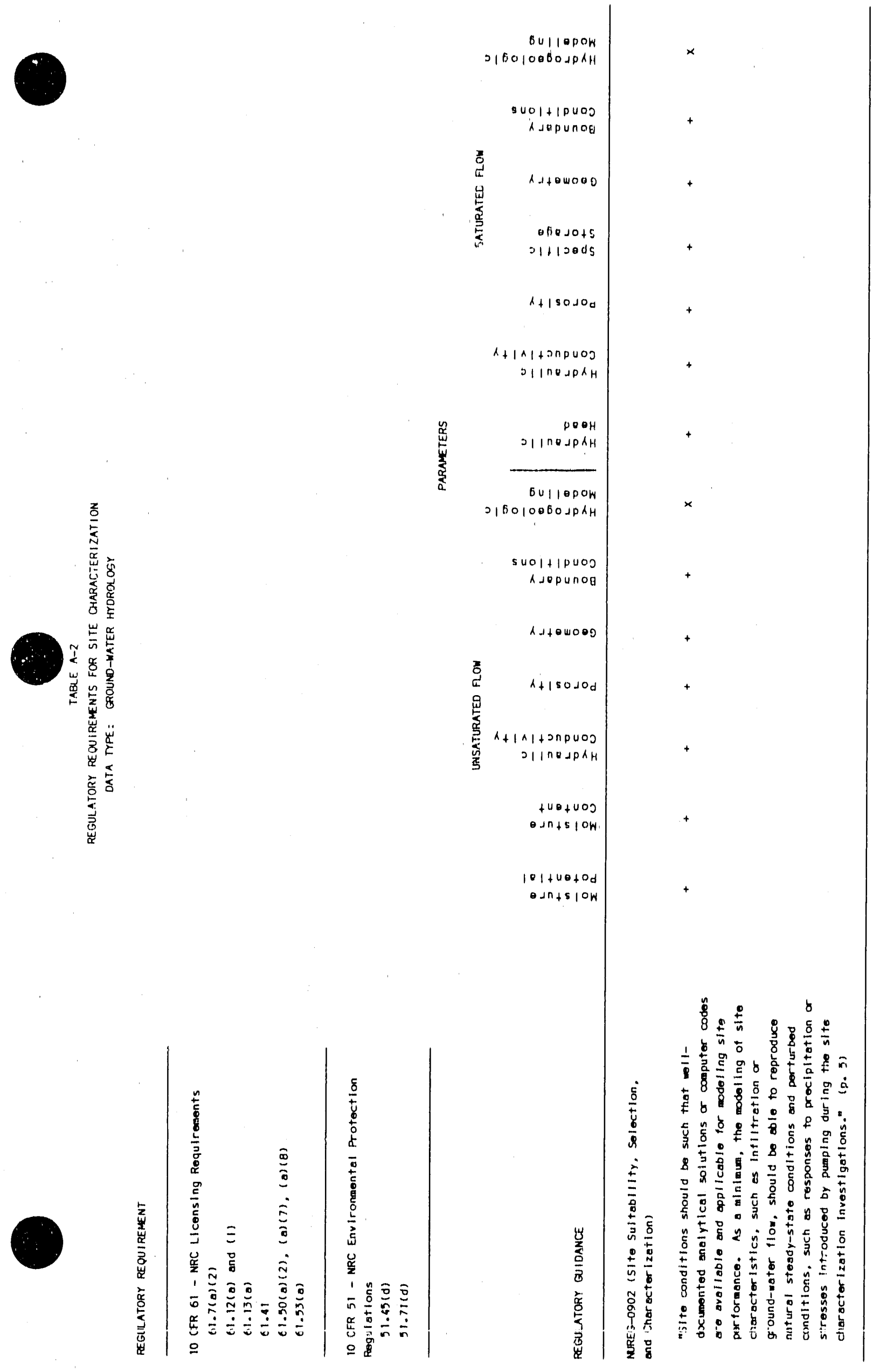




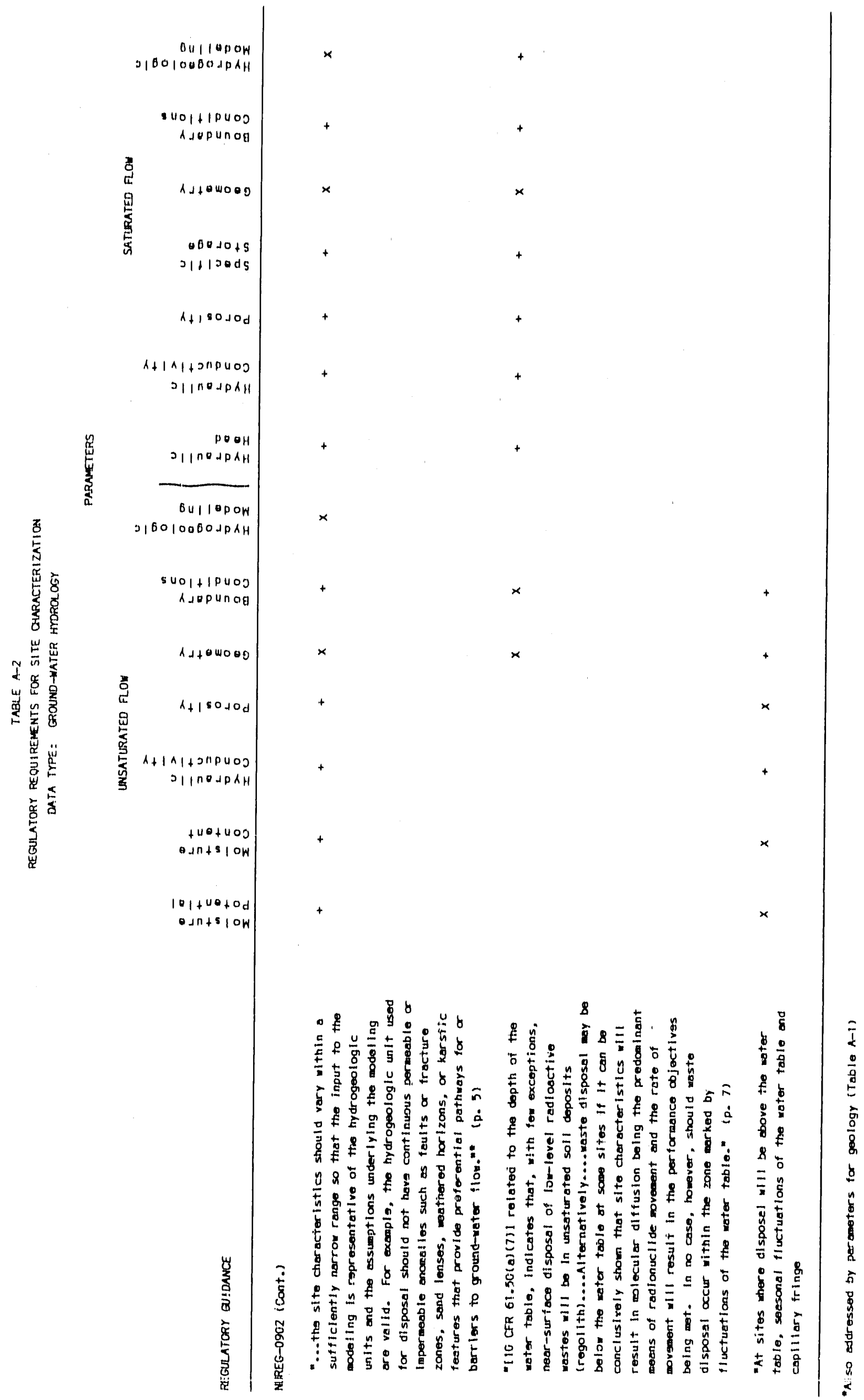




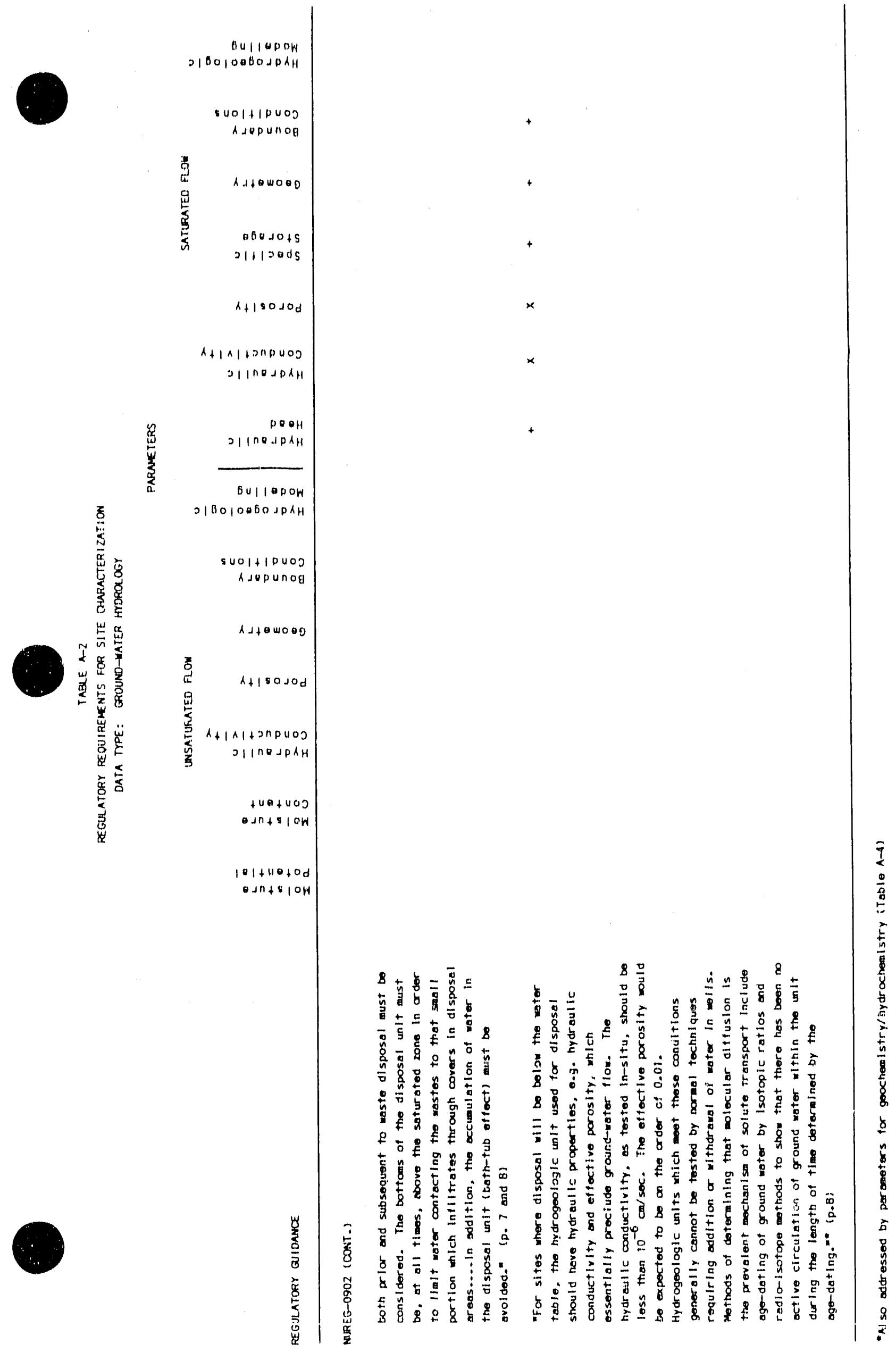




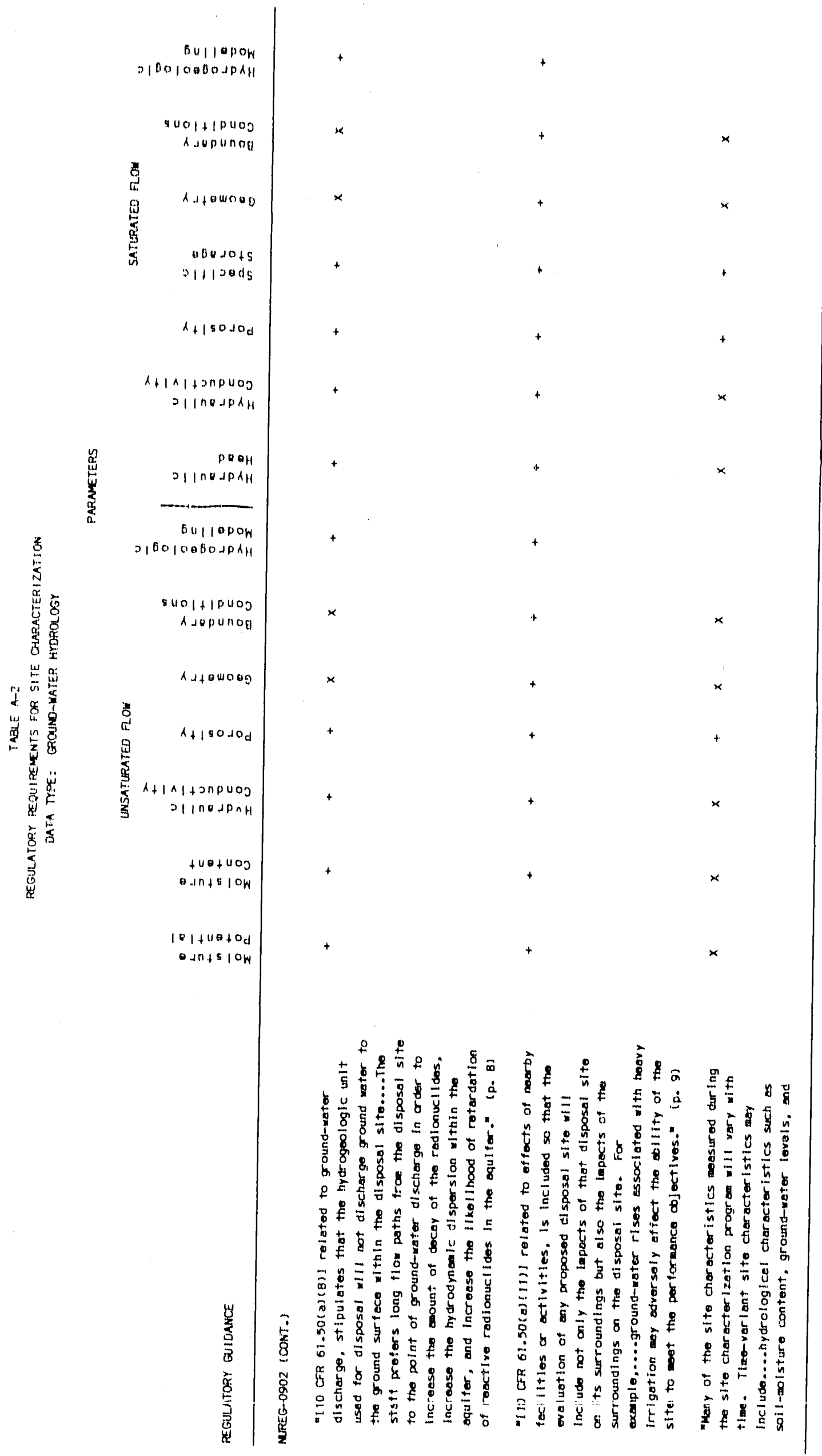




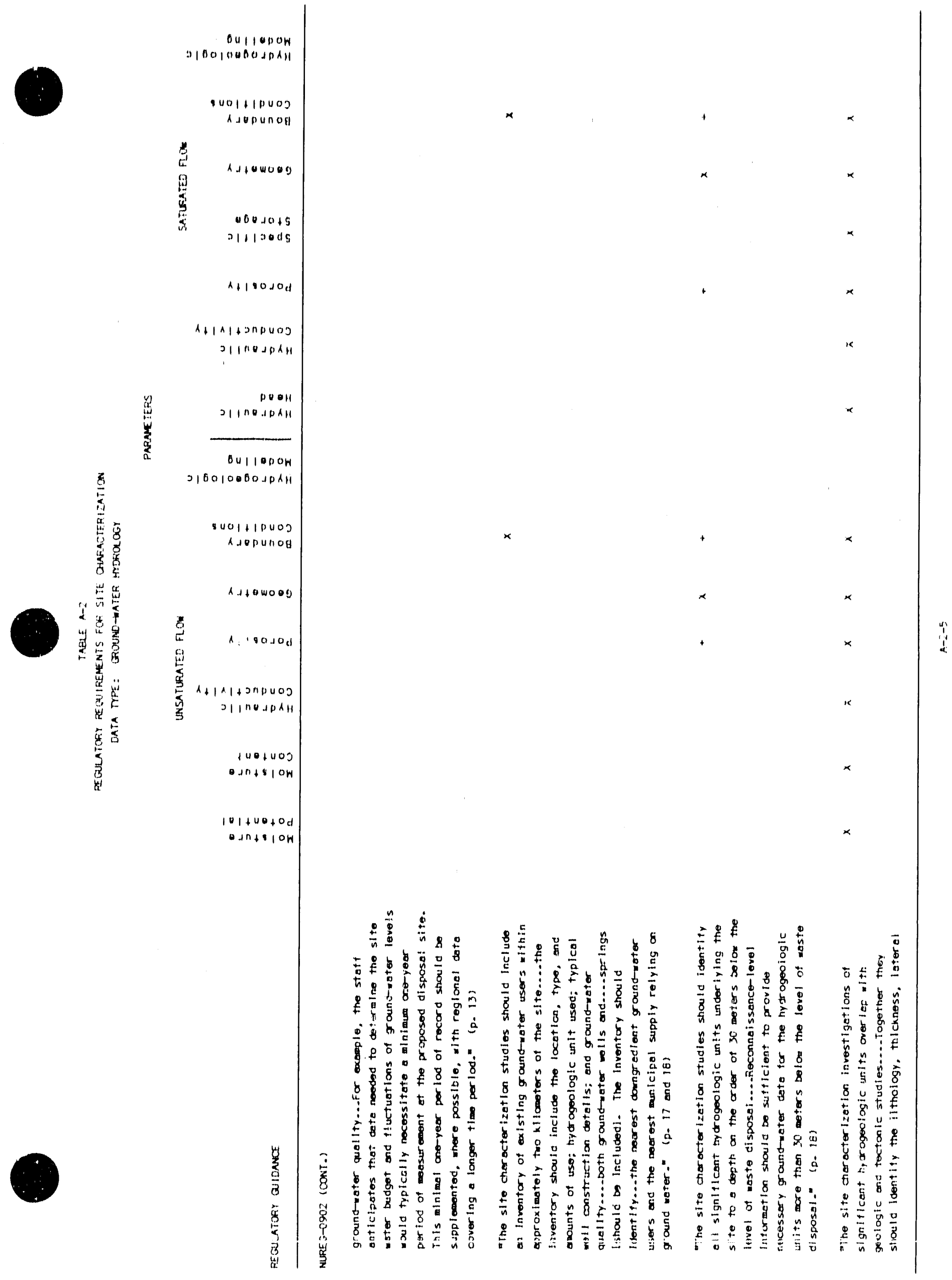




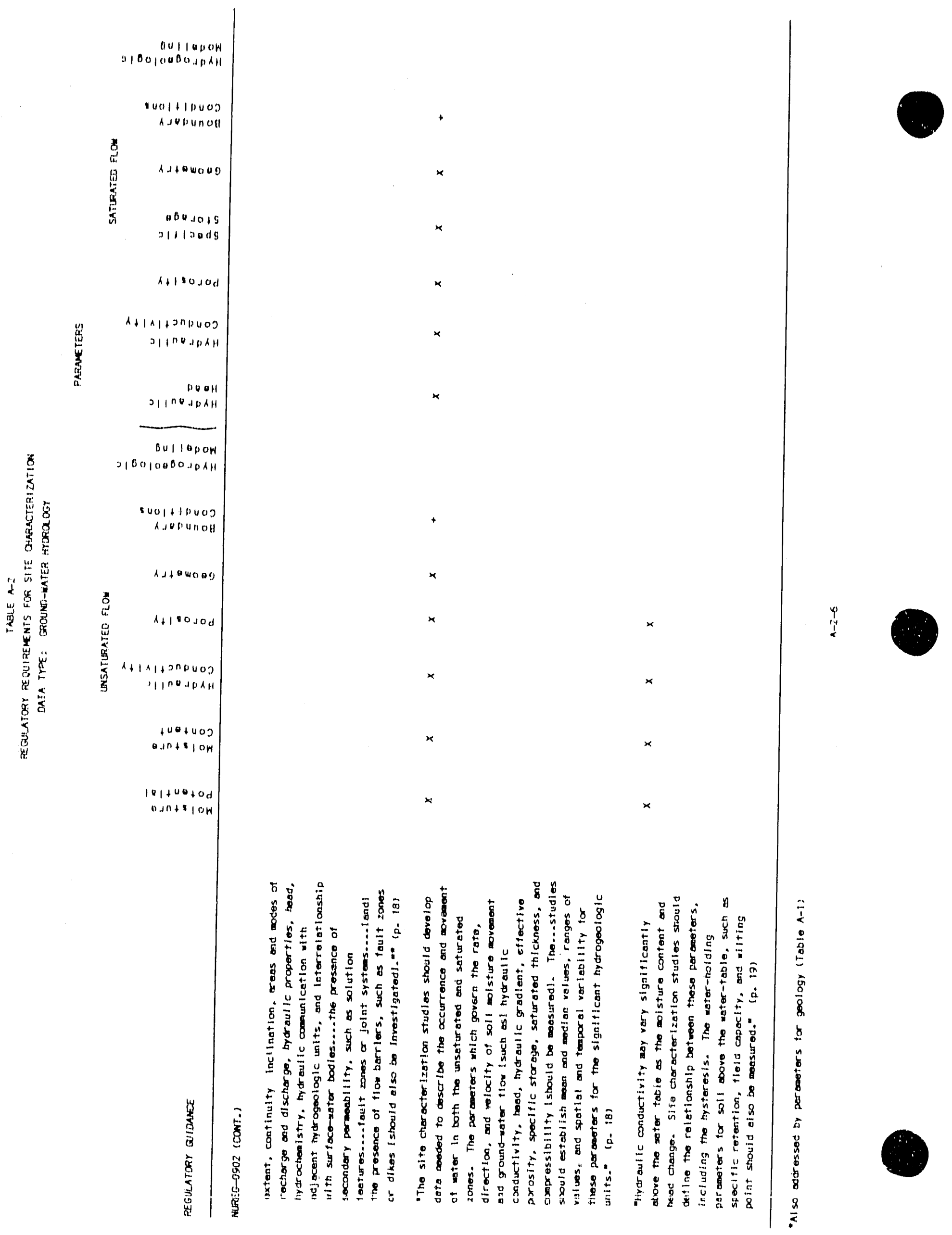




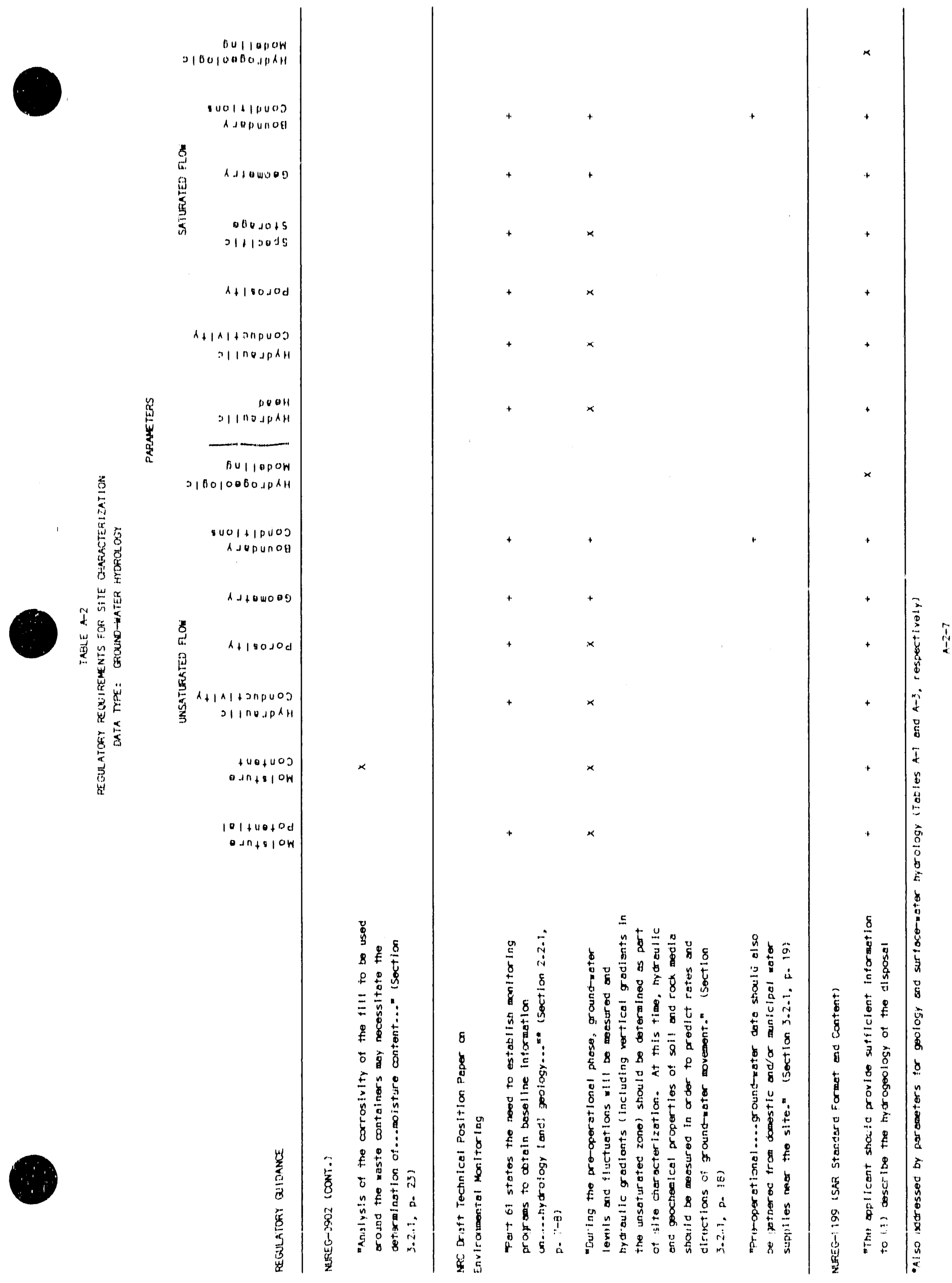




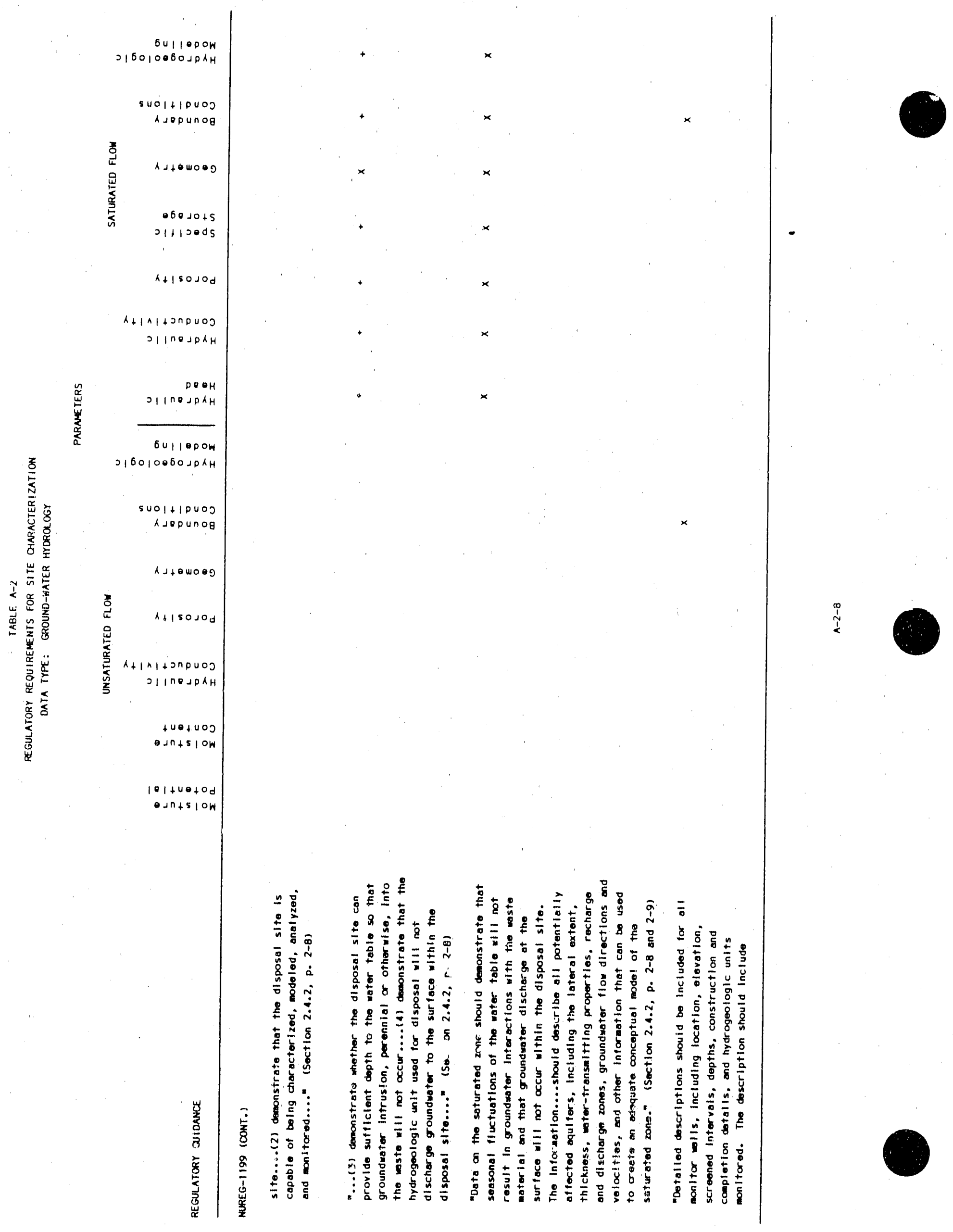




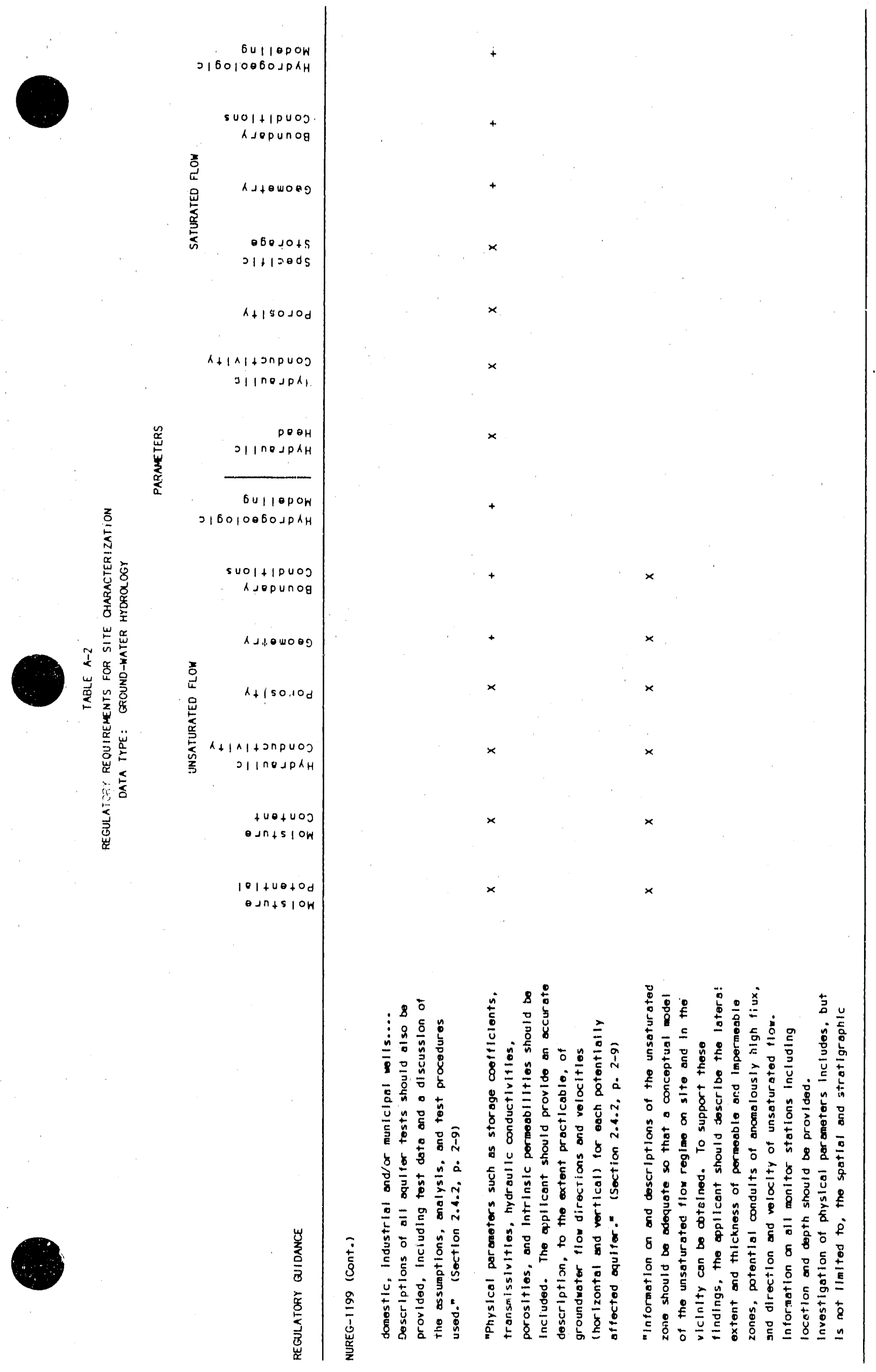




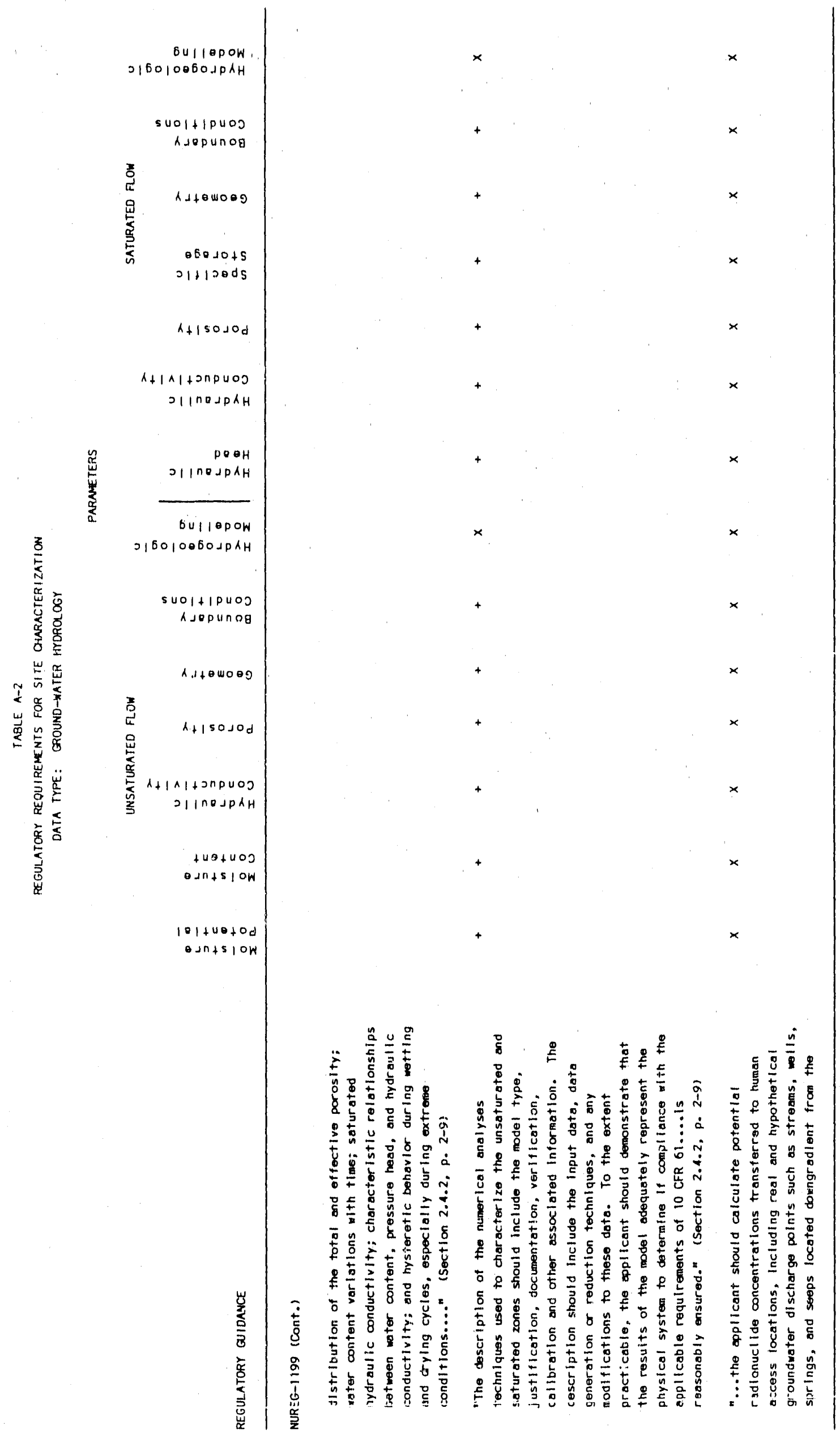



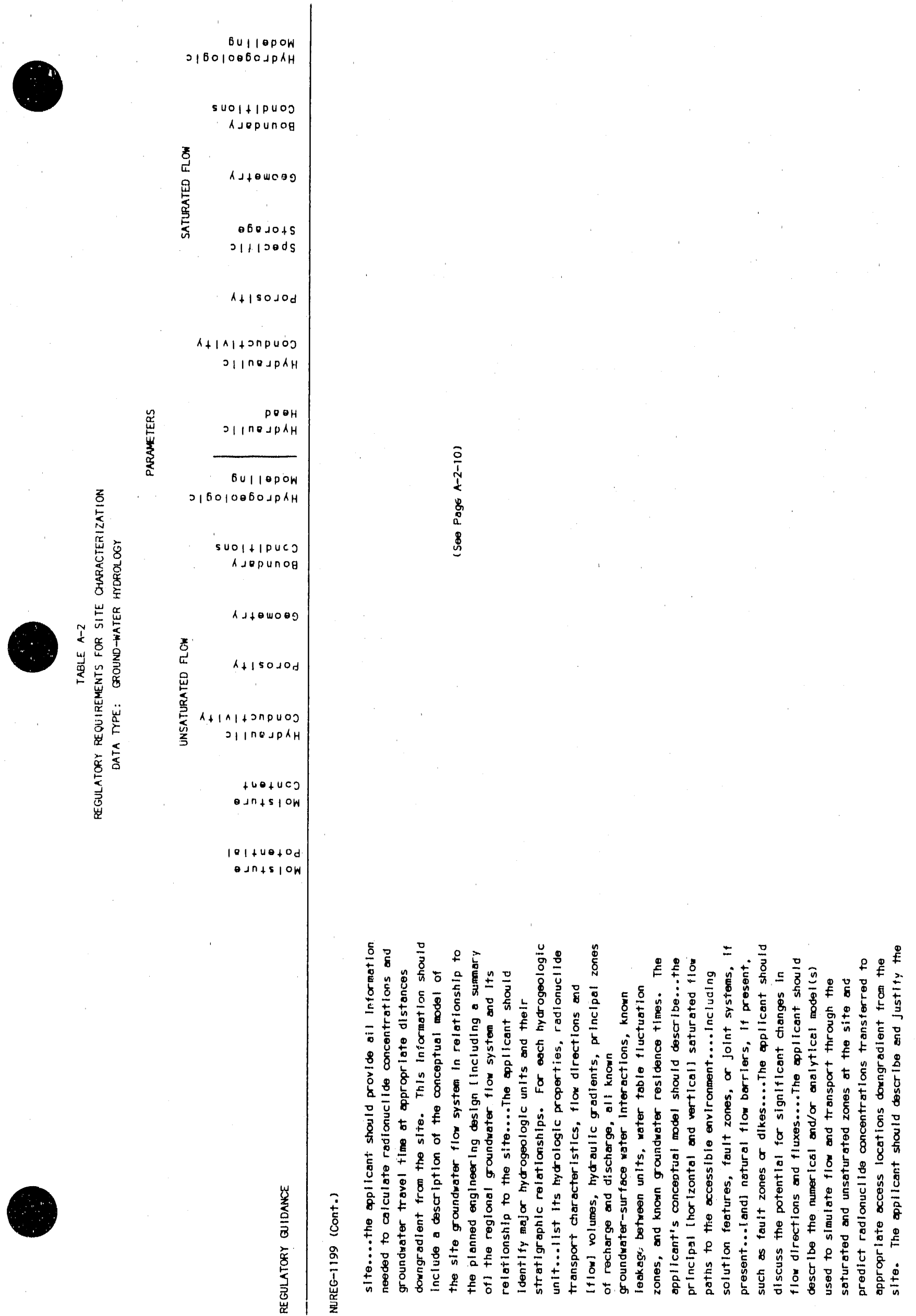


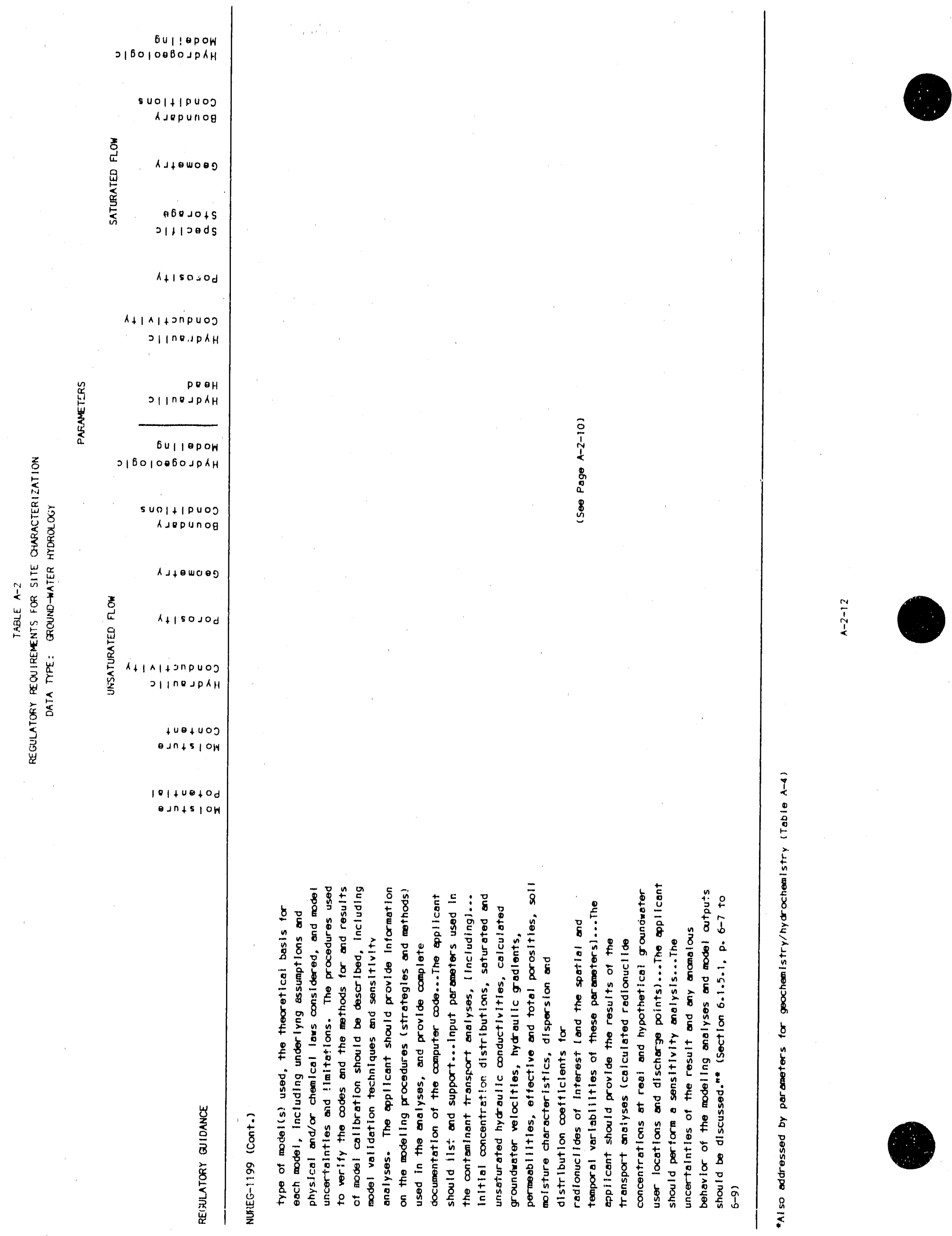



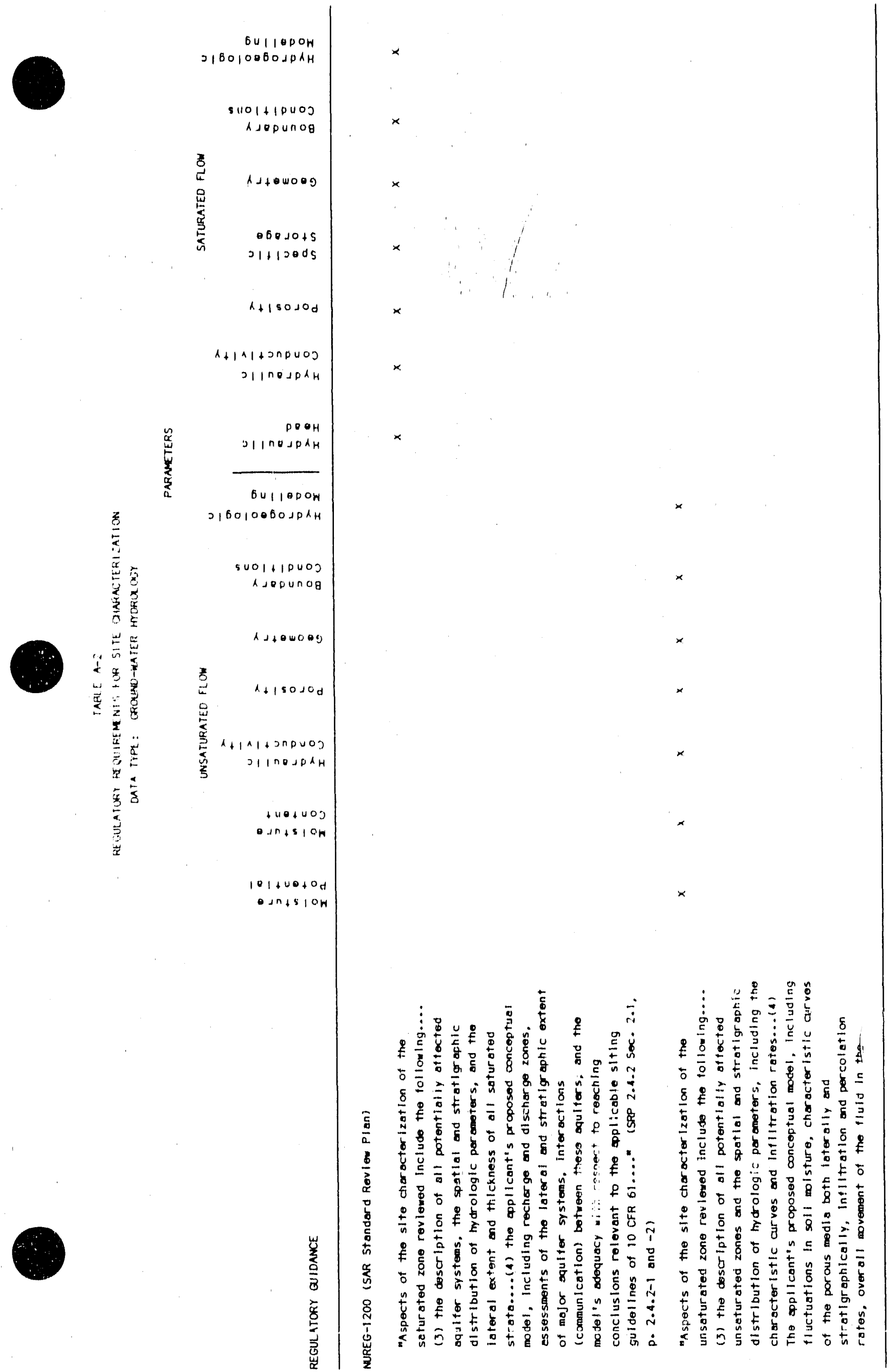

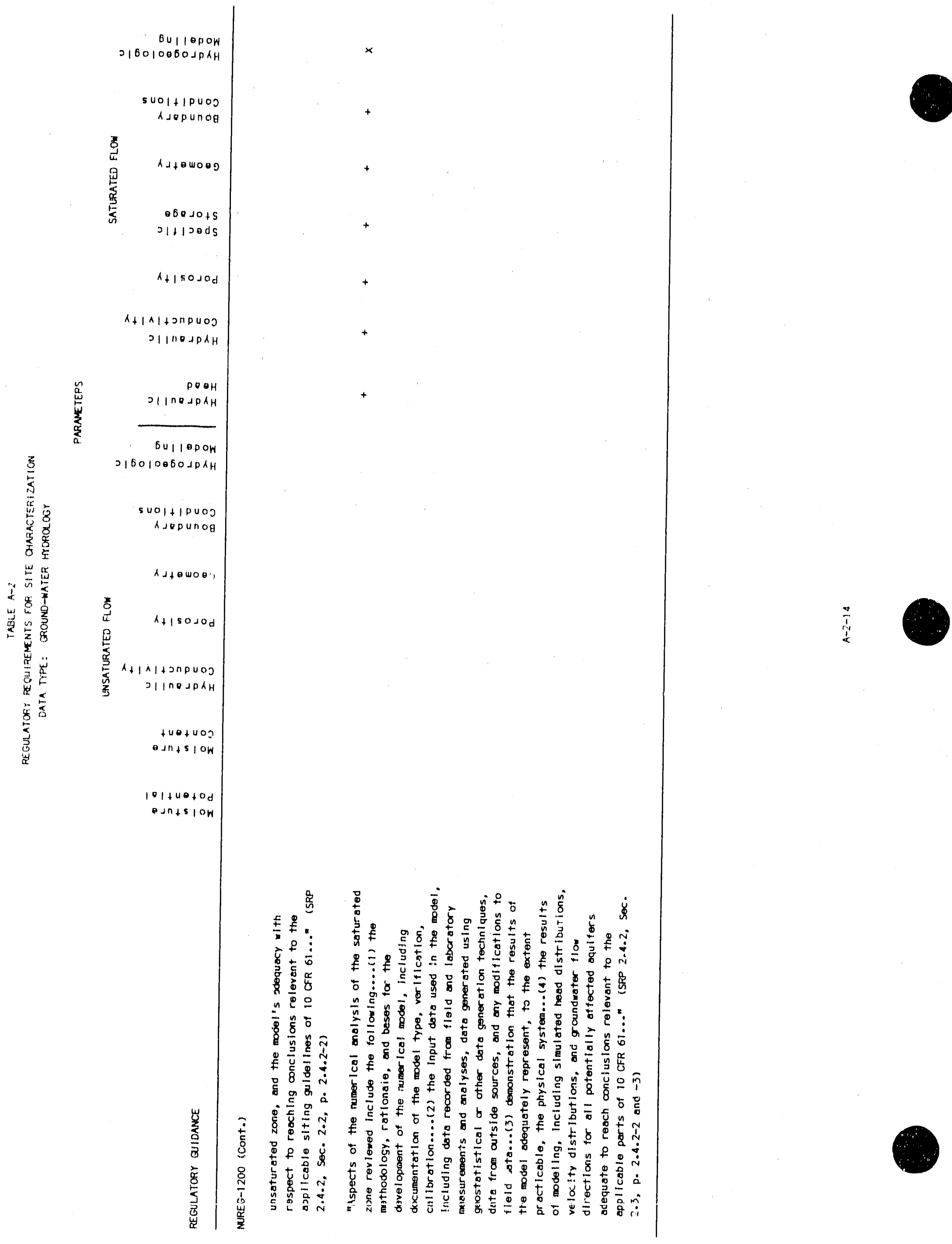


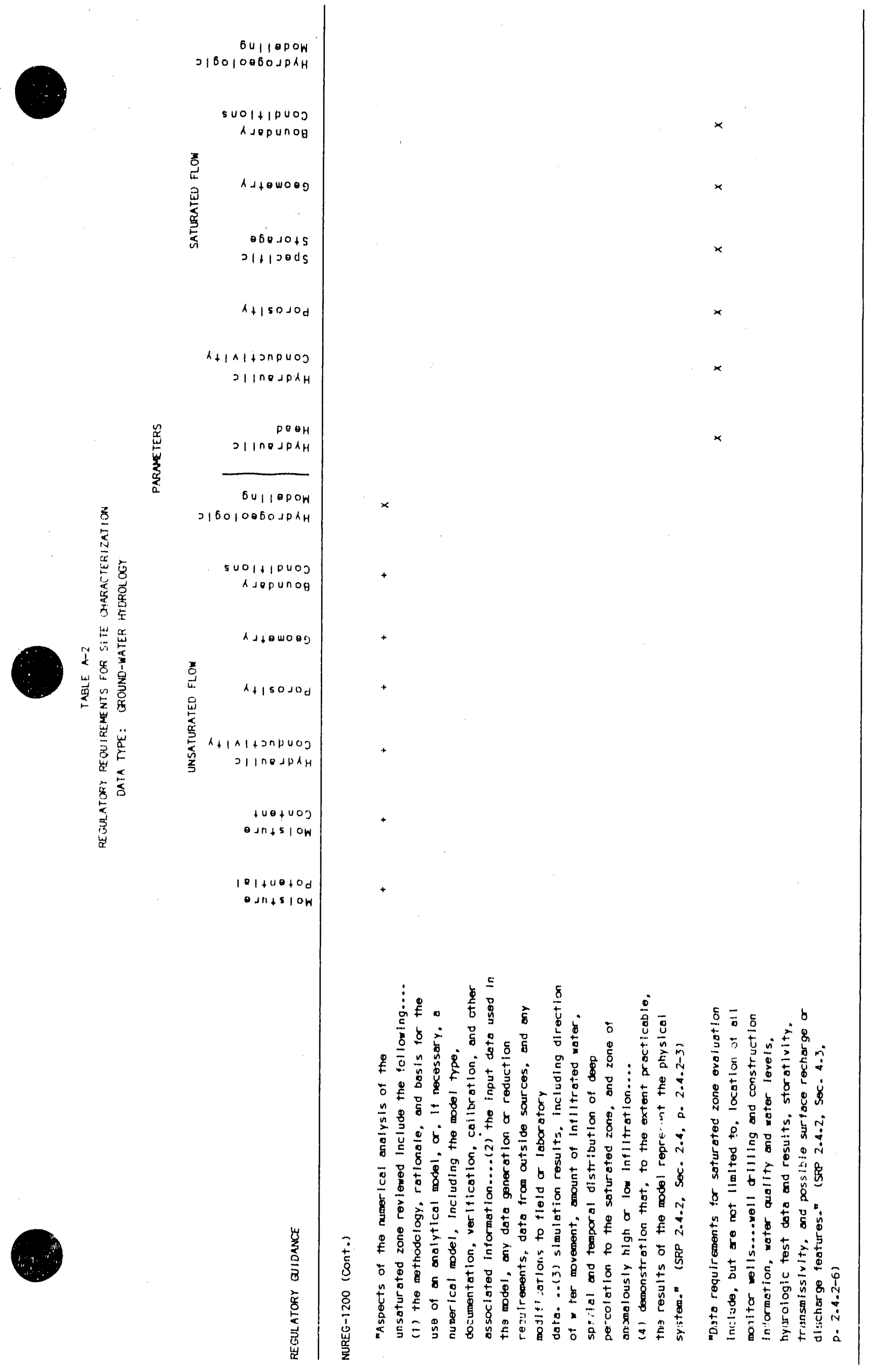




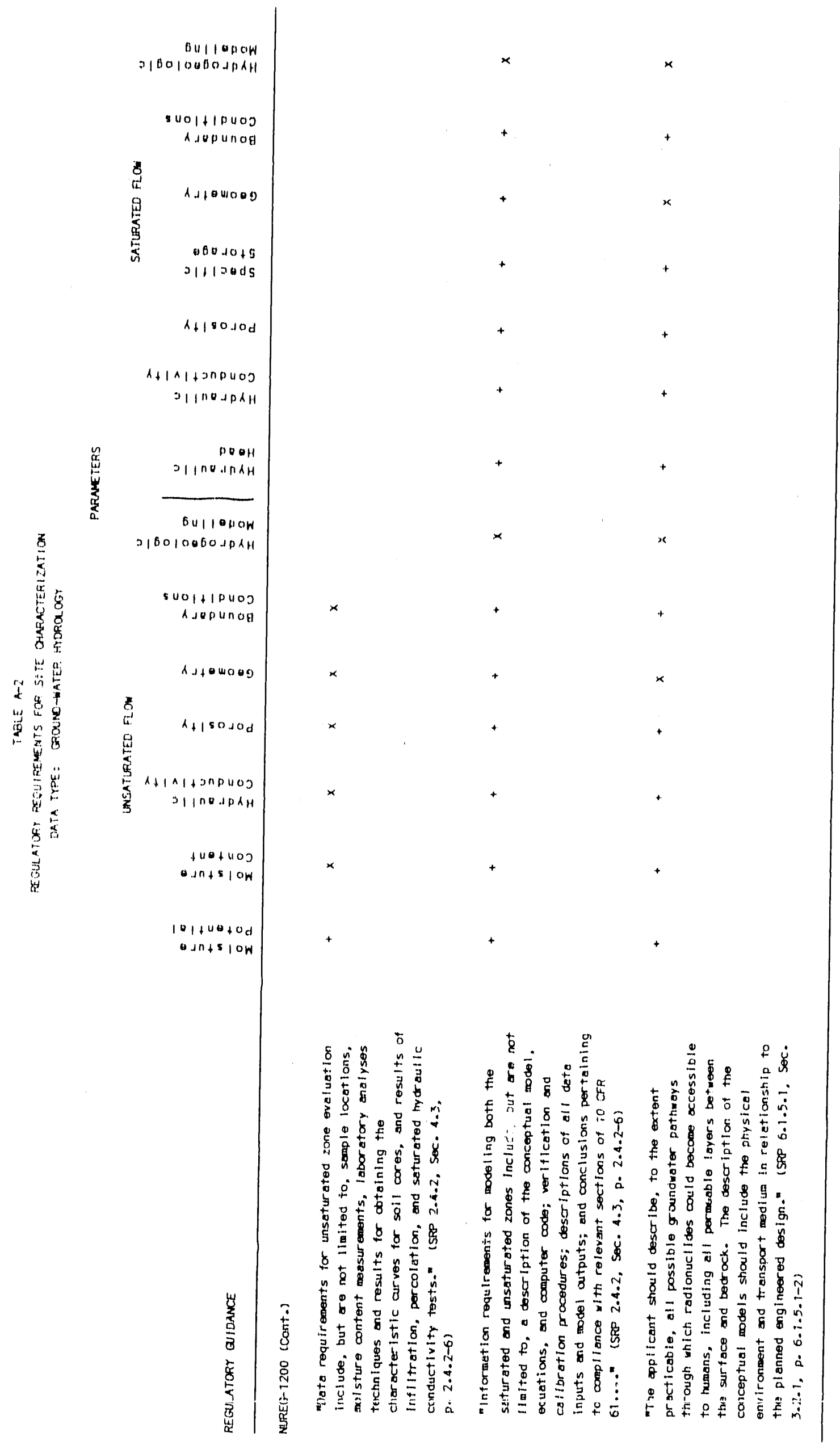



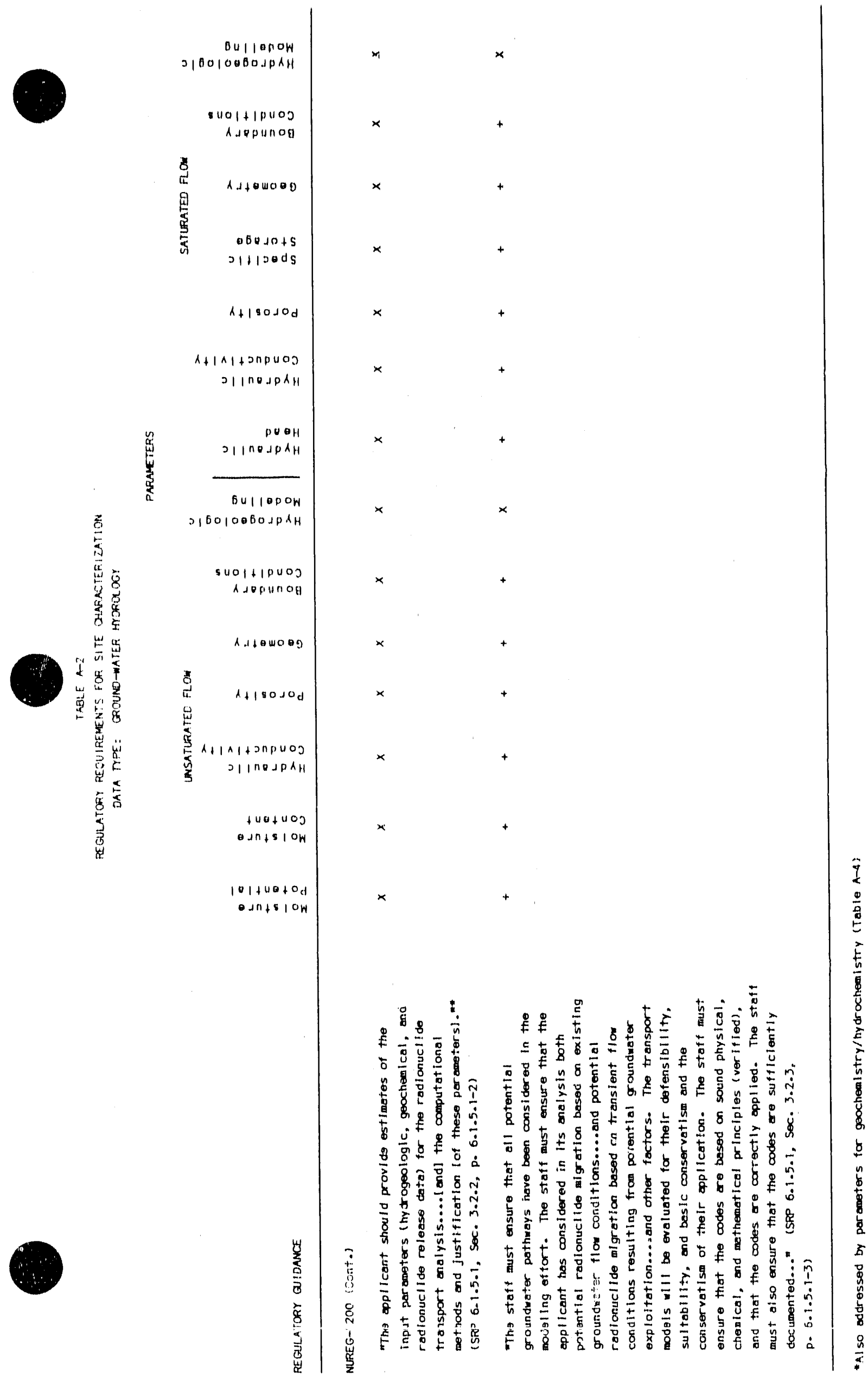

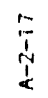




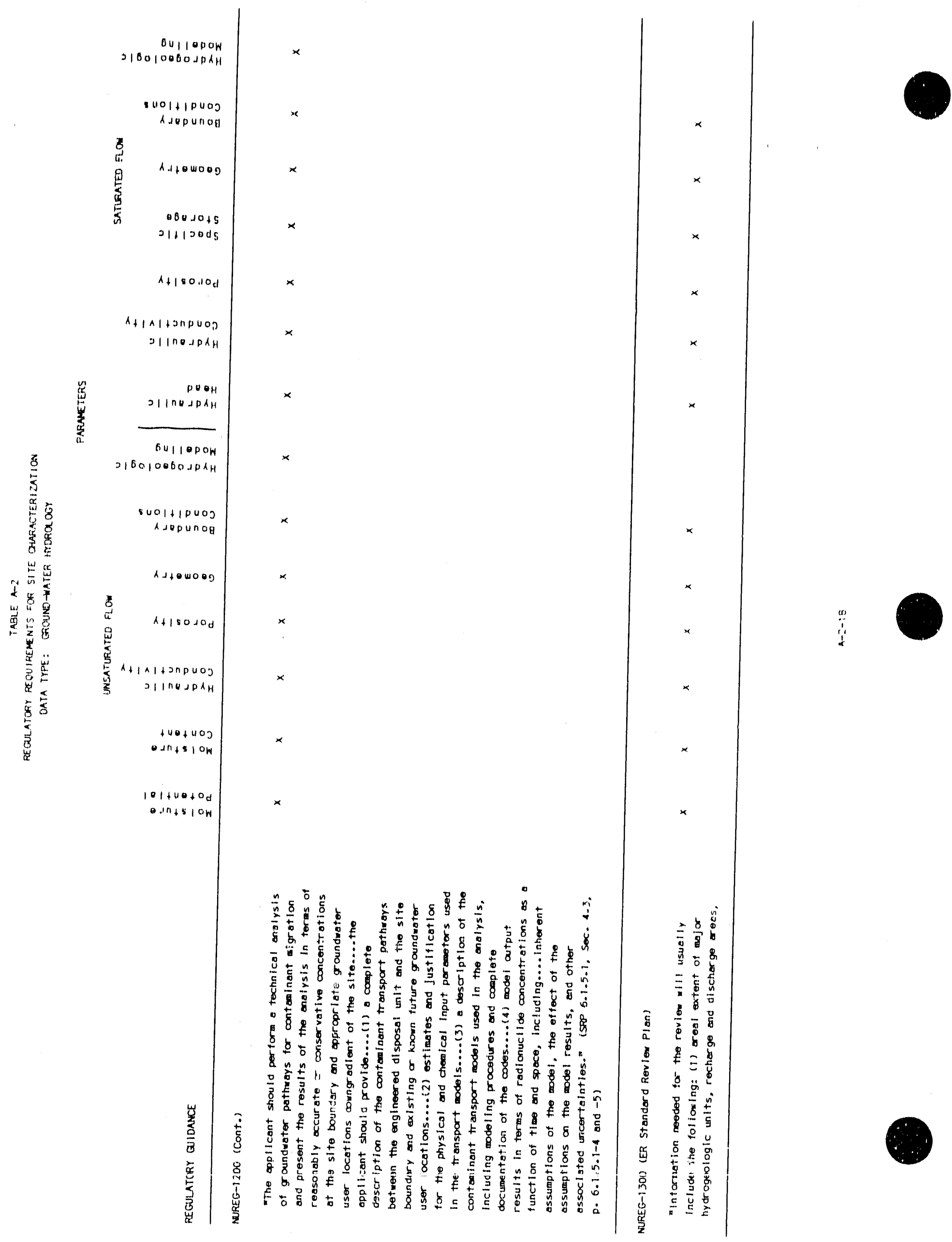




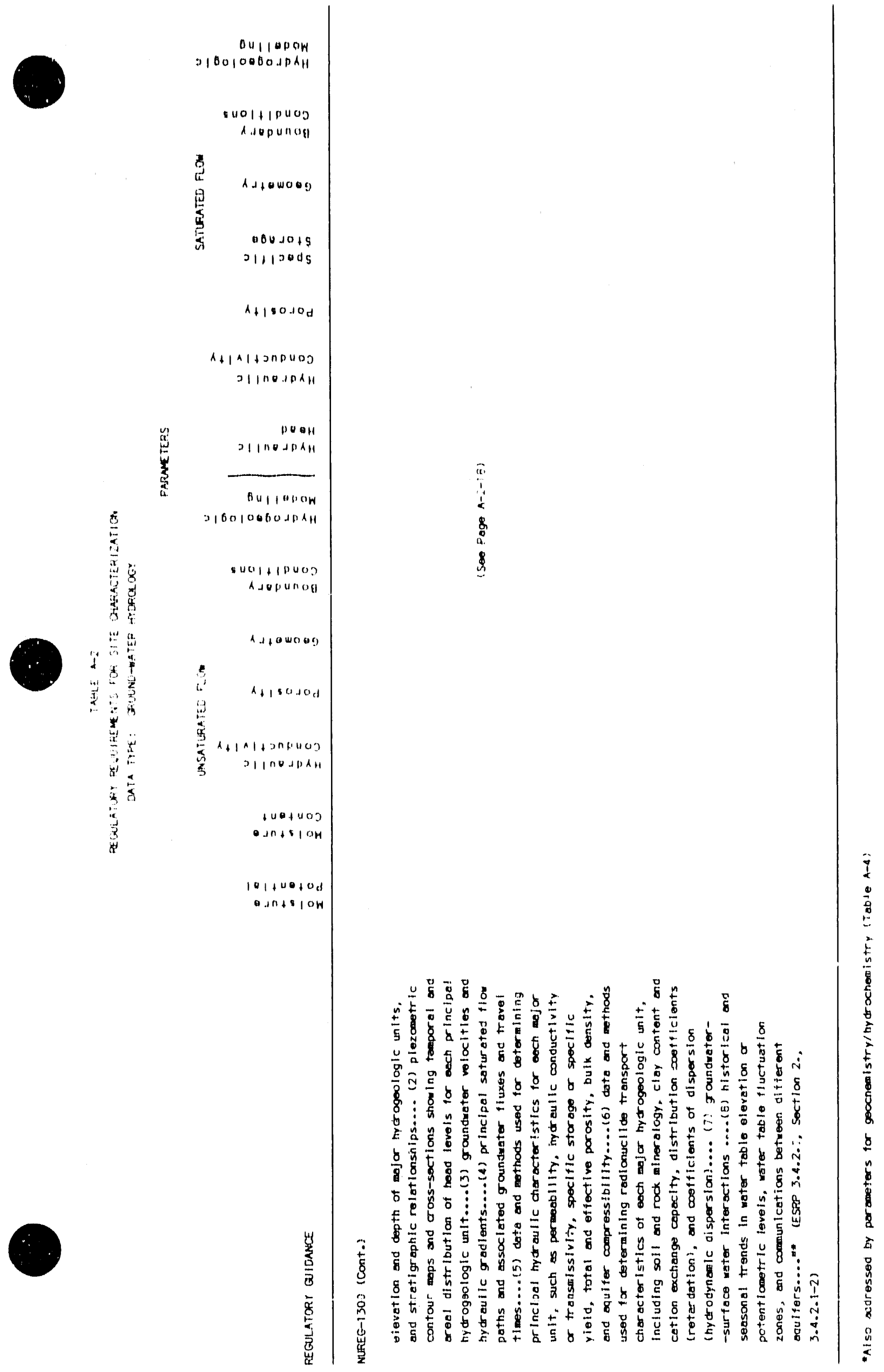




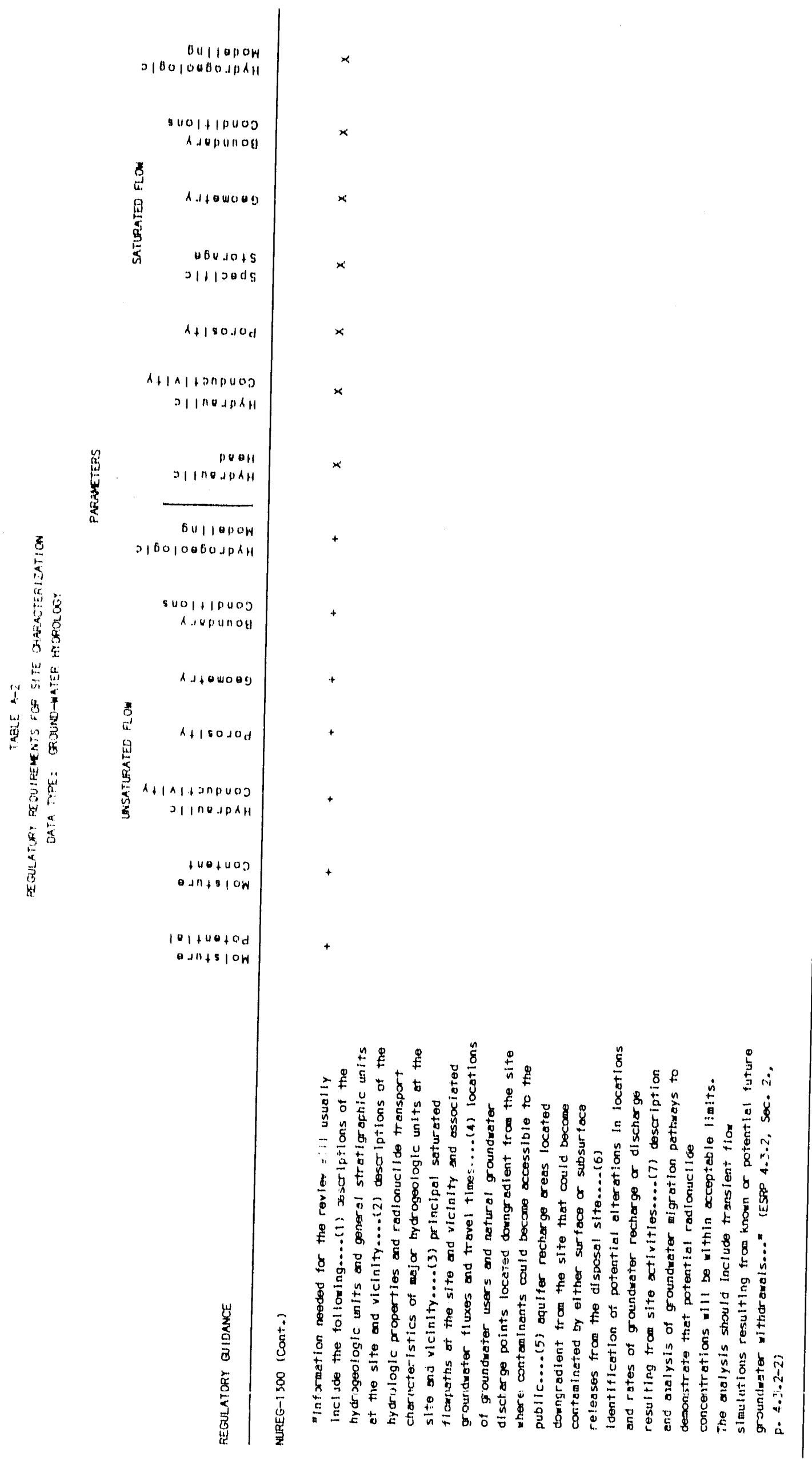


TABLE $A-2(a)$

PARAMETER DESCRIPTIONS - GROUND-WATER HYDROLOGY

UNSATURATED FLOW

Motsture Patential: Soll water moves in the direction of decreasing molsture potential. The motsture potential is the sum of gravitational, osmotic, and matric potentials. Osmotic potential is generally considered negllgtble. Gravitational potential is dependent on differences in elevation. Matric potential is a negative pressure potential that results from the cap 111 ary and adsorptive forces of the soll matrix. Information on molsture potential is needed for determining rates and directions of motsture movement.

Molsture Content: Moisture content is expressed as a dimensionless ratto efther of water mass to dry soll mass or of water volume to total volume. It. is lisually reported as a percentage. The relation batween molsture potential and moisture content is deftned by a motsture charactertstic curve. However, due to the hysieresis phenomenon, the curve for the wetting process is usually not identical to the curve for the drying process. A related parameter, the degree of saturation, is defined as the ratio of the water volume to the vold volume. Information on moisture content is needed as a dependent vartable of hydraulic conductivity.

Hydraulic Conductivity: Hydraulic conductivity is a measure of the ability of soll or rock to transmit water. Hydraulic conductivity depends on the specific weight and viscosity of the water, and the intrinsic permeability and moisture content of the material. Under unsaturated conditions, the hydraulic conductivity may not be constant and will vary with the degree of saturation. In general, hydraultc conductivity has directional variablitty (anisotropy). Information on hydraulic conductivity is needed for determining rates of moisture movement.

Porosity (Total and Effective): Total porosity is the ratio of the vold volume to the total volume of a sample. Effective porosity is the ratio of interconnected void volume in which flutds are able to circulate, to the total volume of a sample. Information on porosity is needed for determining the transport of solutes in the unsaturated zone.

Geometry: The geometry includes the hydrostratigraphy (e.g., thickness, lateral extent, continutty), the depth of the water table, the thickness of capillary fringe, the location of the disposal factlity, and the location of recharge and discharge zones. Intormation on geometry is needed to define the domain in which flow is studied.

Boundary Conditions: Boundary conditions are defined pressure heads or fluxes due to discharge from evapotranspiration, and to steady-state and/or transient recharge from both natural infiltration (dependent on inflitration rate and infiltration capacity of material) and infiltration trenches. Information on boundary conditions is needed to determine conirols on flow with in the domain defined by the geometry. 
Hydrogeologic Modeling: A hydrogeologic model is a mathematical formulation of the hydrologic behavior of the system. The description of the model should include model type, justification, documentation of code, verification, validation, calibration, sensitivity analyses, underiying assumptions, associated uncertainties, limitations, physical laws considered, input data, data reduction and/or generation techniques, and discussion of suitability. Output may include simulated pressure heads, fluxes, discharge, and flow velocities and directions. Modeling is required to provide an integrated understanding for the unsaturated flow regime for site characterization, and to allow a variety of sensitivity and scenario options to be evaluated in support of site performance assessment. 
TABLE $A-2(h)$

PARAMETER DESCRIPTIONS - GROUND-WATER HYDROLOGY

\section{SATURATED FLOW}

Hydraulic Head: The hydraulic head is the sum of the elevation of the point of measurement (elevation head) and the pressure head. Fluid will flow from higher hydraulic head to lower. The hydraulic gradient is the difference in hydraulic head divided by the distance over which it occurs. Information on hydraulic head is needed for determining rates and directions of ground-water flow.

Heiraulic Conductivity: Hydraulic conductivity is a measure of the ability of a material to transmit water. Hydraulic conductivity depends on the specific weight and viscosity of the water and the intrinsic permeability of the material. In general, hydraulic conductivity has directional variability (anisotropy). Information on hydraulic conductivity is needed for determining rates of ground-water flow.

Porosity (Total and Effective): Total porosity is the ratio of void volume to the total volume of a sample. Total porosity approximately equals the sum of two related parameters, specific yield (the amount of water released by a material due to the force of gravity) and specific retention (the amount of water retained by a material under the force of gravity). Effective porosity is the ratio of interconnected void volume in which ground water is able to circulate. to the total volume of a sample. Information on porosity is needed for determining the transport of solutes dissolved in the ground water.

Specific Storage: The specific storage is the amount of water in storage that is released from a unit volume of aquifer per unit decline in head. The related coefficient, storativity or storage coefficient, is the amount of water released from a column of aquifer with unit cross section under a unit decline of head. In unconfined aquifers, storage is measured in terms of the specific yield, a measure of the drainable porosity, whereas in confined aquifers, specific storage and storativity are functions of porosity (the proportion of void space in a sample), fluid compressibility, and medium compressibility. (Compressibility describes the change in volume induced in a material by an applied stress.) Information on specific storage is needed for determining rates and directions of ground-water movement wher boundary conditions are changing with time.

Geometry: The geometry includes hydrostratigraphy (e.g., thickness, latera] extent, continuity, hydraulic interconnectivity, elevation, depth, stratigraphic relationships), location of pathways (e.g., faults, sand lenses, weathered horizons, karstic features, joint systems, solution features), location of barriers (e.g., fracture zones, dikes), location of recharge and/or discharge zones, location of wells and the location of the disposal facility. The geometry should be characterized to a depth of at least $30 \mathrm{~m}$ below the site. Information on geometry is needed to define the domain in which flow is studied. 
Boundary Conditions: Boundary conditions are defined heads or fluxes due to steady state and/or transient recharge from infiltration and injection wells, and discharge from springs and domestic, industrial, irrigation and municipal wells. Information on boundary conditions is needed to determine controls on flow within the domain defined by the geometry.

Hydrogeologic Modeling: A hydrogeologic model is a mathematical formulation of the hydrologic behavior of the system. Proper model documentation should include model type, justification, documentation of code, verification, validation, calibration, sensitivity analyses, underlying assumptions, associated uncertainties, limitations, physical laws considered, input data, data reduction and/or generation techniques, and discussion of suitability. output should include simulated heads and ground-water flow velocities, fluxes, discharge, and directions. Modeling is required to provide an integrated understanding of the saturated flow regime for site characterization, and to allow a variety of sensitivity and scenario options to be evaluated in support of site performance objectives. 


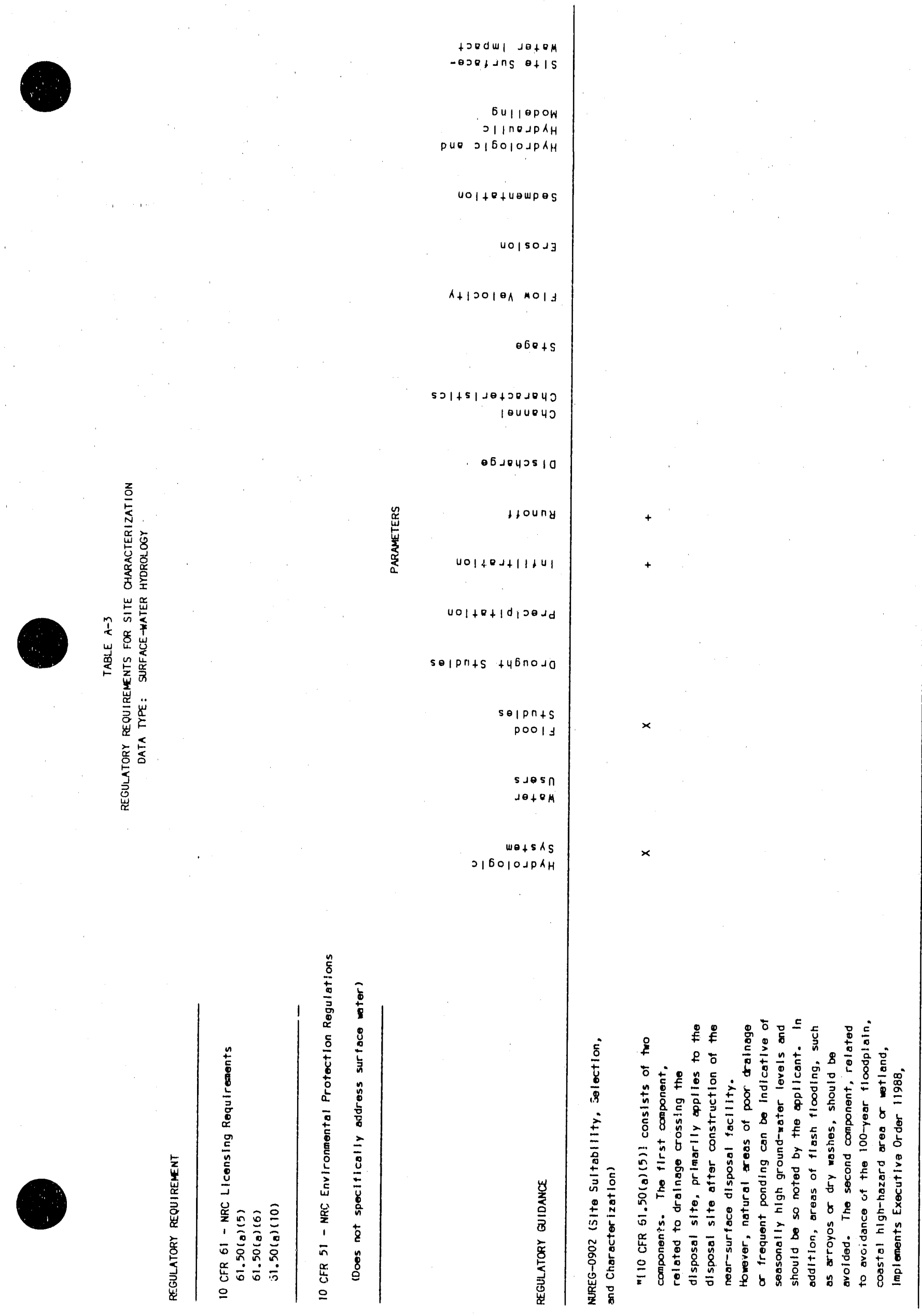




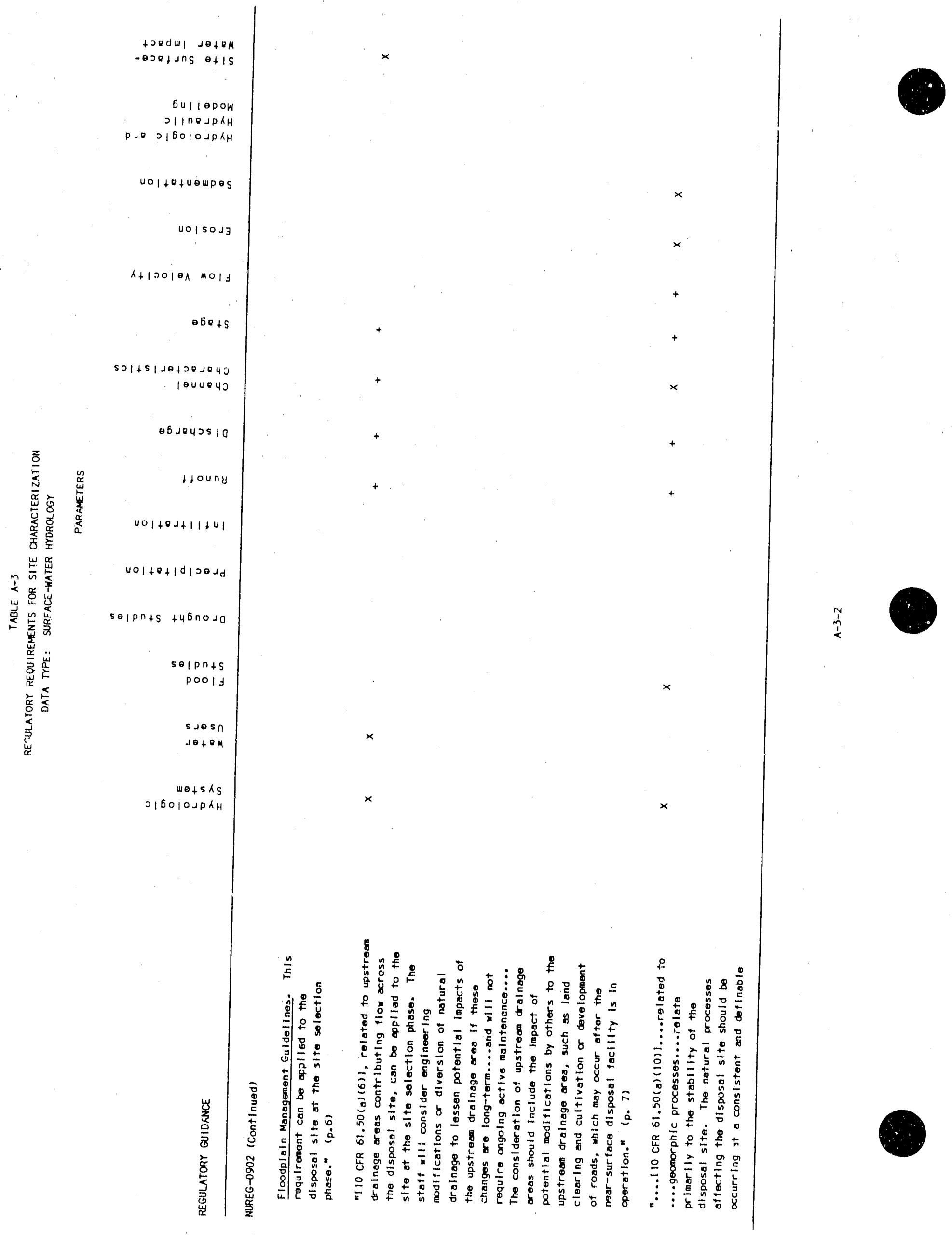




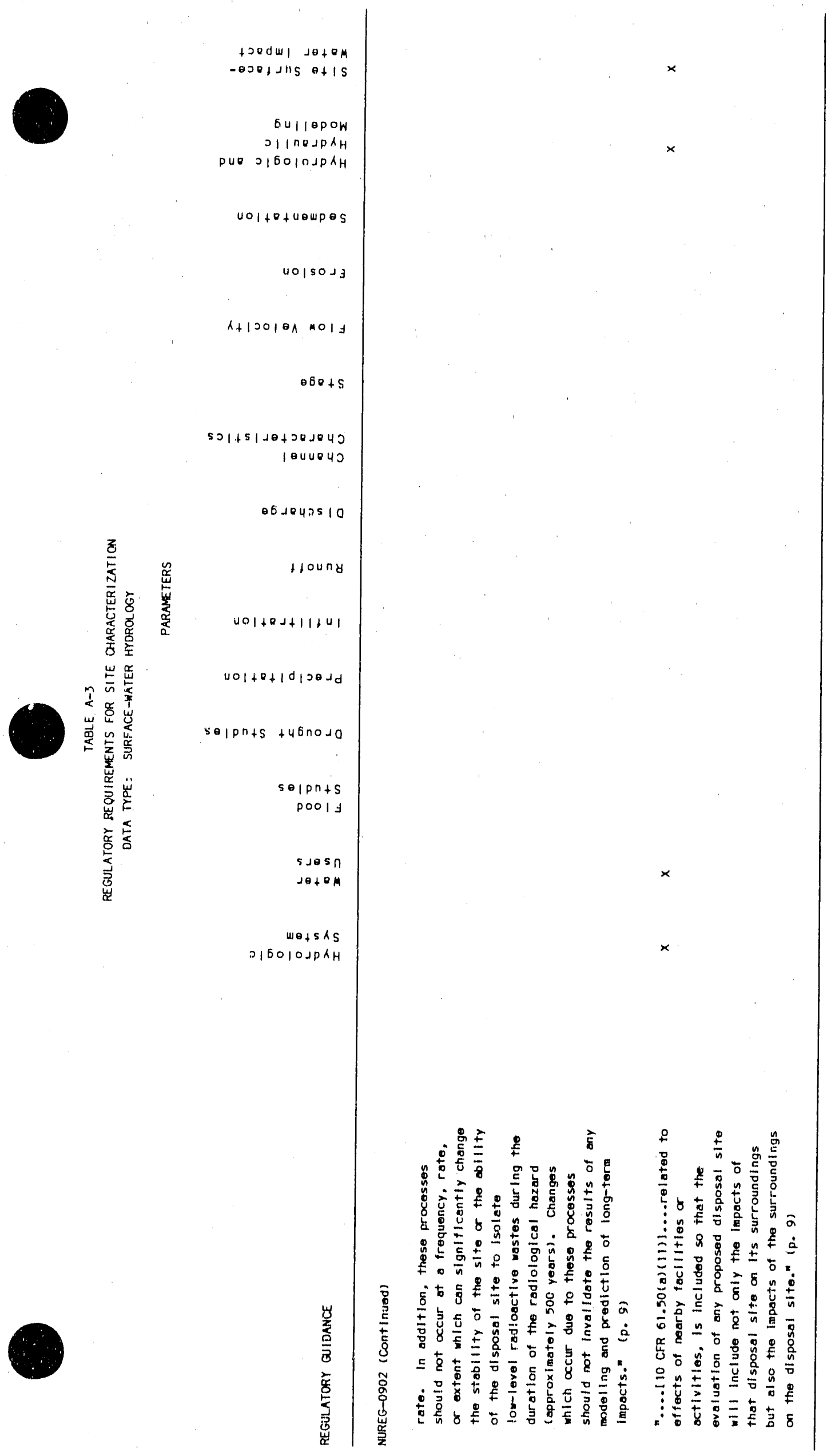




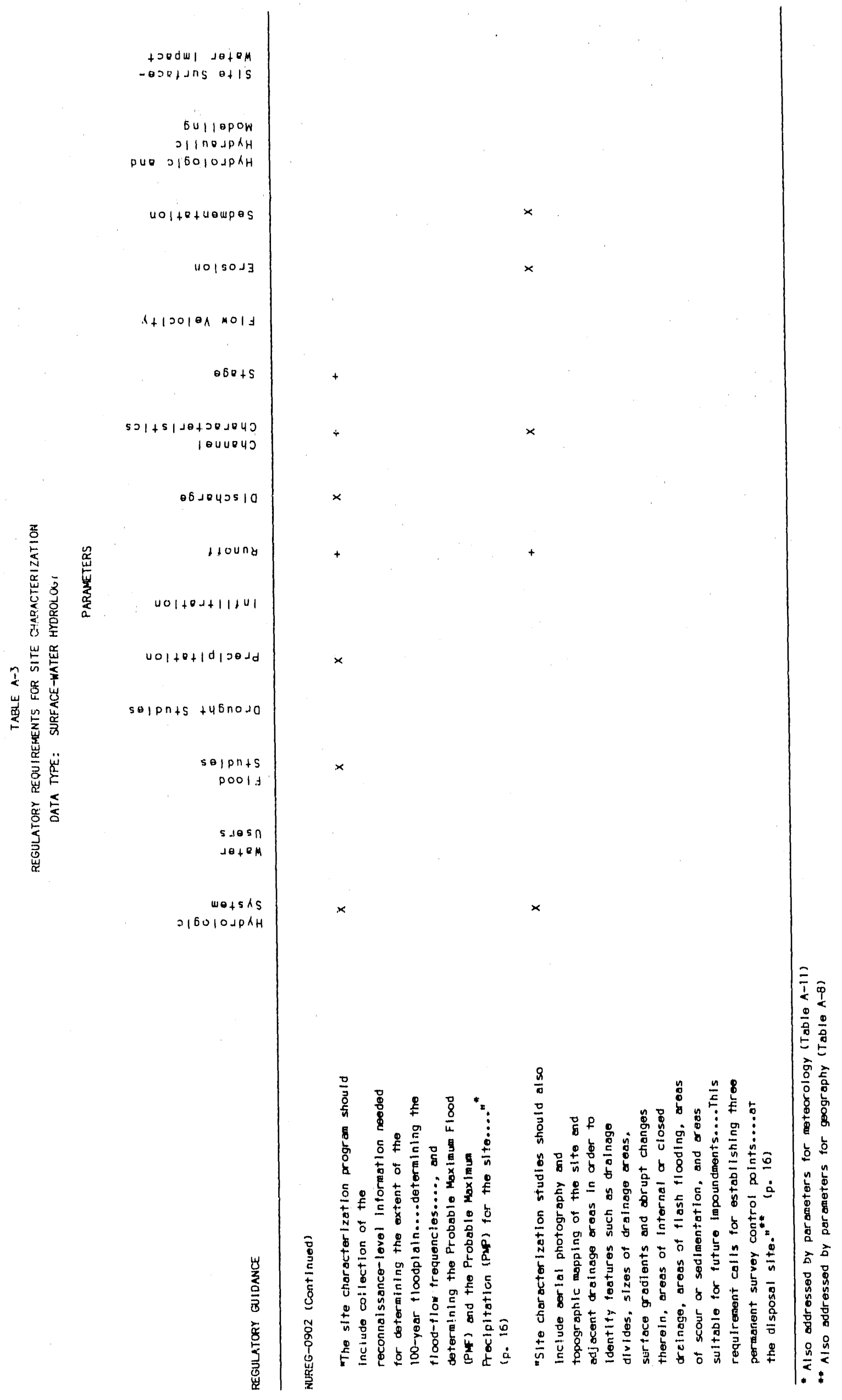




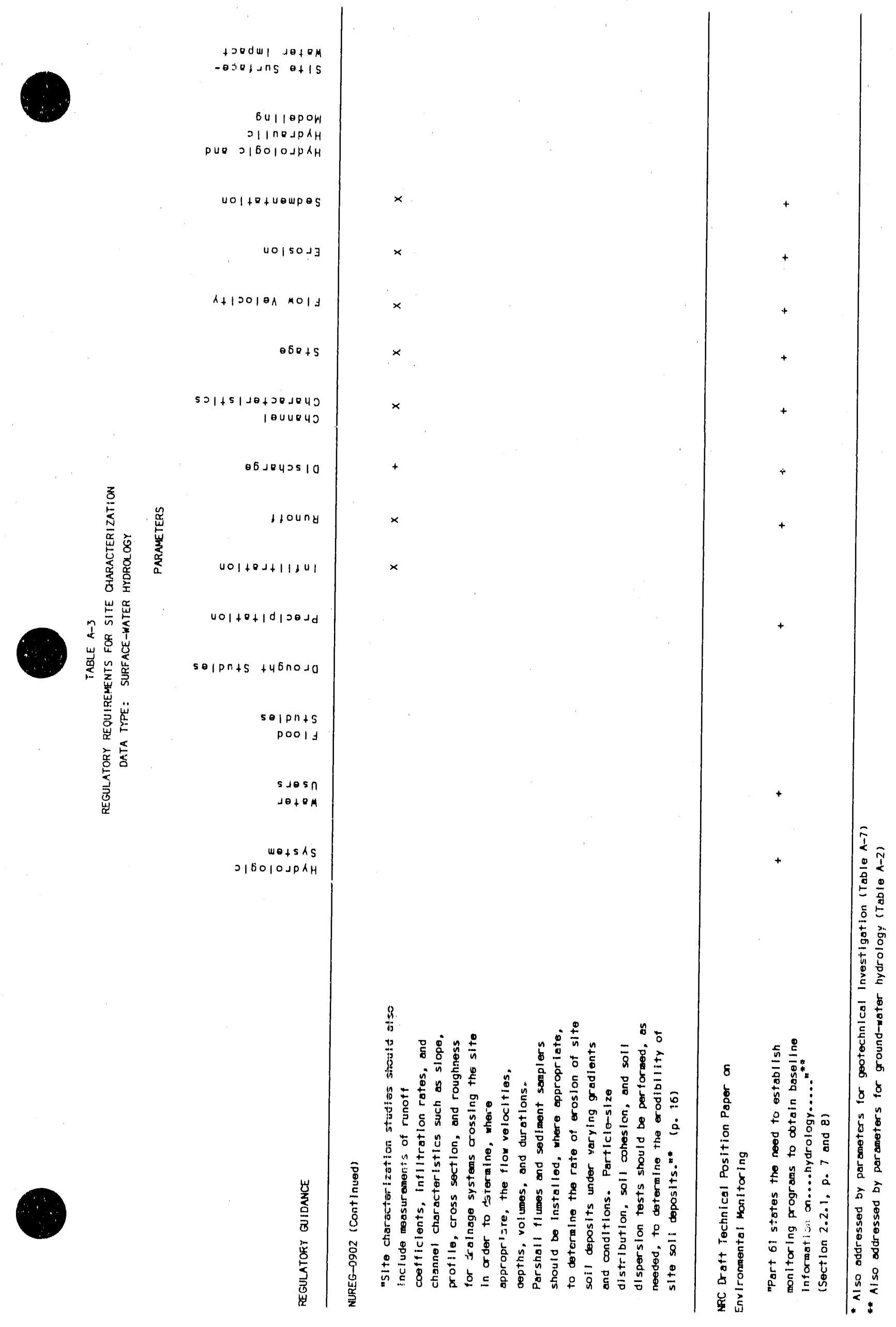




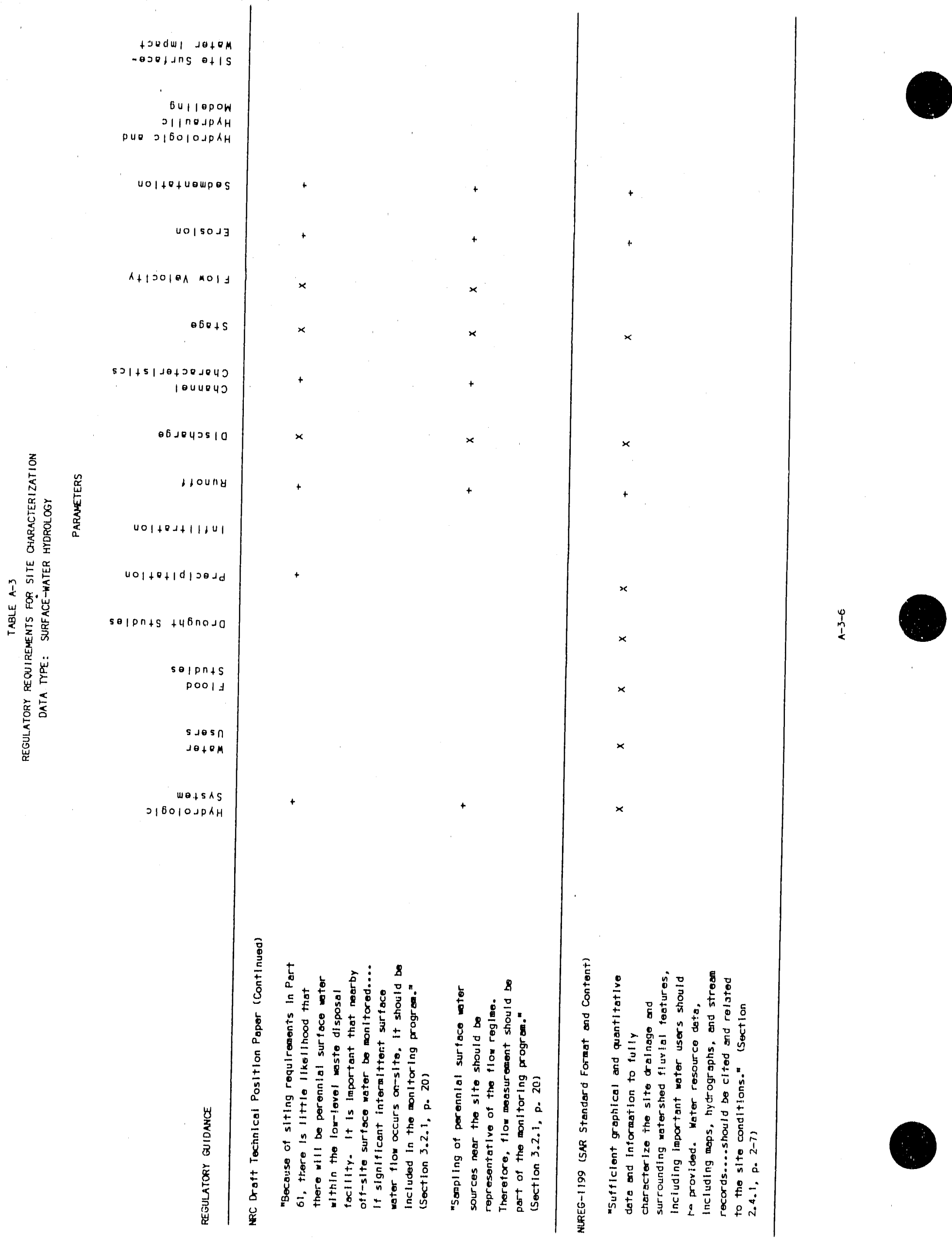




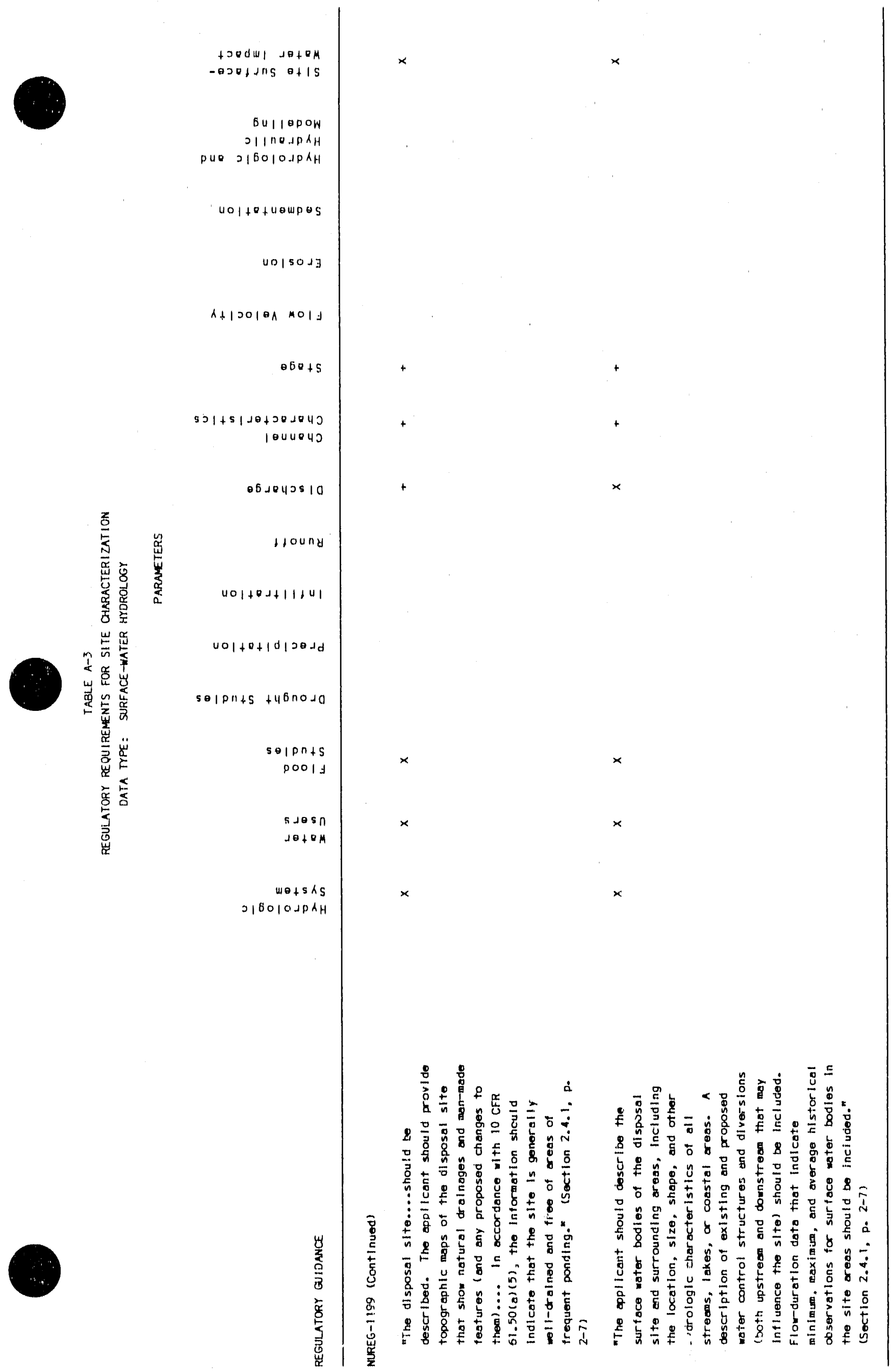




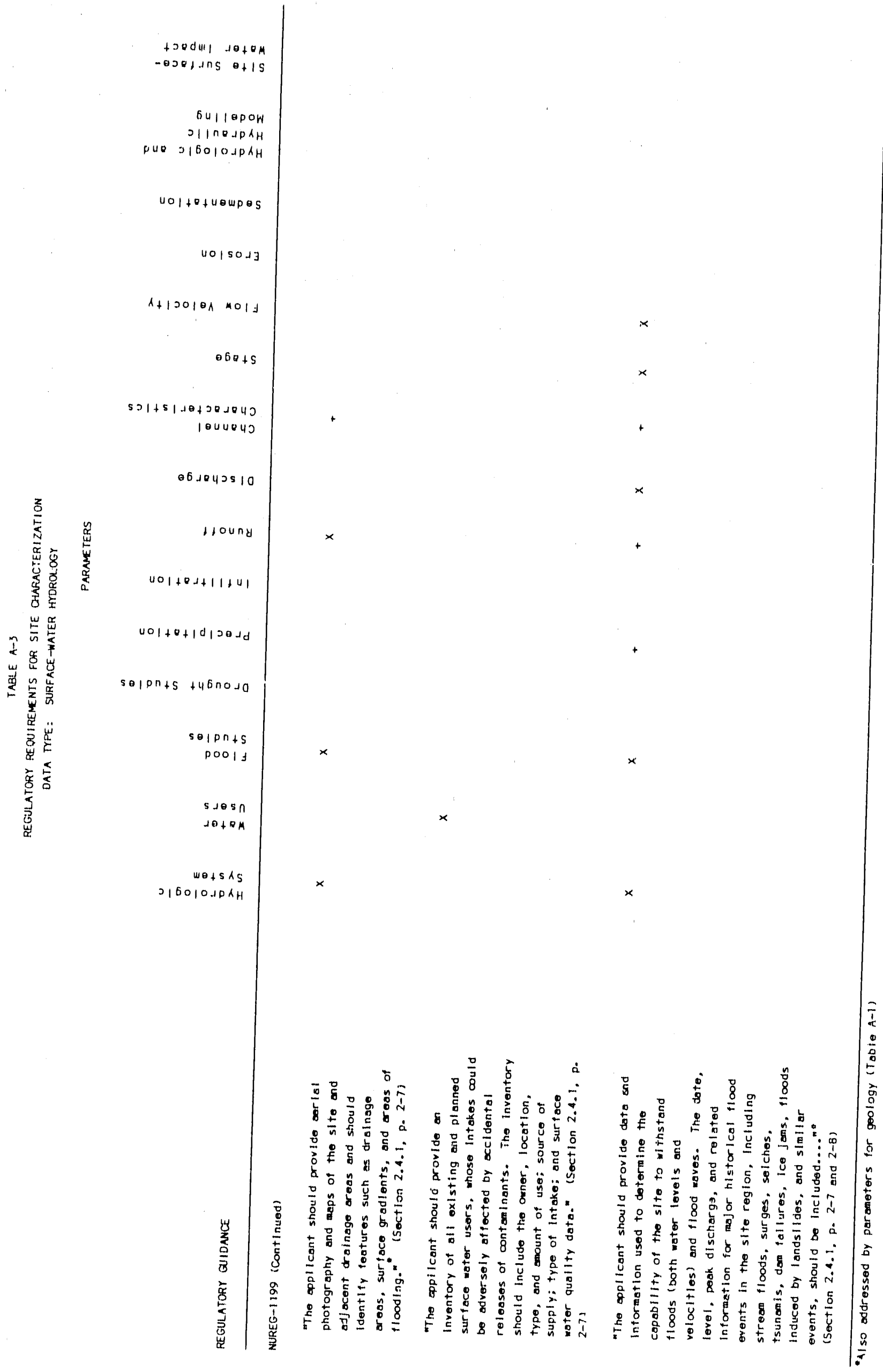




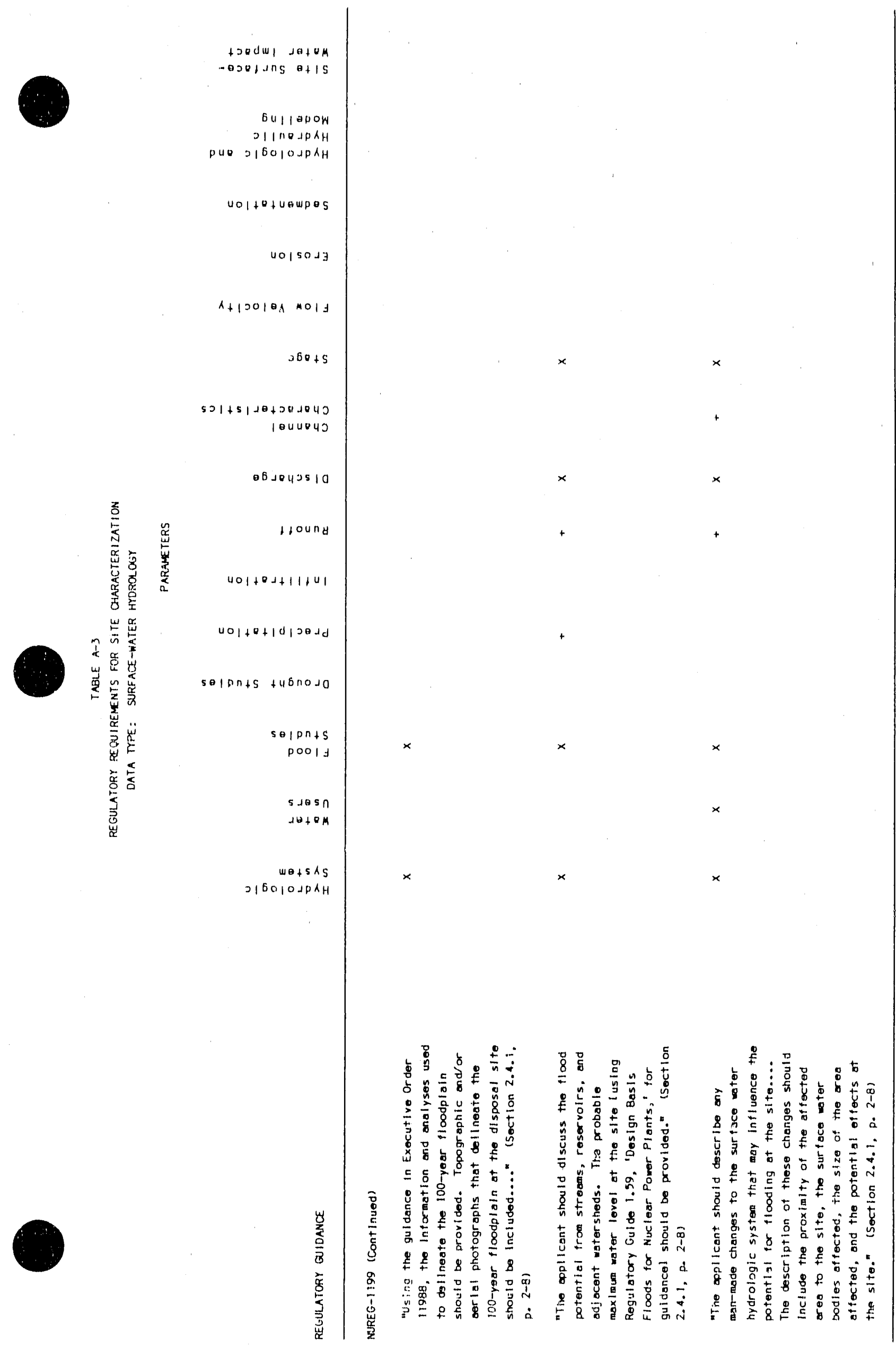



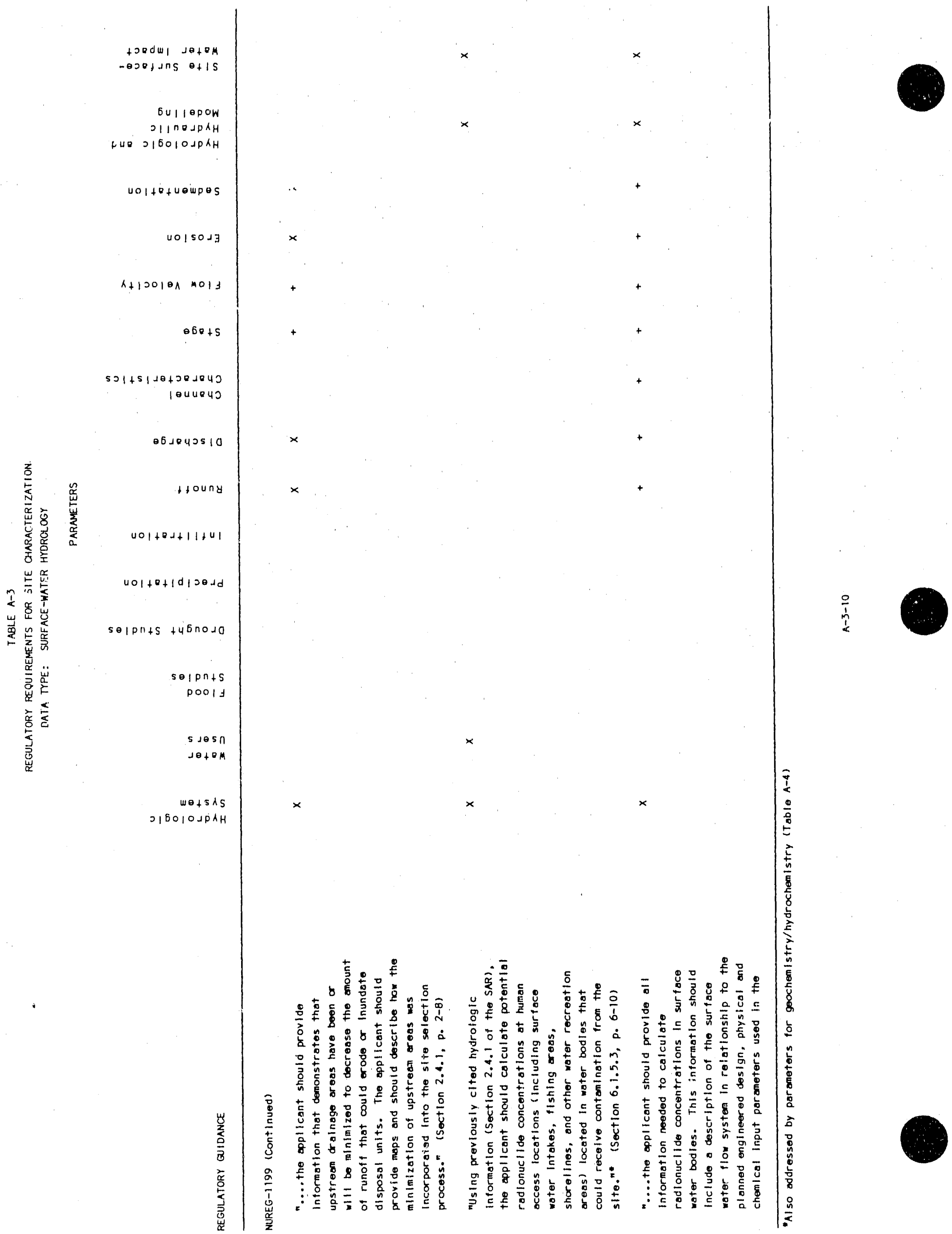


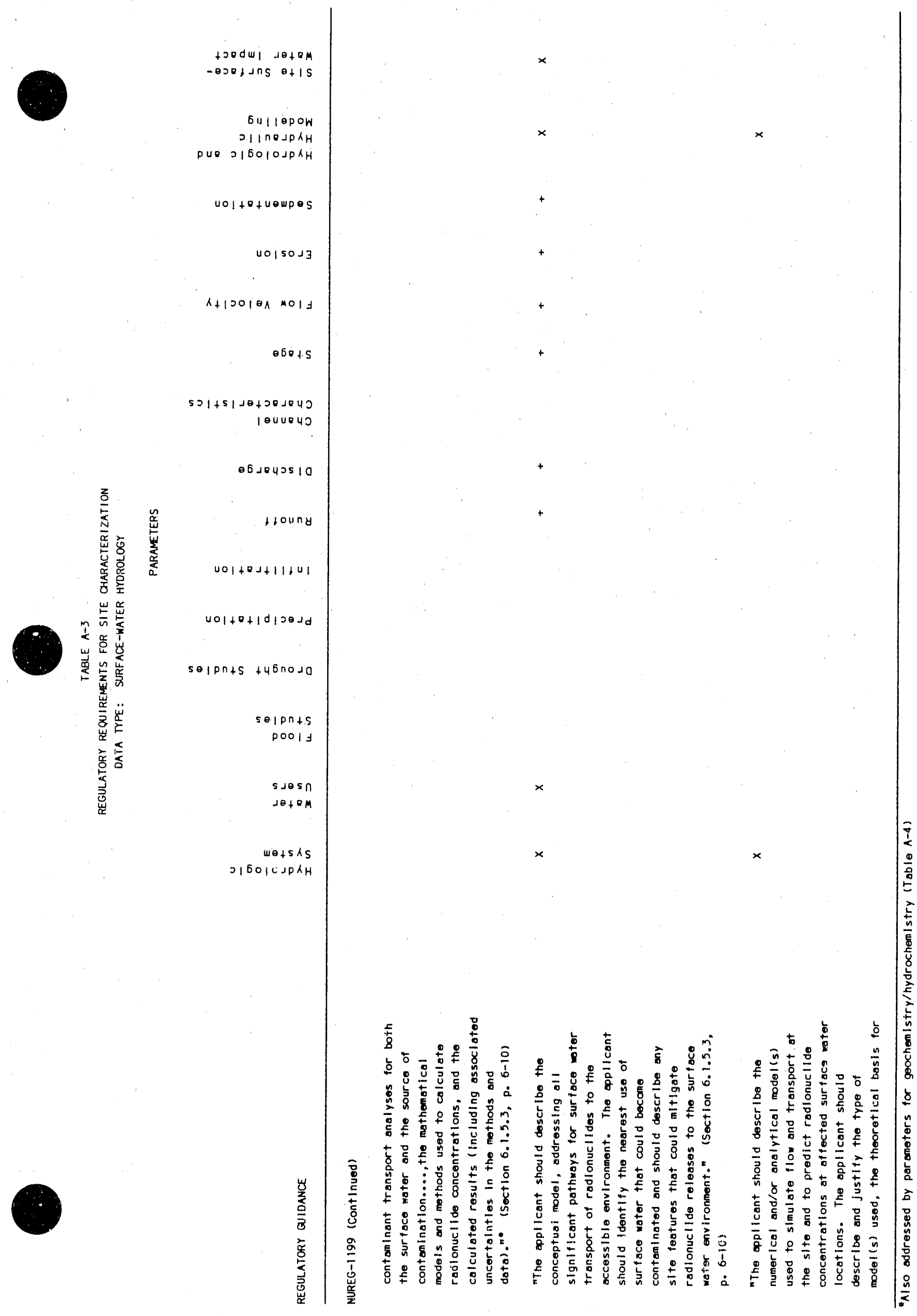

$\bar{z}$ 


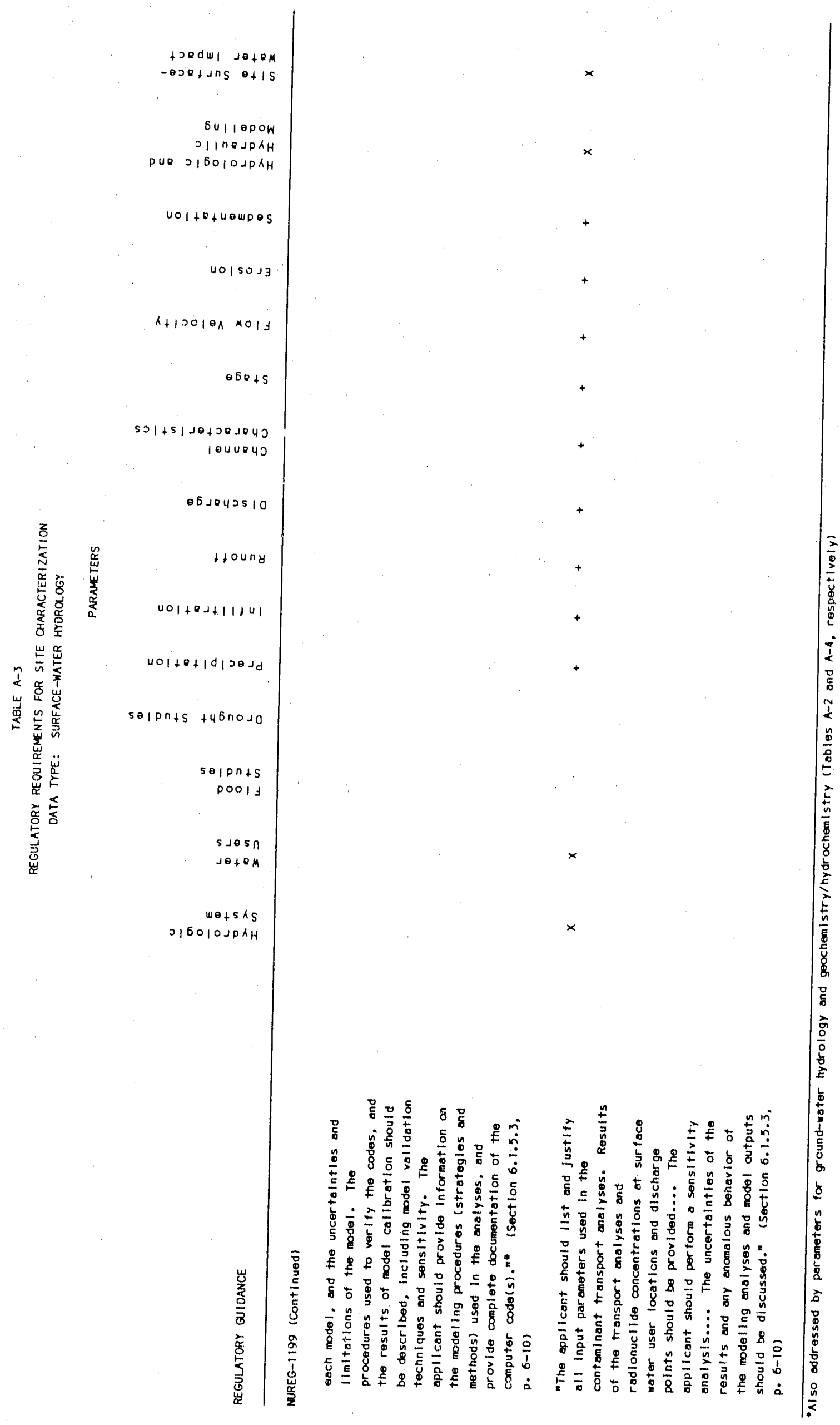




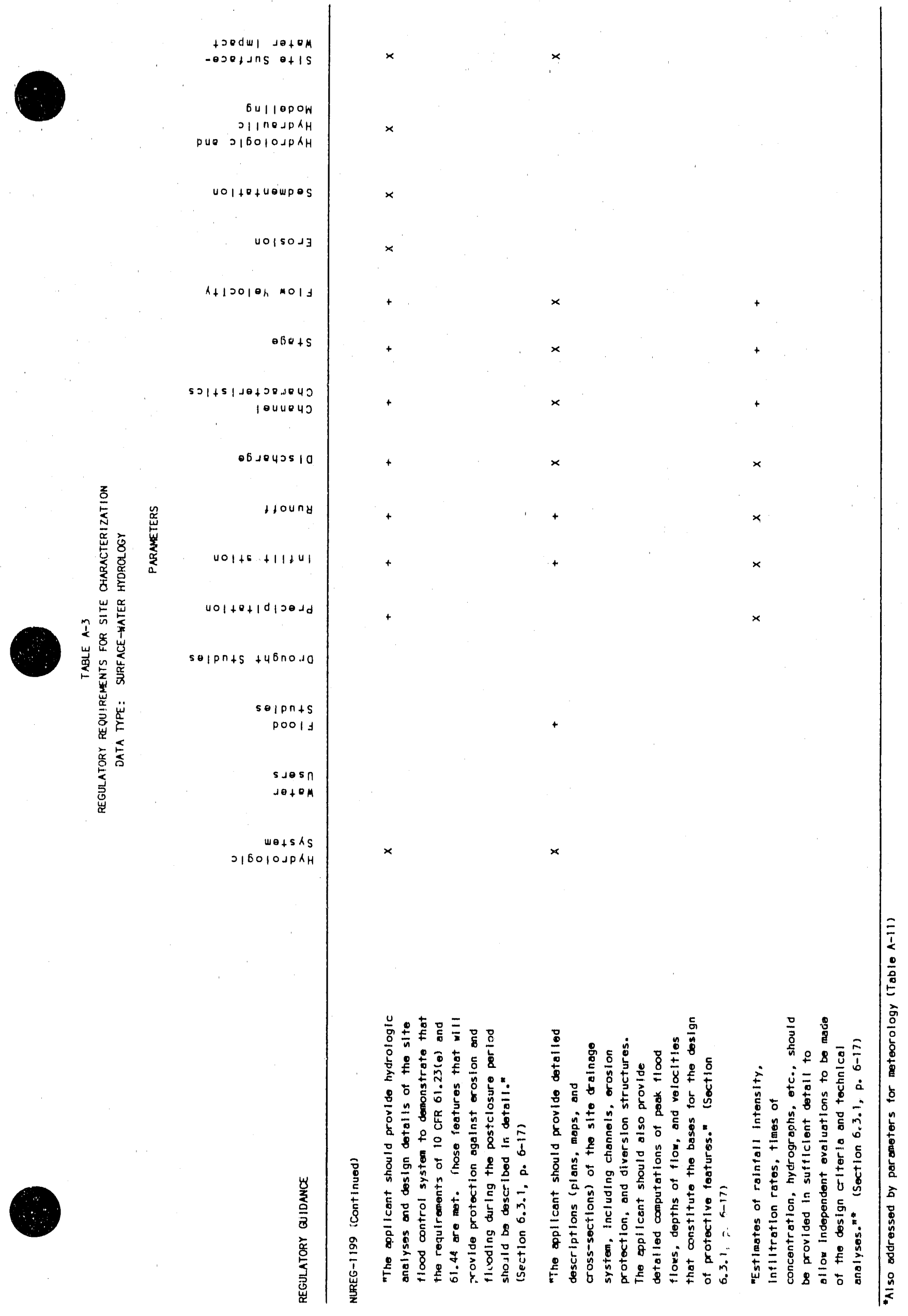




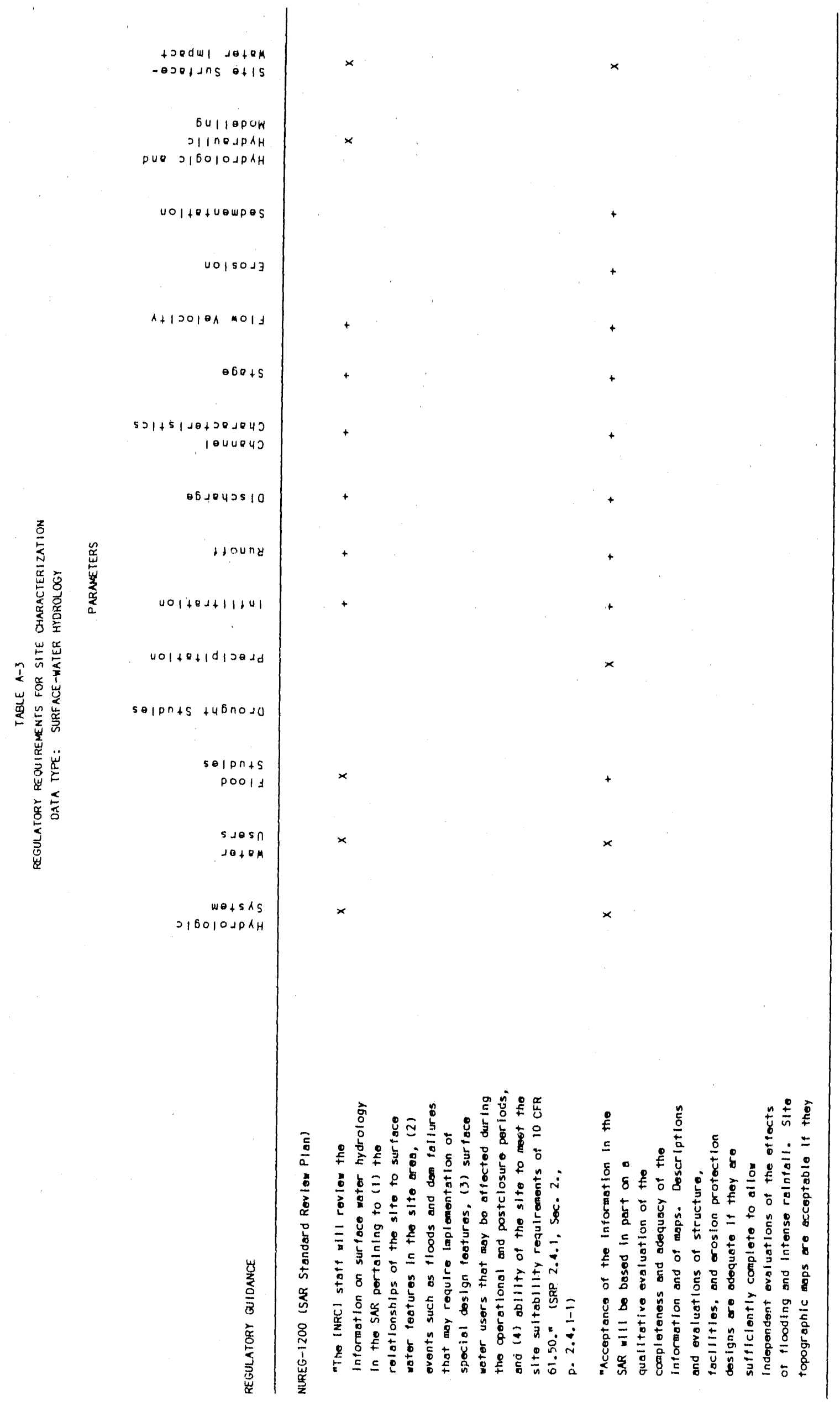




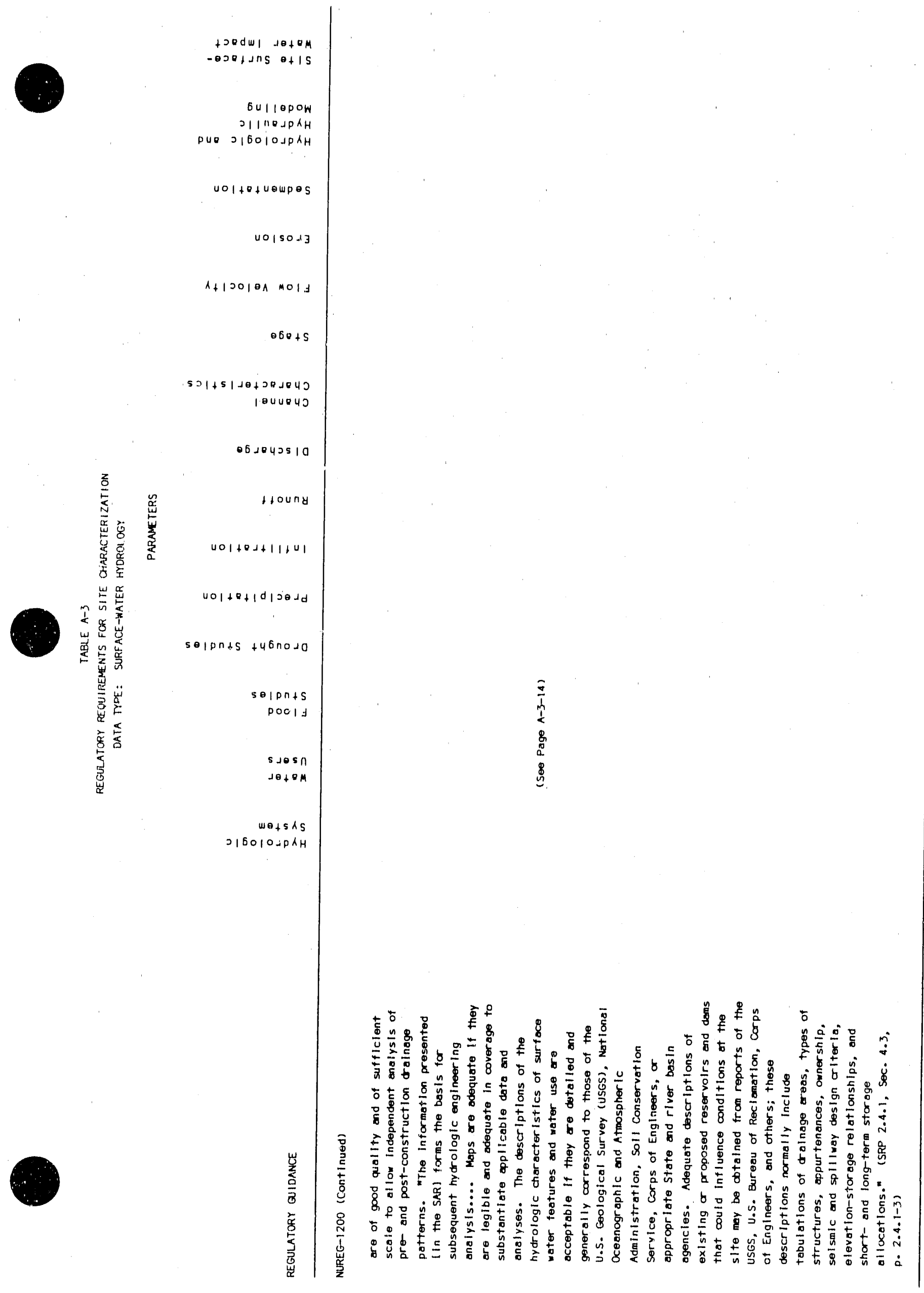




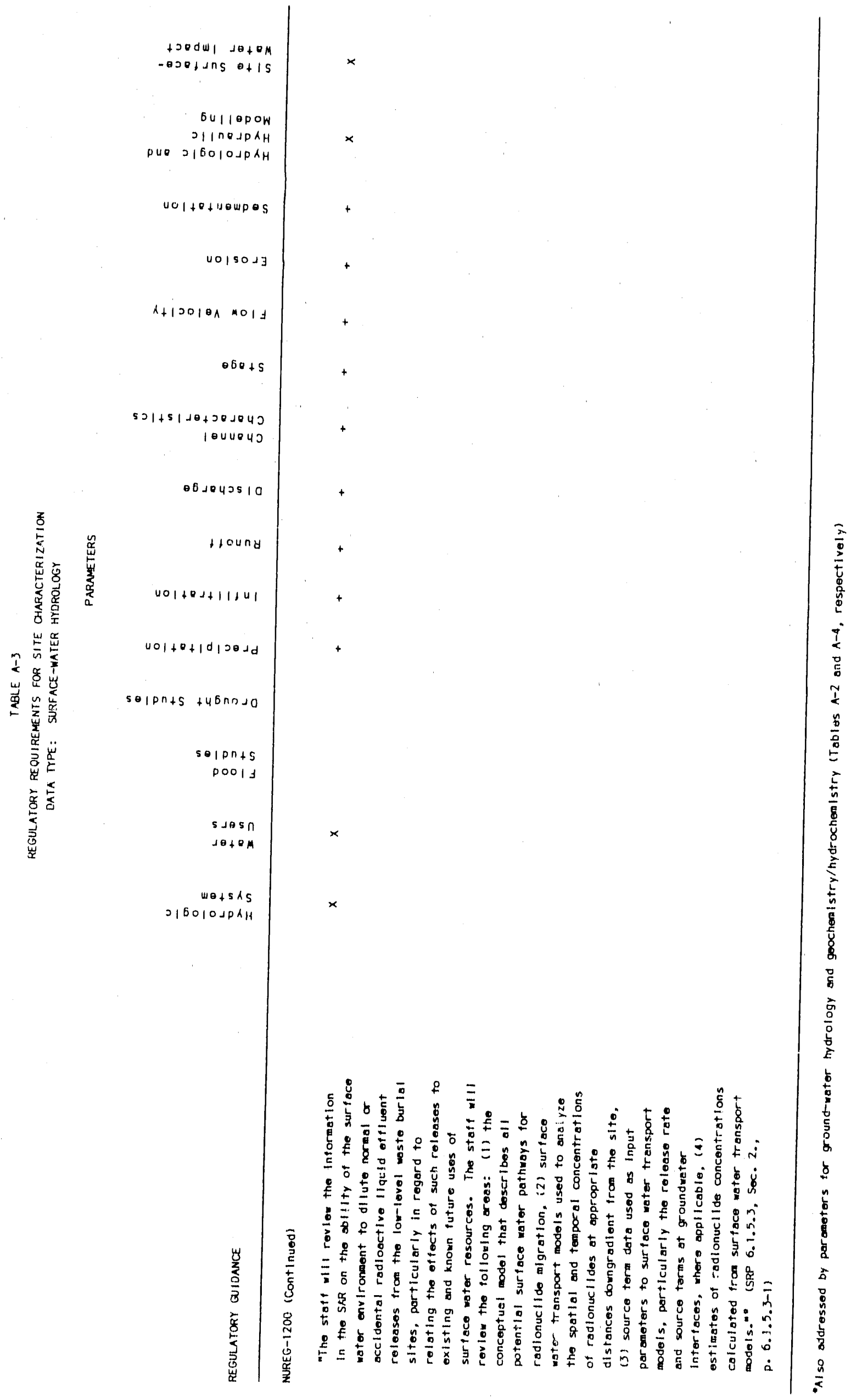




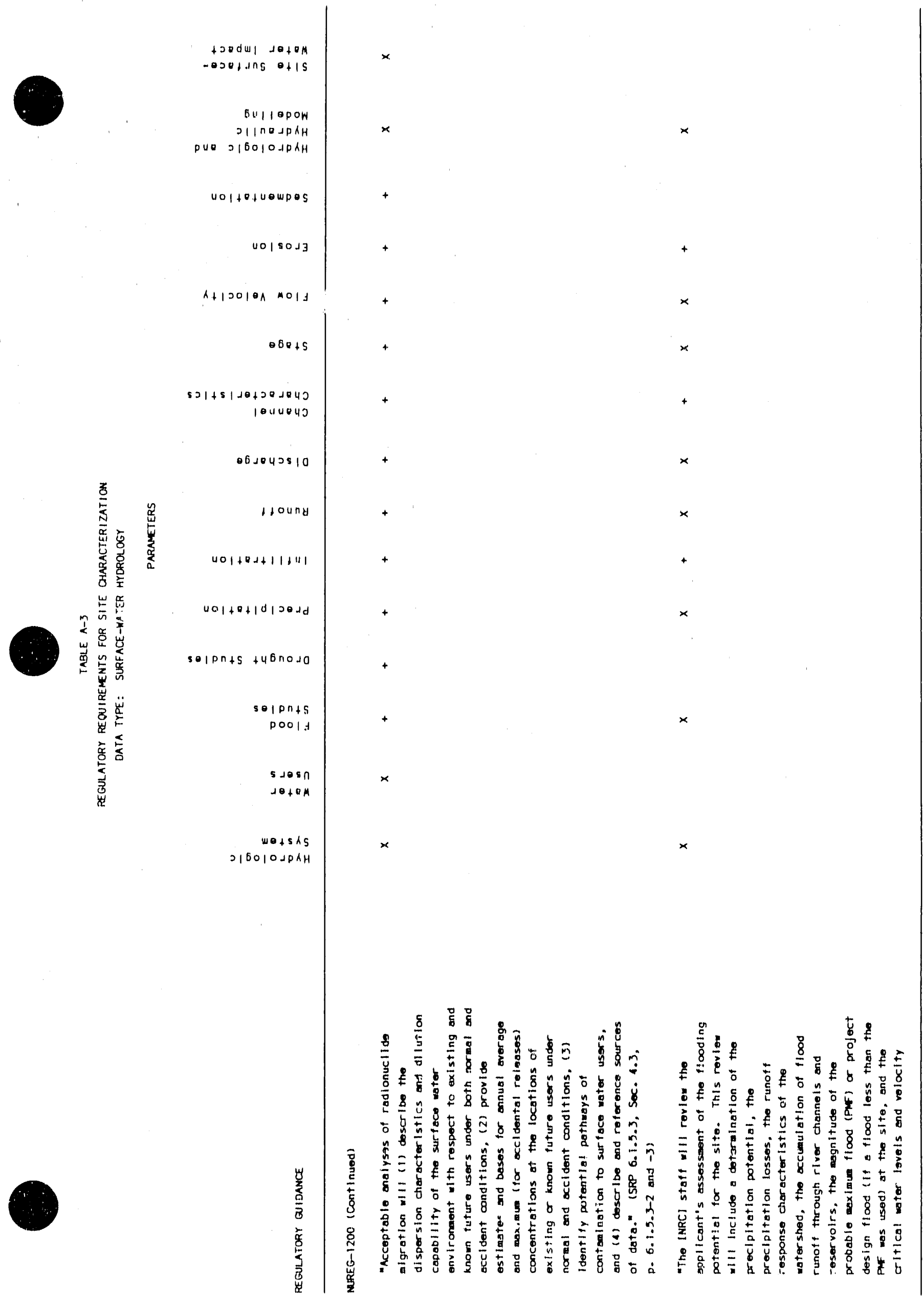




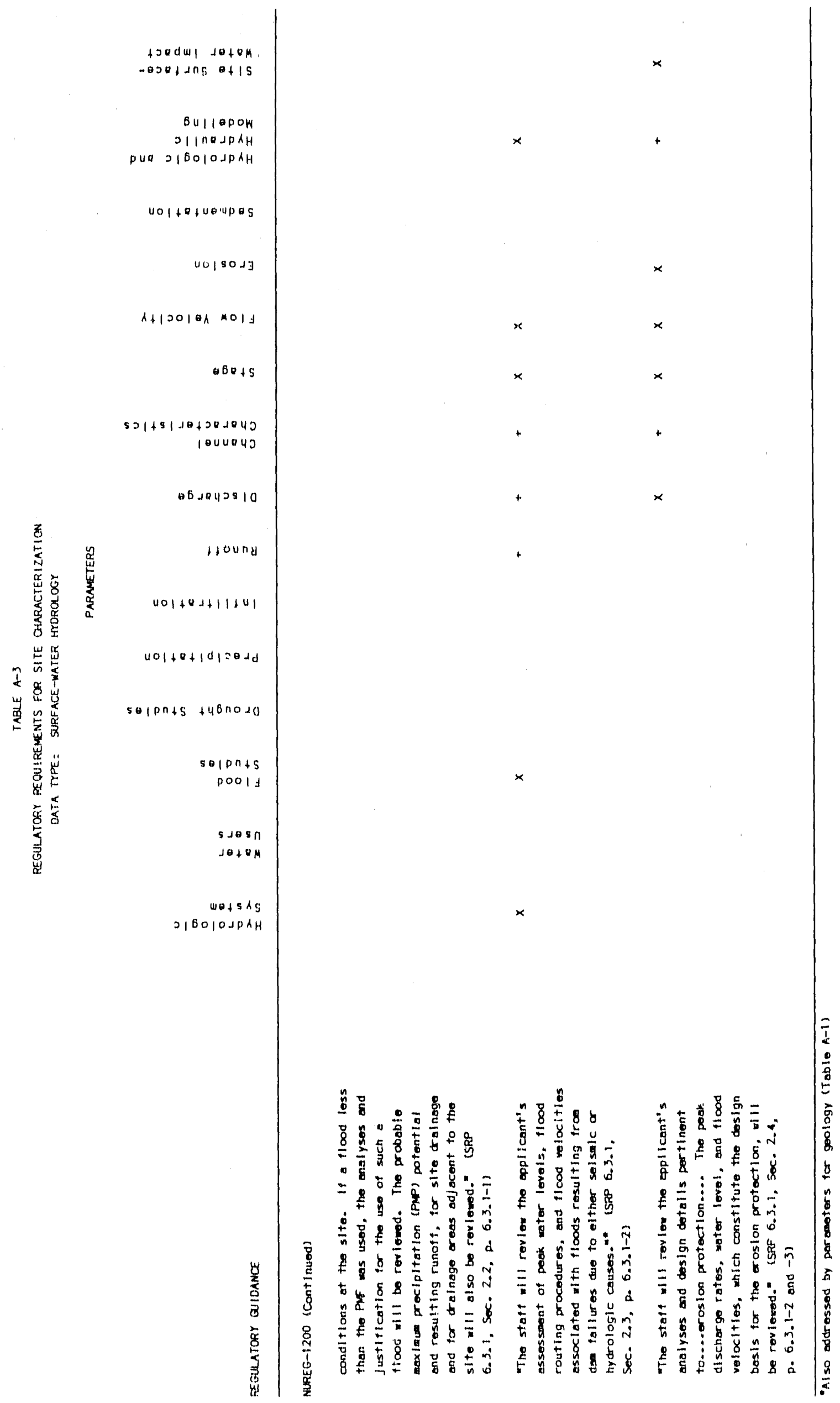




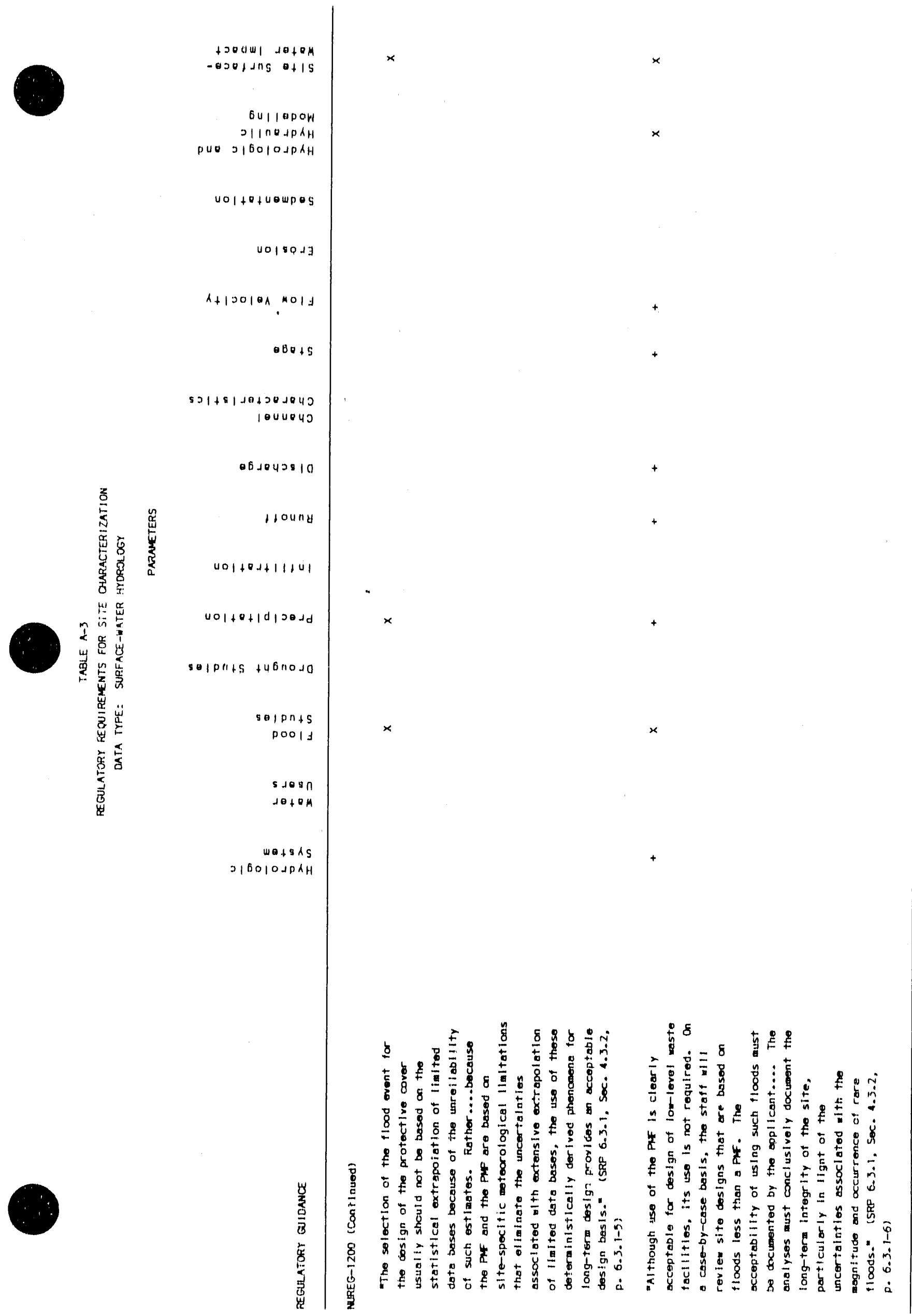




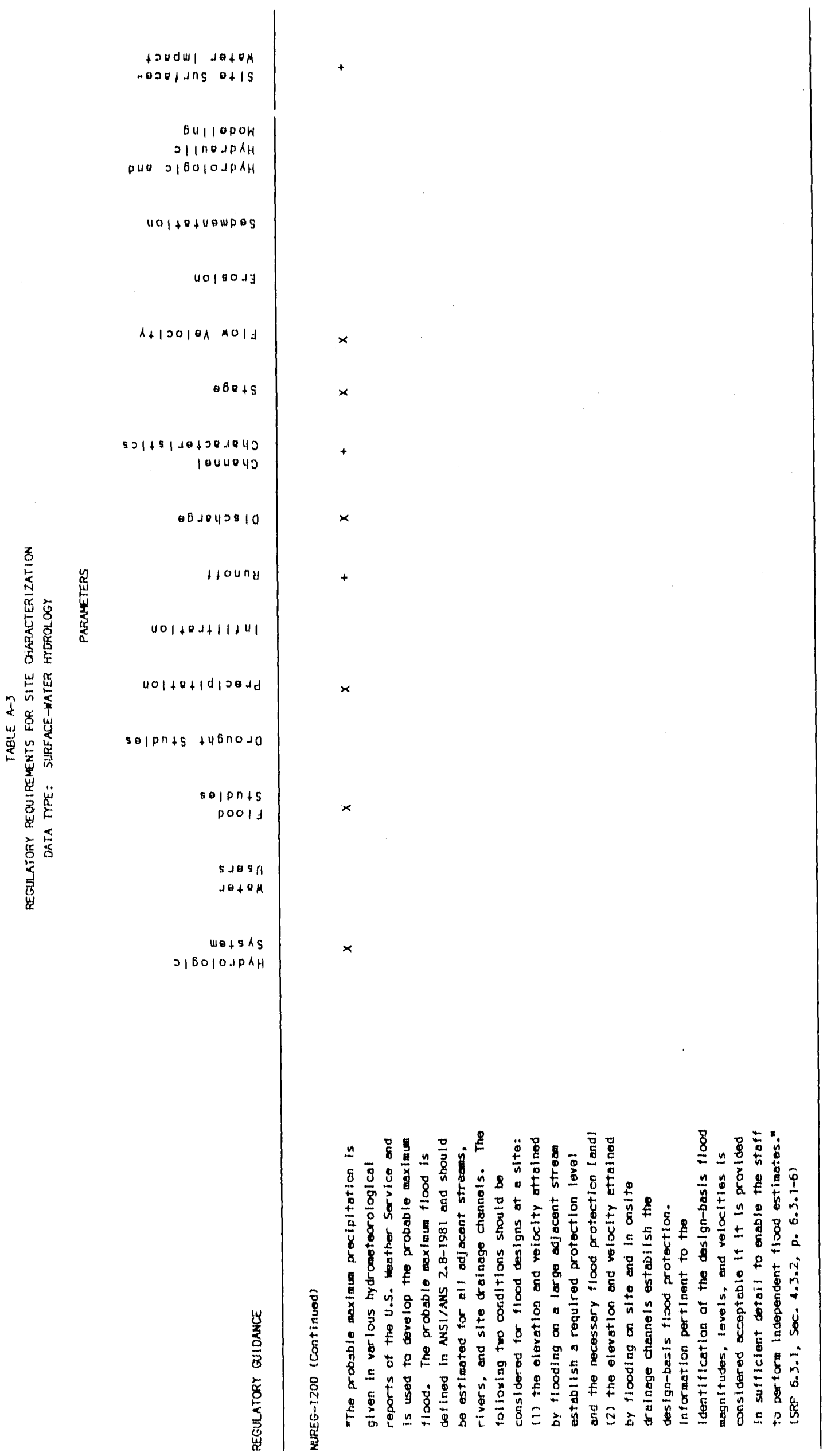




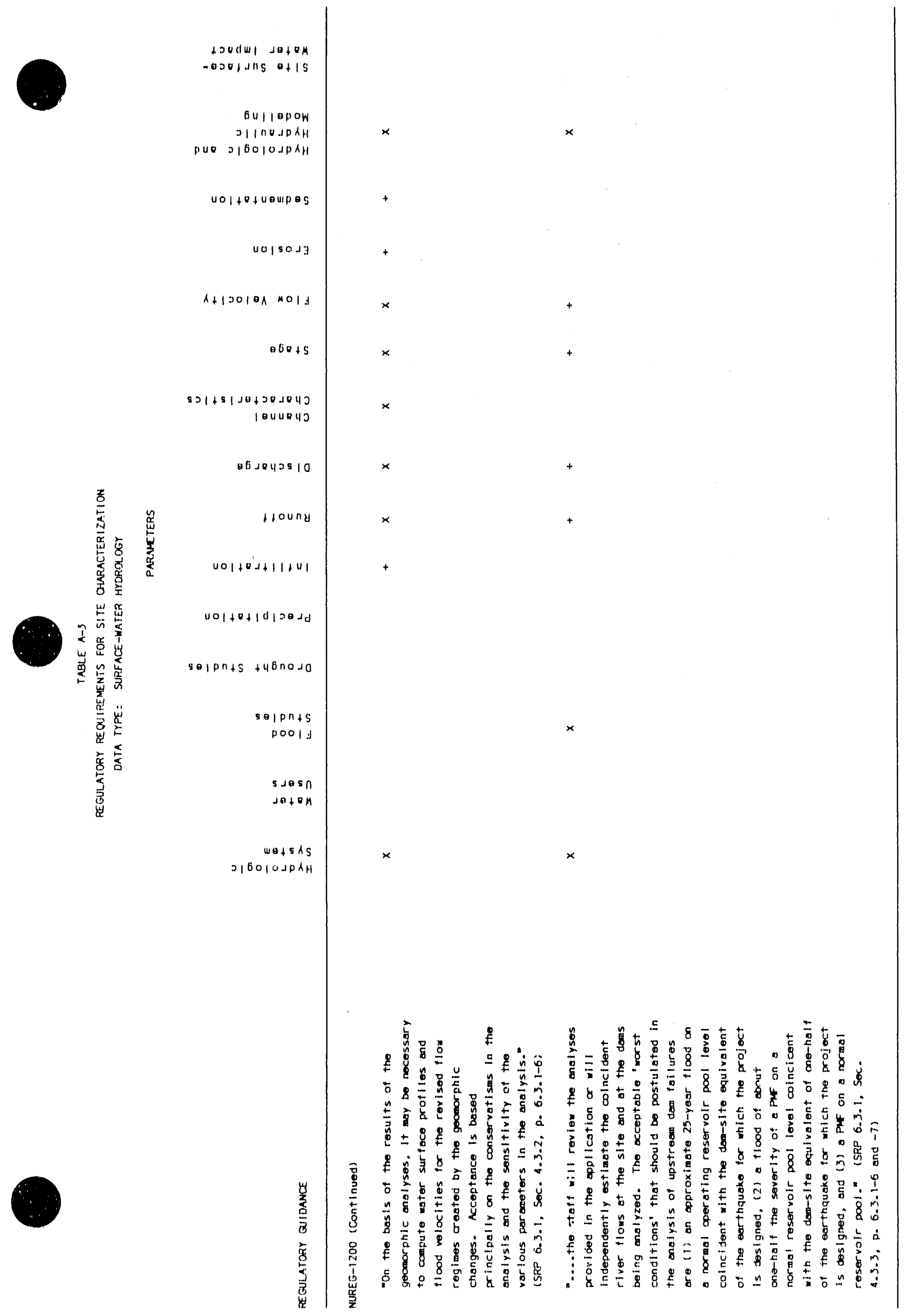




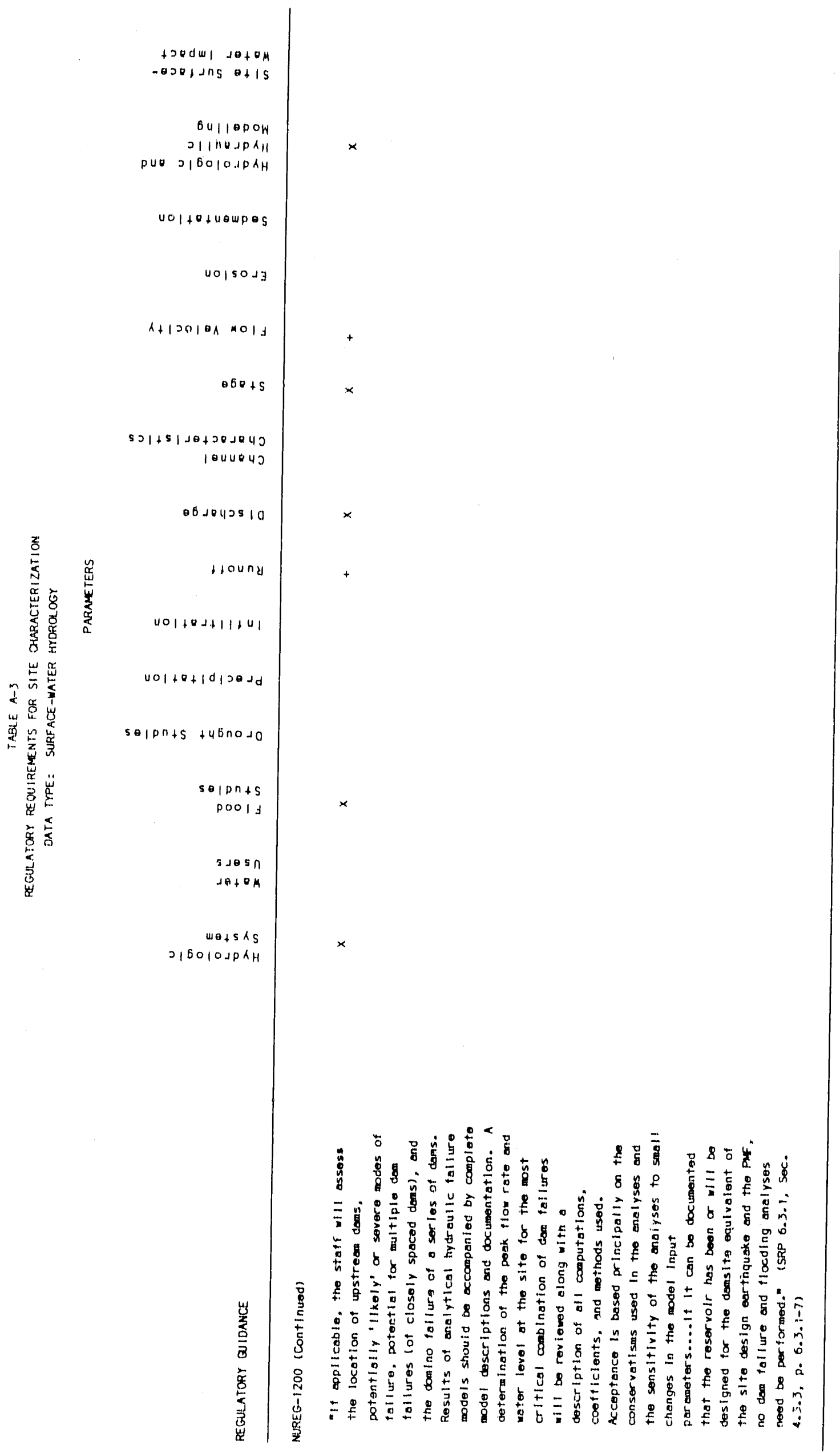

กิ 


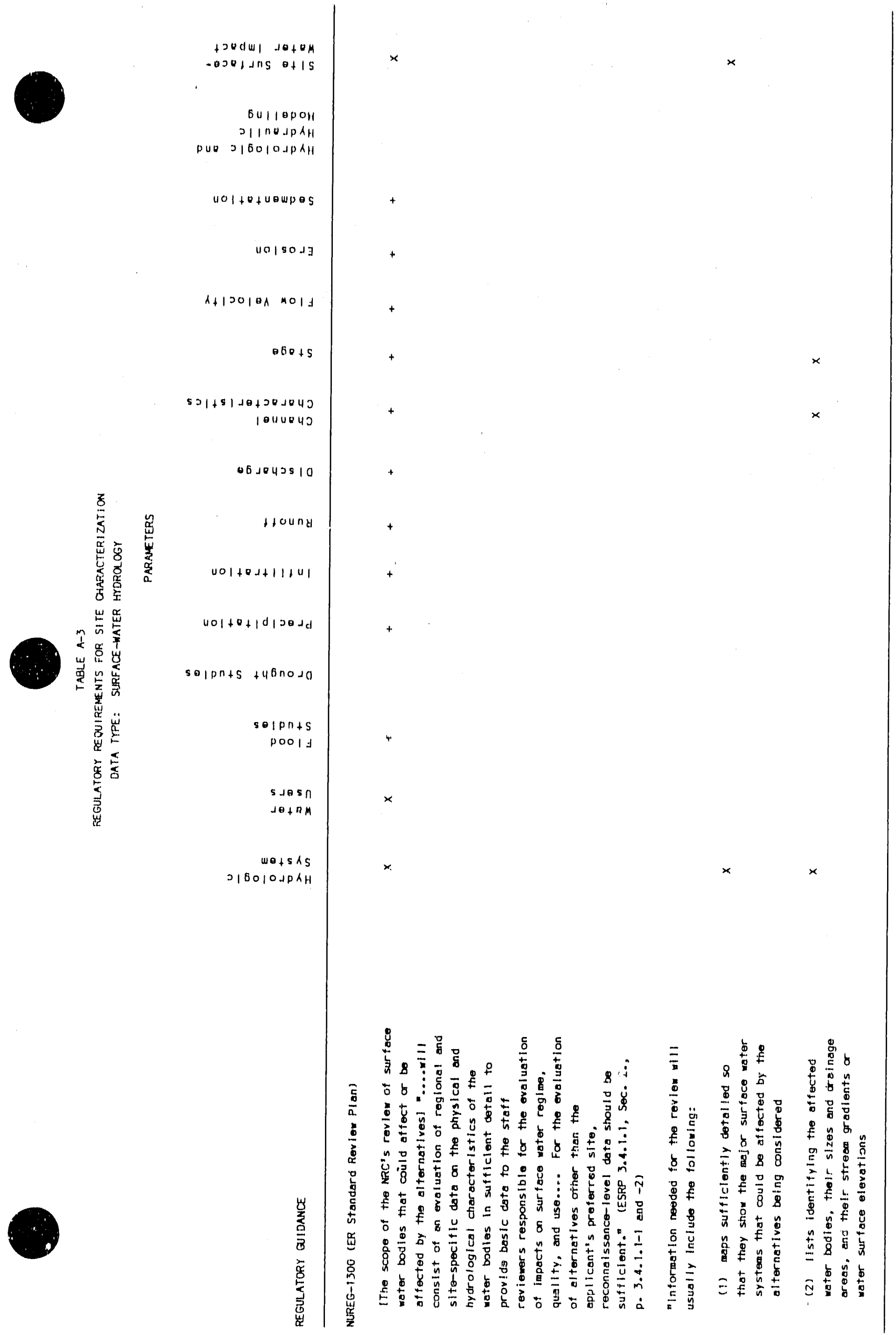




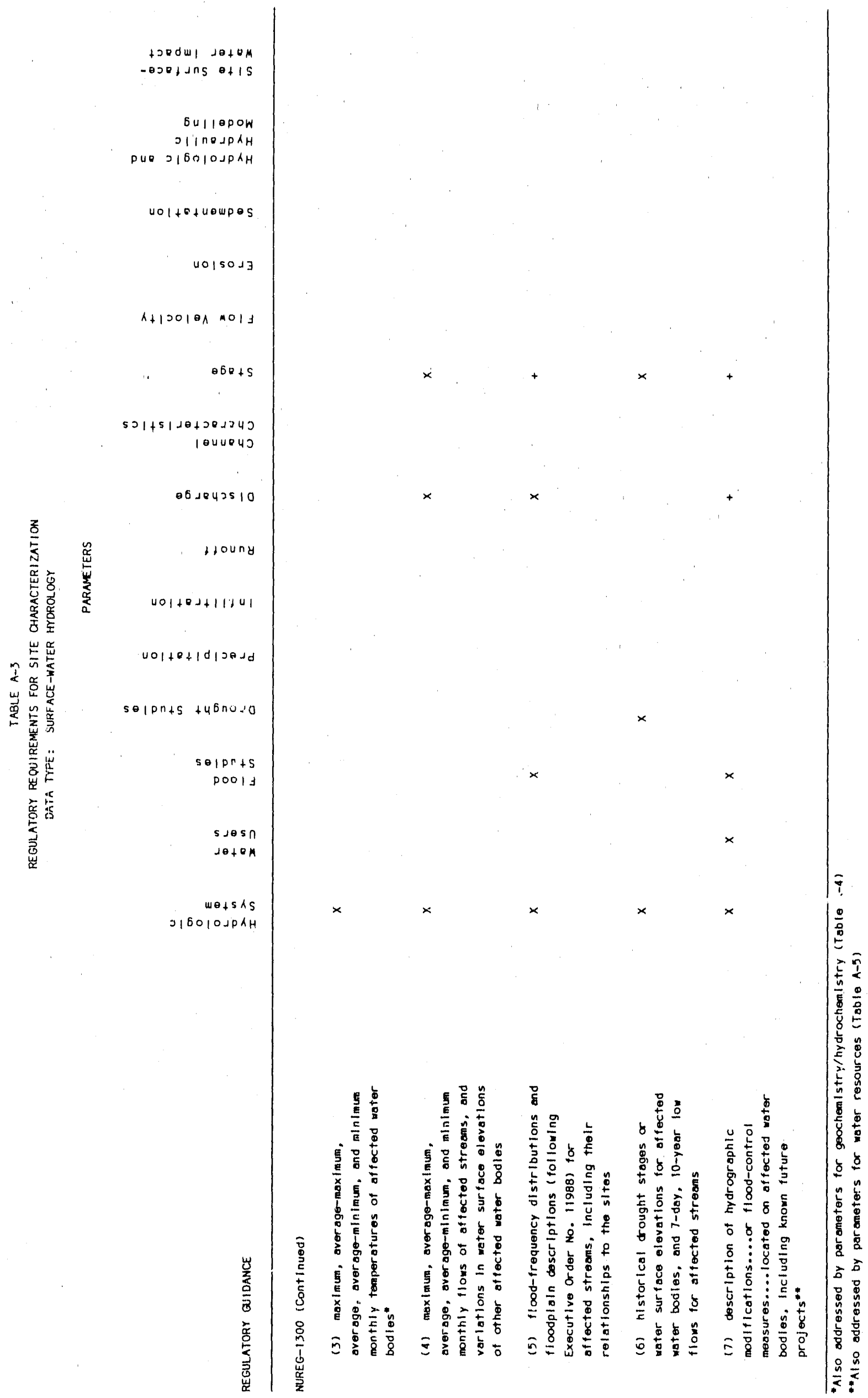




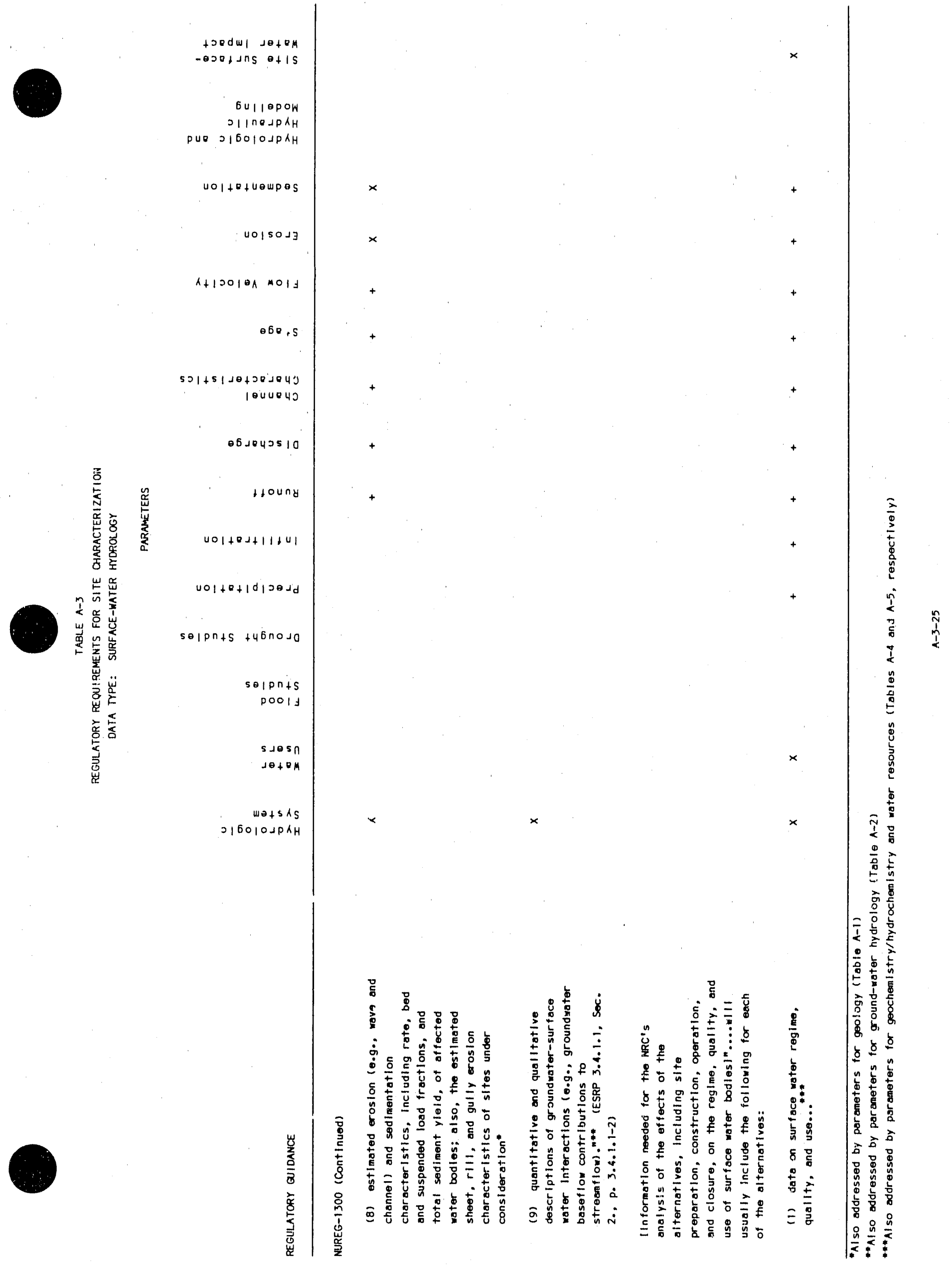



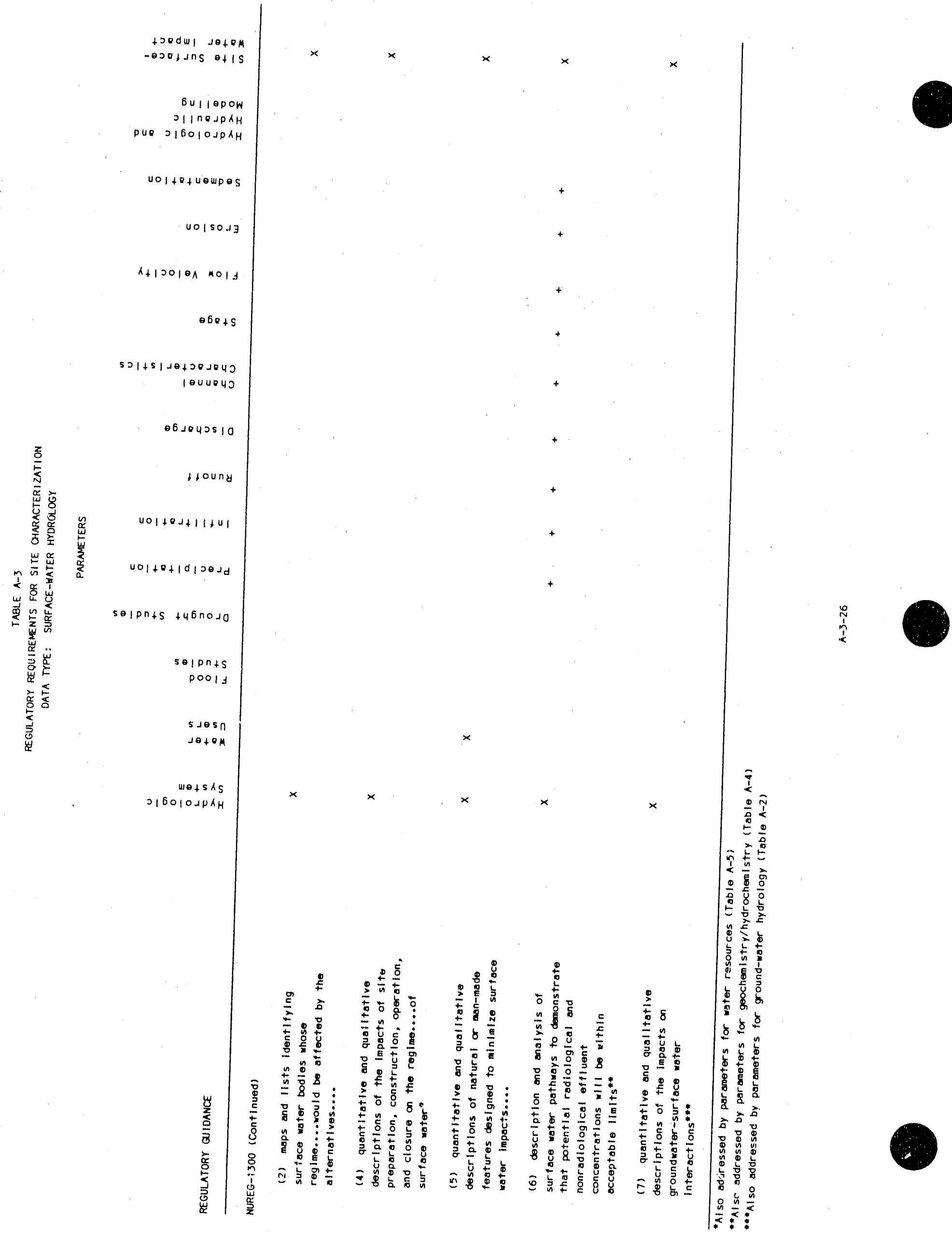


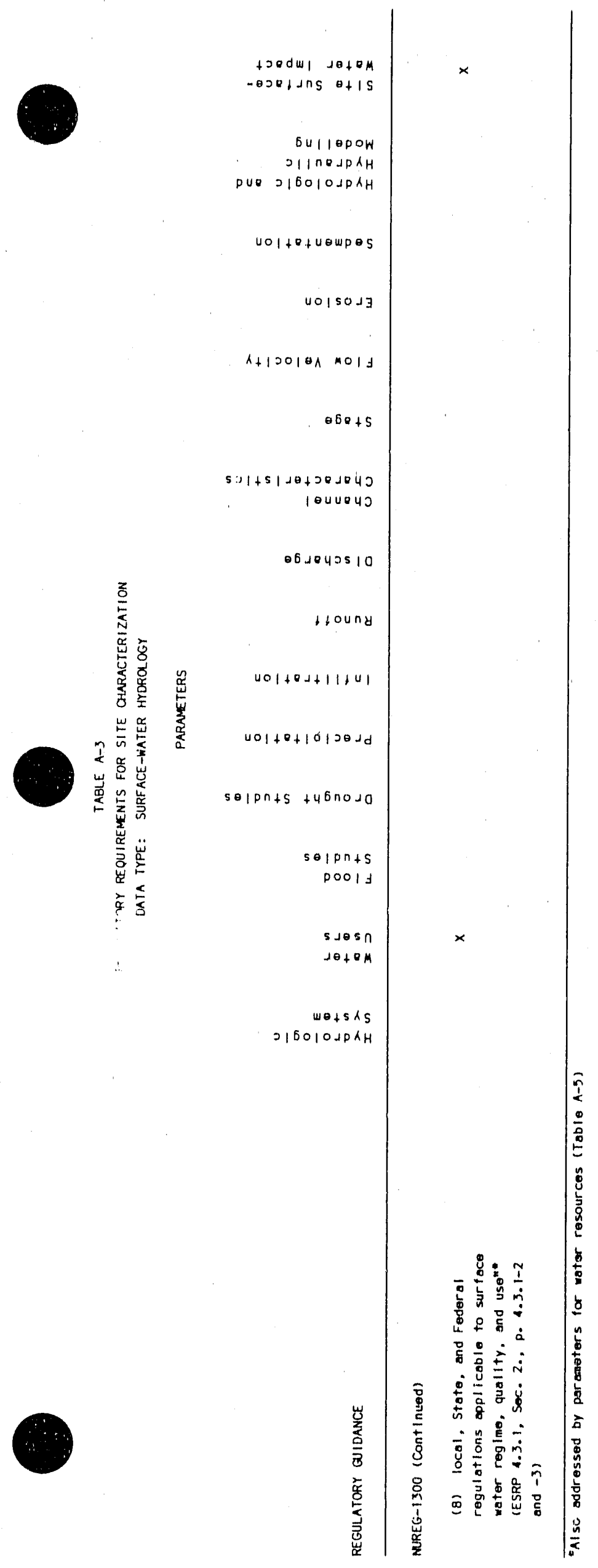


TABLE A-3

PARAMETER DESCRIPTIONS - SURFACE-WATER HYDROLOGY

Hydrologic System: Hydrologic characterization of the site and adjacent watersheds. Identification and descriptions of the natural and man-made system components (1.e., streams, rivers, lakes, wetlands, coastal areas, soil, climate, dams, diversions, and land use) and their interratationship.

Water Users: An inventory of past, present, and potential future surfacewater users in the vicinity of the site and, in particular, within approximately $10 \mathrm{kilometers} \mathrm{downstream} \mathrm{of} \mathrm{the} \mathrm{site.} \mathrm{Information} \mathrm{should}$ include the location, type and amount of use, number of users on the system, rate of withdrawa1, percentage of stream flow withdrawn, sources of water supply, type of intake and pumping equipment, and surface water quality data. The inventory should identify the nearest down-gradient surface-water users and the nearest municipal supply relying on surface water.

Flood Studies: Evaluation of the flooding potential of the site and surrounding area to determine the Probable Maximum Flood (PMF). Information evaluated should include the date, water, levels, peak discharge, and related information for major historic flood events in the region, including stream floods, surges, seiches, tsunamis, dam fallures, ice jams, and floods induced by 1 andslides.

Drought Studies: Evaluation of the occurrence of droughts at the site or surrounding areas. Historic drought water-surface elevations, specifically 7-day, 10-year low flows of affected streams and bodies of water, should be evaluated.

Precipitation: Rainfall and snowfall records that may be used to evaluate flooding and erosion potential. Characteristics to be evaluated include depth of precipitation, duration of storm, intensity of precipitation, recurrence intervals of precipitation, and Probable Maximum Precipitation (PMP).

Infiltration: The movement of water from precipitation into the soil. The infiltration rate of an area depends on the soil properties (e.g., grain size, density, porosity) and antecedent moisture conditions.

Runoff: The total amount of water flowing on the surface, commonly expressed as a depth of water over a specific area. This flow is usually eitifier open channel flow if the water is confined to a channel, or overland flow if the water is flowing without a defined channel.

Discharge: The volumetric rate (flow rate) of runoff in a channel. Channel discharge commonly varies in response to storms. The discharge history of streams and rivers is statistically related to storm recurrence interval for use in evaluating flooding potential.

Channel Characteristics: The physical attributes of a channel (i.e., slope, cross sectional area, and roughness coefficient) that affect the channel's ability to convey a particular discharge. 
Stage: The height of the water surface above an established datum; sometimes referred to as gage height because water-surface elevations are commonly made at stations by one of varlous gage types. River stage is commonly translated into discharge by stage-discharge relationships estabilished for particular stations along a river or stream.

Flow Velocity: The velocity of water in a charnel. An average velocity can be calculated for a specific discharge when particular charnel characteristics are known. Flow velocity is commonly used to evaluate flooding by runup, erosion by scouring, and the transport capability of a stream or river.

Erosion: The breakdown or weathering of geologic materials and the transport of these materials away from their origin.

Sedimentation: The deposition of particulate material after being transported by surface water.

Hydrologic and Hydraulic Modeling: Analytical and numerical methods to simulate flow and transport at the site. The theoretical basis for each model, the uncertainties and limitations of the model, procedures to verify the codes, and results of model calibration, including model validation techniques and sensitivity analyses, must be described and Justified.

Site Surface-Water Impact: Qualitative and quantitative descriptions of the impact of the site on the surface-water system from construction to closure. This would include the impact of any man-made features to minimize surfacewater impacts. 

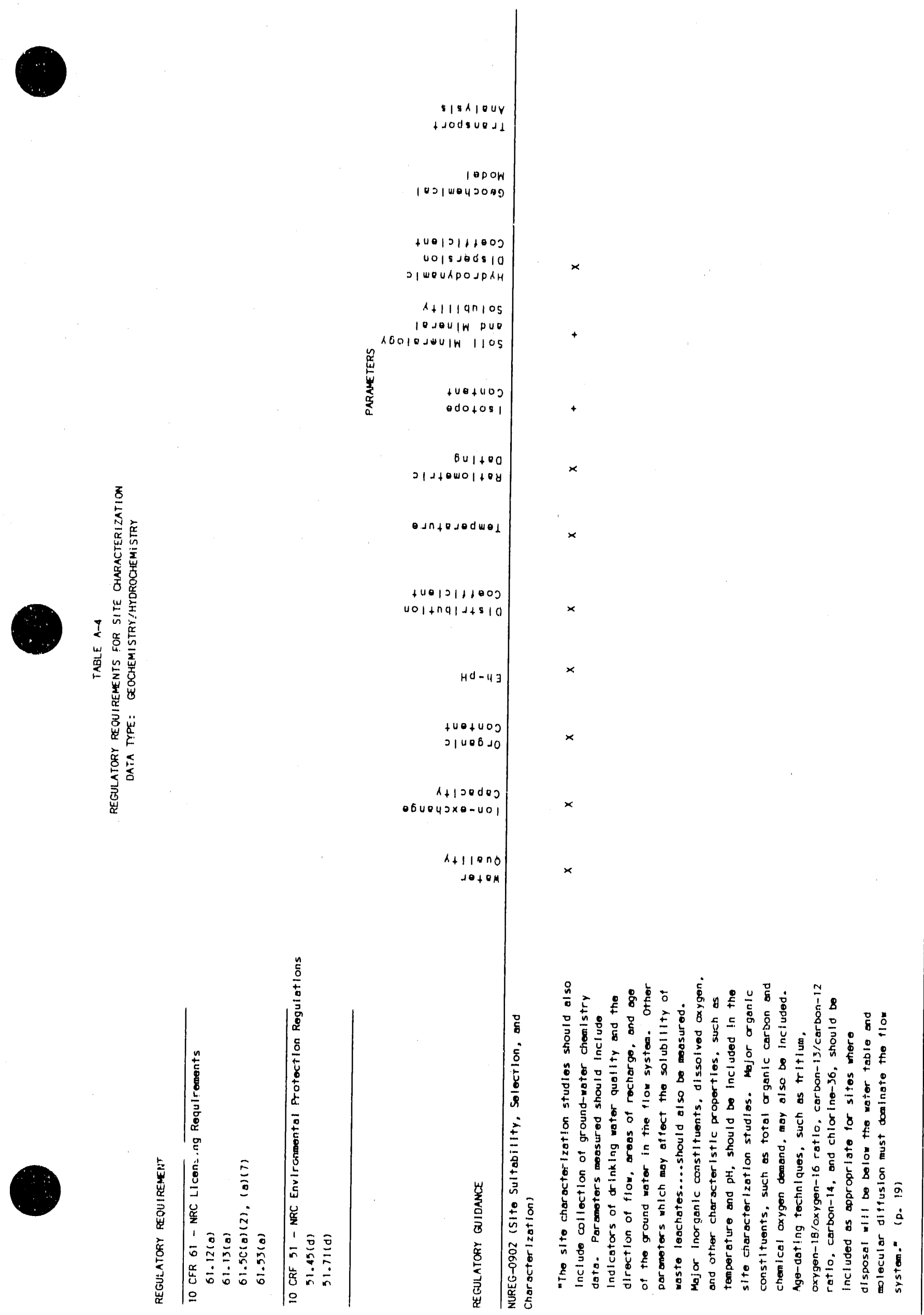


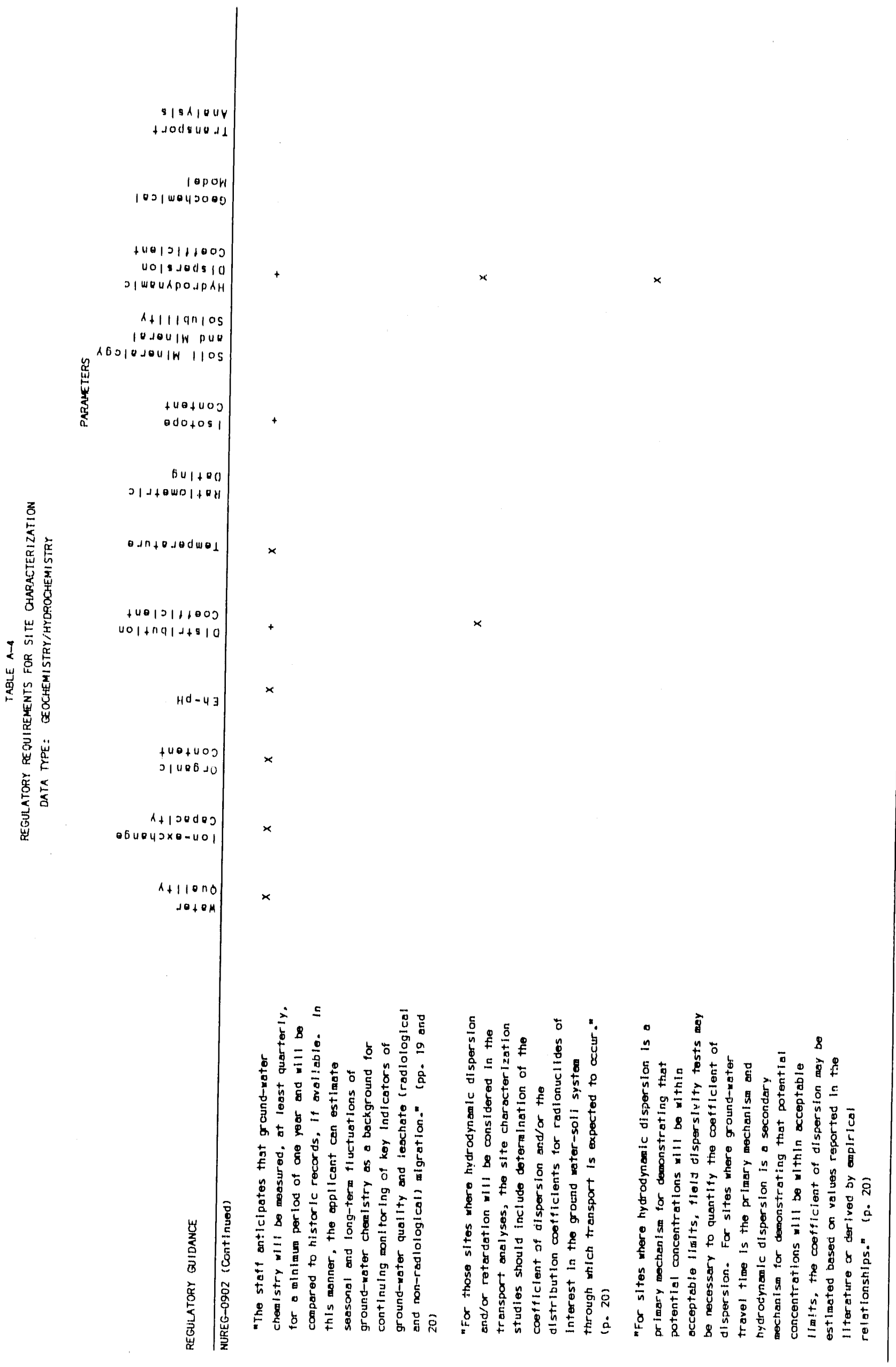




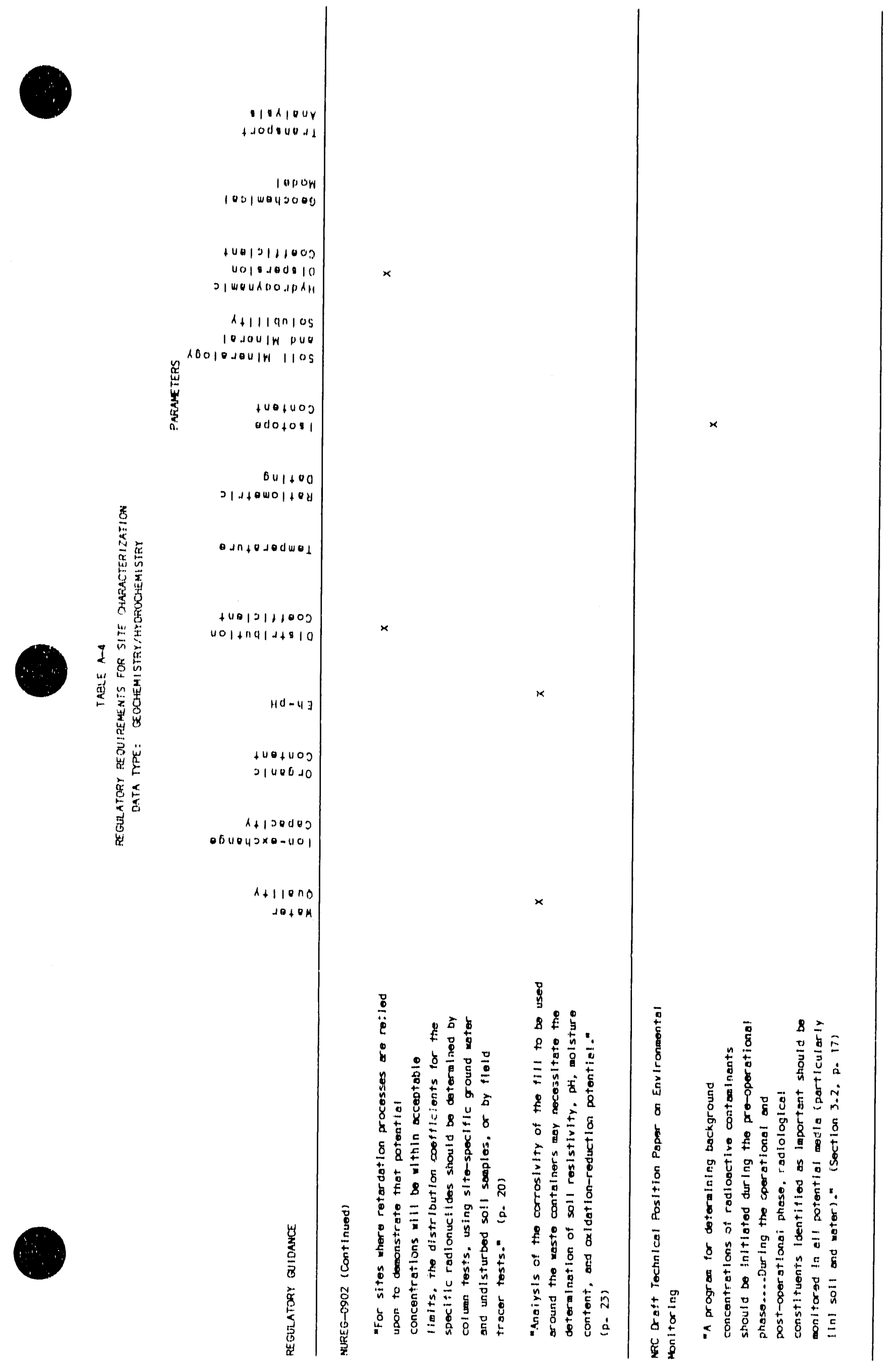




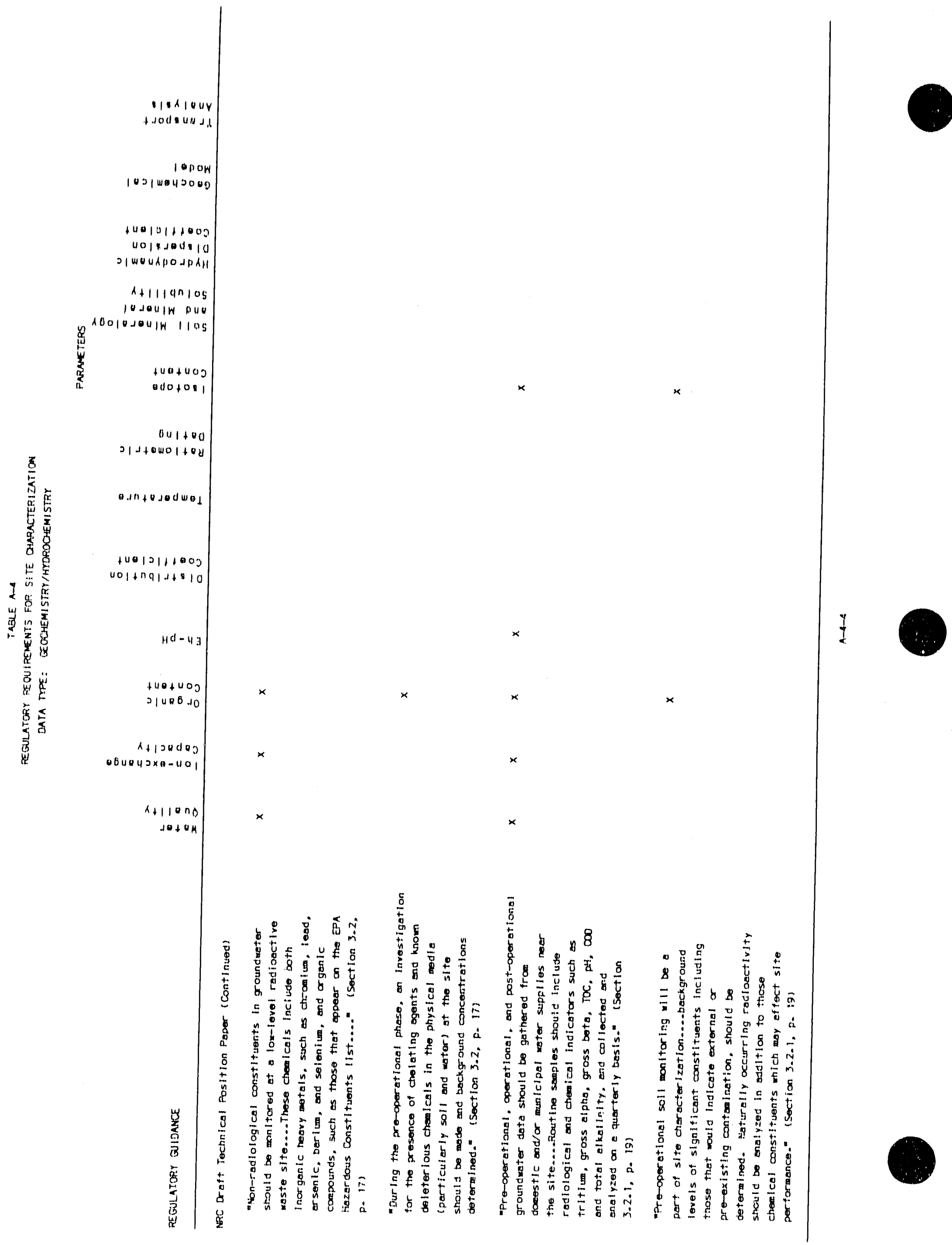




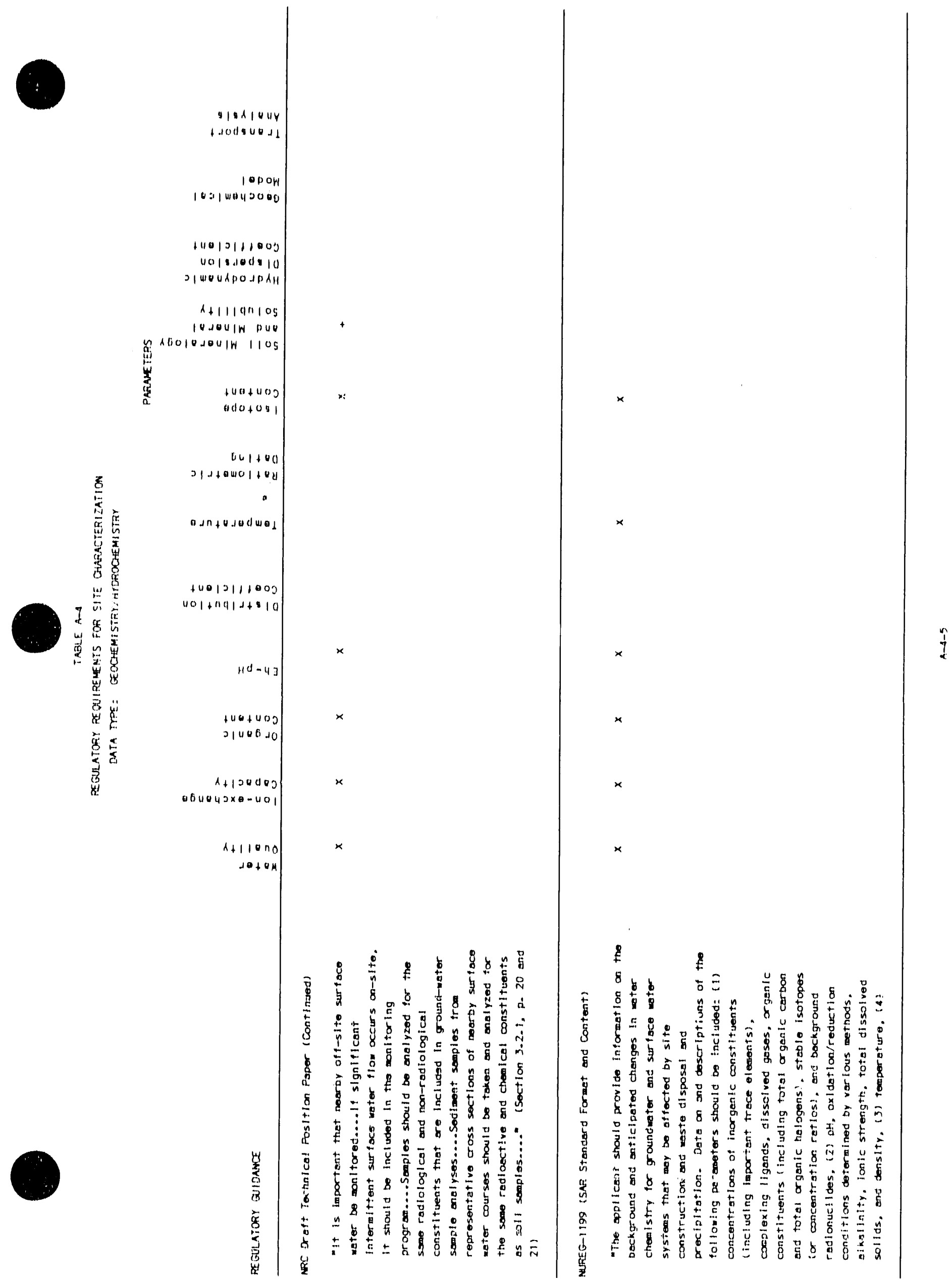




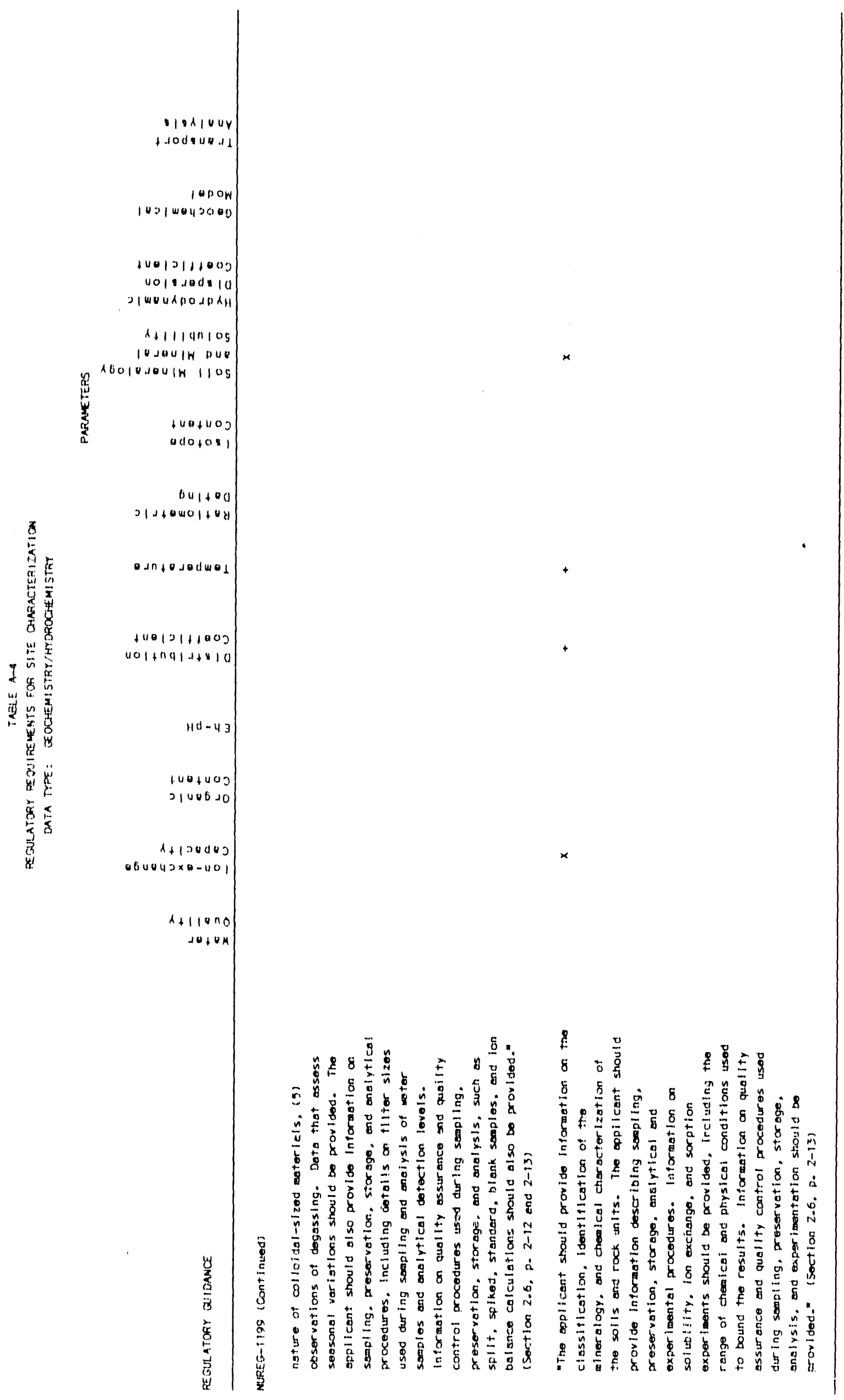




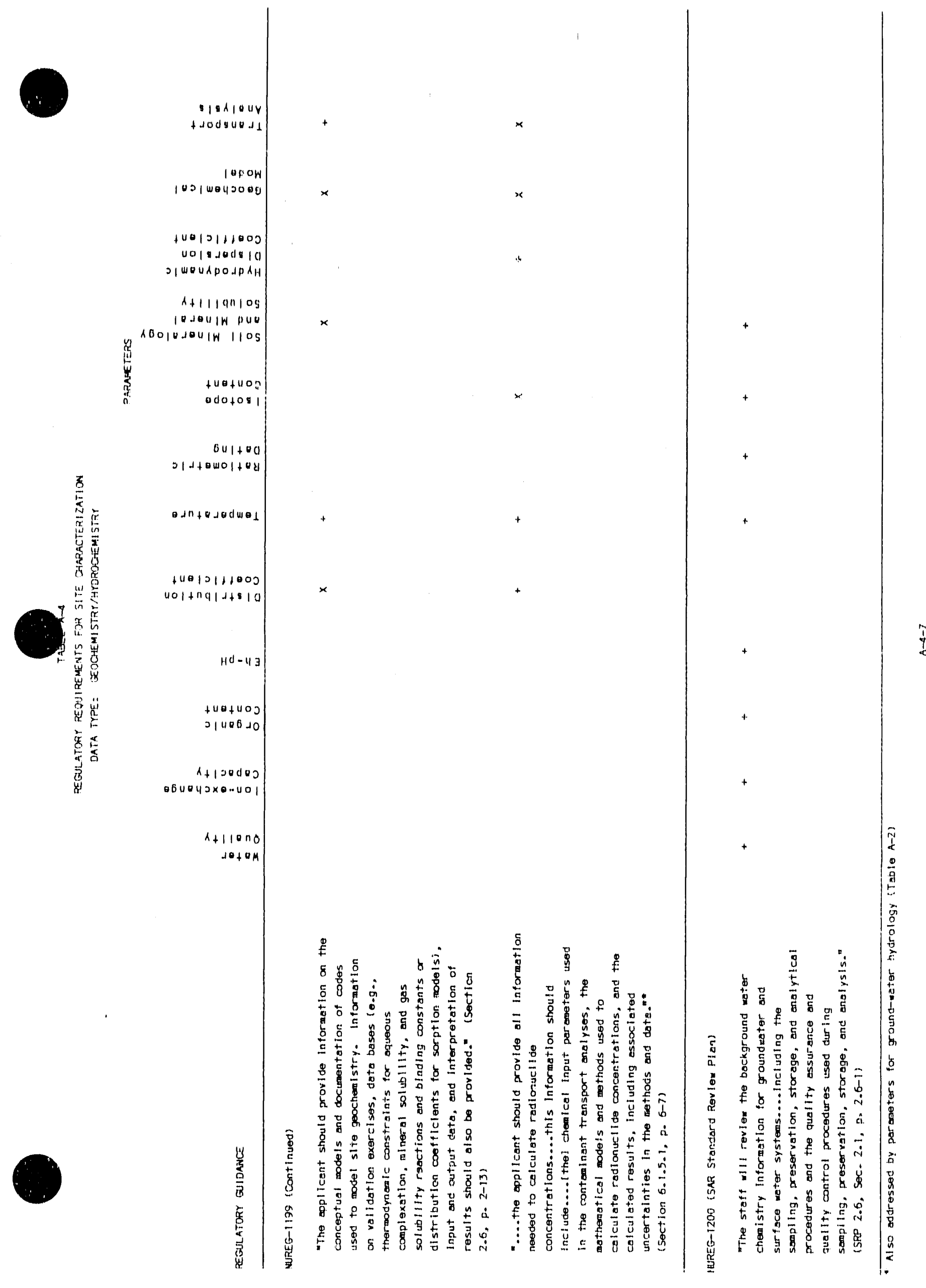




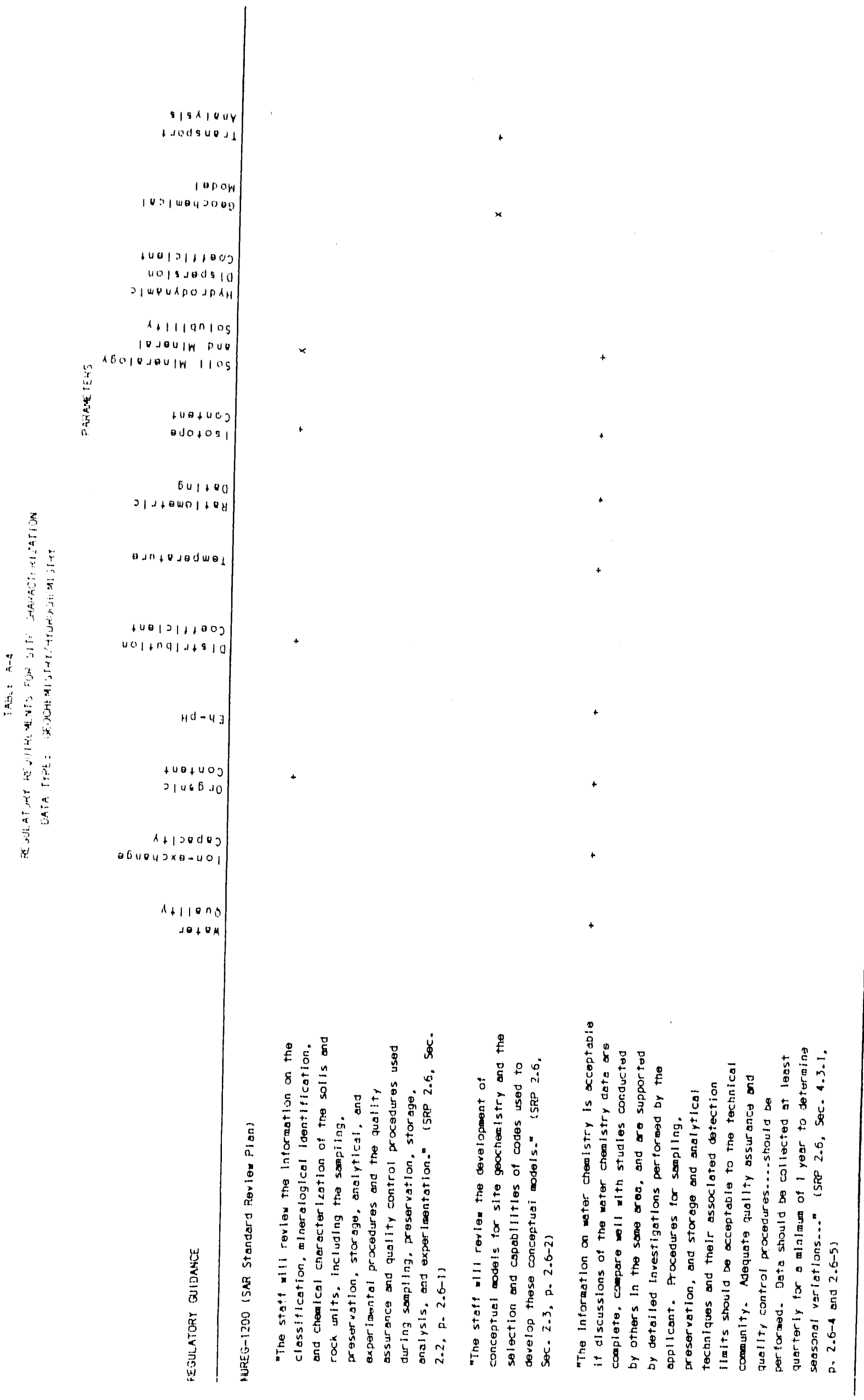



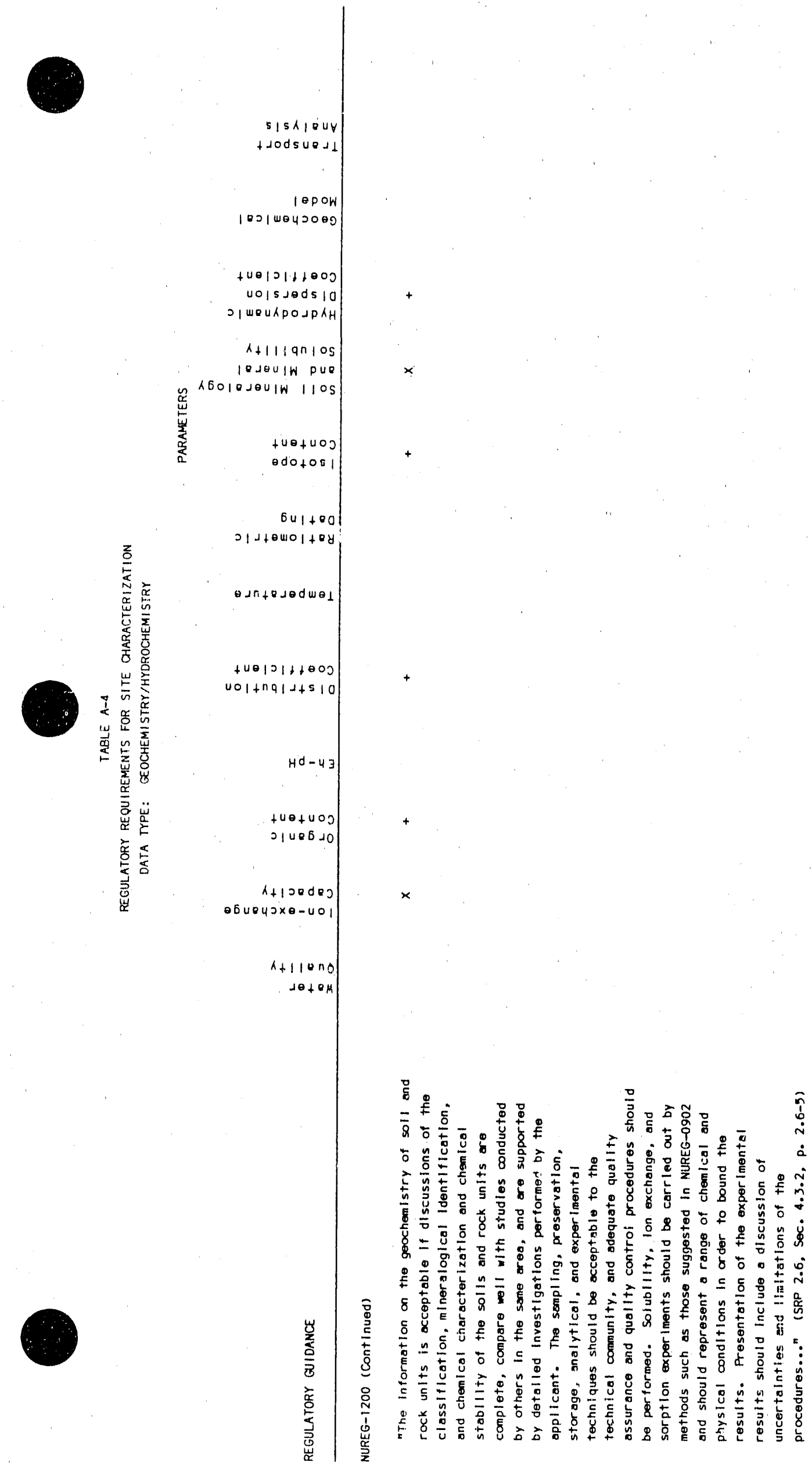


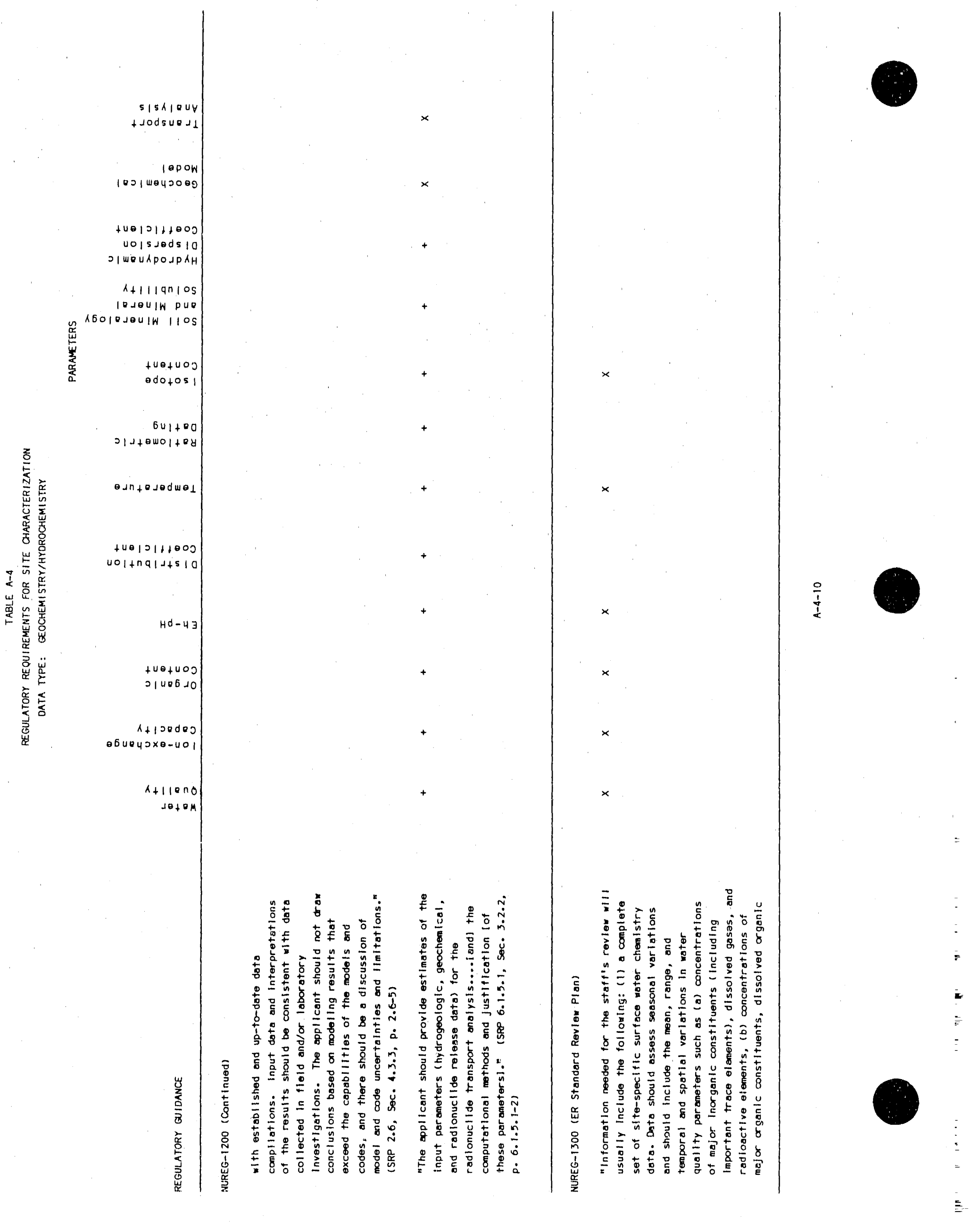




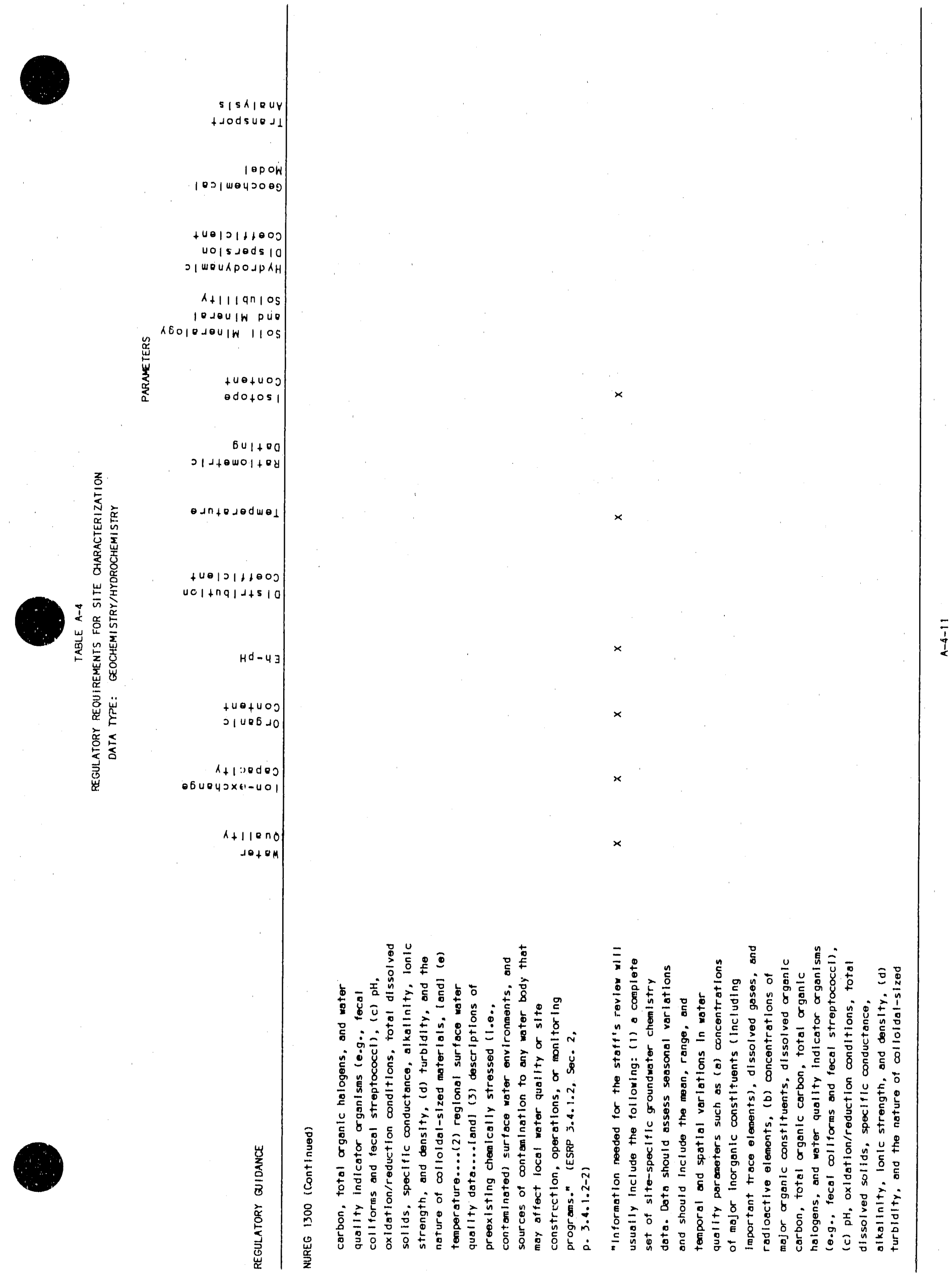




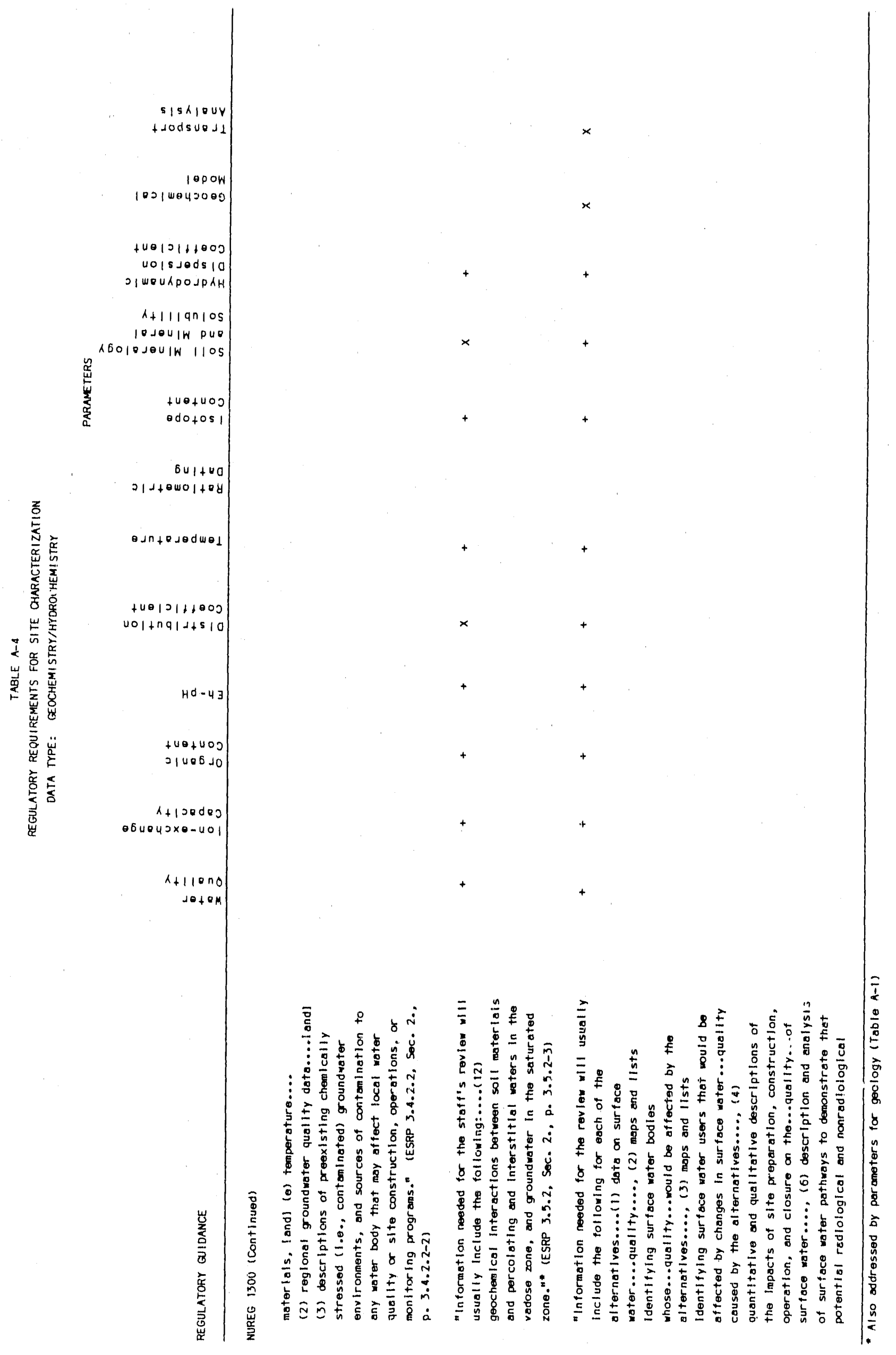




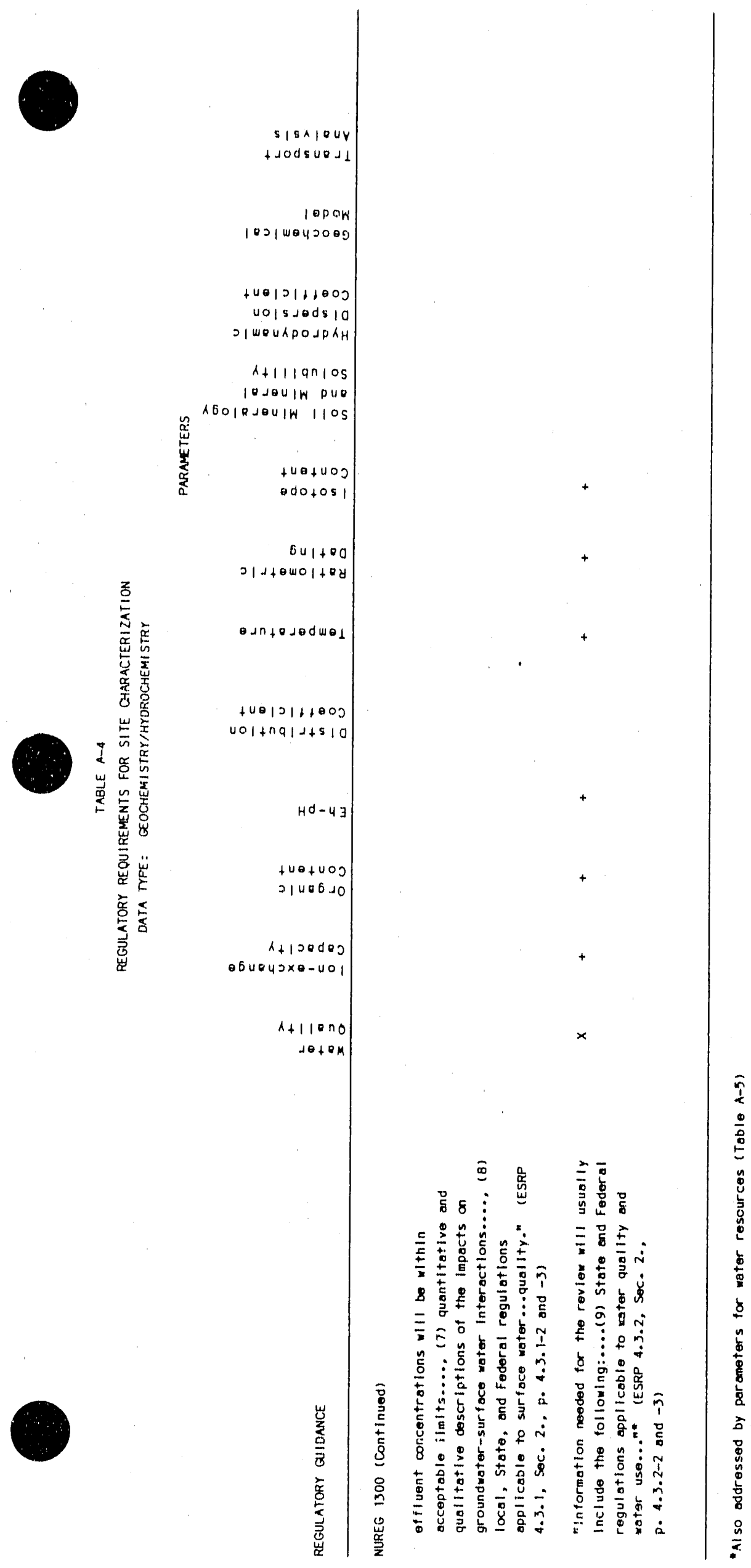


TABL.E A-4

PARAMETER DESCRIPTIONS - GEOCHEMISTRY/HYDROCHEMISTRY

Water Quality: The particular range of chemical attributes that is characteristic of a surface or ground water. Important chemical species for water-quality characterization include total dissolved solids, dissolved oxygen, carbon dioxide and fluoride, major ions, nutrients, dissolved iron and manganese, dissolved heavy metals, silica, $0 i 1$ and grease, and varfous toxicants. Major ions include the cations sodium, potassium, calcium, and magnesium, and the anions sulfate, chloride, bicarbonate, and carbonate. Nutrients typically include total and dissolved organic carbon, orthophosphate, total phosphorous, nitrate, ammonia, and total kjeldahl nitrogen. Heavy metals typically include copper, zinc, nickel, and hexavalent chromium. Toxicants that are present, are suspected as present, or potentially may be introduced to the water will be determined during site characterization. These may include both inorganic chemicals (e.g., dissolved arsenic, dissolved boron, radionuclides) and organic chemicals (e.g., herbicides, pesticides, volatile organics). Hardness, pH, alkalinity, waterquality indicator organisms, turbidity, and nature of colloidal materials in the water will also be determined in a complete water-quality assessment. The particular water characteristics to be determined during site characterization will be a function of site location and of the composition of the waste to be disposed.

Ion-Exchange Capacity: The extent to which a material will exchange ions that are adsorbed on its surface with dissolved ions that are present in a surrounding fluid. The ion-exchange capacity depends on a number of factors, including the material type, concentrations and number of dissolved species present in solution, and system pH. The cation-exchange capacity (CEC) is of particular interest in soil and subsurface environments. Solls with high clay content, and particularly with high organic content, typically will have a high CEC. Cations, such as many of the dissolved radionuclides that migrate through these materials, will be effectively retarded during transport as a result of ion exchange.

Organic content: The proportion of organic matter present in soil. The organic matter may be comprised of living and decomposed plants, roots, and detritus. Organic constituents that may be quantified include total organic carbon (TOC), total and volatile organic acids, chelating agents, tannin, lignin, soil nutrients (e.g., nitrate, ammonia, phosphate), and microorganisms (e.g., total bacteria, coliforms). Constituents may be analyzed in soil and in soil gas. Organic matter, and particularly root systems, can provide pathways for chemical migration through soils and to the soil surface. The organic soil fraction typically has a high sorptive capacity and thus can increase the soil CEC. Organics also may leach and mobilize inorganic constituents in soil. Certain organics may behave as chelating agents, which can bind metallic ions (e.g., radionuclides). The chelating agents, when dissolved in water, may provide a transport mechanism for metals that are normally non-mobile. 
Eh-pH: Eh is commonly referred to as the redox potential, and is a measure of the tendency of a solution to oxidize or reduce susceptible constituents. pH refers to hydrogen fon activity, and is a measure of the acidity of a solution. Both Eh and $\mathrm{pH}$ are typically measured using potentiometric probes. Eh may also be estimated from measured concentrations of both members of redox couples, such as iron species. To address possible redox disequilibrium, if a single Eh value is required for modeling purposes, that value should be determined from as many sources as is practical. The assumptions and methods used in defining an overall Eh for model calculations should be stated and justified. The relationship between Eh and $\mathrm{pH}$ in aqueous systems is commonly illustrated on Eh-pH diagrams. These diagrams can be used to predict stability fields of the various chemical species. Thus, for a given Eh and $\mathrm{pH}$, species that are likely to exist and that contain elements of interest (e.g., radionuclides) can be determined. Eh-pH diagrams can be used to predict the behavior of elements such as radionuclides in the local environment.

Distribution coefficient: The ratio reflecting the allocation of a species between two phases in an aqueous or rock system. In particular, this parameter is useful for estimating the fraction of a species that will be allocated to the aqueous phase and therefore will remain mobile, and the fraction allocated to the solid phase that will be immobile. The distribution coefficient is an empirical parameter whose value is strongly dependent upon site specific or experimental conditions. The distribution coefficient includes the effects of ton exchange and other sorption reactions. This parameter can be used to estimate the extent of retardation of a dissolved species during transport, but the accuracy of that estimate will strongly depend upon the extent to which the conditions approximate those under which the distribution coefficient was measured.

Temperature: The temperature of both in-situ ground water and surface water. This parameter is important because the other parameters are temperature sensitive.

Radiometric dating: Determination of the age of the ground water or rock on the basis of radioisotope abundances.

Isotope Content: The quantity of radioactive and other isotope constituents present in the soil and water.

Soil Mineralogy and Mineral Solubility: The types of minerals present in a soil; also includes their weathering and engineering characteristics. Soil mineralogy is important as it relates both to radionuclide migration and to engineering behavior. Mineral solubility refers to the tendency of soil minerals to dissolve into aqueous phases present in the system. Description of mineral solubility should include the range of chemical and physical conditions bounding various stability fields.

Hydrodynamic Dispersion Coefficient: The hydrodynamic dispersion coefficient describes dispersion of a contaminant in ground water. Dispersion is a result of two processes: molecular diffusion and mechanical mixing. Diffusion is the process whereby contaminants move under the influence of their kinetic 
activity in the direction of their concentration gradient. Mechanfcal mixing or mechantcal dispersion is a result of velocity vartations within the porous medium. The hydrodynamic dispersion coeffictent is dependent on the diffusion coefficient, the concentration gradient, the longitudinal and transverse dispersivities, and the velocity field.

Geochemical Model: A mathematical formulation of predicted geochemical behavior of the rock-soll-ground-water system. Description of such a model should include information on the database used, validation exercises applied, and the capabilities and limitations of the model.

Iransport Analysis: A mathenatical formulation of predicted transport behavior in the saturated and unsaturated ground-water system. Processes of dispersion, diffusion, adsorption, degradation, and radtoactive decay may be included in transport analyses. 


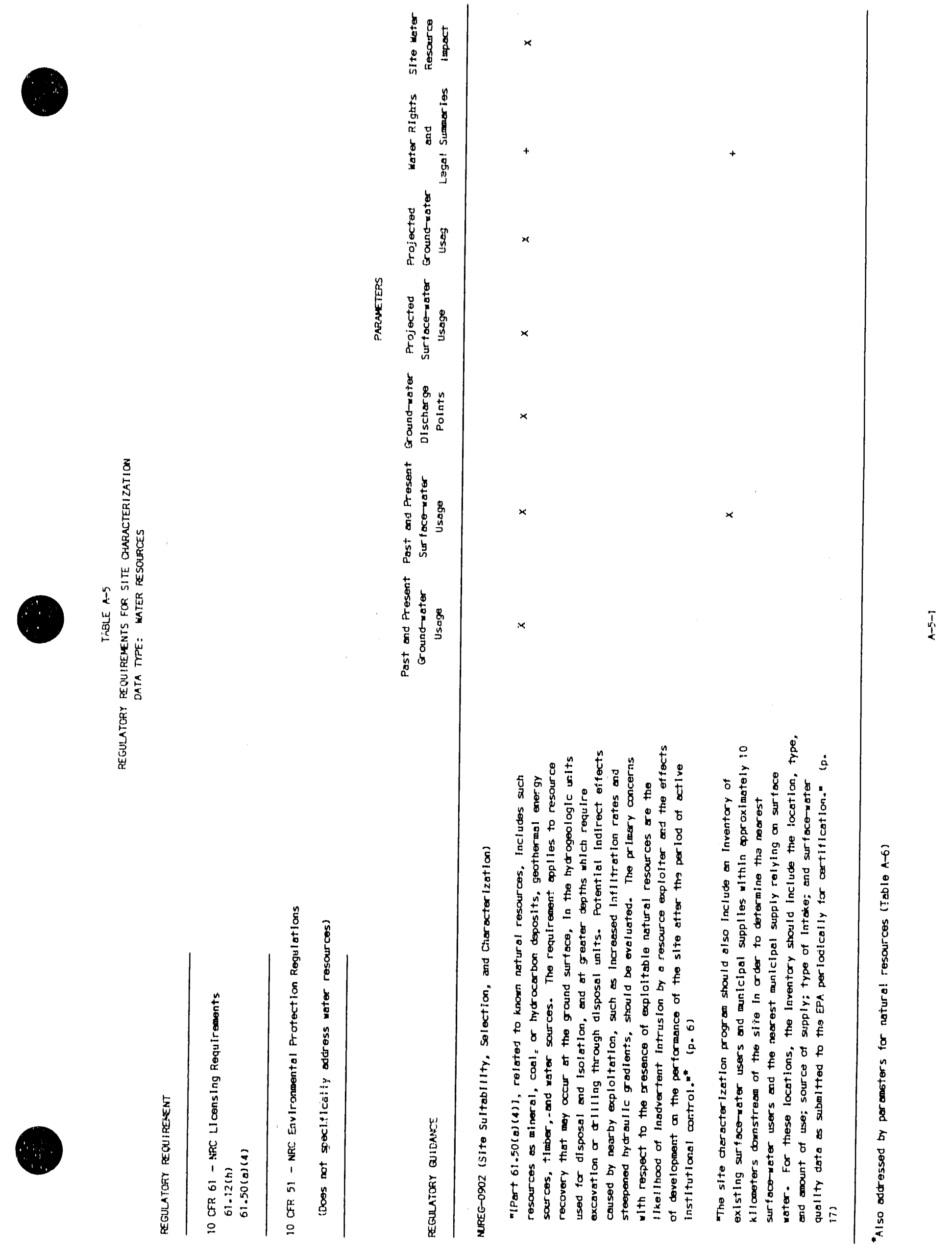



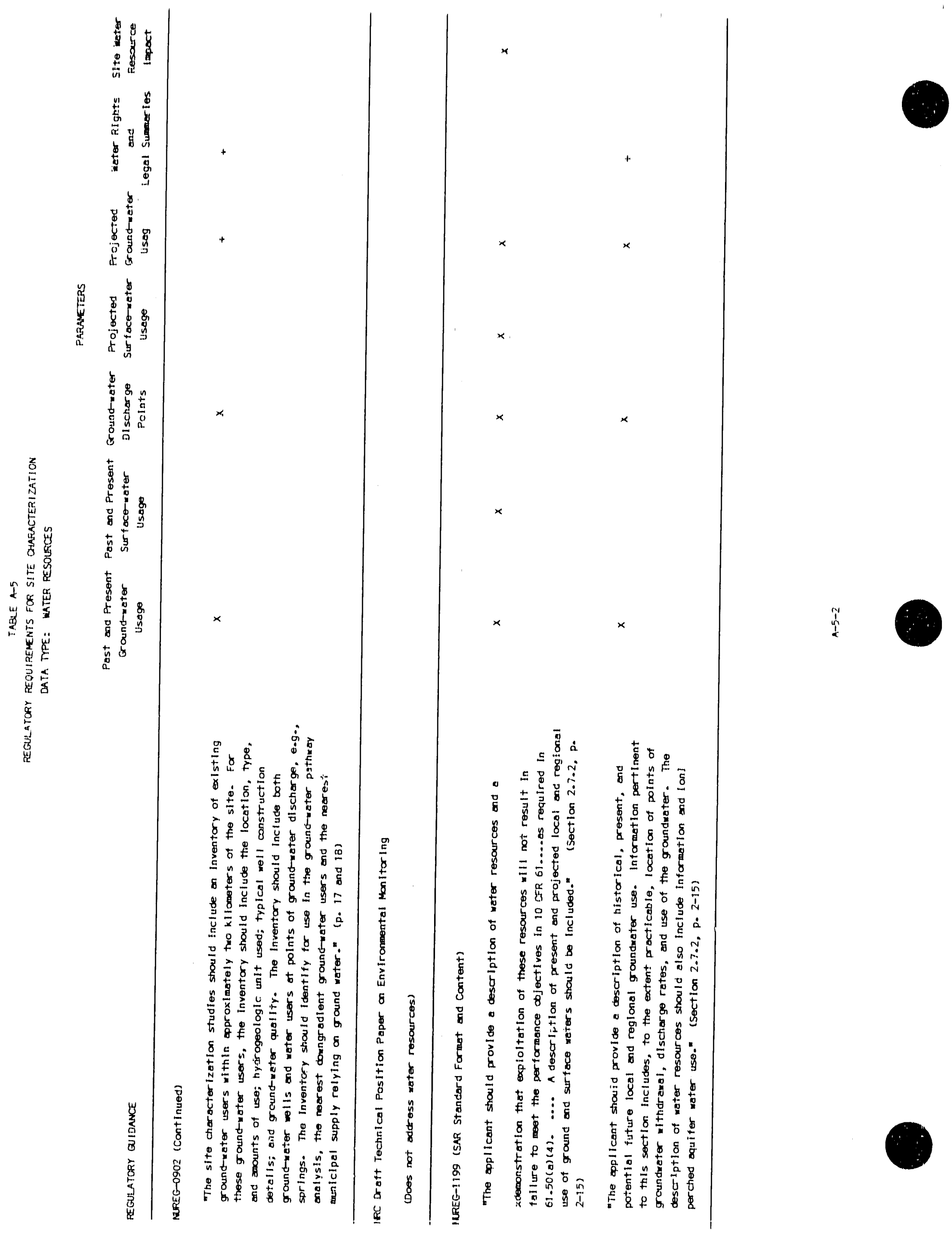


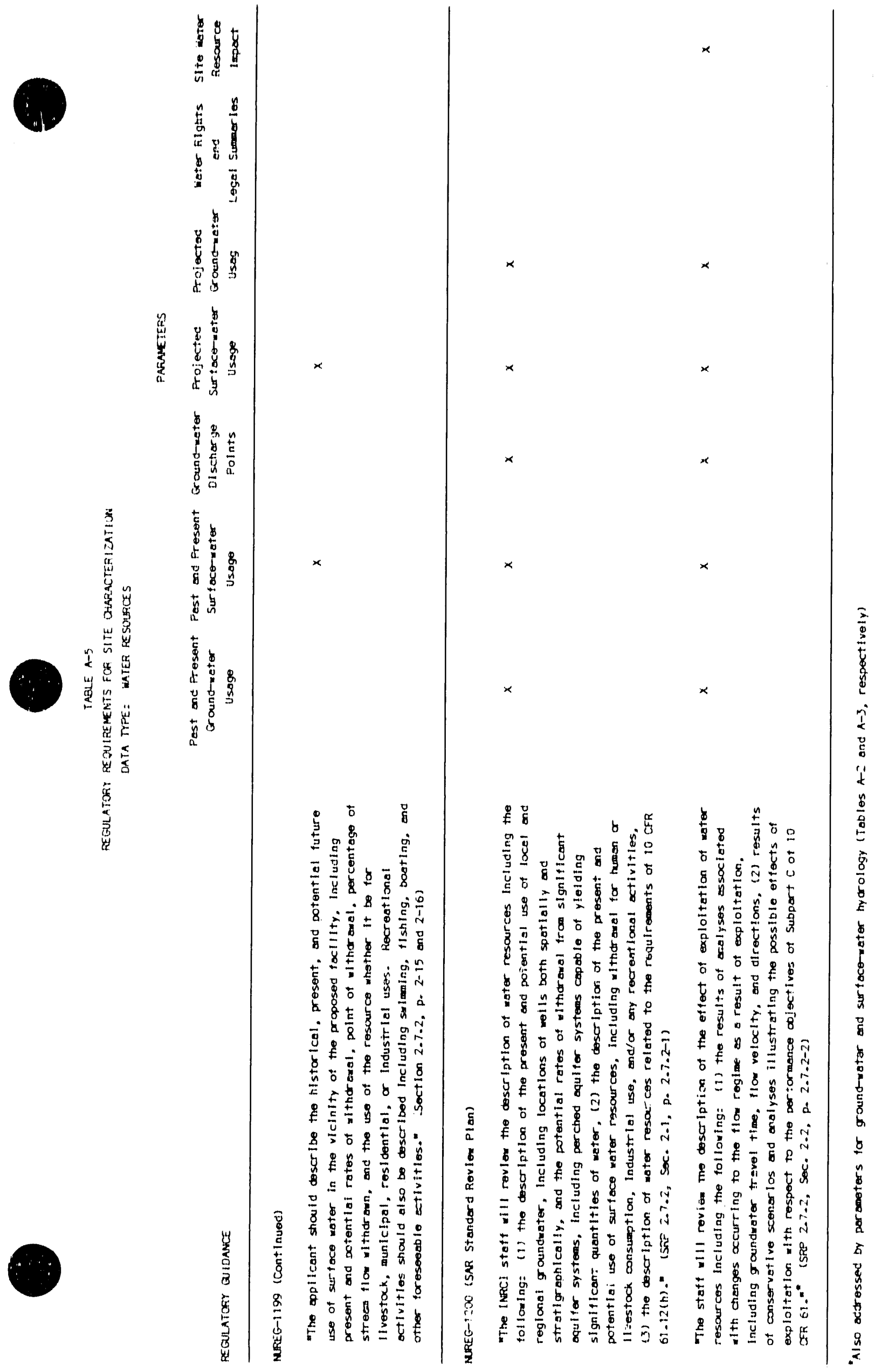




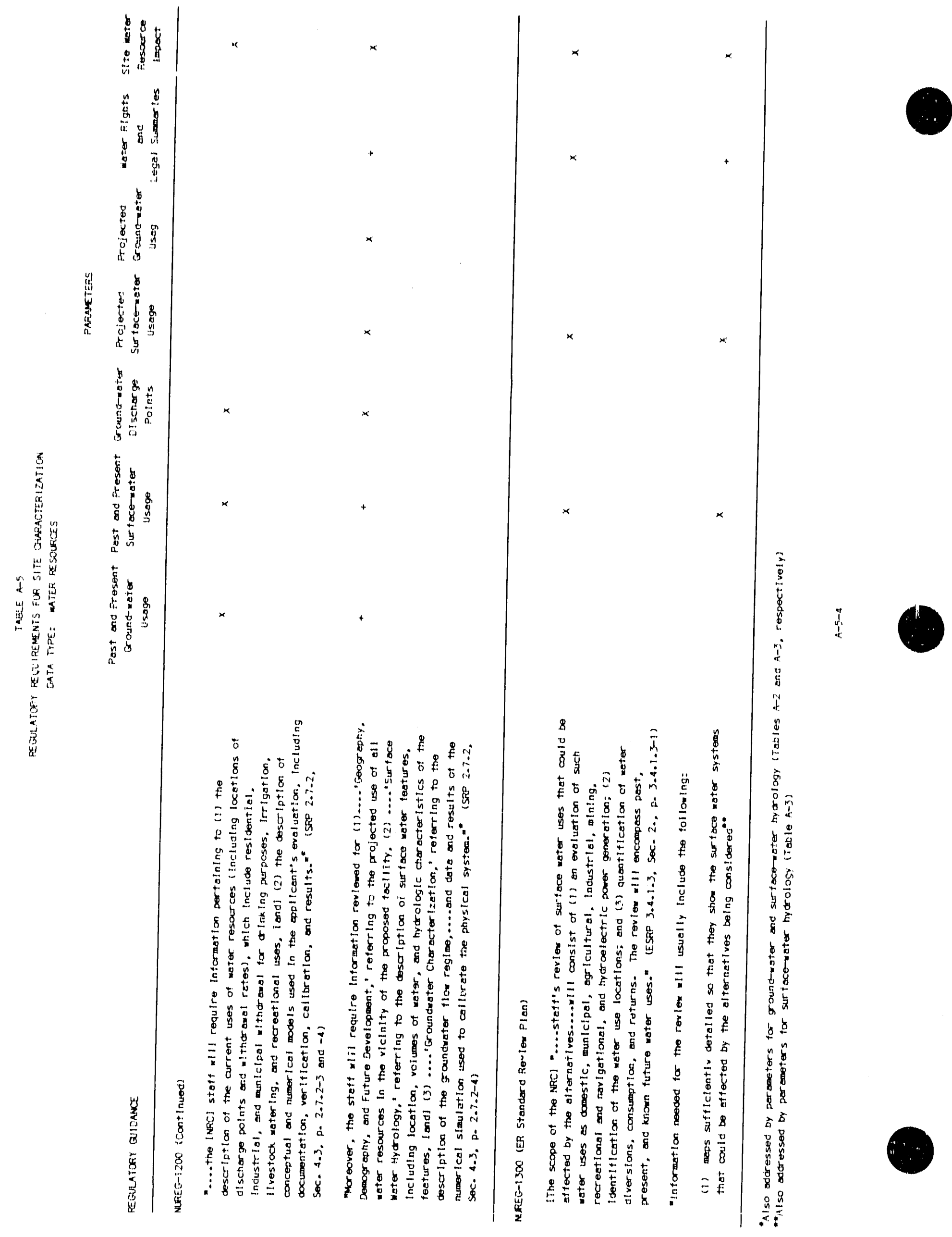




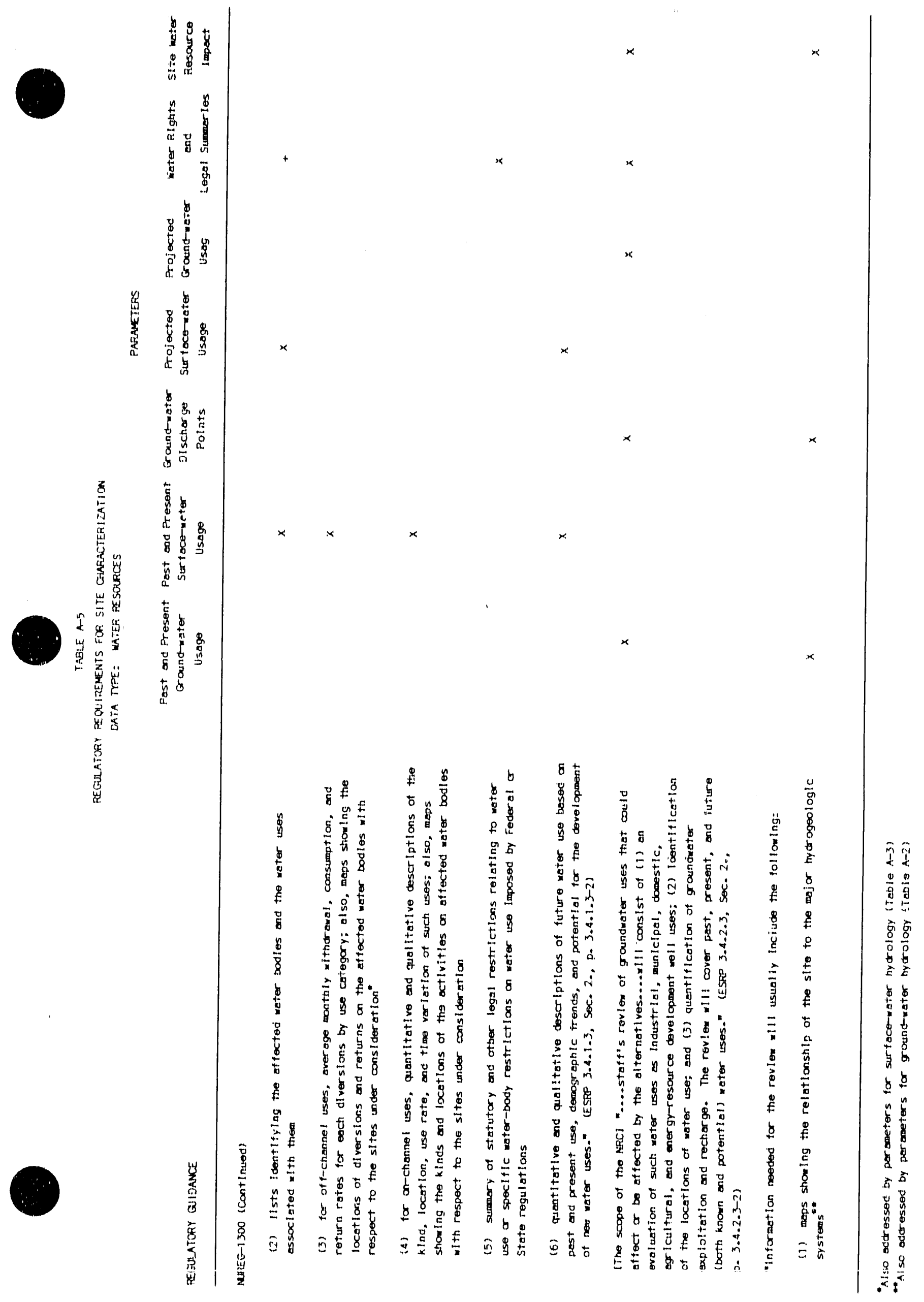




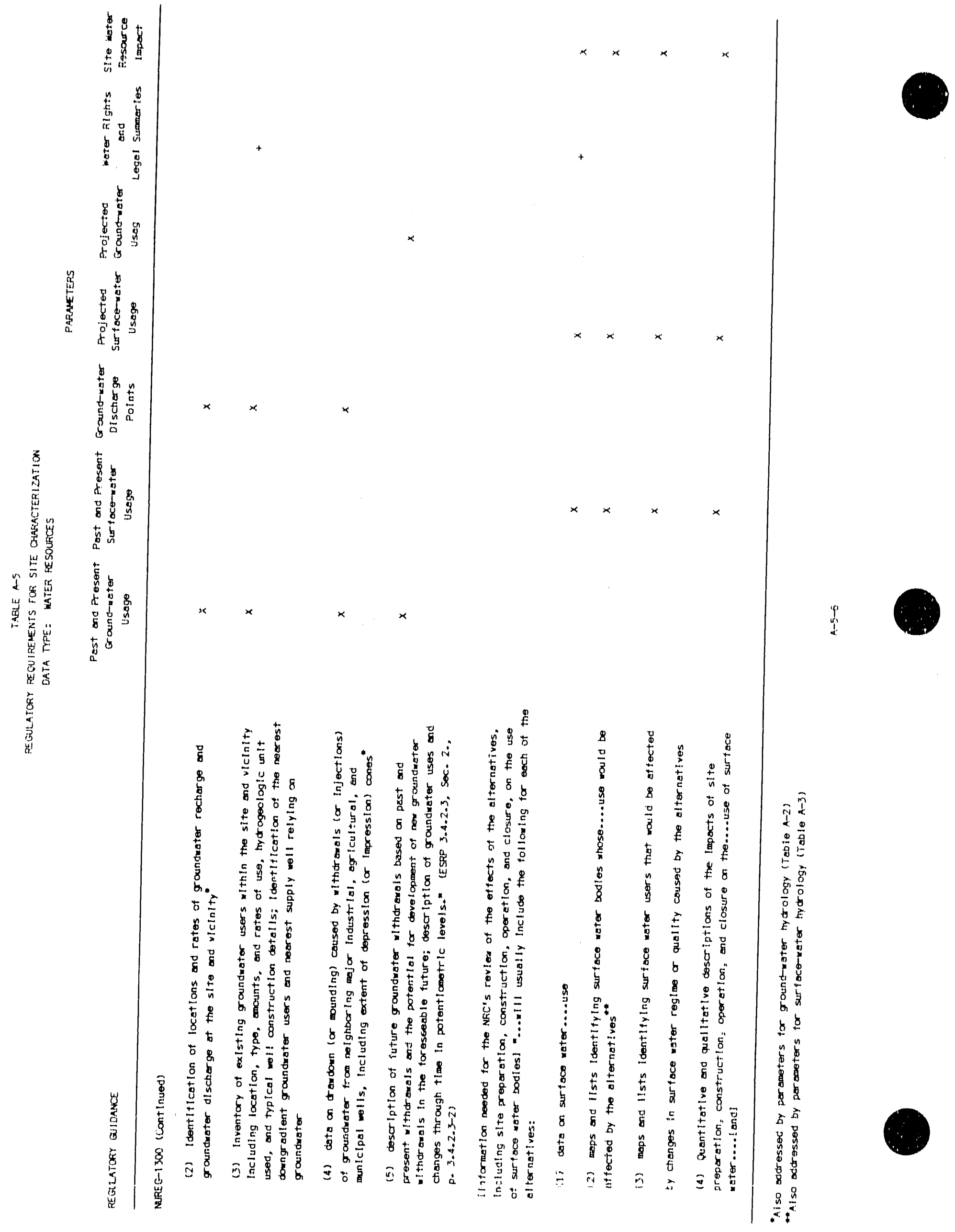




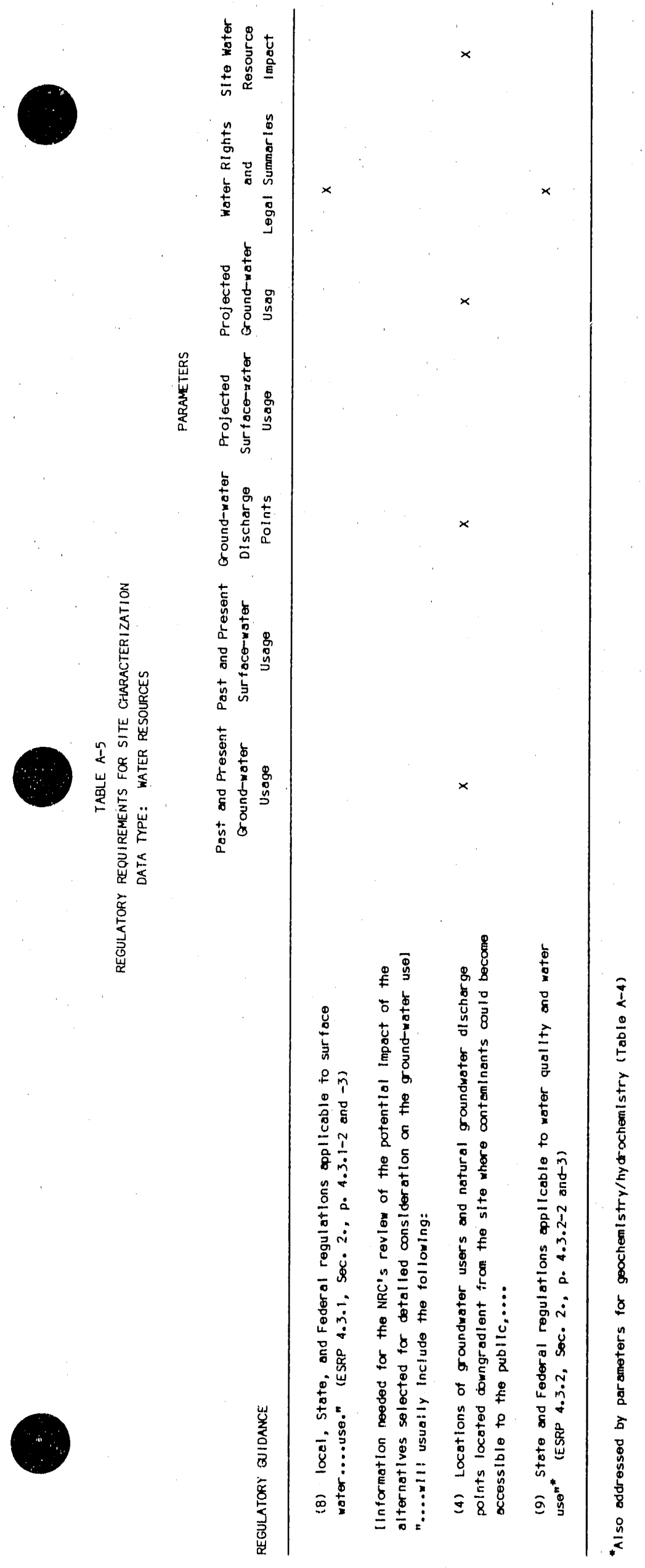


TABLE A-5

PARAMETER DESCRIPTIONS - WATER RESOURCES

Past and Present Ground-water Usage: An inventory of past and present groundwater users within approximately 2 kilometers of the site. Information should include the location, type and amount of use, hydrogeologic unit used, sources of water supply, type of we 11 and pumping equipment, maximum production rate of well, and water quality data. The inventory should identify the nearest down-gradient ground-water users and the nearest municipal supply relying on groundwater.

Past and Present Surface-water Usage: An inventory of past and present surface-water users in the vicinity of the site and, in particular, within approximately 10 kilometers downstream of the site. Information should include the location, type and amount of use, number of users on the system, rate of withdrawal, percentage of stream flow withdrawn, sources of water supply, type of intake and pumping equipment, and surface water quality data. The inventory should identify the nearest down-gradient surface-water users and the nearest municipal supply relying on surface water.

Groundwater-water Discharge Points: An inventory of all springs, seeps, etc., in the vicinity of the site and usage at these points. Inforination should include the location, type and amount of use, hydrogeologic unit used, flow rate, sources of water supply, type of well and pumping equipment, and water quality data.

Projected Surface-water Usage: The projected demand and usage of local and regional surface-water resources for domestic, municipal, agricultural, industrial, mining, recreational, and navigational needs. This projection will include geographic, demographic, and economic information and documentation as part of the evaluation.

Projection Ground-water Usage: The projected demand and usage of iocal and regional ground-water resourses for domestic, municipal, agricultura?, industrial, mining, and recreational needs. This projection will include the potential rates of withdrawal from significant aquifer systems, and geographic, demographic, and economic information and documentation as part of the evaluation.

Water Rights and Legal Summaries: A summary of statutory and other legal restrictions relating to surface-water and ground-water use as imposed by municipal, State, or Federal regulations.

Site Water Resource Impact: A qual itative and quantitative description of the present and projected surface-water and ground-water uses within the site vicinity that could affect or be affected by the site. 


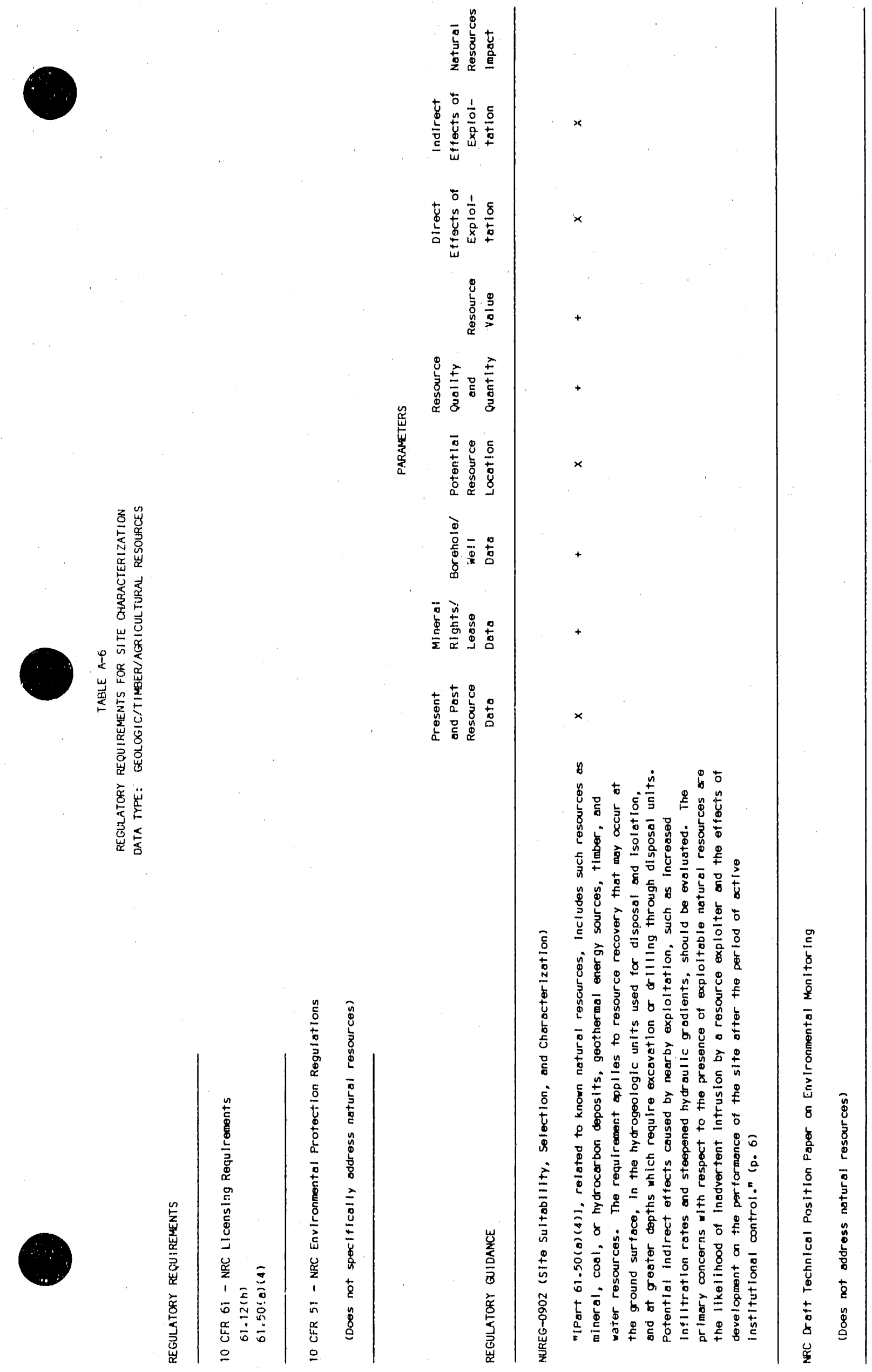




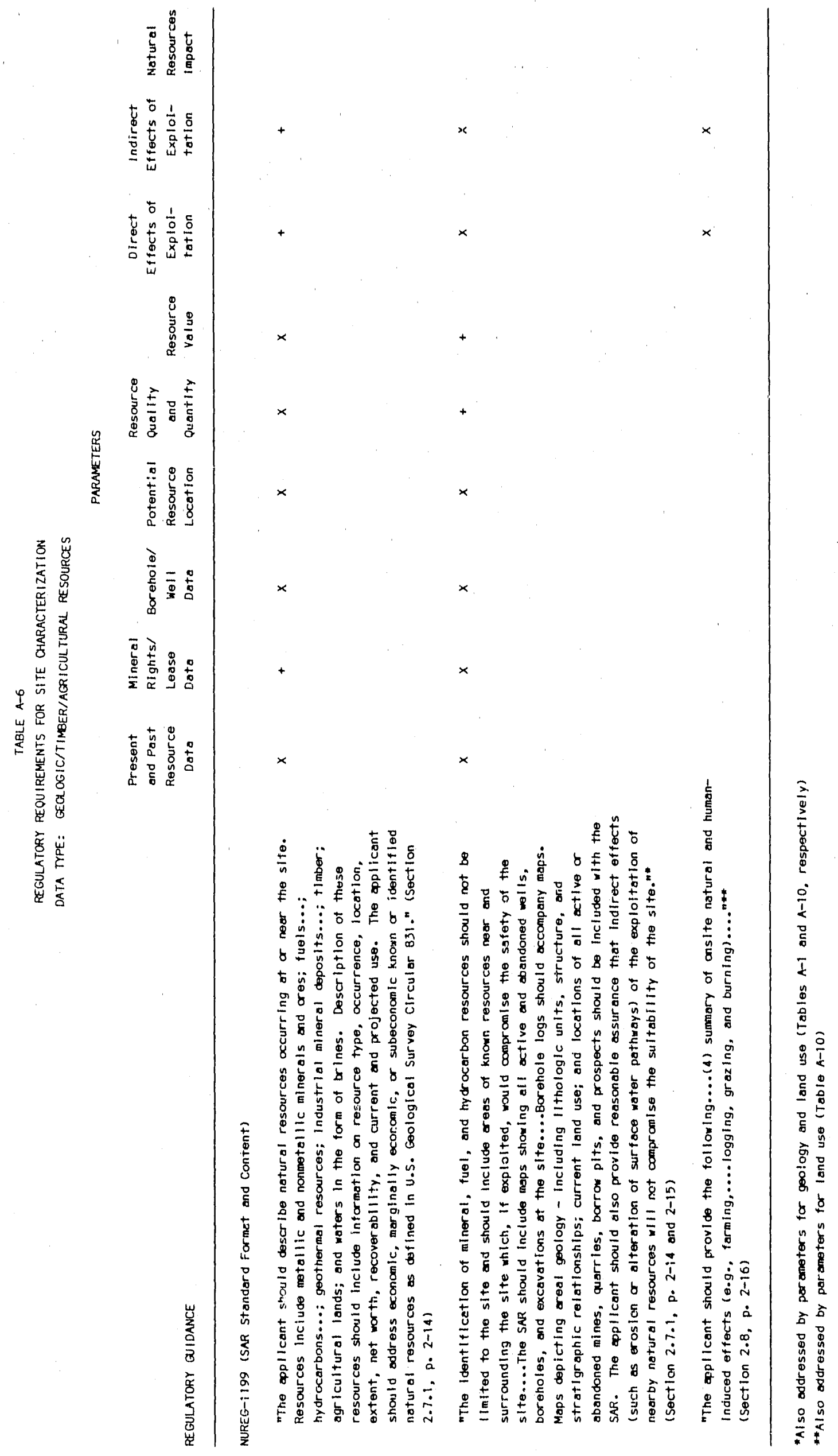




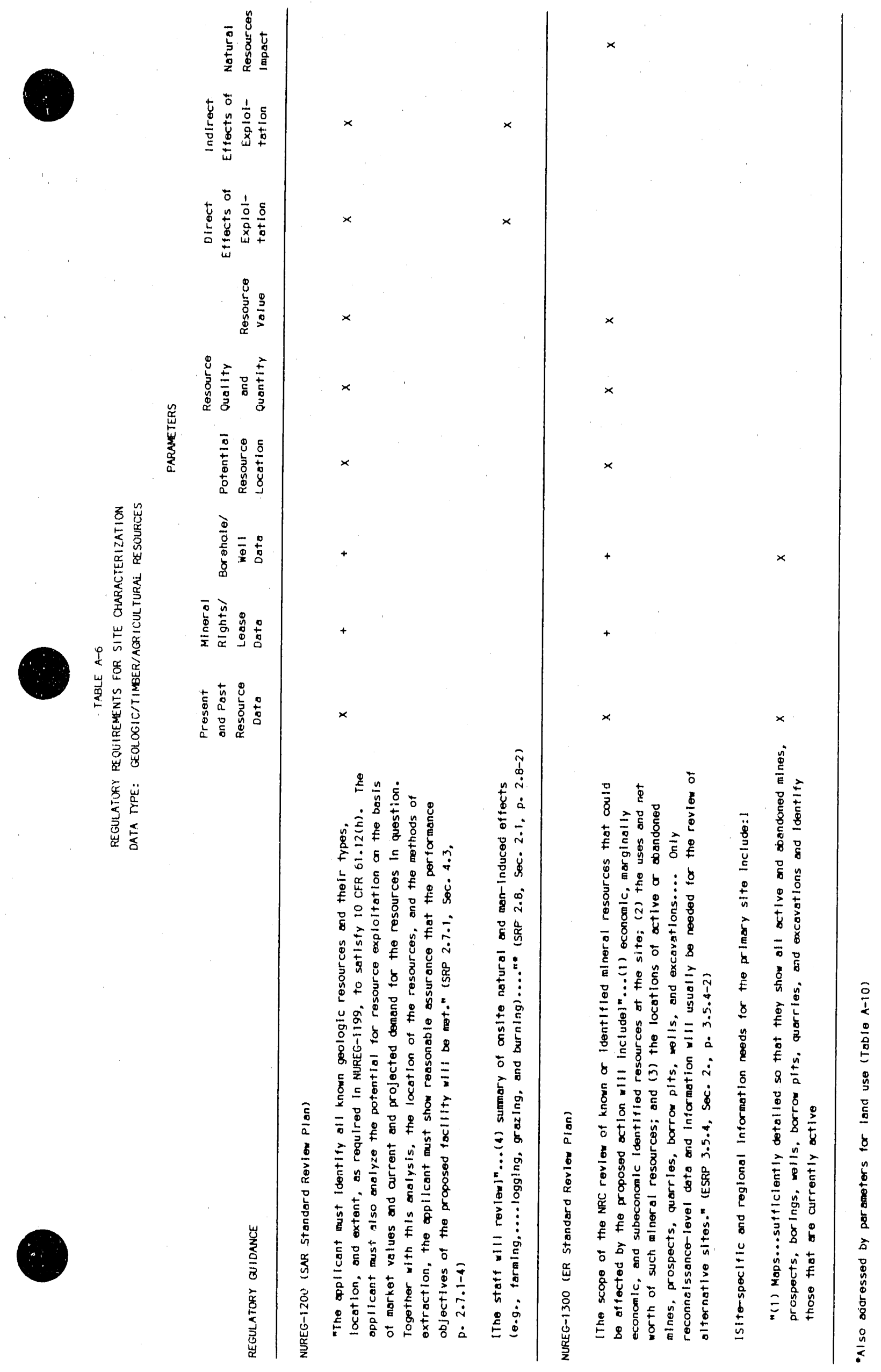




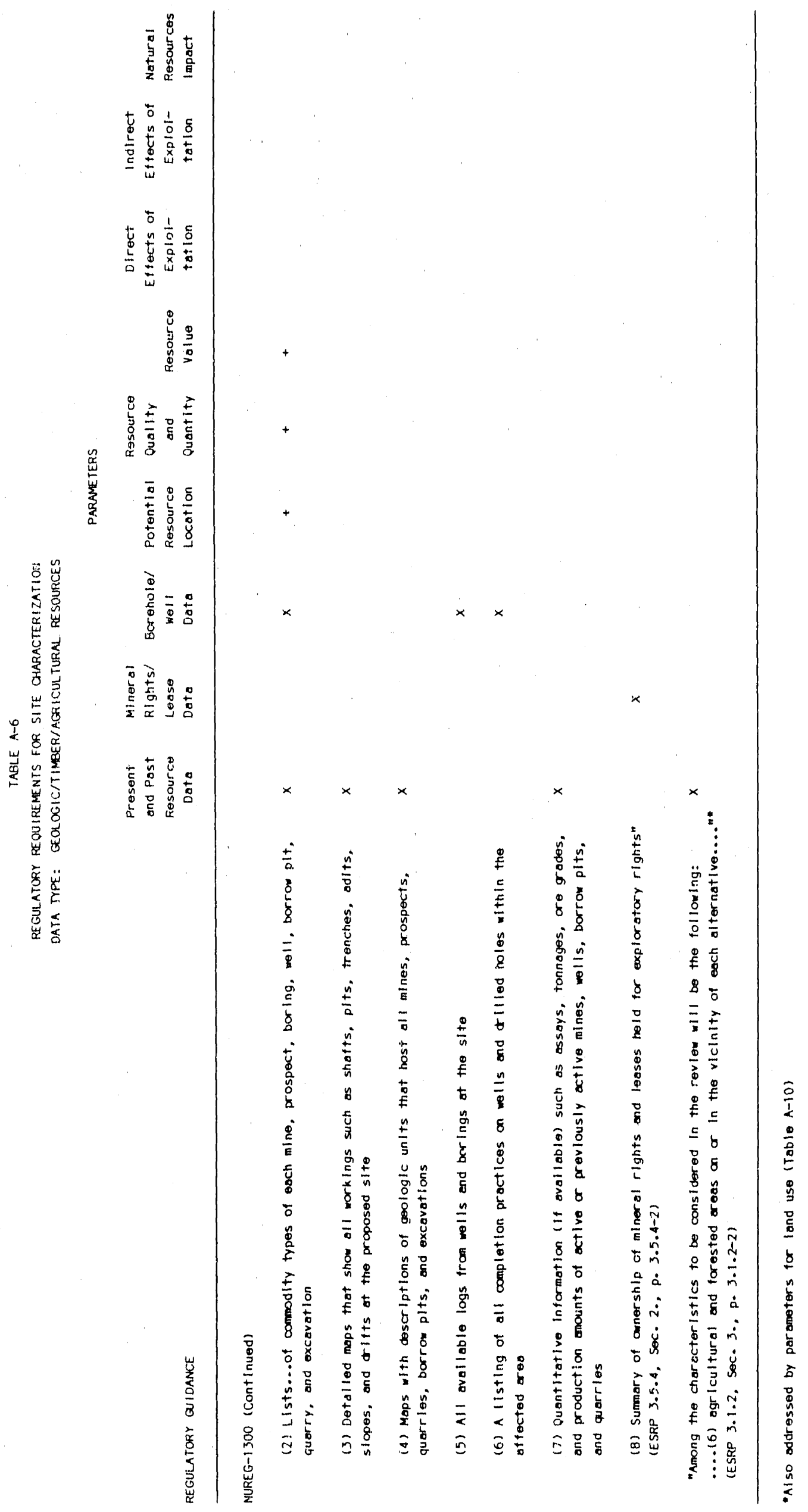




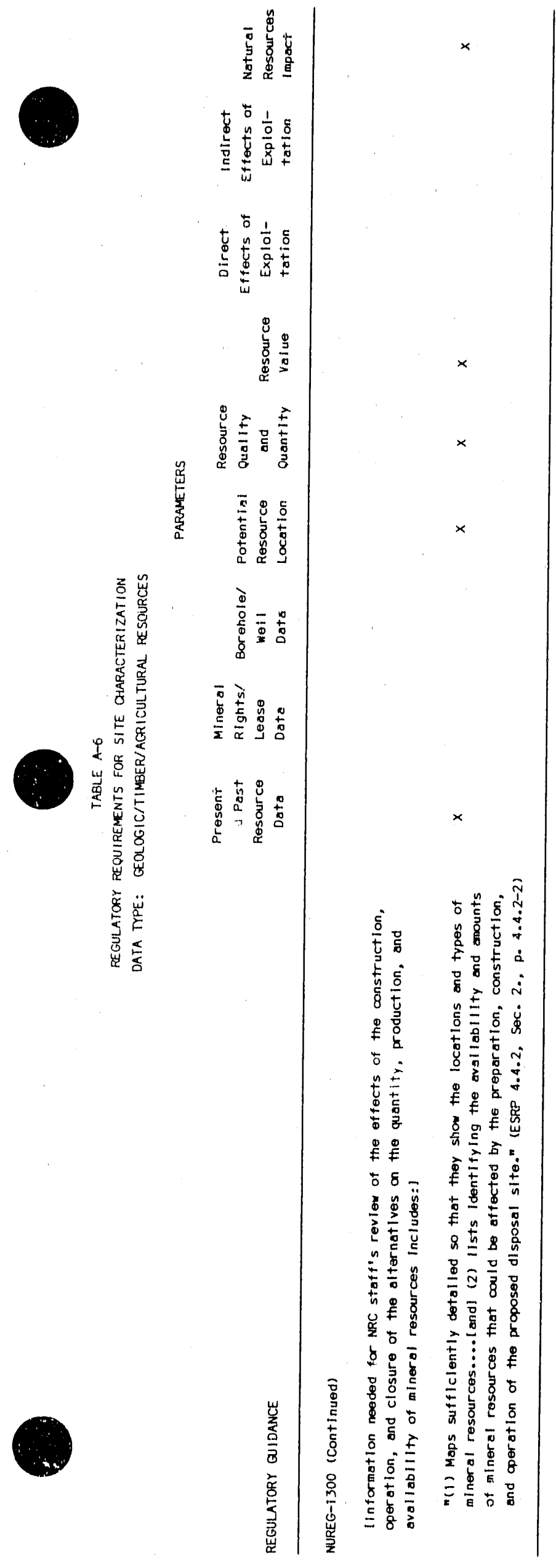


TABLE $A-6$

PARAMETER DESCRIPTIONS - GEOLOGIC/TIMBER/AGRICULTURAL RESOURCES

Past and Present Resource Data: Location maps of active and inactive mines, prospects, exploration boreholes, geothermal and hydrocarbon wal1s, borrow pits, quarries, excavations, and timber and agricultural lands. Data compllations either on or accompanying the maps should include: the commodity occurring at the resource location; the geologic unit in which the present or past geologic resource occurs; quantitative data, if avallable, for geologic materials produced from active or previously active mines, wells, borrow pits, and quarries; quantitative data for agricultural and timber resources; and the mining, harvesting or extraction method (e.g., shaft mining, strip mining, quarrying, borehole injection or pumping, uprooting of vegetation, blasting, etc.). Commodities to be addressed should include: metallic and nonmetalitc minerals and ores; fuels such as peat, lignite, and coal; industrial mineral deposits such as sand and gravel, clays, aggregate sources, shales, and butlding stone; hydrocarbons, including gas, of1, tar sands and asphalt; timber; agricultural lands; and waters in the form of brines.

Mineral Rights/Lease Data: The location, ownership, and types of exploration activity (e.g., drilling, trenching, etc.) carried out on mining claims or mineral leases on and near the site.

Borehole/Well Data: The location, depth, diameter, completion practices, current drilling activity, use, and geological and geophysical logs of exploration boreholes and geothermal, brine, and hydrocarbon wells on and near the site.

Potential Resource Location: Location maps of potential resources that may be exploited in the future. Data compllations either on or accompanying the maps should include: the commodity occurring at the resource location, and for geologic resources, the geologic unit in which the future resource occurs. Commodities to be addressed include: metallic and nonmetallic minerals and ores; fuels such as peat, lignite, and coal; industrial mineral deposits such as sand and gravel, clays, aggregate sources, shales, and building stone; hydrocarbons, including gas, 011 , tar sands and asphalt; timber; agricultural lands; and water's in the form of brines.

Resourc Quality and Quantity: The physical and/or chemical characteristics of the ientfied geologic resource in place, such as quantity (1.e., areal extent, thickness, and depth), tonnage, grade, and/or volume and quality, as applicable to the resource type, and the quantity, quality, and extent of timber and agriculture resources (such as board feet and arable areage, respectively). 
Resource Value: The current net worth of resources, based on: 1) the resource quantity and qualtty as described above, and 2) profttablltty analyses based on the current market price, current use and/or demarid, recoverabllity, extraction/harvesting methods and costs, transportation and mining/processing costs, and capitol investment costs. Projected resource use should be determined based on assumptions and projections for future market conditions. Known or identified geologic resources should be classified into economic, marginally economic, and subeconomic components as defined in U.S. Geological Survey Circular 831, "Princtples of a Resource/Reserve Classification for Minerals."

Direct Effects of Explottation: The potential effects of geologic or timber resource exploration or explottation/extraction at the ground surface, in the hydrogeologic units used for disposal and isolation, or at greater depths, caused by excavation, blasting, drilling, uprooting of timber, or other activities that directiy intrude disposal units.

Indirect Effects of Exploitation: The potential effects of geologic, agricultural, or timber resource exploration or exploitation/extraction that would compromise the sultability of the site through such processes as increased infiltration rates, alteration of ground-water tables, increased runoff up-gradient of site, steepened hydraulic gradients, and creation or modification of surface-water or ground-water pathways. These processes may be affected by activities such as excavation, blasting, uprooting of vegetation, irrigation, pumping or injection, erosion control procedures, or other mining, logging, or agricultural activities that can affect the hydrologic regime.

Natural Resources Impact: Qualitative and quantitative descriptions of the impact of the site on natural resources from consiruction to closure, particularly the denial of resources. 


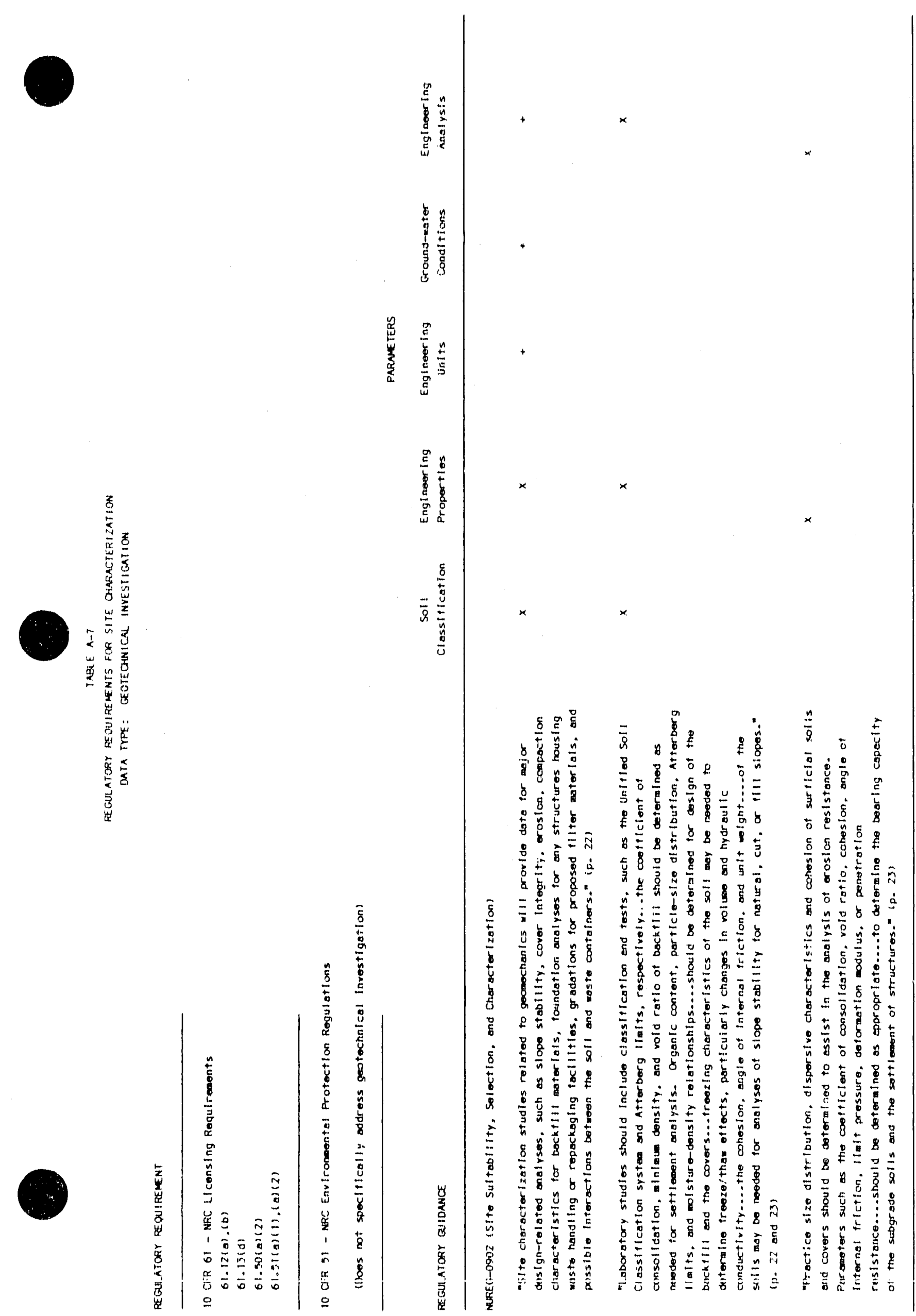




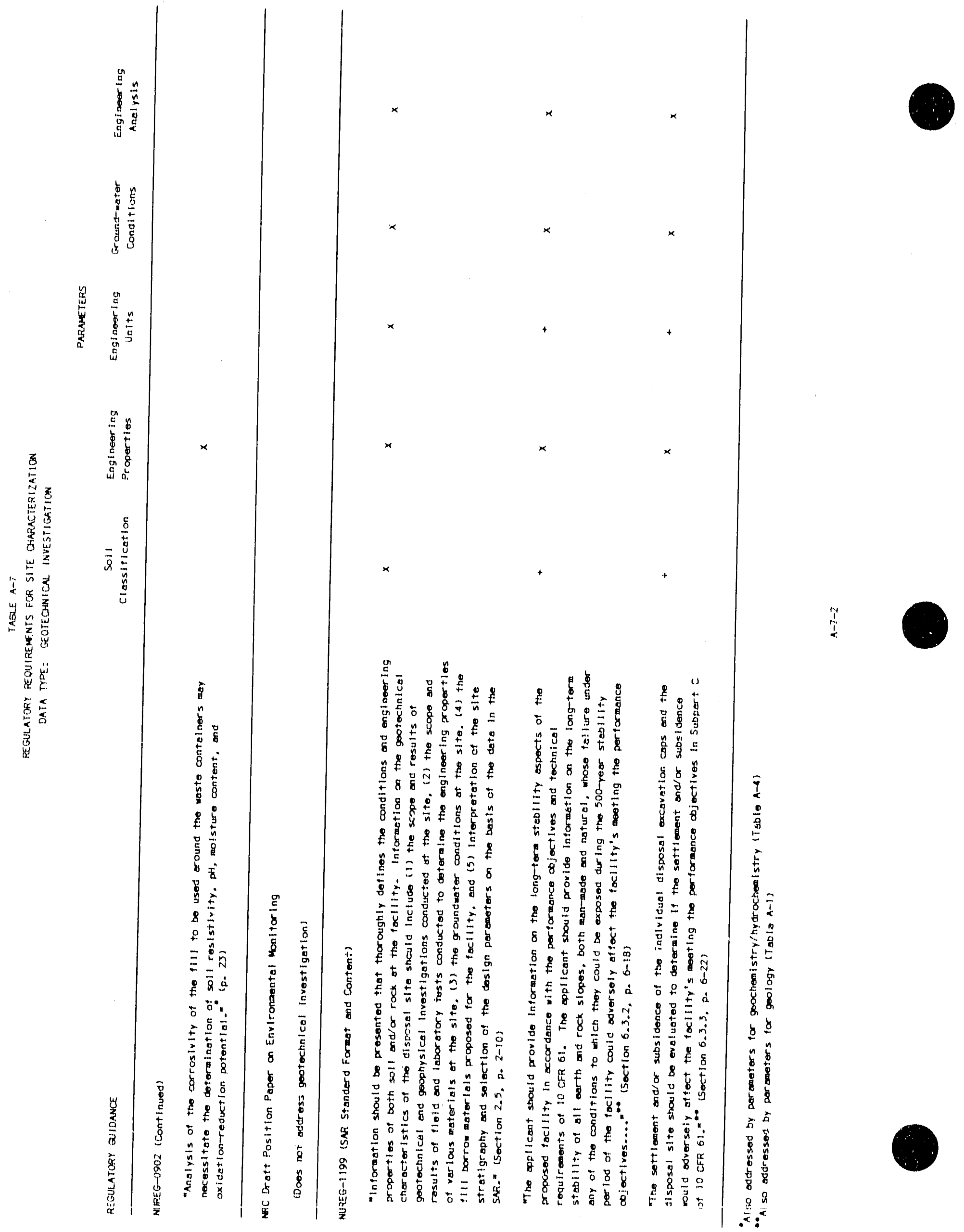




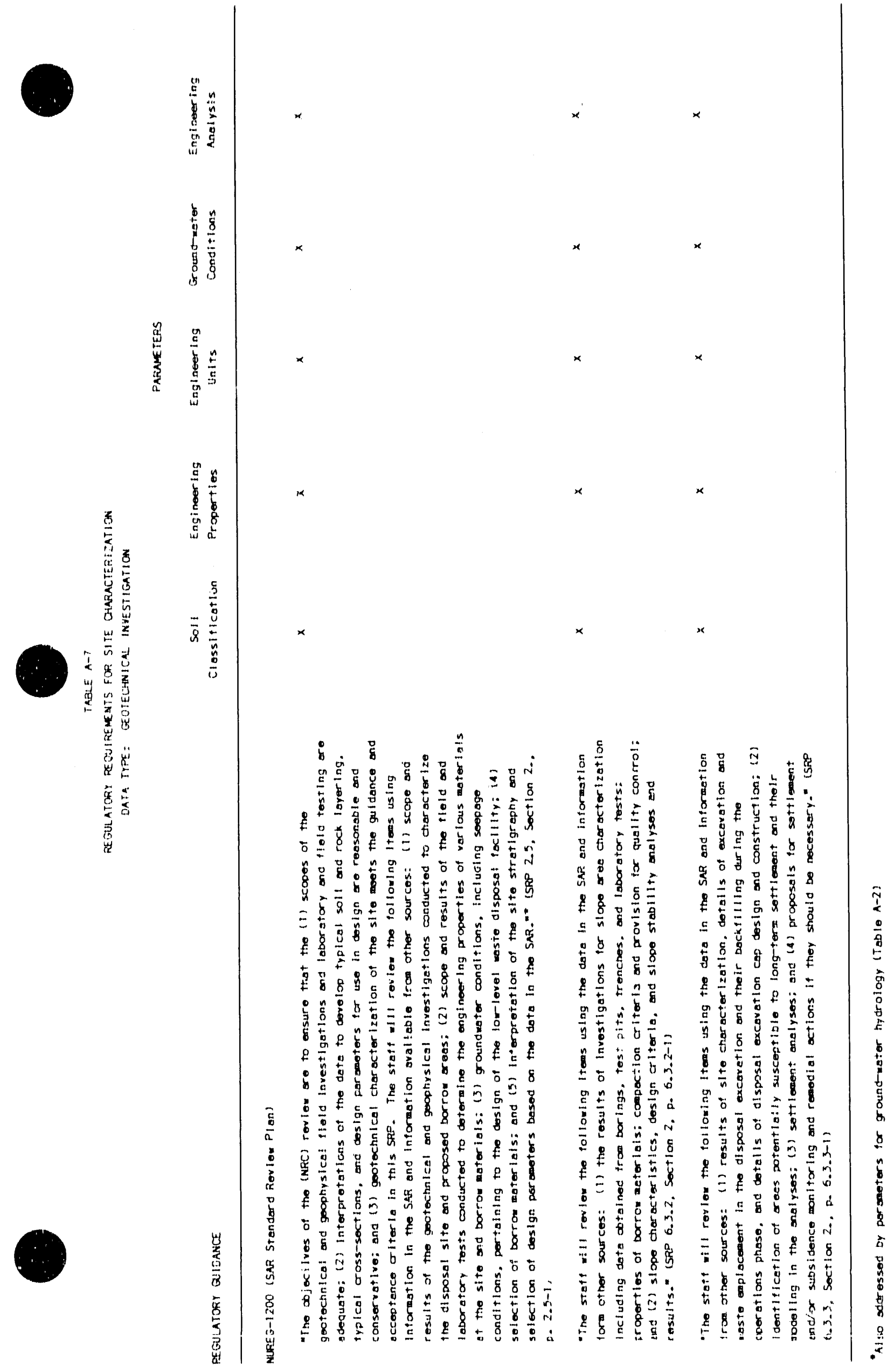




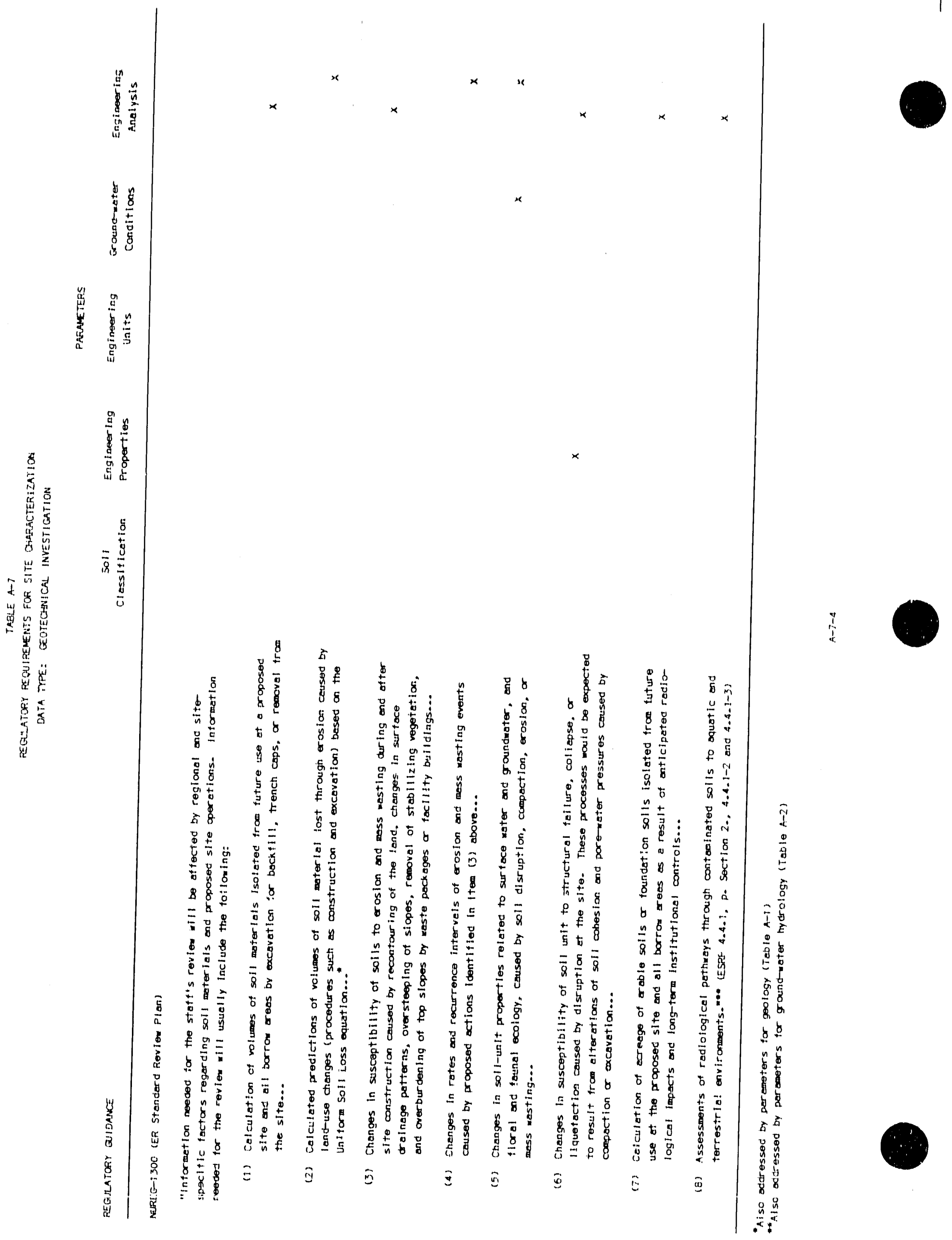


TABLE A-7

\section{PARAMETER DESCRIPTIONS - GEOTECHNICAL INVESTIGATION}

Soll Classification: The system of classifytng soll for engineering purposes, generally the Unifled Soll Classiflcation System. Laboratory tests required to confirm field soll classifications are grain-size distribution and Atterberg $1 \mathrm{im} t \mathrm{ts}$ following ASTM test procedures.

Engineering Properties: The physical and chemical properties of soll matertals that determine their engtneering behavior. These properties, determined mostly by laboratory testing, are required for foundation and settlement analysis, slope stability, and the design arid placement of structural fill. Engtneering properties include: shear strength/internal angle of friction/unit cohesion, consolidation charactertstics, shrink/swell characteristics, freeze/thaw characteristics, plasticity index/Atterberg 1 imits, grain-size distribution, moisture-density/minimum dry density, in-situ weight/density, porosity, vold ratio, molsture content, degree of saturation, specific gravity, permeablitty, relative hydraulic conductivity, ilquefaction potential, soll pH, oxtdation-reduction potential, clay mineralogy, dispersivicy, deformation/Young's modulus, penetration resistance, soll resistivity, soll organics, and limit pressure. Other engineering properties may be appropriate depending on the soll conditions encountered at each site.

Engineering Units: An engineering untt consists of those geologic sections that share similar geotechnical characteristics or engineering properties. For example, a loess and underlying lacustrine silt may have similar molsture contents and strengths and could be incorporated into one engineering unit on the basis of their erigineering behavior. Alternatively, a glactal till unit may contain a permeable sand and gravel layer that might be considered a separate engineering unit because of its engineering properties.

Ground-water conditions: The location and range of seasonal fluctuations of the ground-water table and the design water level within the disposal site and borrow areas.

Engineering Analysis: The process of integrating the engineering units and their respective engineering properties with the site ground-water conditions, potential future geologic events, and conceptual facility design to develop geotechnical recommendations for slope stabilit.y, settlement/subsidence, ilquefaction potential, freeze/thaw potentlal, active and passive earth pressures, bearing capactty, long- and short-term control of surface water, and f 111 -placement procedures. Other analyses may be appropriate depending on the soll conditions encountered at each site. The recommendations should also contain the following: detalled discussions of field and laboratory sample preparation and test procedures, interpretation of engineering characteristics for onsite and borrow area solls and rock, discussions of how and why specific strength parameters were chosen, factors of safety used, plans showing completed subsurface investigations, cross-sections, and proposed borrow area limits, grades, slopes, and locations of test pits and boreholes. 


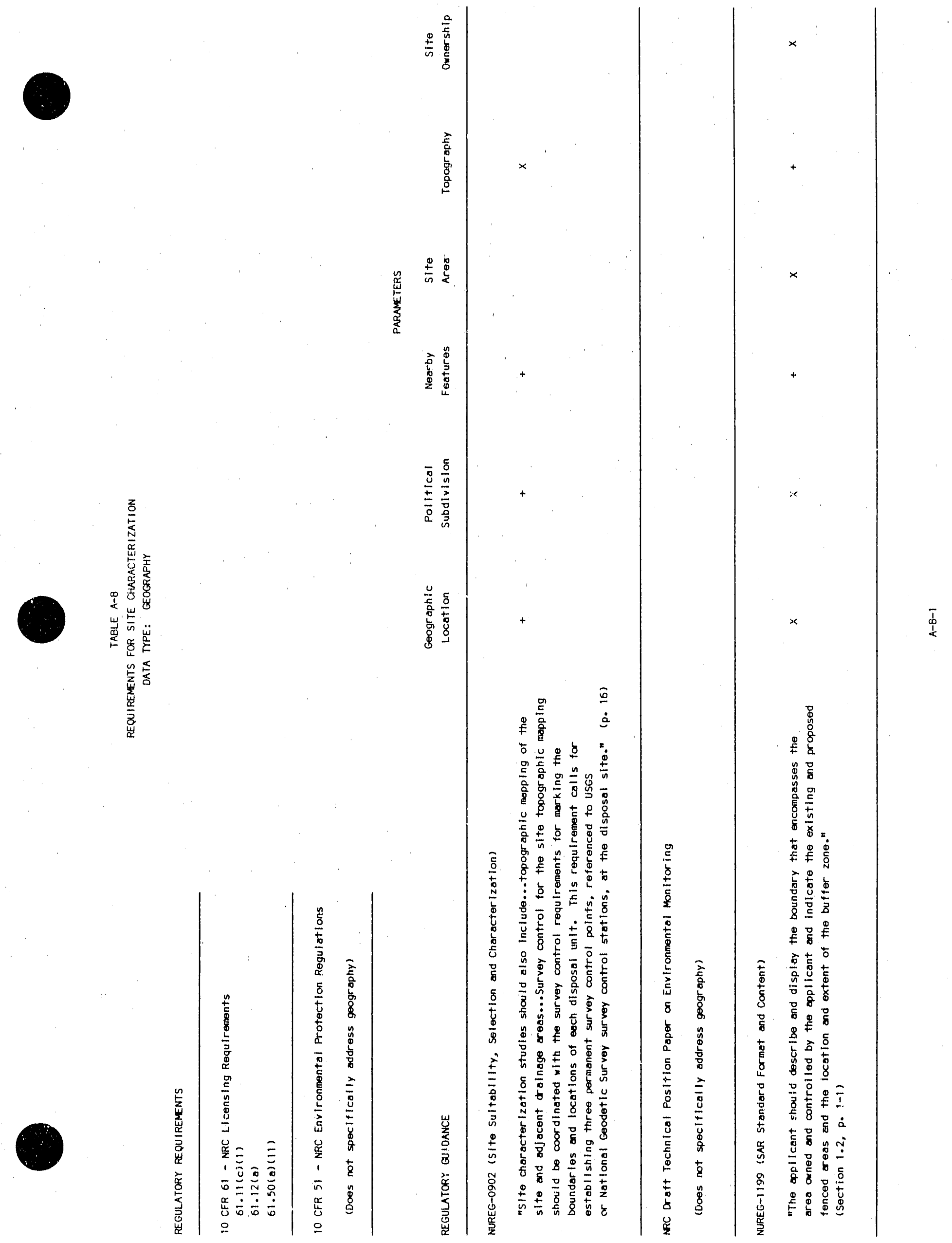




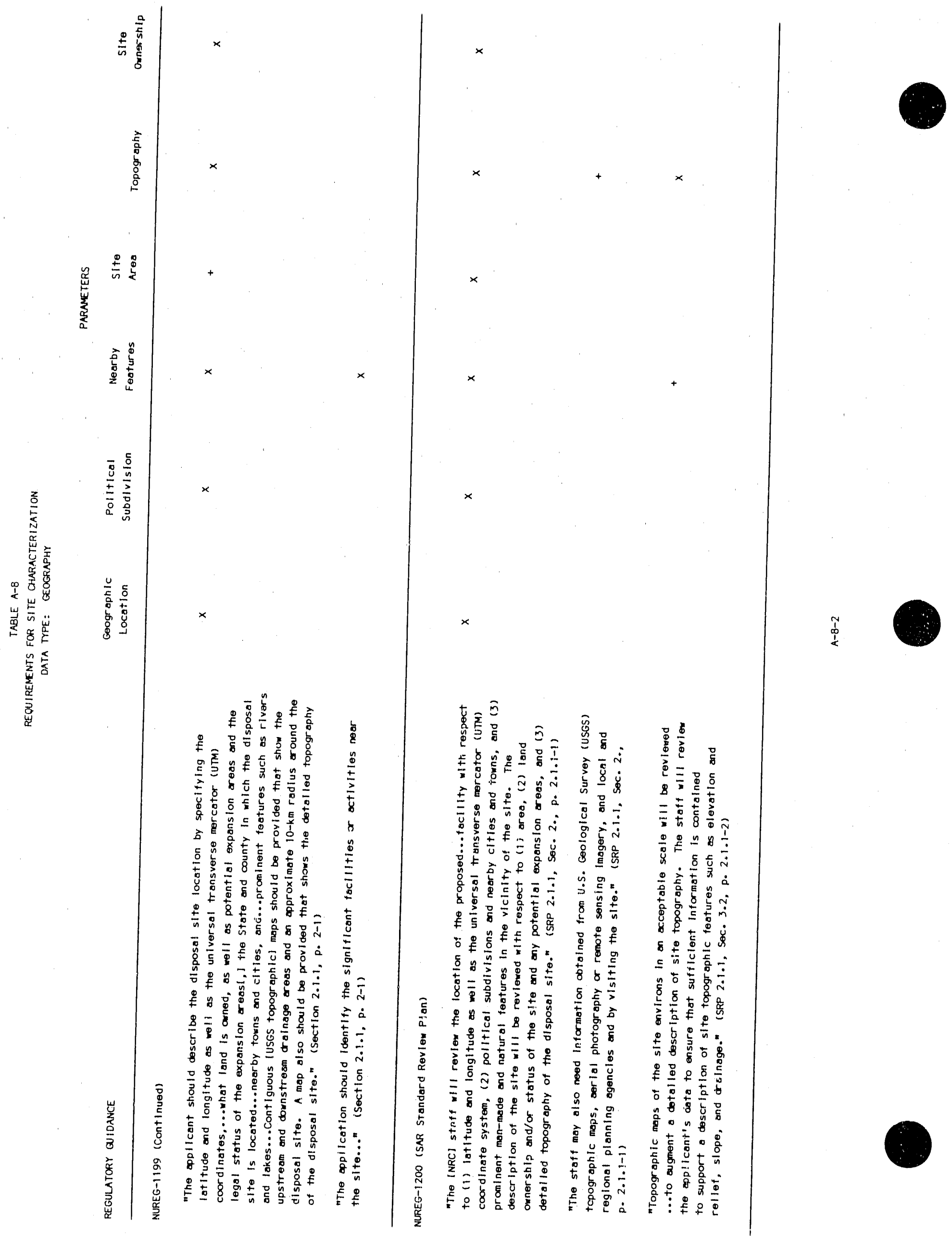




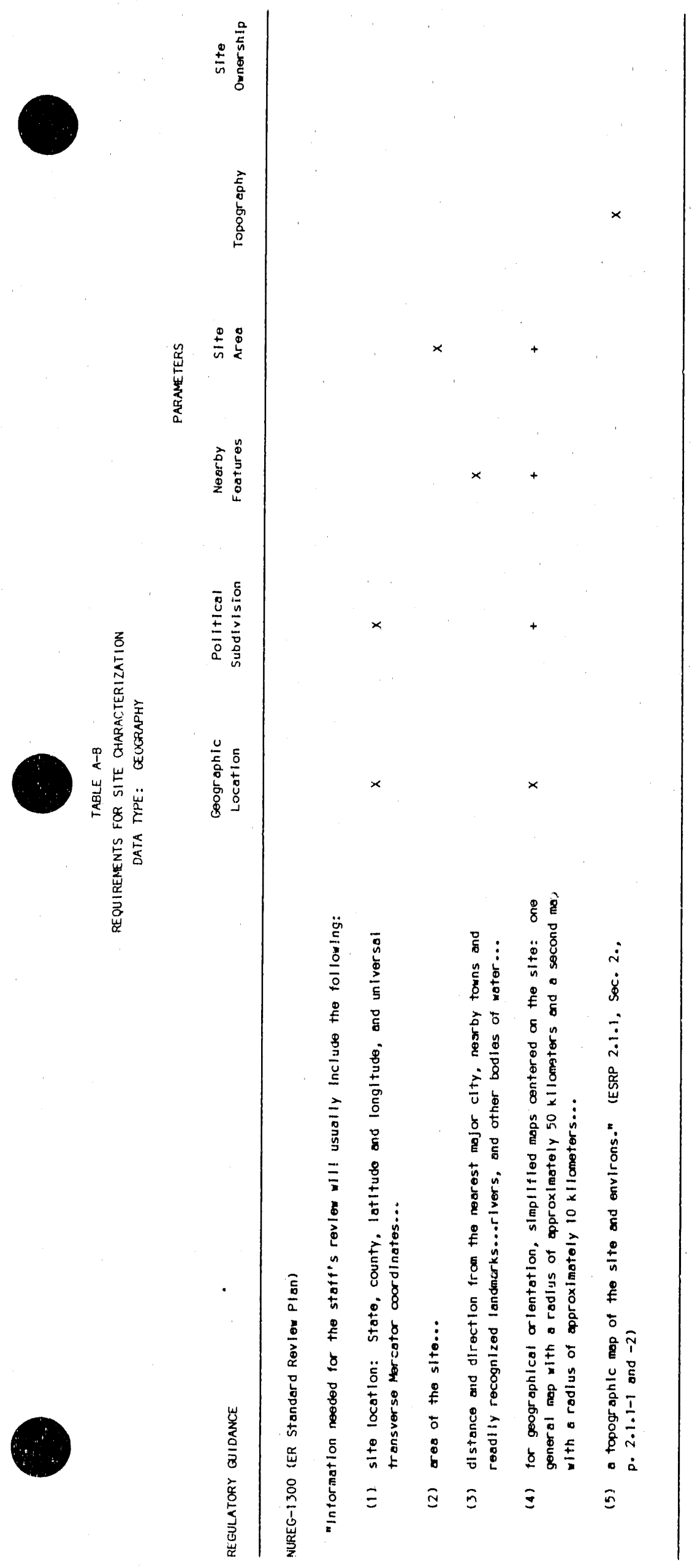


Geographic Location: The location of the site in terms of latitude, longitude, universai transverse mercator (UTM) coordinates, and Public Land Survey designation (i.e., Township, Range and Section).

Political Subdivision: The State, county and/or other pertinent subdivision (e.g., township or municipalities) in which the site is located.

Nearby Features: Features in the vicinity of the site, including cities; readily recognized landmarks; rivers, lakes and other bodies of water; major highways; other prominent man-made and natural features; and significant facilities near the site.

Site Area: The amount of 7 and surface included in the site (including buffer zone), measured in acres (hectares) and square miles (square kilometers).

Topography: The general configuration of the land surface, including its elevation and relief and the position of its natural and man-made features.

Site Ownership: The person or entity entitled to legal possession of the site and adjacent 1 ands. 


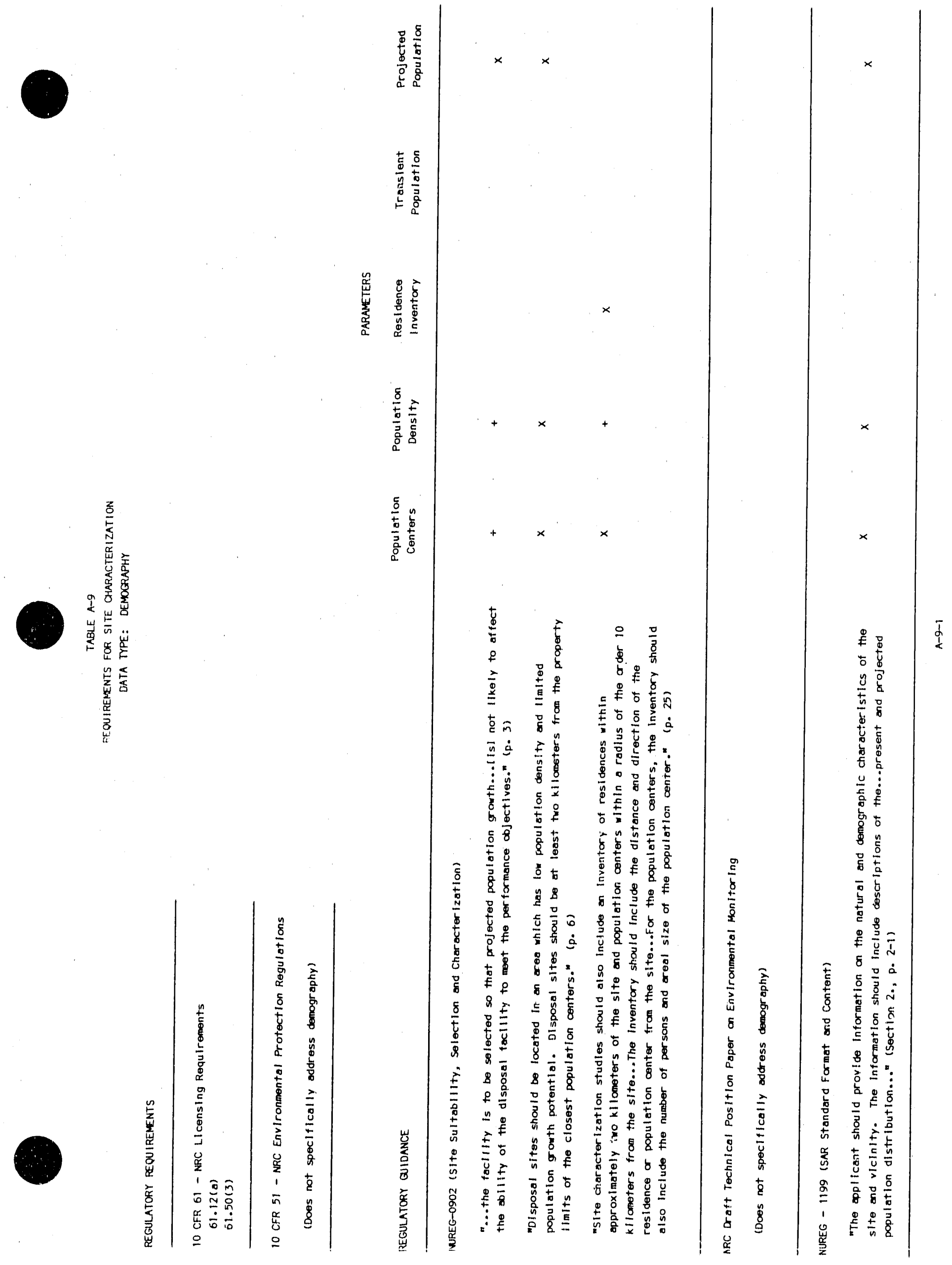



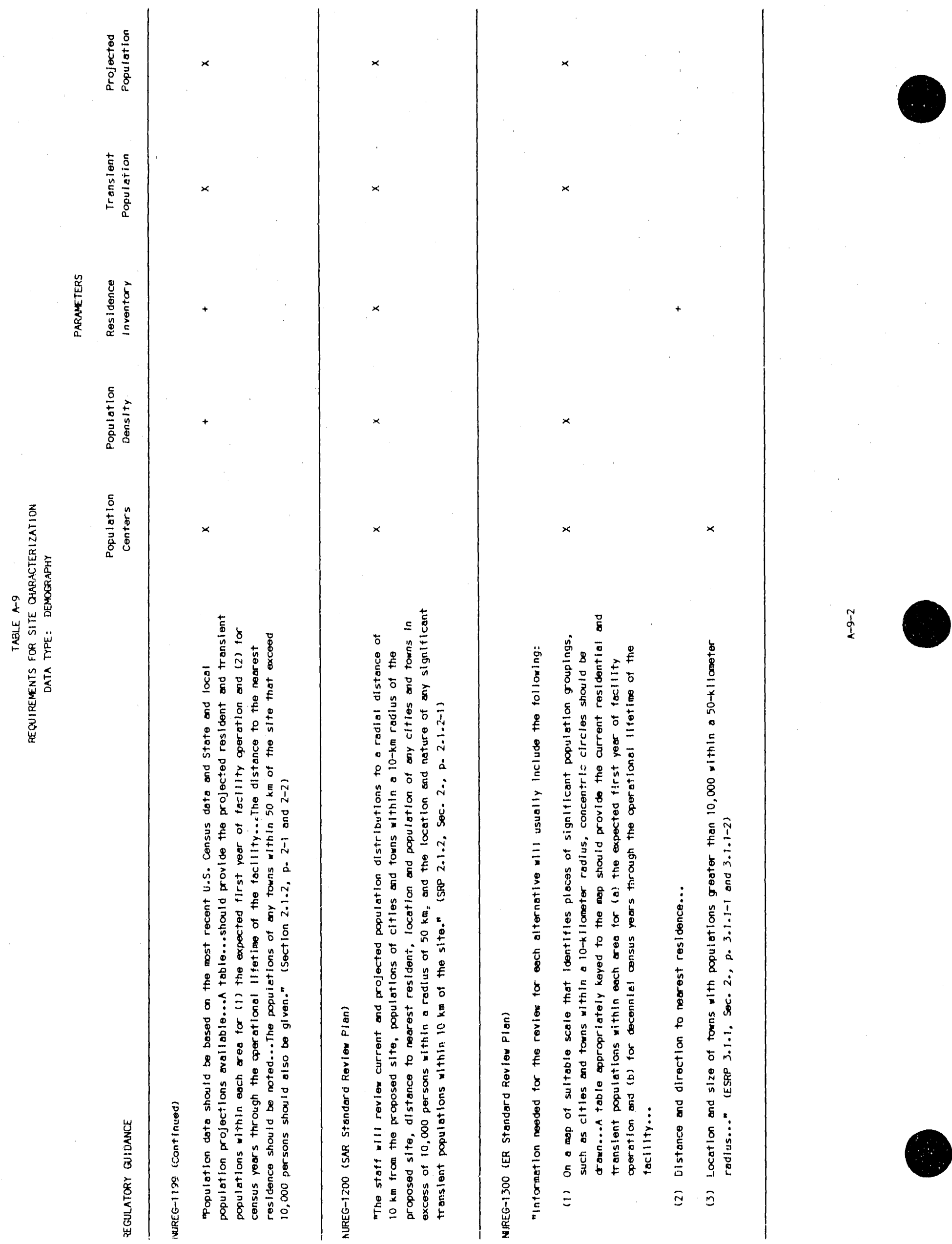
Population Centers: Population size and boundary locations of population places defined by the U.S. Census Bureau and as modified by State and local government agencies.

Population Density: Number of inhabitants per unit area (1.e., population per square kilometer).

Residence Inventory: Identification of occupied housing units (residences) closest to and within $2 \mathrm{~km}$ of the site.

Transient Population: Estimates of population increases to the permanent baseline population resulting from transient influxes due to tourism, seasonal labor, or other factors.

Projected Population: Estimates of future resident and transient populations, in terms of both population density and population centers, for time periods coinciding with the expected first year of facility operation and for decennial census years through the operation lifetime of the facility. 


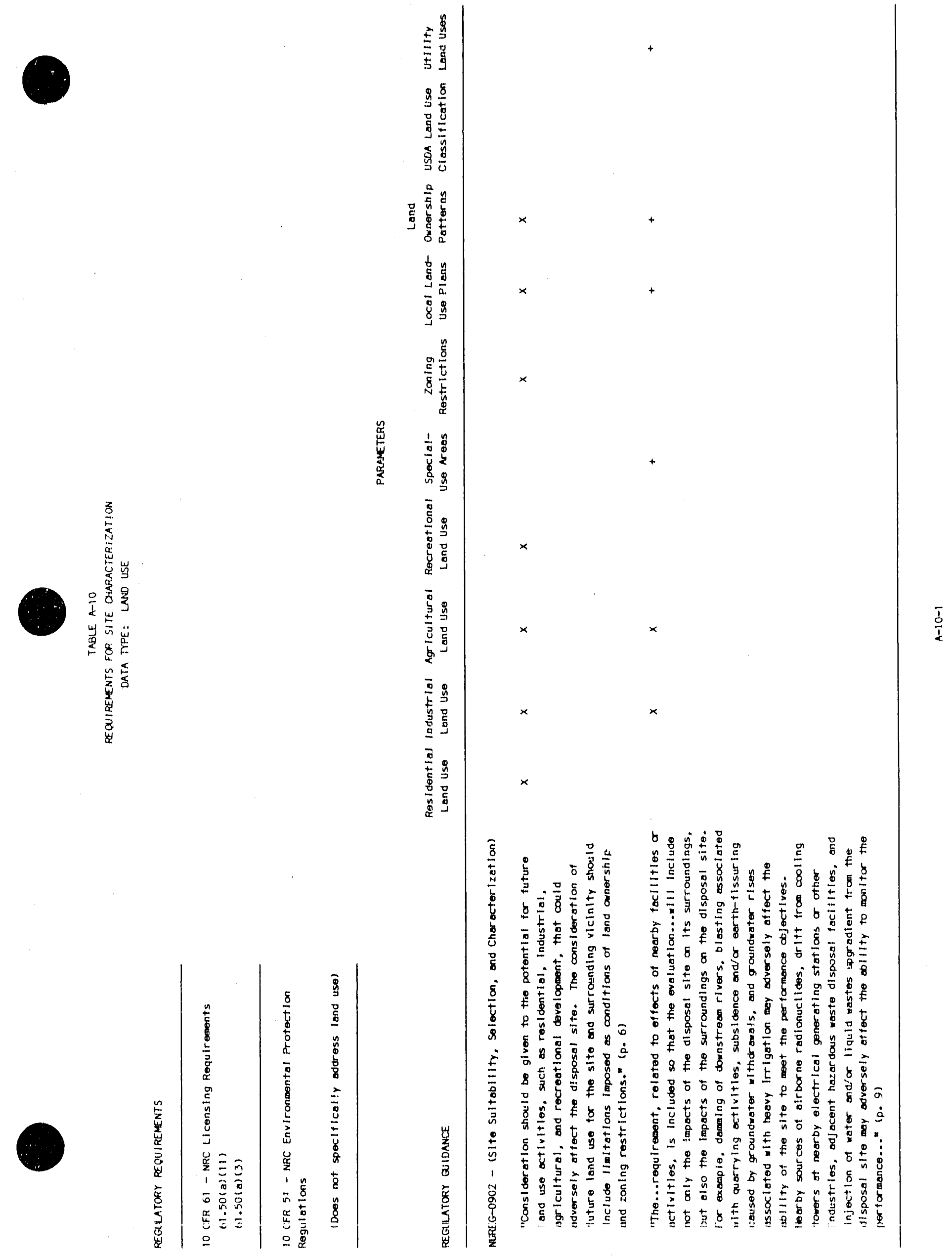



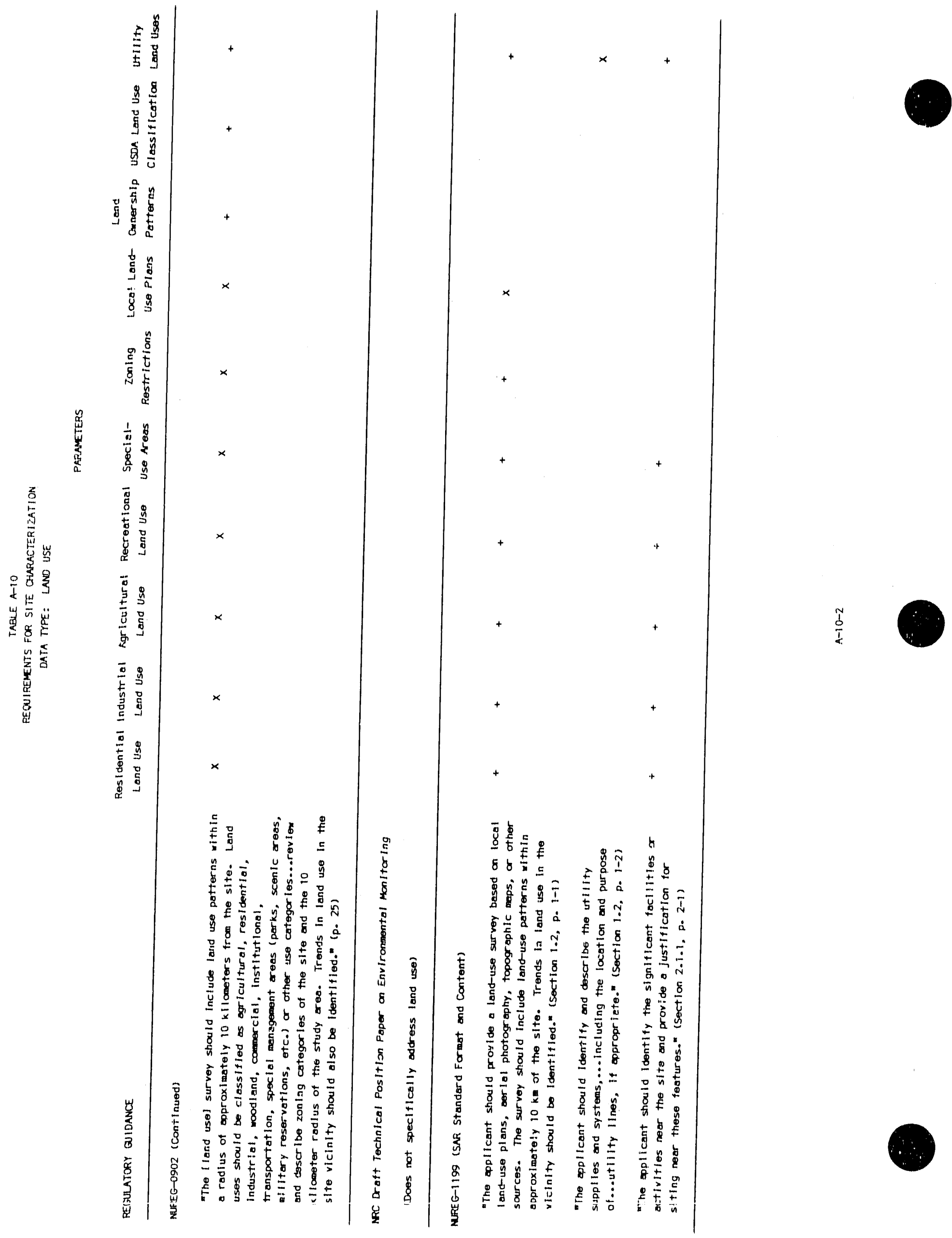


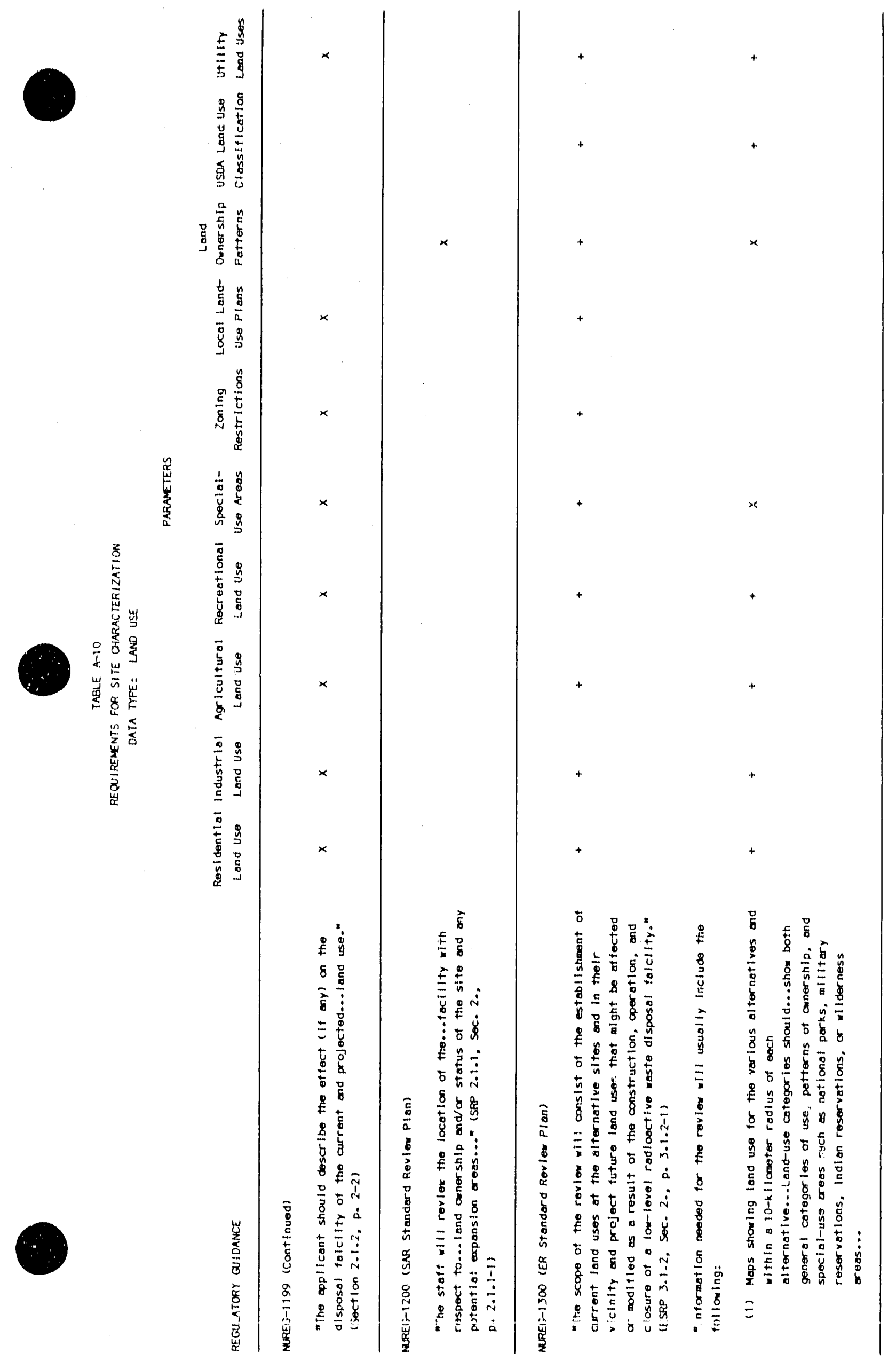



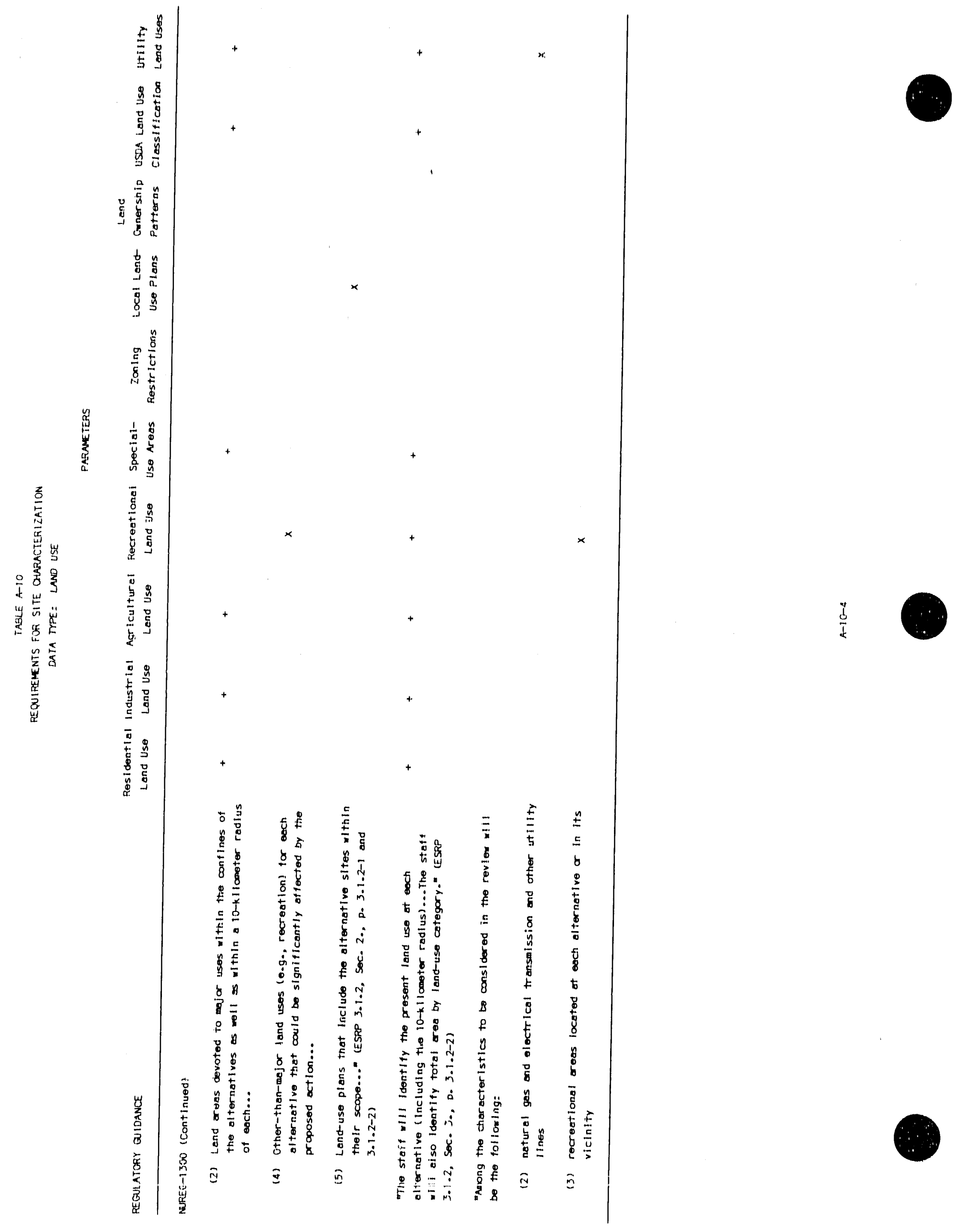


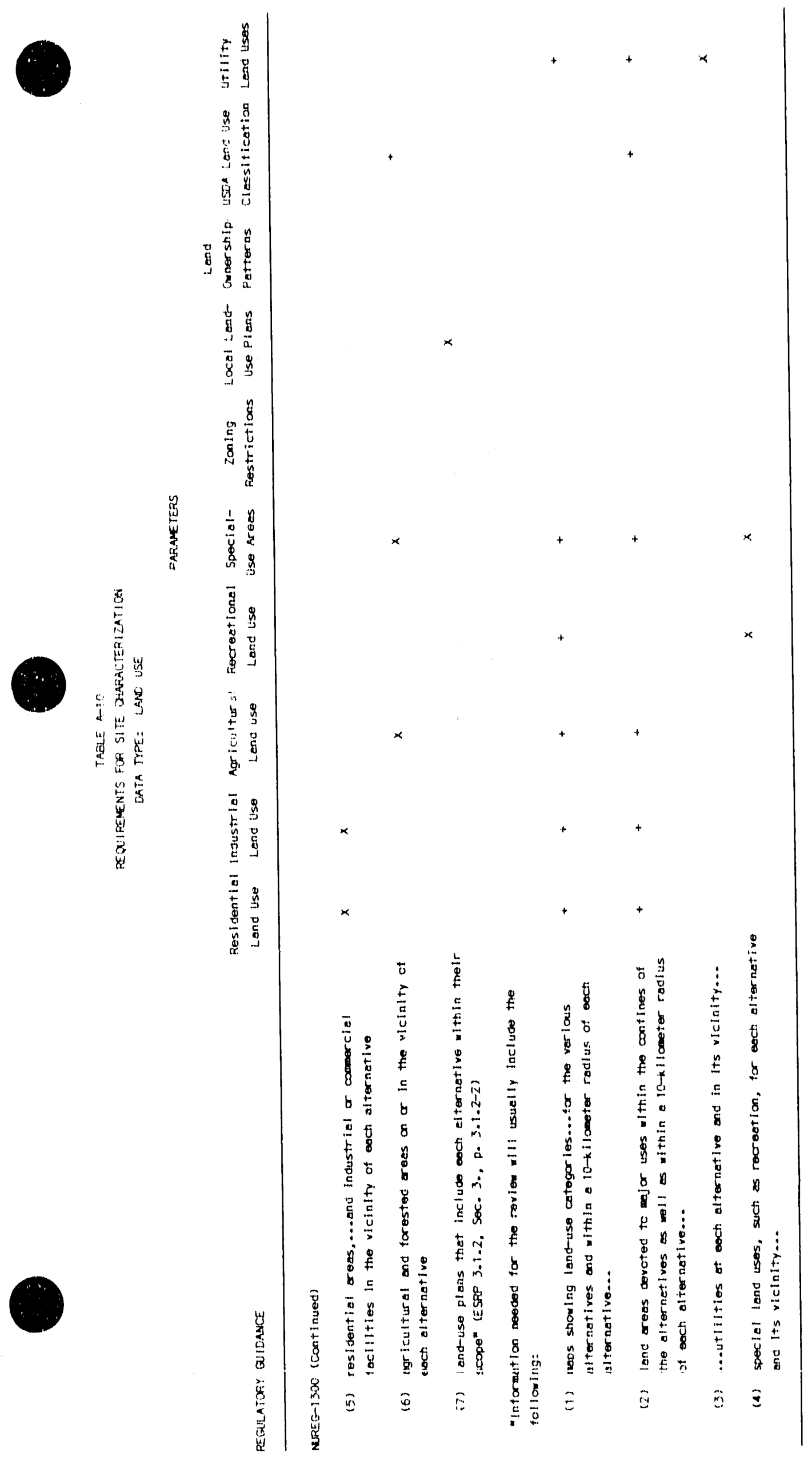




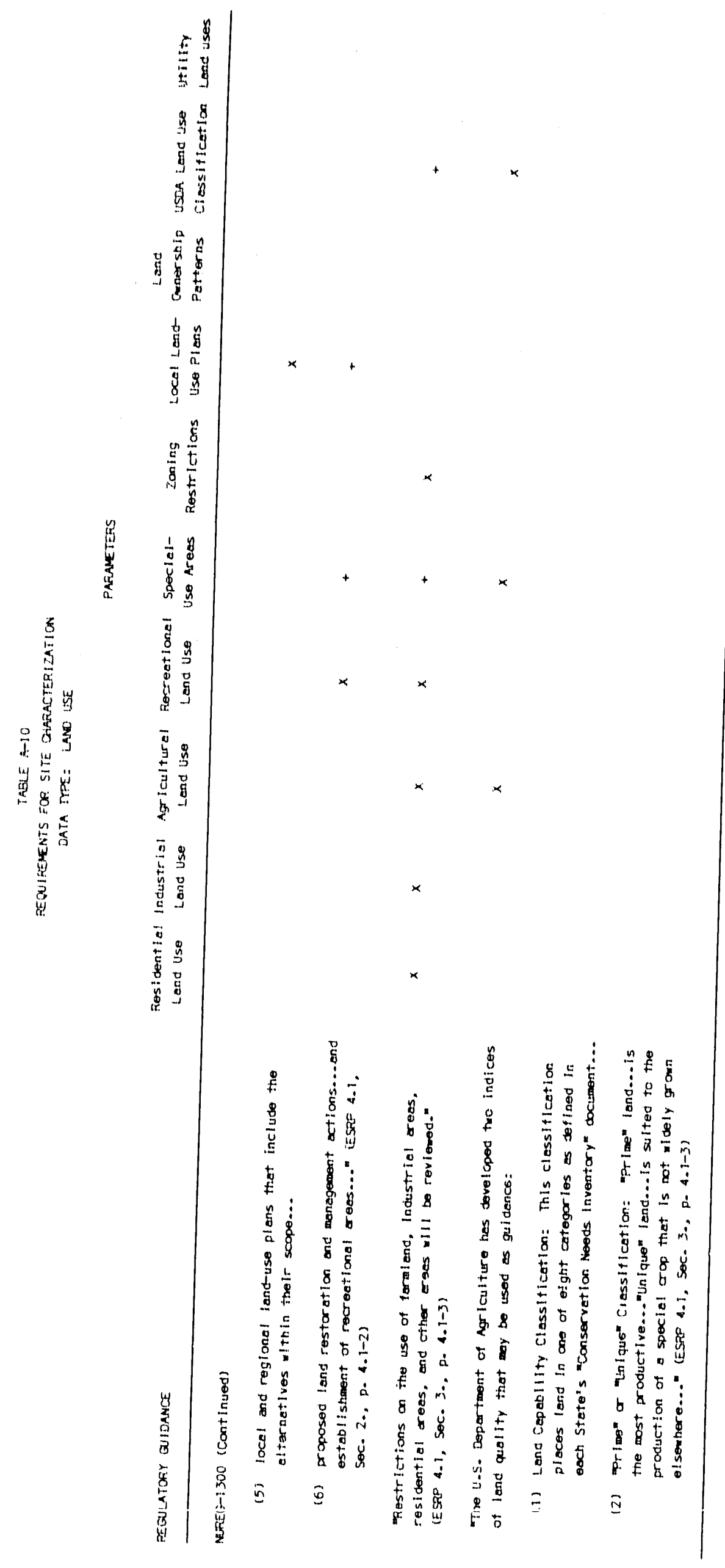


Resfdentfal Land Use: Current and projected uses of land on which the site is located and within $10 \mathrm{~km}$ as housing, classifled according to residential density and housing type.

Industrlal band Use: current and projected uses of land on which the site is located and within $10 \mathrm{~km}$ for manufacturing, processing, or other industrial purposes.

Agricultural Land Use: Current and projected uses of 1 and on which the stte is located and within $10 \mathrm{~km}$ for crop production or domestic animal husbandry.

Recreational Land Use: Current and projected uses of land on which the stte is located and within $10 \mathrm{~km}$ for publtc recreational purposes, e.g., parks, tralls, water courses, etc.

Special-Use Areas: Current and projected uses of 1 and on which the site is located and within $10 \mathrm{~km}$ for destgnated spectal-status uses such as national parks, mllttary reservations, Indlan reservations, and wilderness areas.

Zoning Restrictions: Local restrictions on land use promulgated by county, city, town, township, or other loca: Jurisdictional planning entities, which designate land for specifted uses or constrain certain types of uses.

Local Land-Use Plans: Existing plans prepared by local planning entities that codify land use status, constraints, and profected trends in land usage.

Land Ownership Patterns: Type of land ownership (e.g., publitc versus private) and speciffic entities that own the land on which the site is located and within $10 \mathrm{~km}$.

USDA Land Use Classification: Land parcels classified by the U.S. Department of Agriculture as being in one of eight categortes of land capacity, or as being classifted as prime or unique land on the site and within $10 \mathrm{~km}$.

Utility Land Use: Utility facilities, pipelines, transmission systems, and other utility uses of land on which the site is located and within $10 \mathrm{~km}$. 


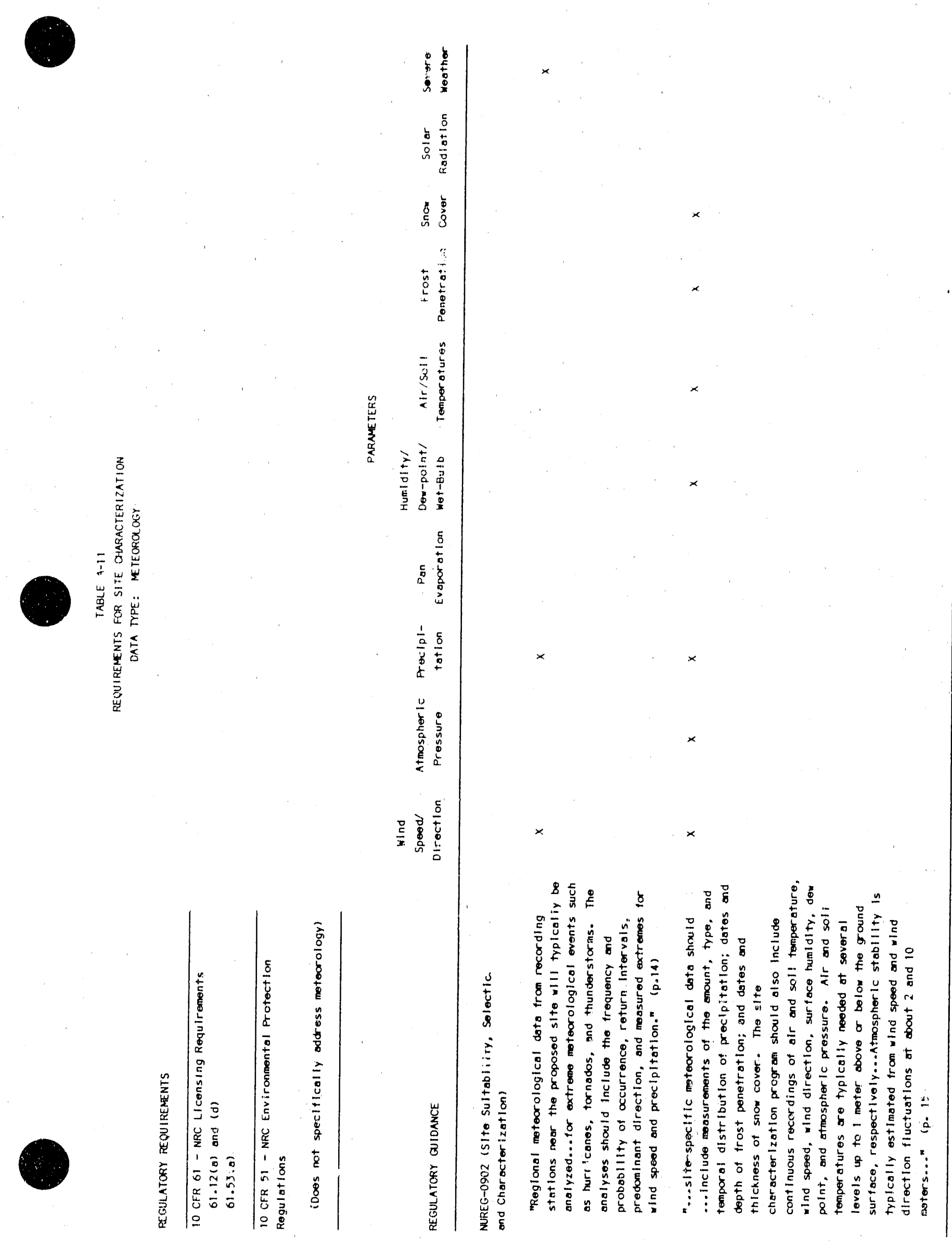



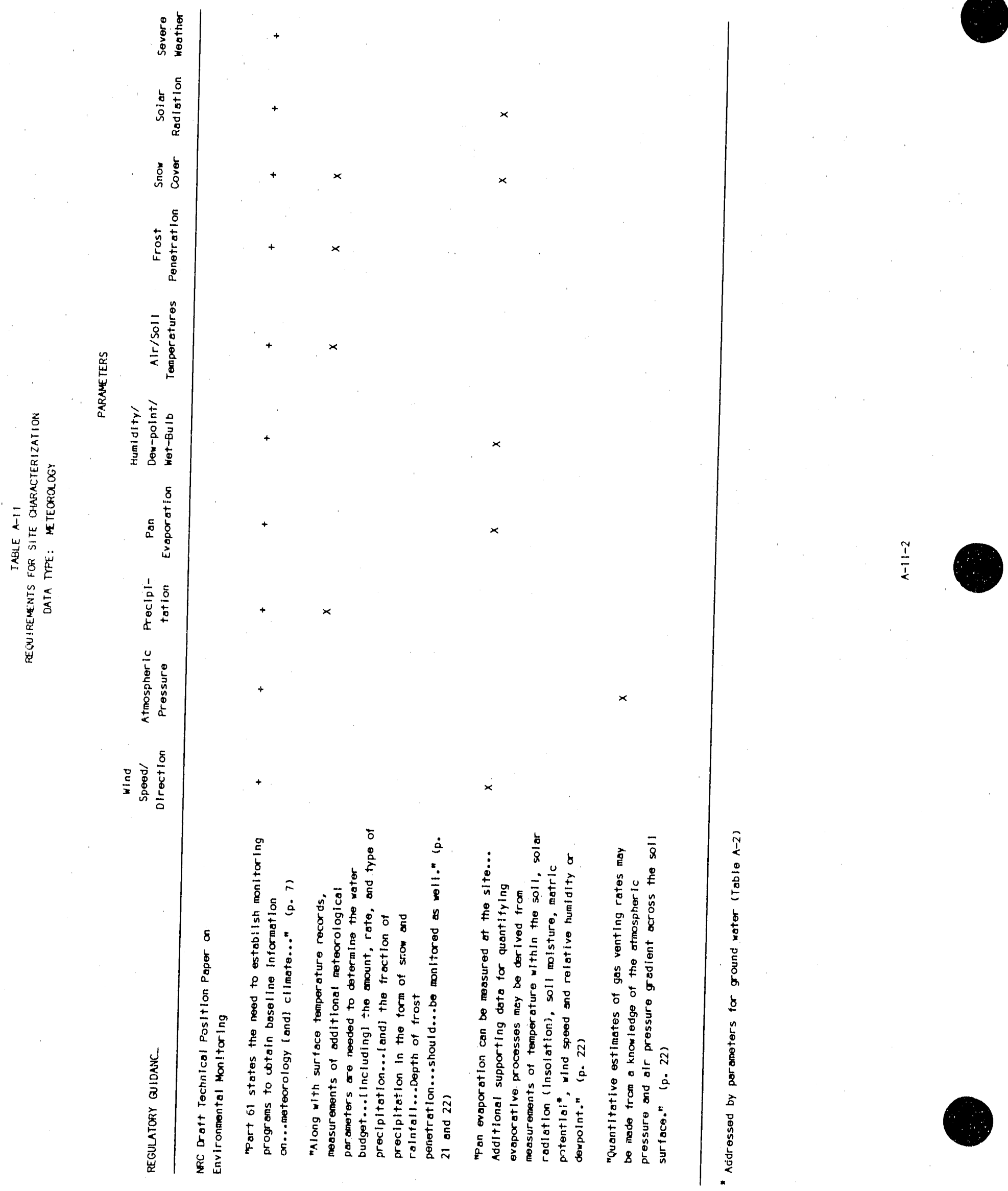


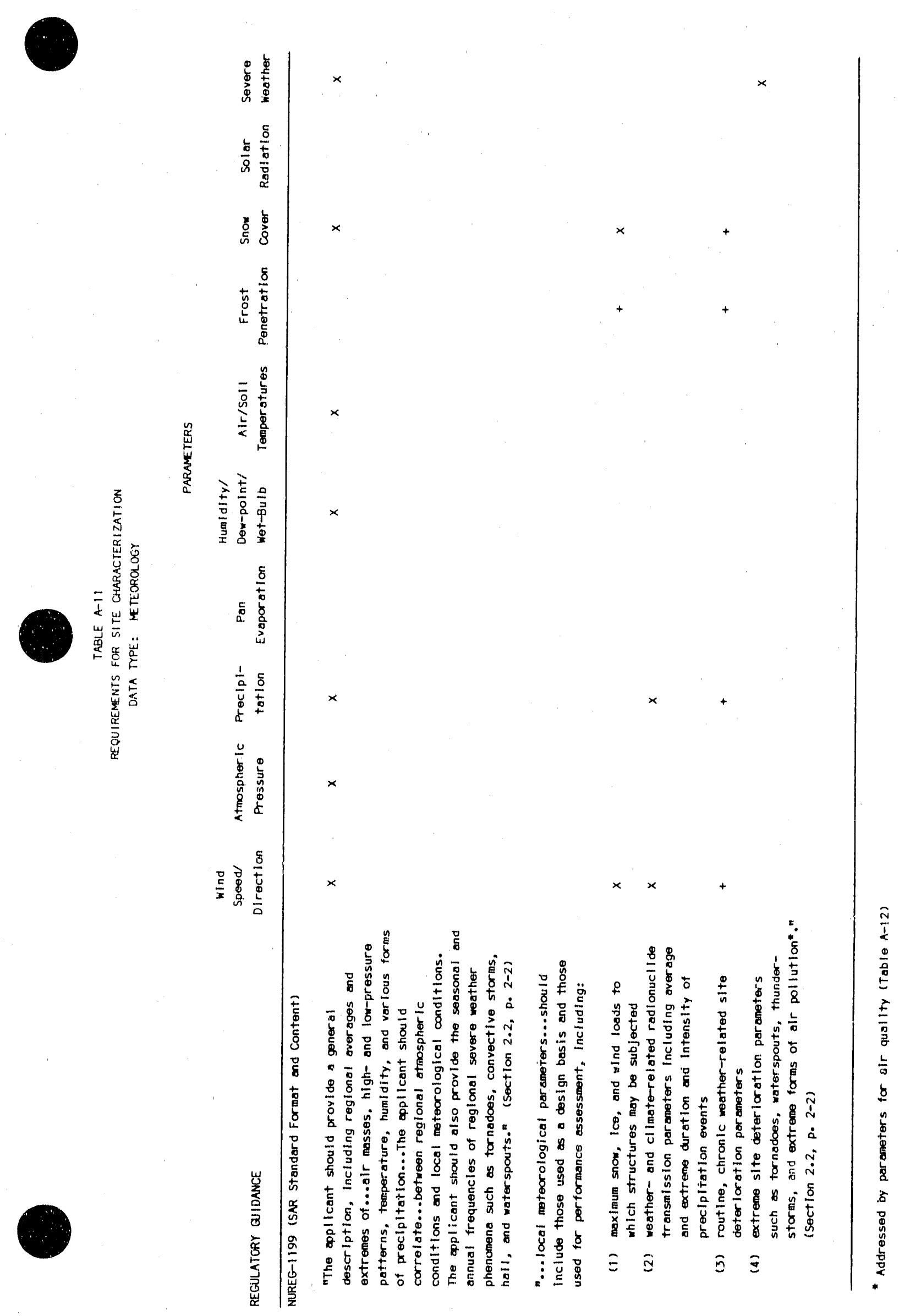




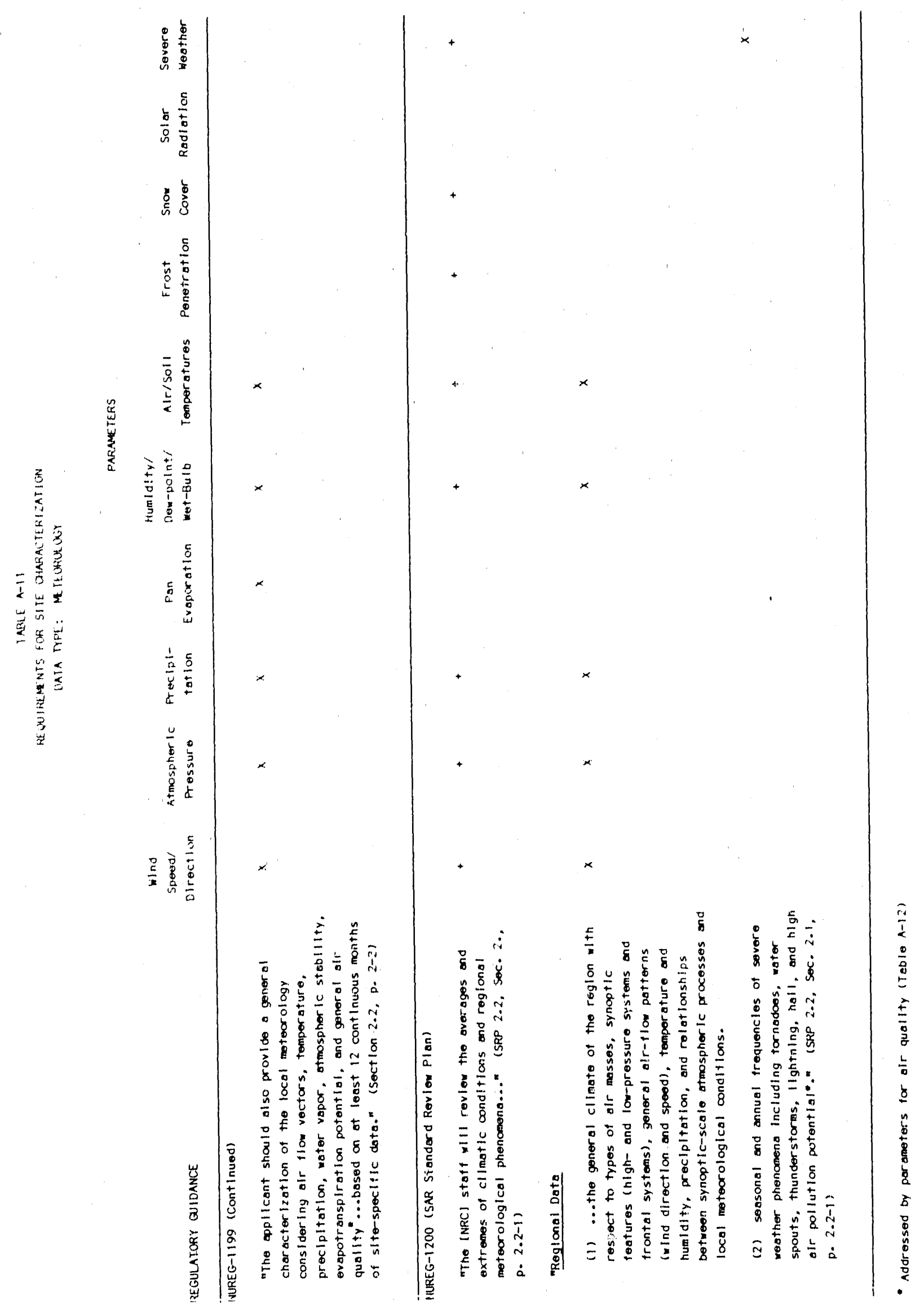




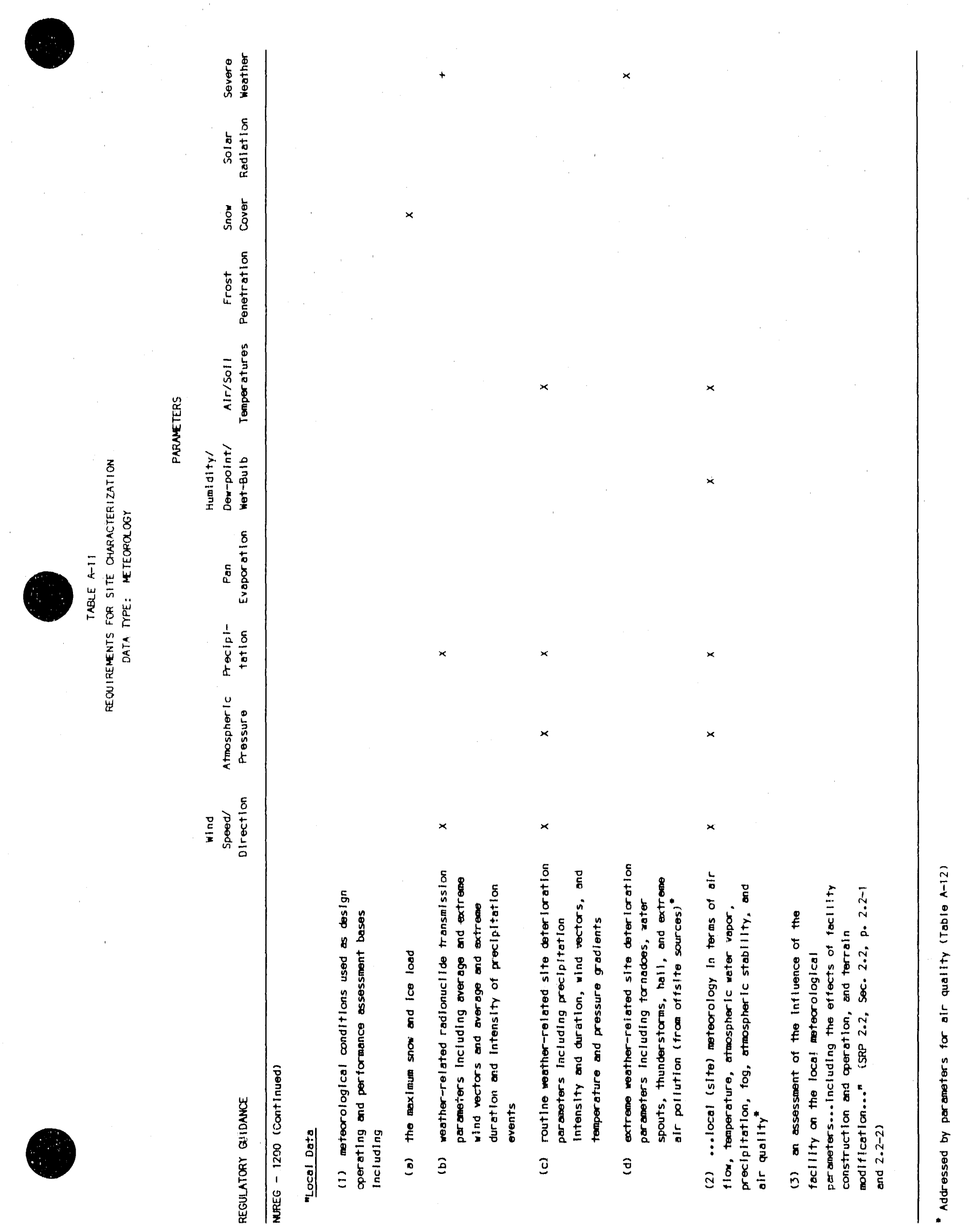




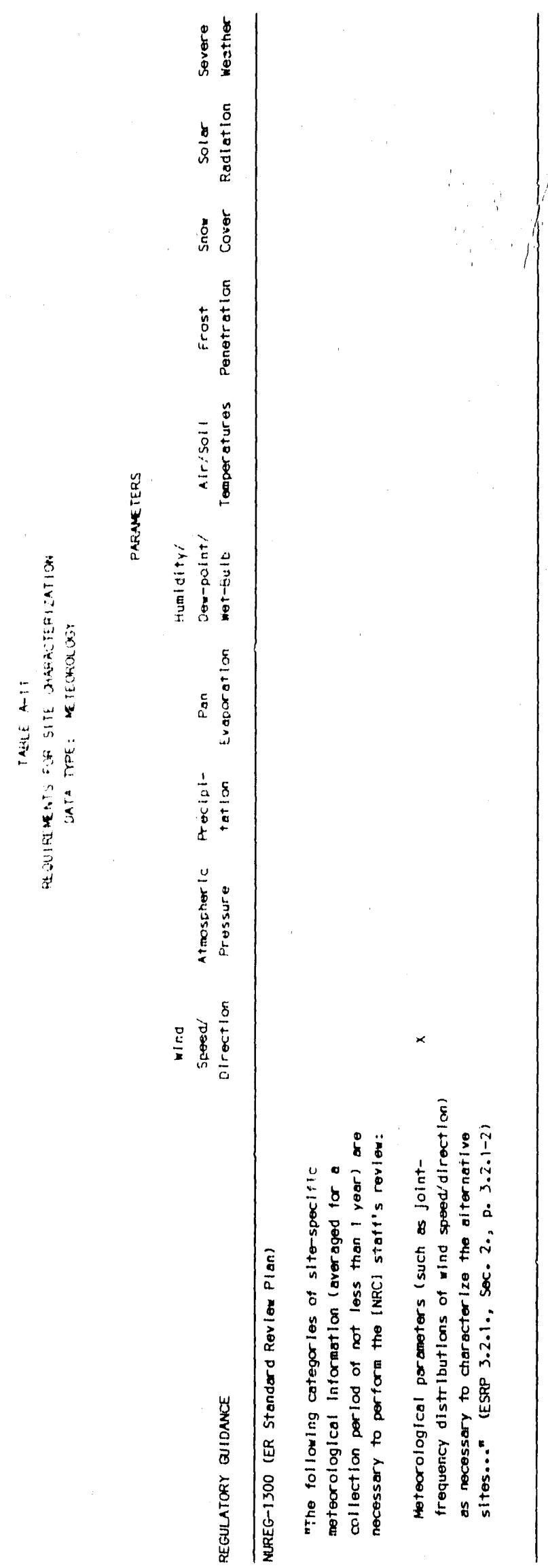


TABLE $A-11$

PARAMETER DESCRIPTIONS - METEOROLOGY

Wind Speed/Direction: The rate of air flow and its trajectory, measured continuousiy at various helghts above ground level as hourly means (scalar speed and resultant vector speed and direction) and peak instantaneous gust speeds; hourly data calculated to long-term (monthly, seasonal, annual) summaries by joint frequency distrlbutions using six speed categories and sixteen direction categories, average scalar speeds, and maximum gust speeds.

Atmospheric Pressure: Force per unit area exerted by overlying air mass at the earth's surface, typically as hourly values; calculated to monthly and annual averages.

Precipitation: Water particles that fall from the air and reach the ground including liquid (rain, drizzle) and frozen (snow, hail) water; measured as hourly or dafly totals, and calculated to monthly and annual totals, both as water equivalent and depth of snow; also calculated to extreme values of precipitation rates and totals by varfous time periods.

Pan Evaporation: Amount of water evaporated dafly from a standard pan, calculated to monthly and seasonal totals. Used as an indication of evaporation from free water surfaces (such as lakes, ponds) and with soil and vegetation information to estimate evapotranspiration.

Humidity/Dew-Point/Wet-Bulb: Heasures of atmospheric water vapor; humidity is the water vapor fraction of saturation conditions; dew-point temperature is the air temperature at which ambient water vapor will condense on a surface; simply, wet-bulb temperature is the temperature measured as hourly average values and calculated to monthly, seasonal and annual averages, often for specific hours of the day.

Air/Soil Temperatures: Measurements of ambient air temperature at various heights above ground level, usually 2 meters and others as required; used in water and energy balance, and air quality dispersion analyses; measured as hourly values or dally maximum/minimum and average values by month, and annual average temperatures. Measurements of soil temperature made at selected depths within the soil, used in water and energy budget analyses.

Frost Penetration: Depth within the soll to which water is frozen, measured as depths by month or season.

Snow Cover: Snow depth in undisturbed areas, measured daily or less often; measured as occurrence of depths at least one inch, snow depth (both incremental storm events and cumulative depths), and water equivalent (obtained by weighing or melting a snow core); calculated to monthly or seasonal averages. 
Solar Radiation: Total incoming solar radiation, typically measured at 2 meters above ground as hourly and dally total incoming energy, calculated to monthly totals: also can be used with terrestrial long wave radiation to compute net radiation, measured as hourly average amounts; used in energy and water budget analyses.

Severe Weather: Occurrences of significant weather events such as tornadoes, hurricanes, thunderstorms, hail, blizzards, etc. Magnitude of events can be treated along with individual parameter, such as extreme temperature and precipitation events. 


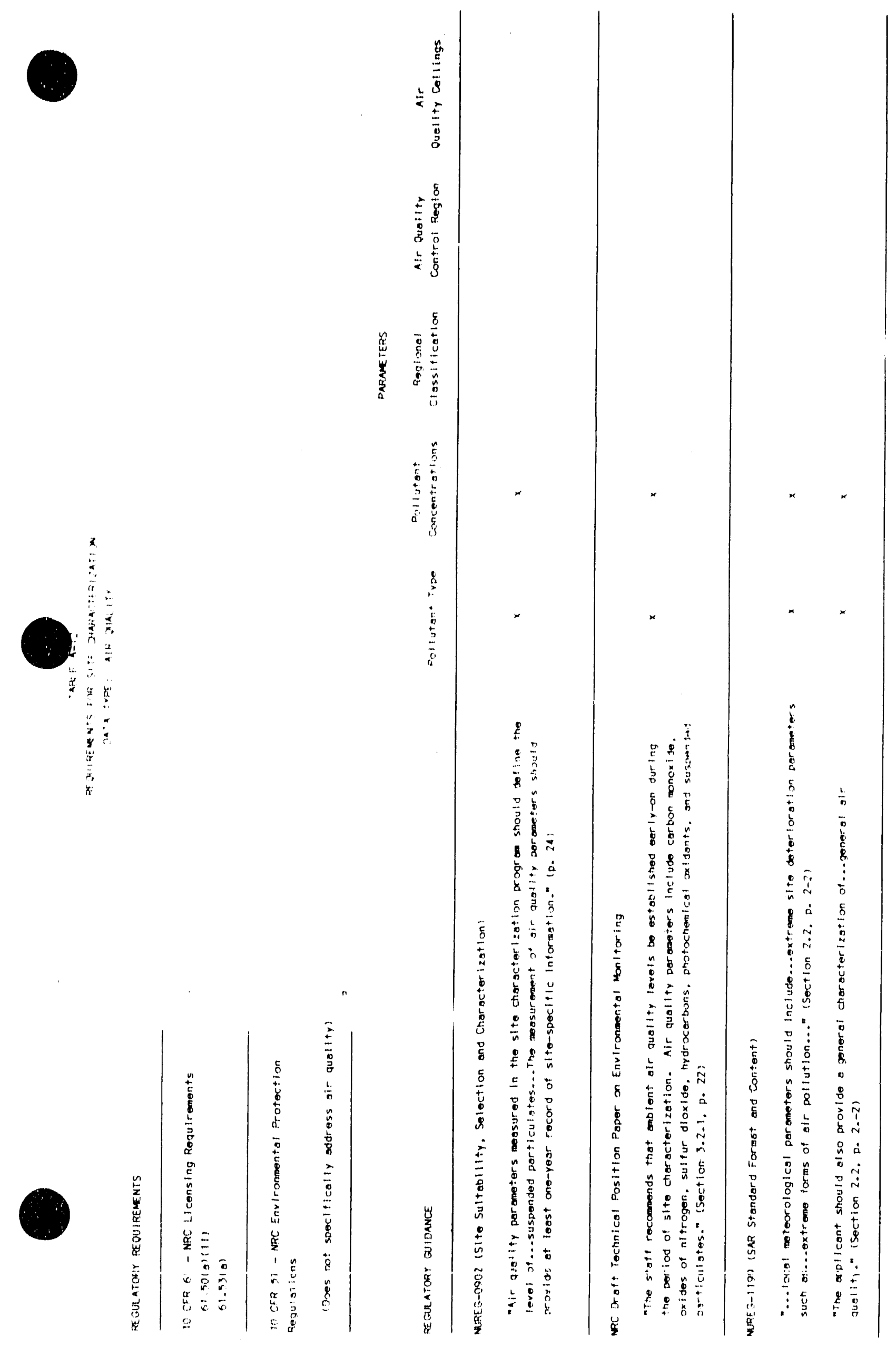




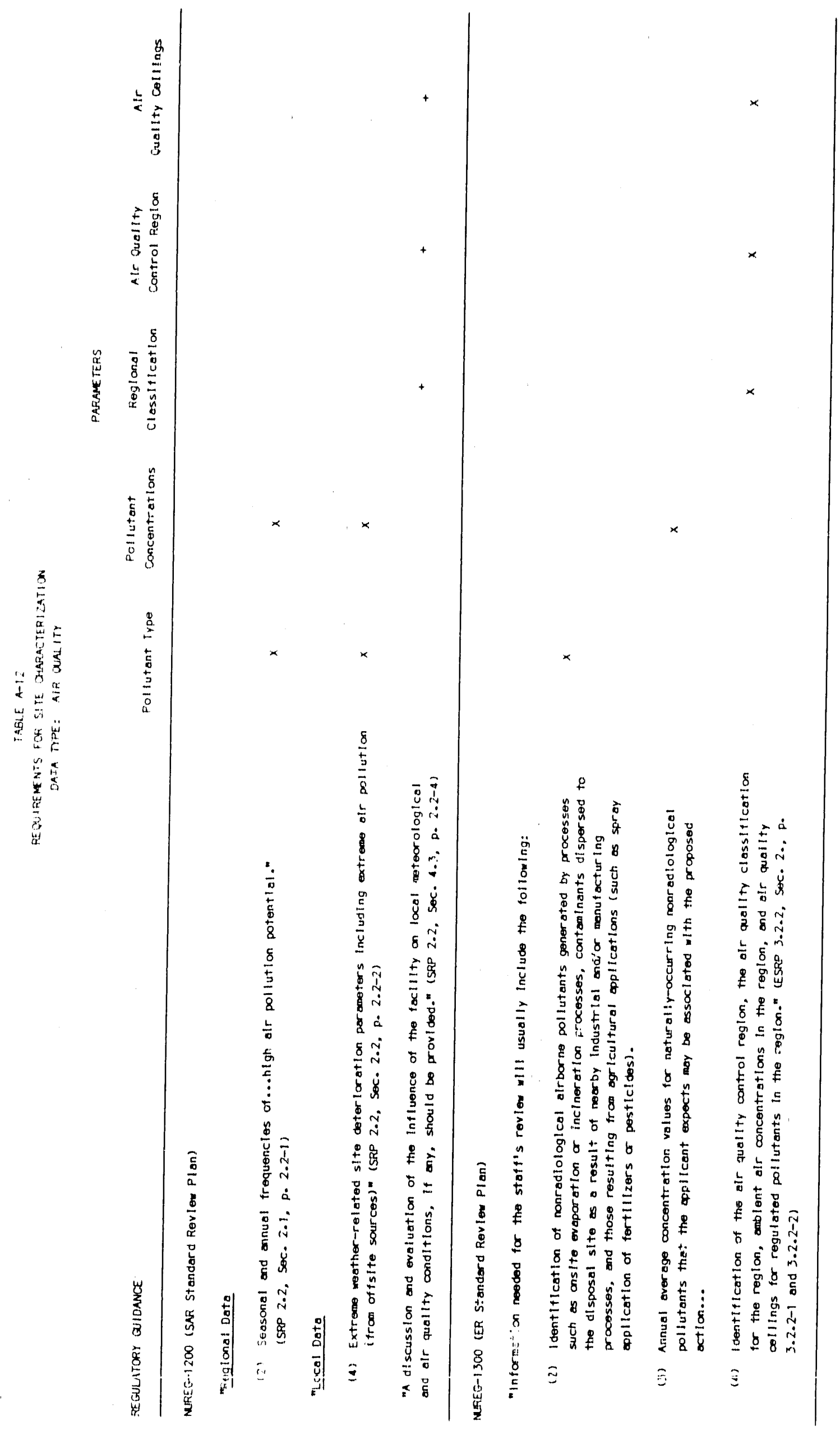


Pollutant Type: The classification of non-radiological, alrborne, pollutants 11kely to be found at a proposed site as existing background or expected to be present during site development, operation, or closure; includes EPA criteria pollutants ( 40 CFR 50); sulfur dioxide, partfculate matter, carbon monoxide. ozone, nitrogen dioxide, and lead. Also includes hydrocarbons that may cause health impacts.

Pollutant Concentrations: Measured or estimated amount of the pollutant types, based on averaging times corresponding to the ambient air quality standards.

Regtonal Classification: The designation given to the air quality control region through regulation or agency evaluation to denote attainment (1.e., compliance with the National Ambient Air quality Standards) or non-attainment for each air pollutant. Special restrictions and control requirements for air pollution exist in the non-attainment areas.

Air Quality Control Regton: The region of the country, as designated by U.S. EPA for control and management of air pollutants, within which the site is located.

Air Quality Cellings: Upper limits on concentrations of non-radiologic air pollutants, as set forth in 40 CFR 50 (National Primary and Secondary Ambient Air Quality Stanciards) and State regulations. 

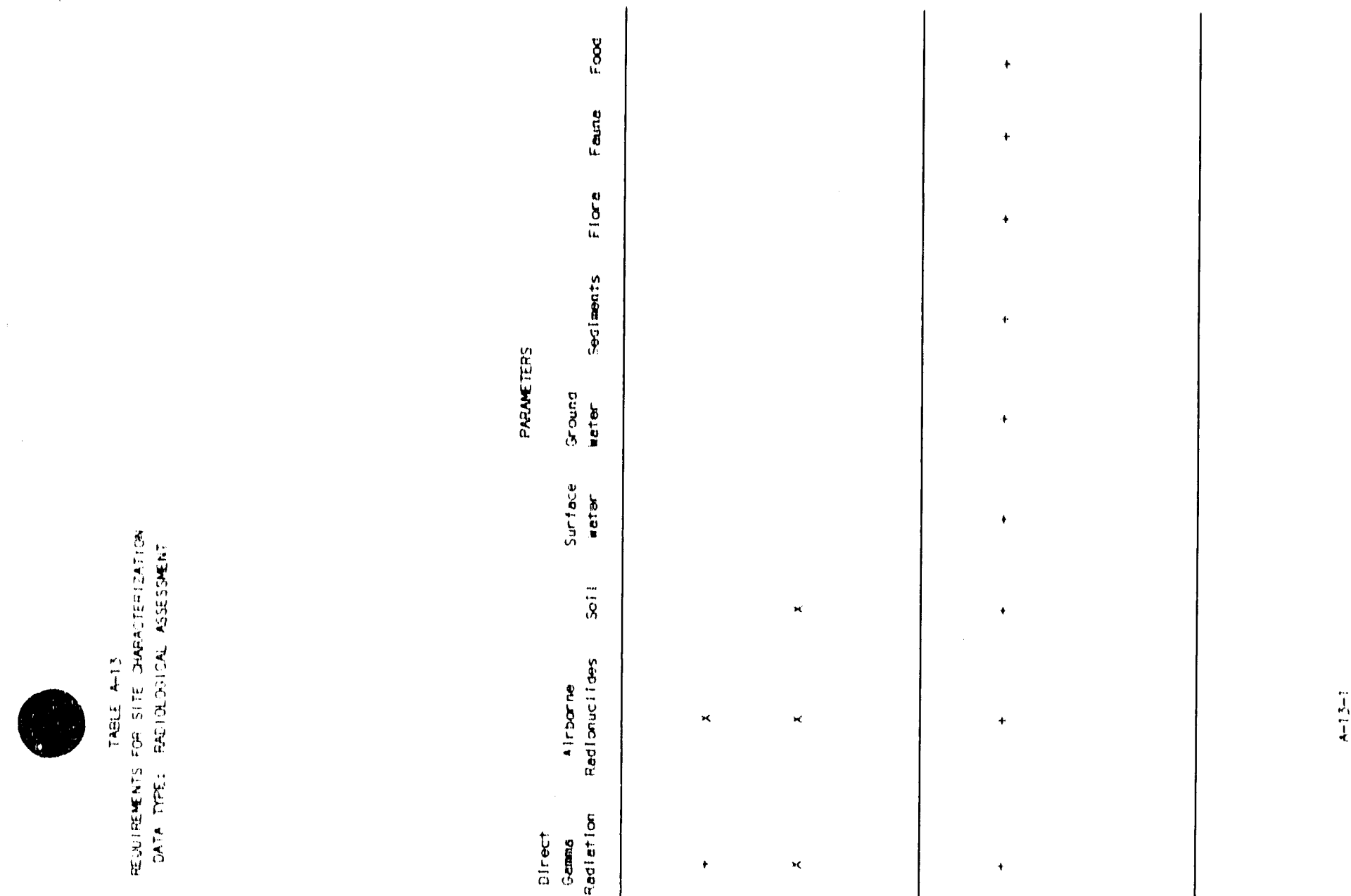

总落
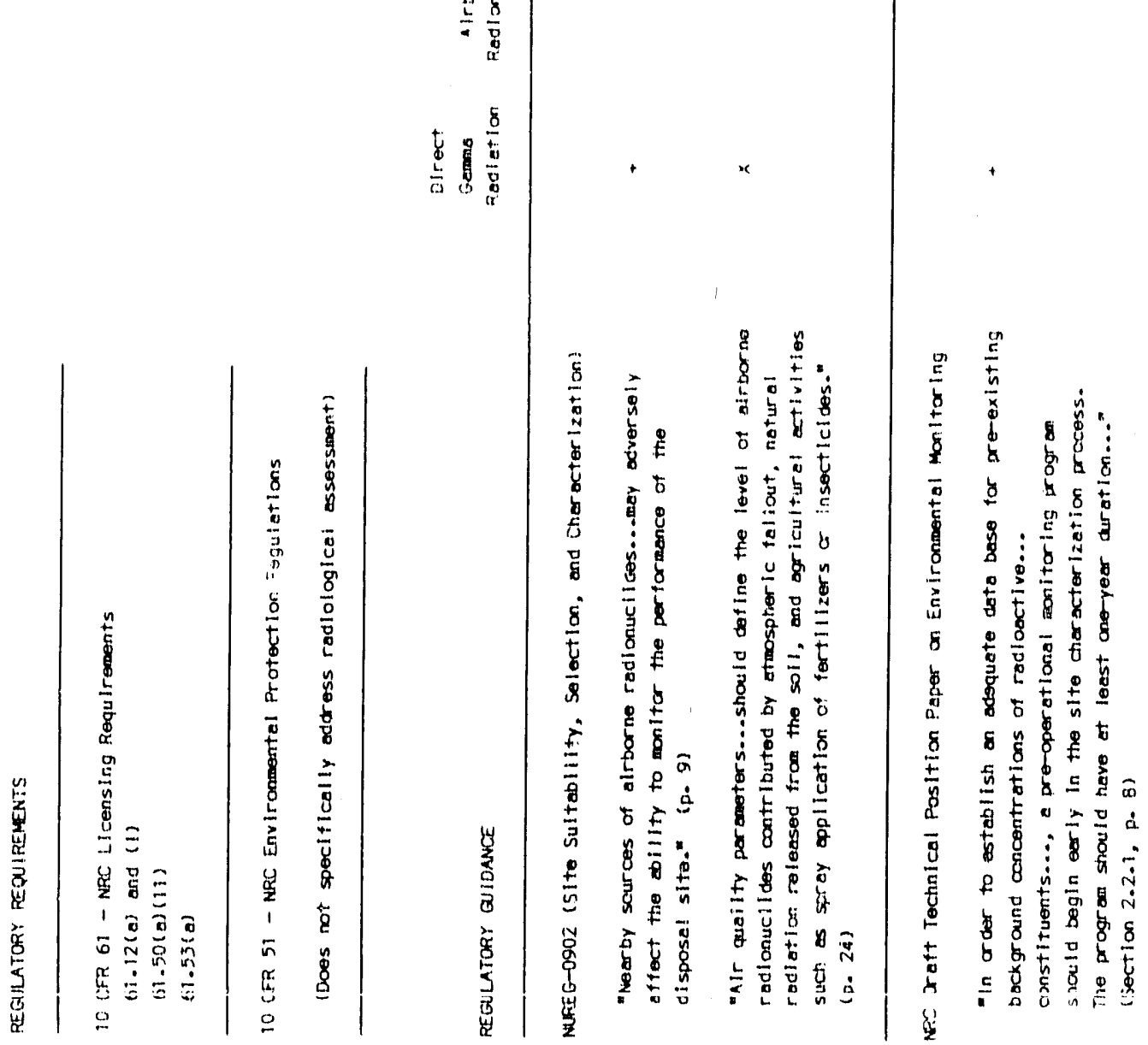


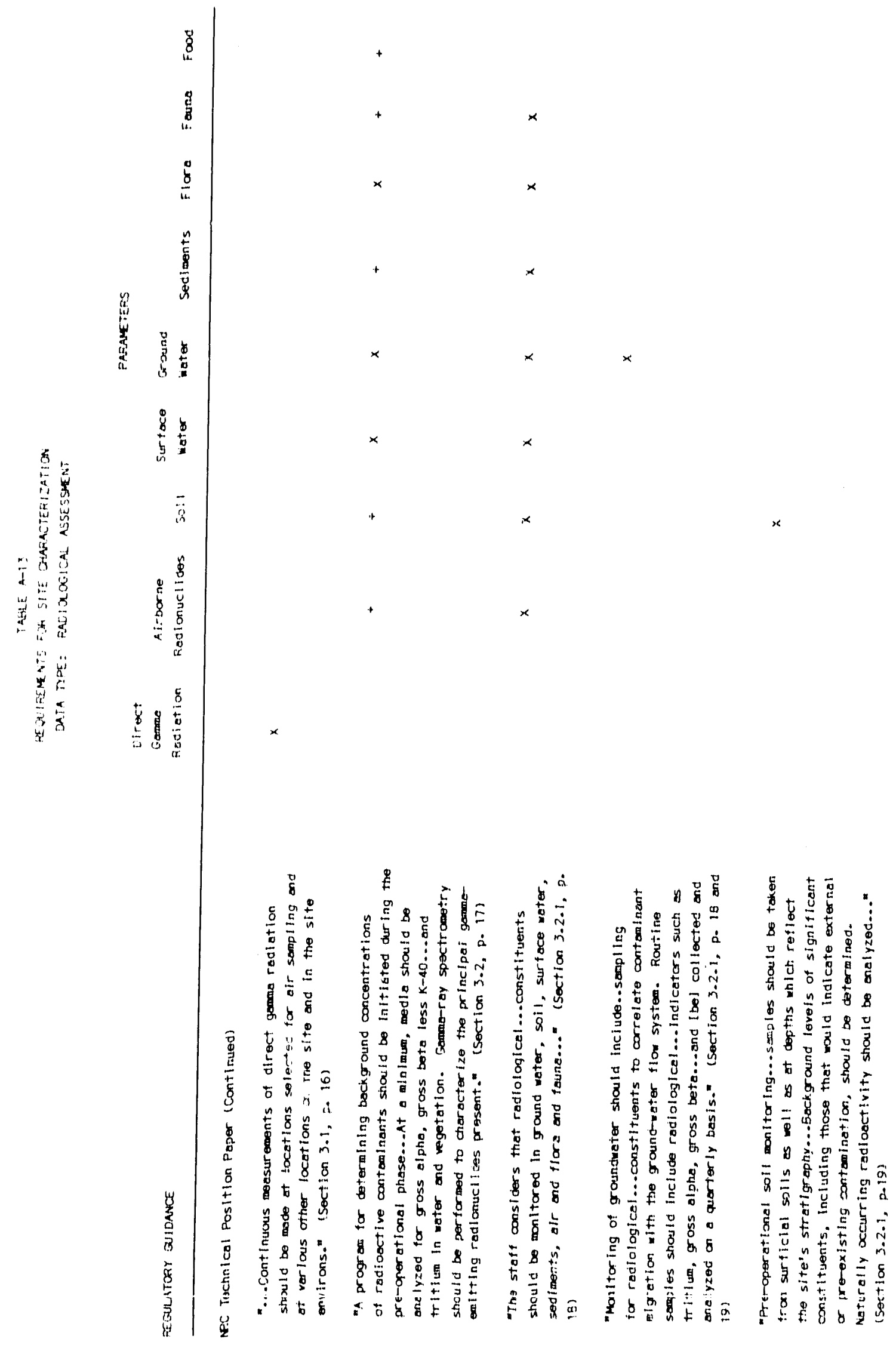




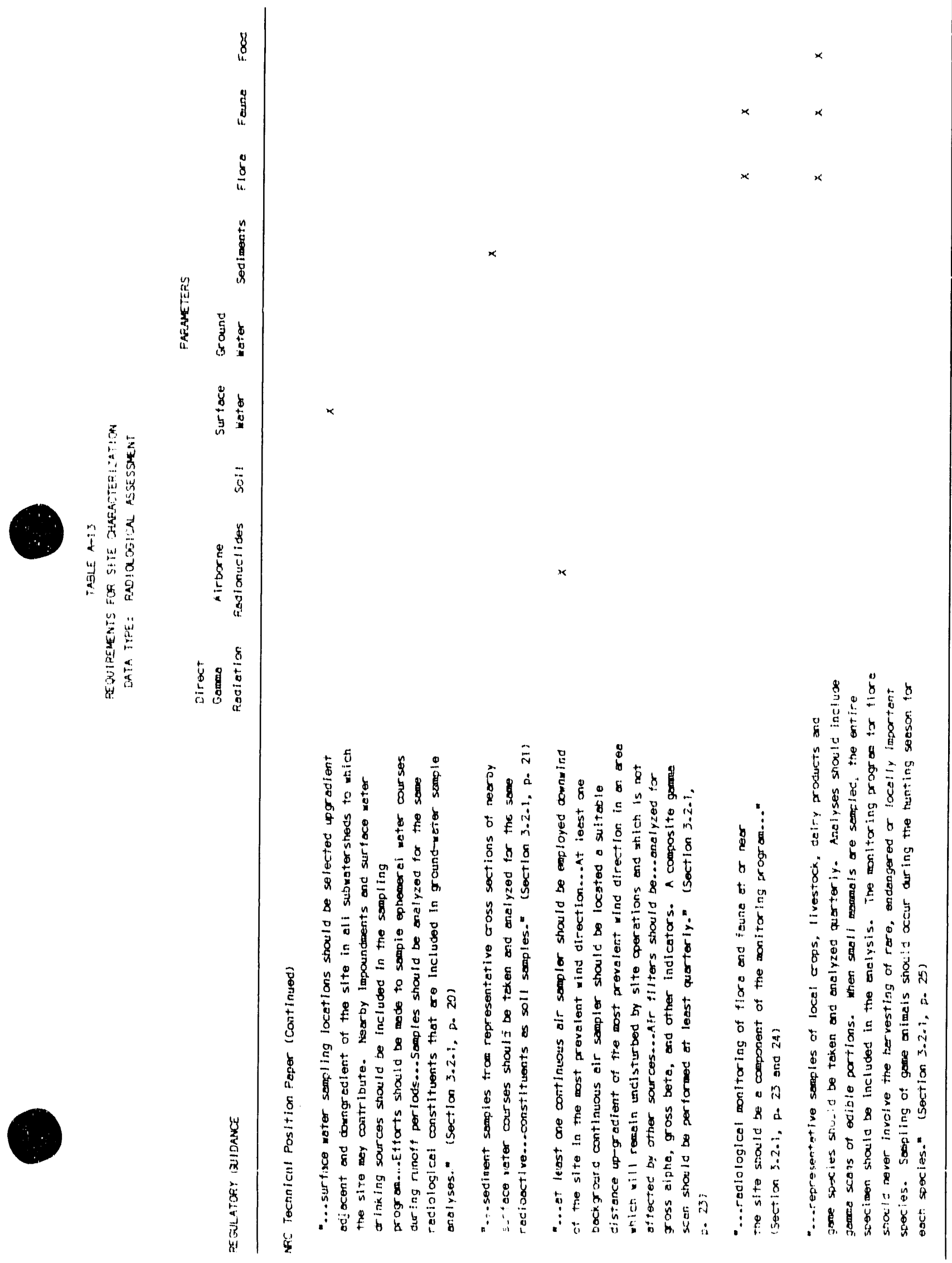




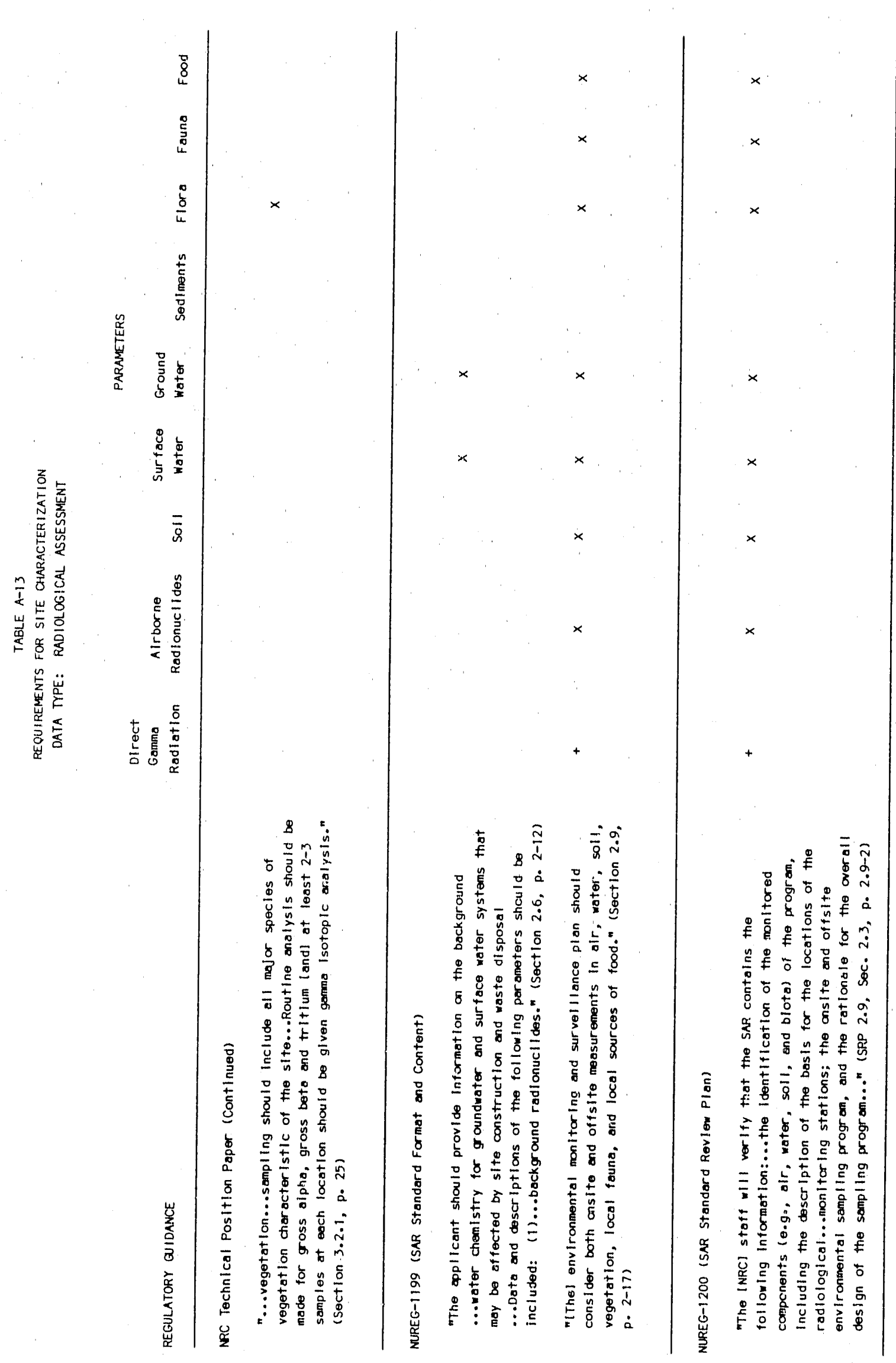




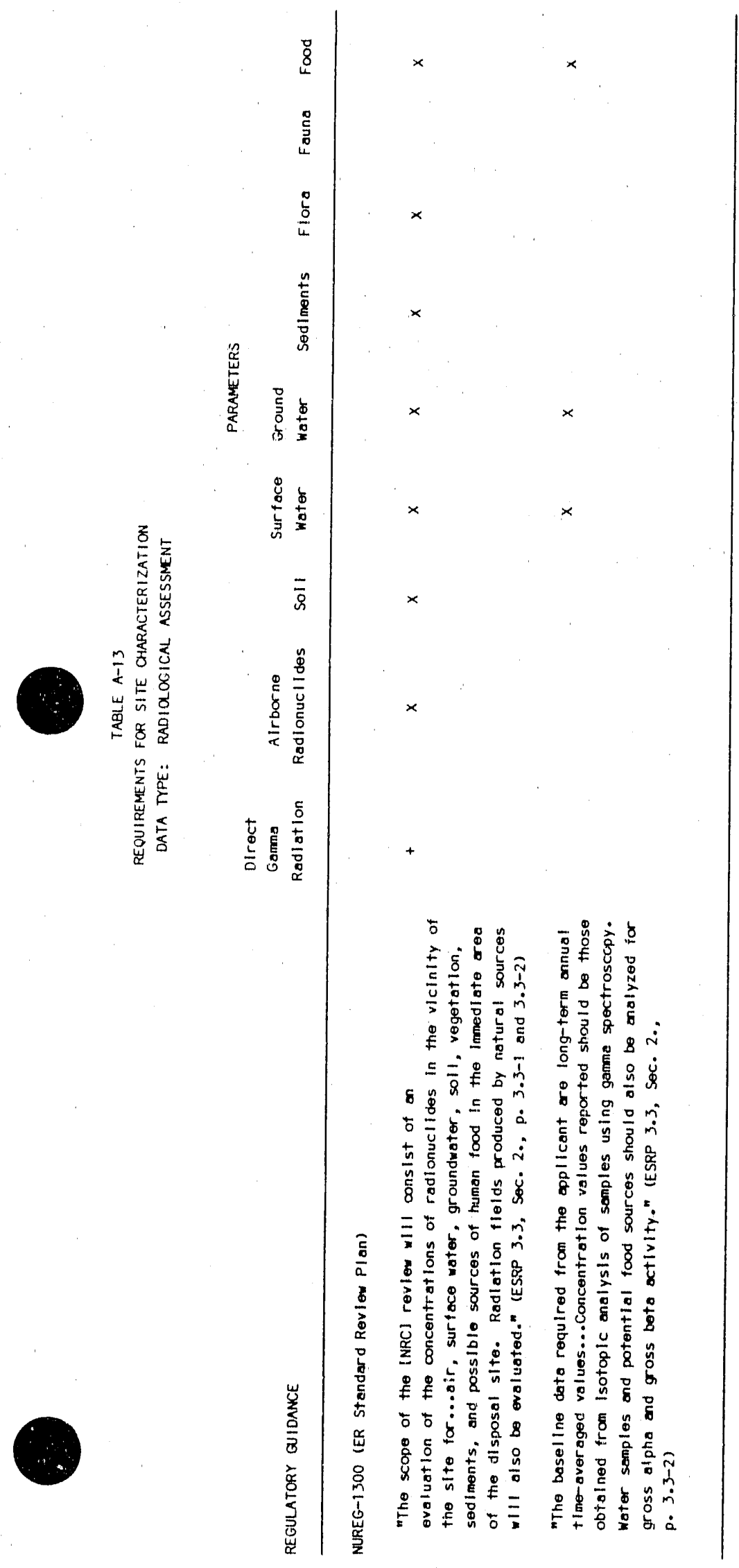


TABLE $A-13$

PARAMETER DESCRIPTIONS - RADIOLOGICAL ASSESSMENT

Direct Gamma Radiation: A measure of the ionization produced in air by $x$ or gamma radiation. The special unit of exposure is the roentgen.

Airborne Radionuclides: The sampling of a known volume of air with subsequent identification of radionuclide and activity concentration (in picocuries per liter). These analyses will be for both naturally occurring and man-made radionuclides.

Soil: Indentification of the radioactivity in soil. This includes direct or in vivo measurements of gamma-rays emitted from radionuclides in the surface soils (e.g., radium bearing soils) or by the collection of surface or subsurface samples with subsequent gamma-ray spectroscopy or radiochemical separation with alpha of beta counting techniques.

Surface Water: The sampling of flowing streams, ponds, lakes, and rivers with the subsequent analysis of radionuclide type and activity concentration in picocuries per liter recognizing the distinction between soluble species and suspended matter.

Ground Water: The sampling and subsequent analysis of groundwater to identify radionuclides and measure the activity concentration in picocuries per liter $(p c / 1)$, recognizing the distinction between soluble species and suspended matter.

Sediments: Sampling of loose, unconsolidated sediments (sand, gravel, silt, mud, etc.) including the suspended fraction with the subsequent identification of radionuclide and activity concentration in picocuries per gram of solid fraction.

Flora: Radionuclides in abiotic compartments can enter plants by uptake from soil, deposition from air, or sorbtion from water in the case of aquatic plants. Uptake implies internal incorporation within tissues of the plant. Frequently radioactive materials in soil adhere to the root or shoot surface of plants but are not actually incorporated into plant tissues. Radionuclides in air or water can be deposited on or otherwise attached to plant surfaces directly without passage through soil. Analyses should be made to identify the radionuclide and determine the activity concentration in picocuries per gram.

Fauna: Passage of radioactive material to terrestrial and aquatic species occurs primarily by ingestion and inhalation. Each step of the food chain provides some form of discrimination in that radionuclides are channeled physiologically into certain tissues, depending on their physical/chemical properties. Analyses of fauna can be urgan specific (e.g., I-131 in the thyroid) depending on the radionuclide of concern, or whole body specific (e.g., Cs-i37). Analyses should be made to identify the radionuclide and determine the activity concentration in picocuries per gram.

Food: Measurement of radioactivity in crops, livestock, dairy products and game animals consumed by humans including radionuclide and concentration. 


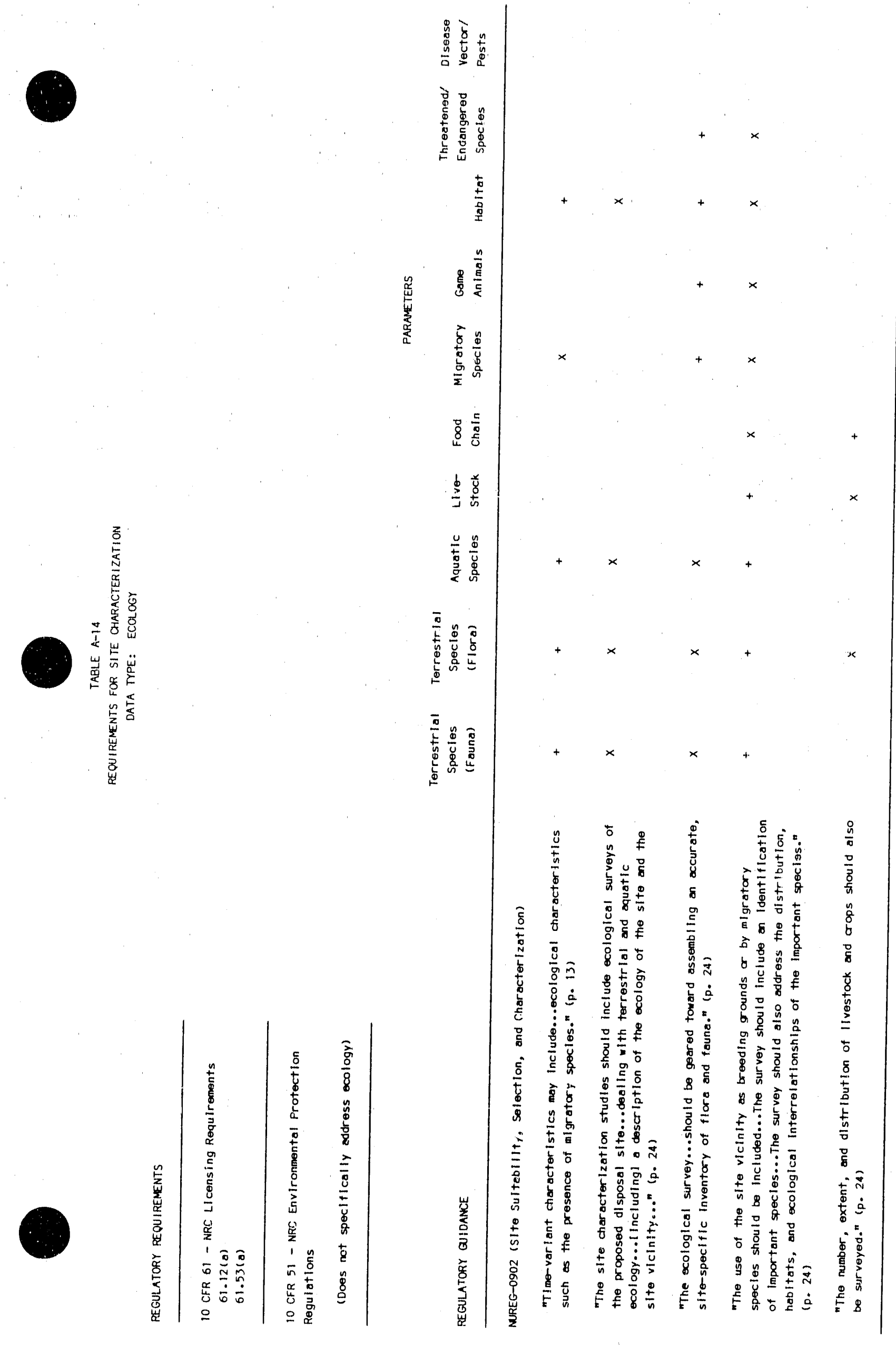

$\frac{7}{3}$ 


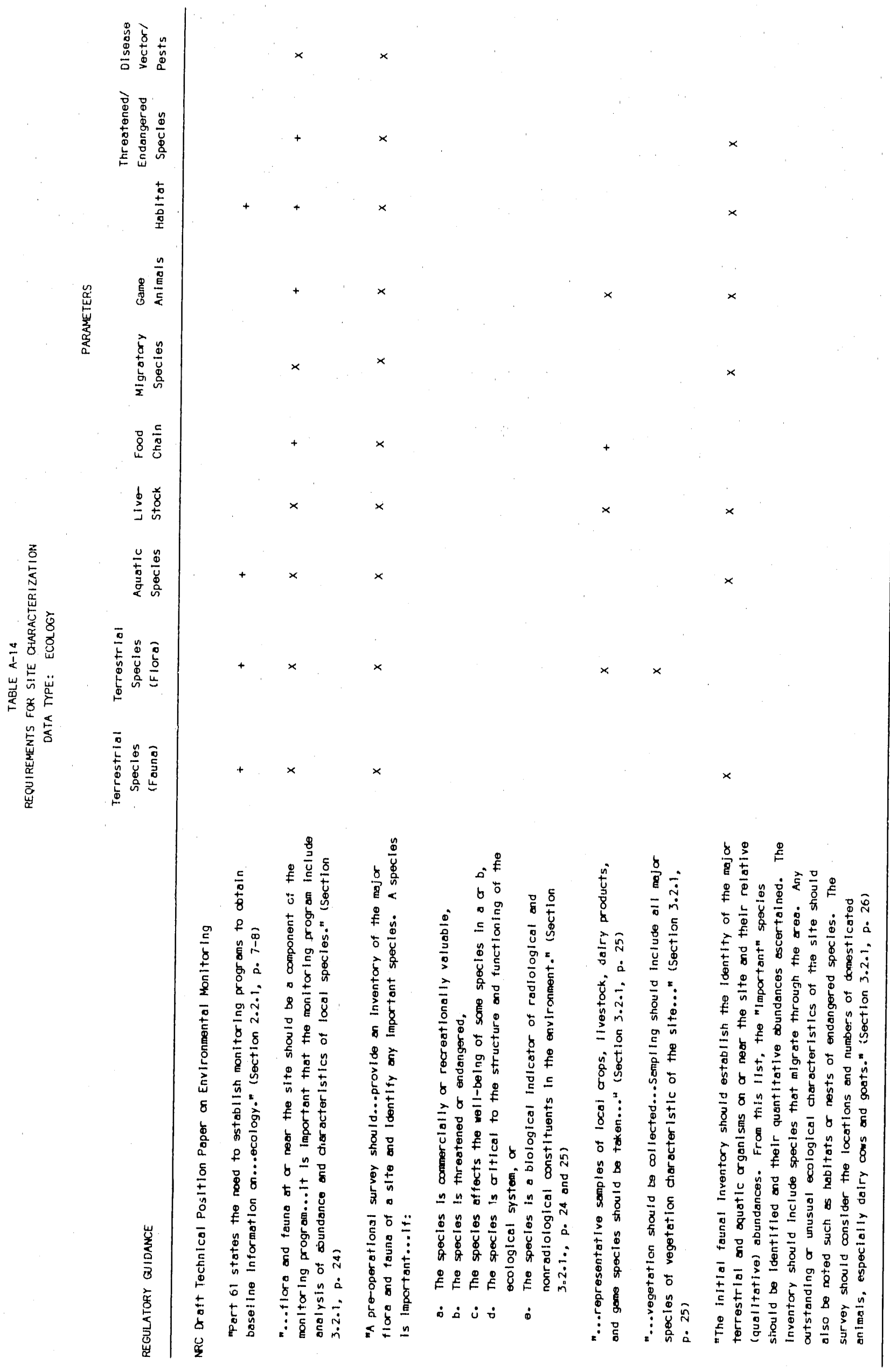




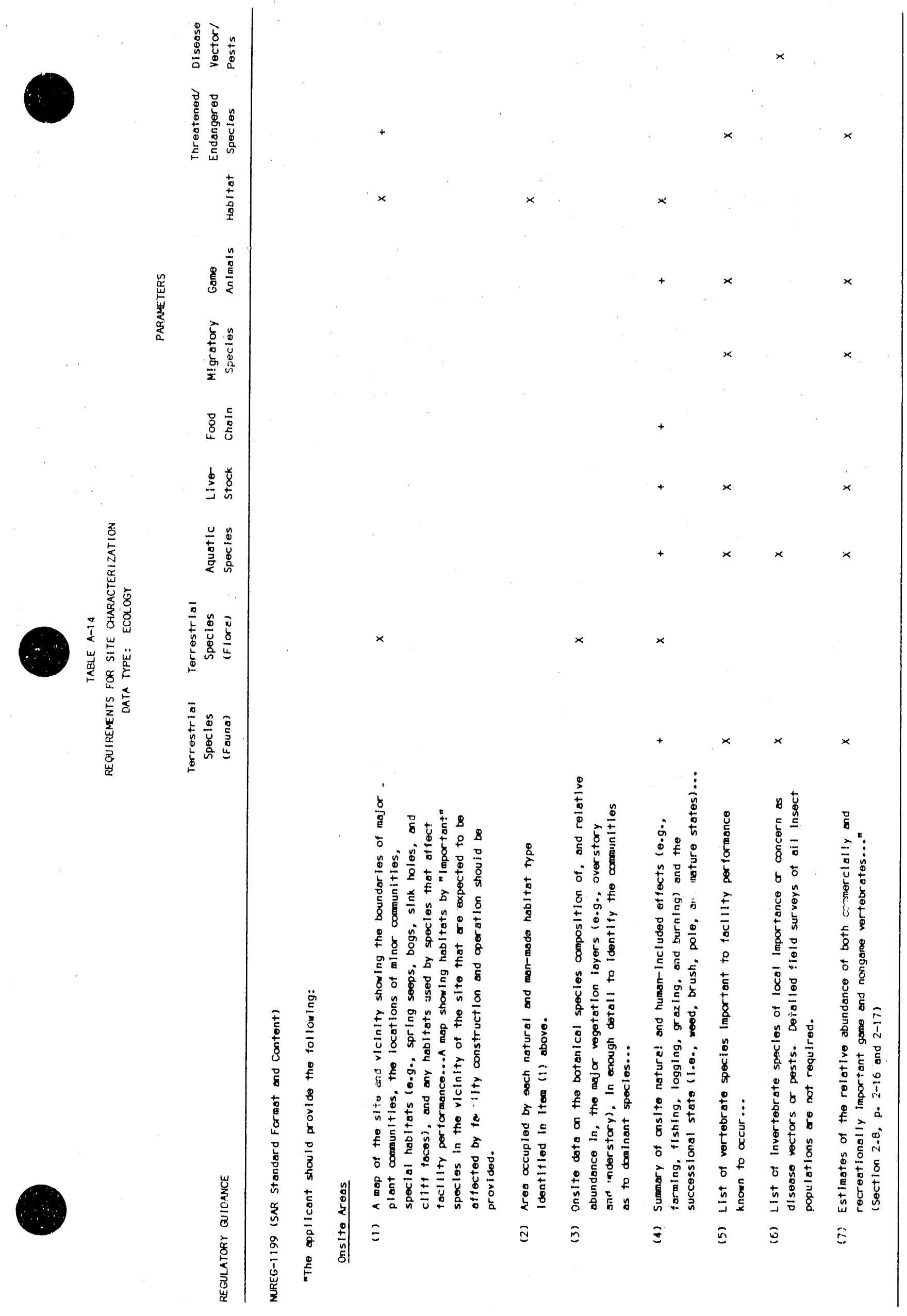

$\frac{m}{\frac{1}{2}}$ 

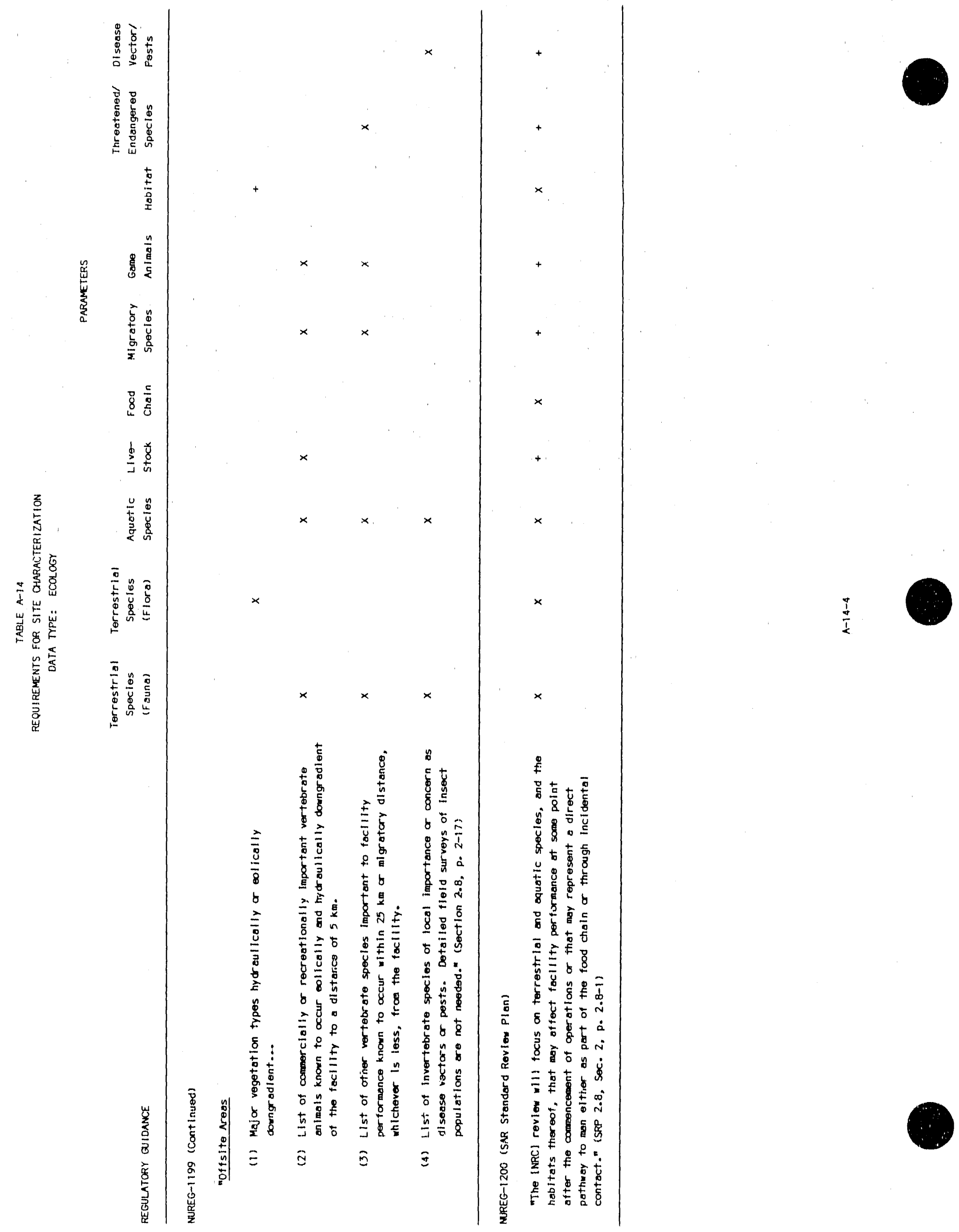


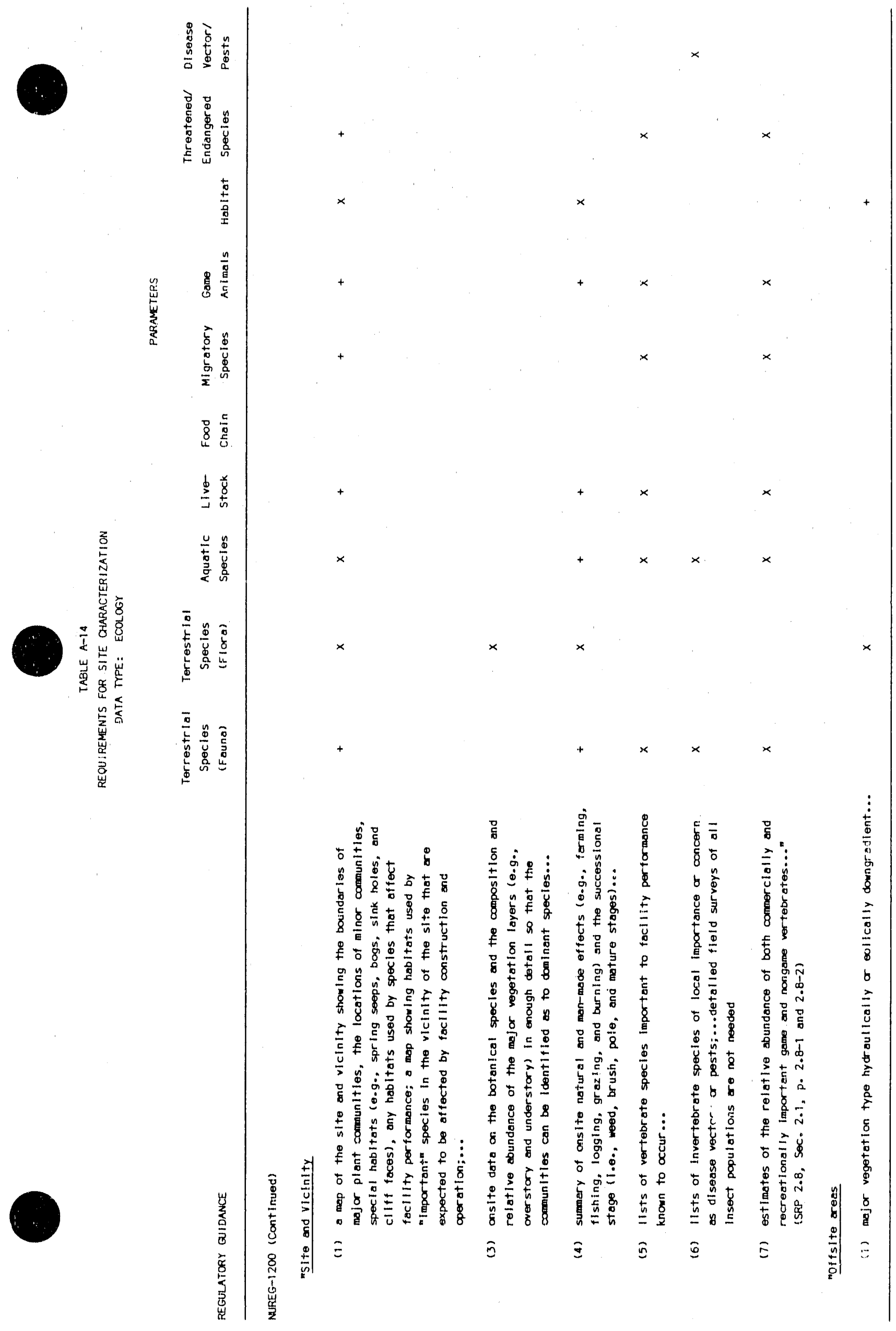




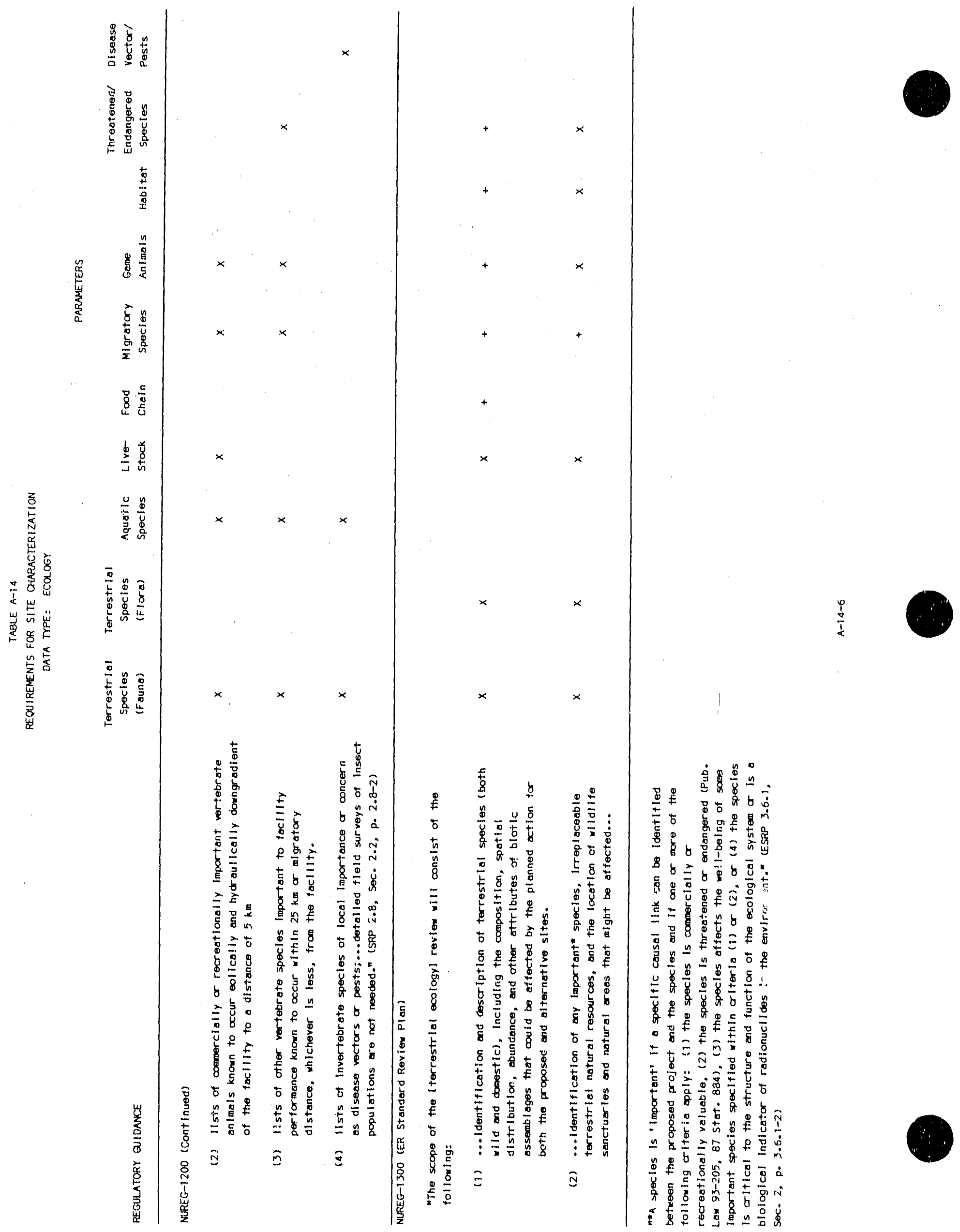




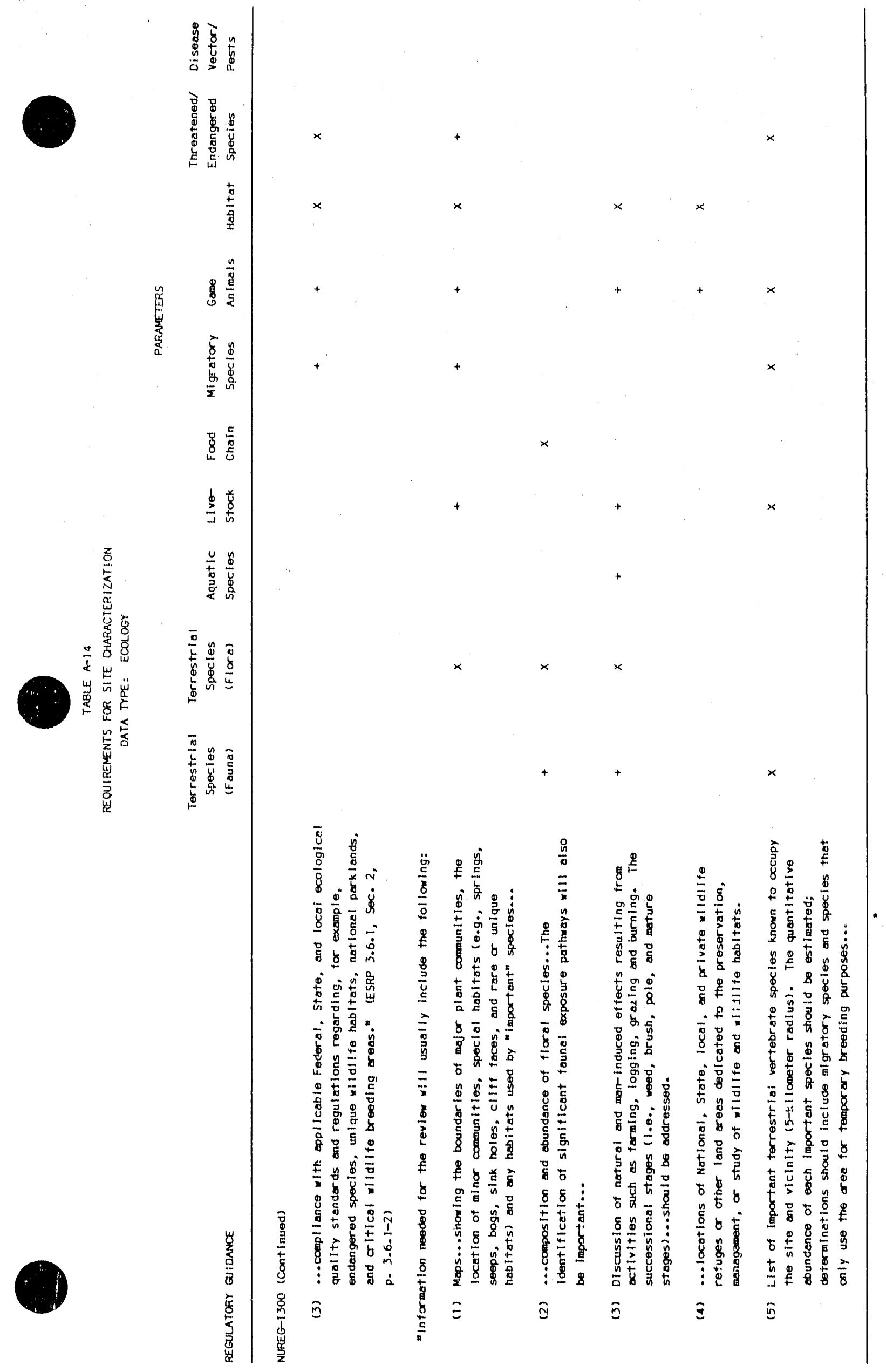




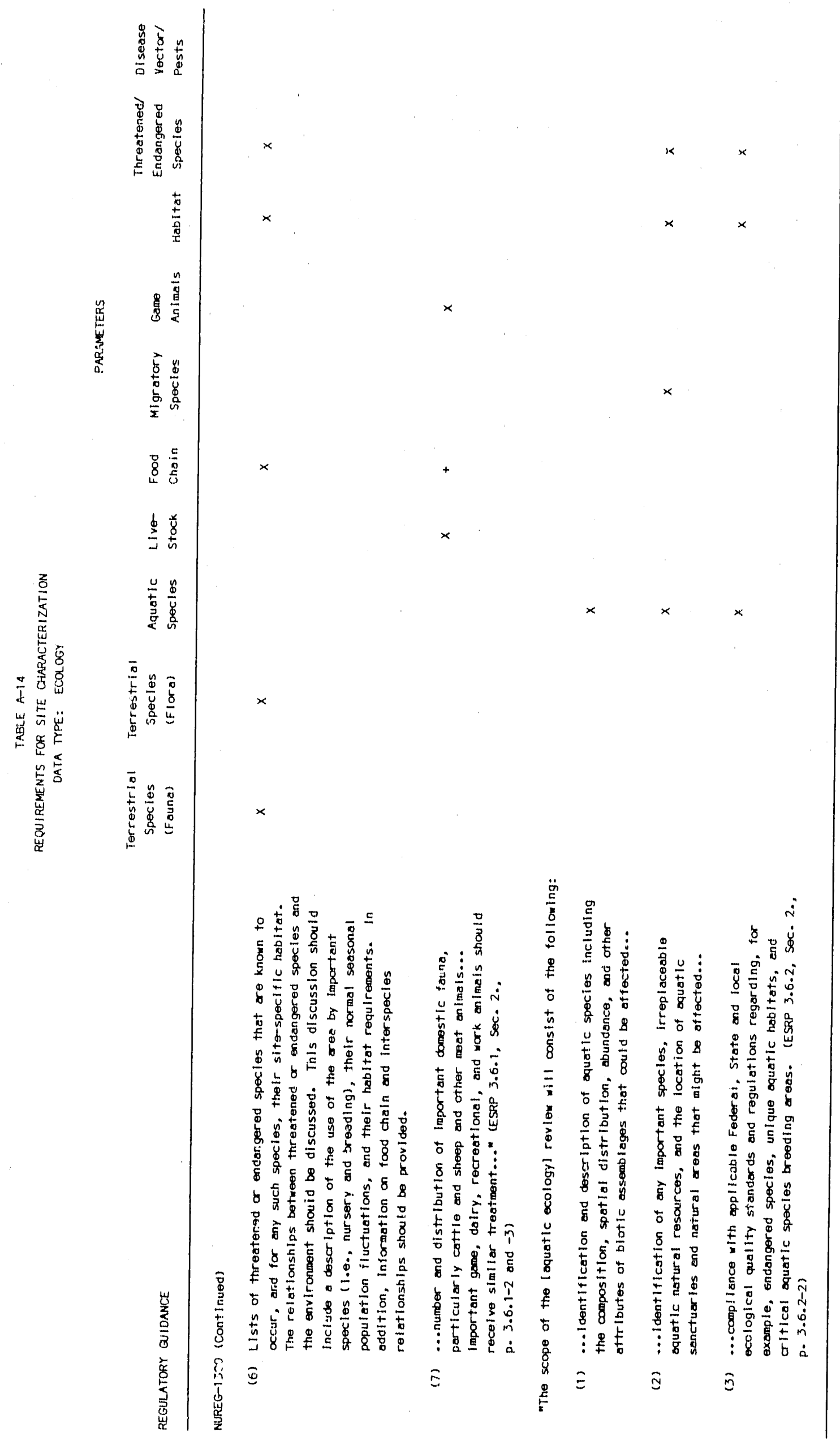

$\underset{\substack{1 \\ ⿱}}{\frac{1}{x}}$ 


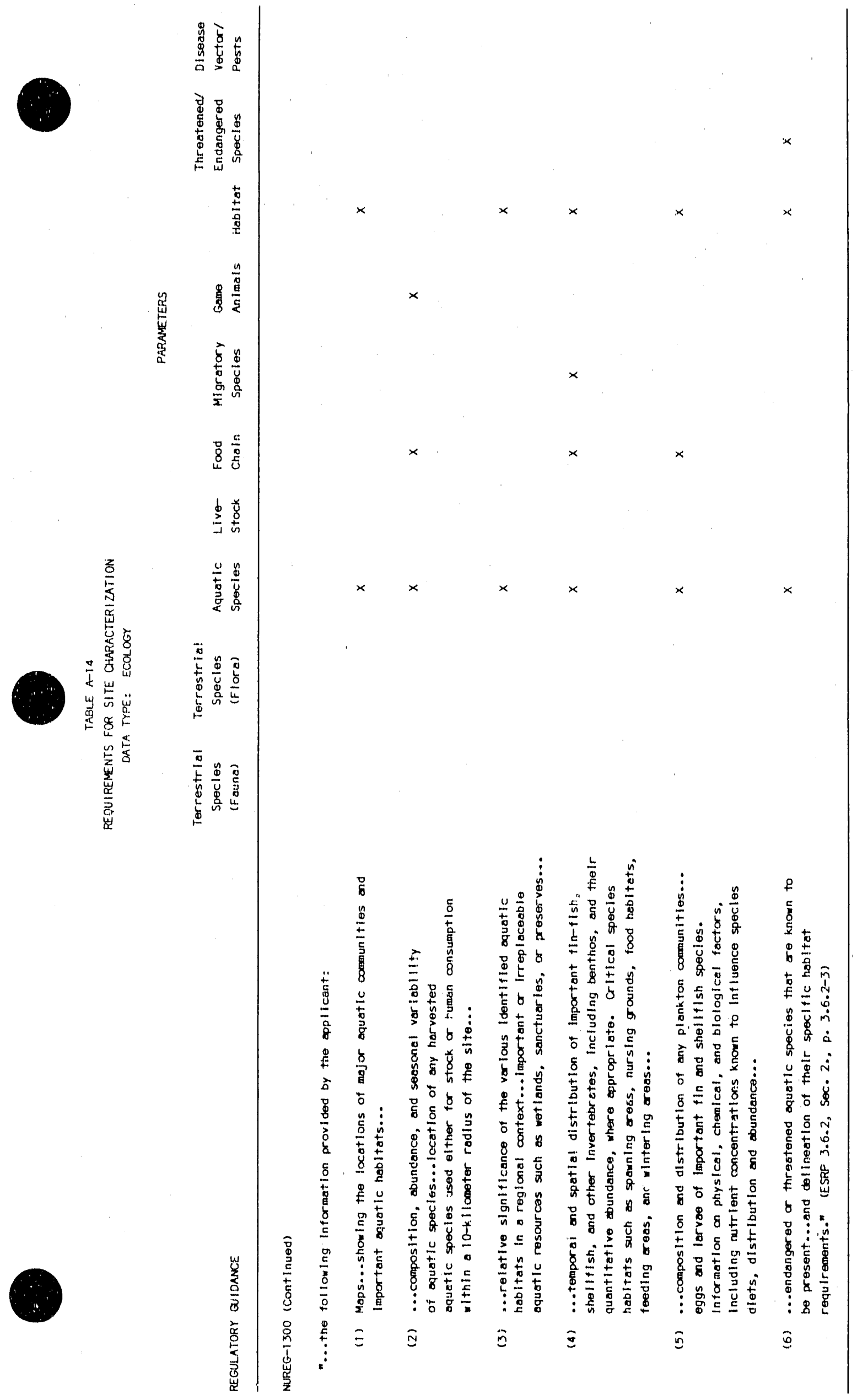


Terrestrial Species (Fauna): Important wild and domestic animal species, including abundance, characteristics, distribution, ecological interrelationships, and breeding grounds.

Terrestrial Species (Flora): Major species of vegetation, including plant communities, species composition, relative abundance, successional stage, and vegetation types.

Aquatic species: Aquatic species (flora and fauna), including composition, distribution, abundance, importance, seasonal variability, harvest, and nutrient concentrations.

Livestock: Domestic animals such as dairy cows and goats, with food chain significance.

Food Chain: An abstract representation of the passage of energy (or possible contaminants) through populations of terrestrial and aquatic organisms in a community.

Migratory Species: Species that migrate through the site or the vicinity.

Game Animals: Wild animal species (on the site and in the vicinity), which are hunted and potentially consumed.

Habitat: Habitats for important terrestrial or aquatic species, including location and area occupied; wildlife sanctuaries or natural areas; special, rare, unique habitats; and site-specific habitat for any identified threatened or endangered species.

Threatened/Endangered Species: Species existing in the site area or vicinity (or potentially present) that are designated by the U.S. Fish and Wildlife Service or a cognizant State agency as threatened or endangered.

Disease Vectors/Pests: Vertebrate and invertebrate species of local importance or concern as disease vectors or pests that could impact workers or operations on the site. 


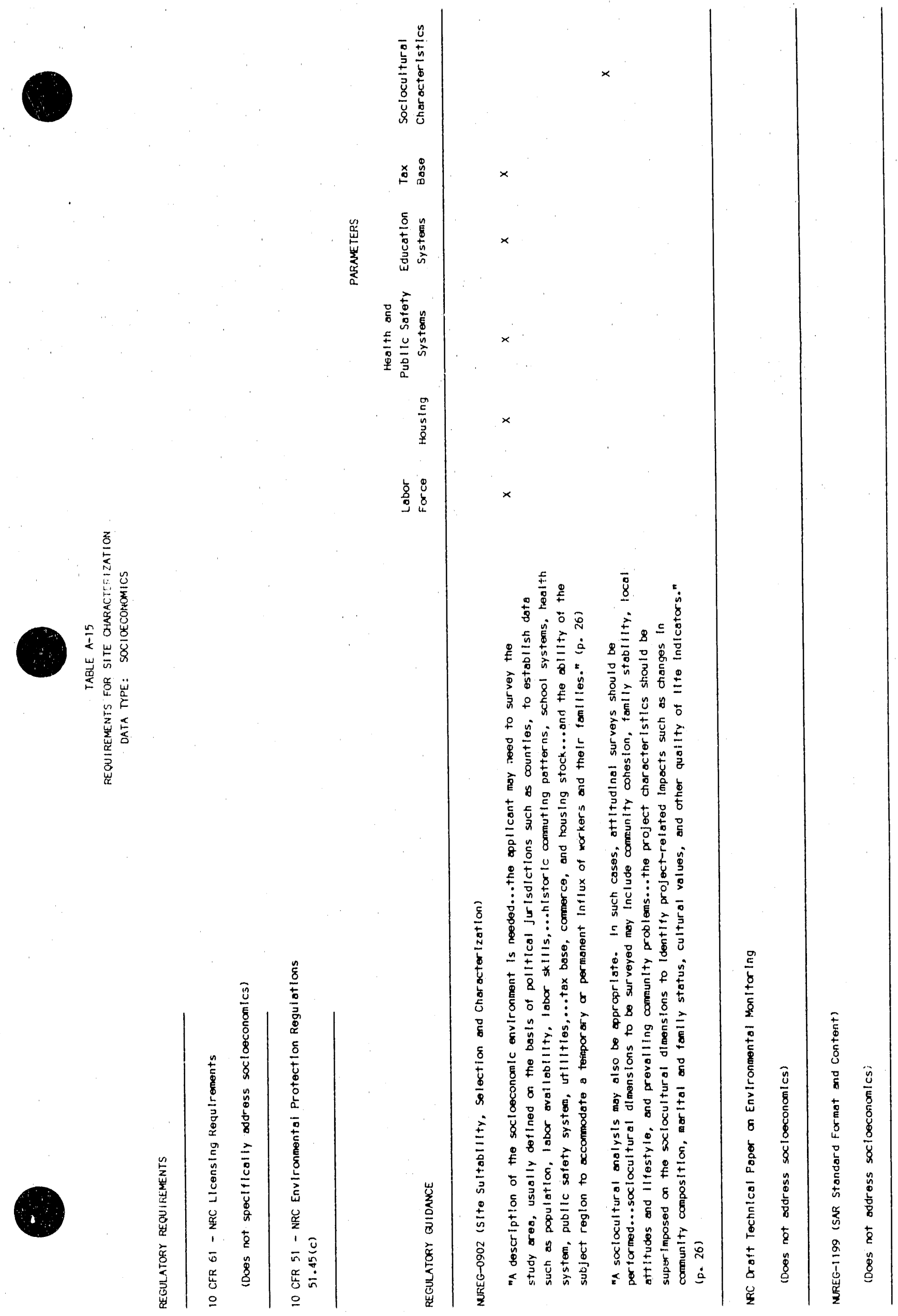




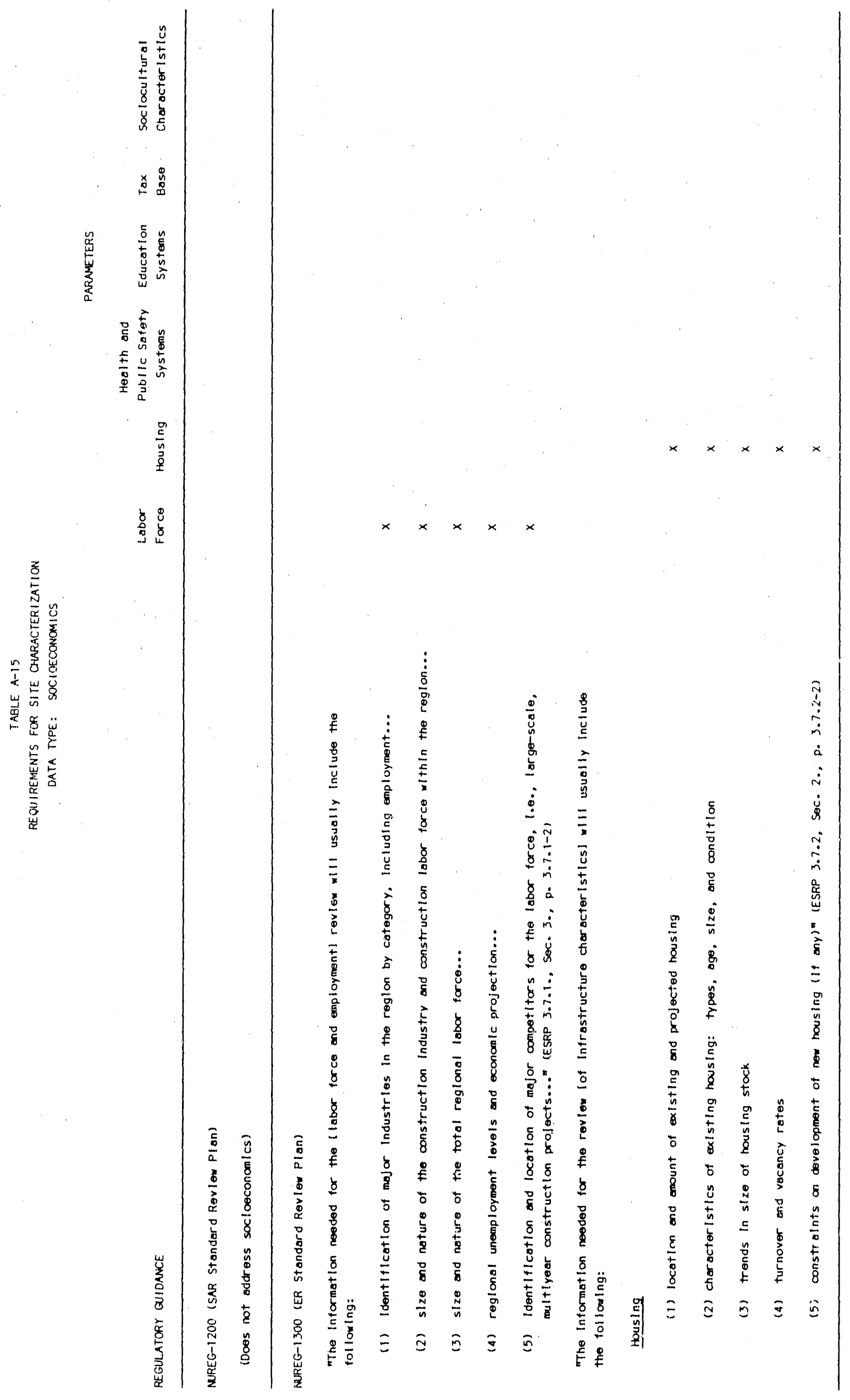




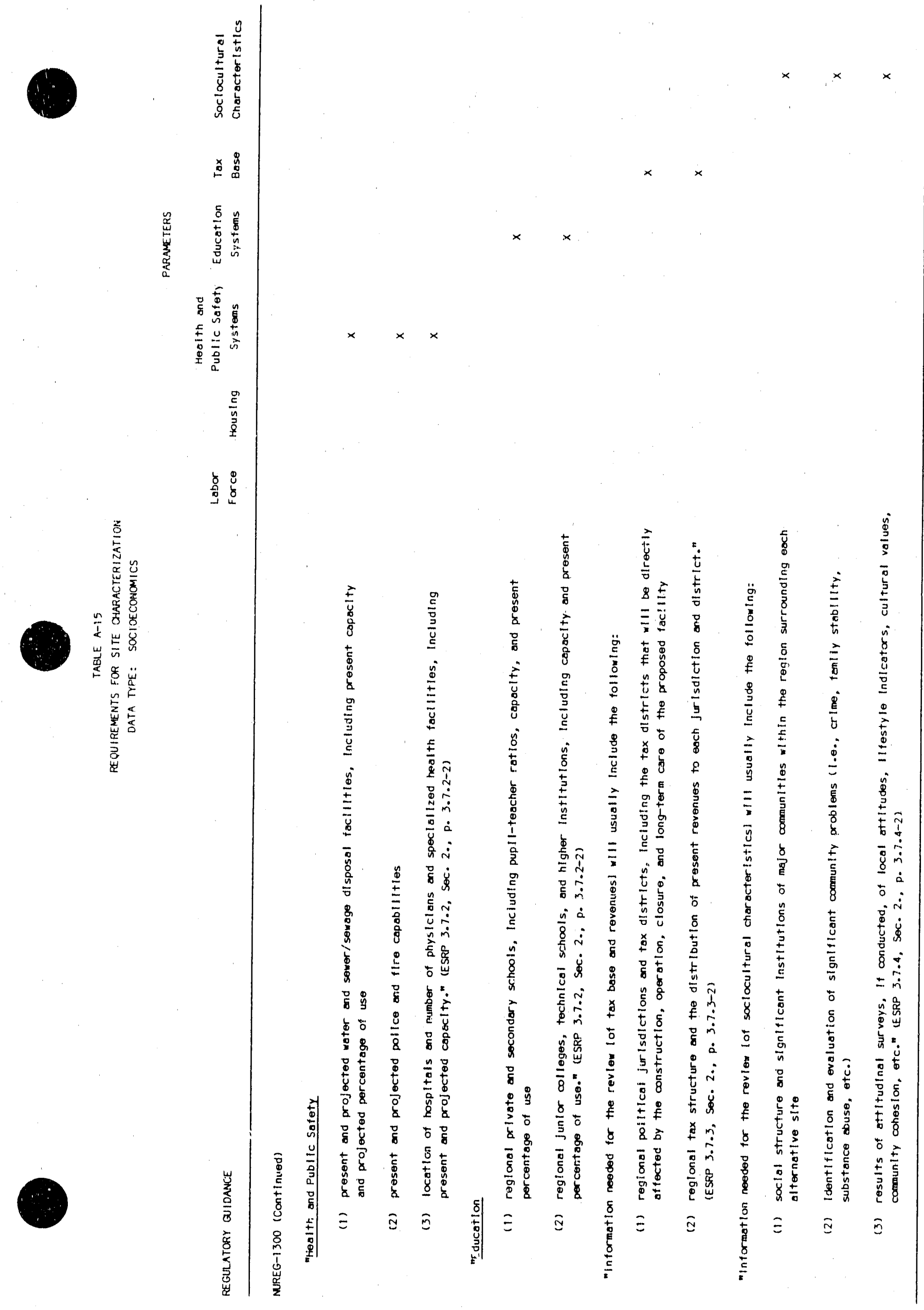


TABLE A-15

PARAMETER DESCRIPTIONS - SOCIOECONOMICS

Labor Force: The size, composition, and availability of the labor force in the region, including the county in which the site is located and those specific portions of surrounding counties and urbanized areas (up to $40 \mathrm{~km}$ from the site) from which the work force would be principally drawn.

Housing: The types, amounts, age, condition, and availability (turnover rates, vacancy rates, price) of existing housing and the location and amount of projected housing in the region from which the work force would be principally drawn or which would be affected because workers changed residence.

Health and Public Safety Systems: Capacity of utilities (e.g., solid waste disposal, water and sewer), and capabilities of police, fire, hospitals, physicians, and specialized health facilities to meet projected needs in the region from which the work force would be principally drawn or which would be affected because workers changed residence.

Education Systenis: Capacity and availability of primary and secondary schools, junior colleges, technical schools, and higher institutions in the region from which the work force would be principaliy drawn or which would be affected because workers changed residence.

Iax Base: The regional political jurisdictions and tax districts that will be affected by the facility, the regional tax structure, and present tax revenues.

Sociocultural Characteristics: The social structure (i.e., community composition and cohesion), local attitudes, cultural values, life style indicators, family stability, and community problems in major communities within the region around the site. 


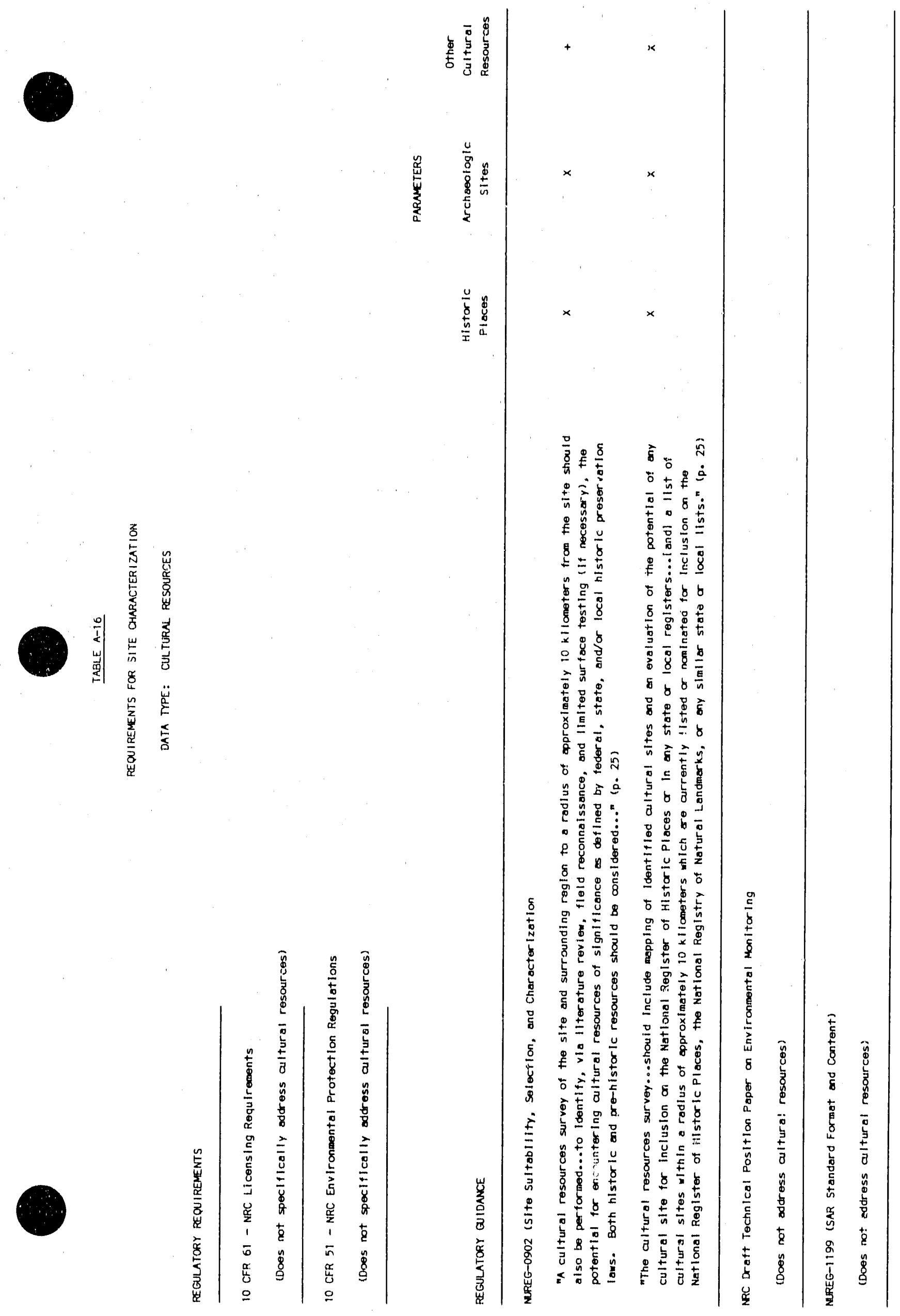

$\frac{7}{1}$ 


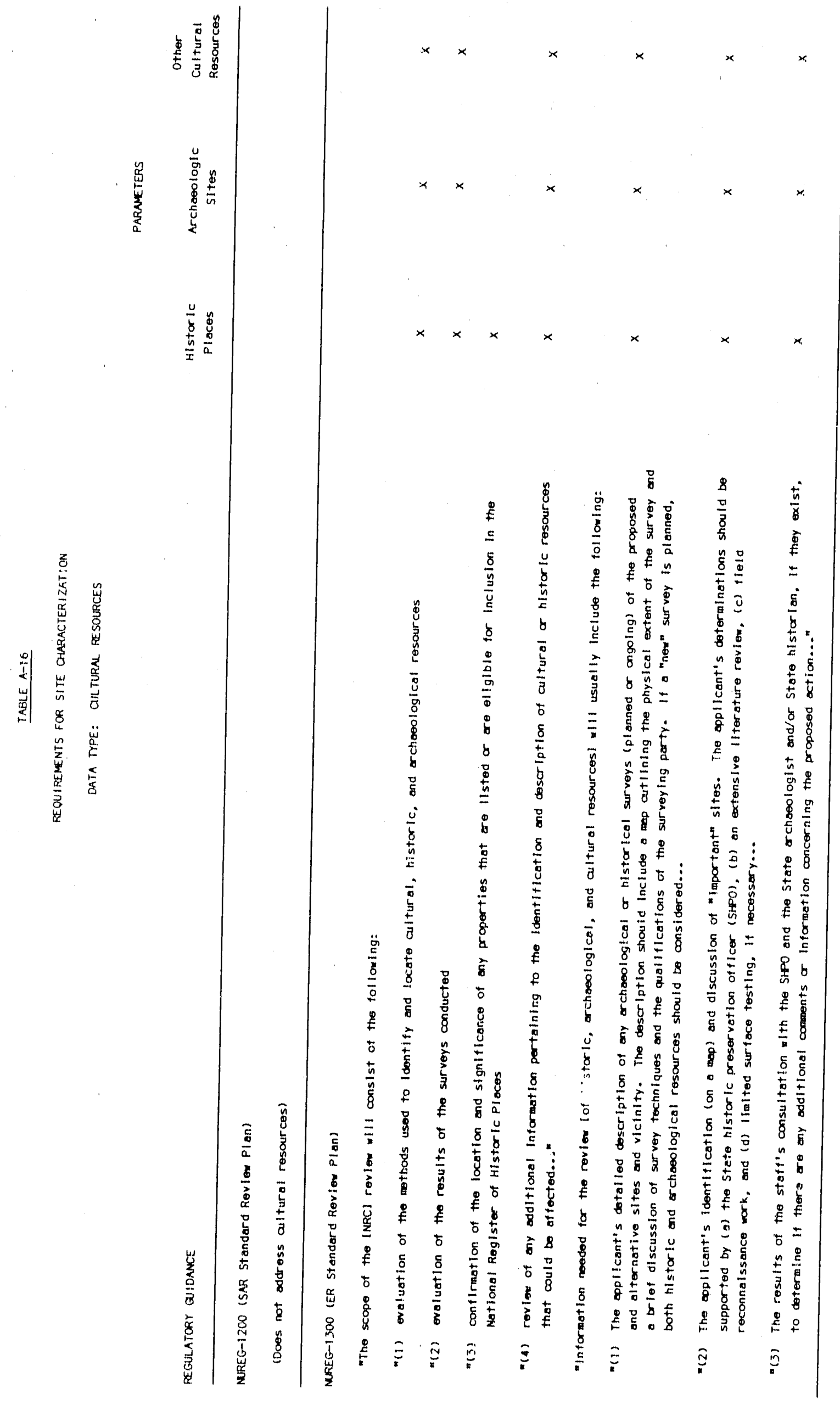


Historic Places: Districts, sites, bulldings, structures or objects of historical significance listed or eligible for inclusion in the National Register of Historic Places, or of State or local signtficance.

Archaeologic Sites: Sites containing artifacts of the 1ife and culture of ancient peoples.

Other Cultural Resources: Other sites, bulldings, structures, or objects of historical, archaeological, architectural, scentc, cultural or landmark significance, including traditional folklife remnants, Native American religious or sacred sites, and paleontological (i.e., fossil) resources. 


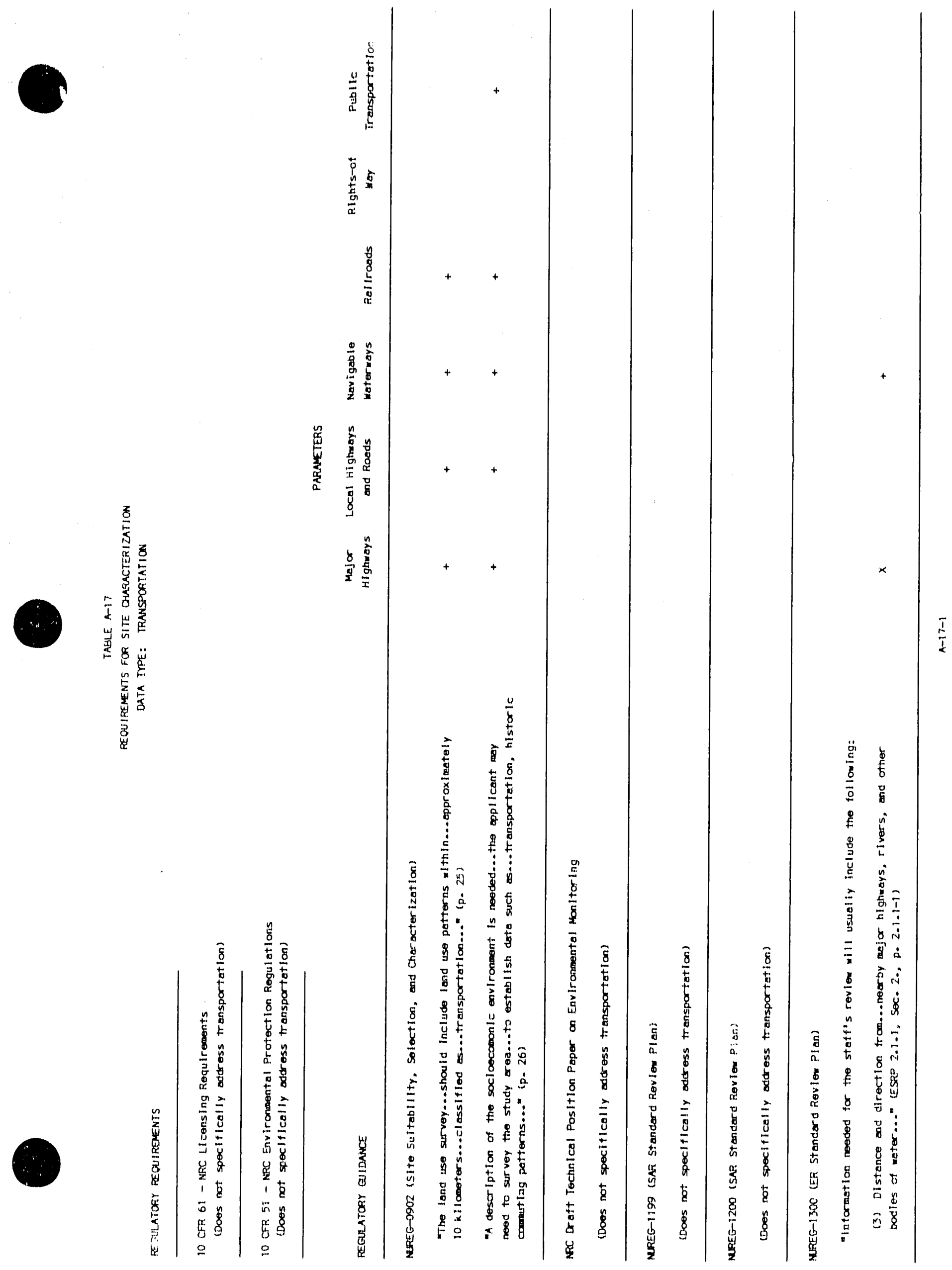



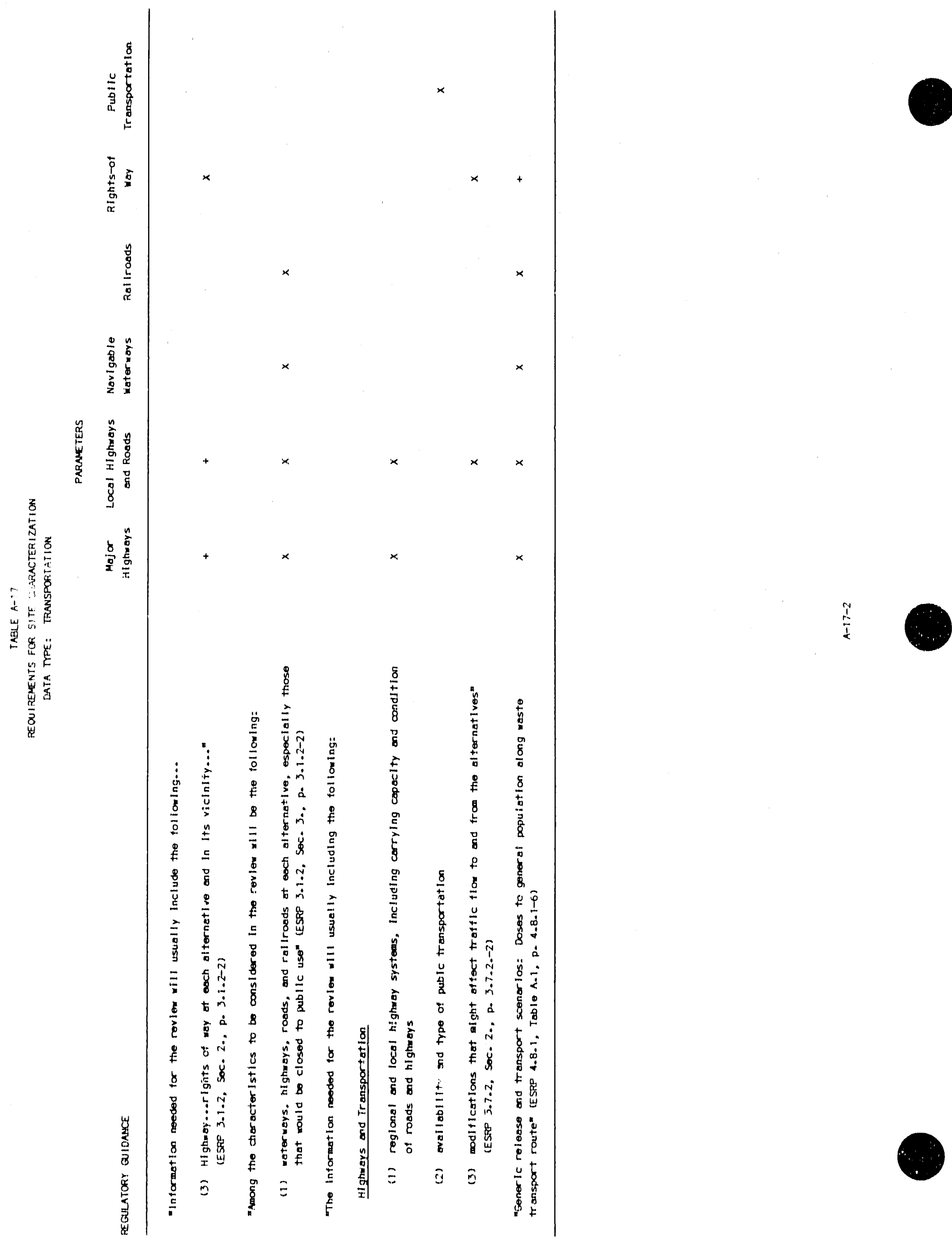
Major Highways: Major interstate, U.S, and State highways enroute to the site from centers of waste generation, statewide and/or reglonwide, and in the vicinity of the site.

Local Hiahways and Roads: County and local highways and roads in the vicinity of the site, especially connectors to major highways.

Navigable Waterways: Rivers, canals, and other navigable waterways, statewide and/or regionwide, and in the vicinity of the site.

Railroads: Existing major and short line roads and classification yards enroute to the site from centers of waste generation, statewide and/or regionwide, and in the vicinity of the site.

Rights-of-way: Rights-of-way needed to provided access to the site from iocal transportation routes.

Public Transportation: Existing modes of public transportation (buses, trains, atr service) providing access to the site. 


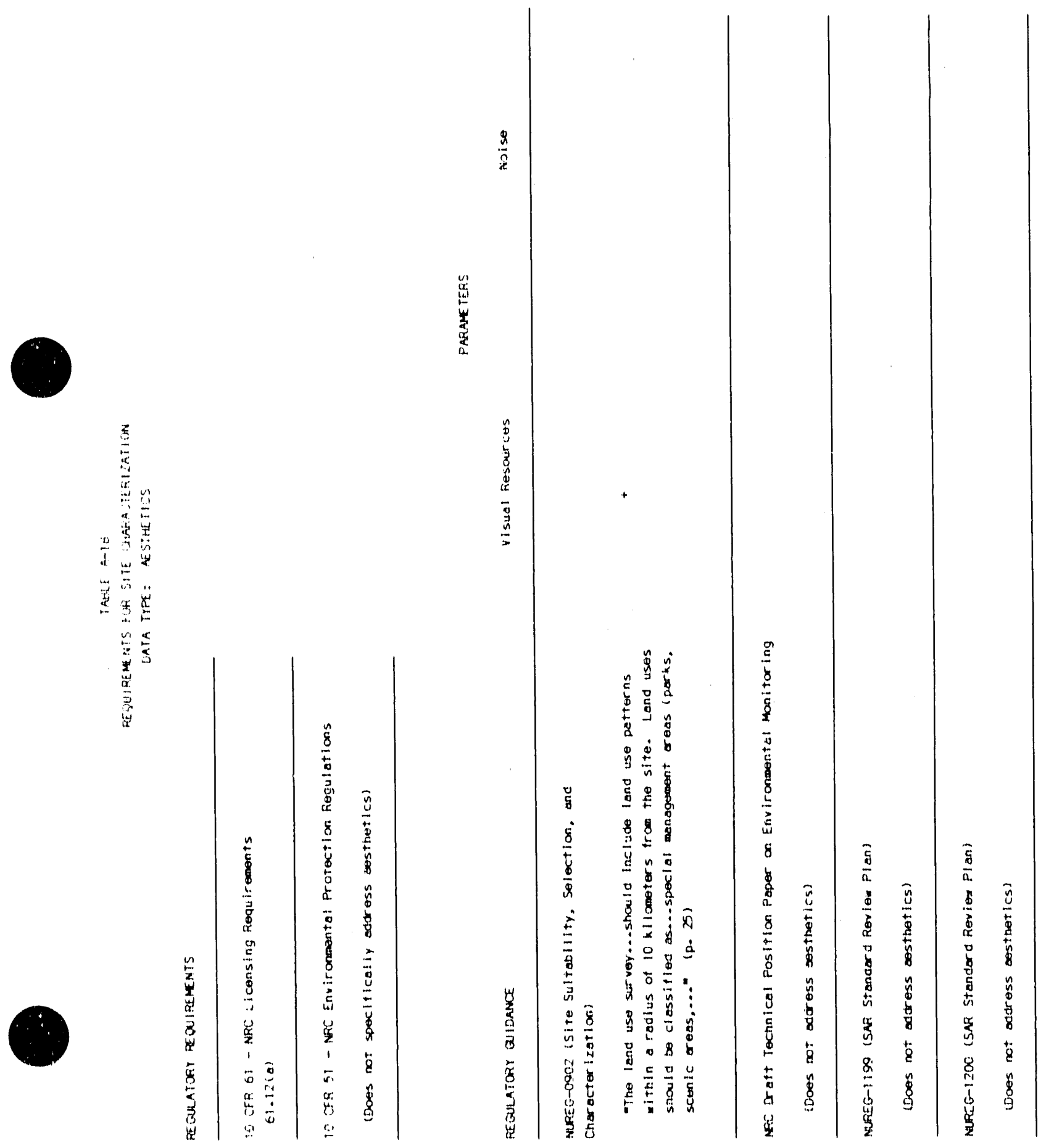




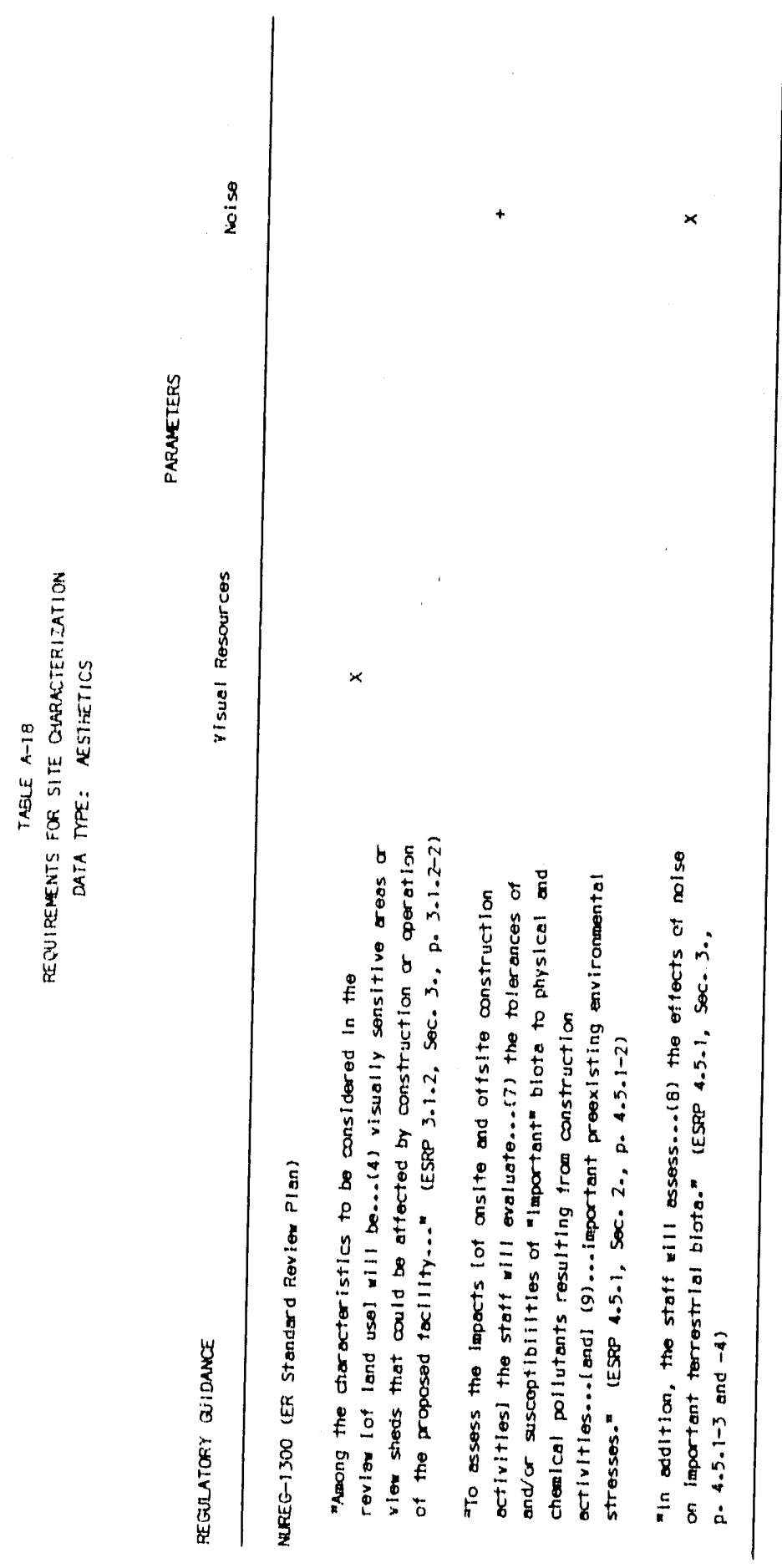


TABLE A-18

PARAMETER DESCRIPTIONS - AESTHETICS

Visual Resources: Assessment of visual quality for specific geographic areas, based on numbers and types of viewers, uniqueness of the landscape; determined through viewsheds (i.e., depiction of what is seen from selected offsite viewer locations) and resource classiffications (e.g., U.S. Forest Service Visual Resource Management System).

No1se: The measurement of background noise levels to support determinations of incremental noise impacts from factlity construction and operation; measured in dectbels. 
1. U.S. Nuclear Regulatory Commission, Licensing Requirements for Land Disposal of Radioactive Waste, Title 10 Code of Federal Regulations Part 61 (10 CFR 61), 1987.

2. U.S. Nuclear Regulatory Commission, Environmental Protection Regulations for Domestic Licensing and Related Regulatory Functions, Title 10 Code of Federal Regulations Part 51 (10 CFR 51), 1987.

3. D. Seifken et al., Site Suitability, Selection, and Characterization, NUREG-0902, U.S. Nuclear Regulatory Commission, Branch Technical Position - Low-Level Waste Licensing Branch, 1982.

4. U.S. Nuclear Regulatory Commission, Technical Position Paper, Environmental Monitoring of Low-Level Waste Disposal Facilities, Working Draft, Division of Waste Management, 1986.

5. U.S. Nuclear Regulatory Commission, Standard Format and Content of a License Application for a Low.Level Radioactive Waste Disposal Facility: Safety Analys is Report, NUREG-1199, Office of Nuclear Material Safety and Safeguards, 1987.

6. U.S. Nuclear Regulatory Commission, Review Plan for the Review of a License Application for a Low-Level Radioactive Waste Disposal Facility: Safety Analys is Report, NUREG-1200, Office of Nuclear Material Safety and Safeguards, 1987.

7. U.S. Nuclear Regulatory Commission, Environmental Standard Review Plan for the Review of a License Application for a Low-Level Radioactive Waste Disposal Facility: Environmental Report, NUREG-1300, Office of Nuclear Material Safety and Safeguards, 1987.

8. U.S. Nuclear Regulatory Commission, Standard Format arid Content of Environmental Reports for Near-Surface Disposal of Radioactive Waste, Regulatory Guide 4.18, Office of Nuclear Regulatory Research, 1983. 


\section{APPENDIX B}

TECHNICAL ACTIVITIES/

STUDY METHODS TABLES 


\section{INSTRUCTION ON THE USE OF THE SITE CHARACTERIZATION TECHNICAL GUIDANCE TABLES \\ IN APPENDIX B}

The tables in this appendix contain technical information to support the eighteen data types included in the Regulatory Requirements Matrices in Appendix $A$. The purpos: of these tables is to provide technical guidance on sources and methods of obtaining data specific to the 142 parameters identified in Appendix $A$. The tables are organized by data type as in Appendix A. References cited and parameter descriptions for each table follow the table.

The following information is provided for each parameter on the eighteen data type tables:

- Paramete' - The technical parameter identified in Appendix A. The parameter descriptions, which are the same as those in Appendix $A$, are included harein with each table to help the reader use the tables more efficientiy.

- Technical Activities/Study Methods - The technical activities and study methods that can be used to obtain and analyze the site characterization data specific to the technical parameter. Where possible, the activities are listed in a logical sequence of performance, beginning with the compilation of existing data and proceeding to original data collection activities on-site. It should be noted that the sequence of techniques described for each data parameter si not necessarily additive. For example, the compilation of existing data may preclude the need to conduct a field program. Conversely, existing data may be very sparse or nonexistent, requiring extensive field activities to confirm suite suitability. In addition, the tables describe standard activities and recognized state-of-theart study methods that are applicable to sites with widely varying geological, hydrogeological, and environmental characteristics, and are not intended to be prescriptive. The specific activities and methods selected for use at any region or site will depend on its particular physical, natural, and social environment.

- Data Formats - The formats in which data may be obtained and/or displayed, as appropriate.

- Data Sources The commonly utilized sources of existirig data and newly collect d data during site characterization for the specific technical parameter.

- References - Selected representative references that contain additional information on data collection and analysis techniques and methods. The references listed were selected because they provide useful background information; they do not comprise a comprehensive bibliography of available reference materials. 
These tables summarize the technical activities for collection and analysis of the data defined in the NRC regulatory guidance documents listed in Appendix $A$ as being necessary for site characterization. It is recommended that project staff involved in site characterization consult the NRC documents in their entirety, particularly the requirements for the 12 -month monitoring studies, for technical guidance on data collection acituities and data analysis.

It is important to note that some of the parameters and activities 1isted on the tables will only be evaluated if site characterization studies reveal conditions that require further analysis. For instance, the resource value parameter will be evaluated only if potential resources are identified. These tables can be used, therefore, as guidance in planning a site characterization program, but they should not be interpreted to be a prescriptive 1 ist of all the technical activities and parameters that will be necessary to characterize every site. It should also be noted that planning for a data collection program for many of the data types should involve one or more appropriate land management or regulatory agencies. These agencies can ensure that the techniques selected, the planned sampling intensity, and other technical factors are considered as suitable technical practice for the region and site(s) involved, and that the data abtained will be consistent in format with data bases maintained by the reviewing agencies.

Finally, it should be noted that the inherent differences in technical approach and complexity among the 18 data types are reflected in the varying levels of information presented in the tables. For this reason, some parameters are quite straightforward, and therefore relatively brief, whereas other paramoters exhibit much more complexity and require lengthier explanation. 
TABLE B-1

PARAMETER DESCRIPTIONS - GEOLOGY

Geamorphology: The characteristics, origin, and development of the regional and site landforms, their relationships to underlving structures, and the history of geologic changes as recorded by these surface features. Topography, slopes, drainage basis, stream channels, mass wasting, weathering, and erosion, and the rate, frequencies, and controlling mecianisms of these processes are included in this parameter.

Stratigraphy: The classification, correlation, and interpretation of surficial and Quaternary deposits and underlying rocks. Stratigraphy is concerned with accepted unit names, genetic relationships, depositional environment, areal extent, unit depth, thickness, geometry, vertical and lateral extent arid variations, heterogeneity, paleontology, age (geochronology), and the geologic history of the site area.

Lithology: The description of surficial and Quaternary deposits and underlying rocks based on visual and laboratory characteristics. Information such as the gross lithology, lithologic trends, color, mineralogy, grain-size distribution, texture/fabric, primary and sedimentary structures, facies changes and relationships, lithologic contacts, cementation, alteration, metamorphic grade, weathering, type of clay, inclusions, degree of devitrification of volcanic rocks, organic content, carbonate content, and natural radioactivity is part of a complete lithologic description.

Structure: The characteristics, origin, and development of the faults, folds, joints, solution cavities or crevices, and other discontinuities or zones of weakness within the region and site. This includes their location, orientation, relative position, length, spacing/density, relative age, aperture or infilling, roughness, mineralization history, type of structure, displacement history or deformation rate, potential recurrence intervals, relationship of structures to present-day local stress field, and capability or activity.

Iectonics: The large-scale structure of the Earth's crust and the nature and rates of the processes responsible for these structures. This parameter includes the tectonic provinces within 200 miles of the site and their history, uplift, subsidence, tilting, folding, faulting, nature of volcanism and volcanic history, the regional and local stress regime, and the potential for unrelieved stresses to produce creep and rebound within the tine frame of interest ( 500 years).

Sefsmology: The study of earthquakes and their relationship to the tectonics and structure of an area by both natural and artificially generated seismic waves. This includes determining, within a 200 -mile radius of site: the historical seismicity of magnitude 3 or greater, or of modified Mercalli intensity Iy or greater, with all avallable details; the earthquake recurrence intervals; the correlation of earthquakes with structures or tectonic provinces and rationale; the maximum earthquake potential of each geologic structure or tectonic province, its frequency content, and the resulting 
ground motion at the site; and the design earthquake and accelerations at the site developed, if possible, from probabilistic seismic hazard estimates. The seismic wave transmission characteristics of the site, including velocities, bulk densities, and the shear and elastic modulf, and historical and potential fault rupture, selsmically-induced hillislope fallure, and liquefaction or settlement are also included in this parameter.

Geologic Hazards: The potential natural or man-induced hazards that could present a risk or potential danger to the site or to life. Evaluation of fault displacement, seismicity, slope failures, landslides, renewed volcanism, subsidence, collapse, 1 lquefaction, karst terrain, flooding, expanding clays and other unstable elements in near-surface stratigraphic units and solls, and corrosivity of solls should be part of the site geologic hazards assessment. 


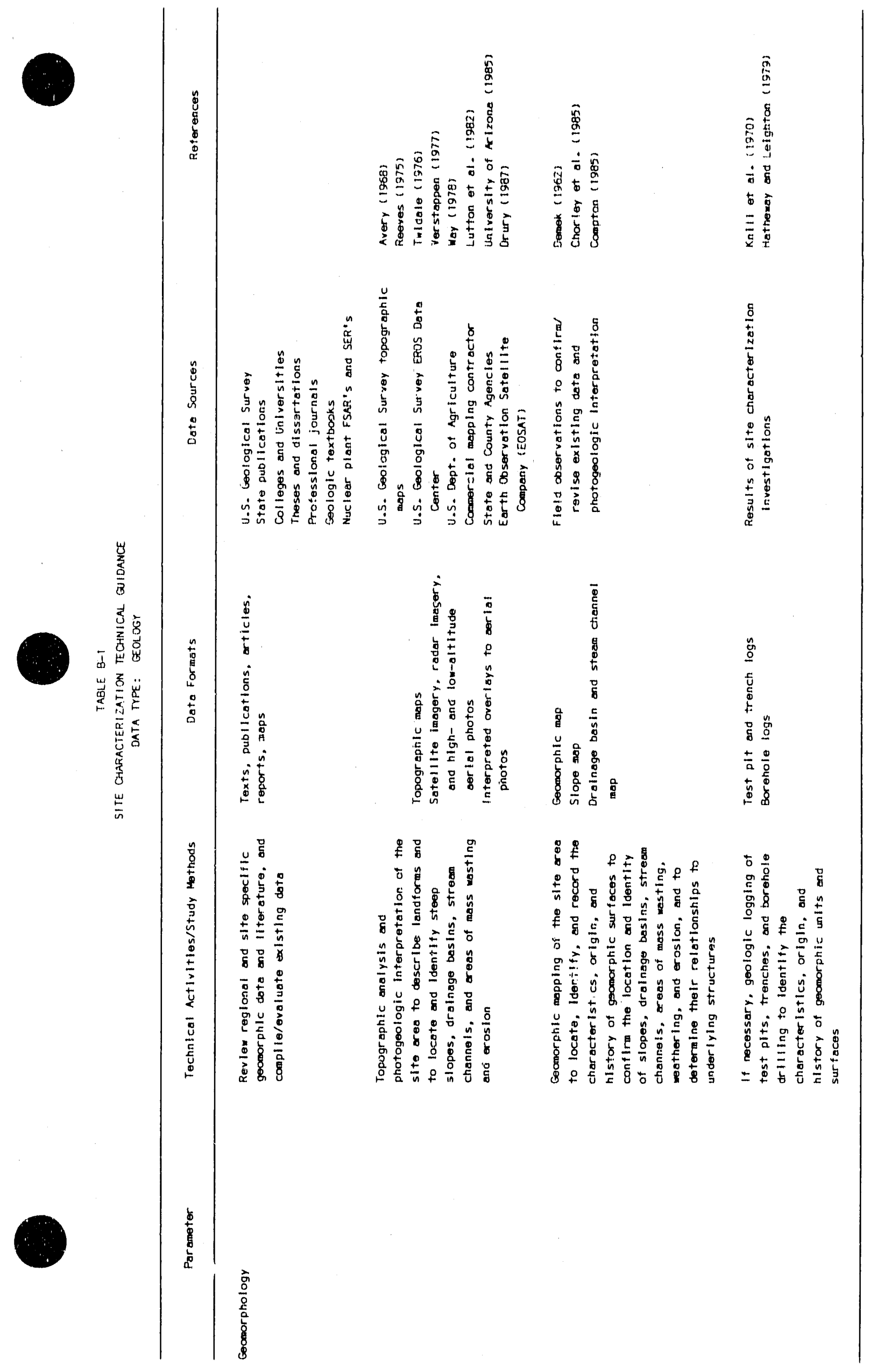




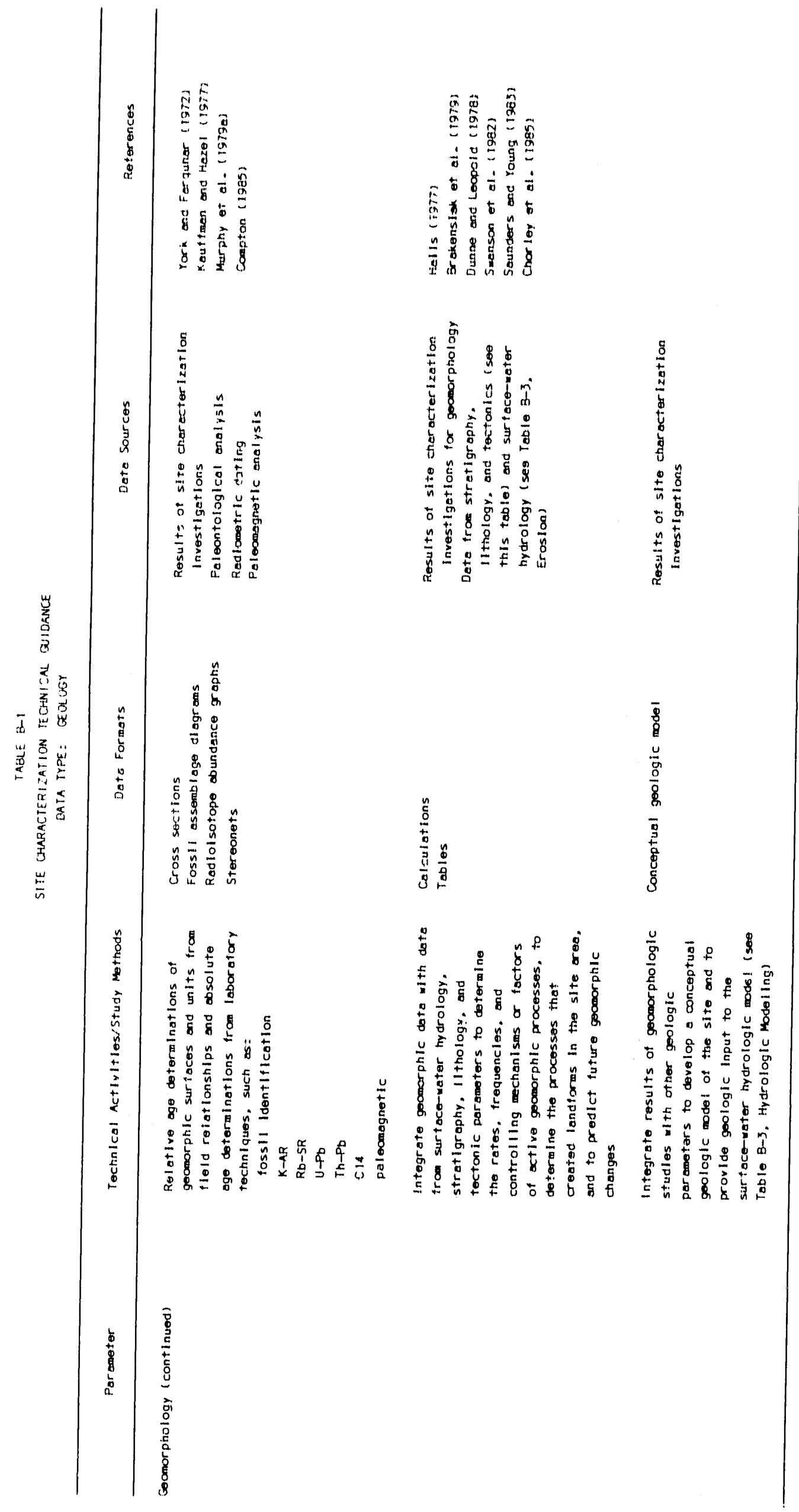




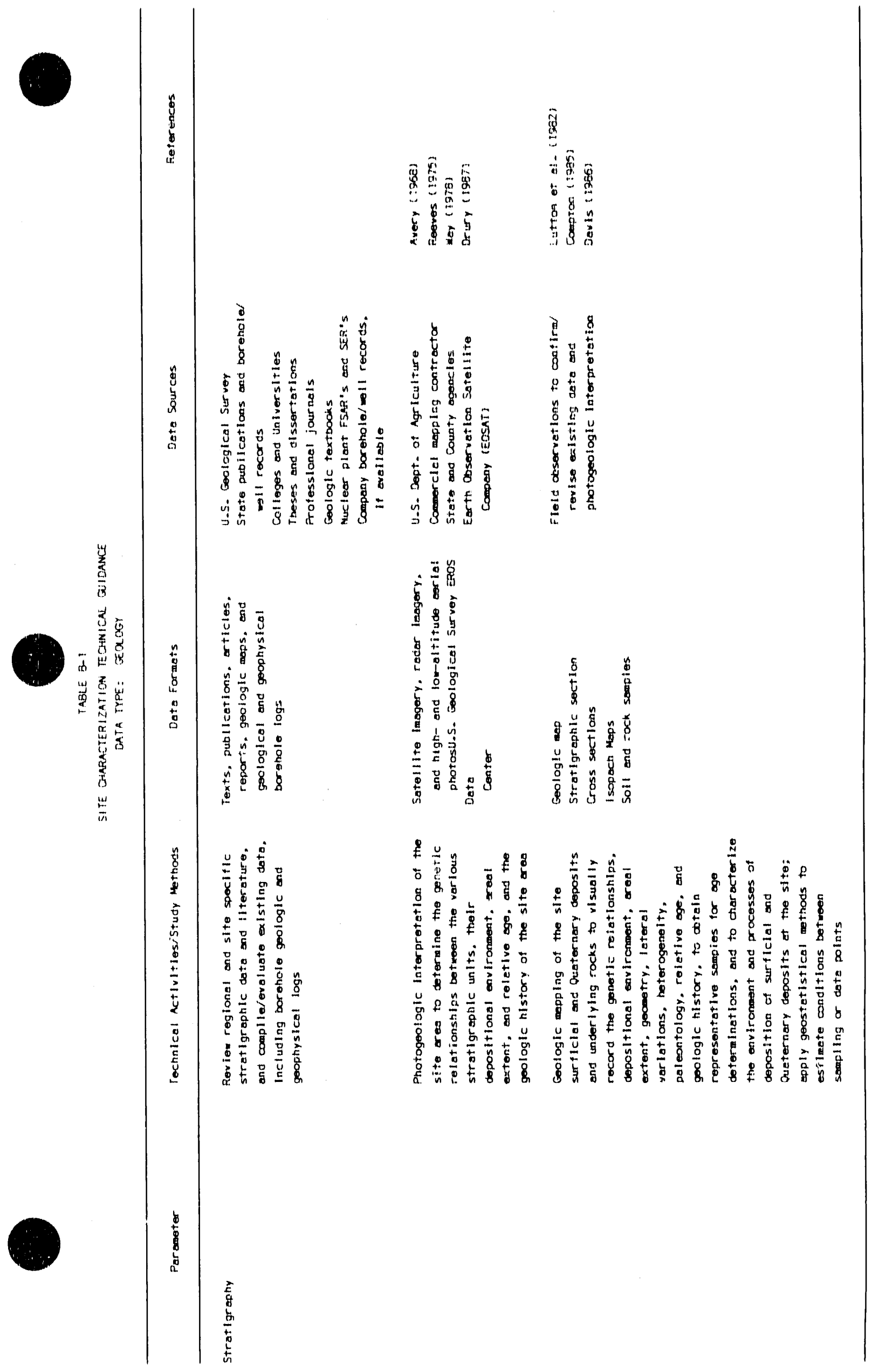

$\frac{1}{i}$ 


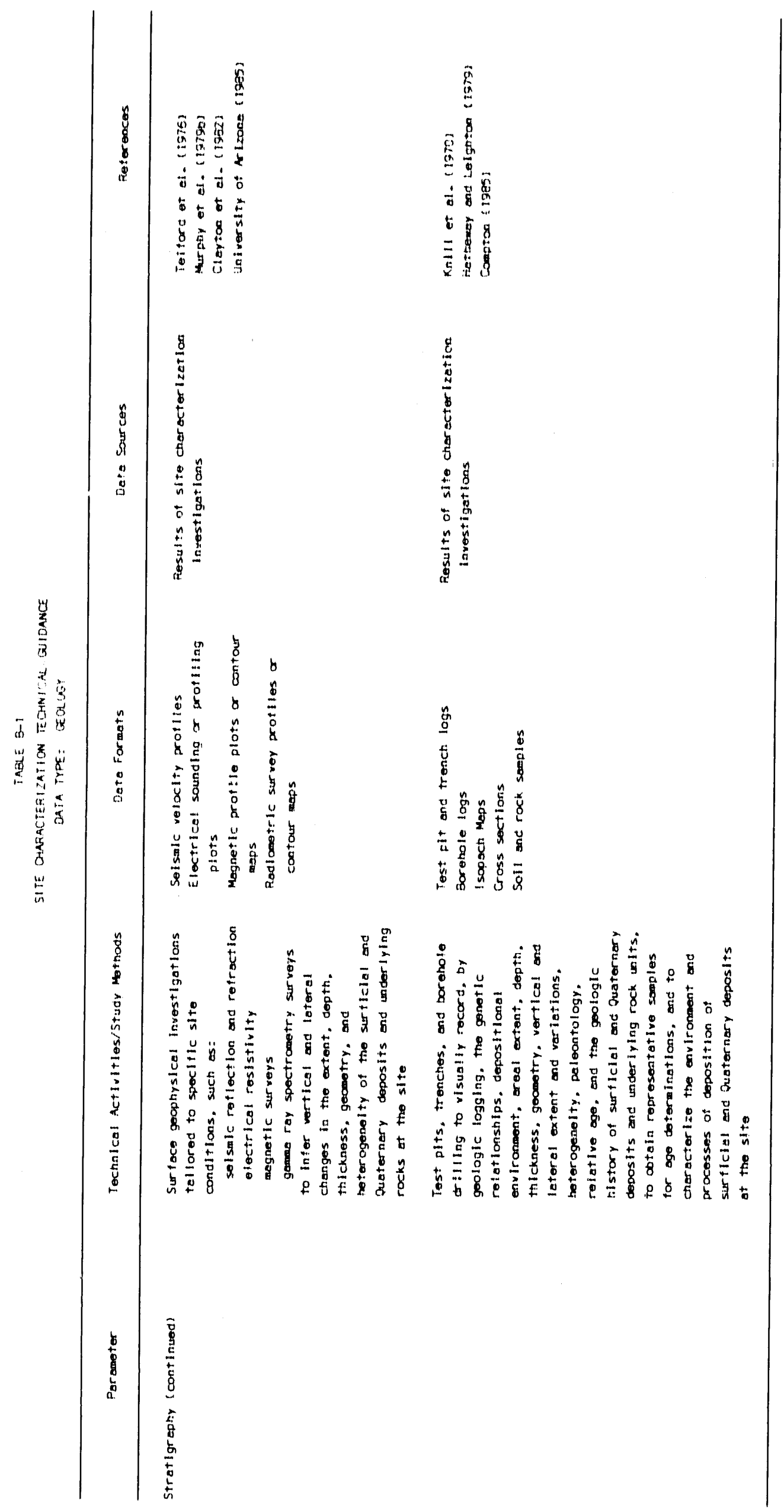




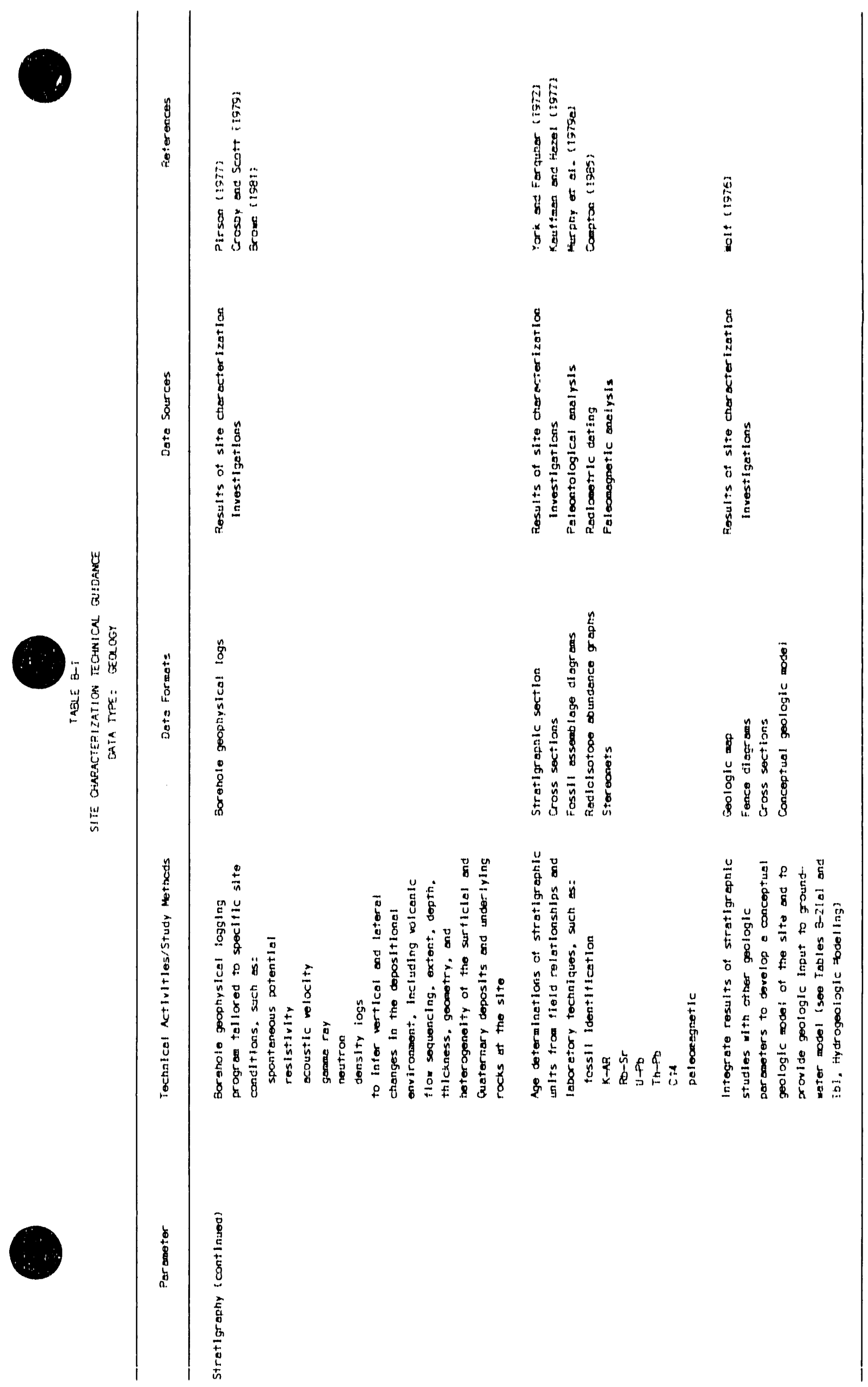




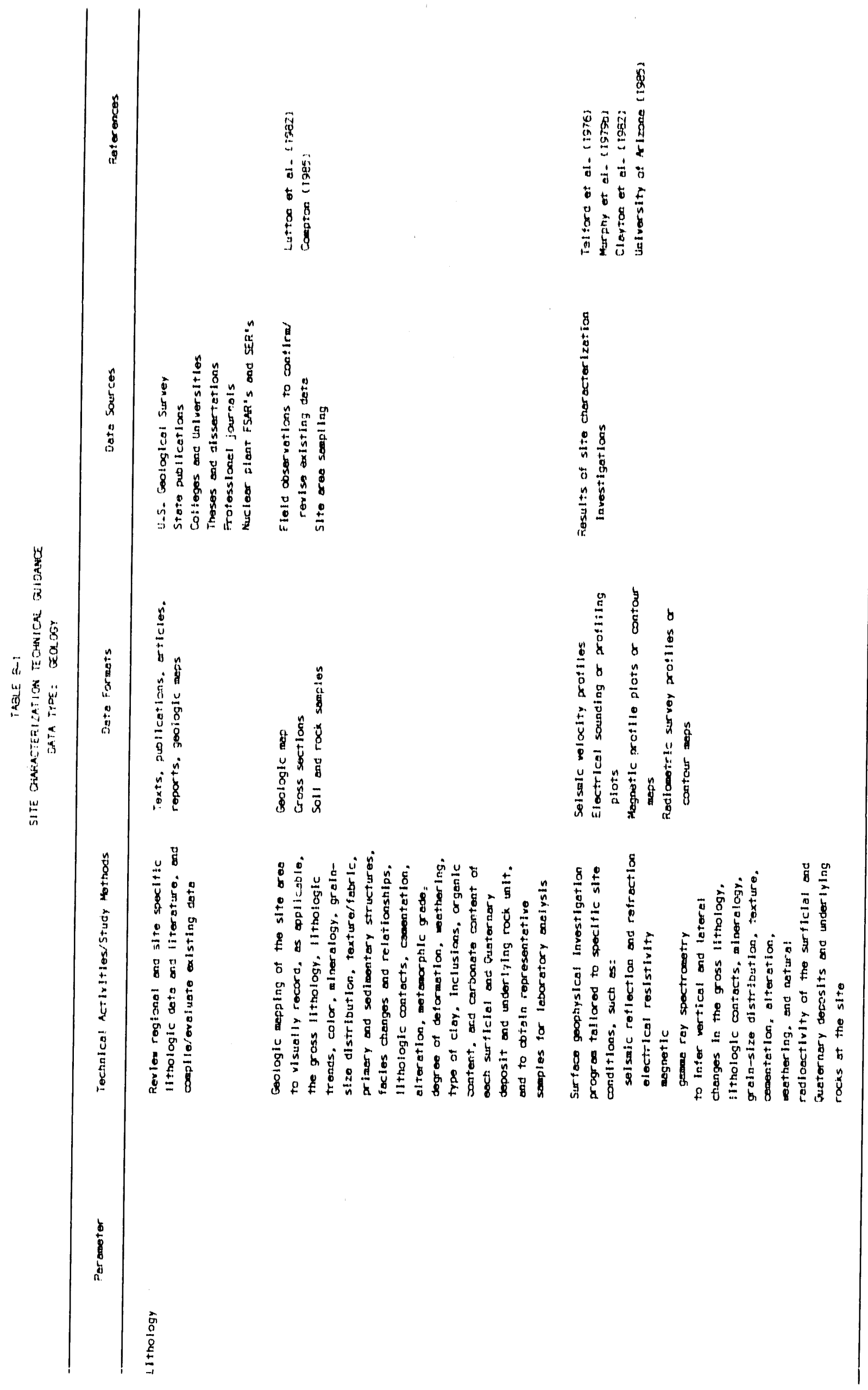




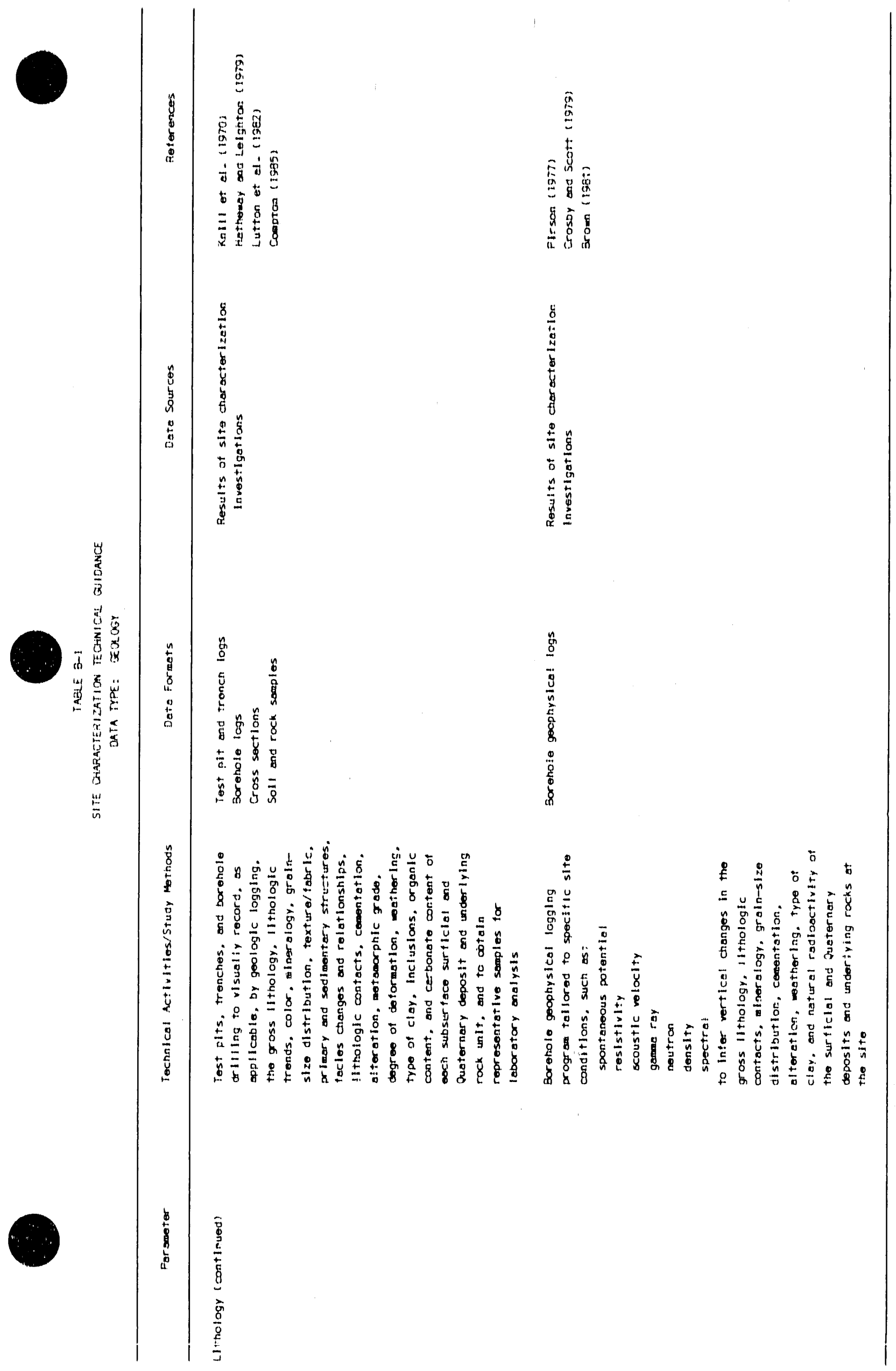




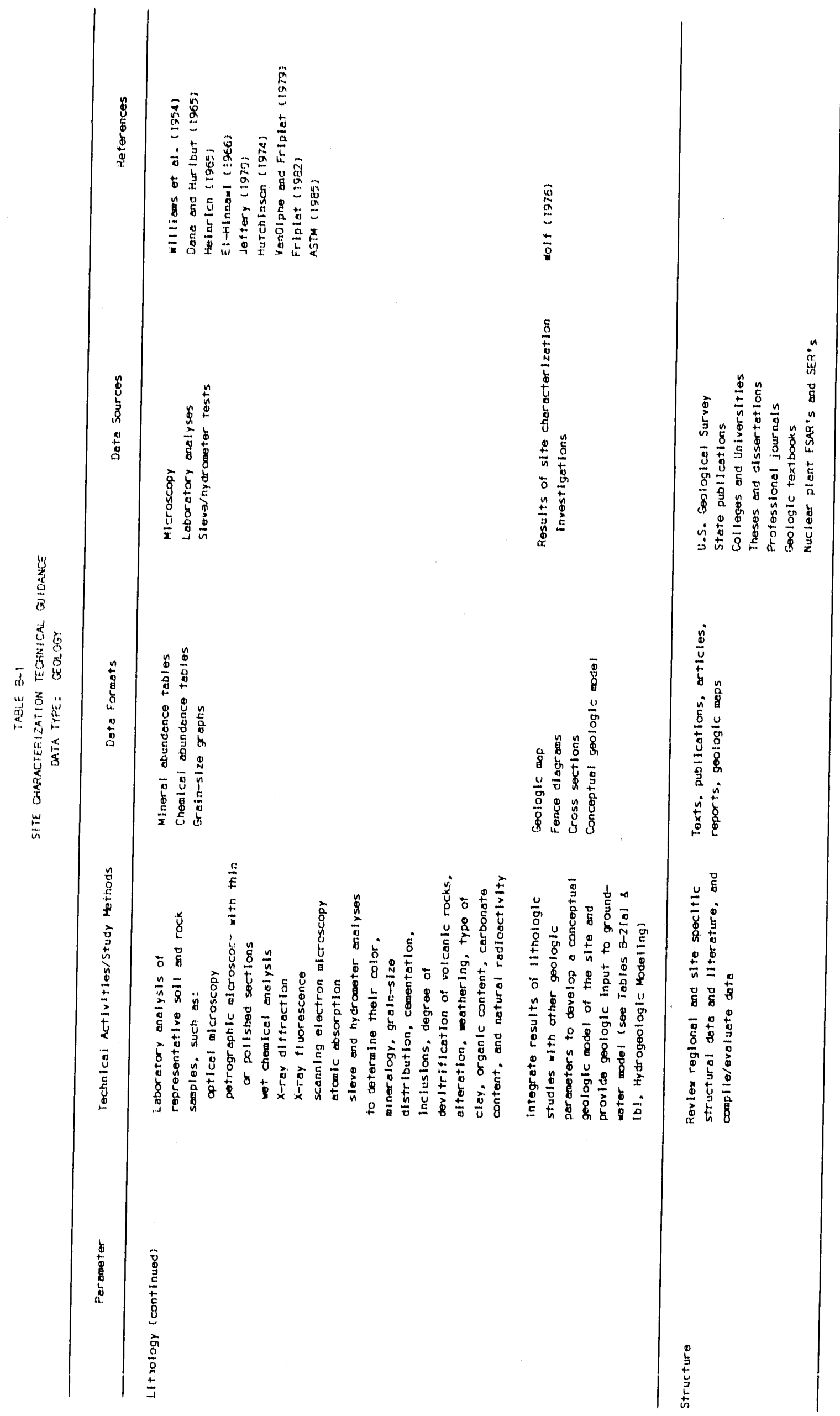

$\frac{a 1}{1}$ 


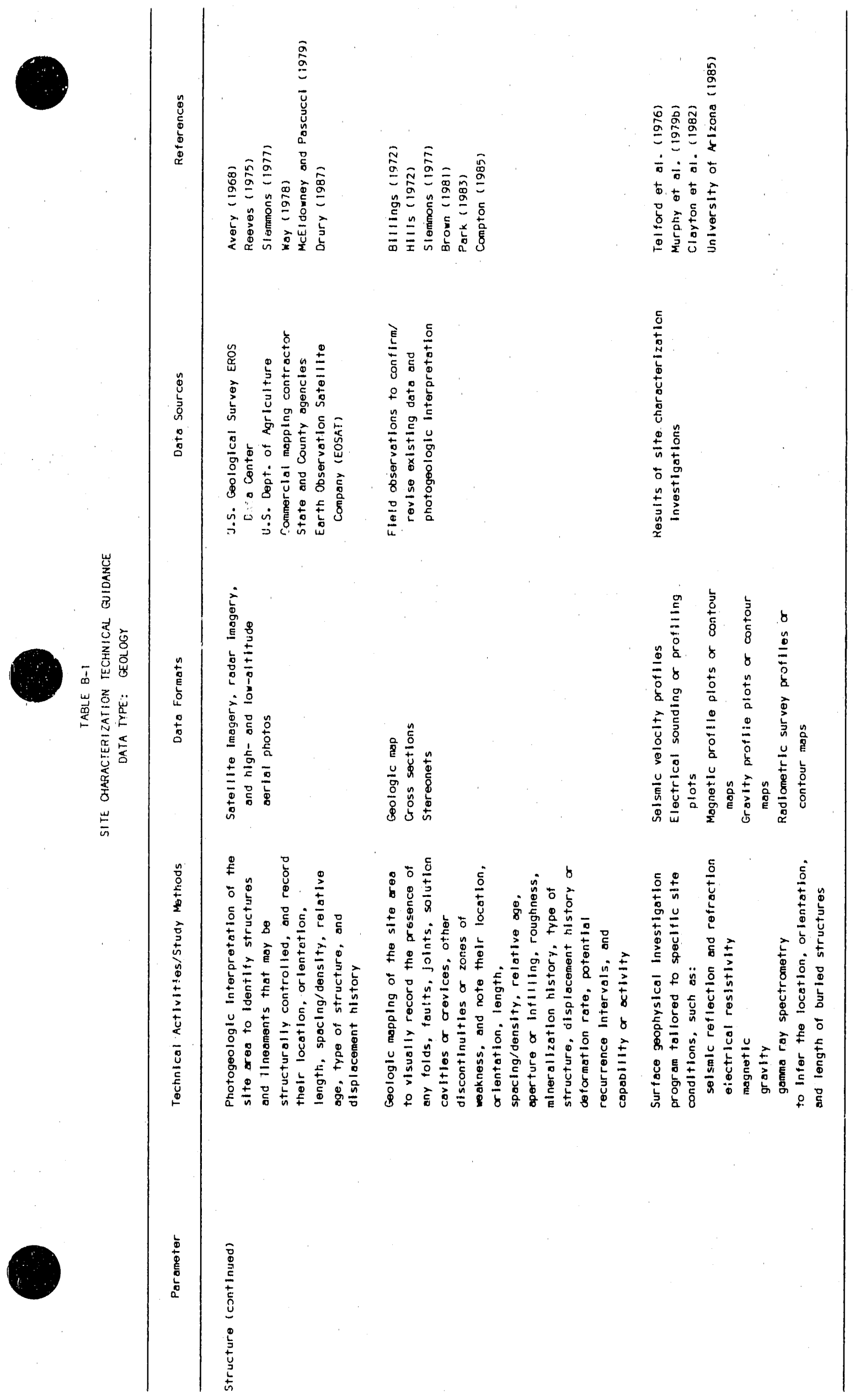




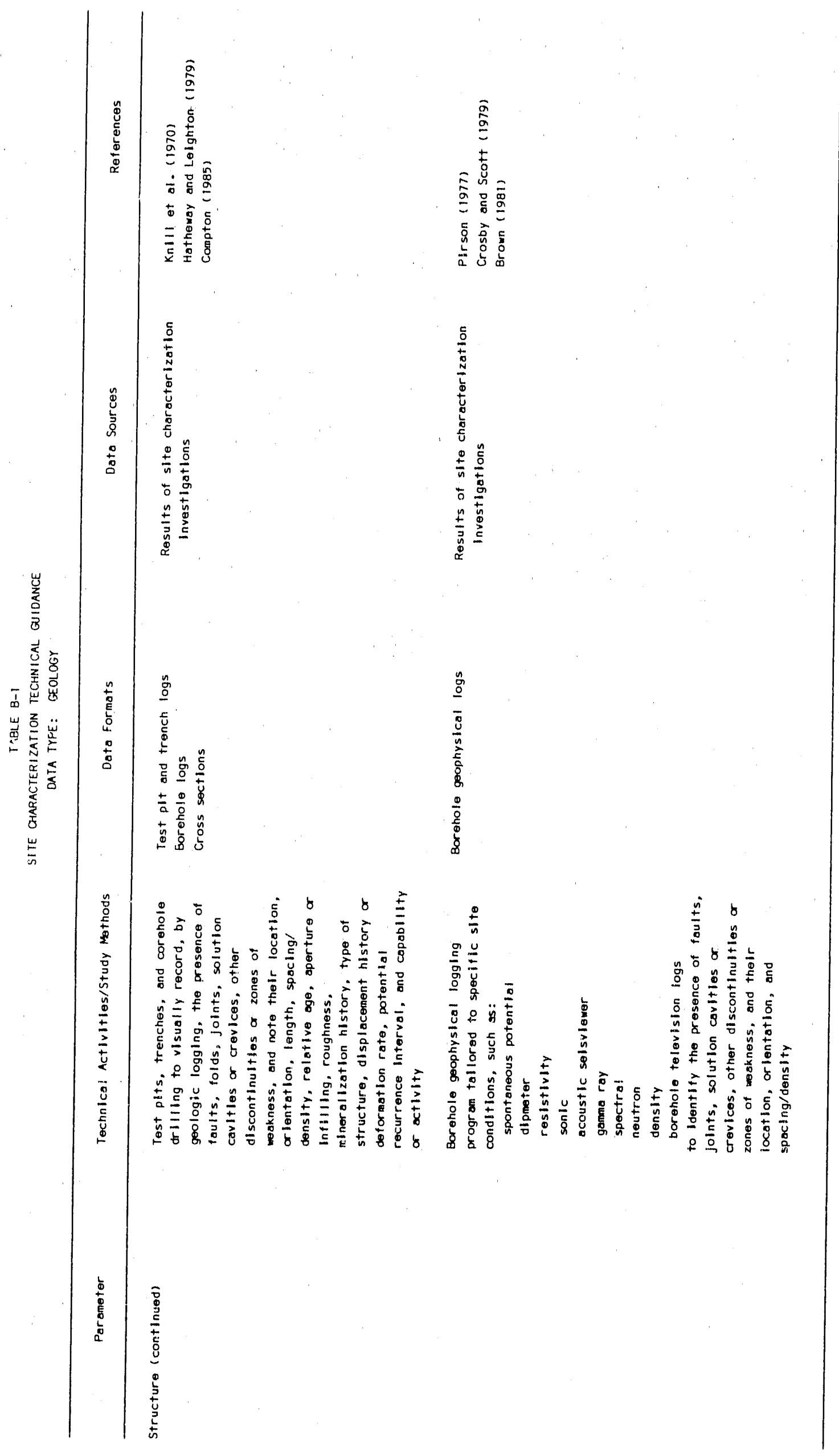

$\frac{7}{1}$ 


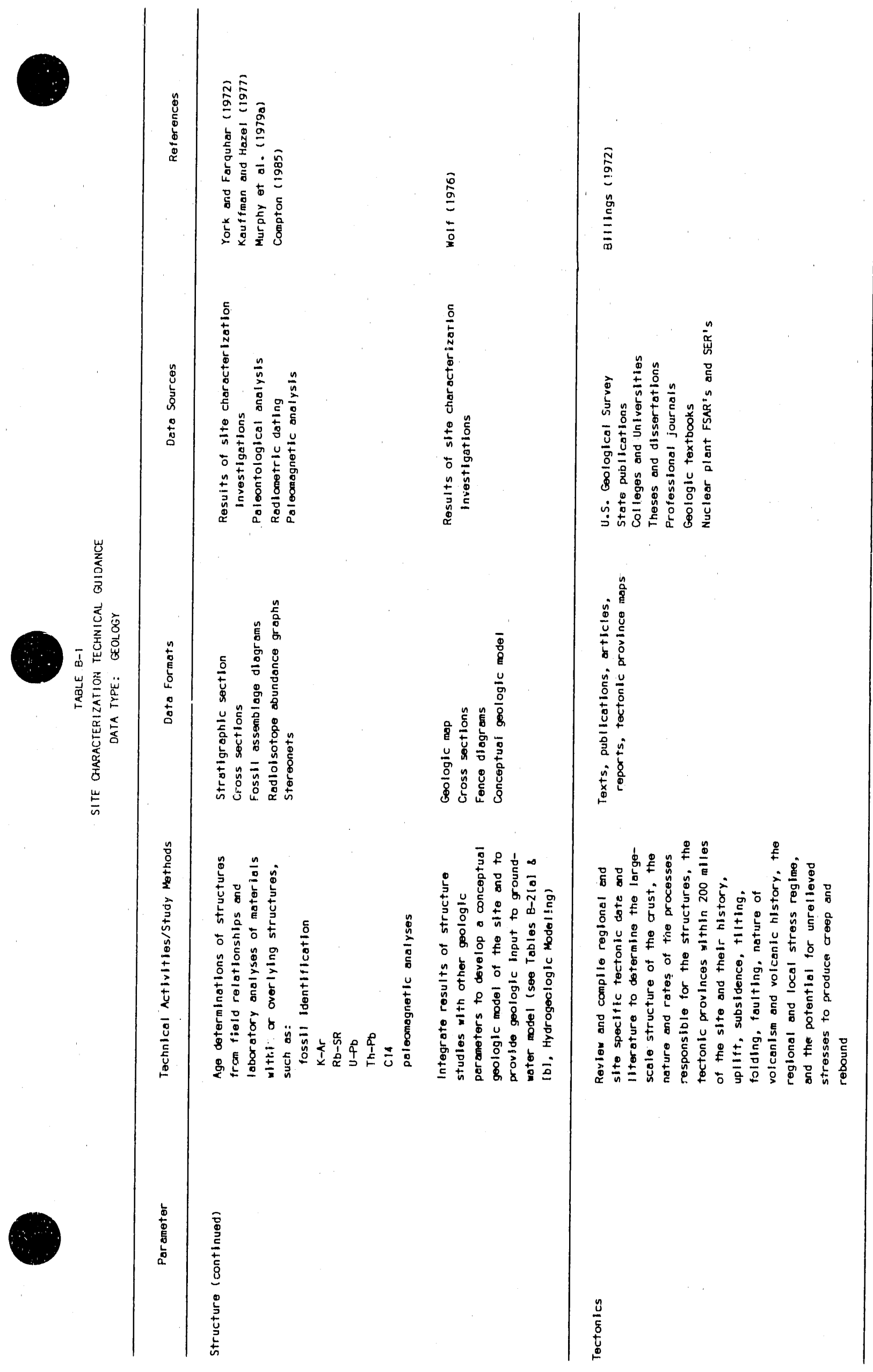




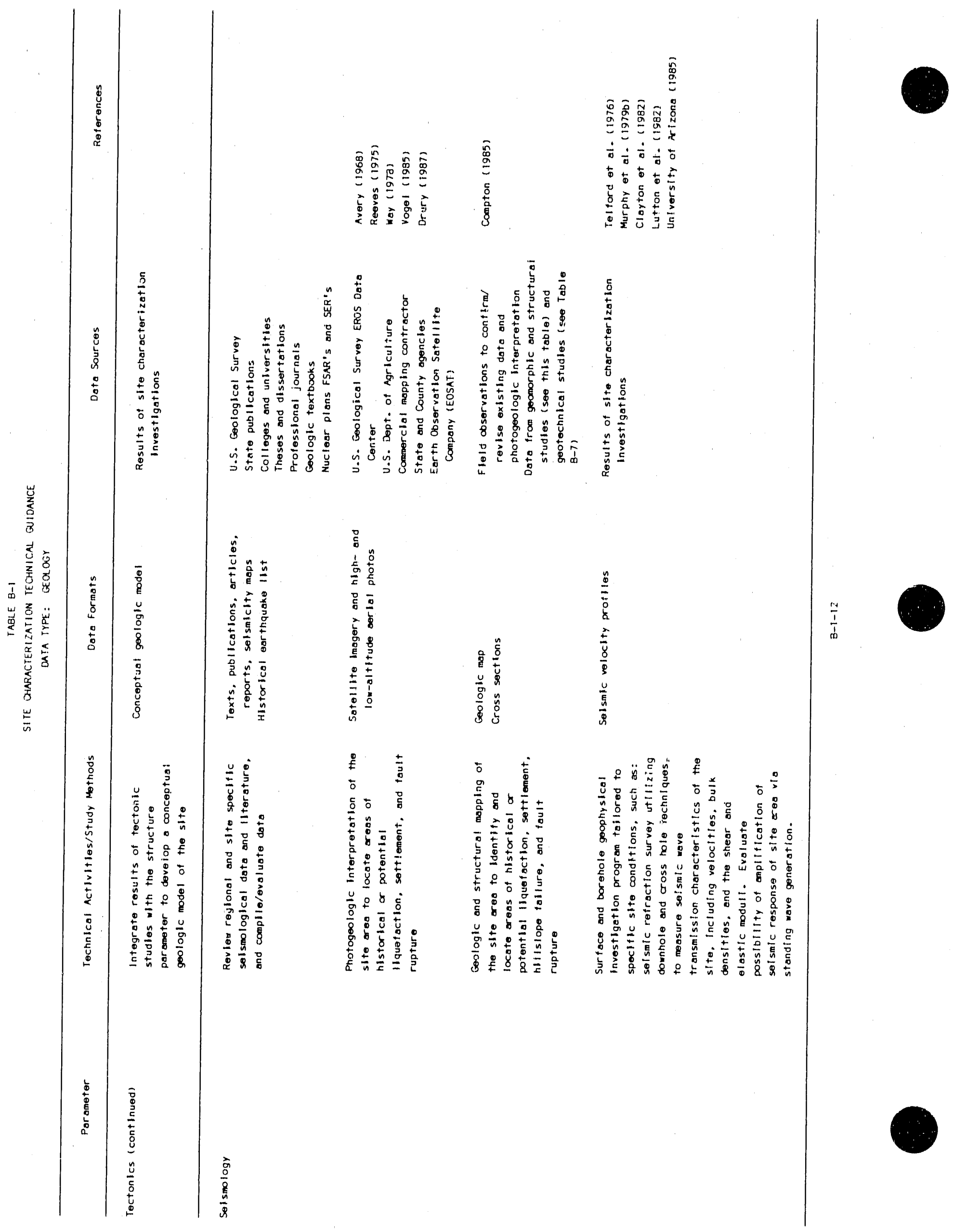




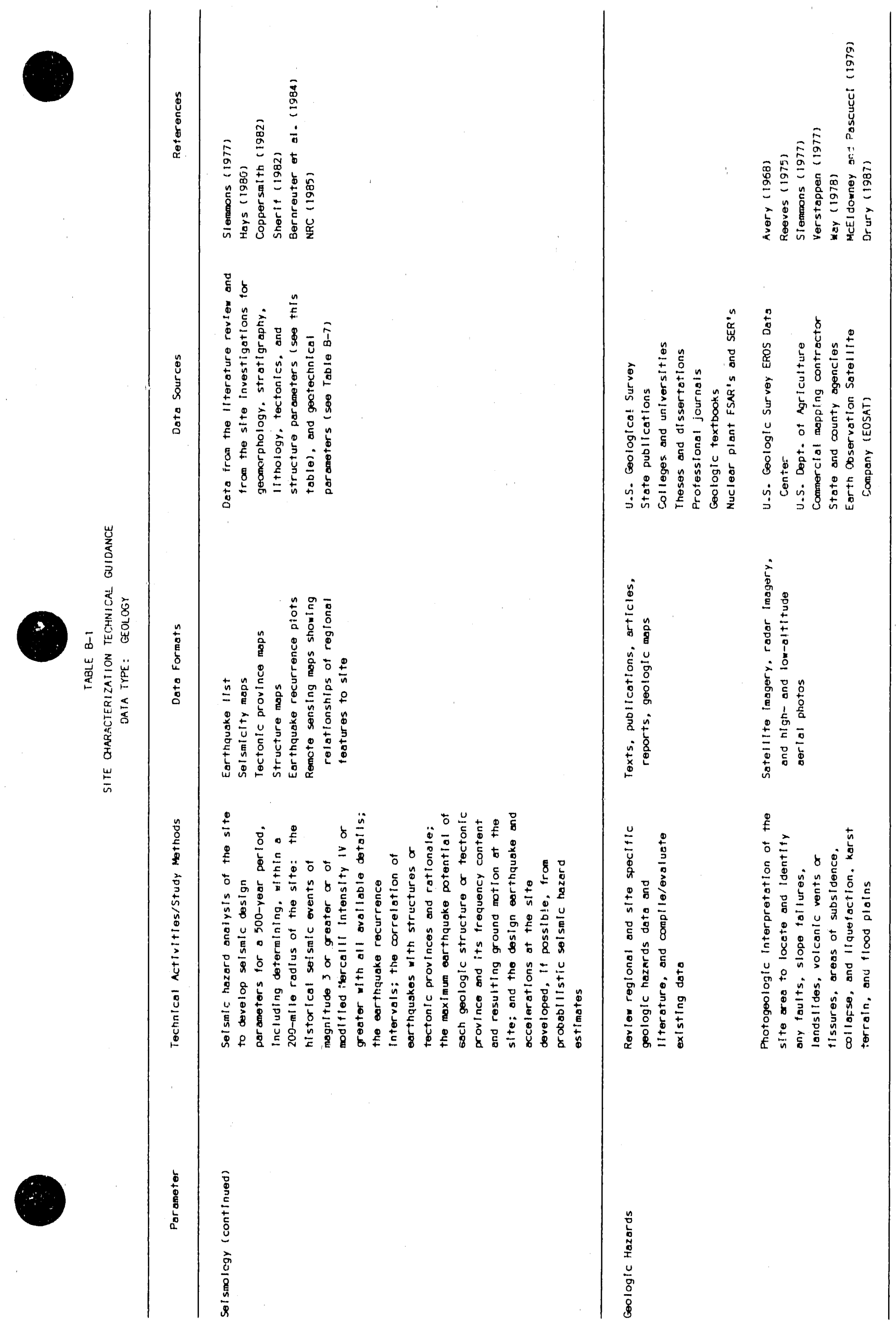

$\frac{m}{1}$ 


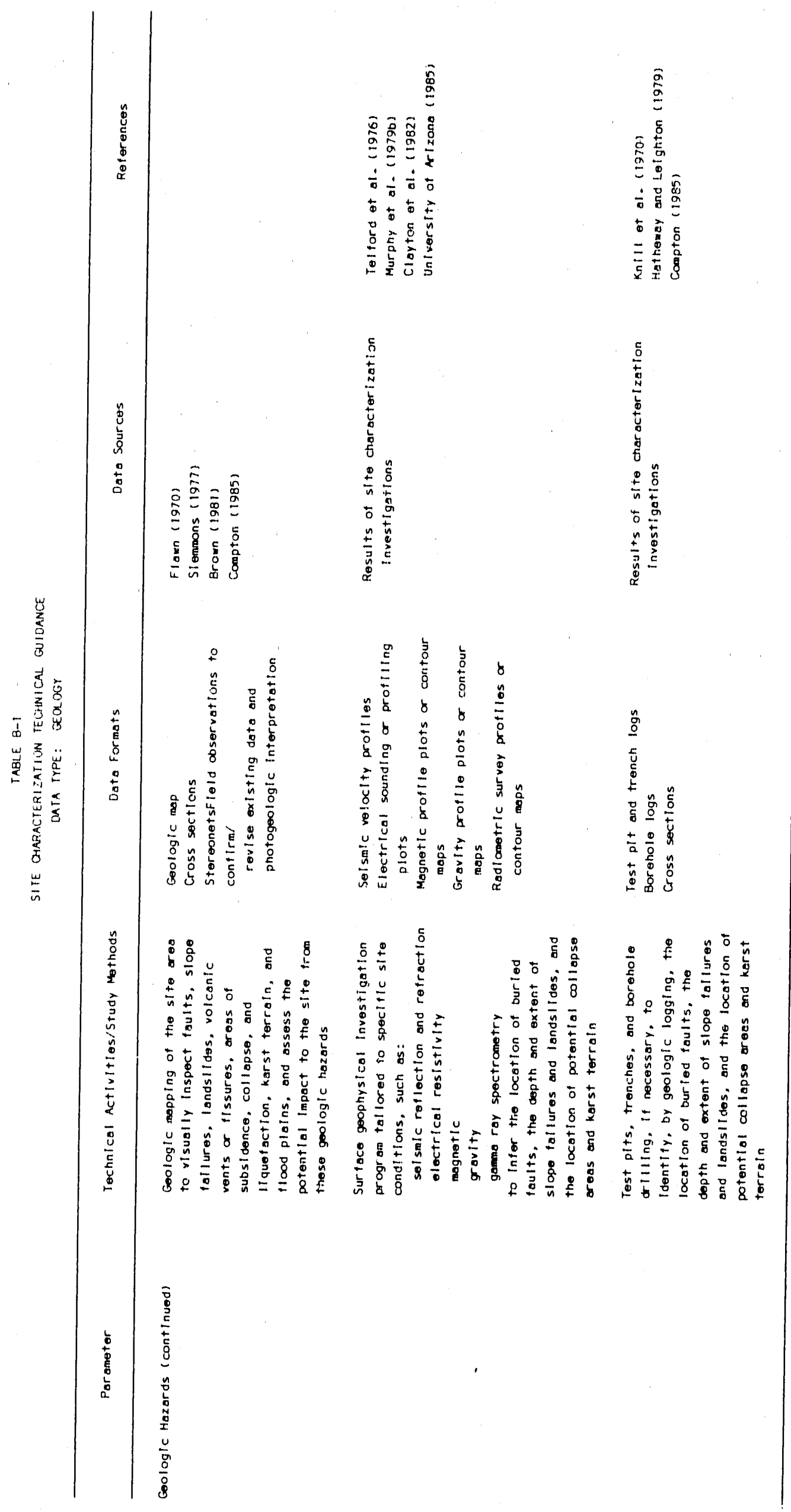




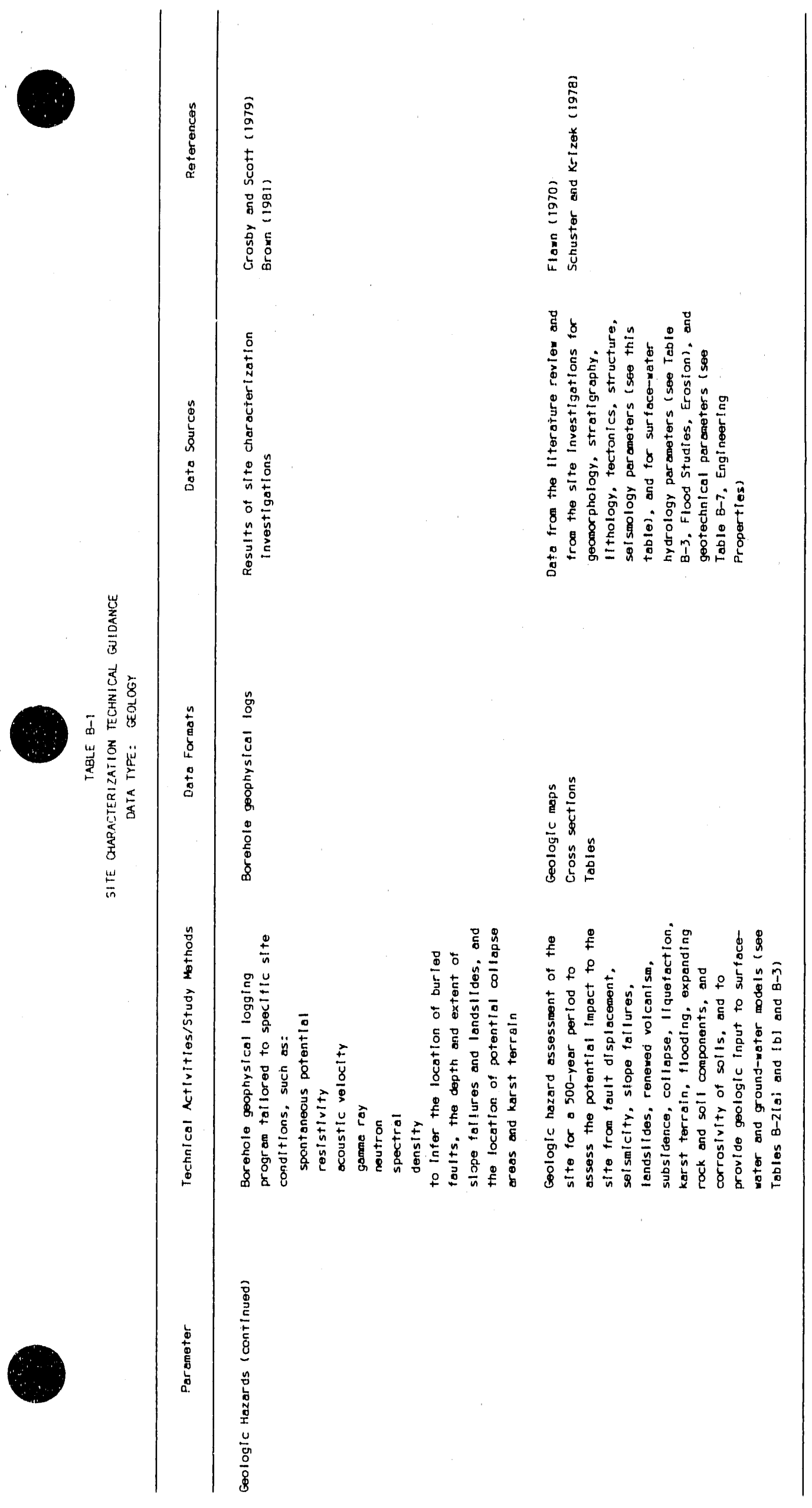

$\frac{n}{\frac{1}{1}}$ 
TABLE B-1

REFERENCES - GEOLOGY

American Soclety for Testing and Materlals, "Standard Method for Particle-Size Analysts of Solls, Designation D422-63, "Annual Book of American Soctety for Iesting and Materials Standards, Vol, 04.08, 1985, pp. 117-127.

ASTM; see American Soctety for Testing and Materials.

T. E. Avery, Interpretation of Aertal Photographs, Minneapolis: Burgess Publishing Co., 1968.

M. P. B 111 ings, Structural Geology, New York: Prenttce-Ha11, Inc., 1972.

D. L. Bernreuter et a1., Selsmic Hazard Characterization of the Eastern Untted States: Methodo]ogy and Interim Results for Ten Sites, NUREG/CR-3756, 1984.

D. L. Brakensiek, H. B. Osborn, W. J. Raw1s, Eleld Manual for Research in Agricultural Hydrology, U.S. Department of Agriculture Agricultural Handbook No. 224, 1979.

E. T. Brown (ed.), Rock Characterization Testing and Monitoring, ISRM Suggested Methods, Oxford: Pergamon Press, 1981.

R. J. Chorley, S. A. Schumm, D. E. Sugden, Geamorphology, New York: Methuen \& Co., 1985.

C. R. I. Clayton, N. E. Simmons, M. C. Matthews, Site Investigation - A Handbook for Engineers, New York: Halsted Press, 1982.

R. R. Compton, Geology in the Fleld, Somerset: John Wiley and Sons, Inc., 1985.

K. J. Coppersmith, "Probabilistic Evaluations of Earthquake Hazards, " in E. W. Hart, S. E. Hirschfeld, S. S. Schulz (eds.), Proceedings Conference on Earthquake Hazards in the Eastern San Franctsco Bay Area, Californta Divtsion of Mines and Geology Special Publication 62, 1982, pp. 125-134.

J. W. Crosby, III and J. D. Scott, "Borehole Geophysics in Nuclear Power Plant Siting," in A. W. Hatheway and C. R. McClure, Jr. (eds.), Geology in the Siting of Nuclear Power Plants, The Geological Soctety of America Reviews in Engineering Geology, Vo1. 4, 1979, pp. 215-225.

E. S. Dana and C. S. Hurlbut, Mineralogy, New York: John Wiley \& Sons, Inc., 1965.

J. C. Davis, Statistics and Data Analys is in Geology, Second Edition, New York: John Wiley \& Sons., Inc., 1986.

J. Demek (ed.), Manual of Detailed Geomorphological Mapping, Prague: Academia, 1962. 
S. A. Drury, Image Interpretation in Geology, London: A1len \& Unwin (Publishers) Lt.d., 1987.

T. Dunne and L. B. Leopold, Water in Envtronmental Planning, San Franctsco:

W.H. Freeman and Co., 1978.

E. E. E1-Hinnawt, Methods in Chemical and Mineral Microscopy. Amsterdam:

Elsevter Publishing Company, 1966.

P. T. Flawn, Envtronmental Geology, Conservation, Land-Use Planning, and Resource Management, New York: Harper and Row Publishers, 1970.

J. J. Friplat (ed.), Advanced Techniques for Clay Mineral Analysis, Amsterdam: Elsevier Sctentific Pubitshing Co., 1982.

J. R. Hatls (ed.), Applled Geomorphology, Amsterdam: Elsevter Publishing Company, 1977.

A. W. Hatheway and F. B. Leighton, "Trenching as an Exploratory Method," in A. W. Hatheway and C. R. McClure, Jr. (eds.), Geology in the Siting of Nuclear Power Plants, The Geological Soctety of America Reviews in Engtneering Geology, Vol. A, 1979, p. 169-195.

W. W. Hays, Procedures for Est tmating Earthquake Ground Motions, U.S. Geolngical Survey Professtonal Paper 1114, 1980.

E. W. Heinrich, Microscoptc Identiftcatton of Minerals, New York: McGraw-Hill Book Co., 1965.

E. S. Hills, Elements of Structural Geology, New York: John Wiley \& Sons, Inc., 1972.

c. S. Hutchinson, Laboratory Handbook of Petrographic Techniques, New York: John Wiley \& Sons, Inc., 1974.

P. G. Jeffery, Chemical Methods of Rock Analysts, Oxford: Pergamon Press, 1970.

E. G. Kauffman and J. E. Hazel (eds.), Concepts and Methods of Biostrat Igraphy, Stroudsburg: Dowden, Hutchionson, and Ross, Inc., 1977.

J. L. Knill et a1., "Geological Soctety Engtneering Group Working Party Report. on the Logging of Rock Cores for Engineering Purposes, "Quarterly Journal of Engineering Geology, 3, 1970, pp. 1-24.

R. J. Lutton et a1., Tests for Evaluating Sites for Disposal of Low-Level Radioactive Waste, NUREG/CR-3038, U. S. Nuclear Regulatory Commission, 1982.

R. C. McE.Tdowney and R. F. Pascucci, "Application of Remote Sensing Data to Nuclear Power Plant Site Investigations," in A. W. Hatheway and C. R. McClure, 
Jr. (eds.), Geology in the sitting of Nuclear Power Plants, The Goological Socitety of America Reviews in Engineering Goology, Vol. 4, 1979, pp. 121-139.

P. J. Murphy, J. Briedis, J. H. Peck, "Dating Techntques in Fault Investigations," in A. W. Hatheway and C. R. McClure, Jr. (eds.), Geology in the siting of Nuclear Power Plants, The Geological Soctety of America Reviews in Engineering Geology, Vol. 4, 1979a, pp. 153-168.

V. J. Murphy, T. F. Sexton, E. N. Levine, "Geophysics as Related to Stting of Nuclear Power Plants", In A. W. Hatheway and C. R. McClure, Jr. (eds.), Geology in the siting of Nuclear Power Plants. The Geological Soctety of Amertca Reviews in Engineering Geology, Vol. 4, 1979b, p. 197-199.

NRC; See U.S. Nuclear Regulatory Commisston.

R. G. Park, Eoundations of Structural Geluloay, Glasgow: Blackte \& Son, l.td., 1983.

S. J. Pirson, Geologic Well Log Analysis, Second Edition, Houston: Gulf Publishing Company, 1977.

R. G. Reeves (ed.), Manual of Remote Sensing, Vols, 1 and 2, Falls Church: American Soctety of Photogrammetry, 1975.

I. Saunders and A. Young, "Rates of Surface Processes on Slopes, Slope Retreat and Denudation," Earth Surface Processes and Landforms, 8, 1983, pp. 473-501.

R. L. Schuster and R. J. Krizek (eds.), Landslides Analysis and Control, National Academy of Sciences Transportation Research Board Spectal Report 176, 1978 .

M. A. Sherif (chmn), Ihird International Earthquake Microzonation Conference Proceedings, Seattle, June 28-August 1, Vols. 1-3, University of Washington, 1982 .

D. B. Slemmons, State-of-the-art for Assessing Earthquake Hazards in the United States, Report 6, Faults and Earthquake Magnitude, U. S. Army Engineer Waterways Experiment Station Miscellaneous Paper S-73-1, 1977.

F. J. Swanson et al. (eds.), Workshop on Sediment Budgets and Routing in Eorested Drainage Basins: Proceedings, U.S. Department of Agriculture, Forest Service, Pacific Northwest Range Experiment Station General Technical Report: PNW-141, 1982.

W. M. Telford et a1., Applied Geophystcs, Cambridge: Cambridge University Press, 1976.

C. R. Twidale, Analysts of Landforms, Sidney: John Wiley \& Sons, Inc., 1976.

University of Arizona, Site Characterization Field Manual for Near Surface Geologic Disnosal of Low-Level Radioact ive Waste, U. S. Department of Energy report DE FG07 $841012514,1985$. 
U.S. Nuclear Regulatory Commisston, Standard Review Plan for UMTRCA THtle Mill Tallings Remedtal Action Plans, 1985, p. 2-8 to 2-12.

H. Van0iphe and J. J. Friplat (eds.), Data_Handbook for Clay Minerals and other Non-Metallic Minerals, Oxford, England: Pergamon Press, 1979.

H. T. Verstappen, Remete Senstng in Geomorphology, New iork: Elsevter, 1977.

A. Voge1, "The Use of Space Technology in Earthquake Hazard Assessment," Proceedings of 18th International Sympos ium on Remote Sensing and the Envitronment, Parts, 1985.

D. S. Way, Ierrain Analysis, New York: McGraw-H111 Book Co., 1978.

H. W111 lams, F. J. Turner, C. M. Gillbert, Petrography an Introduction to the Study of Rocks in Thin Sections, San Francisco: W. H. Freeman and Co., 1954.

K. H. Wolf (ed.), Handbook of Strata-Bound and Straty form Ore Deposits, Vol. 1. Chapter 1, Amsterdam: Elsevier Publishing Company, 1976.

D. York and R. M. Farquhar, The Earth's Age and Geochronology, Oxford: Perganion Press, 1972. 
TABLE $B-2$ (a)

PARAMETER UESCRIPTIONS - GROUND-WATER HYDROLOGY

\section{UNSATURATED FLOW}

Motsture Petentiali Soll water moves in the direction of decreasing motsture potentyal. The motsture potentfal is the sum of gravitational, osmotic, and matric potentlals. Osmotic potentlal is generally constdered negliglble. Gravttational potentlal is dependent on differences in elevation. Matric potentlal is a negative pressure potentlal that results from the captllary and adsorptive forces of the soll matrix. Information on moisture potential is needed for determining rates and directions of motsture movement.

Mofsture Content: Moisture content is expressed as a dimensforless ratto either of water mass to dry soll imass or of water volume to total volume. It is usually reported as a perceritage. The relation between molsture potential and motsture content is deftned by a motsture characteristic curve. However, due to the hysteresis phenomenon, the curve for the wetting process is usually not identical to the curve for the drying process. A related parameter, the degree of saturation, is defined as the ratto of the water volume to the vold volume. Information on molsture content is needed as a dependent vartable of hydraulic conductivity.

Hydraulic Conductivity: Hydraultc conductivity is a measure of the abtlity of roll or rock to transmit water. Hydraulic conductivity depends on the specific weight and viscosity of the water, and the intrinstc permeability and motsture content of the material. Under unsaturated condittons, the hydraultc conductivity may not be constant and will vary with the degree of saturation. In general, hydrautic conductivity has directional variablitty (anisotropy). Information on hydraultc conductivity is needed for determinting rates of moisture movement.

Porosity (Total and Effective): Total porosity is the ratio of the void volume to the total volume of a sample. Effective porosity is the ratio of interconnected void volume in which fluids are able to circulate, to the total volume of a sample. Information on porosity is needed for determining the transport of solutes in the unsaturated zone.

Geometry: The geometry includes the hydrostratigraphy (e.g., thickness, Tateral exterit, continuity), the depth of the water table, the thickness of captllary fringe, the location of the disposal factlity, and the location of recharge and discharge zones. Information on geometry is needed to define the domain in which flow is studied.

Boundary Conditions: Boundary conditions are defined pressure heads or fluxes due to discharge from evapotranspiration, and to steady-state and/or transient recharge from both natural infiltration (dependent on infiltration rate and infiltration capacity of material) and infiltration trenches. Information on boundary conditions is needed to determine controls on flow within the domain deftned by the geometry. 
Hydrogeologic Modeling: A hydrogeologic model is a mathemattcal formulation of the hydrologic behavior of the system. The description of the model should include model type, justification, documentation of code, verffication, validation, caltoration, sensitivity analyses, underlying assumptions, assoctated uncertalnttes, 11 mitations, physical laws constdered, input data, data reduction and/or generation techniques, and discussion of sultablitty. output may include simulated pressure heads, fluxes, discharge, and flow velocities and directions. Modeling is required to provide an integrated understanding for the unsaturated fiow regime for site characterization, and to allow a varlety of sensitivity and scenarto options to be evaluated in support of stte performance assessment. 
TABLE $B-2(b)$

PARAMETER DESCRIPT'IONS “ GROUND WATER HYDROLOGY

\section{SATURATED FLOW}

Hydraulic Head: The hydraulic head is the sum of the elevation of the point of measurement (elevation head) and the pressure head. Flutd will flow from higher hydraultic head to lower. The hydraulic gradient is the difference in hydraulic head divided by the distance over which it occurs. Information on hydraulic head is needed for determining rates and directions of ground-water flow.

Hydraulic Conductivity: Hydraultc conductivity is a measure of the ability of a material to transmit water. Hydraulic conductivity depends on the specific welght and viscosity of the water and the intrinsic permeability of the material. In general, hydraulic conductivity has directional variability (anisotropy). Information on hydraulic conductivity is needed for determining rates of ground-water flow.

Porosity (Total and Effective): Total porosity is the rat to of vold volume to the total volume of a sample. Total porosity approximately equals the sum of two related parameters, specific yleld (the amount of water released by a materlal due to the force of gravity) and specific retention (the amount of water retained by a material under the force of gravity). Effective porosity is the ratio of interconnected void volume in which ground water is able to circulate, to the total volume of a sample. Information on porosity is needed for determining the transport of solutes dissolved in the ground water.

Spectfic Storage: The specific storage is the amount of water in storage that is released from a unit volume of aquifer per unit declithe in head. The related coefficlent, storativity or storage coefficient, is the amount of water released from a column of aquifer with untt cross section under a unit. declitne of head. In unconfined aquifers, storage is measured in terms of the specific yteld, a measure of the drainable porosity, whereas in confined aquifers, speciftc storage and storativity are functions of porosity (the proportion of void space in a saniple), fluid compressibility, and medium compressibility. (Compressibility describes the change in volume induced in a material by an applied stress.) Information on specific storage is needed for determining rates and directions of ground-water movement when boundary conditions are changing with time.

Geometry: The geometry includes hydrostratigraphy (e.g., thickness, lateral extent, continuity, hydraulic interconnectivity, elevation, depth, stratigraphic relationships), location of pathways (e.g., faults, sand lenses, weathered horizons, karstic features, joint systems, solution features), location of barriers (e.g., fracture zones, dikes), location of recharge and/or discharge zones, location of wells and the location of the disposal facility. The geometry should be characterized to a depth of at least $30 \mathrm{~m}$ below the site. Information on geometry is needed to define the domain in which flow is studied. 
Boundary Conditions: Boundary conditions are defined heads or fluxes due to steady state and/or transient recharge from infiltration and injection wells, and discharge from springs and domestic, industrial, irrigation and municipai wells. Information on boundary conditions is needed to determine controls on flow within the domain defined by the geometry.

Hydrogeologic Modeling: A hydrogeologic model is a mathematical formulation of the hydrologic behavior of the system. Proper model documentation should include model type, justification, documentation of code, verification, validation, calibration, sensitivity analyses, underlying assumptions, associated uncertainties, limitations, physical laws considered, input data, data reduction and/or generation techniques, and discussion of suitability. Output should include simulated heads and ground-water flow velocities, fluxes, discharge, and directions. Modeling is required to provide an integrated understanding of the saturated flow regime for site characterization, and to 1 llow a variety of sensitivity and scenario options to be evaluated in suppo of site performance objectives. 


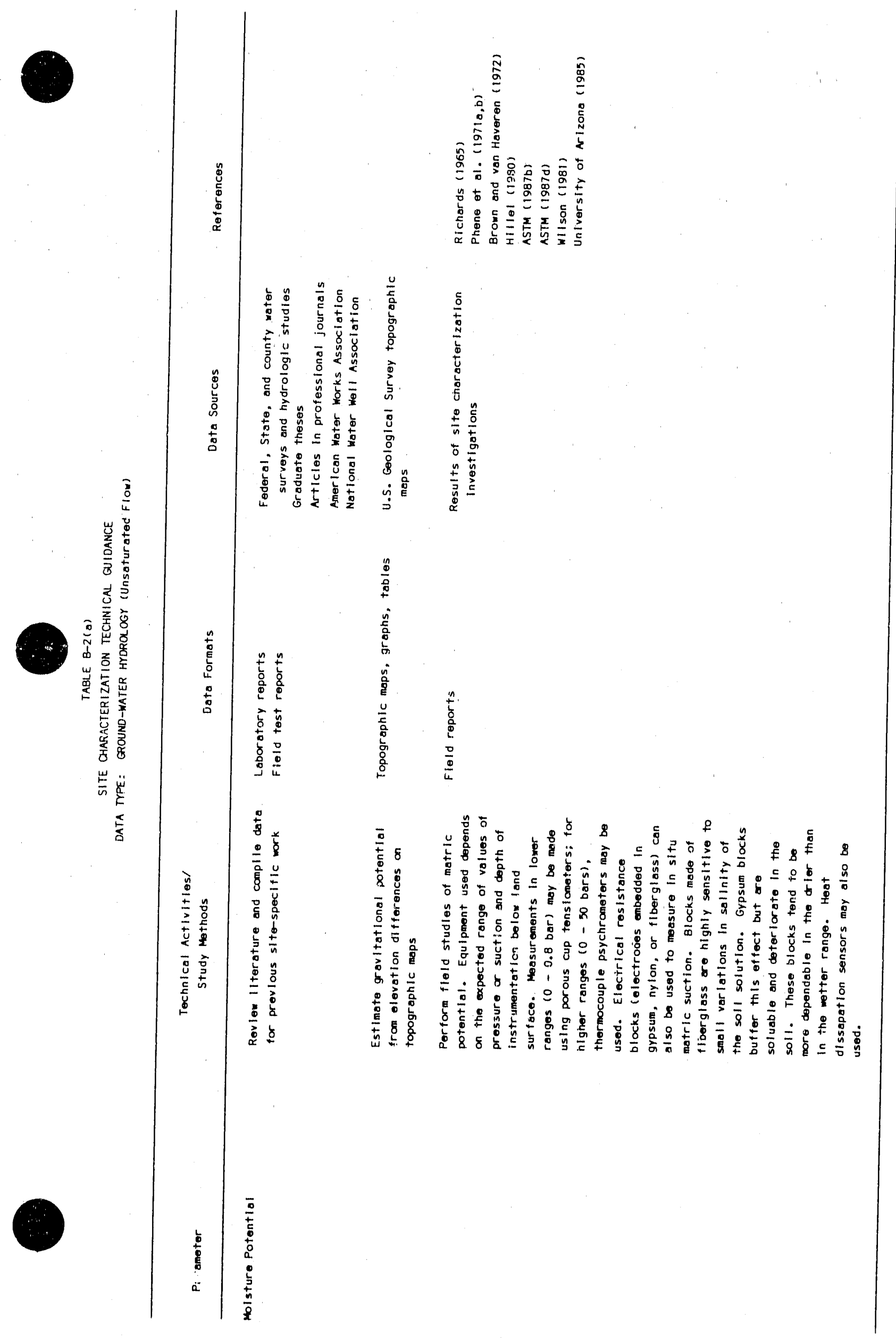



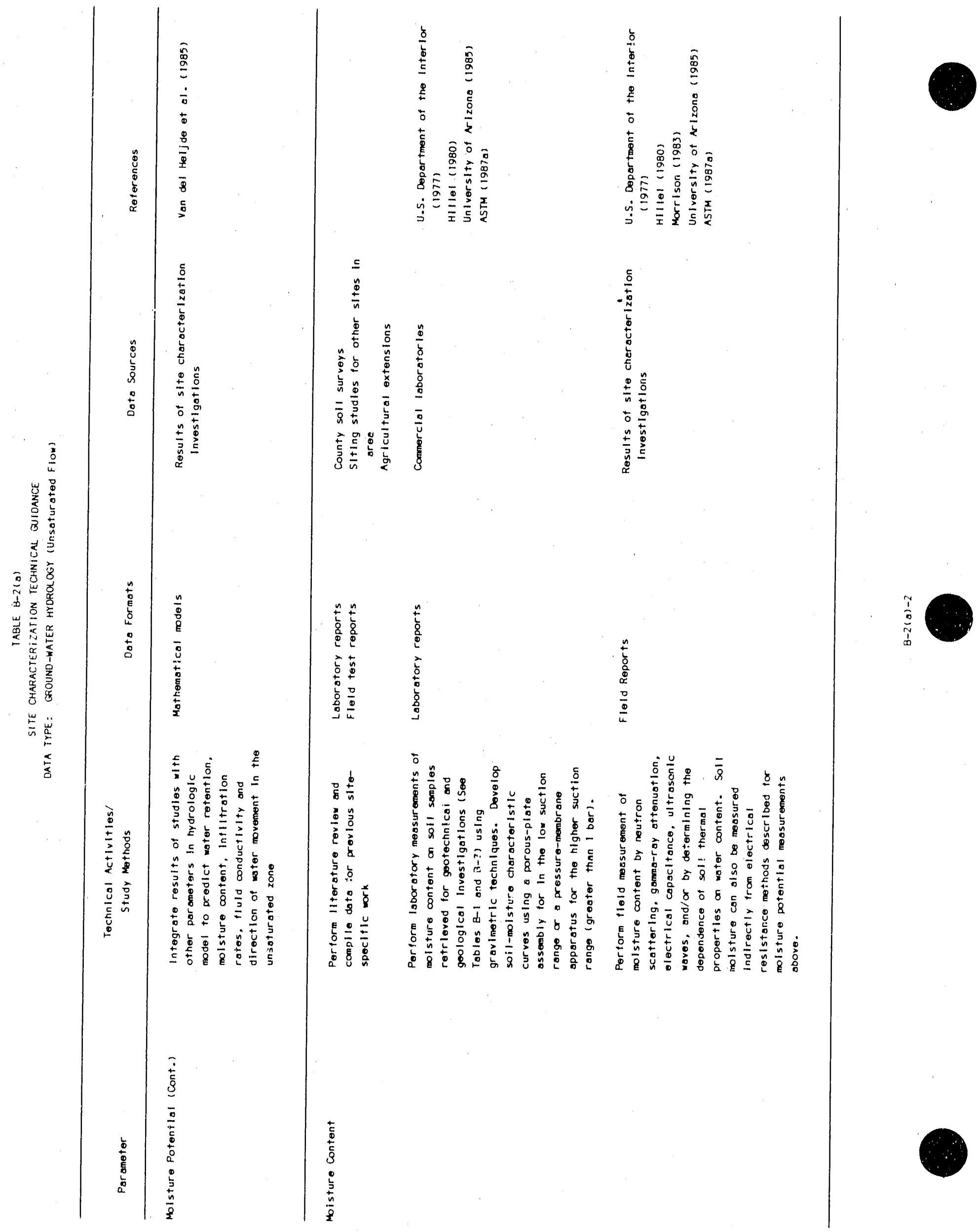


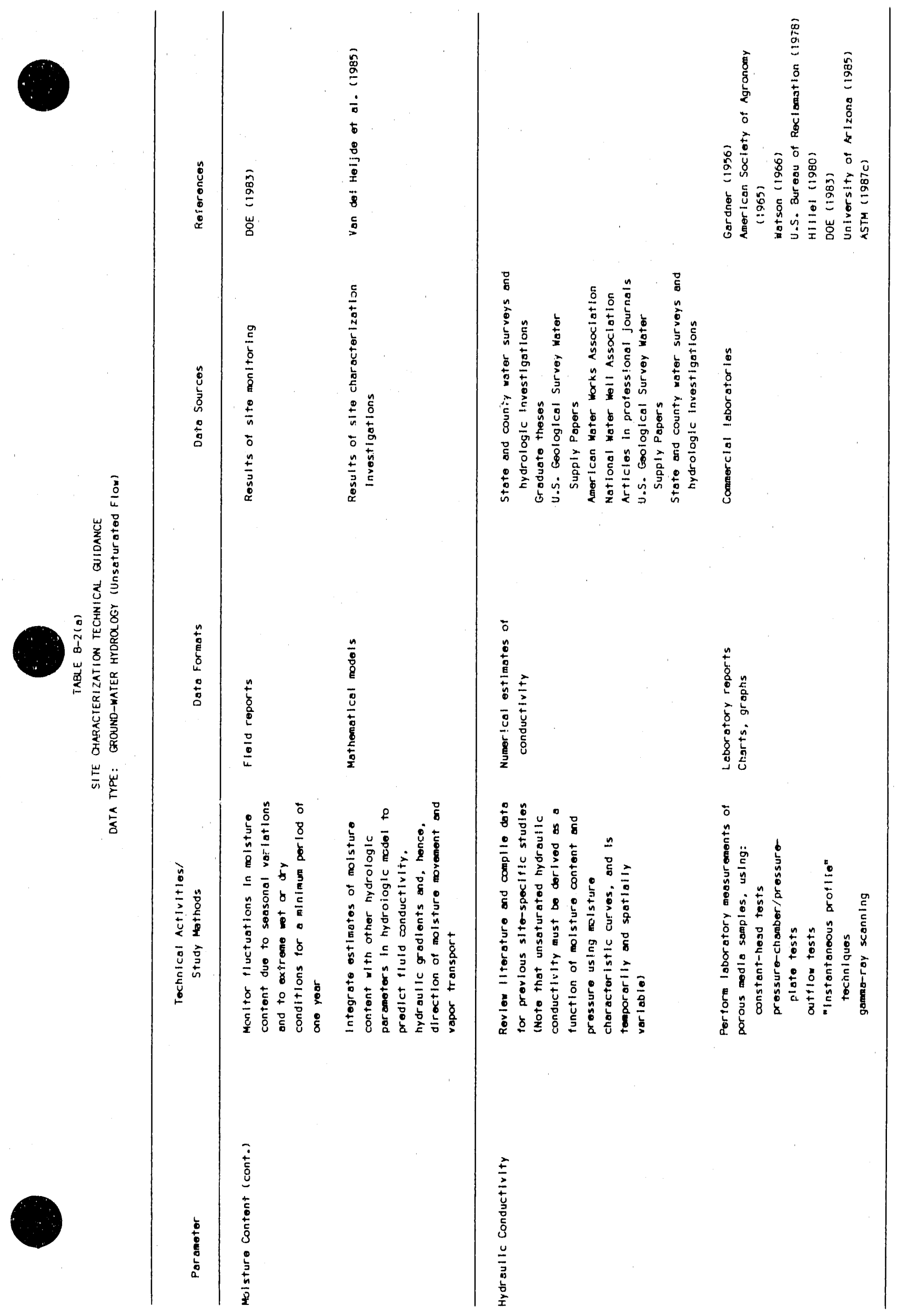

$\frac{m}{a}$ 

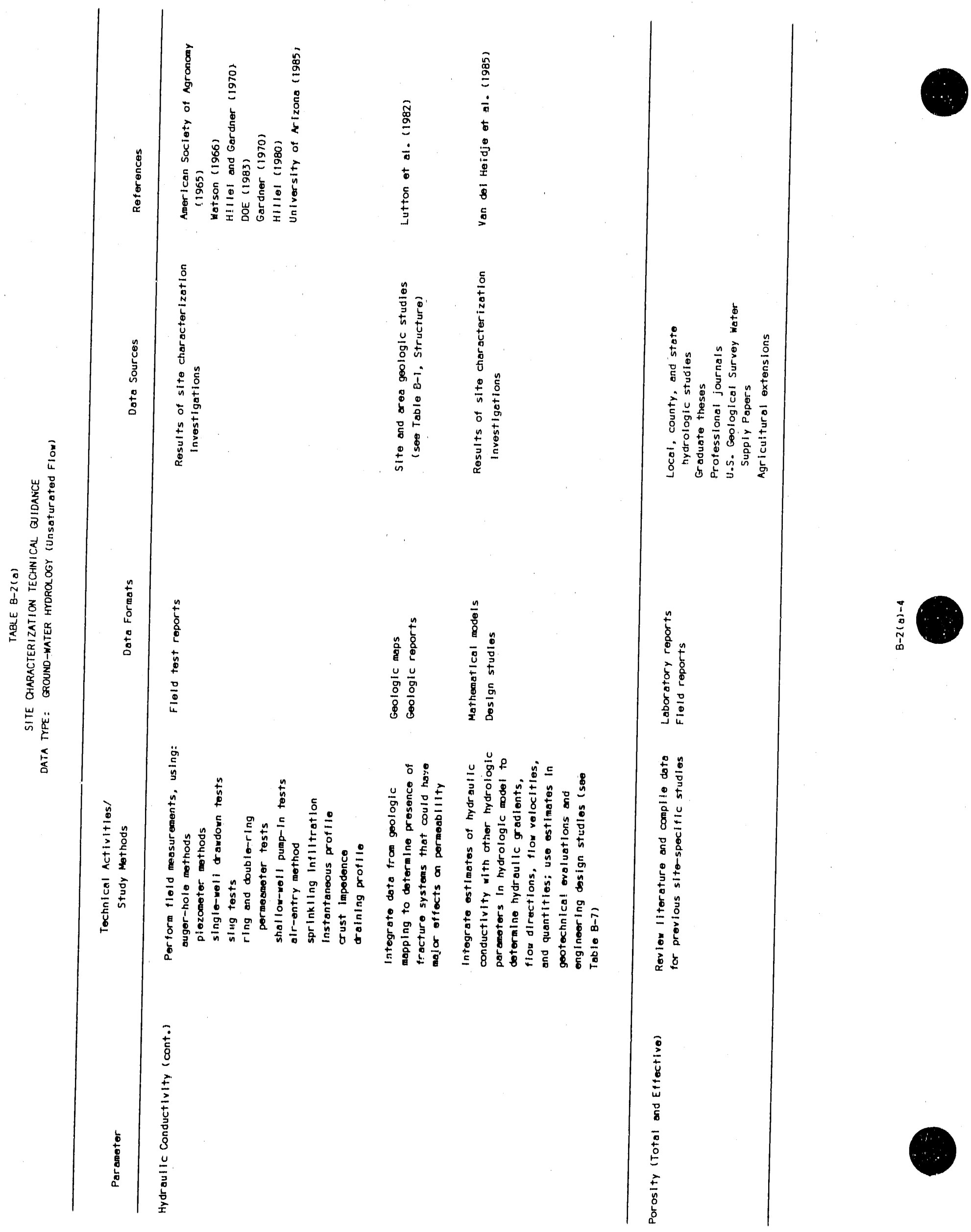


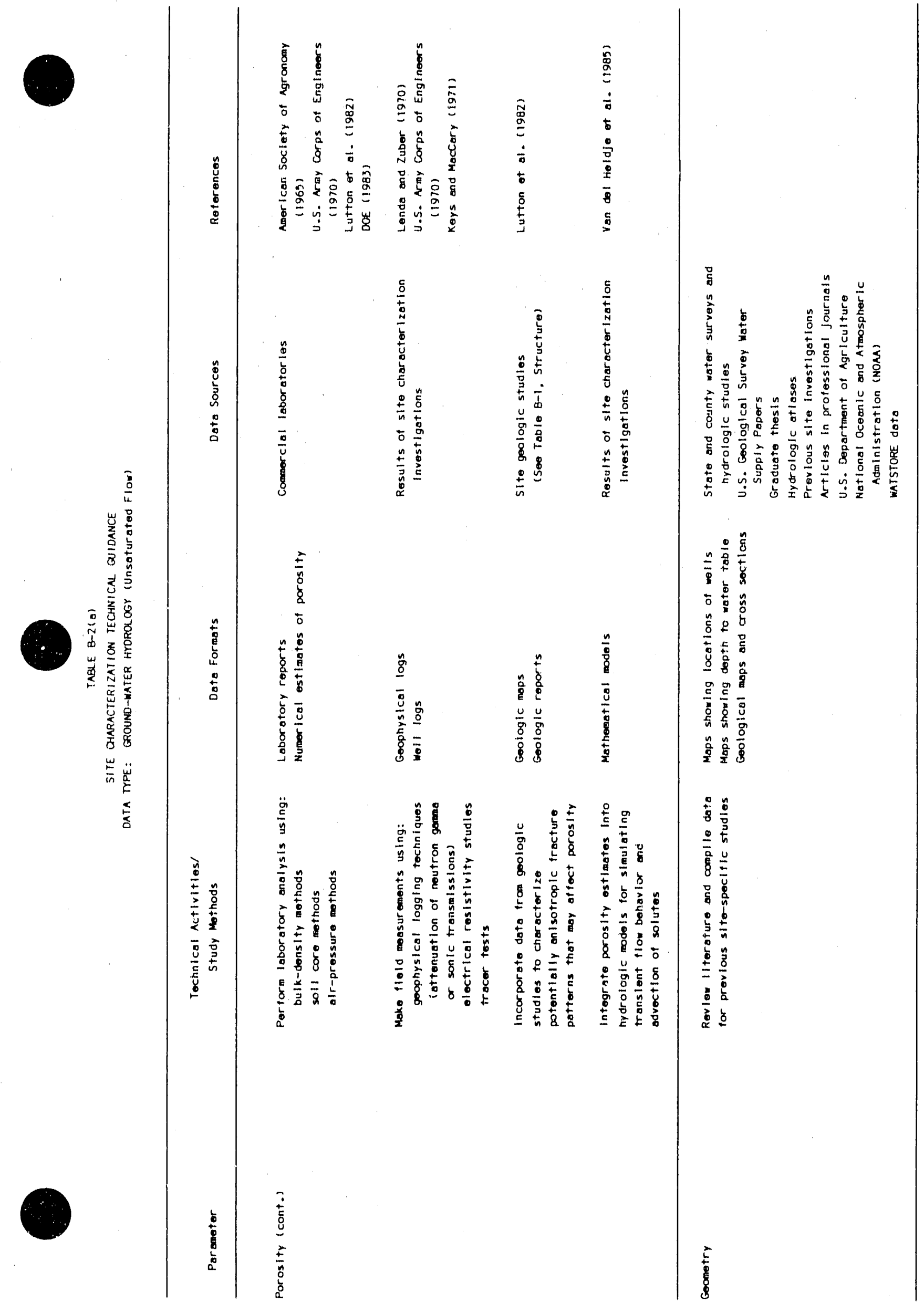




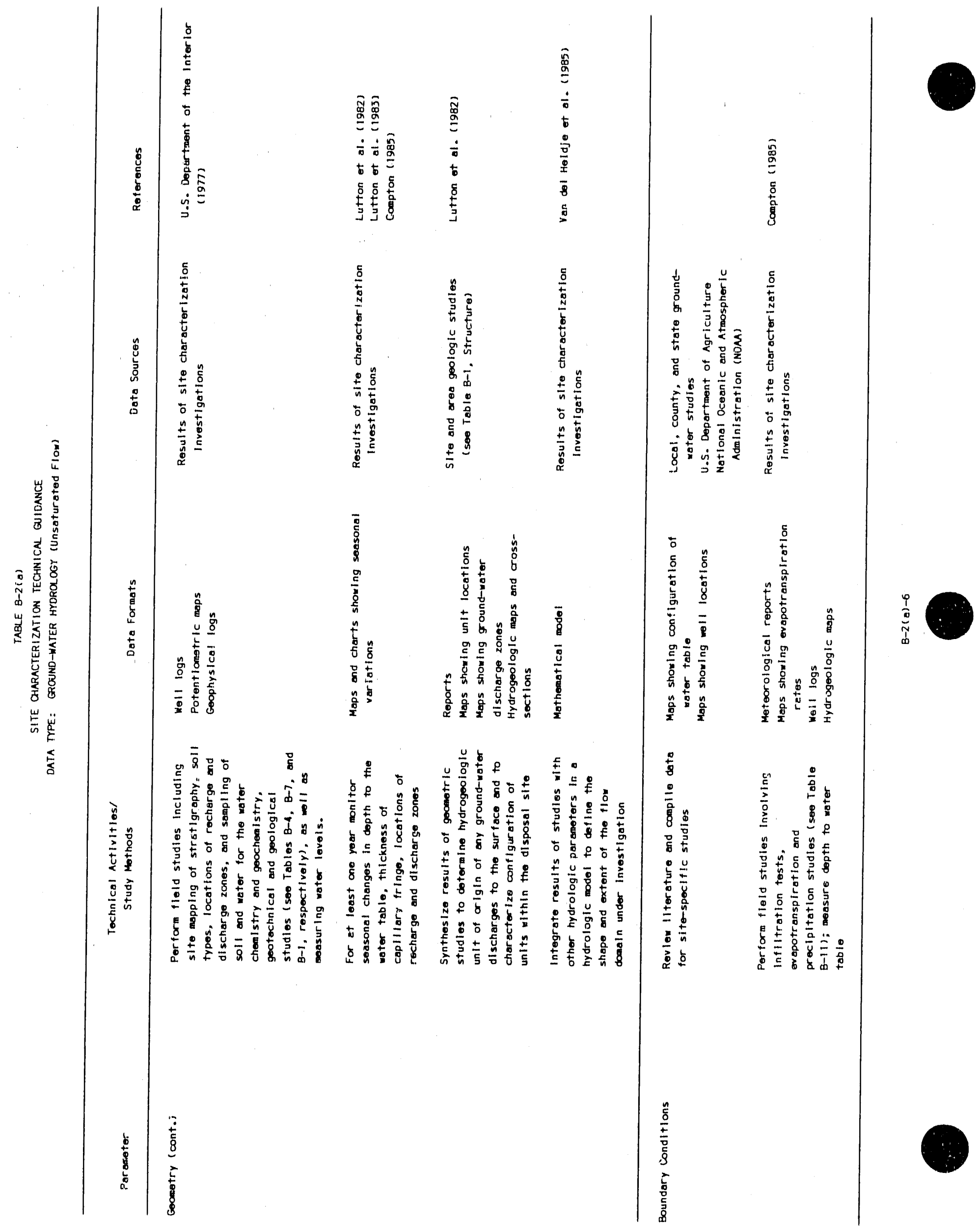




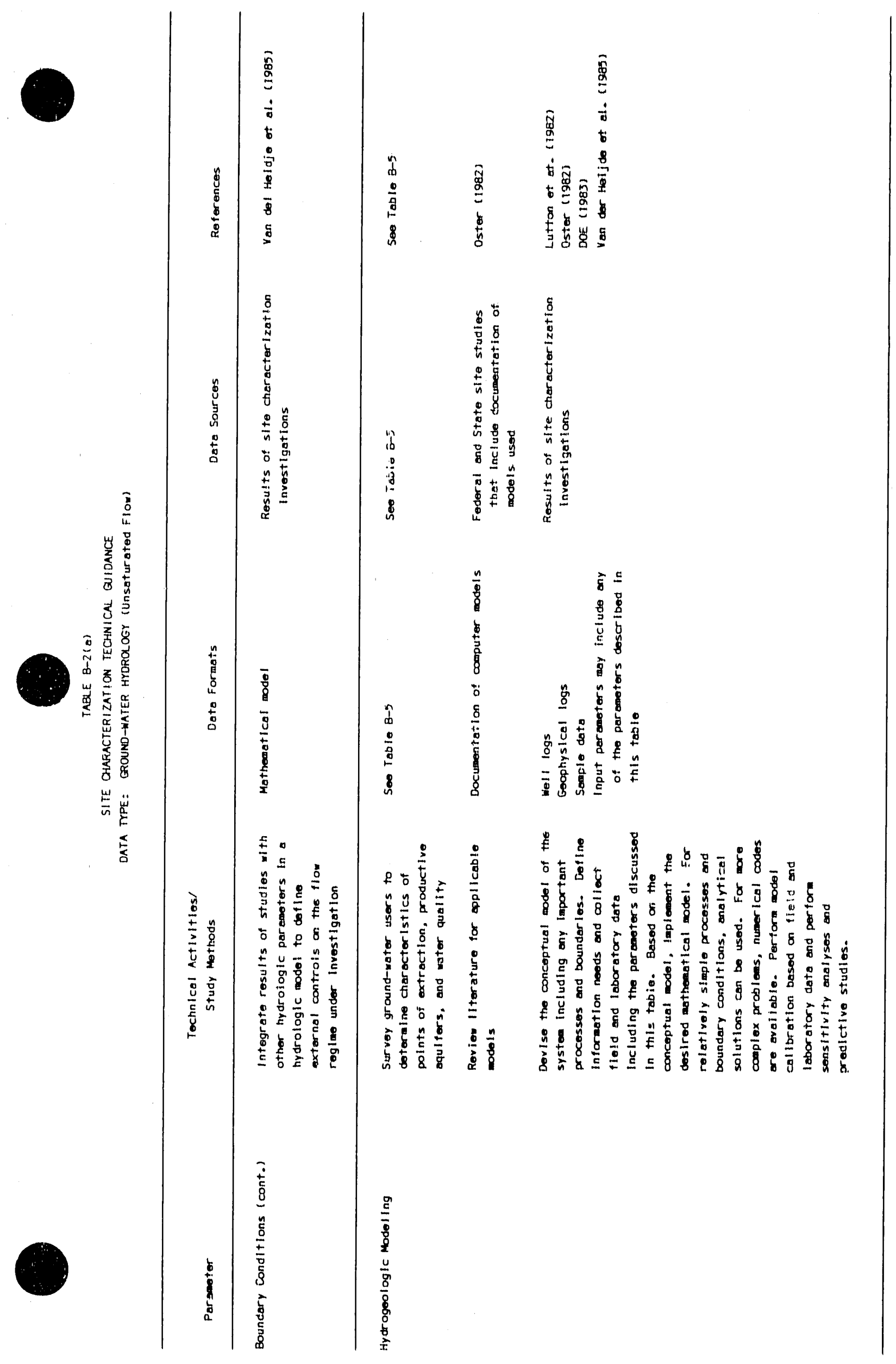




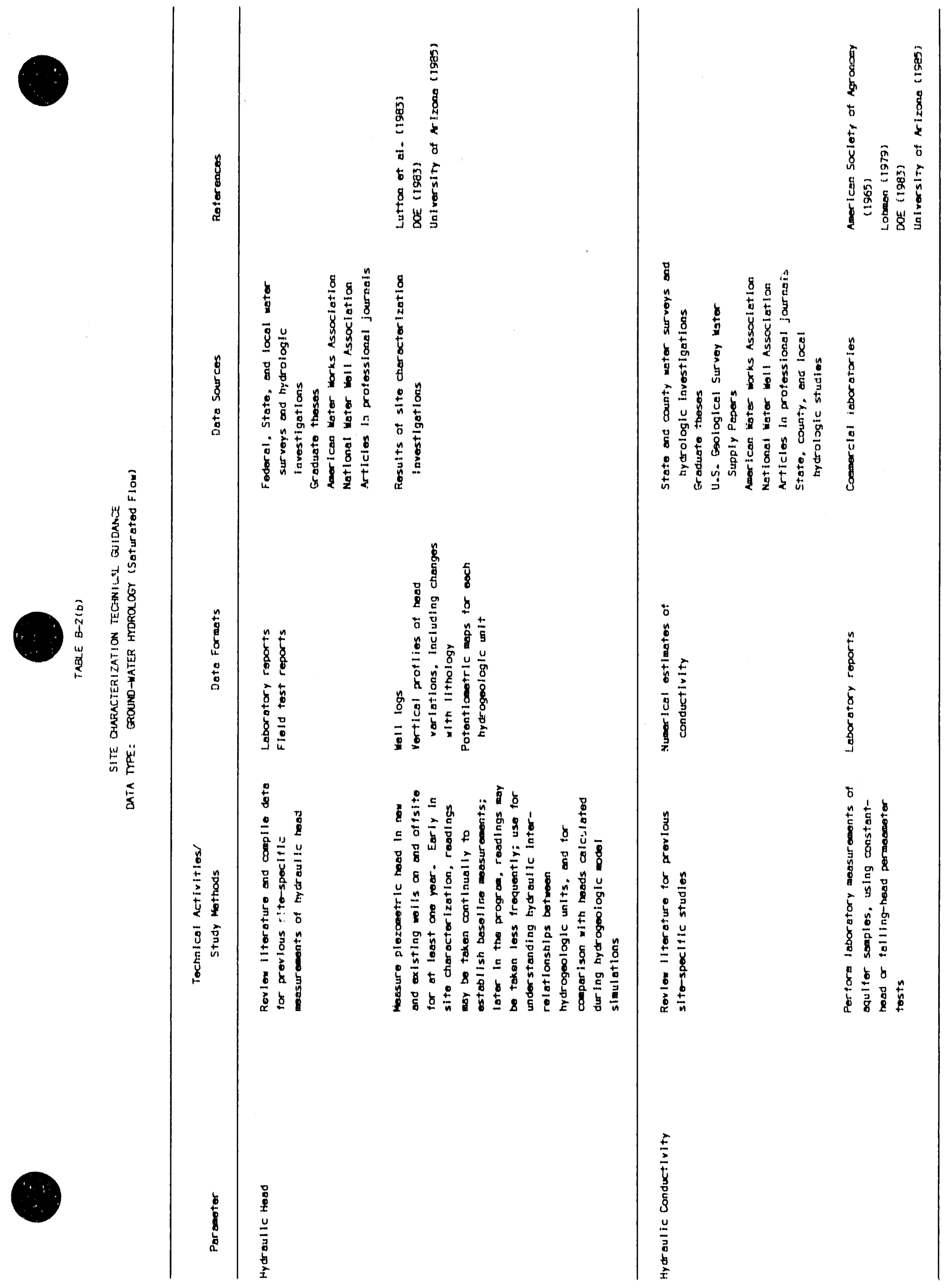

$\frac{I}{a}$ 


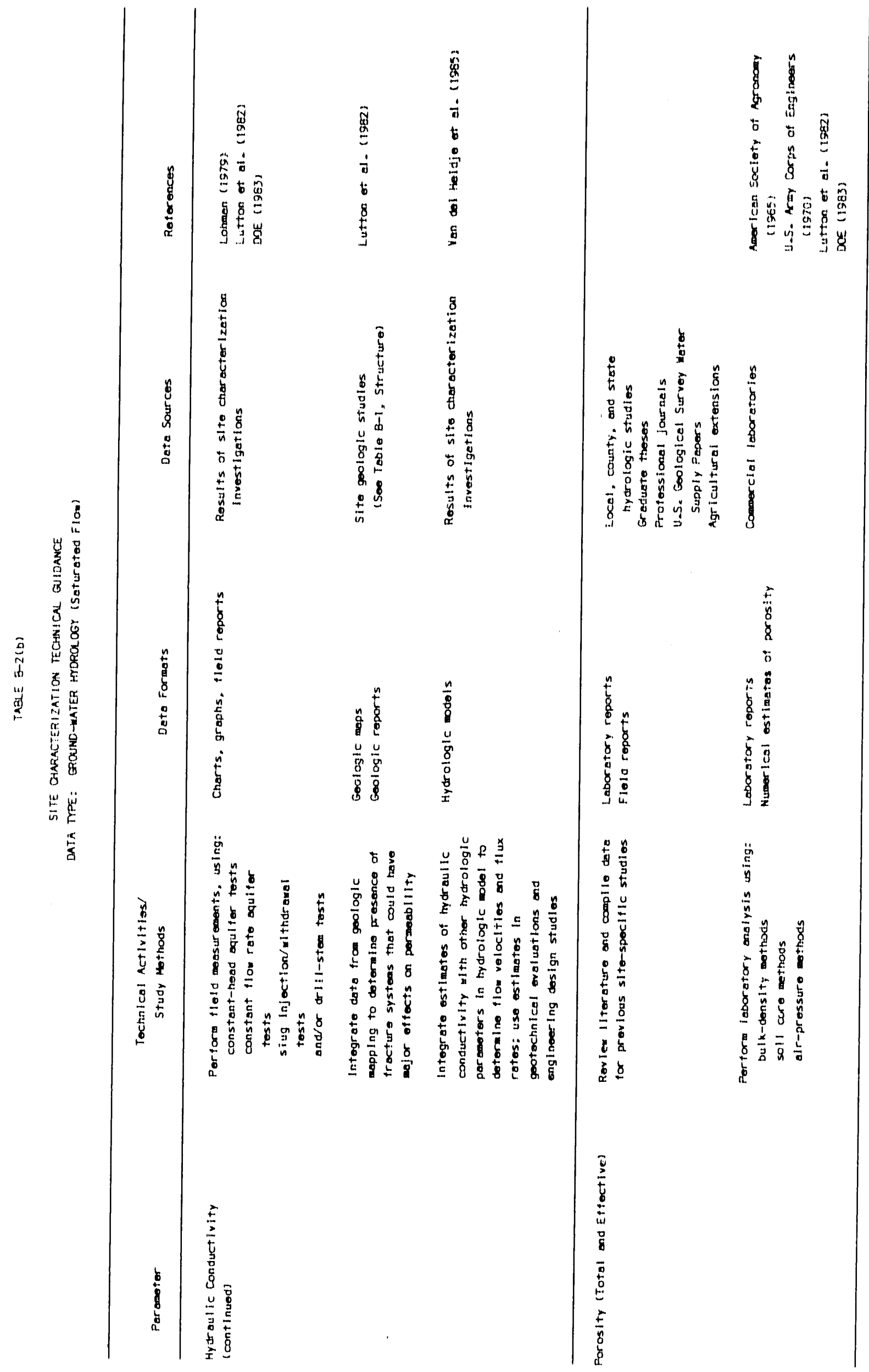




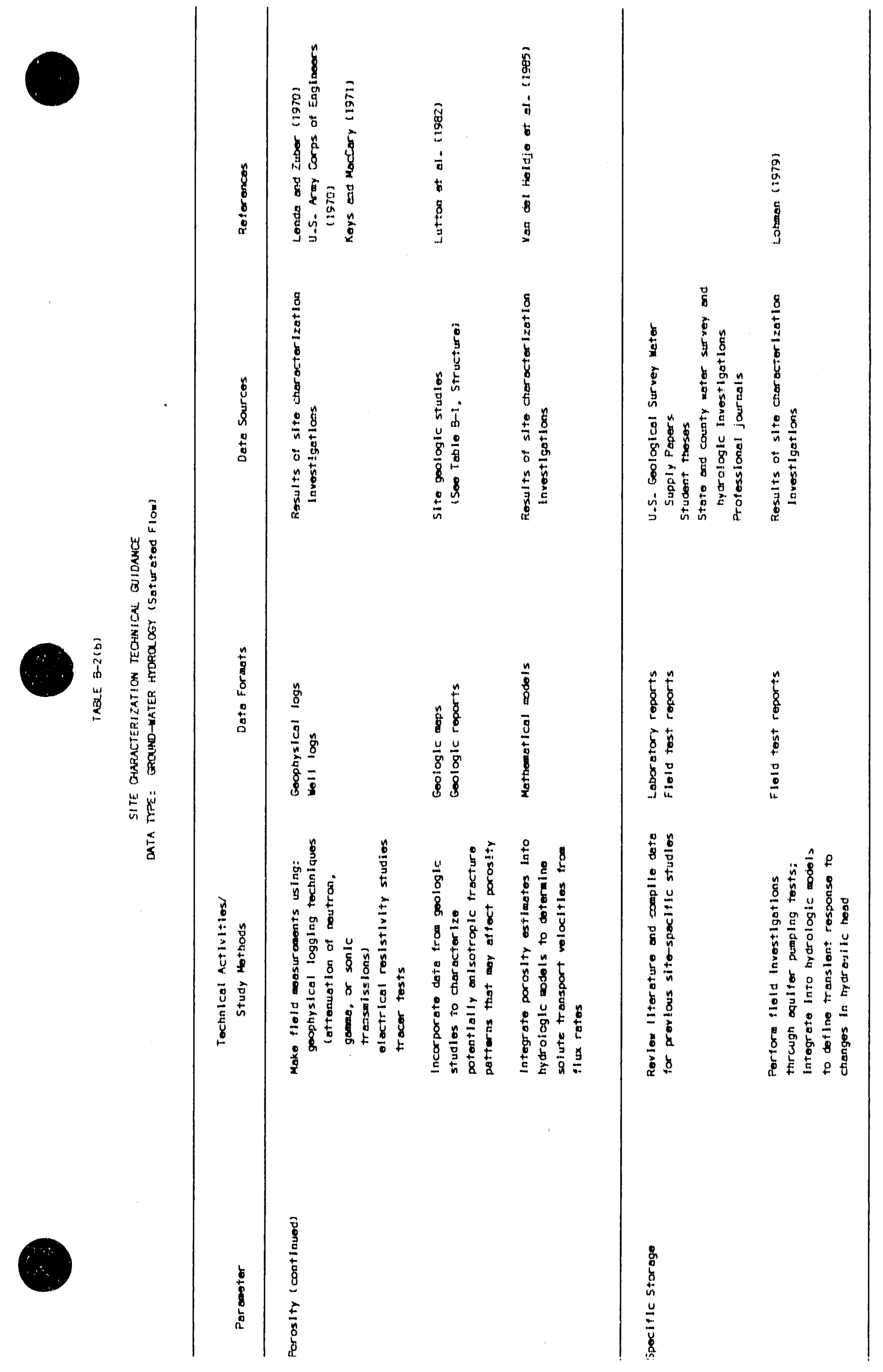




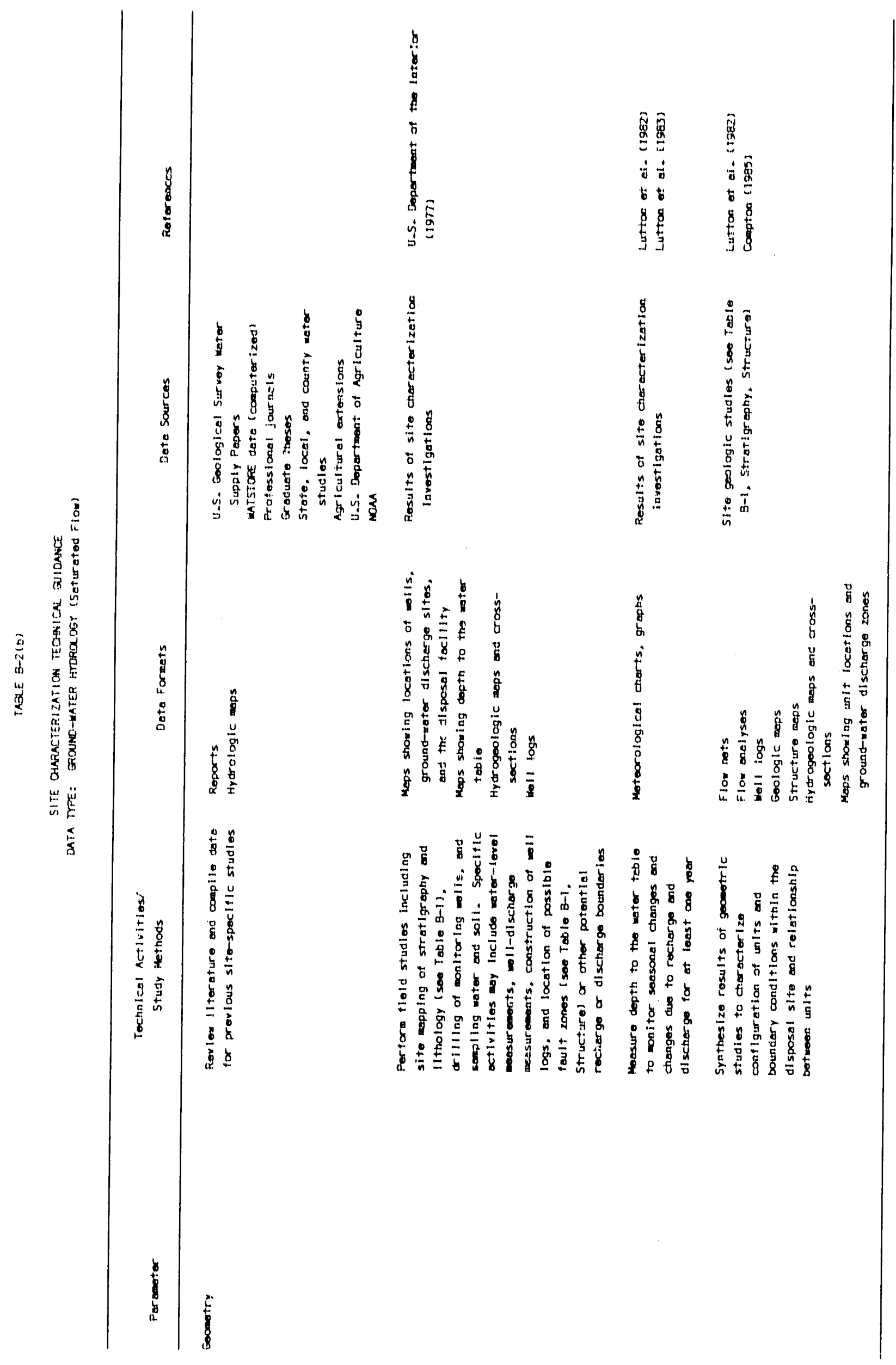




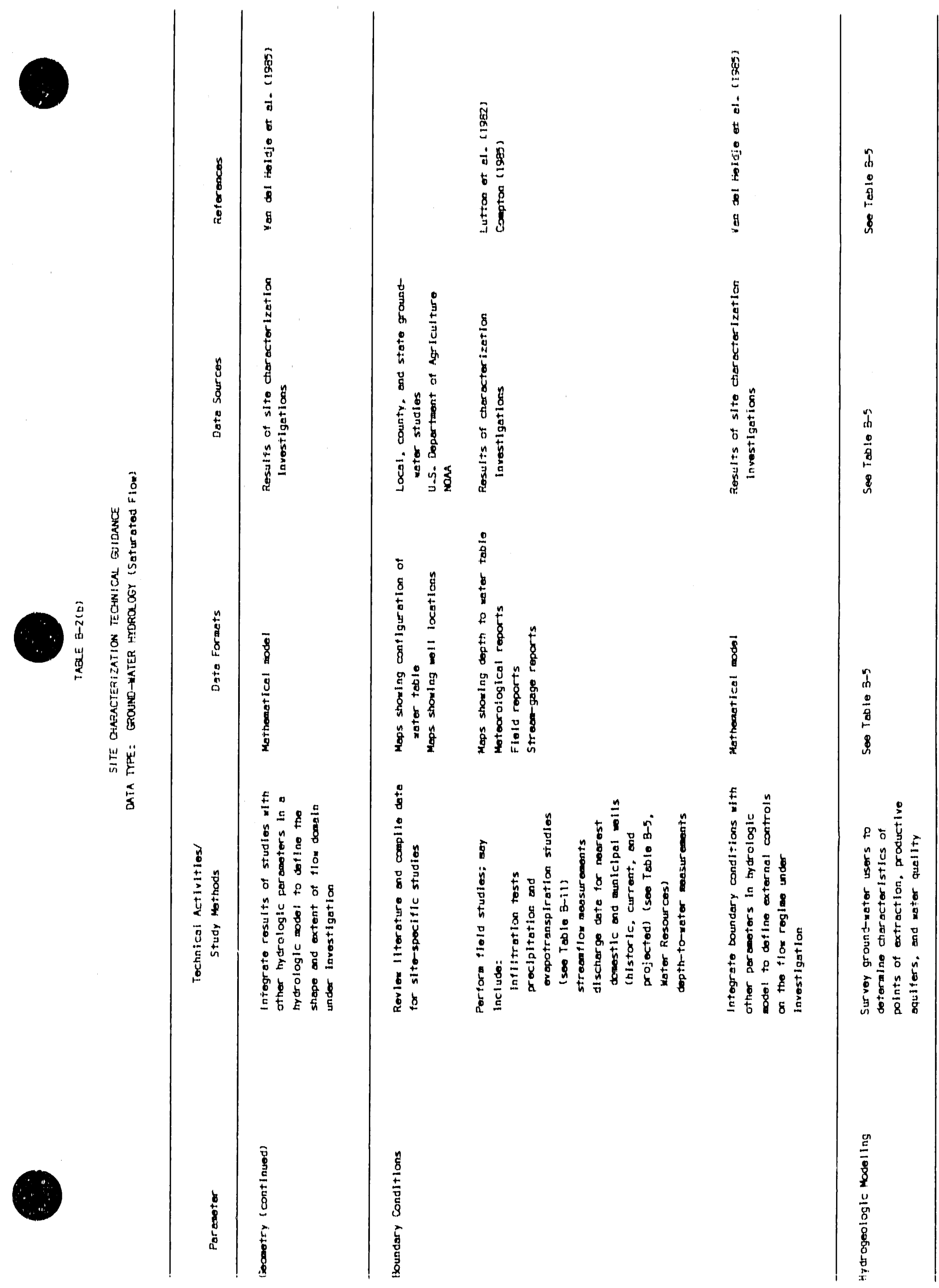



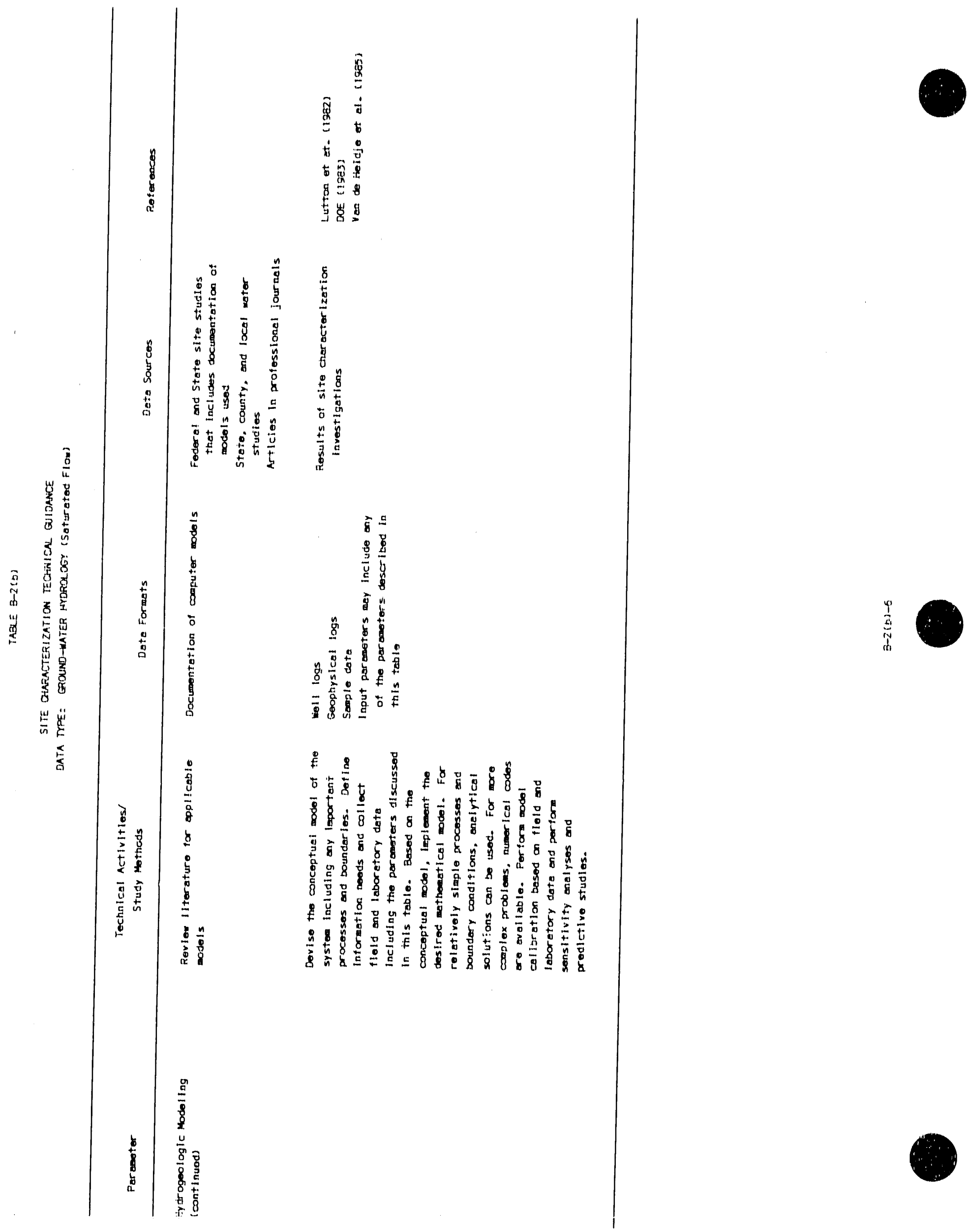
American Society of Agronomy, Methods of Soil Analysis: Part 2 - Chemical and Microbiological Properties, 1965.

American Society for Testing and Materials, "Standard Method for Laboratory Determination of Water (Moisture) Content of Soil, Rock, and Soil-Aggregate Mixtures," Annual Book of ASTM Standards, Vol. 04.08, Designation D2216-80, $1987 a$, p. $355-358$.

American Society for Testing and Materials, "Standard Test Method for Capillary-Moisture Relationships for Coarse- and Medium-Textured Soils by Porous-Plate Apparatus," Annual Book of ASTM Standards, Vol. 04.08, Designation D2325-68 (1981), 1987b, p. 363-369.

American Society for Testing and Materials, "Standard Test Method for Permeability of Granular Soils (Constant Head), " Annual Book of ASTM Standards, Vo1. 04.08, Designation D2434-68 (1974), 1987c, p. 381-387.

American Society for Testing and Materials, "Standard Test Method for Capillary-Moisture Relationships for Fine-Textured Solls by Pressure-Membrane Apparatus," Annual Book of ASTM Standards, Designation D3152-72 (1977), 1987d, p. $522-528$.

ASTM; see American Society for Testing and Materials.

R.W. Brown and B.P. van Haveren (eds.), Psychrometry in Water Relations Research, Utah Agricultural Experiment Station, Utah State University, Logan, Utah, 1972.

R.R. Compton, Geology in the Field, Somerset: John Wiley and Sons, Inc., 1985.

DOE, see U.S. Department of Energy.

W.R. Gardner, "Calculation of Capillary Conductivity From Pressure Plate Outflow Data," Soil Science Society of America Proceedings, 20, 1956, p. 317 320.

W.R. Gardner, "Field Measurement of Soil Water Diffusivity," Soil Science of America Proceedings, 1970.

D. Hillel, Soil and Water Physical Principles and Processes, New York:

Academic Press, 1980.

D. Hillel and W.R. Gardner, "Measurement of Unsaturated Conductivity and Diffusivity by Infiltration Through an Impeding Layer," Soil Science, 109, 1970. 
W.S. Keys and L.M. MacCary, "Application of Borehole Geophysics to WaterResources Investigations," Iechniques in Water-Resources Investigations, Chapter E1, Book 2, U.S. Department of the Interior, Geological Survey, 1971.

A. Lenda and A. Zuber, Tracer Dispersion in Groundwater Experiments, IAEA-SM129/37, International Atomic Energy Agency, Vienna, Austria, 1970.

S.W. Lohman, Ground-Water Hydraulics, U.S. Geological Survey Professional Paper No. 708, 1979.

R.J. Lutton et al., Tests for Evaluating Sites for Disposal of Low-Level Radioactive Waste, NUREG/CR-3038, U.S. Nuclear Regulatory Commission, 1982.

R.J. Lutton, W.E. Strohm, Jr., A.G. Strong, Subsurface-Monitoring Programs at Sites for Disposal of Low-Level Radioact ive Waste, NUREG/CR-3164, prepared for U.S. Nuclear Regulatory Commission, 1983.

R.D. Morrison, Ground Water Monitoring Technology: Procedures, Equipment, and Applications, Praire du Sac, WI: Timco Mfg., Inc., 1983.

C.A. Oster, Review of Ground-Water Flow and Transport Models in the Unsaturated Zone, NUREG/CR-2917, Battelle Memorial Institute, Pacific Northwest Laboratory, 1982.

C.J. Phene, G.J. Hoffman, S.L. Raglins, "Measuring Soil Matric Potential In Situ by Sensing Heat Dissipation Within a Porous Body: I. Theory and Sensor Construction," Soil Science Society of America Proceeding, 35, 1971a, p. 2733 .

C.J. Phene, G.J. Hoffman, S.L. Raglins, "Measuring Soil Matric Potential In Situ by Sensing Heat Dissipation Within a Porous Body: II. Experimental Results," Soil Science Society of America Proceedings, 35, 1971b, p. 225-229.

L.A. Richards, "Physical Conduction of Water in Soil," in C.A. Black et a1. (eds.), Methods of Soil Analysis, American Society of Agronomy, Madison, Wisconsin, 1965.

University of Arizona, Site Characterization Field Manual for Near Surface Disposal of Low-Level Radioactive Waste, U.S. Department of Energy Report $D E$ FGO7 $841012514,1985$.

U.S. Army Corps of Engineers, Laboratory Soil Testing, EM-1110-2-1906, U.S. Army Engineers Experiment Station, Vicksburg, MS, 1970.

U.S. Bureau of Reclamation, Drainage Manual: A Water Resources Technical Publication, Washington, D.C., 1978.

U.S. Department of Energy, Environmental Monitoring for Low-Level WasteDisposal Sites, Low-Level Radioactive Waste Management Handbook Series, DOE/LLW-13Tg, 1983. 
U.S. Department of the Interior, "Chemical and Physical Quality of Water and Sediment," Chapter 5, National Handbook of Recommended Methods for Water-Data Acquisition, U.S. Geological Survey, 1977.

P. Van del Heijde et a1., "Groundwater Management: the Use of Numerical Models," American Geophysical Union Water Resources Monograph 5, 1985.

K. K. Watson, "An Instantaneous Profile Method for Determining the Hydraulic Conductivity of Unsaturated Porous Materials," Water Resources Research, 2, 1966 , p. $709-715$.

L.G. Wilson, "Monitoring of the Vadose Zone, Part 1: Storage Changes, "Ground Water Monitoring Review, Fall 1981, p. 32-41. 
TABLE B-3

PARAMETER DESCRIPTIONS - SURFACE-WATER HYDROLOGY

Hydrologic System: Hydrologic characterization of the site and adjacent watersheds. Identification and descriptions of the natural and man-made system components (i.e., streams, rivers, lakes, wetlands, coastal areas, soil, climate, dams, diversions, and land use) and their interrelationship.

Water Users: An inventory of past, present, and potential future surfacewater users in the vicinity of the site and; in particular, within approximately 10 kilometers downstream of the site. Information should include the location, type and amount of use, number of users on the system, rate of withdrawal, percentage of stream flow withdrawn, sources of water supply, type of intake and pumping equipment, and surface water quality data. The inventory should identify the nearest down-gradient surface-water users and the nearest municipal supply relying on surface water.

Flood Studies: Evaluation of the flooding potential of the site and surrounding area to determine the Probable Maximum Flood (PMF). Information evaluated should include the date, water levels, peak discharge, and related information for major historic flood events in the region, including stream floods, surges, seiches, tsunamis, dam failures, ice jams, and floods induced by landslides.

Drought Studies: Evaluation of the occurrence of droughts at the site or surrounding areas. Historic drought water-surface elevations, specifically 7-day, 10-year low flows of affected streams and bodies of water, should be evaluated.

Precipitation: Rainfall and snowfall records that may be used to evaluate flooding and erosion potential. Characteristics to be evaluated include depth of precipitation, duration of storm, intensity of precipitation, recurrence intervals of precipitation, and Probable Maximum Precipitation (PMP).

Infiltration: The movement of water from precipitation into the soil. The infiltration rate of an area depends on the soil properties (e.g., grain size, density, porosity) and antecedent moisture conditions.

Runoff: The total amount of water flowing on the surface, commonly expressed as a depth of water over a specific area. This flow is usually either open channel flow if the water is confined to a channel, or overland flow if the water is flowing without a defined channel.

Discharge: The volumetric rate (flow rate) of runoff in a channel. Channel discharge commonly varies in response to storms. The discharge history of streams and rivers is statistically related to storm recurrence interval for use in evaluating flooding potential.

Channel Characteristics: The physical attributes of a channel (i.e., slope, cross sectional area, and roughness coefficient) that affect the channel's ability to convey a particular discharge. 
Stage: The height of the water surface above an established datum; sometimes referred to as gage height because water-surface elevations are commonly made at stations by one of various gage types. River stage is commonly translated into discharge by stage-discharge relationships established for particular stations along a river or stream.

Flow Velocity: The velocity of water in a channel. An average velocity can be calculated for a specific discharge when particular channel characteristics are known. Flow velocity is commonly used to evaluate flooding by runup, erosion by scouring, and the transport capability of a stream or river.

Erosion: The breakdown or weathering of geologic materials and the transport of these materials away from their origin.

Sedimentation: The deposition of particulate material after being transported by surface water.

Hydrologic and Hydraulic Modeling: Analytical and numerical methods to simulate flow and transport at the site. The theoretical basis for each model, the uncertainties and limitations of the model, procedures to verify the codes, and results of model calibration, including model validation techniques and sensitivity analyses, must be described and justified.

Site Surface-Water Impact: Qualitative and quantitative descriptions of the impact of the site on the surface-water system from construction to closure. This would include the impact of any man-made features to minimize surfacewater impacts. 


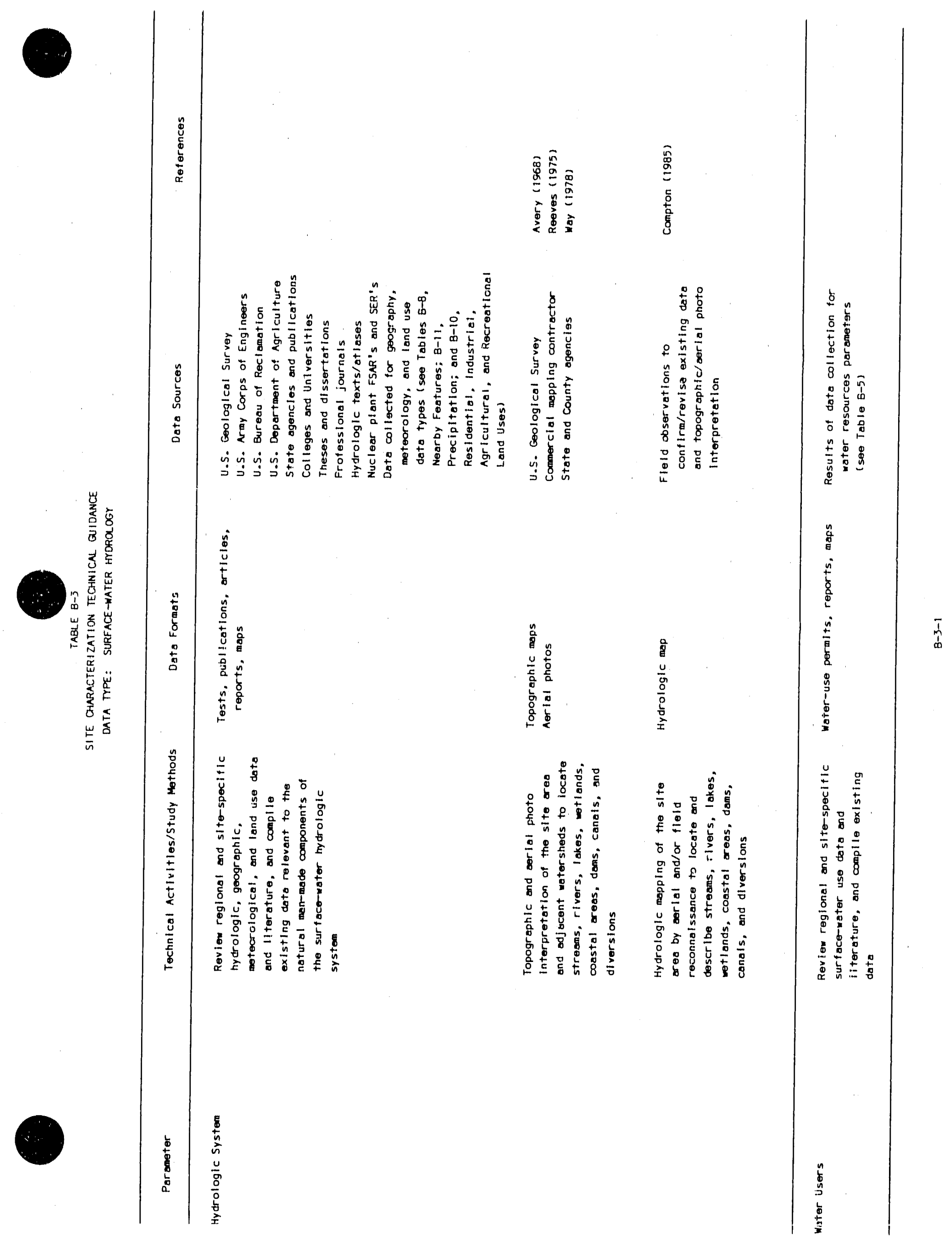



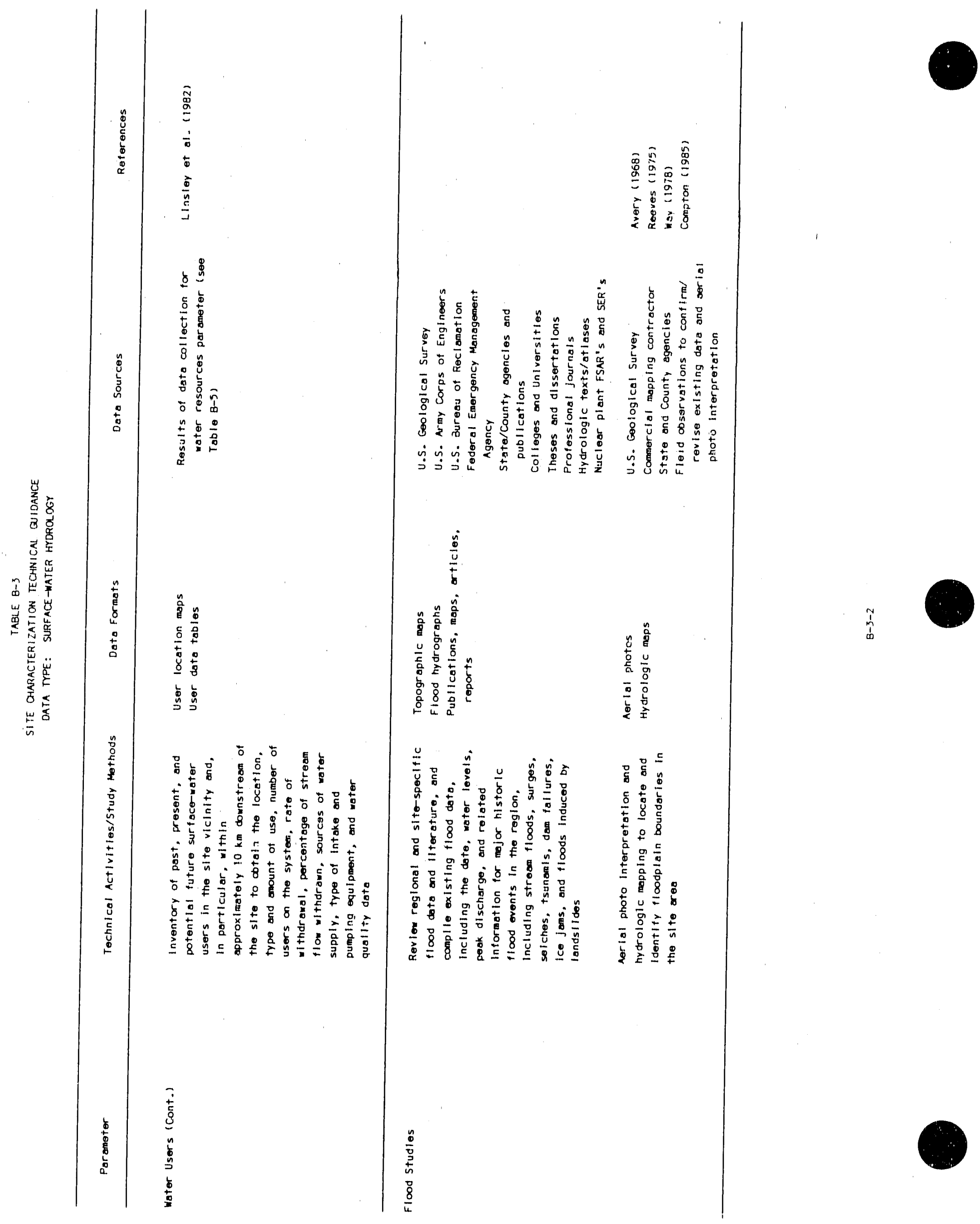


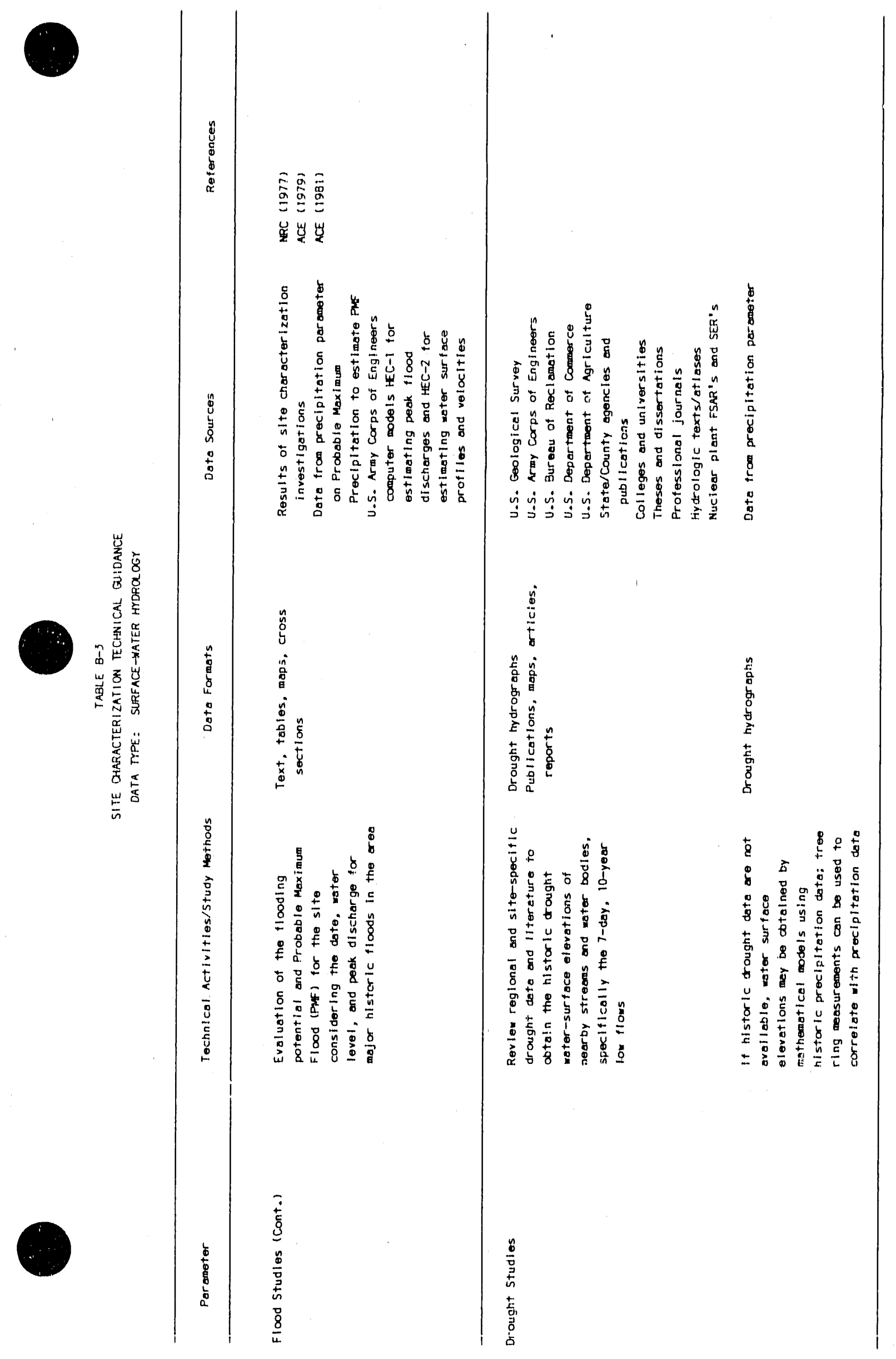




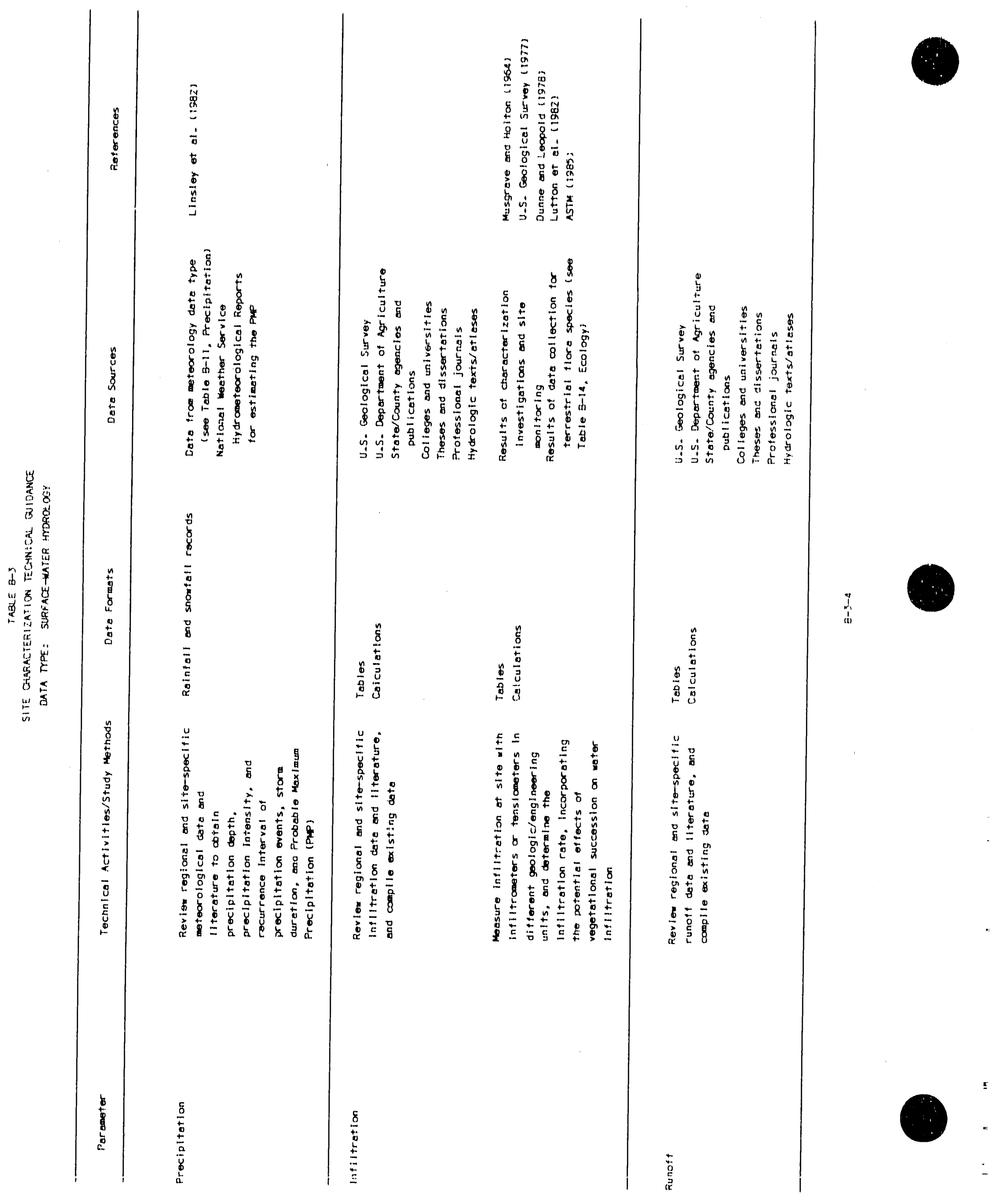




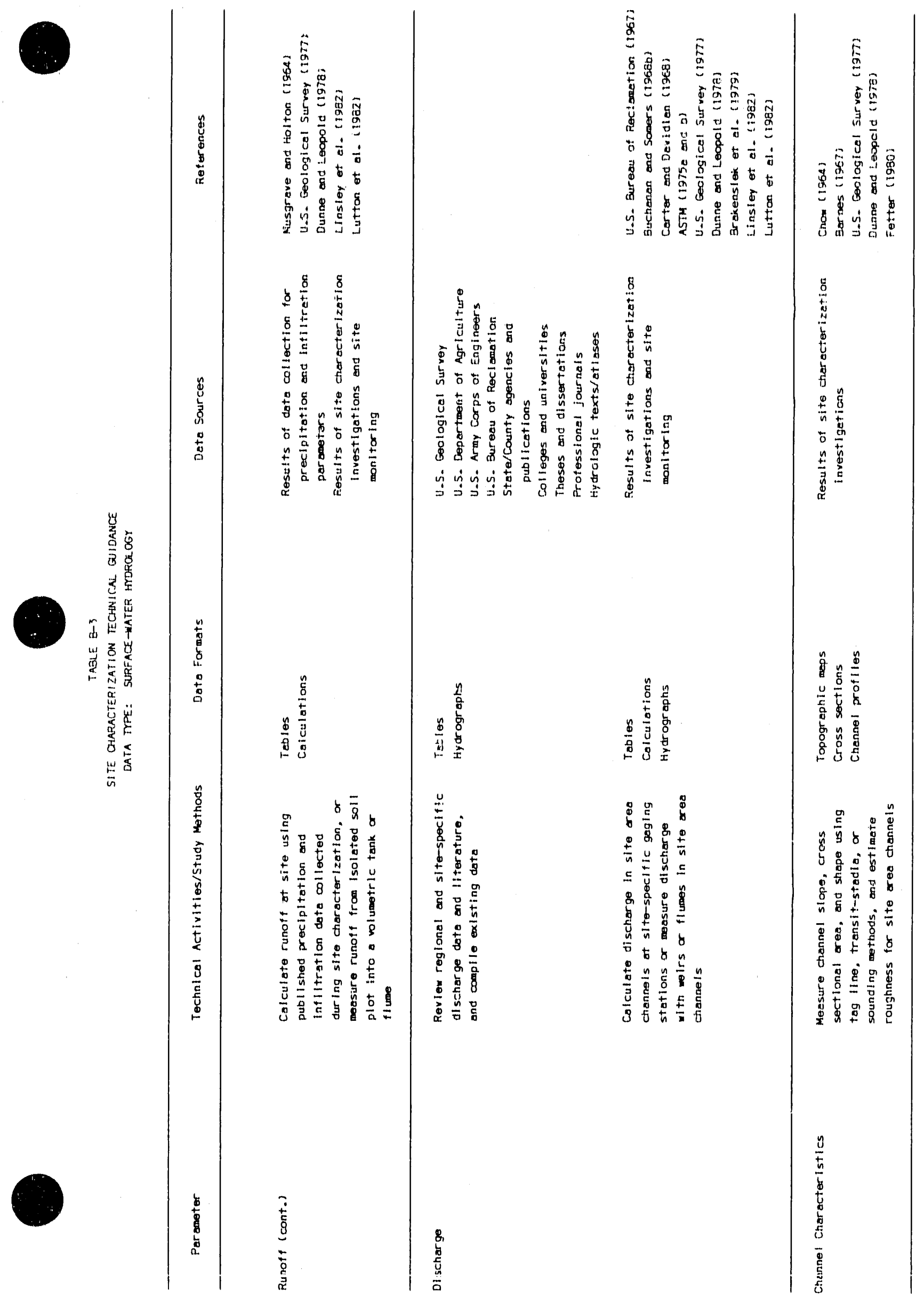




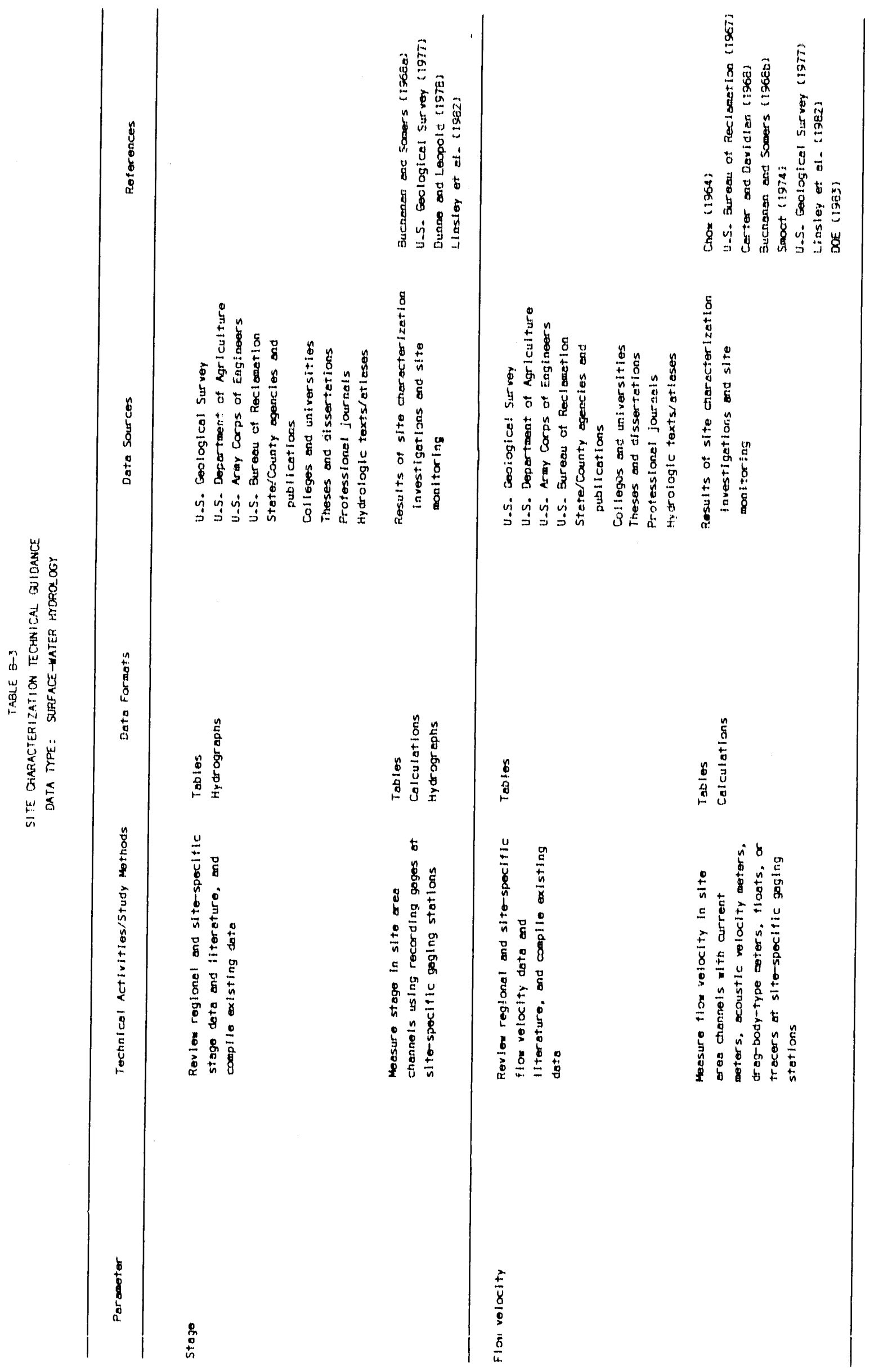




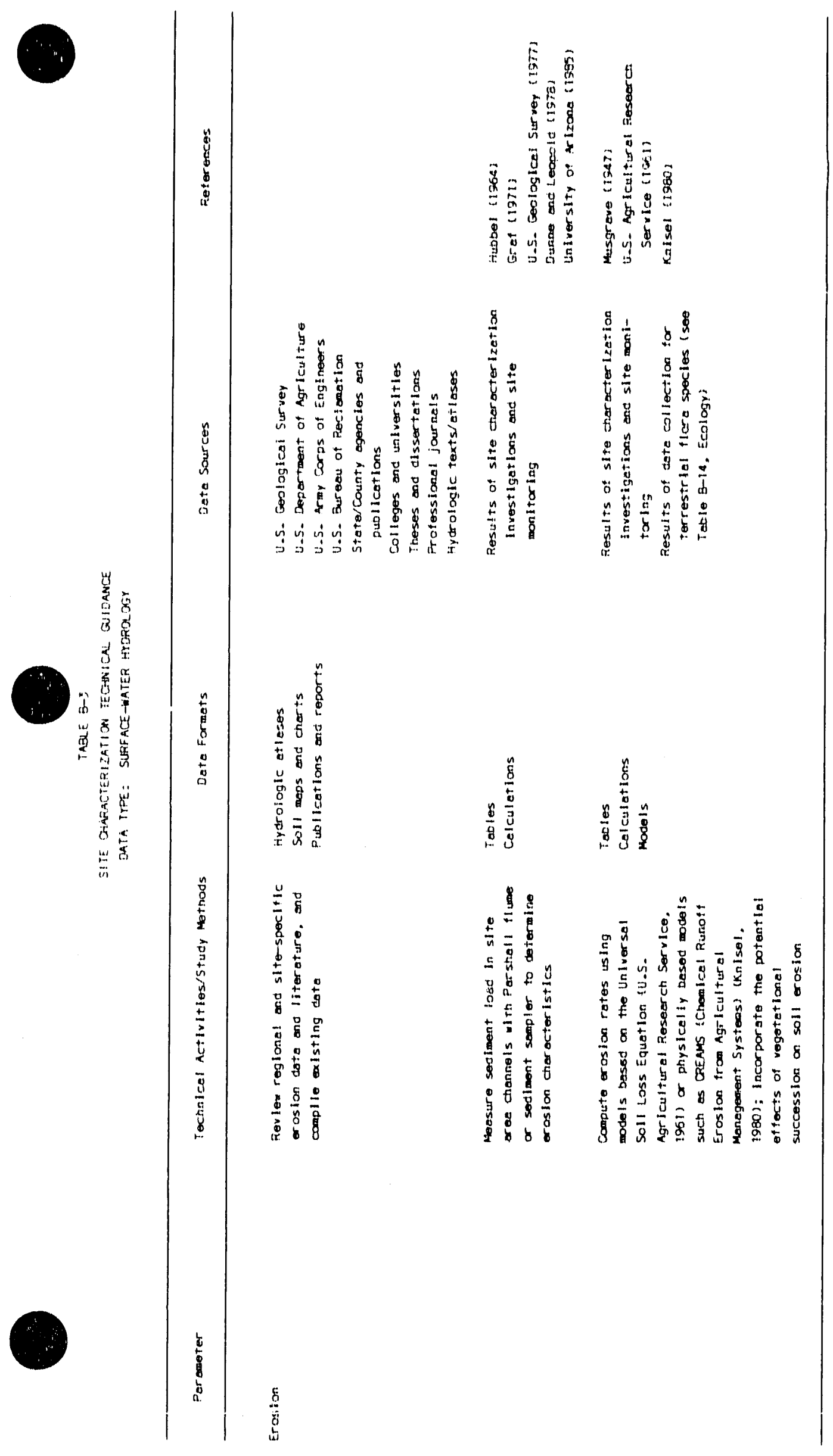




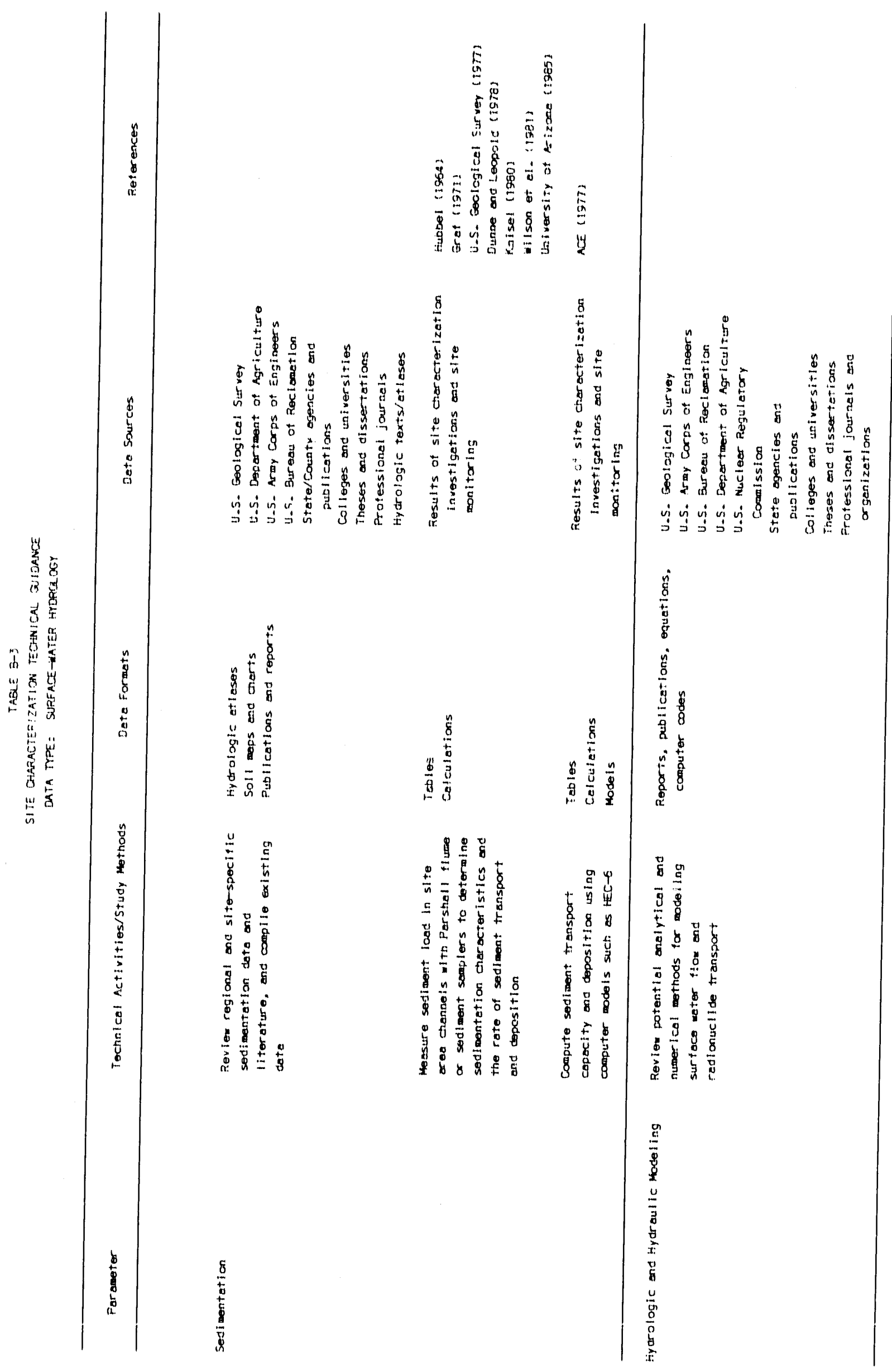




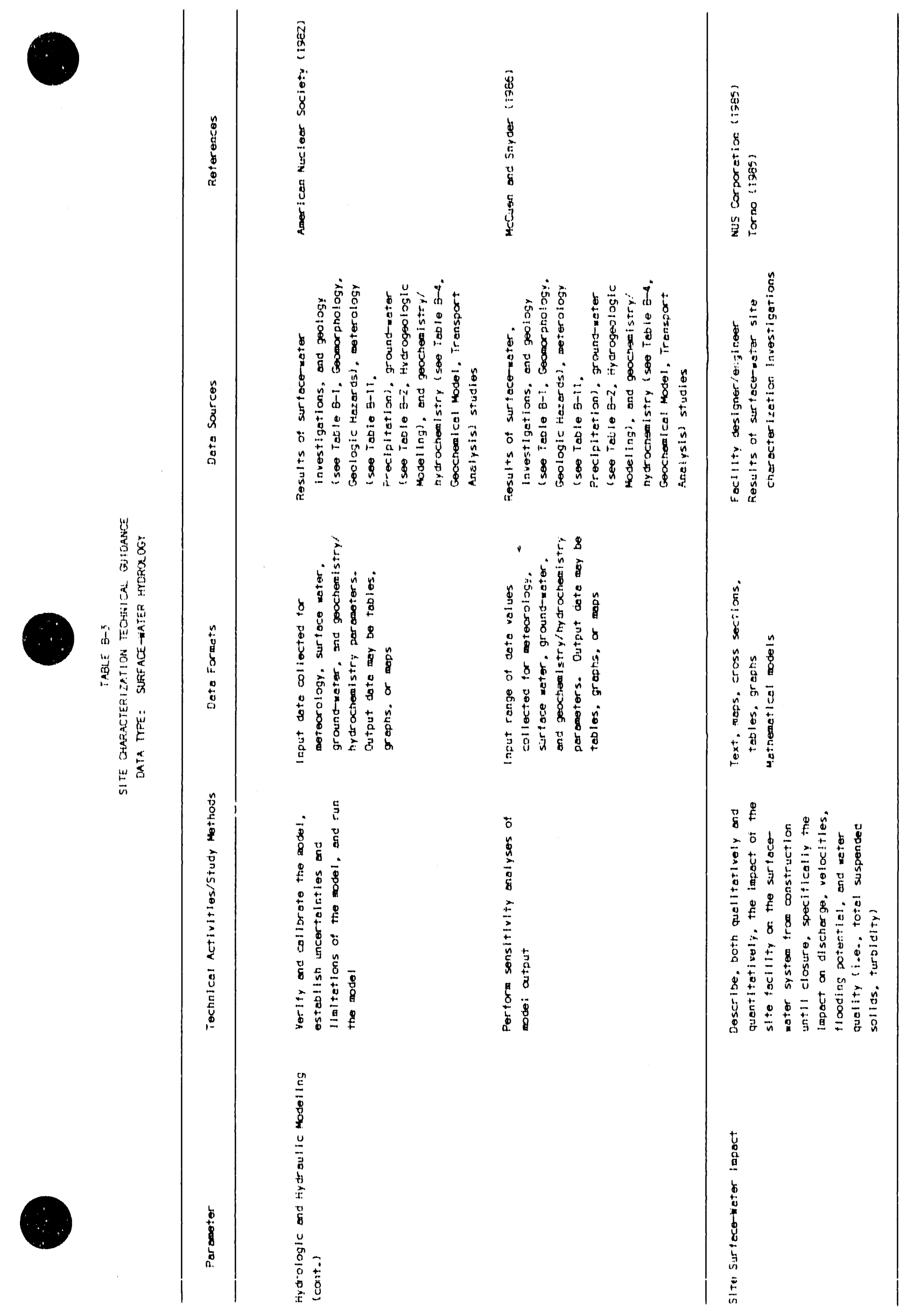

a 
TABLE B-3

REFERENCES - SURFACE - WATER HYDROLOGY

ACE; See U.S. Army Corps of Engineers.

American Nuclear Society, American National Standard Recommended Programming Practices to Facilitate the Portability of Scientific Computer Programs, ANSI/ANS-10.2-1982, 1982.

American Society for Testing and Materials, "Standard Method for Open-Channel Flow Measurement of Water and Waste Water by the Parshall Flume, Designation 01941," Annual Book of American Society for Testing and Materials Standards, Vol. $11.01,1975 a$.

American Su-iety for Testing and Materials, "Standard Method for Open Channel Flow Measurement of Water and Waste Water by Weirs," ASTM Designation D2034-68, Annual Book of Standards: Part 31 - Water, 1975b.

American Society for Testing and Materials, "Standard Test Method for Infiltration Rate of Soils in Field Using Double-Ring Infiltrometers, Designation D3385-75," Annual Book of American Society for Testing and Materials Standards, Vol. 04.08, 1985, pp. 544-549.

ASTM; See American Society for Testing and Materials.

T. E. Avery, Interpretation of Aerial Photographs, Minneapolis: Burgess Publishing Co., 1968.

H. H. Barnes, Roughness Characteristics of Natural Channels, U. S. Geological Survey Water-Supply Paper 1849, 1967.

D. L. Brakensiek, H. B. Osborn, and W. J. Rawls, Field Manual for Research in Agricultural Hydrology, U.S. Department of Agriculture Agricultural Handbook No. 224, 1979.

T. J. Buchanan and W. P. Somers, "Stage Measurements at Gaging Stations," in

U. S. Geological Survey, Techniques of Water-Resources Investigations, Book 3, Chpt. A7, 1968a.

T. J. Buchanan and W. P. Somers, "Discharge Measurements at Gaging Stations," in U. S. Geological Survey, Techniques of Water-Resources Investigations, Book 3, Chpt. A8, 1968b.

R. W. Carter and J. Davidian, "General Procedures for Gaging Streams" in U. S. Geological Survey, Techniques of Water-Resources Investigations, Book 3, Chpt. A6, 1968.

V. T. Chow (ed.), Handbook of Applied Hydrology, New York: McGraw ii11 Book Co., 1964. 
R. R. Compton, Geology in the Field, Somerset: John Wiley and Sons, Inc., 1985.

DOE; See U.S. Department of Energy.

T. Dunne and L. B. Leopold, Water in Environmental Planning, San Francisco:

W.H. Freeman and Co., 1978.

C. W. Fetter, Jr., Applied Hydrology, Columbus: Charles E. Merrill Publishing Co., 1980.

W. H. Graf, Hydraulics of Sediment Transport, New York: McGraw-Hill Book Co., 1971.

D. W. Hubbel, Apparatus and Techniques for Measuring Bed-Load, U. S. Geological Survey Water-Supply Paper 1748, 1964.

W. G. Knisel (Ed.), CREAMS: A Field-Scale Model for Chemicals, Runoff, and Erosion from Agricultural Management Systems, U.S. Department of Agriculture, Conservation Research Report No. 26, 1980.

R. K. Linsley, M. A. Kohler, J. L. H. Paulhus, Hydrology for Engineers, New York: McGraw-Hi11 Book Co., 1982.

R. J. Lutton et a1., Tests for Evaluation Sites for Disposal of Low-Level Radioactive Waste, NUREG/CR-3038, December 1982.

R. H. McCuen and W. M. Snyder, Hydrologic Modeling: Statistical Methods and Applications, Englewood Cliffs: Prentice-Hall, 1986.

G. W. Musgrave, "The Quantitative Evaluation of Factors in Water Erosion: $A$ First Approximation," Journal of Soil Water Conservation, 2, 3, 1947.

G. W. Musgrave and H. N. Holton, "Infiltration," in V. T. Chow (ed.), Handbook of Applied Hydrology, New York: McGraw-Hill Book Cr , 1964.

NRC; See U.S. Nuclear Regulatory Commission.

NUS Corporation, Water Supply and Use in Deaf Smith. Swisher, and Nearby Counties in the Texas Panhandle, BMI/ONWI-557, February 1985.

R. G. Reeves (ed.), Manual of Remote Sensing, Vols. 1 and 2, Falls Church: American Society of Photogrammetry, 1975.

G. F. Smoot, A Review of Velocity-Measuring Devices, U. S. Geological Survey Open-File Report, 1974.

H. C. Torno (ed.), Computer Applications in Water Resources, New York, June 10-12, 1985, New York: American Society of Civil Engineers, 1985. 
University of Arizona, Site Characterization Field Manual for Near Surface Geologic Disposal of Low-Level Radioactive Waste, U.S. Department of Energy Report DE FG07 841D 12514, 1985.

U. S. Agricultural Research Service, A Universal Equation for Predicting Rainfall-Erosion Losses, U. S. Department of Agriculture Special Report 22.26, 1961.

U. S. Army Corps of Engineers, HEC-6, Scour and Deposition in Rivers and Reservoirs, Users Manual, Hydrologic Engineering Center, Davis, California, 1977.

U. S. Army Corps of Engineers, HEC-2 Water Surface Profiles, Users Manual, Hydrologic Engineering Center, Davis, California, 1979.

U. S. Army Corps of Engineers, HEC-1 Flood Hydrograph Package, Users Manual, Hydrologic Engineering Center, Davis, California, 1981.

U. S. Bureau of Reclamation, Water Measurement Manual, 1967.

U. S. Department of Energy, Environmental Monitoring for Low-Level WasteDisposal Sites, Low-Leve1 Radioactive Waste Handbook Series, DOE/LLW-13Tg, 1983.

U. S. Geological Survey, National Handbook of Recommended Methods for Water-Data Acquisition, U. S. Geological Survey Office of Water Data Coordination, 1977.

U. S. Nuclear Regulatory Commission, Design Basis Floods for Nuclear Power Plants, U. S. Nuclear Regulatory Commission Regulatory Guide 1.59, 1977.

D. S. Way, Terrain Analysis, New York: McGraw-Hill Book Co., 1978.

B. N. Wilson et a1., "SEDIMOT II: A Design Hydrology and Sedimentology Model for Surface Mine Lands," Proceedings, 1981 Symposium on Surface Mine Hydrologx, Sedimentology, and Reclamation, College of Engineering, University of Kentucky, Lexington, 1981. 
TABLE B-4

PARAMETER DESCRIPTIONS - GEOCHEMISTRY/HYDROCHEMISTRY

Water Quality: The particular range of chemical attributes that is characteristic of a surface or ground water. Important chemical species for water-quality characterization include total dissolved solids, dissolved oxygen, carbon dioxide and fluoride, major ions, nutrients, dissolved iron and manganese, dissolved heavy metals, silica, oil and grease, and various toxicants. Major ions include the cations sodium, potassium, calcium, and magnesium, and the anions sulfate, chloride, bicarbonate, and carbonate. Nutrients typically include total and dissolved organic carbon, orthophosphate, total phosphorous, nitrate, ammonia, and total kjeldahl ritrogen. Heavy metals typically include copper, zinc, nickel, and hexavalent chromium. Toxicants that are present, are suspected as present, or potentially may be introduced to the water will be determined during site characterization. These may include both inorganic chemicals (e.g., dissolved arsenic, dissolved boron, radionuclides) and organic chemicals (e.g., herbicides, pesticides, volatile organics). Hardness, pH, alkalinity, waterquality indicator organisms, turbidity, and nature of colloidal materials in the water will also be determined in a complete water-quality assessment. The particular water characteristics to be determined during site characterization will be a function of site location and of the composition of the waste to be disposed.

Ion-Exchange Capacity: The extent to which a material will exchange ions that are adsorbed on its surface with dissolved ions that are present in a surrounding fluid. The ion-exchange capacity depends on a number of factors, including the material type, concentrations and number of dissolved species present in solution, and system pH. The cation-exchange capacity (CEC) is of particular interest in soil and subsurface environments. Solls with high clay content, and particularly with high organic content, typically will have a high CEC. Cations, such as many of the dissolved radionuclides that migrate through these materials, will be effectively retarded during transport as a result of ion exchange.

Organic content: The proportion of organic matter present in soil. The organic matter may be comprised of living and decomposed plants, roots, and detritus. Organic constituents that may be quantified include total organic carbon (TOC), total and volatile organic acids, chelating agents, tannin, lignin, soil nutrients (e.g., nitrate, ammonia, phosphate), and microorganisms (e.g., total bacteria, coliforms). Constituents may be analyzed in soil and in soil gas. Organic matter, and particularly root systems, can provide pathways for chemical migration through soils and to the soil surface. The organic soil fraction typically has a high sorptive capacity and thus can increase the soil CEC. Organics also may leach and mobilize inorganic constituents in soil. Certain organics may behave as chelating agents, which can bind metallic ions (e.g., radionuclides). The chelating agents, when dissolved in water, may provide a transport mechanism for metals that are normally non-mobile. 
Eh-pH: Eh is commonly referred to as the redox potential, and is a measure of the tendency of a solution to oxidize or reduce susceptible constituents. pH refers to hydrogen ion activity, and is a measure of the acidity of a solution. Both Eh and $\mathrm{pH}$ are typically measured using potentiometric probes. Eh may also be estimated from measured concentrations of both members of redox couples, such as iron species. To address possible redox disequilibrium, if a single Eh value is required for modeling purposes, that value should be determined from as many sources as is practical. The assumptions and methods used in defining an overall Eh for model calculations should be stated and justified. The relationship between Eh and $\mathrm{pH}$ in aqueous systems is commonly lilustrated on Eh-pH diagrams. These diagrams can be used to predict stability fields of the various chemical species. Thus, for a given Eh and $\mathrm{pH}$, species that are likely to exist and that contain elements of interest (e.g., radionuclides) can be determined. Eh-pH diagrams can be used to predict the behavior of elements such as radionuclides in the local environment.

Distribution coefficient: The ratio reflecting the allocation of a species between two phases in an aqueous or rock system. In particular, this parameter is useful for estimating the fraction of a species that will be allocated to the aqueous phase and therefore will remain mobile, and the fraction allocated to the solid phase that will be immobile. The distribution coefficient is an empirical parameter whose value is strongly dependent upon site specific or experimental conditions. The distribution coefficient includes the effects of ion exchange and other sorption reactions. This parameter can be used to estimate the extent of retardation of a dissolved species during transport, but the accuracy of that estimate will strongly depend upon the extent to which the conditions approximate those under which the distribution coefficient was measured.

Temperature: The temperature of both in-situ ground water and surface water. This parameter is important because the other parameters are temperature sensitive.

Radiometric dating: Determination of the age of the ground water or rock on the basis of radioisotope abundances.

Isotope content: The quantity of radioactive and other isotope constituents present in the soil and water.

Soil Mineralogy and Mineral Solubility: The types of minerals present in a soil; also includes their weathering and engineering characteristics. Soil mineralogy is important a : it relates both to radionuclide migration and to engineering behavior. Mineral solubility refers to the tendency of soil minerals to dissolve into aqueous phases present in the system. Description of mineral solubility should include the range of chemical and physical conditions bounding various stability fields.

Hydrodynamic Dispersion Coefficient: The hydrodynamic dispersion coefficient describes dispersion of a contaminant in ground water. Dispersion is a result of two processes: molecular diffusion and mechanical mixing. Diffusion is, the process whereby contaminants move under the influence of their kinetic 
activity in the direction of their concentration gradient. Mechanical mixing or mechanical dispersion is a result of velocity variations within the porous medium. The hydrodynamic dispersion coeffictent is dependent on the diffusion coefficient, the concentration gradient, the longitudinal and transverse dispersivities, and the velocity field.

Geochemical Mode]: A mathematical formulation of predicted geochemical behavior of the rook-soli-ground-water system. Description of such a model should include information on the database used, validation exercises applied, and the capabilitias arid limitations of the model.

Iransport Analysis: A mathematical formulation of predicted transport behavior in the saturated and unsaturated ground-water system. Processes of dispersion, diffusion, adsorption, degradation, and radioactive decay may be included in transport analyses. 


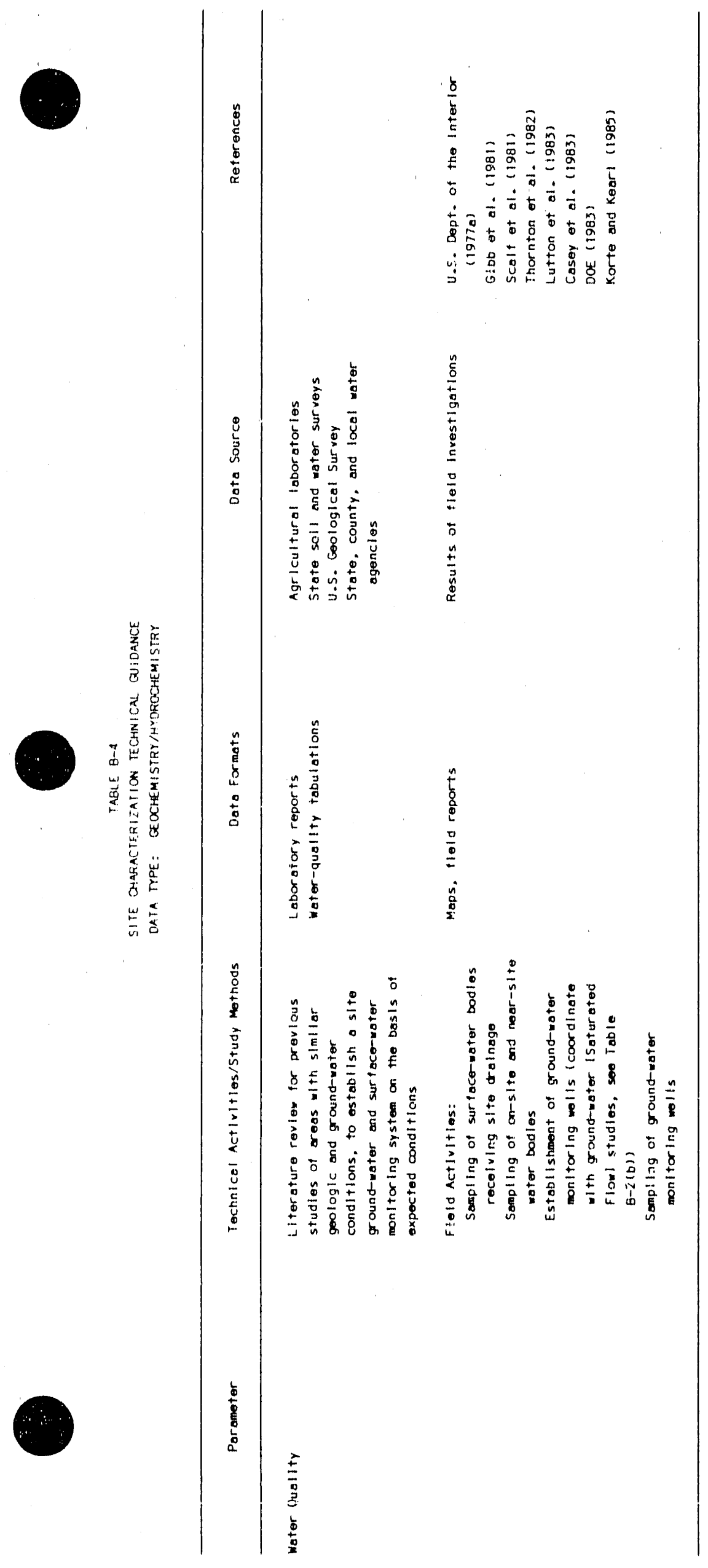




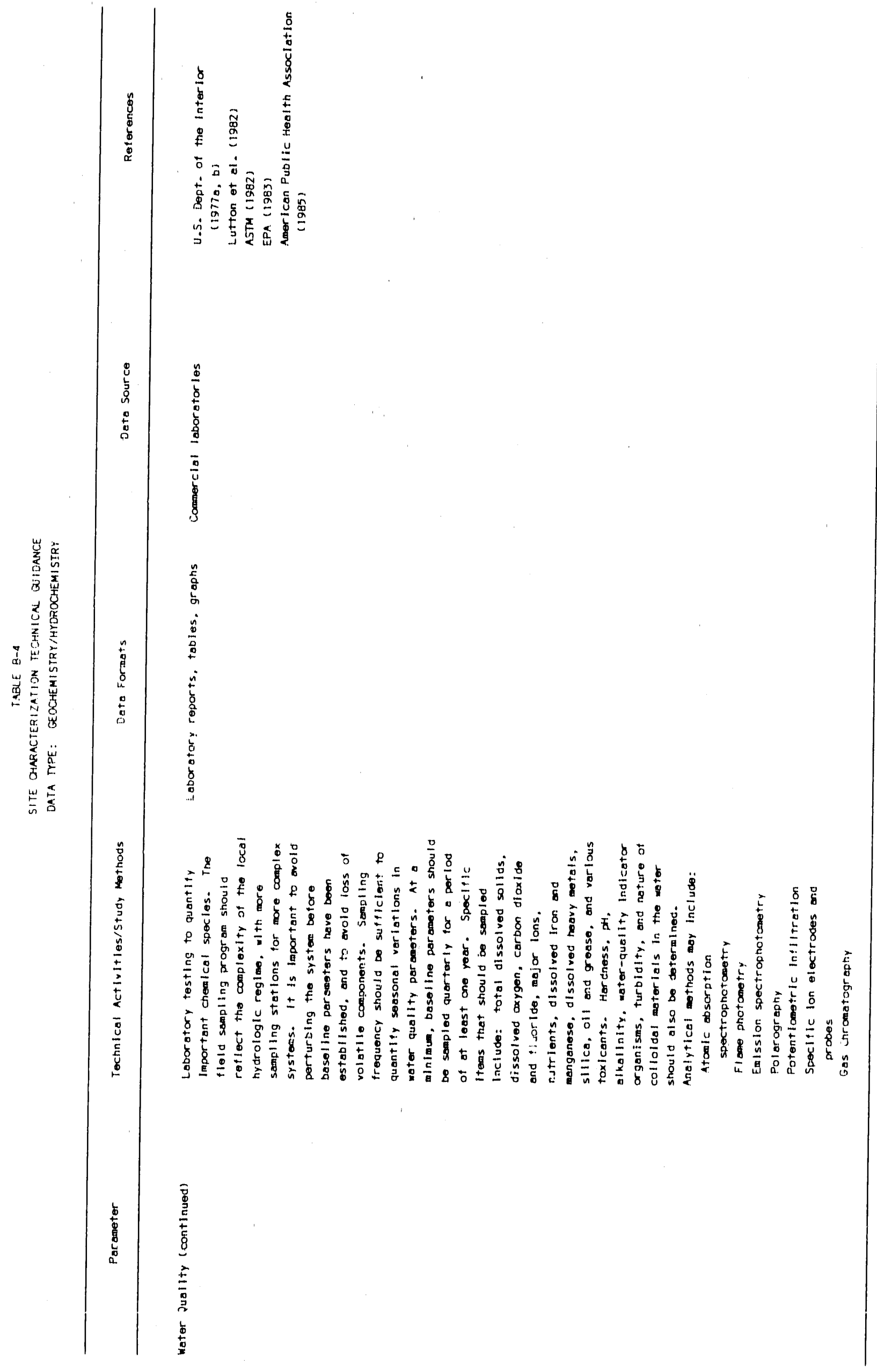




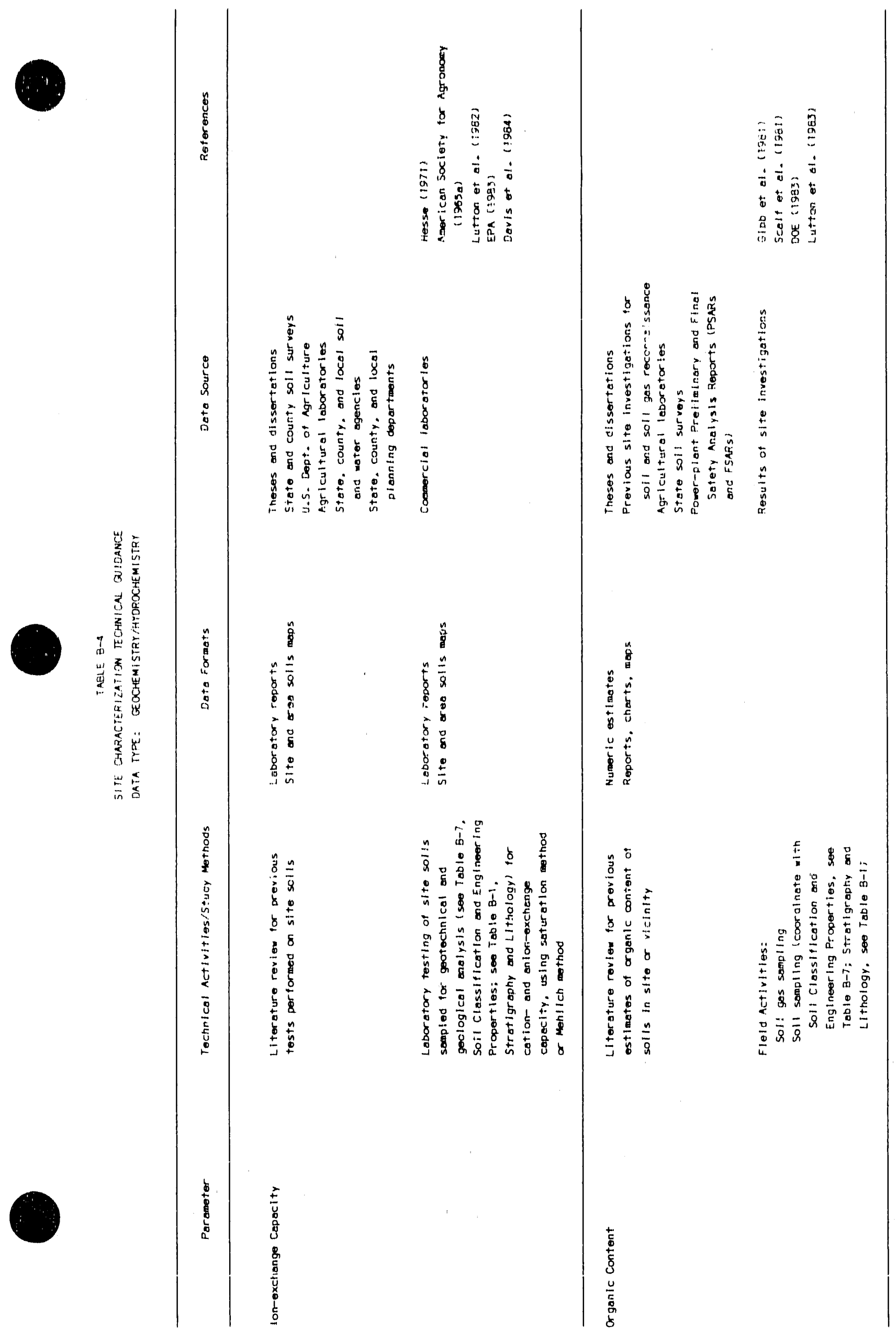




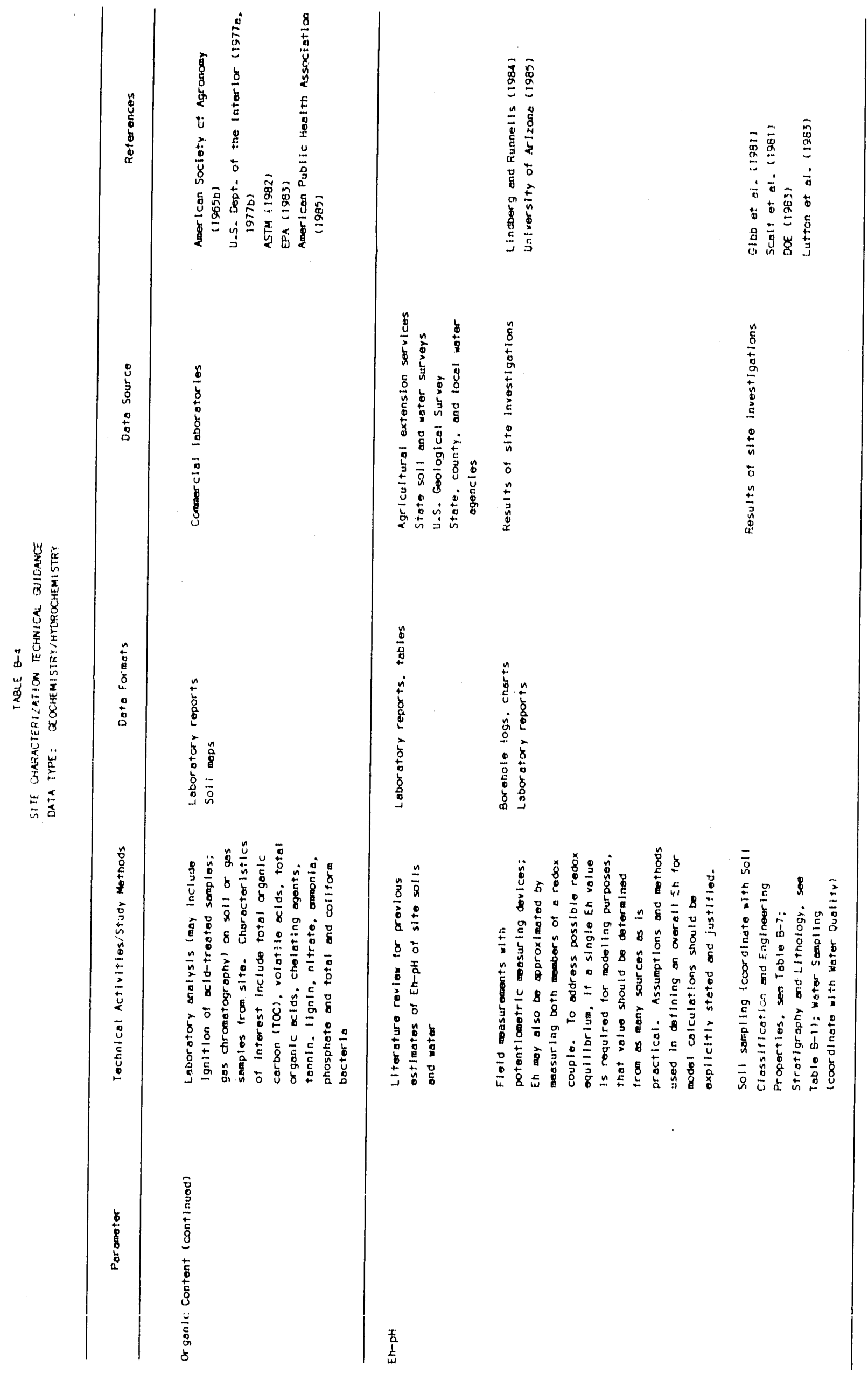




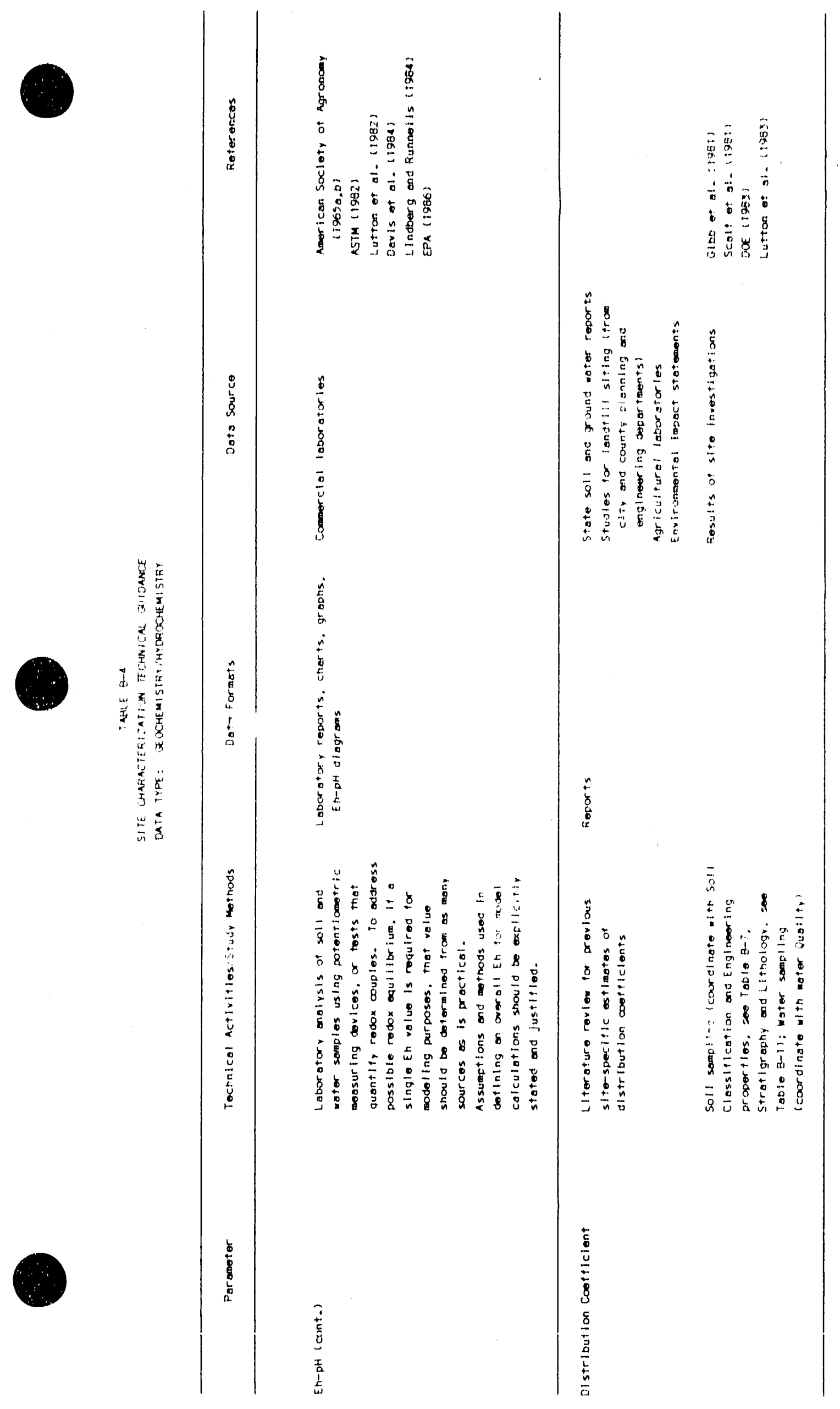




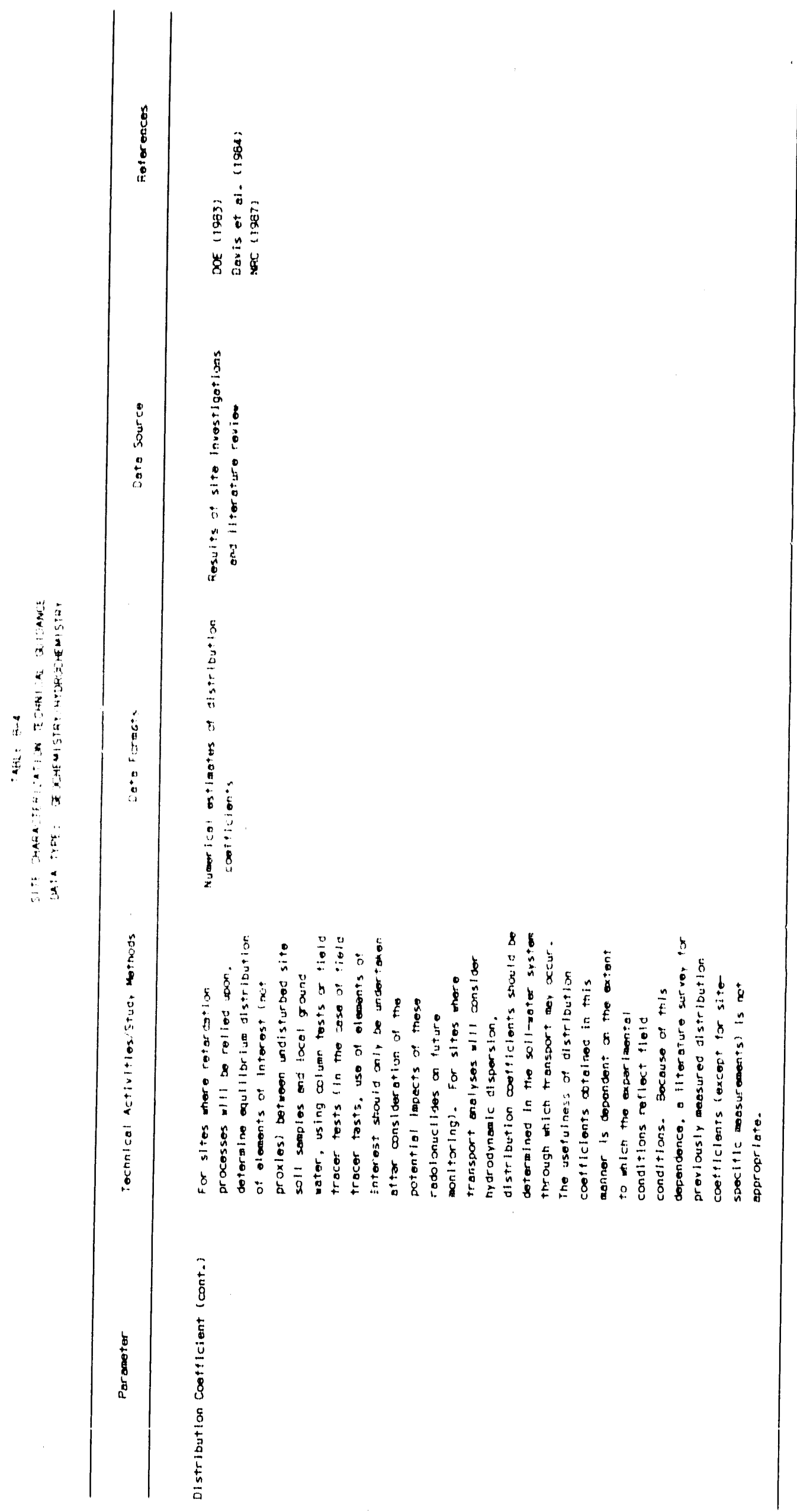




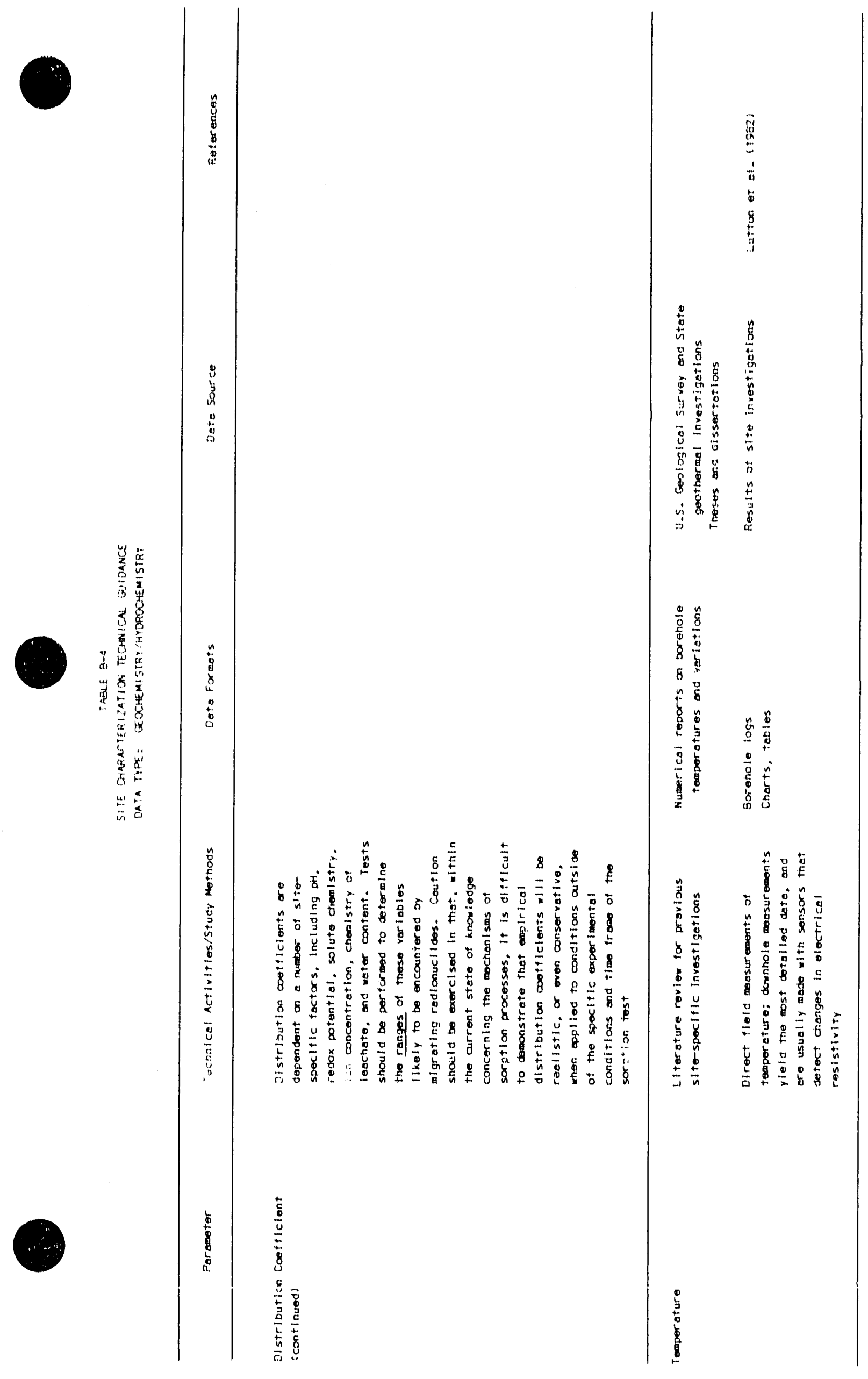



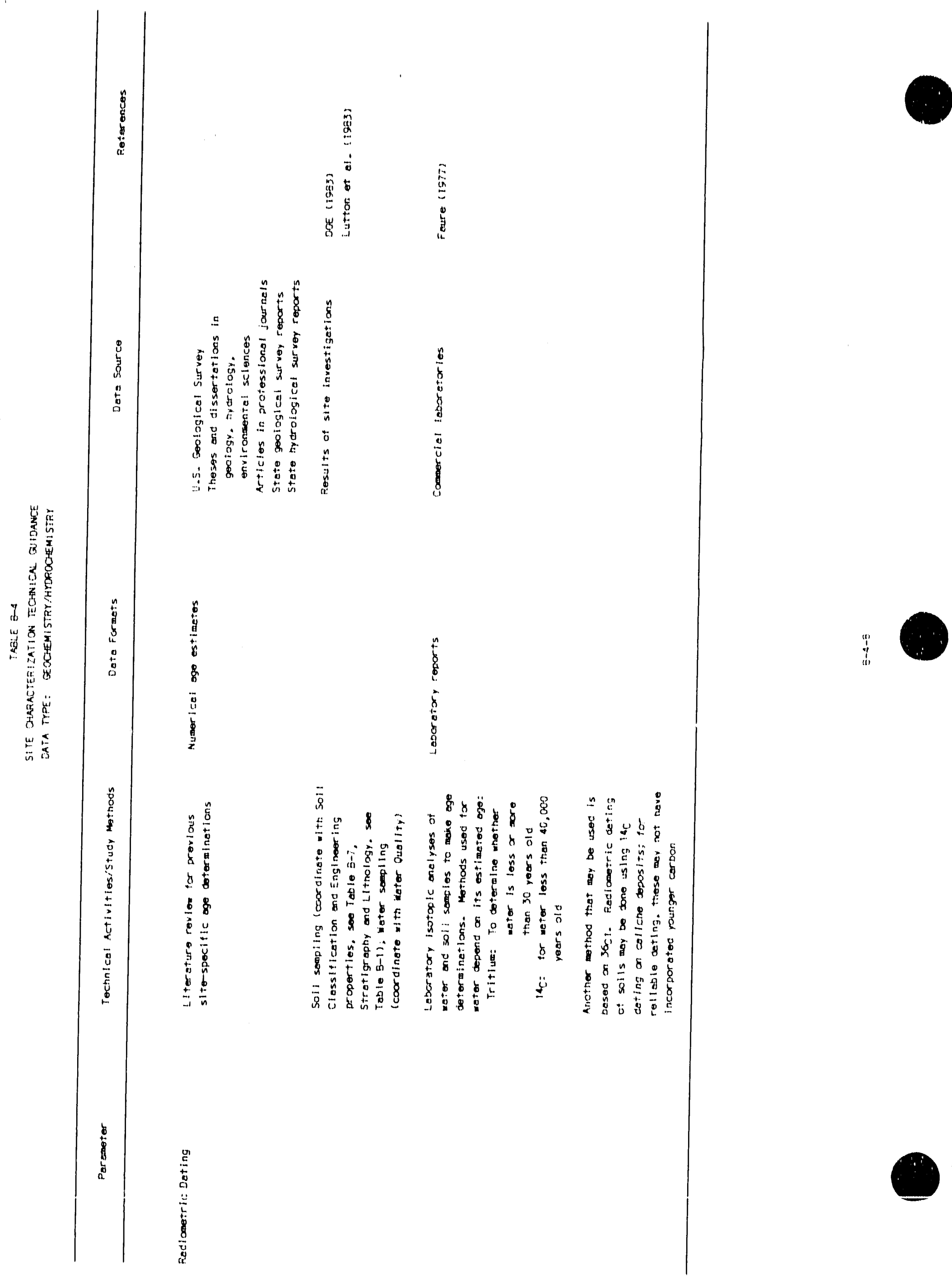


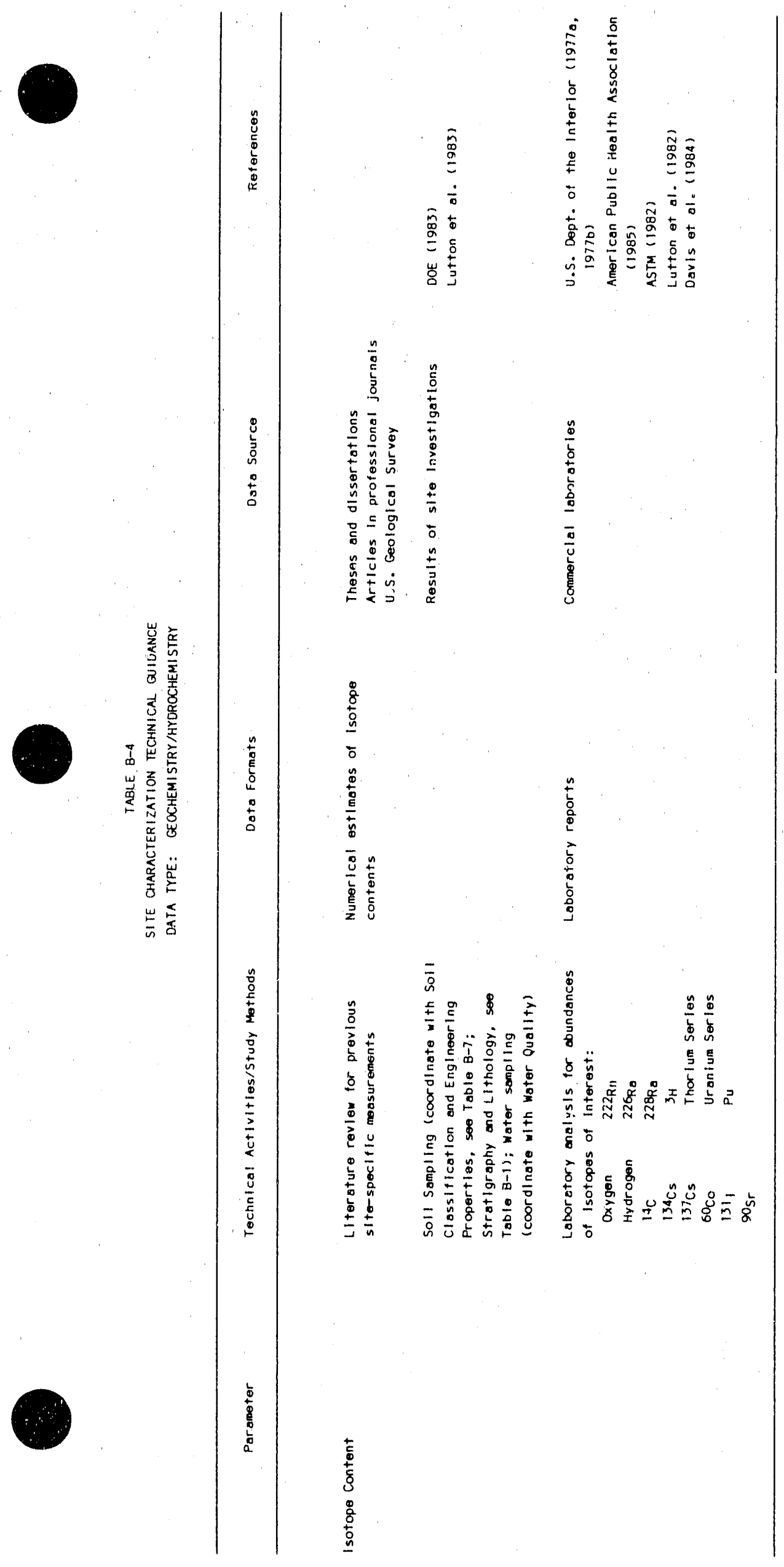



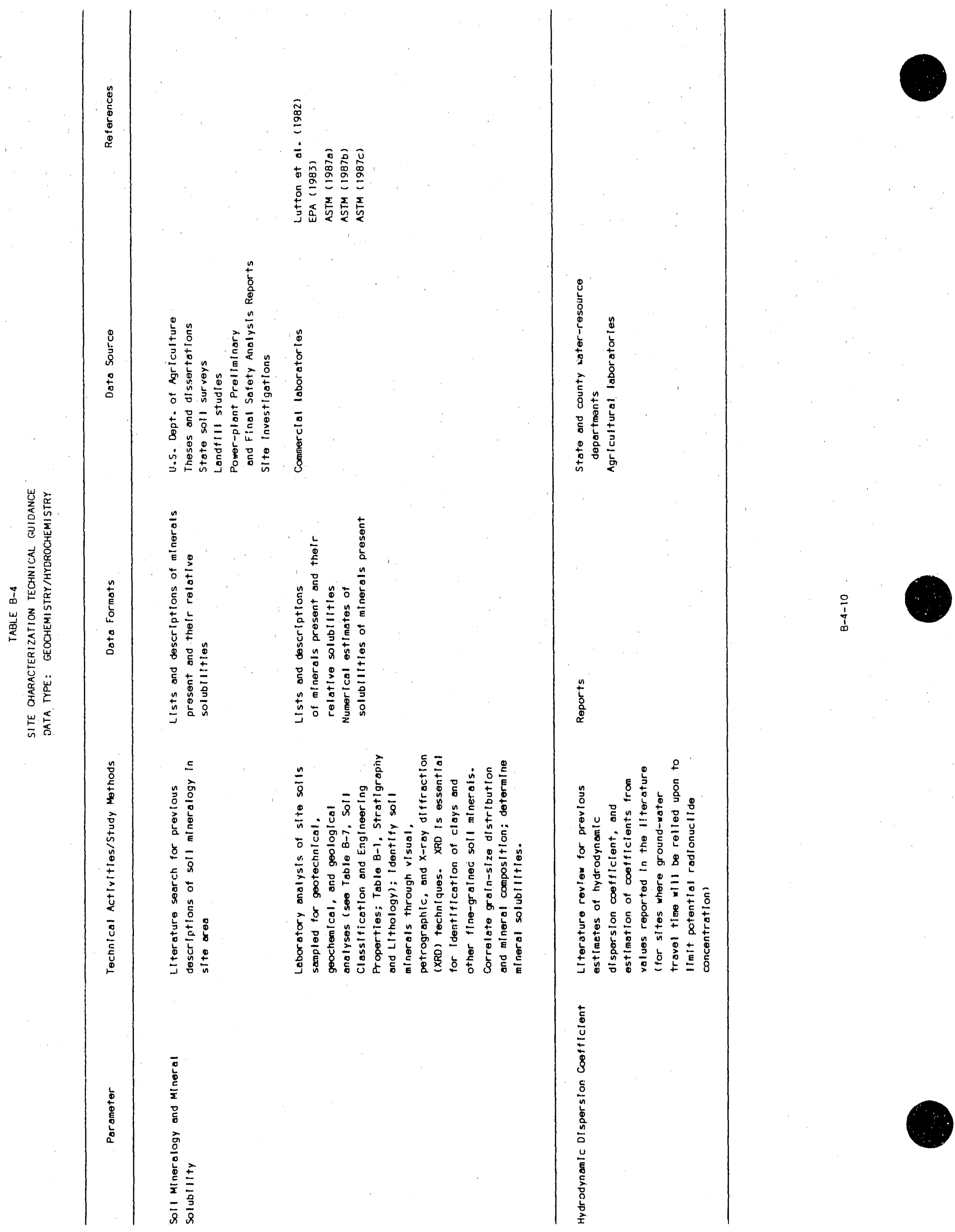


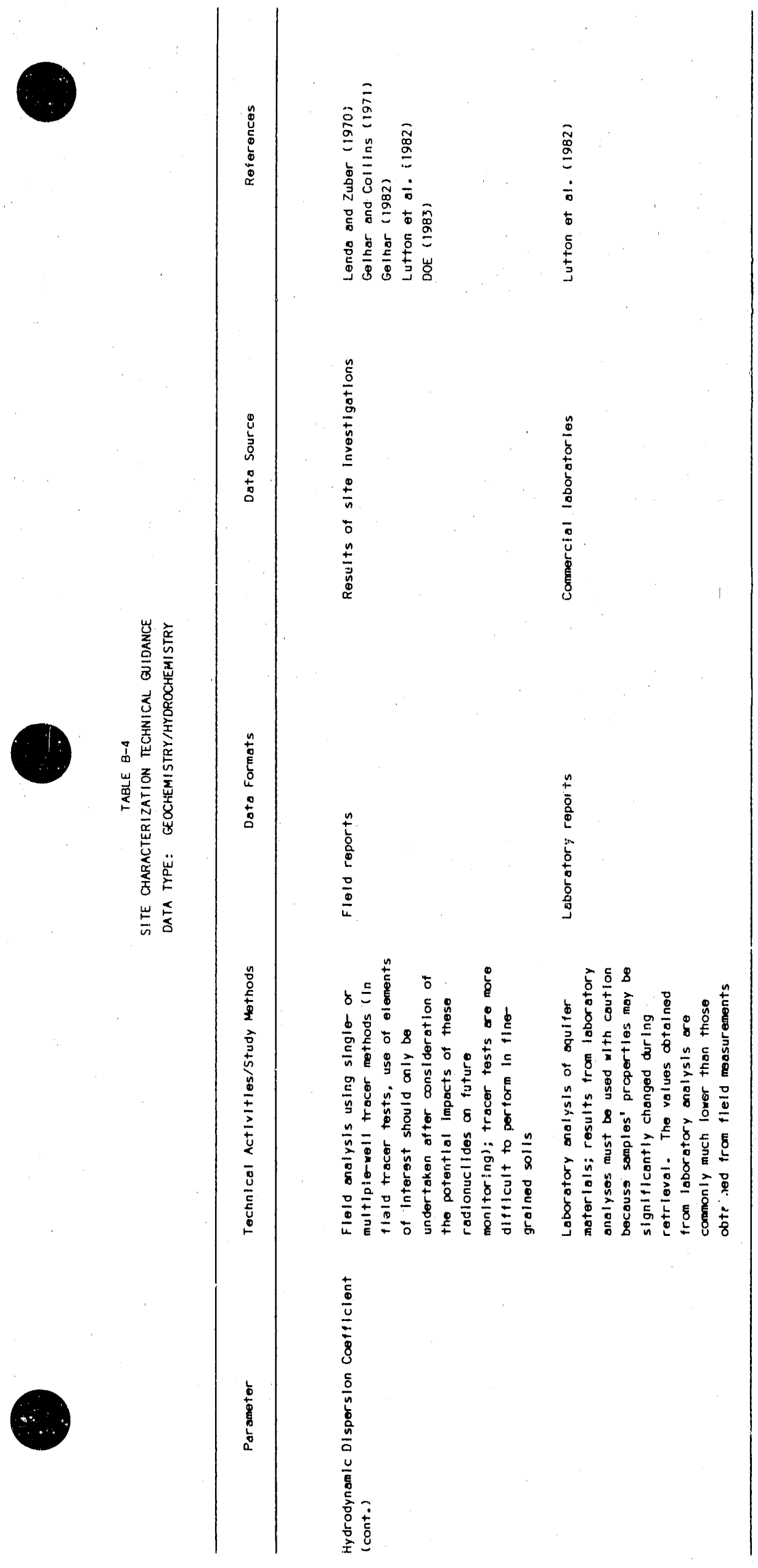

7
$\vdots$
1
0 


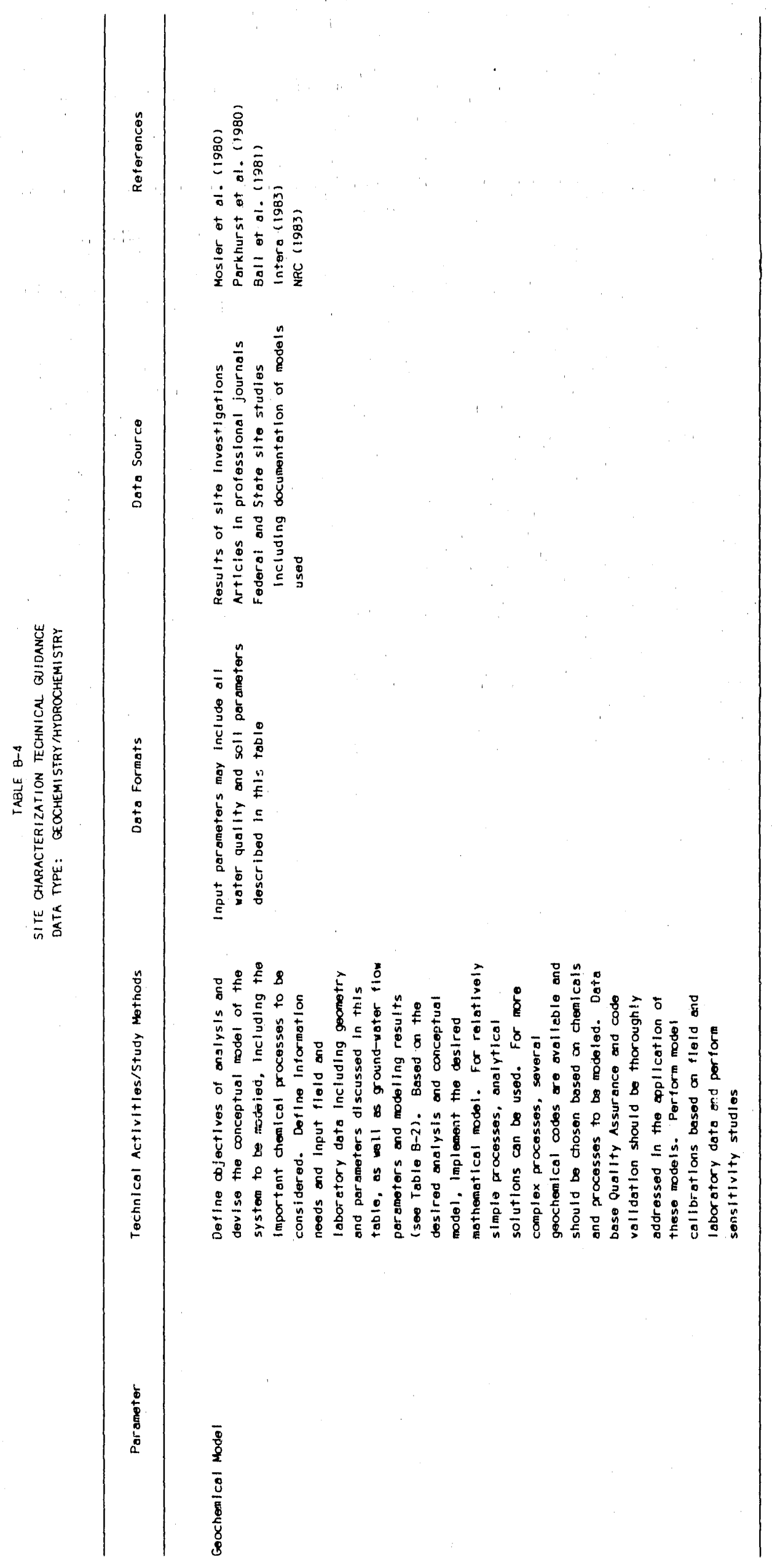




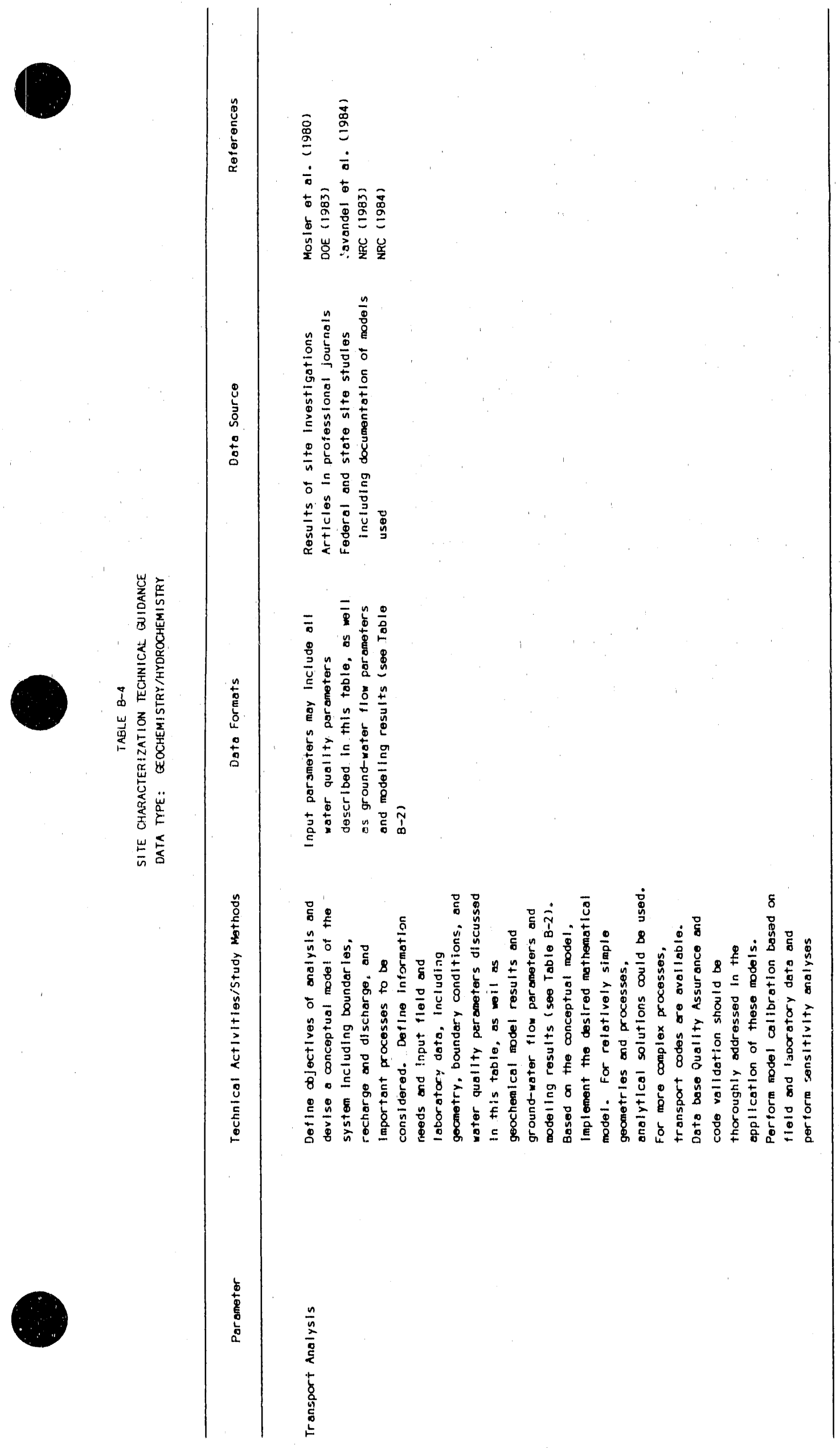


TABLE B-4

REFERENCES - GEOCHEMISTRY/HYDROCHEMISTRY

American Public Health Association, Standard Methods for the Examination of Water and Wastewater, 16th Ed., 1985.

American Society of Agronomy, Methods of Soll Analysis: Part 1. Physical Properties, 1965a.

American Society of Agronomy, Methods of Soil Analysis: Part 2 - Chemical and Microbiological Properties, $1965 \mathrm{~b}$.

American Society for Testing and Materials, Annual Book of ASTM Standards: Part 31 - Water, American Society for Testing and Materials, 1982.

American Society for Testing and Materials, "Standard Descriptive Nomenclature of Constituents of Natural Mineral Aggregates," Annual Book of ASTM

Standards, Vo1. 04.02, Construction, C294-69, 1987a, p. 216-224.

American Society for Testing and Materials, "Standard Practice for Petrographic Examination of Aggregates for Concrete," Annual Book of ASTM Standards, Vol. 04.02, Construction, C295-79, 1987b, D. 225.

American Society for Testing and Materials, "Standard Recommended Practice for Description and Identification of Soils (Visual-Manual Procedure)", Annual Book of ASTM Standards, Vol. 04.08, Construction, D2488-69, 1987C, p. 409.

ASTM; See American Society for Testing and Materials.

J. W. Ba11, E. A. Jenne, M. W. Cantre11, WATEQ3: A Geochemical Model with Uranium Added, U.S. Geological Survey Open-File Report 81-1183, 1981.

D. Casey et al., "Sampling Frequency for Water Quality Monitoring: Measures of Effectiveness," Water Resources Research, 19, 5, 1983, pp. 1107-1110.

E. C. Davis et a1., Site Characterization Techniques Used at a Low-Level Waste Shallow Land Burial Field Demonstration Facility, Oak Ridge National Laboratory, ORNL/TM-9146, Environmental Sciences Division Publication No. $2306,1984$.

DOE; See U.S. Department of Energy.

EPA; See U.S. Environmental Protection Agency.

G. Faure, Principles of Isotope Geology, New York: John Wiley and Sons, 1977.

L. W. Gelhar, Analys is of Two-Hell Trac " Tests with a Pulse Innut, prepared for Rockwell Hanford Operations, Energy systems Group, Report No. RHO-BW-CR$13.1 \mathrm{P}, 1982$. 
L. W. Gelhar and M. A. Collins, "General Analysis of Longitudiral Dispersion in Nonuniform Flow," Water Resources Research, 7, 6, 1971, p. 1511-1521.

J. P. Gibb, R. M. Schyller, R. A. Griffin, Procedures for the Collection of Representative Water Quality Data from Monitoring Wells, Cooperative Groundwater Report 7, Illinois State Geological Survey, 1981.

J. D. Hem, study and Interpretation of the Chemical Characteristics of Natural Wate: , U.S. Geological Survey Water-Supply Paper 1473, U.S. Geological Survey, Reston, VA, 1970.

P. R. Hesse, "Anion Exchange Capacity (Mehlich)," Textbook of Soil Chemical Analyses, Section 7:3:4, New York: Chemical Publishing Co., 1971, p. 105.

Intera Environmental Consultants, Inc., E03/E06: A Geochemical Speciation and Reactive Path Code Package Suitable for Nuclear Waste Performance Assessment, Houston, Texas, 1983.

1. Javande1, C. Doughty, and C. F. Tsang, Groundwater Transport: Handbook of Mathematical Models, American Geophysical Union Water Resources Monograph 10, Washington, D.C., 1984.

N. E. Korte and P. M. Kearl, Procedures for the Collection and Preservation of Groundwater and Surface Water Samples and for the Installation of Monitoring Wells, U.S. DOE Technical Measurements Center, 2nd edition, GJ/TMC-08, October 1985 .

A. Lenda and A. Zuber, Iracer Dispersion in Groundwater Experiments, IAEA-SM129/37, International Atomic Energy Agency, Vienna, Austria, 1970.

R. D. Lindberg and D. D. Runne11s, "Ground Water Redox Reactions: Analys is of Equilibrium State Applied to Eh Measurements and Geochemical Modeling," Science, 225, 1984, pp. 925-927.

R. J. Lutton et al., Tests for Evaluating Sites for Disposal of Low-Level Radioactive Waste, NUREG/CR-3038, U.S. Nuclear Regulatory Commission, 1982.

R. J. Lutton, W. 0. Strohm, Jr., A. B. Strong, Subsurface Monitoring Programs at Sites for Disposal of Low-Level Radioactive Waste, NUREG-CR-3146, U.S. Nuclear Regulatory Commission, 1983.

J. E. Mosier et a1., Low-Level Waste Management: A Compilation of Models and Monitoring Techniques, ORNL/SUB-13617/2SAI/OR-562-2, Oak Ridge National Laboratory, 1980.

NRC; See U.S. Nuclear Regulatory Commission.

D. L. Parkhurst, D. C. Thorstenson, L. N. Plummer, PHREEQE: A Computer Program for Geochemical Calculations, U.S. Geological Survey Water-Resources Investigations 80-96, 1980. 
M. R. Scalf et a1., Manual of Ground-Water Quality Sampling Procedures, NWWA/EPA Series, National Water We11 Association, Worthington, Ohio, 1981.

K. Thornton et a1., "Reservoir Water quality Sampling Design," Water Resources Bulletin, American Water Resources Association, 18, 3, 1982.

University of Arizona, Site Characterization Field Manual for Near Surface Disposal of Low-Level Radioactive Waste, U.S. Department of Energy Report DE FG07 841D 12514, 1985.

U.S. Department of Energy, Environmental Monitoring for Low-Level Waste Disposal Sites, DOE/LLW-13Tg, January 1983.

U.S. Department of the Interior, "Chemical and Physical Quality of Water and Sediment," Chapter 5, National Handbook of Recommended Methods for Water-Data Acquisition, U.S. Geological Survey, 1977 a.

U.S. Department of the Interior, "Methods fo" Jetermination of Radioactive Substances in Water and Fluvial Sediments," Chapter A5, Book 5, Techniques of Water-Resources Investigations, U.S. Geological Survey, $1977 \mathrm{~b}$.

U.S. Environmental Protection Agency, Methods for Chemical Analys is of Water and Wastes, EPA 600/4-79-020, Cincinnati, 1983.

U.S. Environmental Protection Agency, Test Methods for Evaluating Solid Waste: Laboratory Manual - Physical/Chemical Methods, Washington, D.C., 1986.

U.S. Nuclear Regulatory Commission, Final Technical Position on Documentation of Computer Codes for High-Level Waste Management, NUREG-0856, 1983.

U.S. Nuclear Regulatory Commission, Determination of Radionuclide Solubility in Groundwater for Assessment of High-Level Radioactive Waste Isolation, Division of Waste Management Technical Position, 1984.

U.S. Nuclear Regulatory Commission, Determination of Radionuclide Sorption for Assessment of High-Level Waste Isolation, Division of Waste Management Branch Technical Position, 1987. 
TABLE B-5

PARAMETER DESCRIPTIONS - WATER RESOURCES

Past and Present Ground-water Usage: An inventory of past and present groundwater users within approximately 2 kilometers of the site. Information should include the location, type and amount of use, hydrogeologic unit used, sources of water supply, type of well and pumping equipment, maximum production rate of well, and water quality data. The inventory should identify the nearest down-gradient ground-water users and the nearest municipal supply relying on groundwater.

Past and Present Surface-water Usage: An inventory of past and present surface-water users in the vicinity of the site and, in particular, within appruximately 10 kilometers downstream of the site. Information should include the location, type and amount of use, number of users on the system, rate of withdrawal, percentage of stream flow withdrawn, sources of water supply, type of intake and pumping equipment, and surface water quality data. The inventory should ident ify the nearest down-gradient surface-water users and the nearest municipal supply relying on surface water.

Groundwater-water Discharge Points: An inventory of al1 springs, seeps, etc., in the vicinity of the site and usage at these points. Information should include the location, type and amount of use, hydrogeologic unit used, flow rate, sources of water supply, type of well and pumping equipment, and water quality data.

Projected Surface-water Usage: The projected demand and usage of local and regional surface-water resources for domestic, municipal, agricultural, industrial, mining, recreational, and navigational needs. This projection will include geographic, demographic, and economic information and documentation as part of the evaluation.

Projection Ground-water Usage: The projected demand and usage of local and regional ground-water resources for domestic, municipal, agricultural, industrial, mining, and recreational needs. This projection will inciude the potential rates of withdrawal from significant aquifer systems, and geographic, demographic, and economic information and documentation as part of the evaluation.

Water Rights and Legal Summaries: A suminary of statutory and other legal restrictions relating to surface-water and ground-water use as imposed by municipal, State, or Federal regulations.

Site Water Resource Impact: A qualitative and quantitative description of the present and projected surface-water and ground-water uses within the site vicinity that could affect or be affected by the site. 


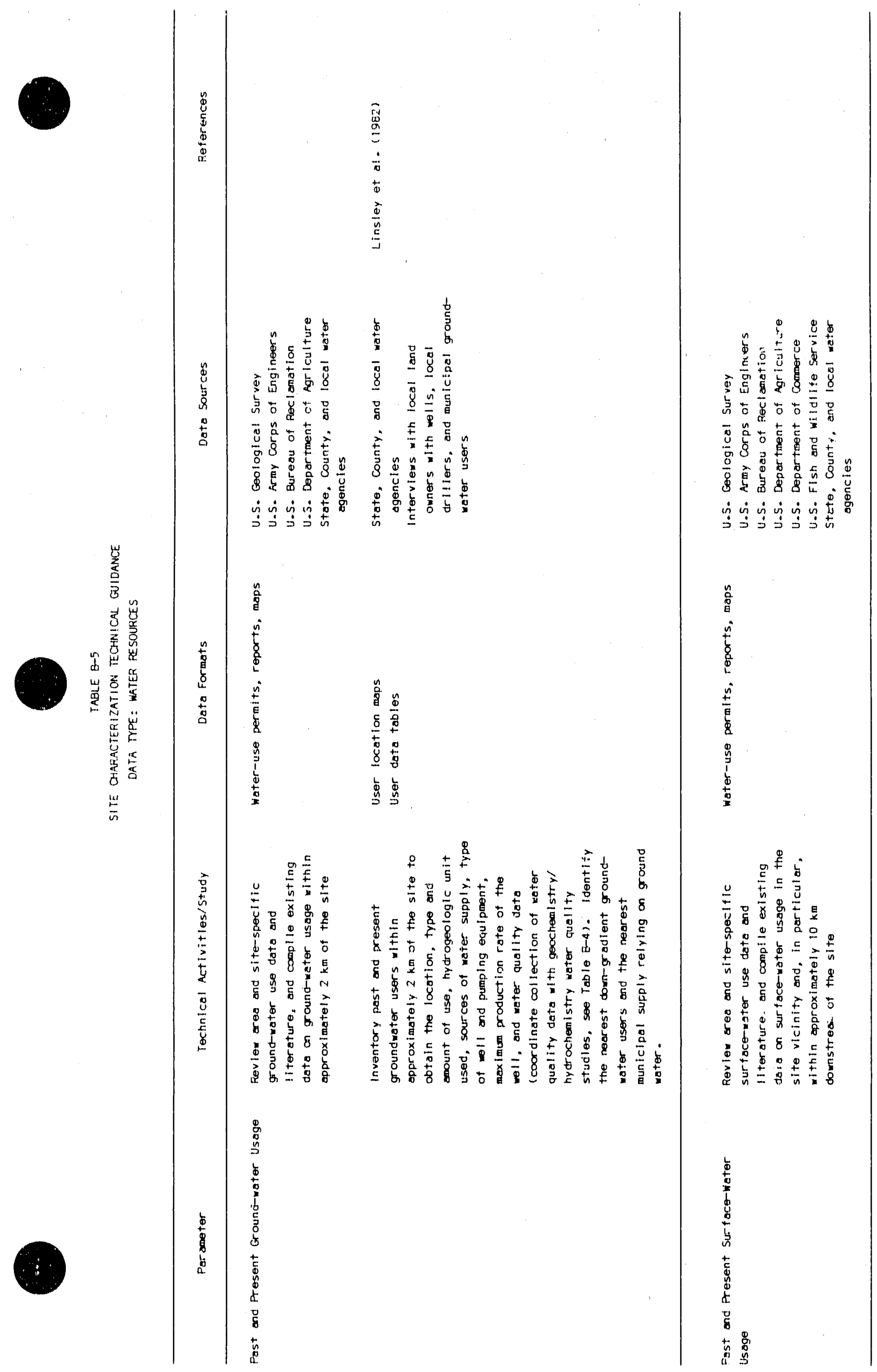




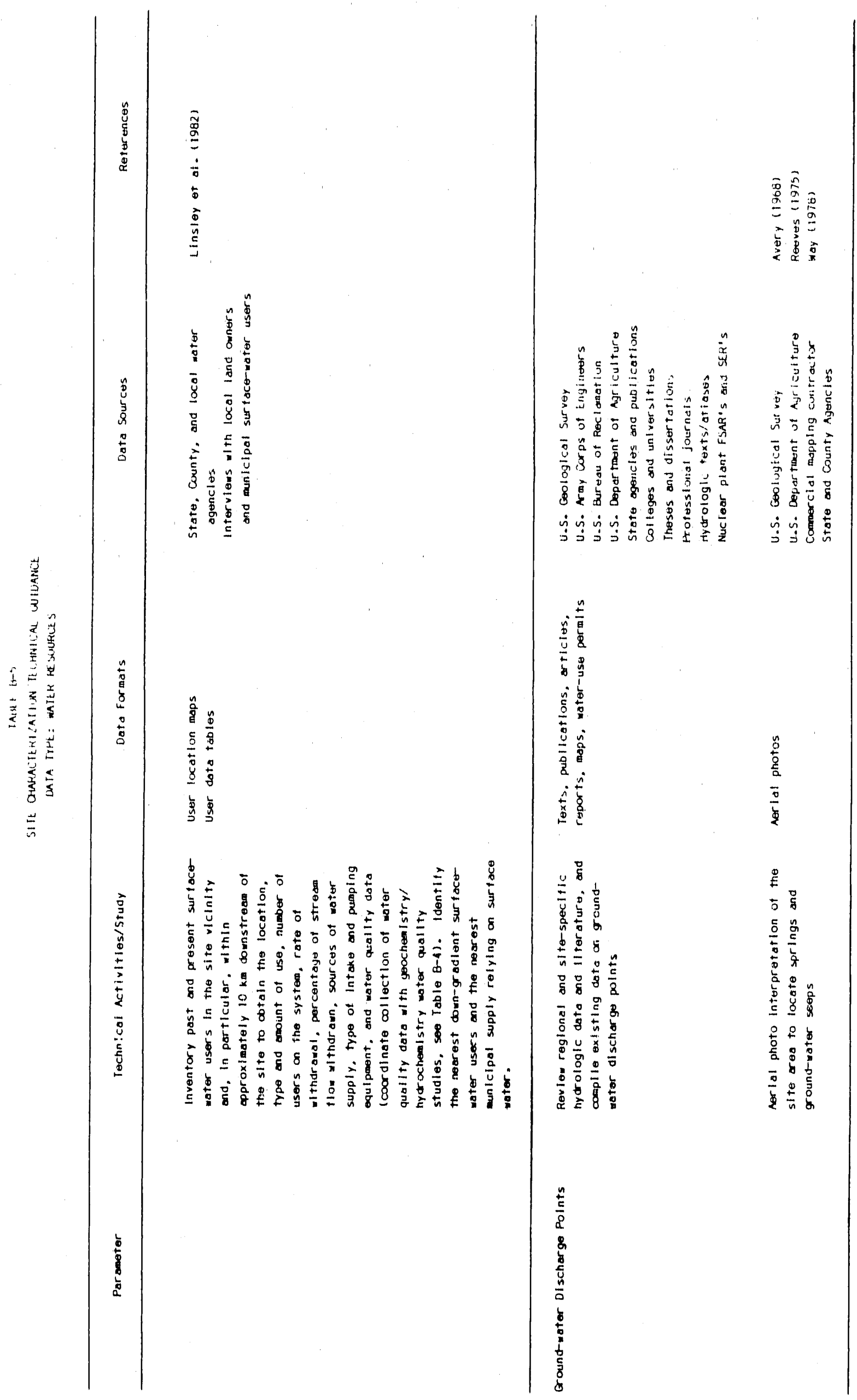

î 


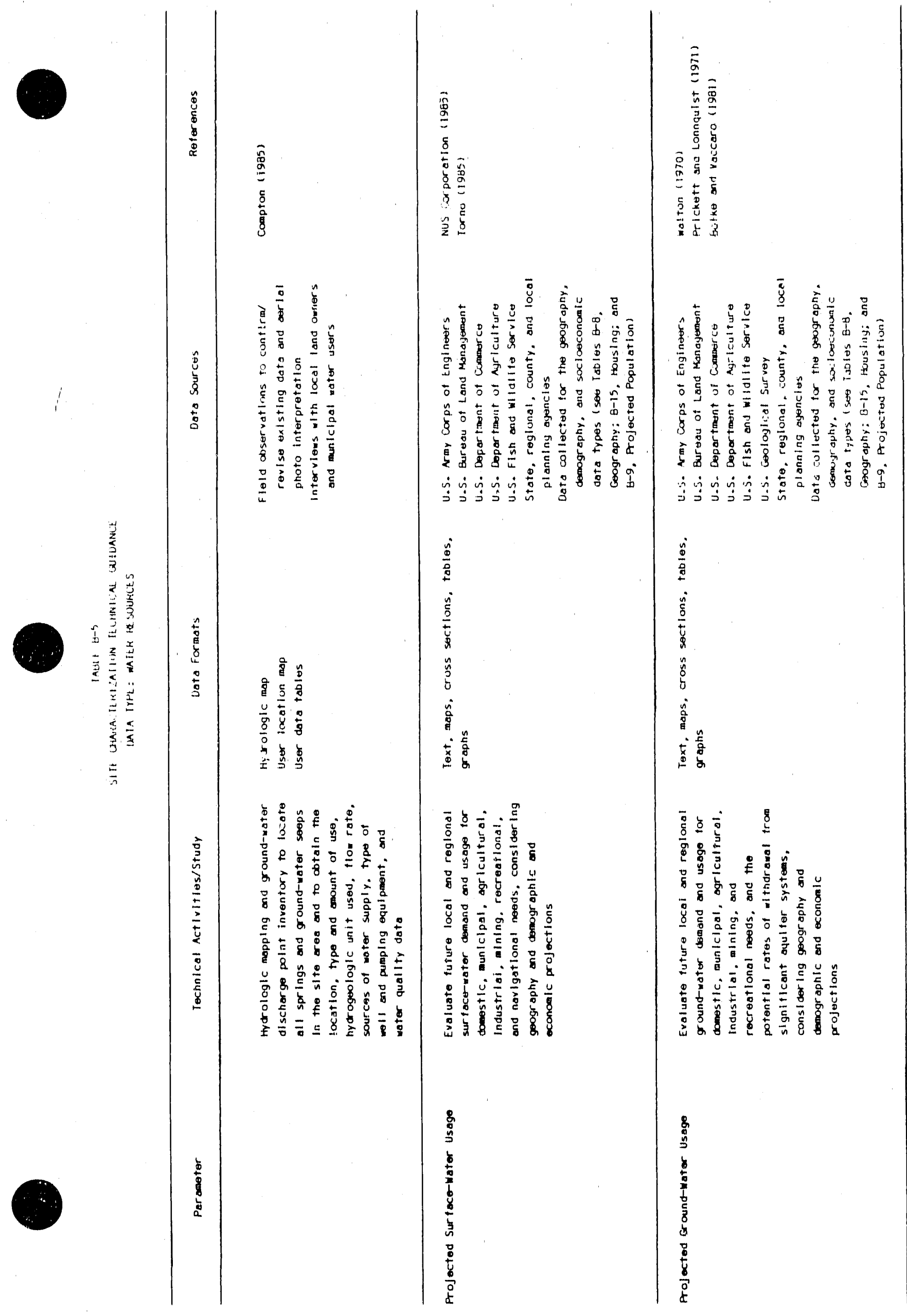



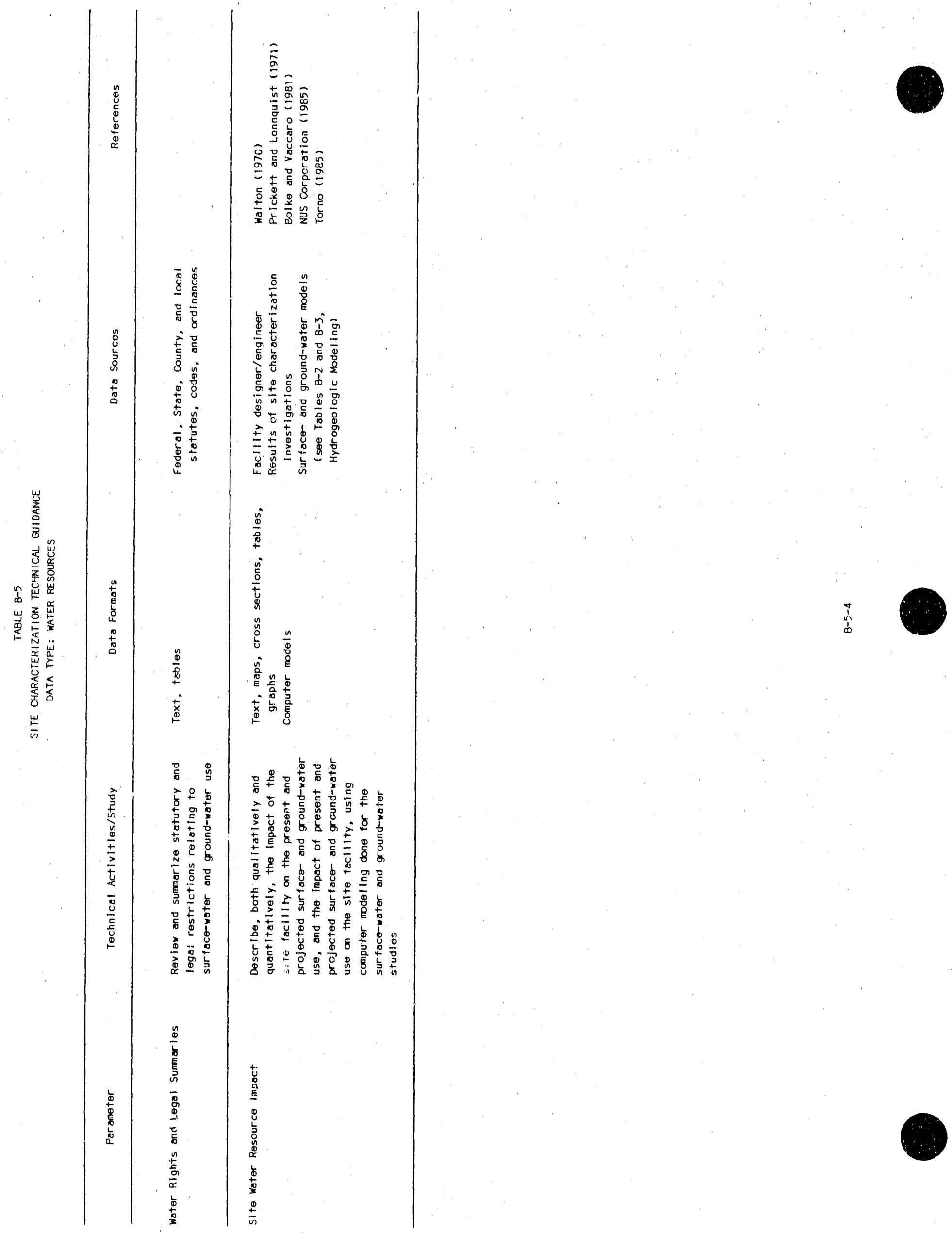
T. E. Avery, Interpretation of Aerial Photographs, Minneapolis: Burgess Publishing Co.,, 1968.

E. L. Bolke and J. J. Vaccaro, Digital-Model Simulation of the Hydrologic Flow System, with emphas is on Groundwater in the Spokane Valley, Washington and Idaho, U. S. Geological Survey Water-Resources Investigations Open-File Report $80-1300,1981$.

R. R. Compton, Geology in the Field, Somerset: John Wiley and Sons, Inc., 1985.

R. K. Linsley, M. A. Kohler, J. L. H. Paulhus, Hydralogy for Engineers, New York: McGraw-Hil1 Book Co., 1982.

NUS Corporation, Water Supply and Use in Deaf Smith, Swisher, and Nearby Counties in the Texas Panhandle, BMI/ONWI-557, February 1985.

T. A. Prickett and C. G. Lonnquist, Selected Digital Computer Techniques for Groundwater Resource Evaluation, I1 1 ino is State Water Survey Bulletin 55, 1971 .

R. G. Reeves (ed.), Manual of Remote Sensing, Vols, 1 and 2, Falls Church: American Society of Photogrammetry, 1975.

H. C. Torno (ed.), Computer Applications in Water Resources, New York, June 10-12, 1985, New York: American Society of Civil Engineers, 1985.

W. C. Walton, Groundwater Resource Evaluation, New York: McGraw-Hill Book Co., 1970.

D. S. Way, Terrain Analysis, New York: McGraw-Hill Book Co., 1978. 
Past and Present Resource Data: Location maps of active and inactive mines, prospects, exploration boreholes, geothermal and hydrocarbon wells, borrow pits, quarries, excavations, and timber and agricultural lands. Data compilations either on or accompanying the maps should include: the commodity occurring at the resource location; the geologic unit in which the present or past geologic resource occurs; quantitative data, if available, for geologic materials produced from active or previously active mines, wells, borrow pits, and quarries; quantitative data for agricultural and timber resources; and the mining, harvesting or extraction method (e.g., shaft mining, strip mining, quarrying, borehole injection or pumping, uprooting of vegetation, blasting, etc.). Commoditios to be addressed should include: metallic and nonmetallic minerals and ores; fuels such as peat, lignite, and coal; industrial mineral deposits such as sand and gravel, clays, aggregate sources, shales, and building stone; hydrocarbons, including gas, 0 il, tar sands and asphalt; timber; agricultural lands; and waters in the form of brines.

Mineral Rights/Lease Data: The location, ownership, and types of exploration activity (e.g., drilling, trenching, etc.) carried out on mining claims or mineral leases on and near the site.

Borehole/We11 Data: The location, depth, diameter, completion practices, current drilling activity, use, and geological and geophysical logs of exploration boreholes and geothermal, brine, and hydrocarbon wells on and near the site.

Potential Resource Location: Location maps of potential resources that may be exploited in the fuicure. Data compilations either on or accompanying the maps should include: the commodity occurring at the resource location, and for geologic resources, the geologic unit in which the future resource occurs. Commodities to be addressed include: metallic and nonmetallic minerals and ores; fuels such as peat, lignite, and coal; industrial mineral deposits such as sand and gravel, clays, aggregate sources, shales, and building stone; hydrocarbons, including gas, 011 , tar sands and asphalt; timber; agricultural lands; and waters in the form of brines.

Resource Quality and Quantity: The physical and/or chemical characteristics of the identfied geologic resource in place, such as quantity (i.e., areal extent, thickness, and depth), tonnage, grade, and/or volume and quality, as applicable to the resource type, and the quantity, quality, and extent of timber and agriculture resources (such as board feet and arable areage, respectively). 
Resource Value: The current net worth of resources, based on: 1) the resource quantity and quality as described above, and 2) profitability analyses based on the current market price, current use and/or demand, recoverability, extraction/harvesting methods and costs, transportation and mining/processing costs, and capitol investment costs. Projected resource use should be determined based on assumptions and projections for future market conditions. Known or identified geologic resources should be classified into economic, marginally economic, and subeconomic components as defined in U.S. Geological Survey Circular 831, "Principles of a Resource/Reserve Classification for Minerals."

Direct Effects of Exploitation: The potential effects of geologic or timber resource exploration or exploitation/extraction at the ground surface, in the hydrogeologic units used for disposal and isolation, or at greater depths, caused by excavation, blasting, drilling, uprooting of timber, or other activ:ties that directly intrud disposal units.

Indirect Effects of Exploitation: The potential effects of geologic, agricu?tural, or timber resource exploration or exploitation/extraction that would compromise the suitability of the site through such processes as increased infiltracion rates, alteration of ground-water tables, increased runoff up-gradient of site, steepened hydraulic gradients, and creation or modification of surface-water or ground-water pathways. These processes may be affected by activities such as excavation, blasting, uprooting of vegetation, irrigation, pumping or injection, erosion control procedures, or other mining, logging, or agricultural activities that can affect the hydrologic regime.

Natural Resources Impact: Qualitative and quantitative descriptions of the impact of the site on natural resources from construction to closure, particularly the denial of resources. 


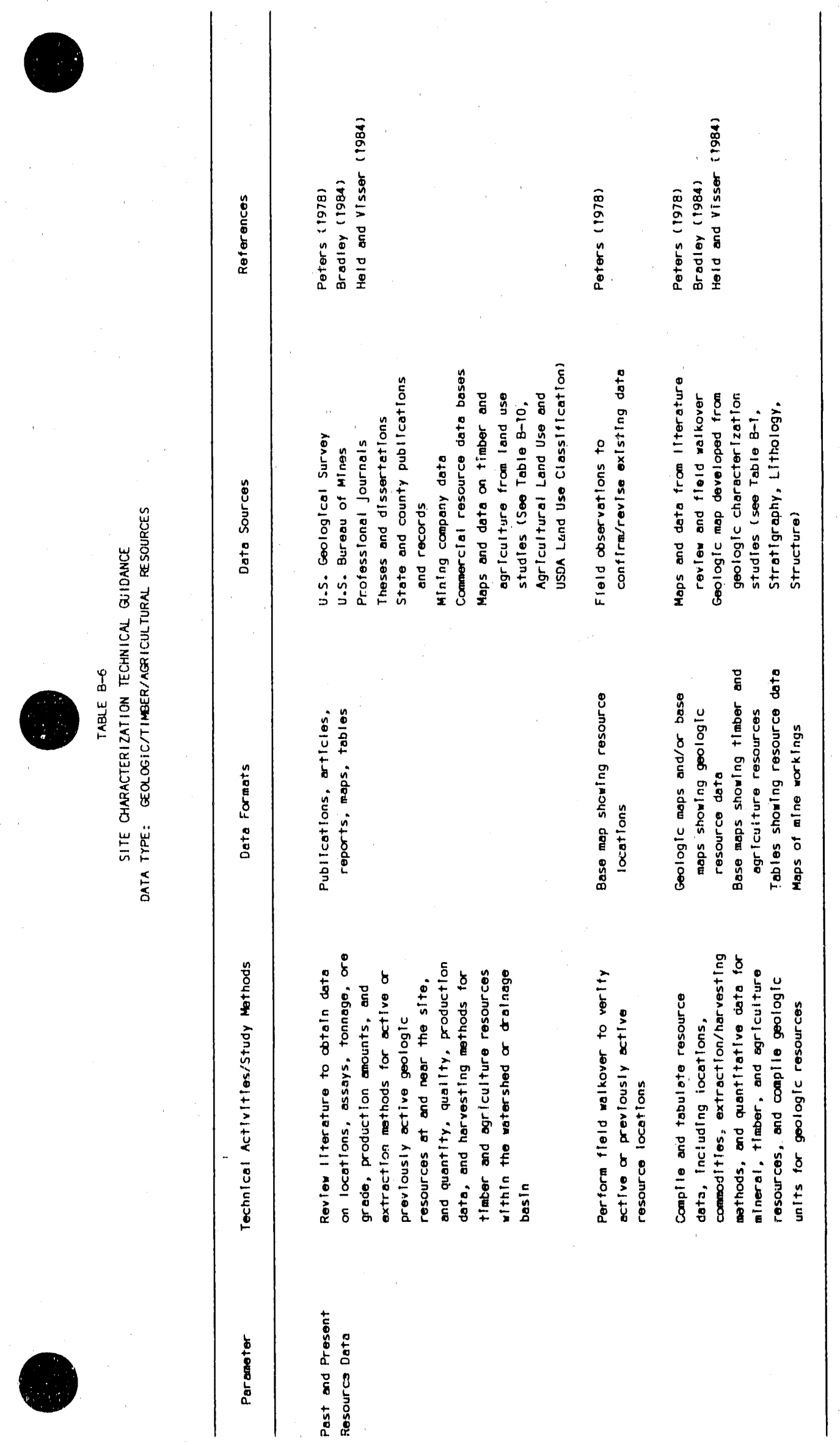




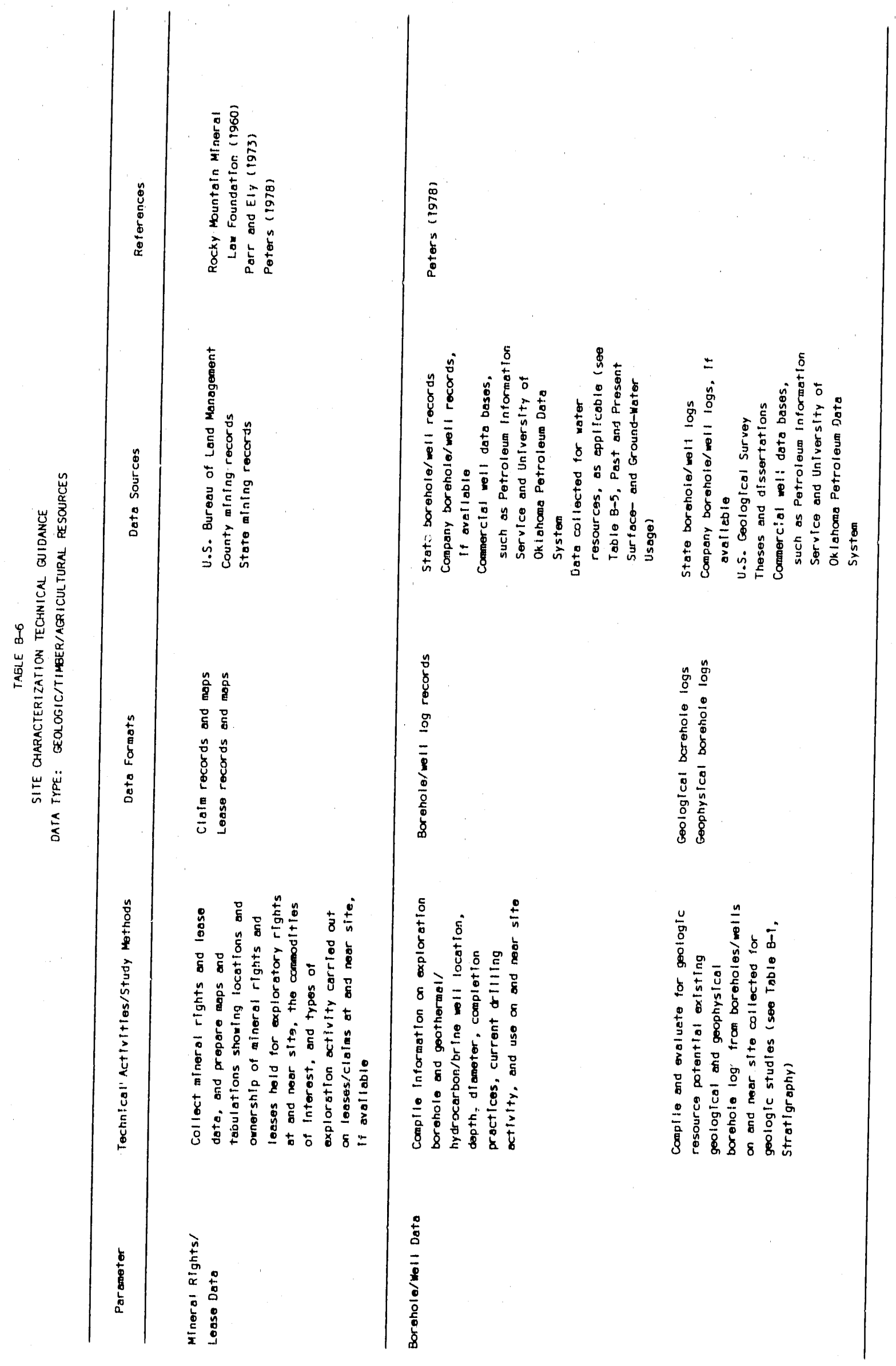

s 


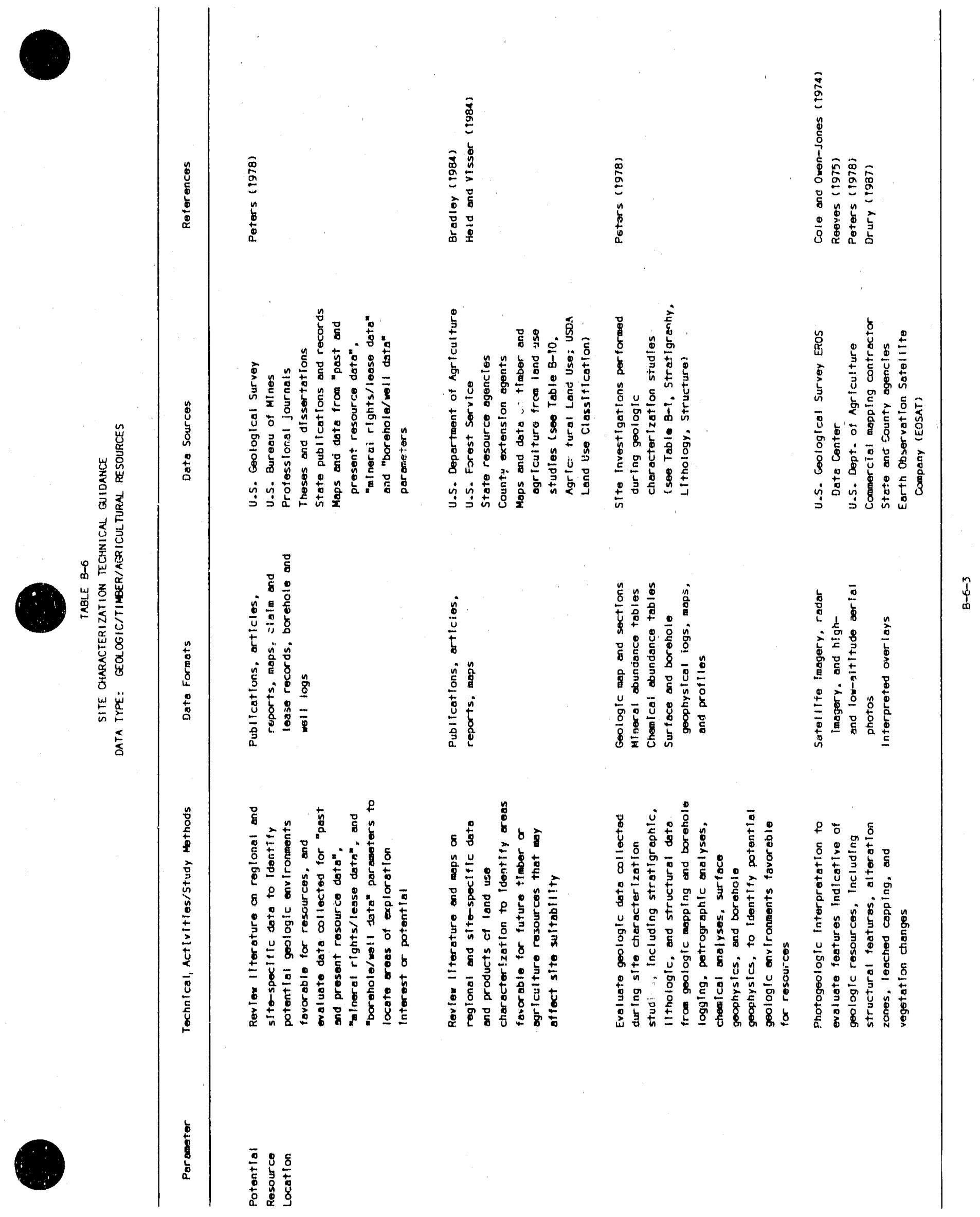




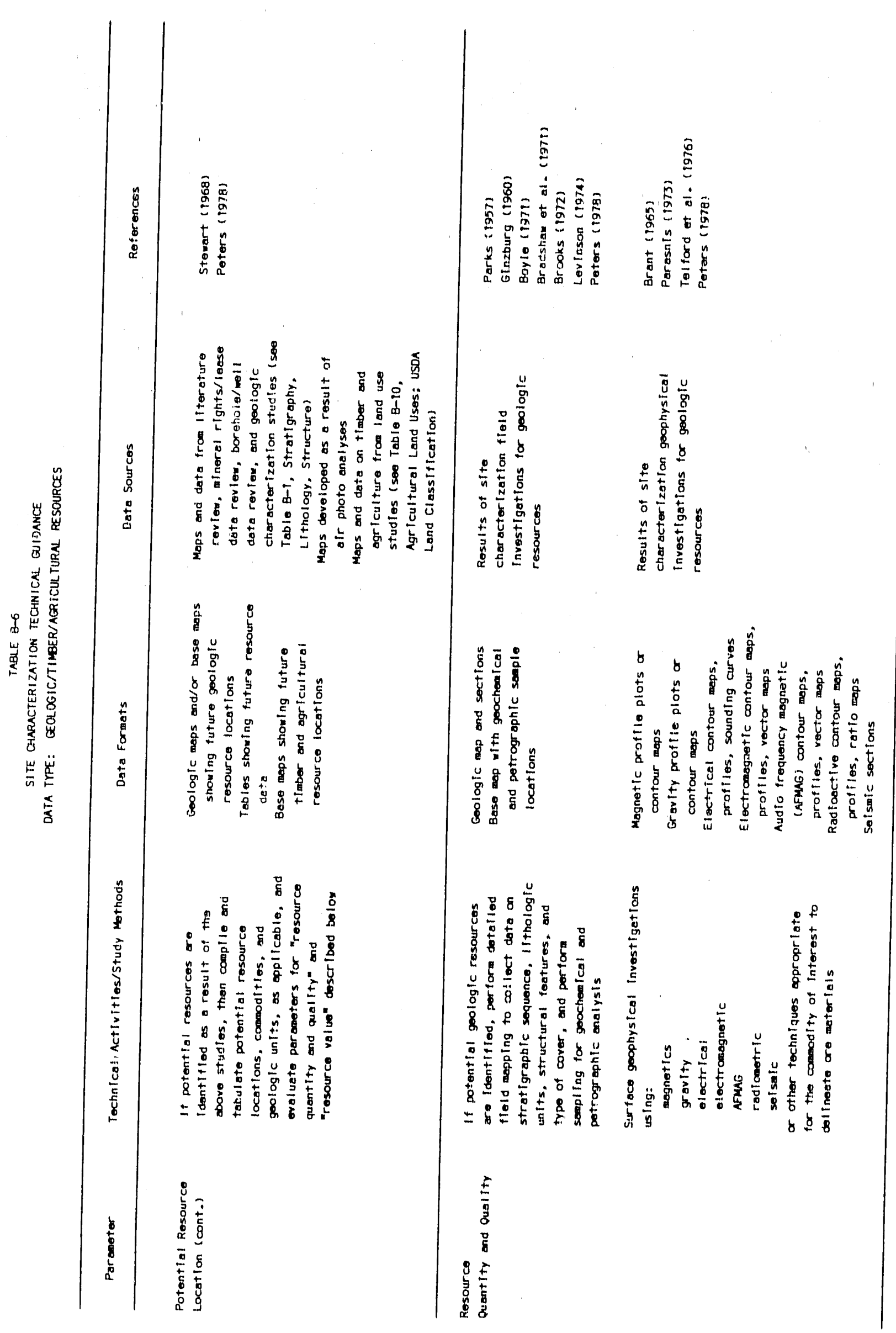

ఫे 


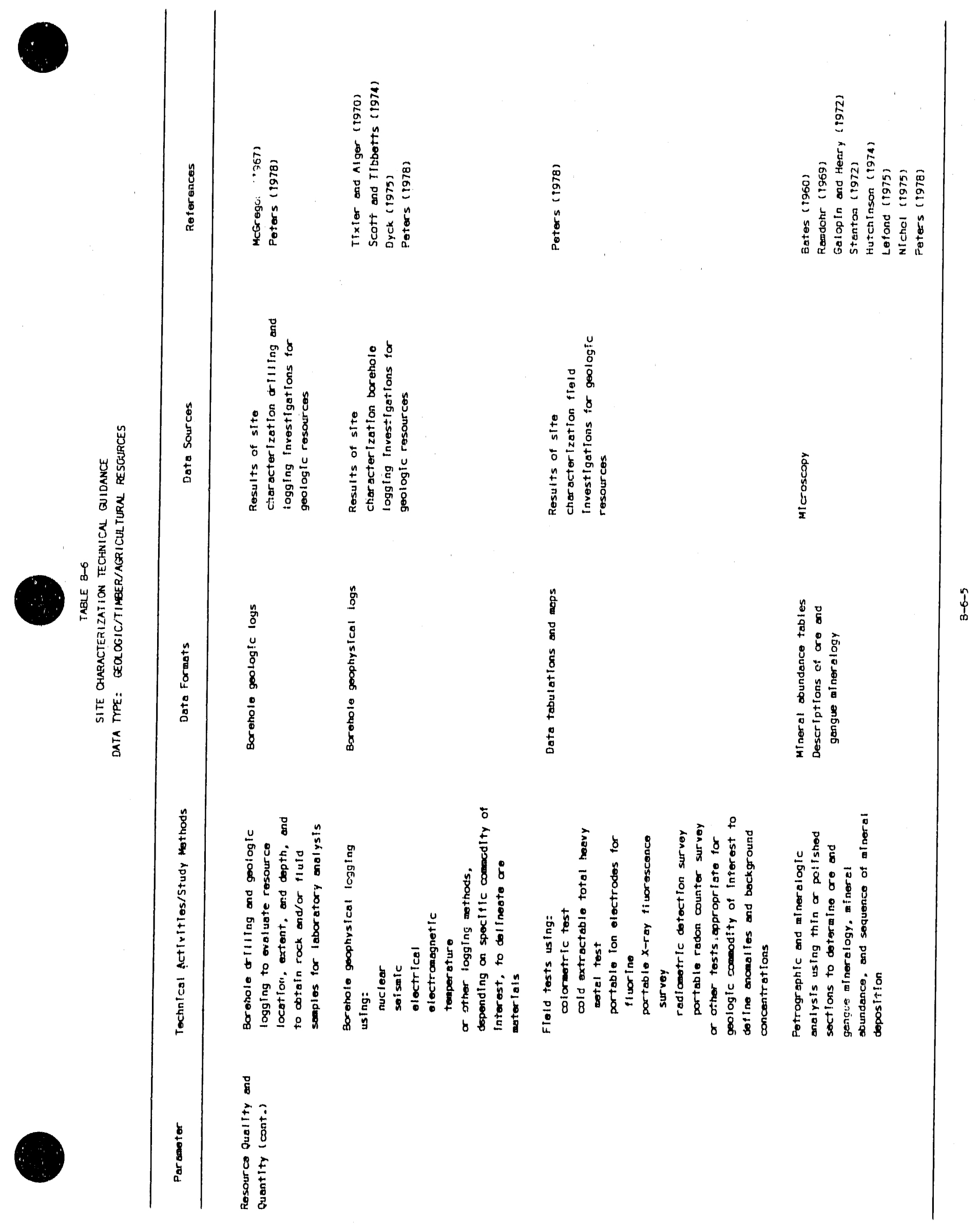




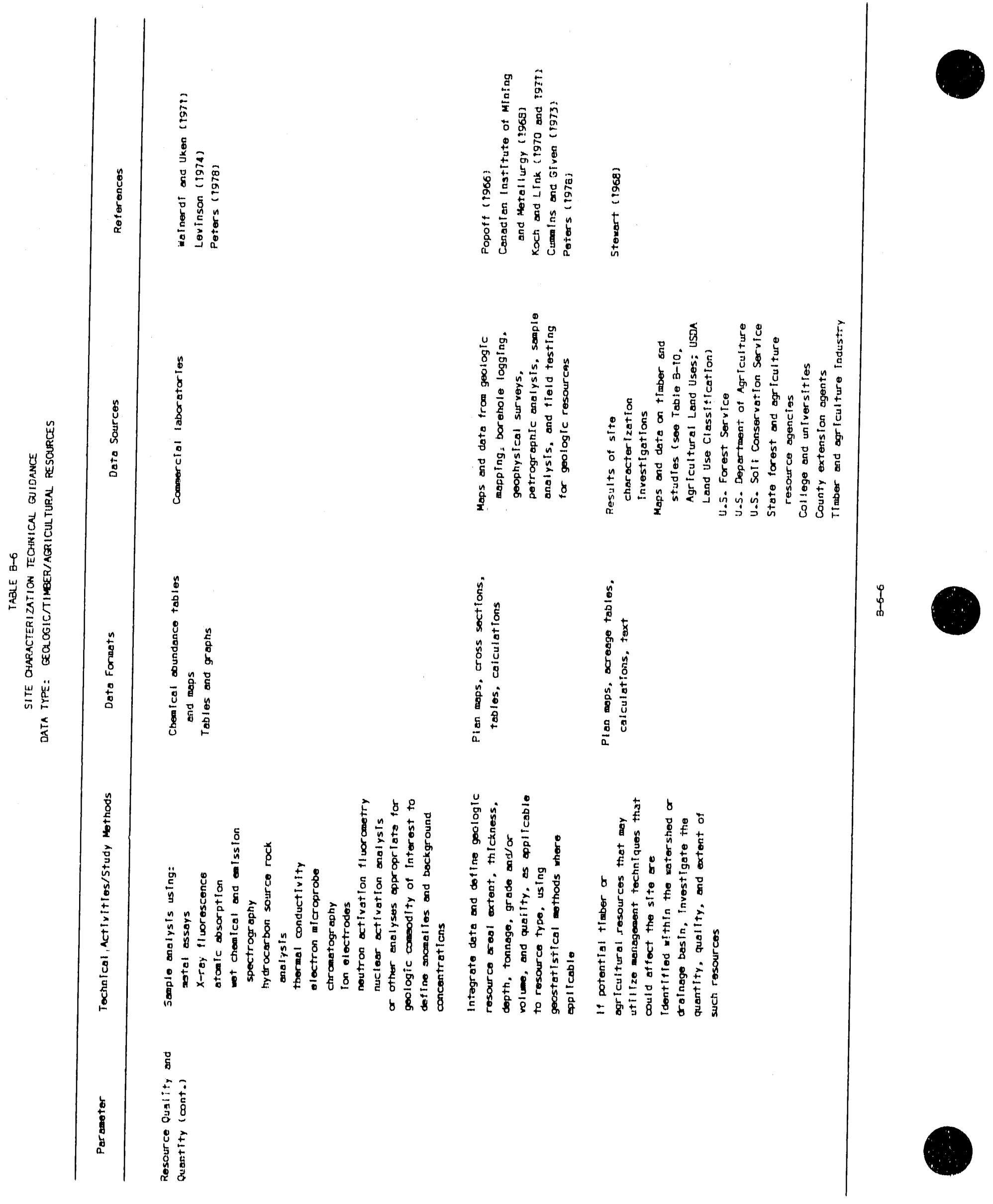




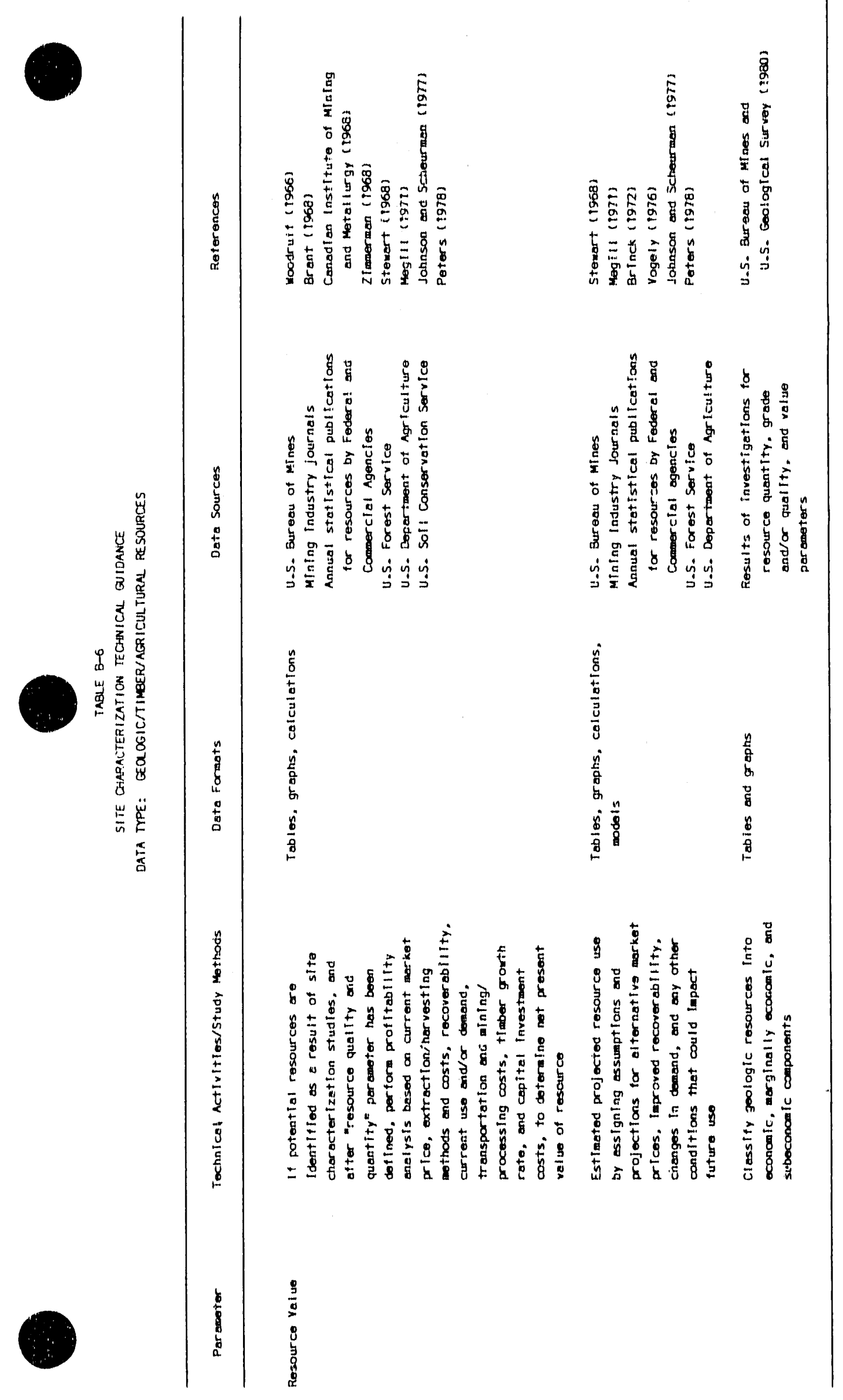




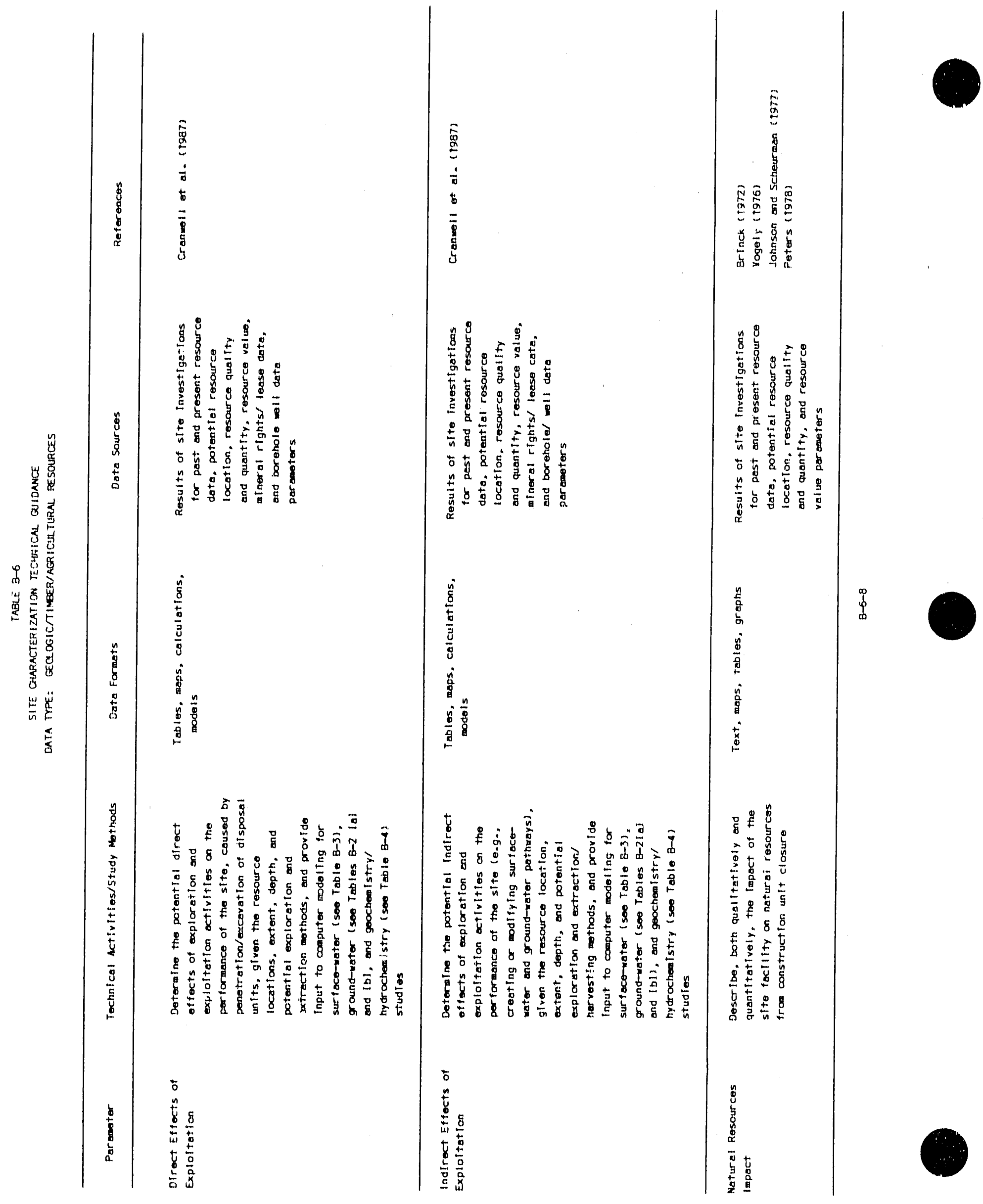


R. L. Bates, Geology of the Industrial Rocks and Minerals, New York: Harper \& Row, 1960.

R. W. Boyle (ed.), Geachemical Exploration, Canadian Institute of Mining and Metallurgy, Special Volume 11, 1971.

G.A. Bradley (ed.), Land Use and Forest Resources in a Changing Environment, Seattle: University of Washington Press, 1984.

P. M. D. Bradshaw, R. R. Clews, and J. L Walker, Exploration Geochemistry, Rexdale, Ontario: Barringer Research L.td., 1971.

A. A. Brant, "A Review and Discussion of Present Geophysical Methods Applied in Mining Exploration," Economic Geology, 60, 1965, pp. 819-821.

A. A. Brant, "The Pre-Evaluation of the Possible Profitability of Exploration Prospects," Minera1ium Deposita, 3, 1968, pp. 1-1\%.

J. W. Brinck, "The Prediction of Mineral Resources and Long-Term Price Trends in the Non-Ferrous Metal Mining Industry, " in Mineral Deposits, Section 4, Ottawa, Canada: International Geologic Congress, 24th, 1972, pp. 3-15.

P. R. Brooks, Geobotany and Blogeochemistry in Mineral Exploration, New York: Harper \& Row, 1972.

Canadian Institute of Mining and Metallurgy, Ore Reserve Estimation and Grade Control, Montreal: Special Volume 9, 1968.

M. M. Cole and E. S. Owen-Jones, "Remote Sensing in Mineral Exploration, in E. C. Barrett and L. C. Curt is (eds.), Environmental Remote Sensing, Applications and Achievements, London: Edward Arnold Publishers Ltd., 1974, pp. 51-65.

R.M. Cranwell et a1., Risk Methodology for Disposal of Radioactive Waste: Elnal Report, Sandia National Laboratories: Prepared for U.S. Nuclear Regulatory Commission, NUREG/CR-2452, SAND 81-2573, 1987.

A. B. Cumnitns and I. A. Given (eds.), SME Mining Engineering Handbook, New York: American Institute of Mining, Metallurgical, and Petroleum Engineers, 2 vols., 1973.

S. A. Drury, Image Interpretation in Geology, London: Allen \& Unwin (Publ ishers) Ltd., 1987.

W. Dyck, Borehole Geophysics Applied to Metallic Mineral Prospecting, Canada Geological Survey Paper 75-31, 1975. 
R. Galopin and N. F. M. Henry, Micrascoptc Study of Opaque Minerals,

Cambridge, England: W. Hefner and Sons, 1972.

1. 1. Ginzburg, Principles of Geochemical Prospecting (translated from the Russian by V. P. Sokoloff), London: Pergamon Press, 1960.

R.B. Held and D.W. Visser, Rural Land Uses and Planning, New York: Elsevter Science Publishing Company, 1984.

C. S. Hutchinson, Laboratory Handbook of Petrographic Techniques, New York: John Wiley \& Sons, 1974.

K.N. Johnson and H.L. Scheurman, "Techniques for Prescribing Optimal Timber Harvest and Investment under Different nbjectives - Discussions and

Synthesis," Forest Sclence Monograph. Supplement to Forest Science, 23, 1 , 1977.

G. S. Koch and R. F. L.ink, Statistical Analys is of Geologic Data, New York: John Wiley \& Sons, 1970 and 1971.

S. J. Lefond (ed.), Industrial Minerals and Rocks (edition 4), New York: American Institute Mining, Metallurgical and Petroleum Engineers, 1975.

A. A. Levinson, Introduction to Exploration Geochemistry, Calgary: Applied Publishing Company, 1974.

K. McGregor, The Drilling of Rock, London: C. R. Books Ltd. (MacLaren), 1967.

R. E. Megi11, An Introduction to Exploration Economics, Tulsa, OK: The Petroleum Publishing Company, 1971.

A. W. Nichol, Physiochenical Methods of Mineral Analysis, New York: Plenum Press, 1975.

D. S. Parasnis, Mining Geophysics, Amsterdam: Elsevier Scientific Publishing Company, 1973.

R. D. Parks, Examination and Evaluation of Mineral Property, Edition 4, Cambridge, MA: Addison-Wesley Press, Inc., 1957.

C. J. Parr and N. Ely, "Mining Law" in A. G. Cummins and I. A. Given (eds.), SME Mining Engineering Handbook, New York: American Institute of Mining and Metallurgical Engineers, Sec. 2, 1973, pp. 2-2 - 2-54.

W. C. Peters, Exploration and Mining Geology, New York: John Wiley \& Sons, 1978.

C. C. Popoff, Computing Reserves of Mineral Deposits; Principles and

Conventional Methods, U. S. Bureau of Mines Information Circular 8283, 1966.

P. Ramdohr, The Ore Minerals and Their Intergrowths, edition 3, 0xford:

Pergamon Press Ltd., 1969. 
R. G. Reeves (ed.), Manual of Remote Sensing, Falls Church, VA: American Society of Photogrammetry, 2 vols, 1975

Rocky Mountain Mineral Law Foundation, American Law of Mining, Albany, NY: Matthew Bender Company, 5 vols., with supplements, 1960.

J. H. Scott and B. L. Tibbetts, Well Logging Techniques for Mineral Deposit Evaluation; A Review, U. S. Bureau of Mines Information Circular 8627, 1974.

R. L. Stanton, Ore Petrology, New York: McGraw-Hill Book Co., 1972.

G.A Stewart (ed.), Land Evaluation, Australia: Canberra \& Macmillian of Australia, 1968.

W. M. Telford et a1., Applied Geophysics, Cambridge: Cambridge University Press, 1976.

M. P. Tixier and R. P. Alger, "Log Evaluation of Nonmetallic Mineral Deposits," Geophysics, 35, 1, 1970, pp. 124-142.

U. S. Bureau of Mines and U. S. Geological Survey, Principles of a Resource/Reserve Classification for Minerals, U. S. Geological Survey Circular $831,1980$.

W. A. Vogely, Economics of the Mineral Industries, New York: American Institute of Mining, Metallurgical, and Petroleum Engineers, 1976.

R. E. Wainerdi and E. A. Uken (eds.), Modern Methods in Geochemical Analysis, New York: Plenum Press, 1971.

S. D. Woodruff, Methods of Working Coal and Metal Mines, New York: Pergamon Press, 3 vols., 1966.

0. T. Zimmerman, "Elements of Capital Cost Estimation," Cost Enaineering, 13, 4, 1968, pp. 4-18. 
TABLE B-7

PARAMETER DESCRIPTIONS - GEOTECHNICAL INVESTIGATION

Soil Classification: The system of classifying soil for engineering purposes, generally the Unified Soil Classification System. Laboratory tests required to confirm field soil classifications are grain-size distribution and Atterberg limits following ASTM test procedures.

Engineering Properties: The physical and chemical properties of soil materials that deiermine thair engineering behavior. These properties, determined mostly by laboratory testing, are required for foundation and settlement analysis, slope stability, and the design and placement of structural fill. Engineering properties include: shear strength/internal angle of friction/unit cohesion, consolidation characteristics, shrink/swell characteristics, freeze/thaw characteristics, plasticity indox/Atterberg limits, grain-size distribution, moisture-density/minimum diy density, in-situ weight/density, porosity, void ratio, moisture content, degree of saturation, specific gravity, permeability, relative hydraulic conductivity, liquefaction potential, soil $\mathrm{pH}$, oxidation-reduction potential, clay mineralogy, dispersivity, deformation/Young's modulus, penetration resistance, soil resistivity, soil organics, and limit pressure. Other engineering properties may be appropriate depending on the soil conditions encountered at each site.

Engineering Units: An engineering unit consists of those geologic sections that share similar geotechnical characteristics or engineering properties. For example, a loess and underlying lacustrine silt may have similar moisture contents and strengths and could be incorporated into one engineering unit on the basis of their engineering behavior. Alternatively, a glacial till unit may contain a permeable sand and gravel layer that might be considered a separate engineering unit because of its engineering properties.

Ground-water Conditions: The location and range of seasonal fluctuations of the ground-water table and the design water level within the disposal site and borrow areas.

Engineering Analysis: The process of integrating the engineering units and their respective encineering properties with the site ground-water conditions, potential future geologic events, and conceptual facility design to develop geotechnical recommendations for slope stability, settlement/subsidence, liquefaction potential, freeze/thaw potential, active and passive earth pressures, bearing capacity, long- and short-term control of surface water, and fill-placement procedures. Other analyses may be appropriate depending on the soil conditions encountered at each site. The recommendations should also contain the following: detailed discussions of field and laboratory sample preparation and test procedures, interpretation of engineering characteristics for onsite and borrow area soils and rock, discussions of how and why specific strength parameters were chosen, factors of safety used, plans showing completed sibsurface investigations, cross-sections, and proposed borrow area limits, grades, slopes, and locations of test pits and boreholes. 


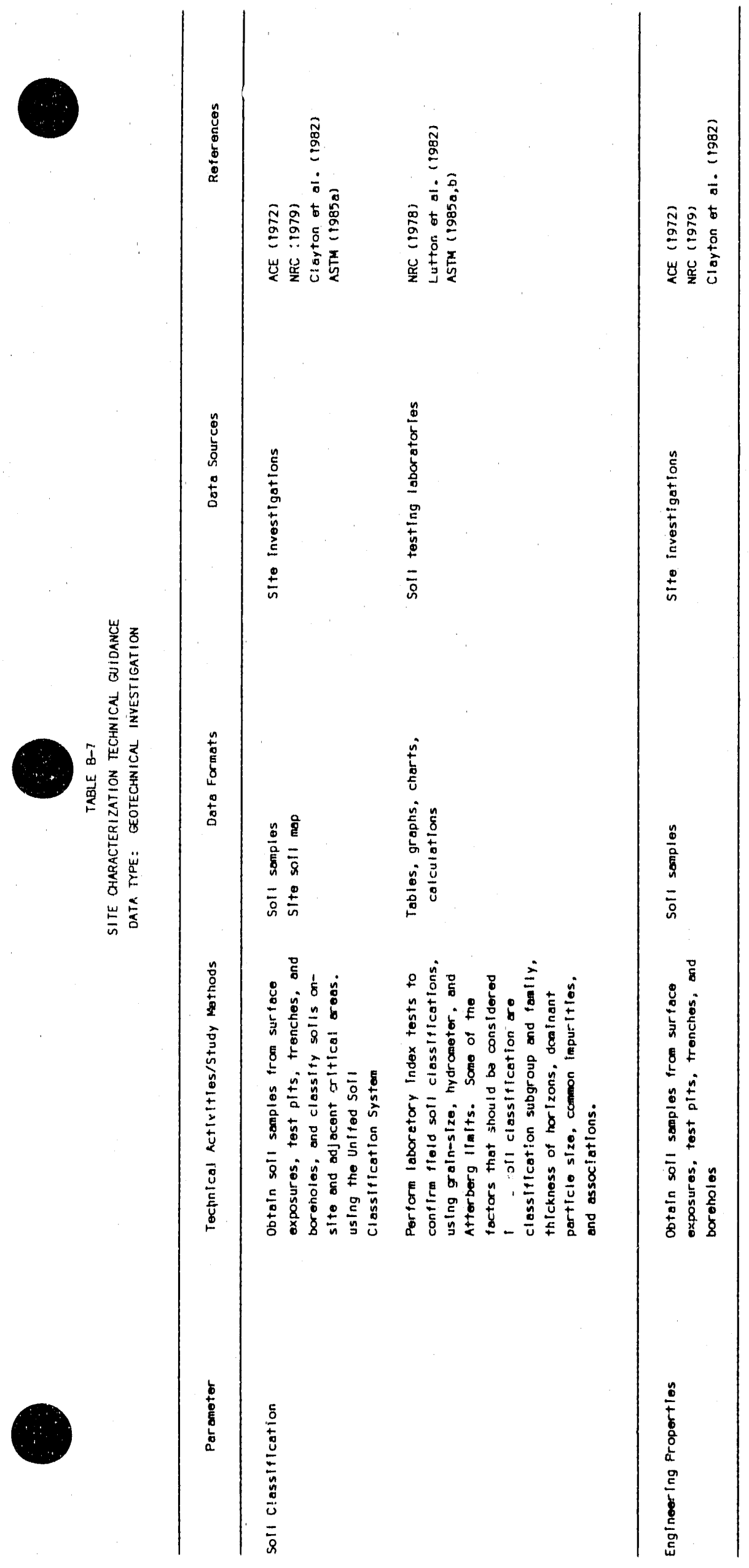




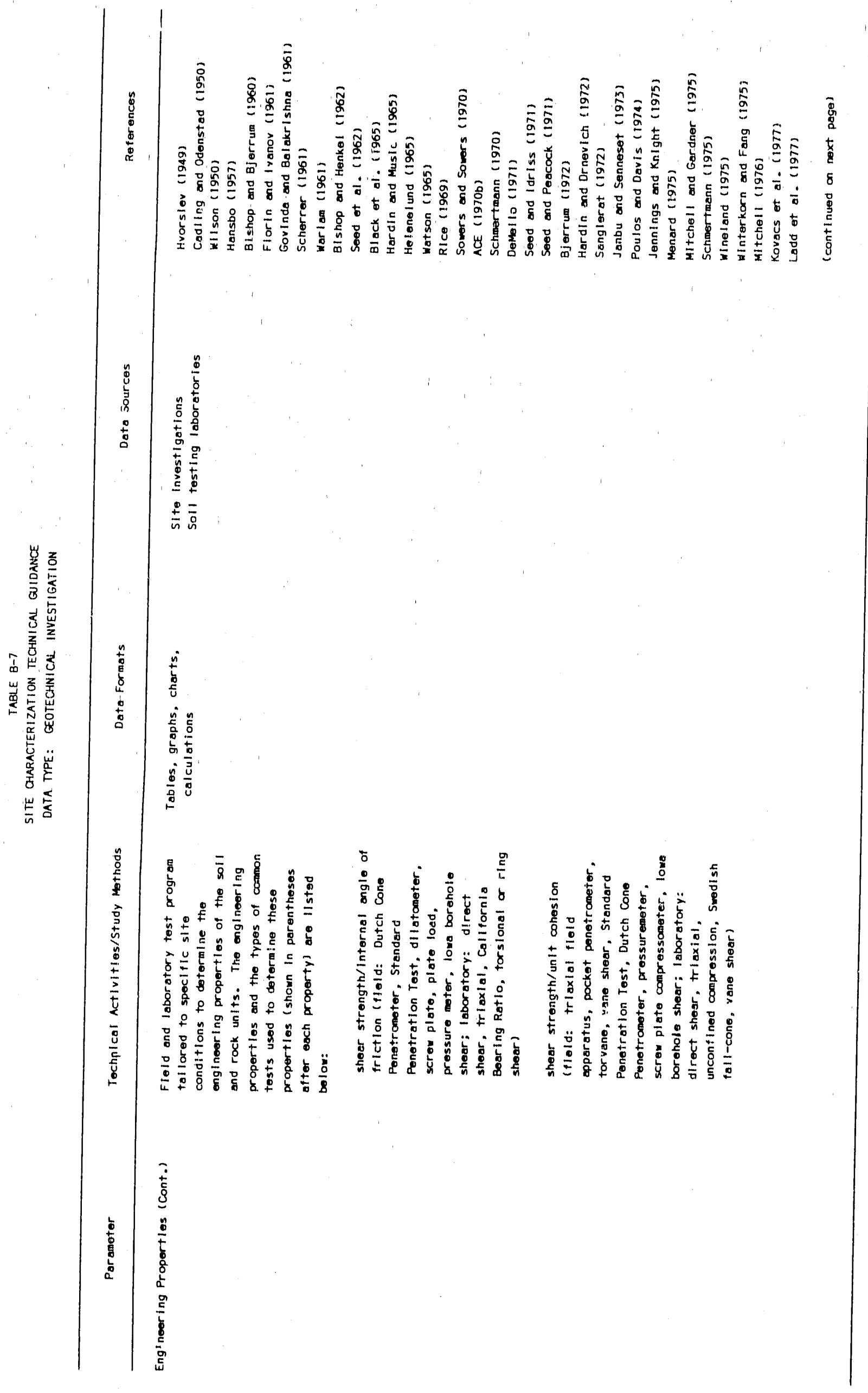




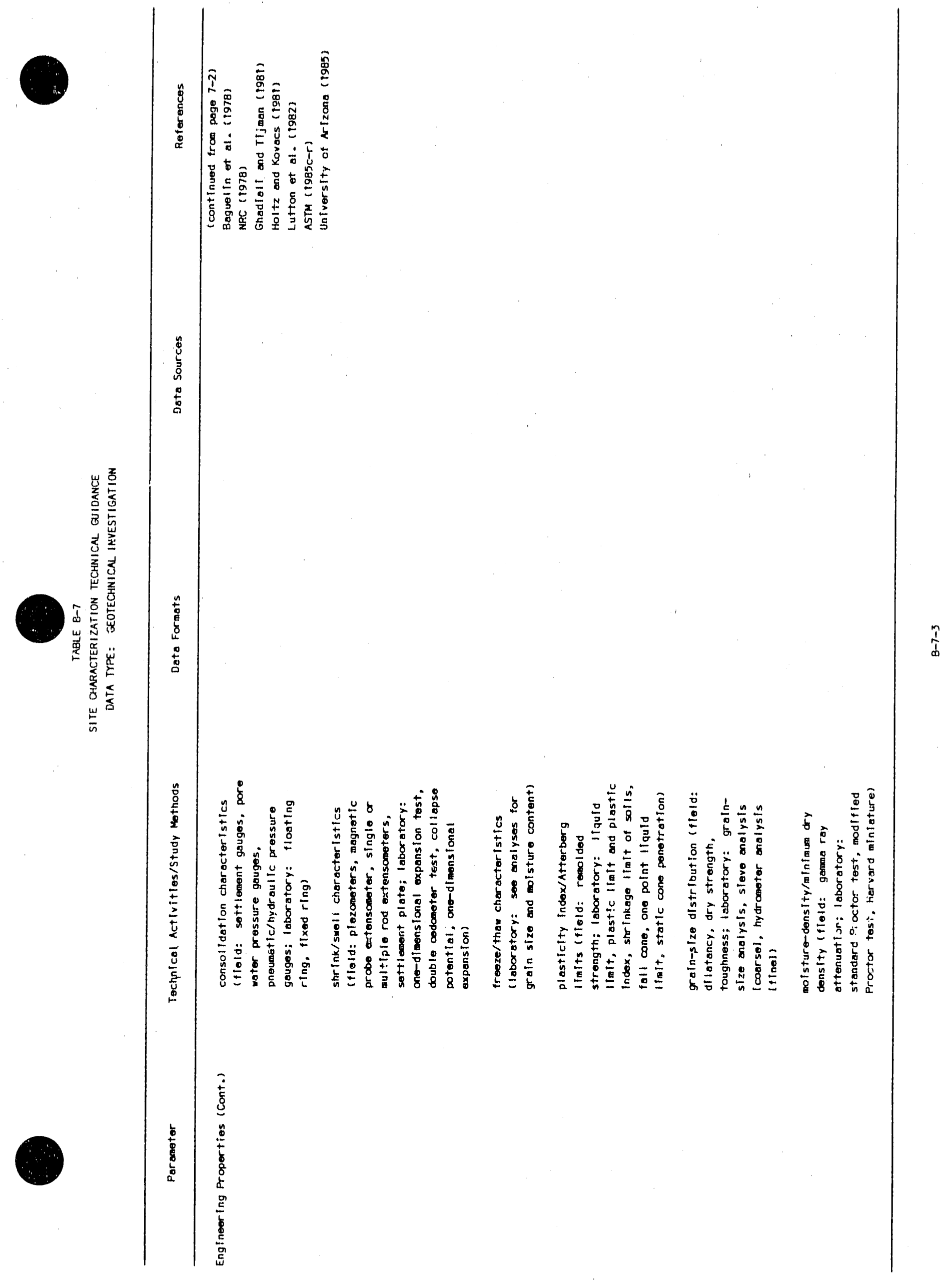




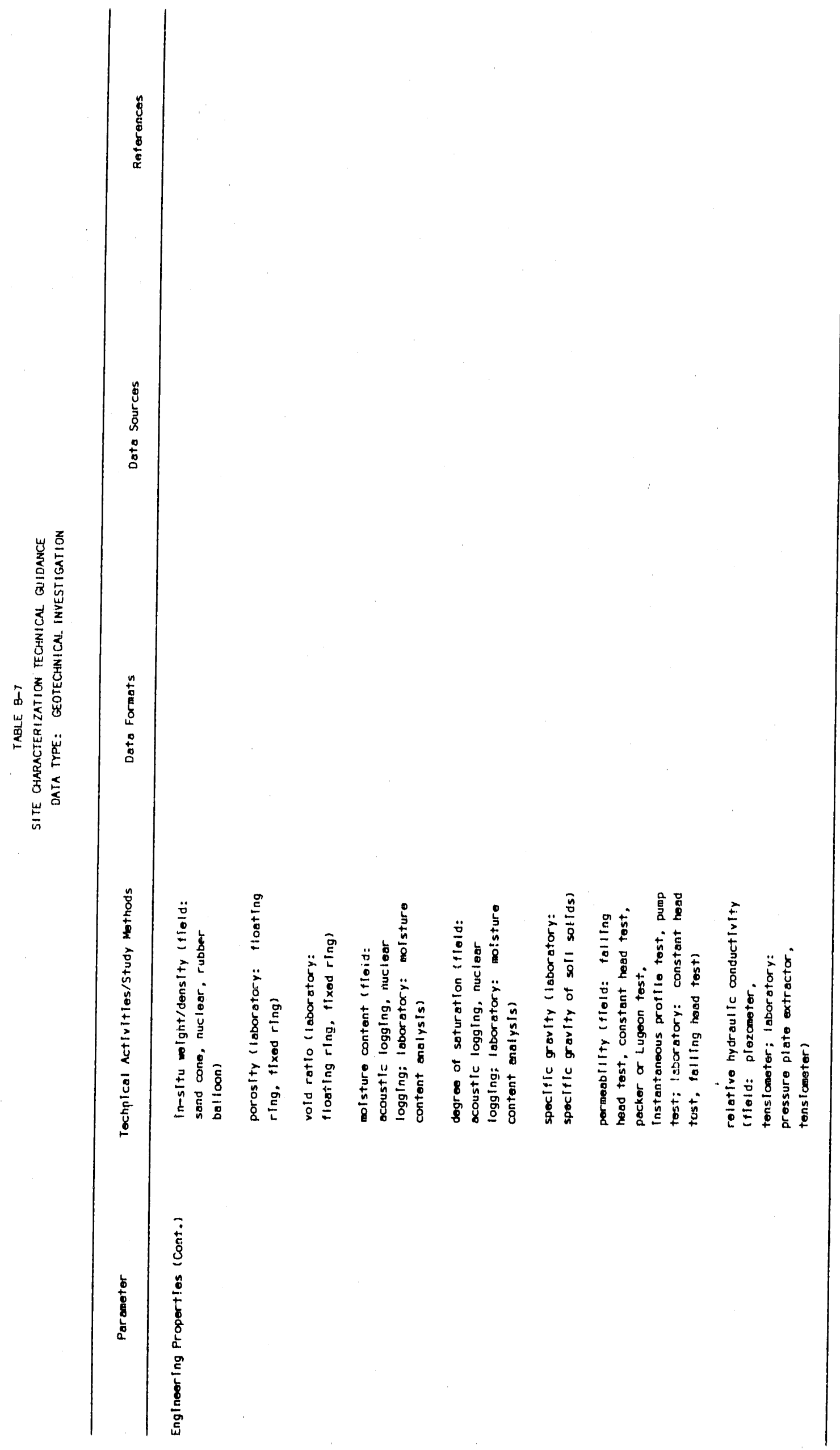




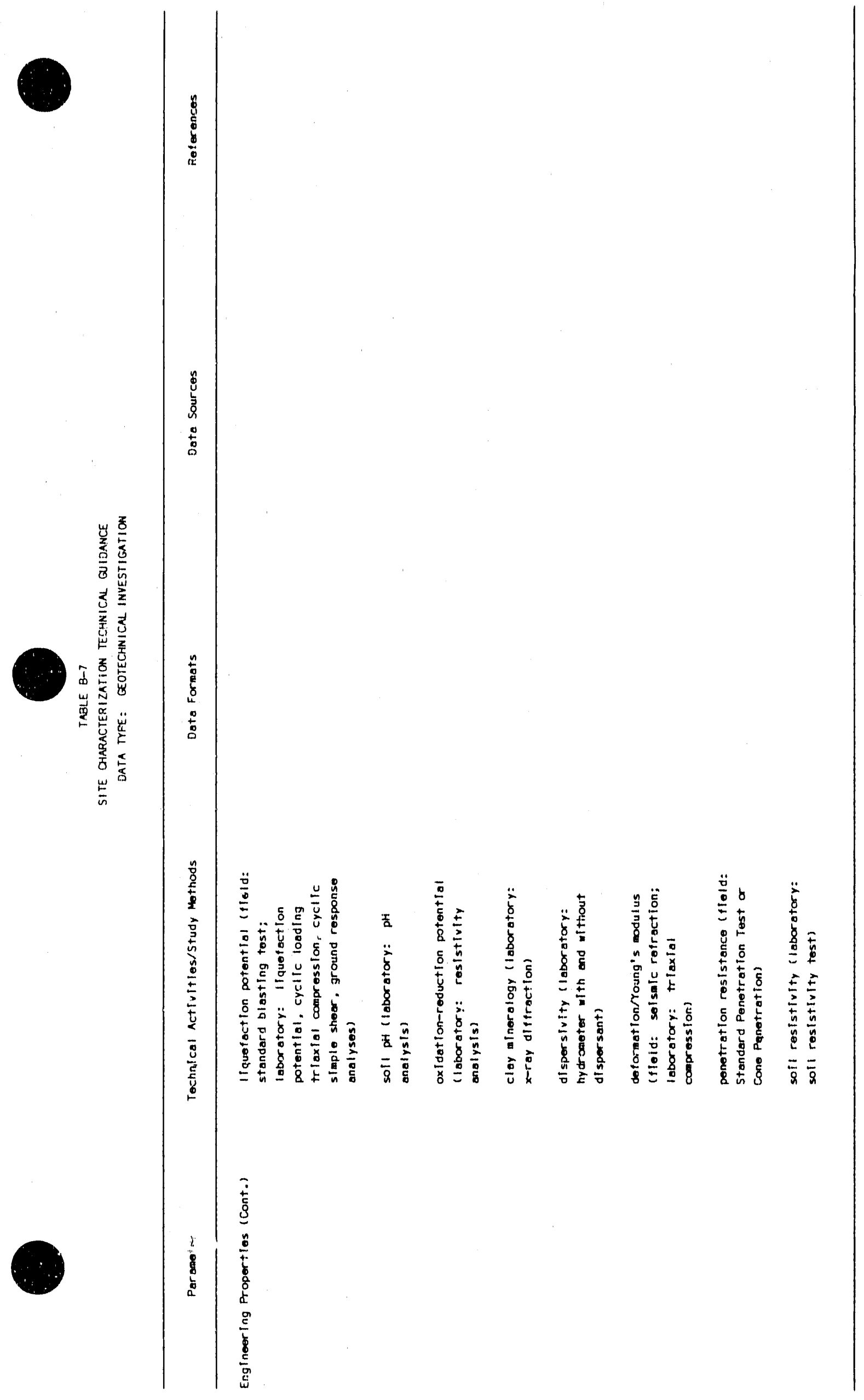




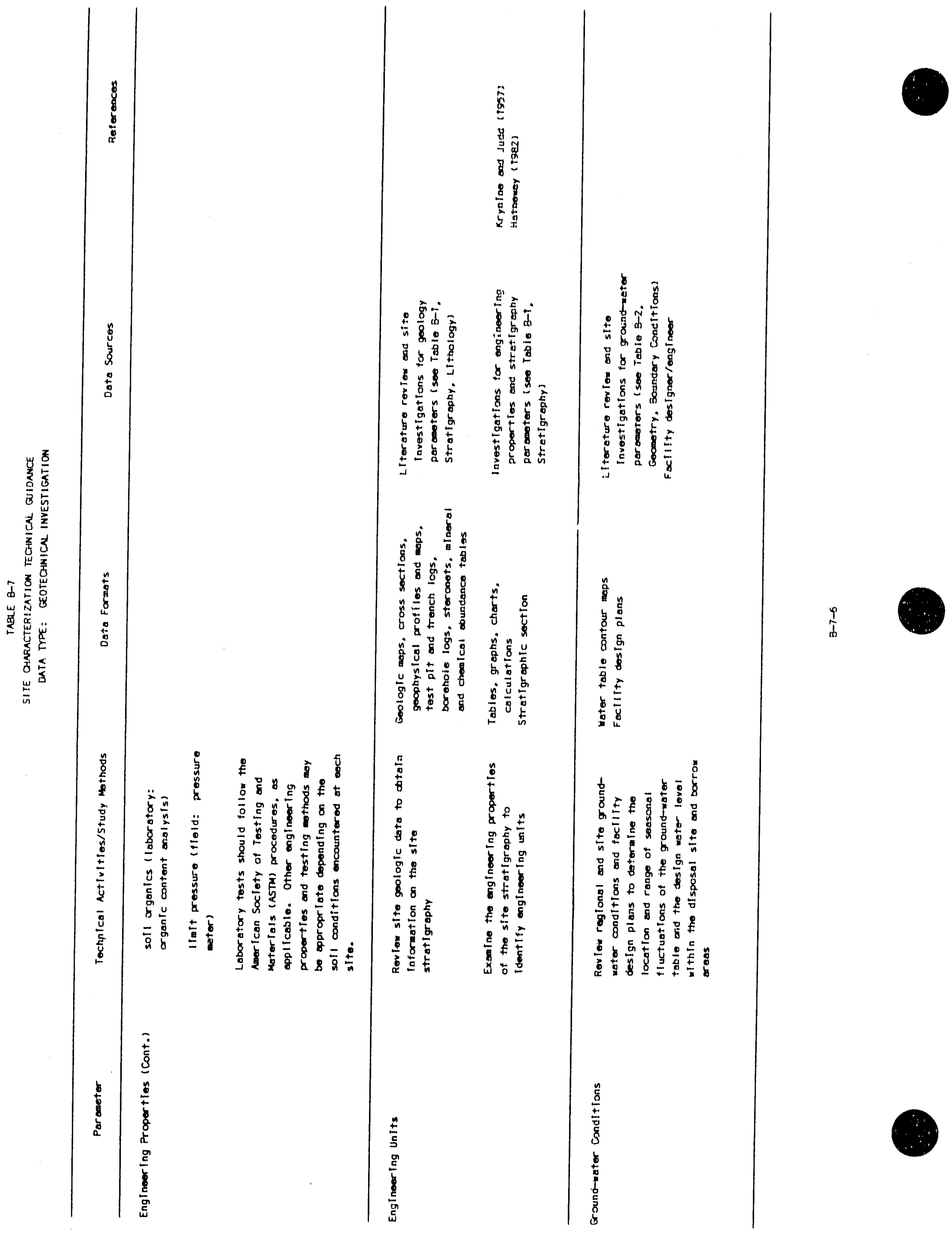




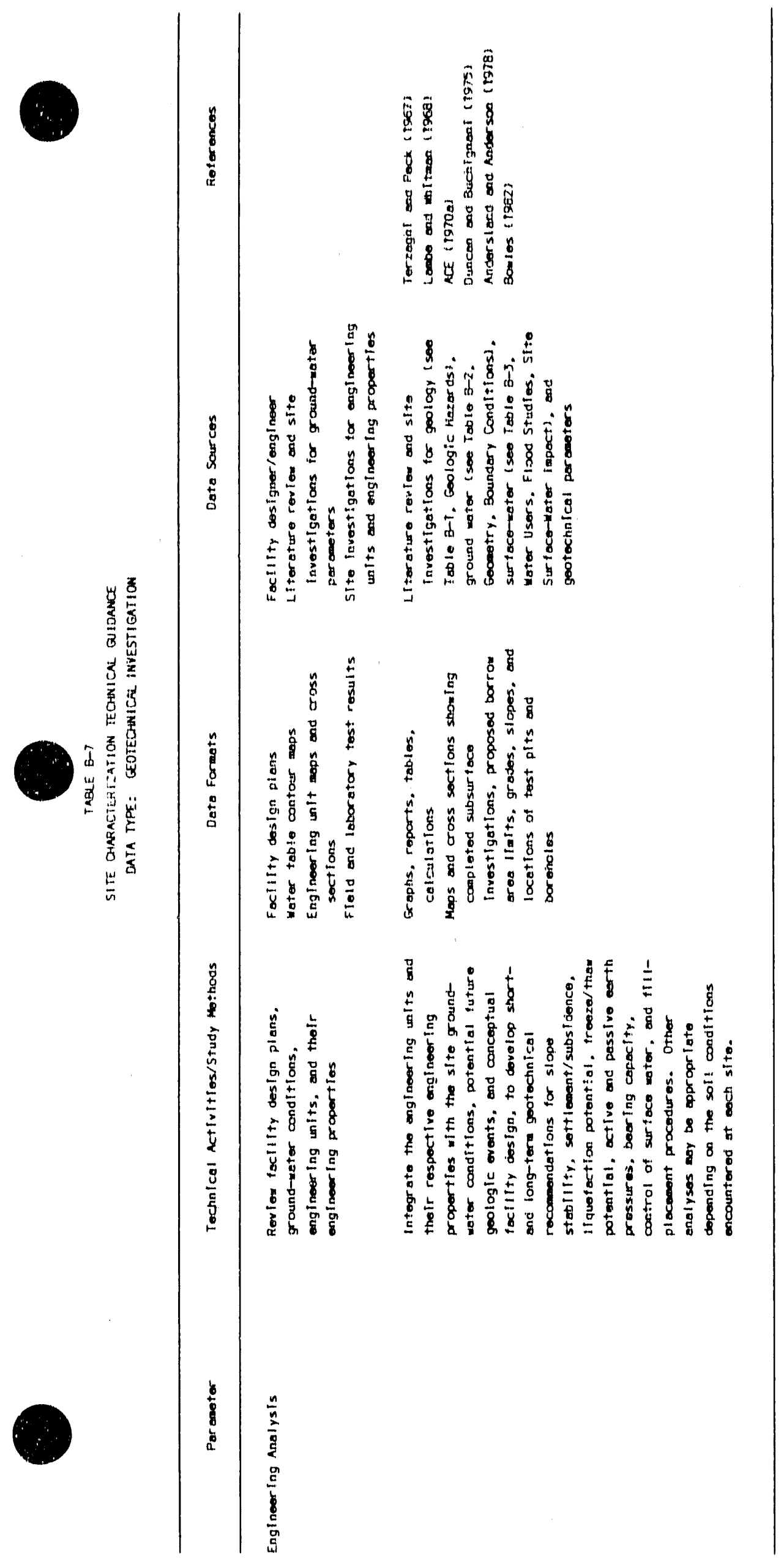

1 
TABLE B-7

REFERENCES - GEOTECHNICAL INVESTIGATION

ACE; see U.S. Army Corps of Engtneers.

Amertcan Soctety for Testing and Materfals, "Standard Test Method for Classiftcation of Sol'ls for Engineering Purposes, "Designation D2487-83, Annual Book of ASTM Standards. Vol. 04.08, Philadelphia, 1985a, p. 338-341.

American Society for Testing and Materlals, "Standard Practice for Description and Identification of Solls (Visual-Manual Procedure), "Designation 02488-84, Annual Book of ASTM Standards, Vol, 04.08, Phtladelphta, 1985b, p. 409.423.

American Soclety for Testing and Materlals, "Standard Test Method for Amourit of Matertal in Solls Finer than the No. 200 Steve," Designation D1140-54, Annual Book of ASTM Standards, Vol, 04.08, 1985c, p. 237-238.

American Soctety for Testing and Matertals, "Standard Test Method for Bearing Rat to of Laboratory-Compacted Sol1s," Designation D1883-73, Annual Book of ASTM Standards, Vol, 04.08, 1985d, p. 325-331.

American Society for Testing and Materials, "Standard Test Method for Unconfined Compressive Strength of Cohesive Sol1, " Designation D2166-66, Annual Book of ASTM Standards, Vol $24.08,1985 \mathrm{e}, p .338-341$.

American Society for Testing and Materlals, "Standard ist Methods for Liquid Limit, Plastic Limit, and Plasticity Index of Sol1s," Designation D4318-84, Annual Book of ASTM Standards, Vol, 04.08, 1985\%, p. 767-782.

American Society for Testing and Matertals, "Standard Test Methods for Moisture, Ash, and Organtc Matter of Peat Materlals," Designation D2974-84, Annual Book of ASTM Standards, Vol. 04.08, $1985 \mathrm{~g}$, p. $497 * 498$.

American Society for Testing and Materials, "Standard Test Methods for Molsture-Density Relations of Solls and Sol1-Aggregate Mixtures Using 10-1b (4.54-kg) Rammer and 18. in. (457-mm) Drop, "Destgnation D1557-78, Annual Book of ASTM Standards, Vol, 04.08, 1985h, p. 282-288.

American Society for Testing and Matertals, "Standard Test Method for One-Dimensional Consolidation Properties of Solls," Designation D2435-80, Annual Book of ASIM Standards, Vol, 04.08, 19851, p. 388-394.

American Society for Testing and Materials, "Standard Test Method for pH of Soil for Use in Corrosion Testing, "Designation G51-77. Annual Book of ASTM Standards. Vol. $04.08,1985 \mathrm{~J}$, p. $928-930$. 
Amertcan Soctety for Testing and Matertals, "Standard Test Method for Rasistance R-Value and Expanston Pressure of Compacted Solls, "Destgnation 02844-69, Annual Book of ASTM Standards, Vol, 04.08, 1985k, p. 435-444.

American Soclety for Testing and Materlals, "Standard Test Method for Shrinkage Factors of Solls, Designation D427-83, Annual Book of ASTM Standards, Vol, 04.08, 19851, p. 134-137.

Amertcan Soctety for Testing and Materials, "Standard Test Method for Spectflc Gravtty of solls," Designation DB54 -83, Annual Beok of ASTM Standards, Vol. 04.08, $1985 \mathrm{~m}, \mathrm{p} .212-215$.

Amertcan Soctety for Testing and Matertals, "Standard Test Method for Unconsolidated, Undratned Compresstve Strength of Cohestve Solls in Triaxtal Compression," Designation D2850-82, Armua1 Book of ASTM Standards, Vol, 04,08, $1985 n$, p. $453-458$.

American Soclety for Testing and Materfals, "Standard Method for Direct Shear Test of Solls Under Consoltdated Dratned Condittons," Designation 03080-72, Annual Book of ASTM Standards, Vol, 04,08, 19850, p. $514 \% 518$.

American Soctety for Testing and Materials, "Standard Test Method for Fleld Vane Shear Test in Cohesive Sol1, "Designation D2573-72, Annual Book of ASTM Standards, Vol. 04.08, 1985p, p. 424-427.

American Society for Testing and Materials, "Standard Method for Particle Stze Analysts of Solls," Designation D42?-63, Annual Book of ASTM Standards, Vol. $04.08,1985 q$, p. $11 \%-127$.

Amertcan Soctety for Testing and Materials, "Standard Method for Determination of Water (Moisture) Content of Soll, Rock, and So 11 -Aggregate Mixtures," Designation D2216-80, Annual Book of ASTM Standards, Vol. 04,08, 1985r, p. $355-358$.

O. B. Anders 1 and and D. M. Anderson, Geotechnical Engineering for Cold Regions, New York: McGraw-H111 Book Co., 1978.

ASTM; see American Society for Testing and Materials.

F. Baguelin, J.F. Jezeque1, D.H. Shlelds, "The Pressuremeter and Foundation Engineering, "Iransaction Technical Publicattons, Clausthal, Germany, and Aedermannsdorf, Switzerland, 1978.

A.W. Bishop, and D.J. Henke1, The Measurement of Soll Properties in the Irlaxtal Test, London: Edward Arnold Ltd., 2nd ed., 1962.

A.W. Bishop, and L. Bjerrum, "The Relevance of the Trlaxtal Test to the Solution of Stability Problems, "Proceedings of the Research Conference or Shear Strength of Cohesion Solls, Boulder Colorado, Amertcan Soctety of Civil Engineers, 1960, p. 437-501. 
T. Bjerrum, "Embankments on Soft Ground, "Proceedings of the ASCE Specialty Conference on Performance of Earth and Earth-Supported Structures, Purdue Untversity, VoT. II, 1972, p. 1-54.

C.A. Black et a 1., Methods of Soll Analys ts Part 1. No. 9, Sertes of AgronomyAmertcan Soctety of Agronomy, Inc., 1965, p. 234-261.

J. E. Bowles, Eoundation Analys is and Design, Now York: McGraw-H1ll Book Co, 1982.

L. Cadiling and S. Odenstad, "The Vane Borer," Proceedings No, 2, Royal Swedish Geotechntcal Institute, 1950, p. 1-88.

C. R. I. Clayton, N. E. Simmons, M. C. Mat thews, Site Investigation - A Handbook for Engtneers, New York: Halsted Press, 1982.

V.F.B. De Me110, "The Standard Penetration Test, State-of-the-Art Paper," Proceedings of the Fourth Panamertcan Conference on Soll Mechantes and Eoundation Engineerting. Vol. I, 1971, p. 1-86.

J. M. Duncan and A. L. Buchignant, An Engineering Manual for Slope Stability Studies, University of Calffornta at Berkley, Department of Civil Engineering, 1975.

V.A. Florin and R.L. Ivanov, "Lquefaction of Saturated Sandy Solls," Proceedings, 5th International Conference on Soll Mechantcs and Foundation Engineering, Parts, France, V1, 1961, p. 107-111.

B.M. Ghadtalt and W.B. TIJmann, "Use of Extensometers at Palo Verde Nuclear Station," American Soctety of Civil Engineer Proceedings, 101, 1981, p. 49-59.

H.A. Govinda Rao and H.A. Balakrtshna Rao, "A Laboratory Pore Pressure "idasu, ing Device, " Proceedings of the Fifth Internattonal Conference on Soll Mechantcs and Foundation Engineering, 1, 1961, p. 305-307.

S. Hansbo, "A New Approach to the Determination of the Shear Strength of Clay by the Fal1-Cone Test, " Proceedings No. 14. Swedish Geotechnical Institute, 1957.

B.0. Hardin and V.P. Drnevtch, "Shear Modulus and Damping in Solls:

Measurement and Parameter Effects, "Journal of the Soll Mechanics and Foundations Diviston, ASCE, Vo1. 98, No. SM6, Proc. Paper 8977, 1972, p. 603. 624.

B.0. Hardin and J. Music, "Apparatus for Vibration of Soll Specimens during the Triaxtal Test, "Instruments and Apparatus for Soll and Rock Mechantcs, ASTM, STP 392, 1965, p. 55-74.

A. W. Hatheway, "Significance of Glactal Till Terminology in Engineered Construction," in 0. C. Farquhar (ed.), Geotechnology in Massachusetts, Amherst: University of Massachusetts, 1982, pp. 193-195. 
K.V. Helenelund, "Torstonal Fleld Tests" Proceediugs of the 6th International Conference on Sotl Mechantcs and Foundatton Engineering, 1965, p. 240-243.

R.D. Holtz and W.D. Kovacs, An Introduct ton to Geotechnical Engineering, Prentlce Hall Clvil Englneering and Engtrieering Mechanics Sertes, 1981, p. $468-469$.

M.J. Hvorslev, Subsurface Exploration and Sampling of Solls for Civ 11 Engtneering Purposes, Vicksburg, Mississippt: U.S. Army Corps of Engtneers, Waterways Experiment Station, 1949.

N. Janbu and K. Senneset, "Field Compressometer-Principles and Applications," Proceedings of the Elahth International Conference on Soll Mechanics and Eoundation Engtneering, 1.1. Moscow, 1973, p. 191"198.

J.E. Jennings and $K$. Knight, "A Guide to Construction on or with Matertals Exhibiting Additional Settlement Due to Collapse of Grain Structure," Proceedings 6th Rerional Conference for Africa on Soll Mechanics and Eoundation Engineering, 1, Durban, 1975, p. 99-105.

W.D. Kovacs, J.C. Evans, A.H. Griffith, "Towards a More Standardized SPT," Proceedings of the Ninth International Conference on Soll Mechanics and Eoundat ton Engineering, 2, Tokyo, 1977, p. 269-276.

D. P. Krynine and W. R. Judd, Princtples of Engineering Geology and Geotechnics, New York: McGraw-Hill Book Co., 1957.

C.C. Ladd et a1., "Stress-Deformation and Strength Characteristics, State-ofthe-Art Report, "Proceedings of the Ninth International Conference on Soll Mechanics and Foundation Engtneering, 2, Tokyo, 1977, p. 421-494.

T. W. Lambe and R. V. Whitman, Soll Mechanics, Somerset: John Wiley and Sons, Inc., 1968.

R.J. Lutton et al., Tests for Evaluation Sites for Disposal of Low-Level Radioact tve Waste, NUREG/CR-3038, December 1982.

L. Menard, "The Menard Pressuremeter," Les Editions Sols-So1ls, 1975, p. 7-43.

J.K. Mitche11, Fundamentals of Soll Behavior, New York: John Wiley \& Sons Inc., 1976.

J.K. Mitchell and W.S. Gardner, "In Situ Measurement of Volume Change Characteristics, State-of-the-Art Report, "Proceedings of the ASCE Specialty Conference on in Situ Measurement of Soll Properties, II, Raleigh, North Carolina, 1975, p. 333 .

NRC; see U.S. Nuclear Regulatory Commission.

H.G. Poulos and E.H. Davis, Elastic Solutions for Soll and Rock Mechanics, New York: John Wtley \& Sons, Inc., 1974. 
R. Rice, "A Fast Response, Fleld Tensiometer system," Iransactions of American Soctety of Agricultural Enqineers, 12.1, 1969, p. 48-50.

G. Sanglerat, The Penetrometer and Soll Exploration, Amsterdam: Elsevier Publishing Co., 1972, p. 5m17.

H.H. Scherrer, "Determination of Llquid Limit by the Static Cone Penetration Test," Proceedings Fifth International Conference on Soll Mechantcs and Eoundation Engineering. VI, 1961, p. 319-322.

J.H. Schmertmann, "Suggested Method for Screw-Plate load Test," Spectal Procedures for Testing Soll and Rock for Engineering Purposes, 5 th Ed., American Soctety for Testing and Matertals Special Technical Publication 479, 1970, p. $81-85$.

J.H. Schmertmann, "Measurement of In Situ Shear Strength, State-of-the-Art Report, "Proceedings of the American Society of Civil Engineers Spectalty Conference on In Situ Measurement of Soll Properties, II, Raleigh, North Carolina, 1975, p. 57-138.

H.B. Seed and I.M. Idriss, "A Simplified Procedure for Evaluating Soil Liquefaction Potential," Journal of the Soll Mechanics and Foundations Dtviston, American Society of Civil Engineers, Vol. 97, No. SM9, 1971, p. 1249-1273.

H.B. Seed and W.H. Peacock, "Test Procedures for Measuring Soll Liquefaction Characteristics, "Journal of the Soll Mechanics and Foundation Division, American Society of Civit Engineers, 97, No. SM8, Paper 8330, 1971, p. 10991119.

H.B. Seed, R.J. Woodward, R. Lundgren, "Prediction of Swelling Potential for Compacted Clays, "Journal of the Soll Mechanics and Foundation Division, American Soclety of Civil Engineers, Vol. 88, No. SM4, 1962, p. 107-131.

B.S. Sowers and G.F. Sowers, Introductory Soll Mechanics and Foundations, 3rd ed., New York: Macmillan Publishing Co., 1970.

K. Terzaghi and R. B. Peck, Soll Mechanics in Engineering Practice, Somerset: John Wiley and Sons, Inc., 1967.

University of Arizuna, Stte Characterization Field Manual for Near Surface Geologic Disposal of Low-Level Radioactive Waste, U. S. Department of Energy report DE FG07 $841012514,1.985$.

U.S. Army Corps of Engineers, Enqineering and Design Stability of Earth and Rock-F 111 Dams, Engineering Manual EM 1110-2-1902, Office of the Chief of Engineers, Department of the Army, Washington DC, 1970a.

U.S. Army Corps of Engineers, Laboratory Soil Testing, Engineering Manual EM 1110-2-1906, Office of the Chief of Engineers, Department of the Army, Washington DC, $1970 \mathrm{~b}$. 
U.S. Army Corps of Engineers, Soll Sampling, Engineering Manual EM 1110-21907, Office of the Chief of Engineers, Department of the Army, Washington DC, 1972.

U.S. Nuclear Regulatory Commission, Laboratory Investigations of Soils for Engineering Analys is and Design of Nuclear Power Plants, Regulatory Guide $1.138,1978$.

U.S. Nuclear Regulatory Commission, Site Investigations for Foundations of Nuclear Power Plants, Regulatory Guide 1.132, 1979.

A.A. Warlam, "Triaxial Apparatus for Field Laboratories," Proceedings, Fifth International Conference on Soil Mechanics and Foundation Engineering, VI, 1961, p. 553-555.

K.K. Watson, "Some Operating Characteristics of a Rapid Response Tensiometer System," Water Resources Research, 1.4, 1965, p. 577-586.

S.D. Wilson, "Small Soil Compaction Apparatus Duplicates Field Results

Close1y," Engineering News Record, 1950, p. 34-36.

J.D. Wineland, "Borehole Shear Device," Proceedings of the American Society of Civil Engineers Specialty Conference on In Situ Measurement of Soil

Properties, I, Raleigh, North Carolina, 1975, p. 511-522.

H.F. Hinterkorn and $i$. Fang, Foundation Engineering Handbook, New York: Van Nostrand Reinhold Company, 1975. 


\section{PARAMETER DESCRIPTIONS - GEOGRAPHY}

Geographic Location: The location of the site in terms of latitude, longitude, universal transverse mercator (UTM) coordinates, and Public Land Survey designation (i.e., Township, Range and Section).

Political Subdivision: The State, county and/or other pertinent subdivision (e.g., township or municipalities) in which the site is located.

Nearby Features: Features in the vicinity of the site, including cities; readily recognized landmarks; rivers, lakes and other bodies of water; major highways; other prominent man-made and natural features; and significant facilities near the site.

Site Area: The amount of land surface included in the site (including buffer zone), measured in acres (hectares) and square miles (square kilometers).

Topography: The general configuration of the land surface, including its elevation and relief and the position of its natural and man-made features.

Site Ownership: The person or entity entitled to legal possession of the site and adjacent Tands. 


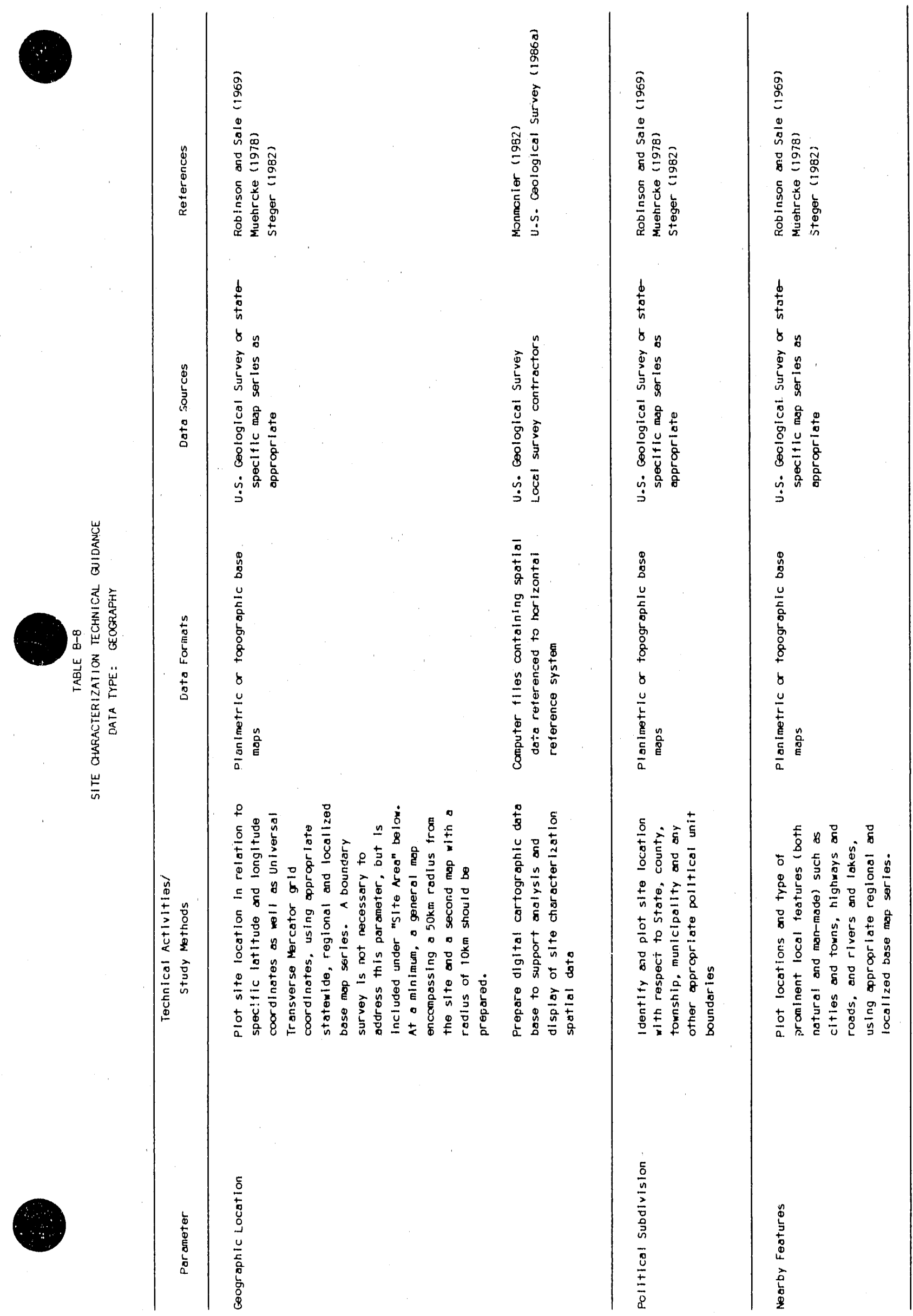




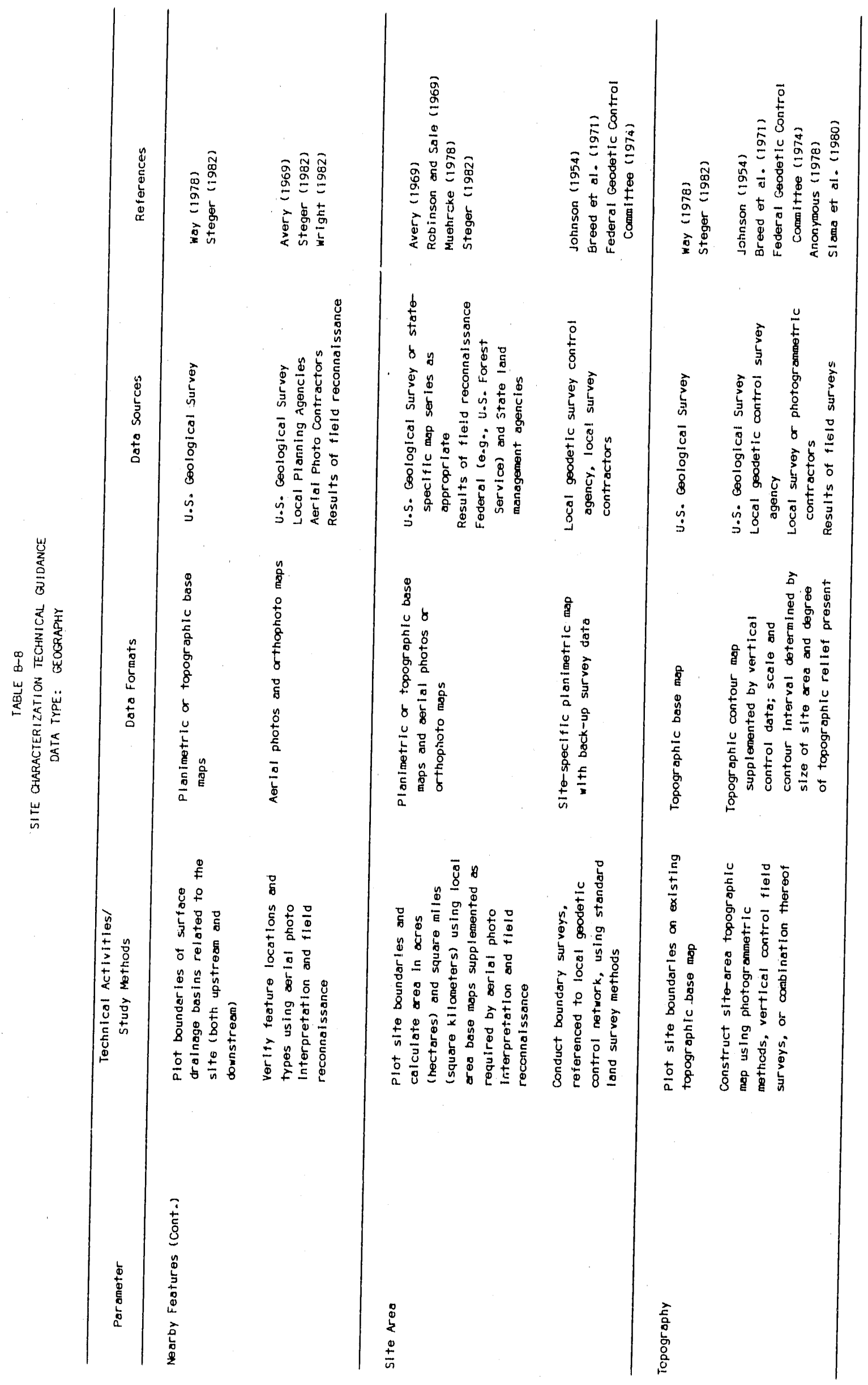




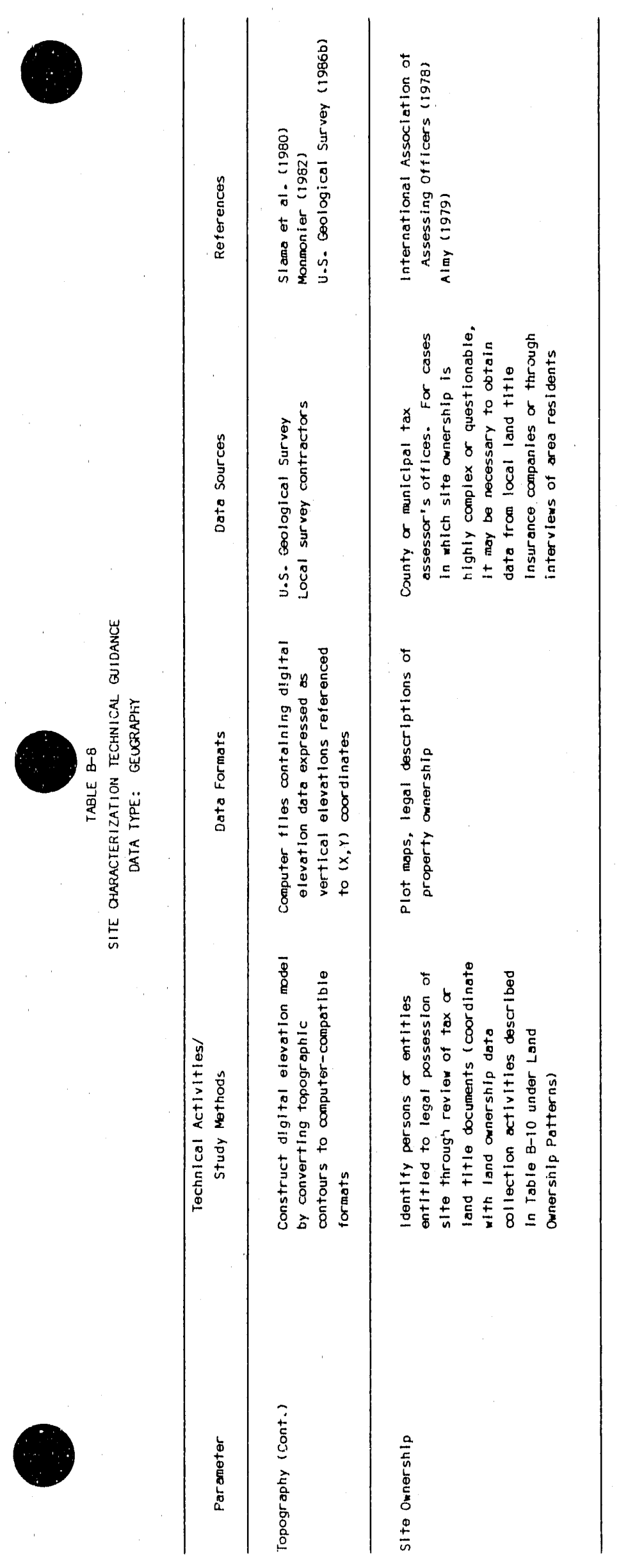




\section{REFERENCES - GEOGRAPHY}

R.R. Almy, "Current Land Record Systems in the U.S., "Monitoring Foreign Ownership of U.S. Real Estate, Volume 2, Washington, D.C.: U.S. Department of Agriculture, 1979.

Anonymous, "Summary of Topographic Mapping Procedures," Topographic Instructions of the United States Geological Survey, Chapter 1B2, U.S. Geological Survey, 1978.

T.E. Avery, Interpretation of Aerial Photographs, 2nd edition, Minneapolis: Burgess Publishing Company, 1969.

C.B. Breed et a1., Surveying, 3rd Edition, New York: John Wiley and Sons, 1971 .

Federal Geodetic Control Committee, Classification, Standards of Accuracy, and General Specifications of Geodetic Control Surveys, National Oceanic and Atmospheric Administration, May 1974.

International Association of Assessing Officers, Improving Real Property Assessment: A Reference Manual, Chicago: IAAO, 1978.

E.W. Johnson, "Ground Control for Planimetric Base Maps," Journal of Forestry, 52, 1954, p. $89-95$.

M.S. Monmonier, Computer-Assisted Cartography - Principles and Prospects, Englewood Cliffs, N.J.: Prentice-Hall, Inc., 1982.

P.C. Muehrcke, Map Use - Reading, Analys is and Interpretation, Madison, WI: JP Publications, 1978.

A.H. Robinson and R.D. Sale, Elements of Cartography, 3rd Edition, New York: John Wiley \& Sons, 1969.

C.C. Slama et a1., (Eds.), Manual of Photogrammetry, 4th Edition, Falls Church, Virginia: American Society of Photogrammetry, 1980.

T.D. Steger, Topographic Maps, U.S. Government Printing Office, 0-383-986, 1982 .

U.S. Geological Survey, Digital Line Graphs from 1:24,000, 1:100,000 and 1:2,000,000 - Scale Maps, Data Users Guides 1, 2, and 3, 1986(a).

U.S. Geological Survey, Digital Elevation Models, Data Users Guide 5, 1986(b). D.S. Way, Terrain Analysis, New York: McGraw-Hil1 Book Co., 1978. 
TABLE B-9

PARAMETER DESCRIPTIONS - DEMOGRAPHY

Population Centers: Population size and boundary locations of population places defined by the U.S. Census Bureau and as modified by State and local government agencies.

Population Density: Number of inhabitants per unit area (i.e., population per square kilometer).

Residence inventory: Identification of occupied housing units (residences) closest to and within $2 \mathrm{~km}$ of the site.

Transient Population: Estimates of population increases to the permanent baseline population resulting from transient influxes due to tourism, seasonal labor, or other factors.

Projected Population: Estimates of future resident and transient populations, in terms of both population density and population centers, for time periods coinciding with the expected first year of facility operation and for decennial census years through the operation lifetime of the facility. 


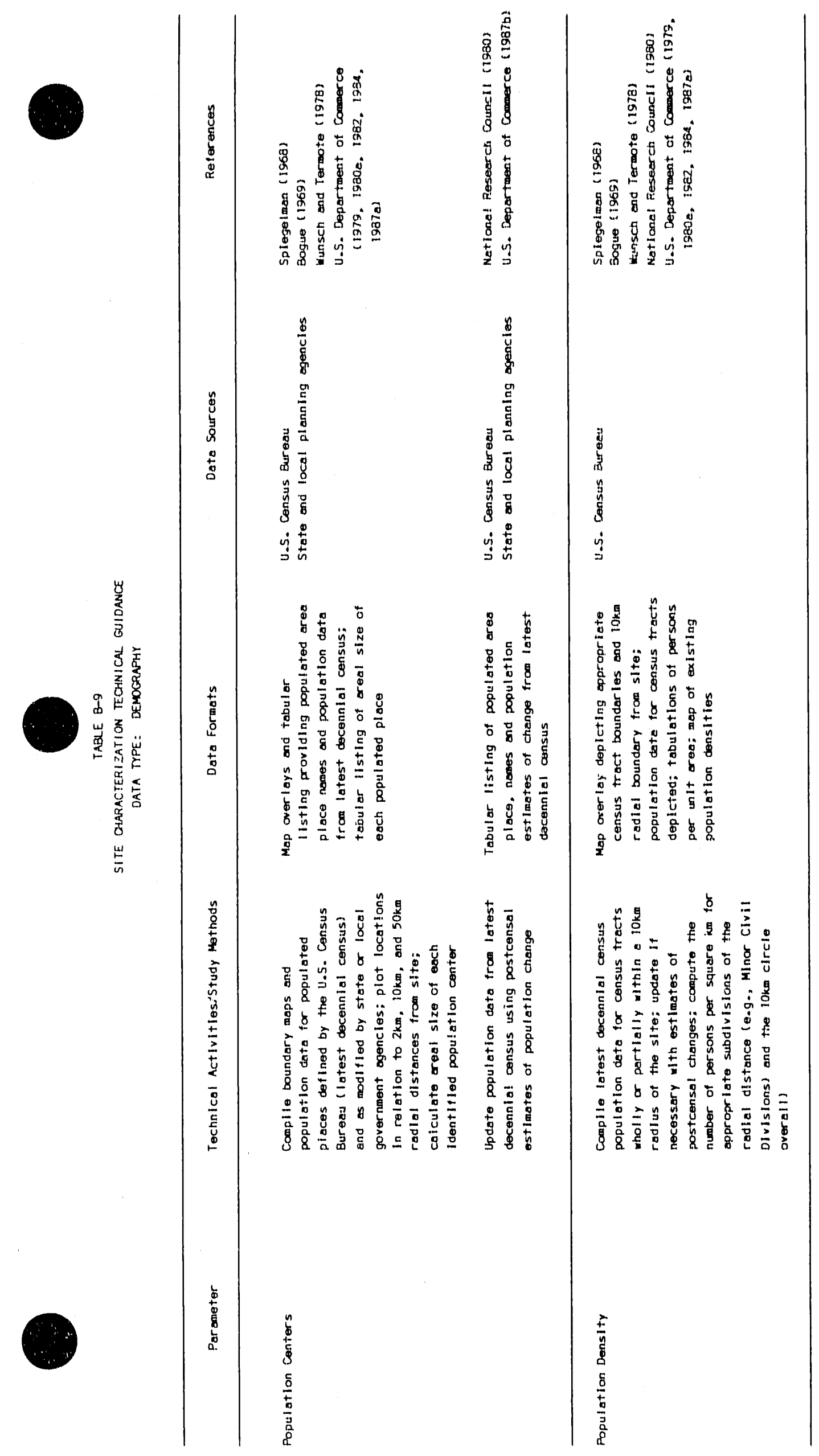

ఏ 


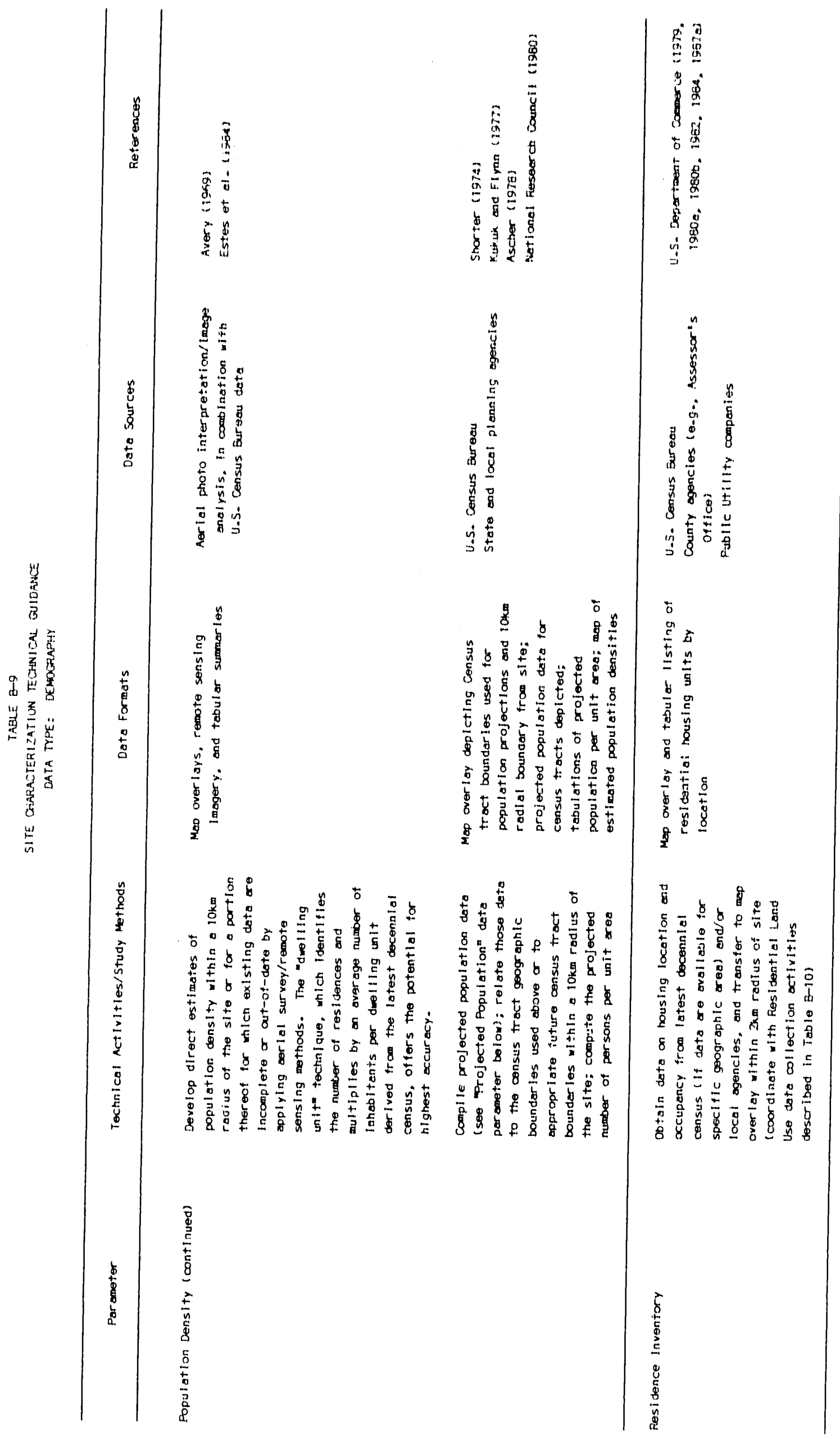




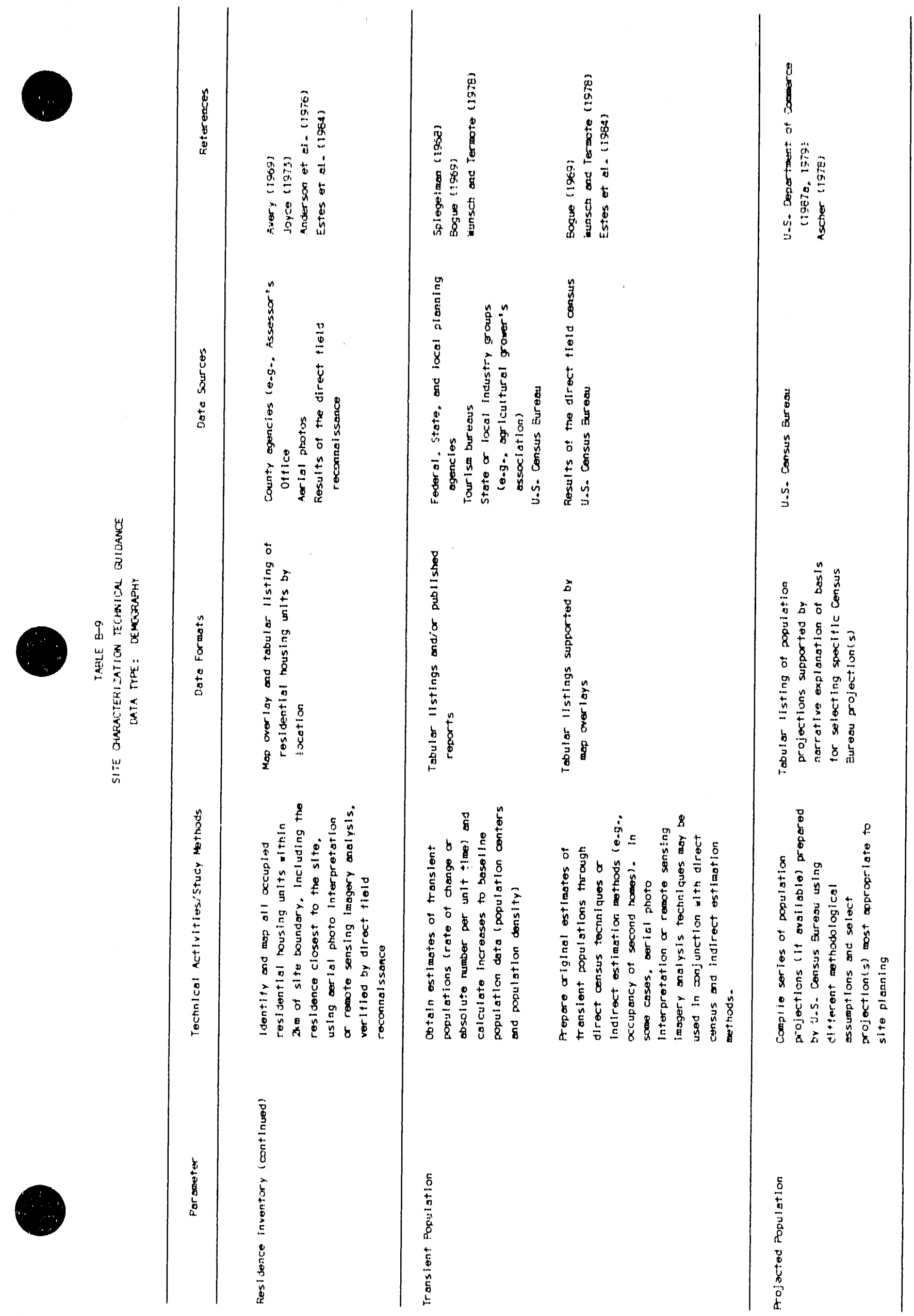




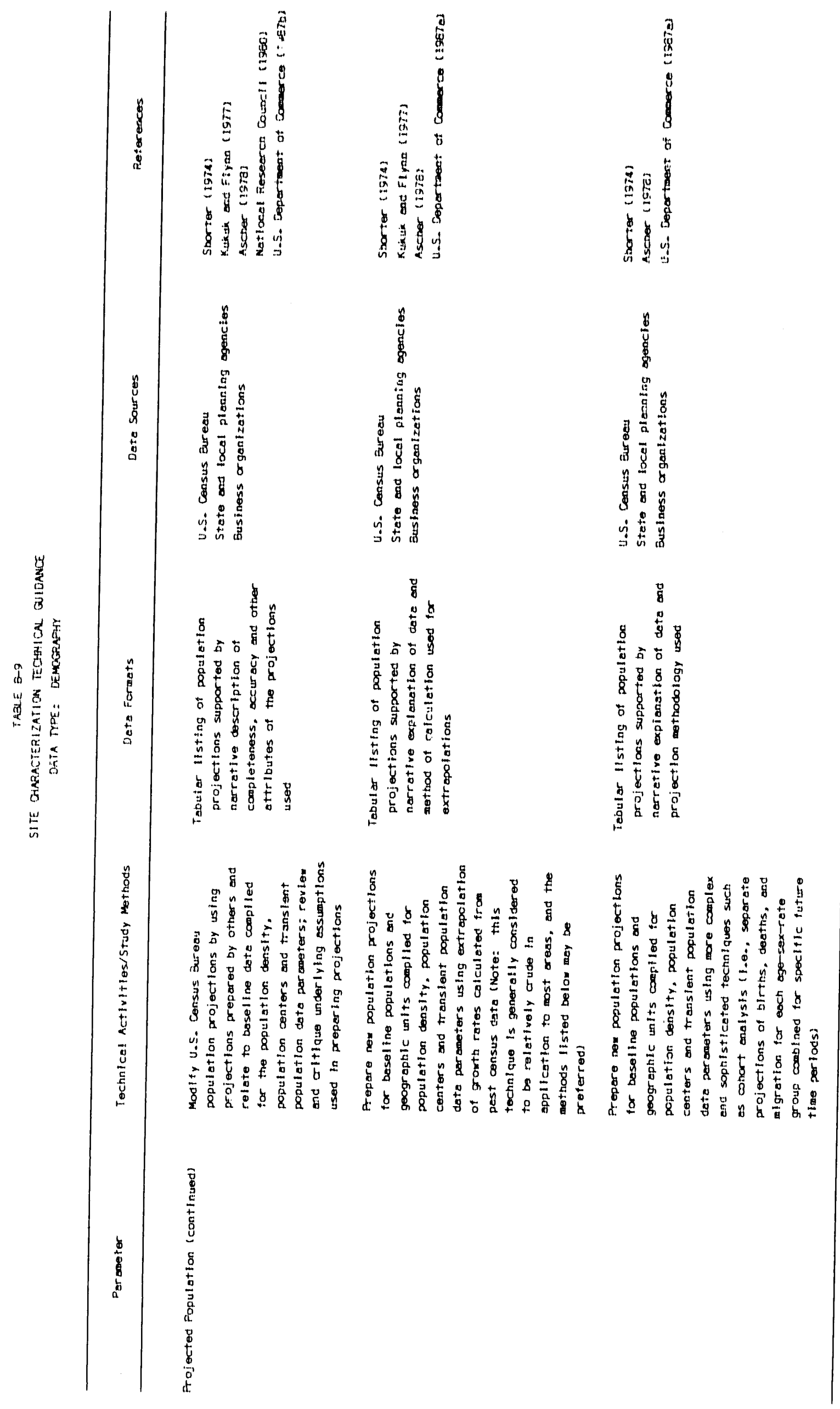


J.R. Anderson et a1., A Land Use and land Cover Class If tcat lon system for Use with Remote Senser Data, U.S. Geological Survey Professtonal Paper 964, 1976.

W. Ascher, Forecasting - An Appratsal for Poltcy Makers and Planners, Baltimore, MD: The Jolins Hopkins University Press, 1978, pp. 38-58.

T.E. Avery, Interpretation of Aerlal Photographs, 2nd editton, Mtnneapolis, MN: Burgess Publishing Company, 1969.

D.J. Bogue, Princtples of Demography, New York: John Wtley and Soris, 1969.

J.E. Estes et a1., Evaluatton of Low-Alt t tude Remote Sensing Techniques for Obtaining Stte Charactertstic Informatton, U.S. Nuclear Regulatory Commlsston NUREG/CR-3583, S-762-R, RE, 1984.

$R$. Joyce, "A Practical Method for the Collection and Analysis of Housing and Urban Environment Data: An Application of Color Infrared Photography, "Proc. Aertal Photography as a Planning Tool. Rochester, NY, October 1973, pp. 15-20.

C.R. Kukuk and C.B. Flynn, How to Make and Evaluate Population Profections, Inst.tute for Soctal and Environmental Studtes Occastonal Paper No. 2 , Universtty of Kansas, 1977.

National Research Counc17, Estimating Population and Income of Small Areas, Washington, D.C.: Nat tonal Academy Press, 1980.

F.C. Shorter, Computational Methods for Population Profections: With Partfcular Reference to Development Planning, New York: The Populatiton Counc 11, 1974.

M. Splegelman, Introduction to Demographx, Rev. Ed., Cambridge, MA: Harvard University Press, 1968.

U.S. Department of Commerce, Guide to County Census Data for Planning Economic Development, Bureau of the Census, 1979.

U.S. Department of Commerce, Ihe Census Bureau'S GBF/Dime System: A Too for Urban Management and Planning, Bureau of the Census, 1980a.

U.S. Department of Commerce, Housing Data Resources: Indicators and Sources of Data for Analyzing Housing and Netghborhood Condittons, Bureau of the Census, $1980 \mathrm{~b}$.

U.S. Department of Commerce, 1980 Census of Population and Housing User's Gutde, PHC80-R1, Bureau of the Census, 1982.

U.S. Department of Commerce, Directory of Data.Elles, Update No. 12, Bureau of the Census, 1984. 
U.S. Department of Commerce, Census Catalog and Gulde, Bureau of the Census, 1987 a.

U.S. Department of Commerce, Ihe Content Development Process for the 1990 Census of Population and Housing, Bureau of the Census, 1987b.

G.J. Wunsch and M.G. Termote. Introduction to Demographic Analys is : Princtoles and Methods, New York, NY: Plenum Press, 1978. 
Residential Land Use: Current and projected uses of land on which the stte is located and within $10 \mathrm{~km}$ as housing, classified according to residential denstty and housing type.

Industrlal Land Use: Current and projected uses of 1 and on which the site is located and within $10 \mathrm{~km}$ for manufacturing, processing, or other industrial purposes.

Agricultural Land Use: Current and projected uses of 1 and on which the site is located and within $10 \mathrm{~km}$ for crop production or domestic antmal husbandry.

Recreational Land Use: Current and projected uses of 1 and on which the site is located and within $10 \mathrm{~km}$ for public recreational purposes, e.g., parks, trafls, water courses, etc.

Special-Use Areas: Current and projected uses of land on which the site is located and within $10 \mathrm{~km}$ for designated special-status uses such as national parks, military reservations, Indtan reservations, and wilderness areas.

Zoning Restrictions: Local restrictions on land use promulgated by county, city, town, township, or other local jurisdictional planning entitis, which designate land for specified uses or constrain certain types of uses.

Local Land-Use Plans: Existing plans prepared by local planning entities that codify land use status, constraints, and projected trends in 1 and usage.

Land Ownership Patterns: Type of land ownership (e.g., public versus private) and specific entities that own the laid on which the site is located and within $10 \mathrm{~km}$.

USDA Land Use Classification: Land parcels classifled by the U.S. Department of Agriculture as being in one of eight categories of land capacity, or as being classified as prime or unique larid on the site and within $10 \mathrm{~km}$.

Ut llity Land Use: Ut llity facilities, pipelines, transmission systems, and other utility uses of land on which the site is located and within $10 \mathrm{~km}$. 


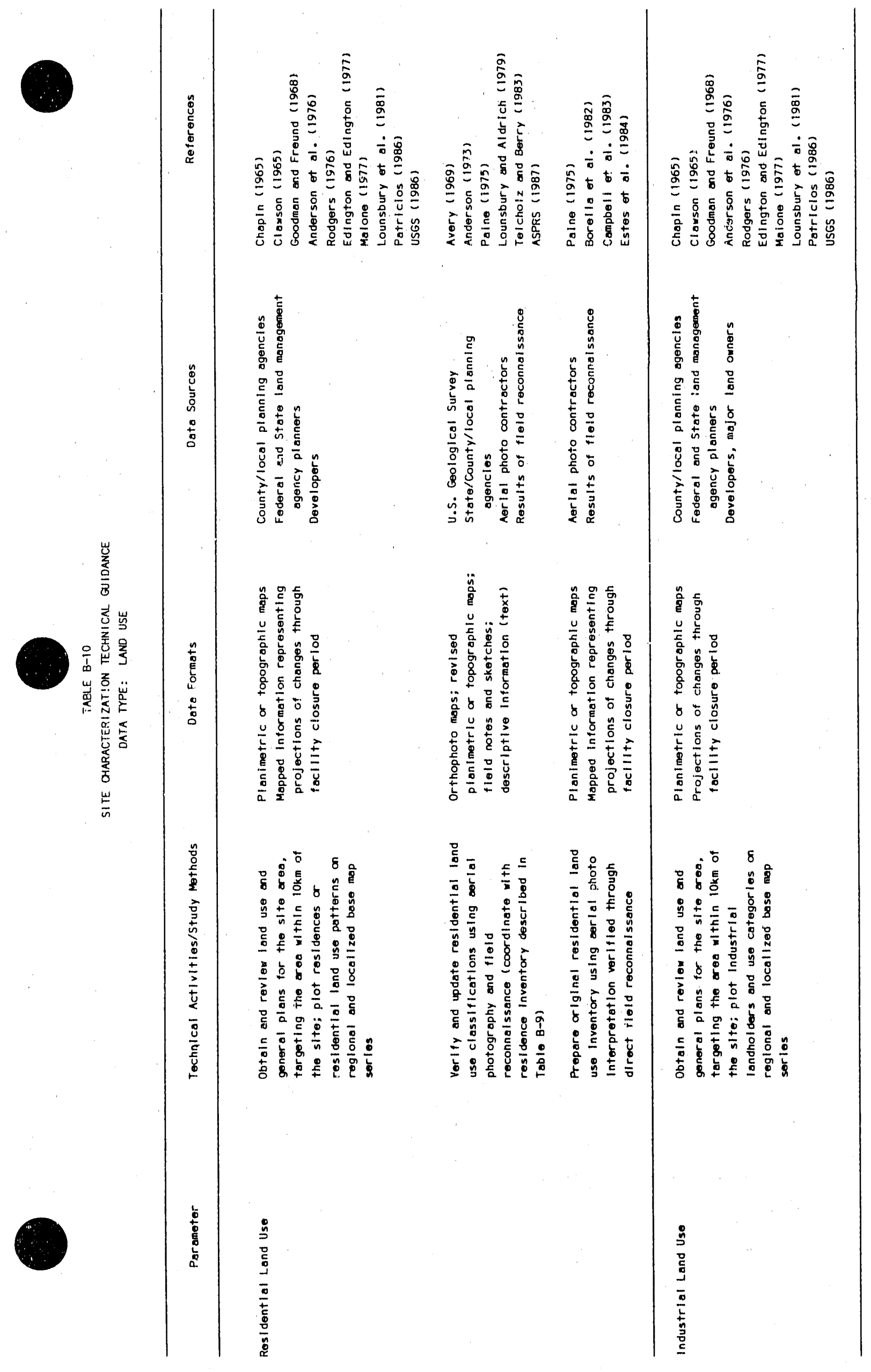




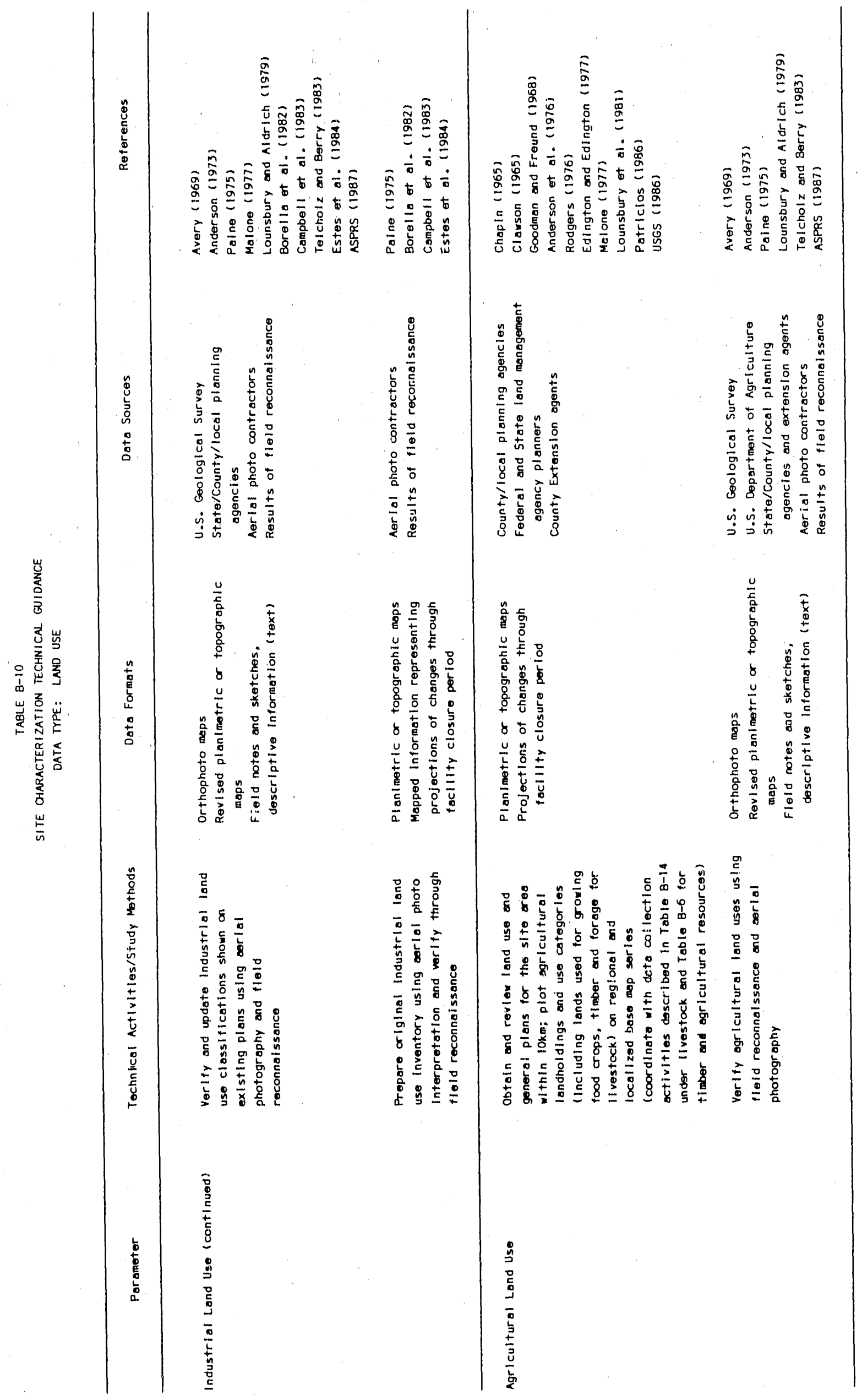




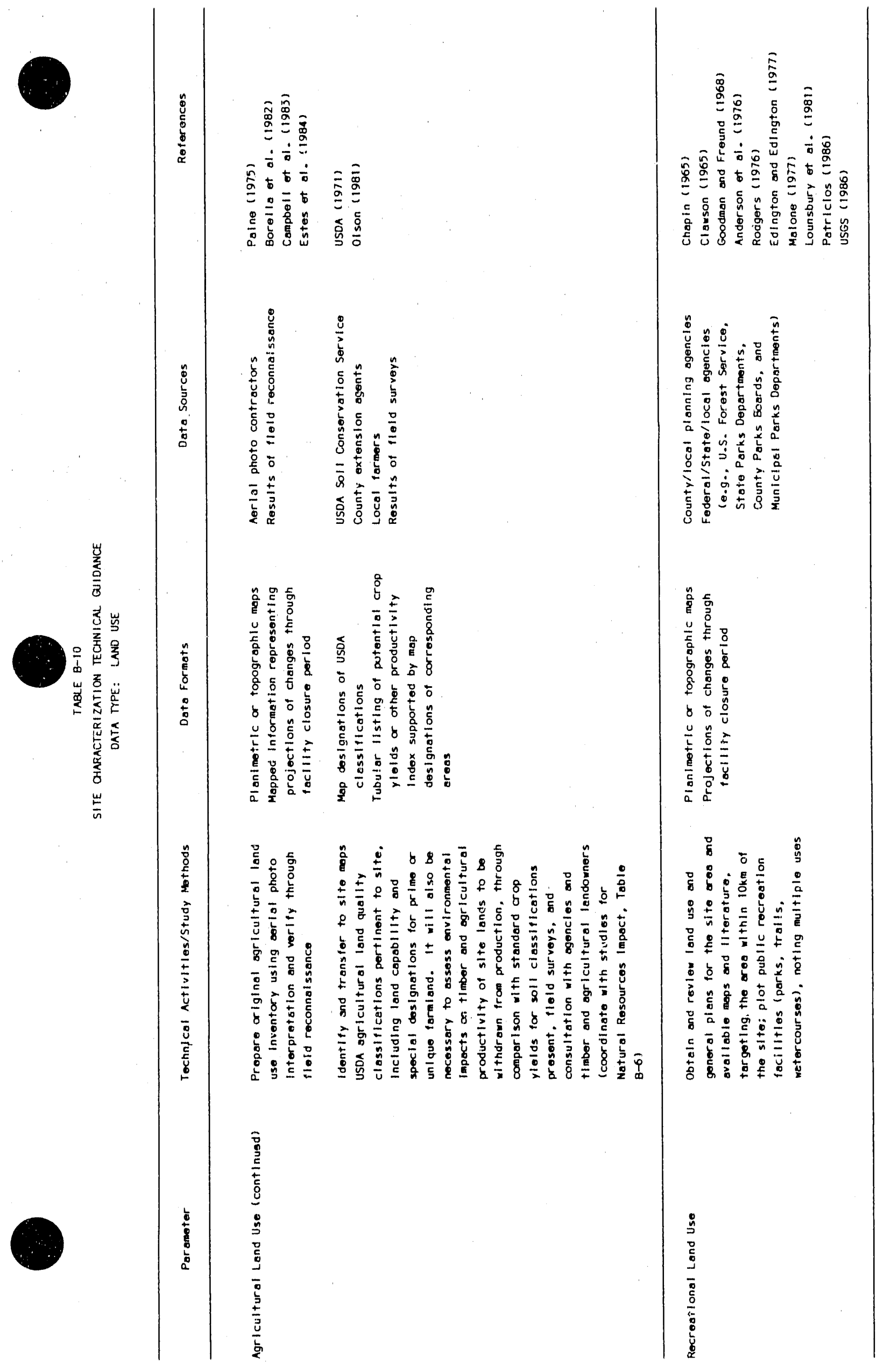




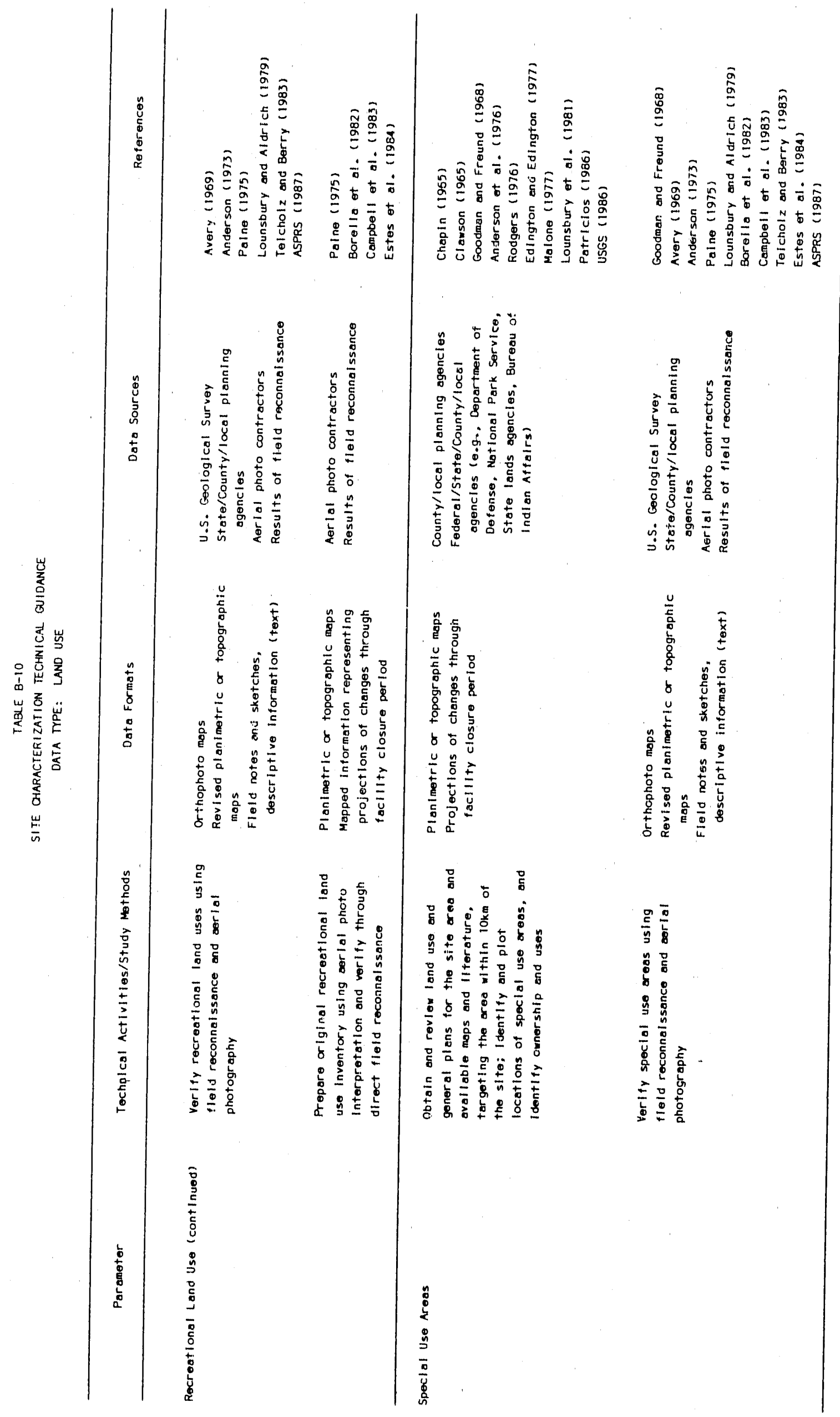




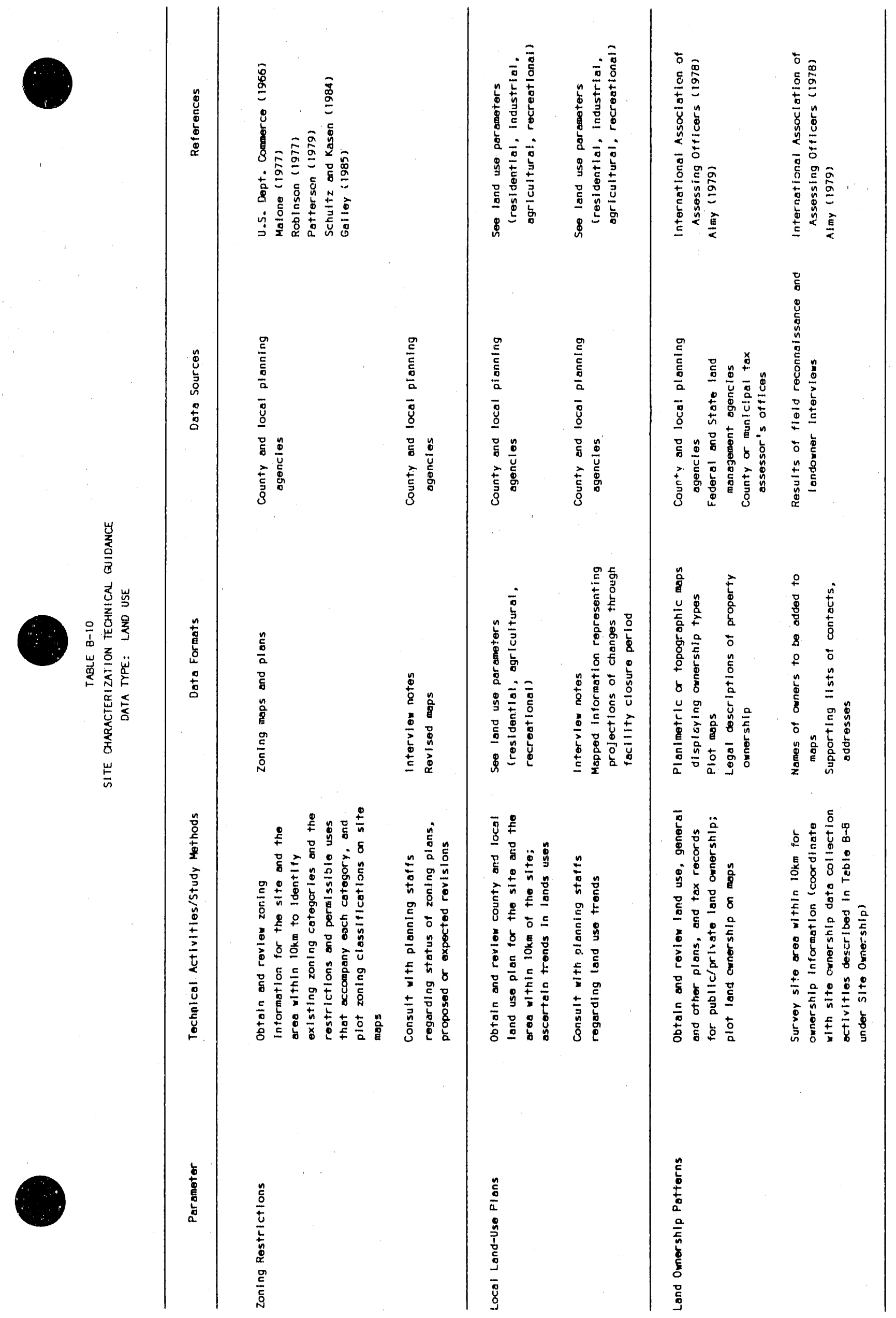

$\frac{n}{1}$ 


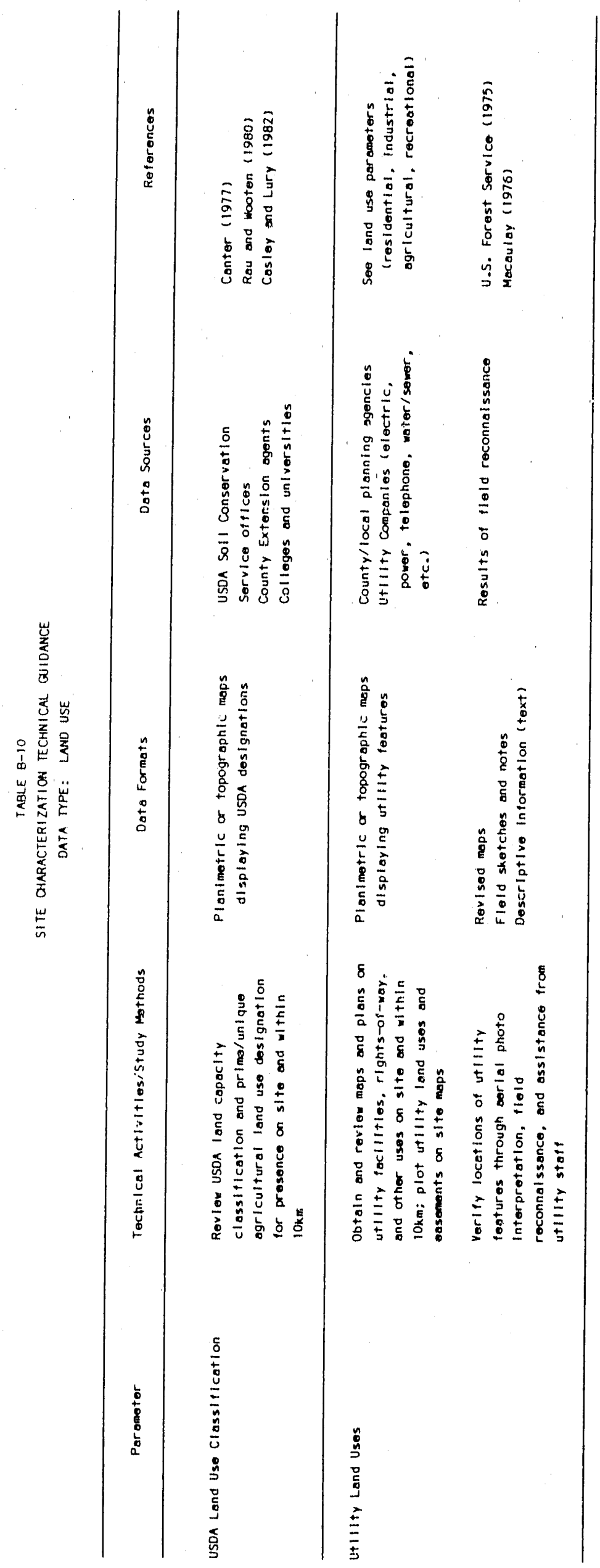


R.R. Almy, "Current Land Record systems in the U.S.," Monitoring Foreign Ownership of U.S. Real Estate, Volume 2, Washington, D.C.: U.S. Department of Agriculture, 1979.

American Society for Photogrammetry and Remote Sensing and American Congress on Surveying and Mapping, Large-Scale Mapping Guidelines, Reston, VA: ASPRS, 1987.

J.R. Anderson, "Land Use Data frorn Remote Sensing for Resource Planning," Proceedings of the Kodak Seminar: Aerial Photography as a Planning Tool, Cornell University, October 15-16, 1973, p. 10.

J.R. Anderson et a1., A Land Use and Land Cover Classification System for Use with Remote Sensor Data, U.S. Geological Survey Professional Paper 964, 1976.

ASPRS; See American Society for Photogrammetry arid Remote Sensing.

T.E. Avery, Interpretation of Aerial Photographs, 2nd edition, Minneapolis, MN: Burgess Publishing Company, 1969.

H.M. Bore11a et a1., Image Analys is for Facility Siting: A Comparison of Lowand High-Altitude Image Interpretability for Land Use/Land Cover Mapping. NUREG/CR-2861, Prepared for U.S. Nuclear Regulatory Commission, 1982.

W.J. Campbell et a1., site Characterization Information Using LANDSAT Satellite and other Remote Sensing Data - Integration of Remote Sensing Data with Geographic Information Systems, NUREG/CR-3247, Prepared for U.S. Nuclear Regulatory Commission, 1983.

L.W. Canter, Environmental Impact Assessment, New York, NY: McGraw-Hill Book Co., 1977.

D. Casley and D. Lury, Monitoring and Evaluation of Agricultural and Rural Development Projects, Baltimore, MD: Johns Hopkins University Press, 1982.

F.S. Chapin, Jr., Urban Land Use Planning, Urbana, IL: University of Illinois Press, 1965.

M. Clawson, Land Use Information, Baltimore, MD: Johns Hopkins University Press, 1965.

J.M. Edington and M.A. Edington, Ecology and Environmental Planning, New York, NY: John Wiley \& Sons, 1977.

J.E. Estes et al., Evaluation of Low-Altitude Remote Sensing Techniques for Obtaining Site Characteristic Information, U.S. Nuclear Regulatory Commission NUREG/CR-3583, S-762-R, RE, 1984. 
J.B. Gatley (Ed.), 1985 Zoning and Planning law Handbook, New York: C. Boardman, 1985.

W. I. Goodman and E.C. Freund, Principles and Practlce of Urban Planning, Washington, D.C.: International City Managers' Association, 1968.

International Association of Assessing Offices, Improving Real Property Assessment: A Reference Manual, Chicago, IL: IAAO, 1978.

J.F. Lounsbury and F. T. Aldrich, Introduction to Geographtc Fleld Methods and Techntques, Columbus, OH: Charles E. Merri Co., 1979.

J.F. Lounsbury et a1, Land Use, A Spatial Approach, Dubuque, IA:

Kendall/Hunt Publishing Com., 1981.

D. Macau1ay, Underground, Boston: Houghton Miffl in Company, 1976.

P.M. Malone, The Language of Planning: A Layman's Glossary of Selected Land Use Planning and Zoning Words and Phrases, Olympla, WA: Planning and Communtty Affairs Agency, 1977.

G.W. Olson, Solls and the Environment - A Gutde to Soll surveys and The ir Applications, New York: Chapman and Hall, 1981, p. 98-104; 122-125.

D.P. Paine, Introduction to Aerial Photography for Natural Resource Management, Corvallis, OR: OSU Book Stores, 1975.

N.N. Patriclos, International Handbook on Land Use Planning, New York, NY: Greenwood Press, 1986.

T.W. Patterson, Land Use Planning: Techniques of Implementation, New York: Van Nostrand Reinhold, 1979.

J.G. Rau and D.C. Wooten, Environmental Impact Analys is Handbook, New York, NY: McGraw-Hil1 Book Co., 1980.

S.D. Robinson, Land Use Guide for Bullders, Developers, and Planners, Farmington, MI: Structures Publishing Company, 1977, p. 43-55.

J.L. Rodgers, Jr., Environmental Impact Assessment, Growth Management and The Comprehensive Plan, Cambridge, MA: Ballinger Publishing Co., 1976.

M. Schultz and V. Kasen, Encyclopedia of Community Planning and Environmental Management, New York: Facts on Flle Publications, 1984.

E. Teicholz and B.J.L. Berry, Computer Graphics and Environmental Planning, Englewood Cliffs, NJ: Prentice-Hall, Inc., 1983.

USDA; See U.S. Department of Agriculture. 
U.S. Department of Agriculture, Conservation Needs Inventory Commlttee, "Nutritional Inventory of Soll and Water Conservation Needs, 1967," Statistical Bulletin 461, 1971.

U.S. Department of Commerce, Zoning for Small Towns and Rural Counties, Economic Development Administration, 1966.

U.S. Forest Service, National Forest Landscape Management, Vo1. 2, Chapter 2 Utilities, U.S.D.A. Agricuiture Handbook 478, 1975.

U.S. Geological Survey, National Mapping Program, Land Use and Land Cover Digital Data from 1:250,00 and 1:100,00-Scale Maps, Washington, D.C.: Data Users Gutdes, 1986, pp. 1-3, 14.

USGS; see U.S. Geological Survey. 
TABLE B-11

PARAMETER DESCRIPTIONS - METEOROLOGY

Wind Speed/Direction: The rate of atr flow and its trajectory, measured continuousiy at vartous helghts above ground level as hourly means (scalar speed and resultant vector speed and direction) and peak instiantaneous gust speeds; hourly data calculated to long-term (monthly, seasonal, annual) summaries by joint frequency distributions using six speed categorles and sixteen direction categortes, average scalar speeds, and maximum gust speeds.

Atmospheric Pressure: Force per untt area exerted by overlytng air mass at the earth's surface, typically as hourly values; calculated to monthly and annual averages.

Precipitation: Water particles that fall from the air and reach the ground including liquid (rain, drizzle) and frozen (snow, hail) water; measured as hourly or dally totals, and calculated to monthly and annual totals, both as water equivalent and depth of snow; also calculated to extreme values of prectpitation rates and totals by vartous time periods.

Pan Evaporation: Amount of water evaporated datly from a standard pan, calculated to monthly and seasonal totals. Used as an indication of evaporation from free water surfaces (such as lakes, ponds) and with soll and vegetation information to estimate evapotranspiration.

Humidity/Dew-Point/Wet-Bulb: Measures of atmospheric water vapor; humidity is the water vapor fraction of saturation conditions; dew-point temperature is the air temperature at which ambient water vapor will condense on a surface; simply, wet-bulb temperature is the temperature measured as hourly average values and calculated to monthiy, seasonal and annual averages, often for specific hours of the day.

Air/Soil Temperatures: Measurements of ambient air temperature at various heights above ground level, usually 2 meters and others as required; used in water and energy balance, and air quality dispersion analyses; measured as hourly values or dafly maximum/minimum and average values by month, and annual average temperatures. Measurements of soll temperature made at selected depths with in the sol1, used in water and energy budget analyses.

Erost Penetration: Depth within the soll to which water is frozen, measured as depths by month or season.

Snow Cover: Sriow depth in undisturbed areas, measured dally or less often; measured as occurrence of depths at least one inch, snow depth (both incremental storm events and cumulative depths), and water equivalent (obtained by weighing or melting a snow core); calculated to monthly or seasonal averages. 
Solar Radiatton: Total incoming solar radtation, typtcally measured at 2 metars above ground as hourly and dally total incoming energy, calculated to monthly totals: also can be llsed with terrestrtal long-wave radlation to compute net radlation, measured as hourly average amounts; used in energy and water budget analyses.

Severe Weather: Occurrences of signiffcant weather events such as tornadoes, hurricanes, thunderstorms, hall, bilzzards, etc. Magnitude of events can be treated along with individual parameter, such as extreme temperature and precipttation events. 


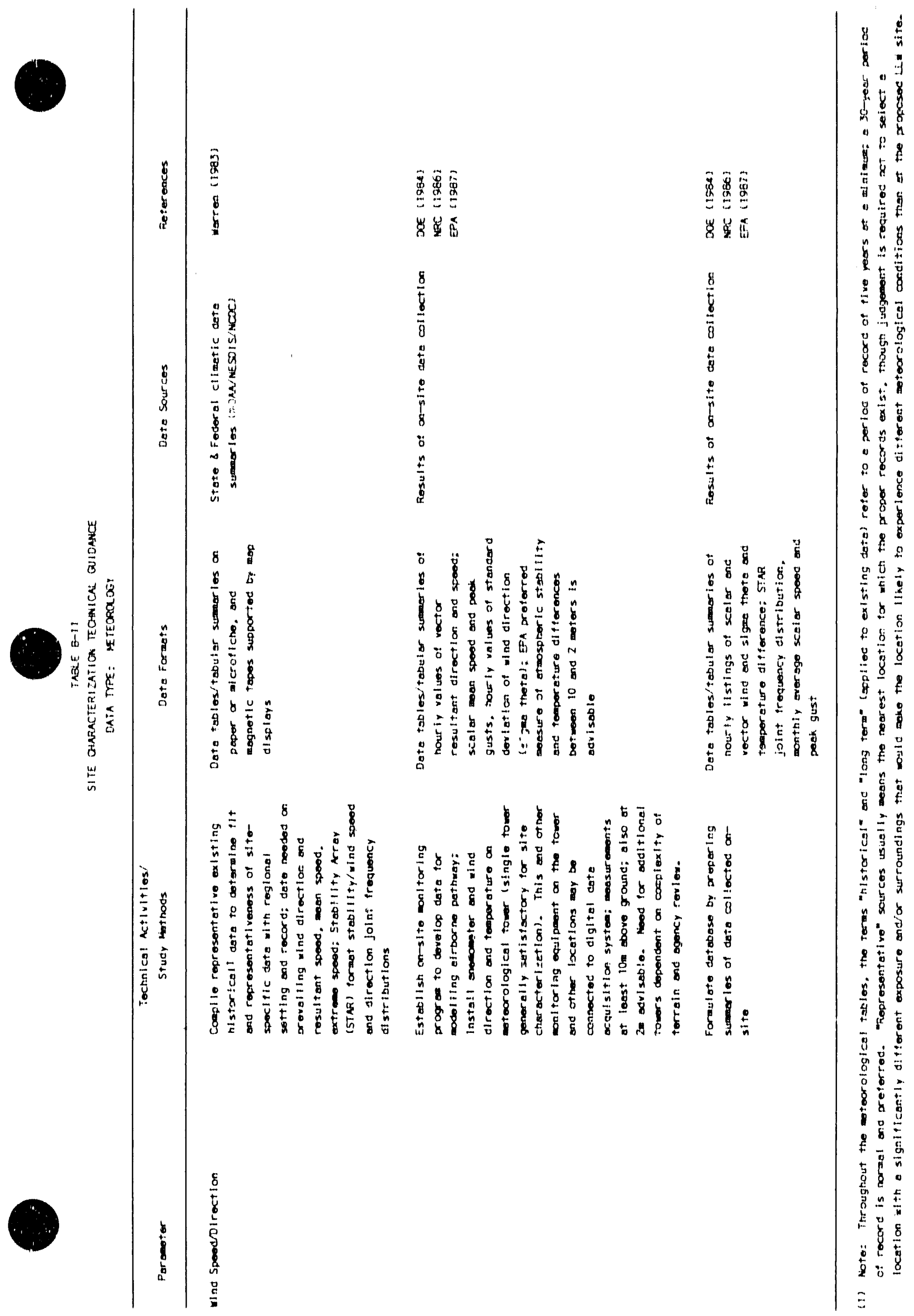




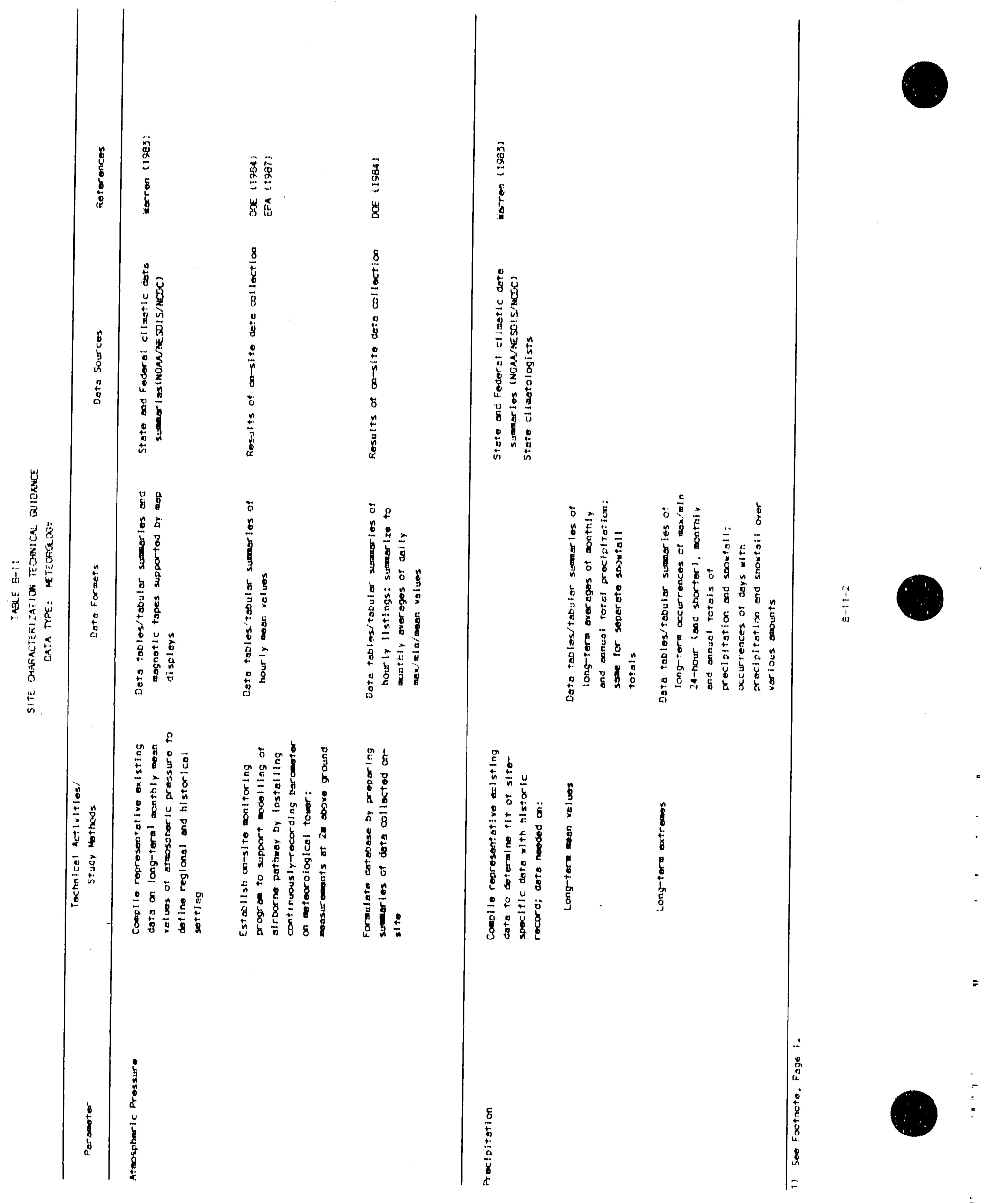




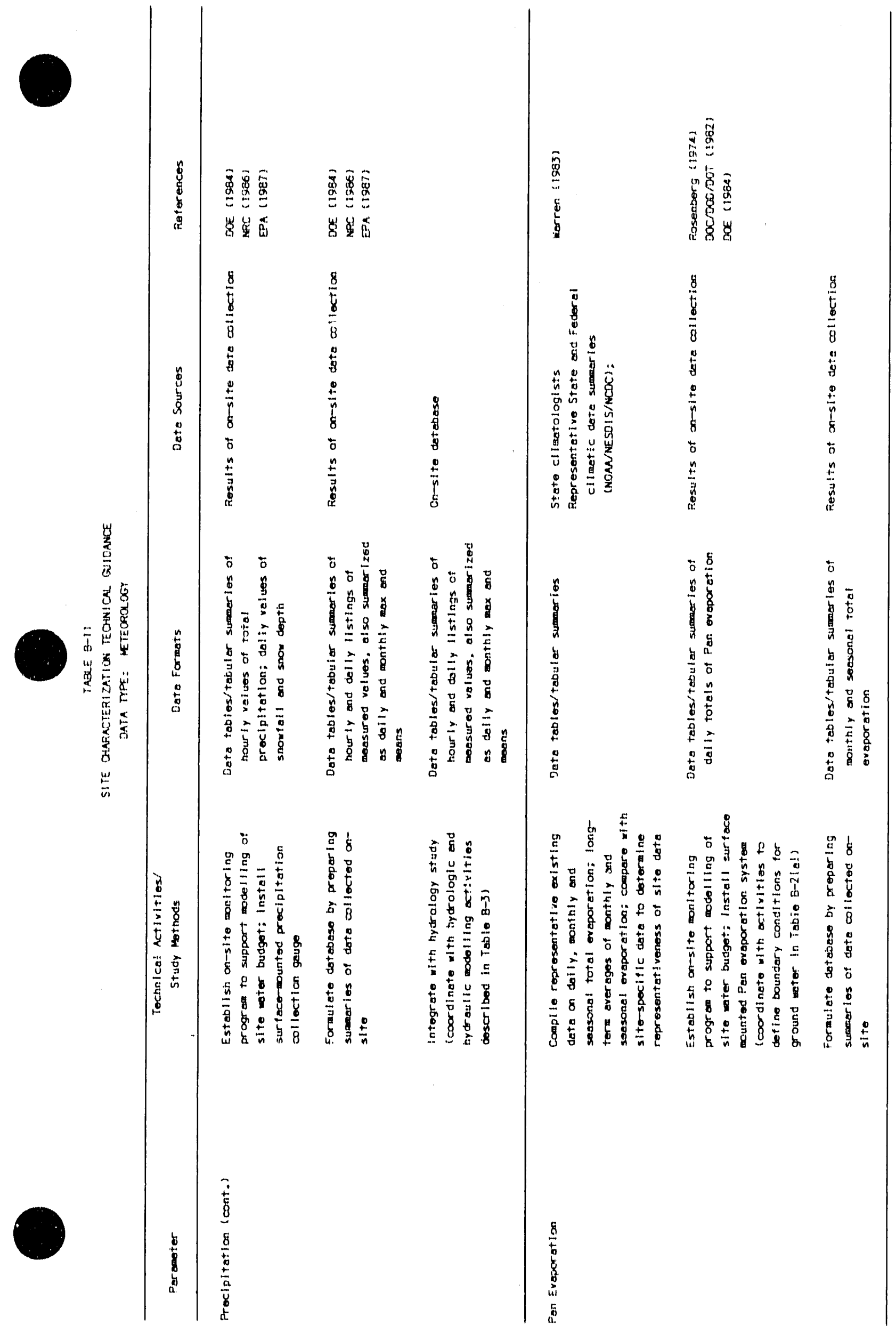



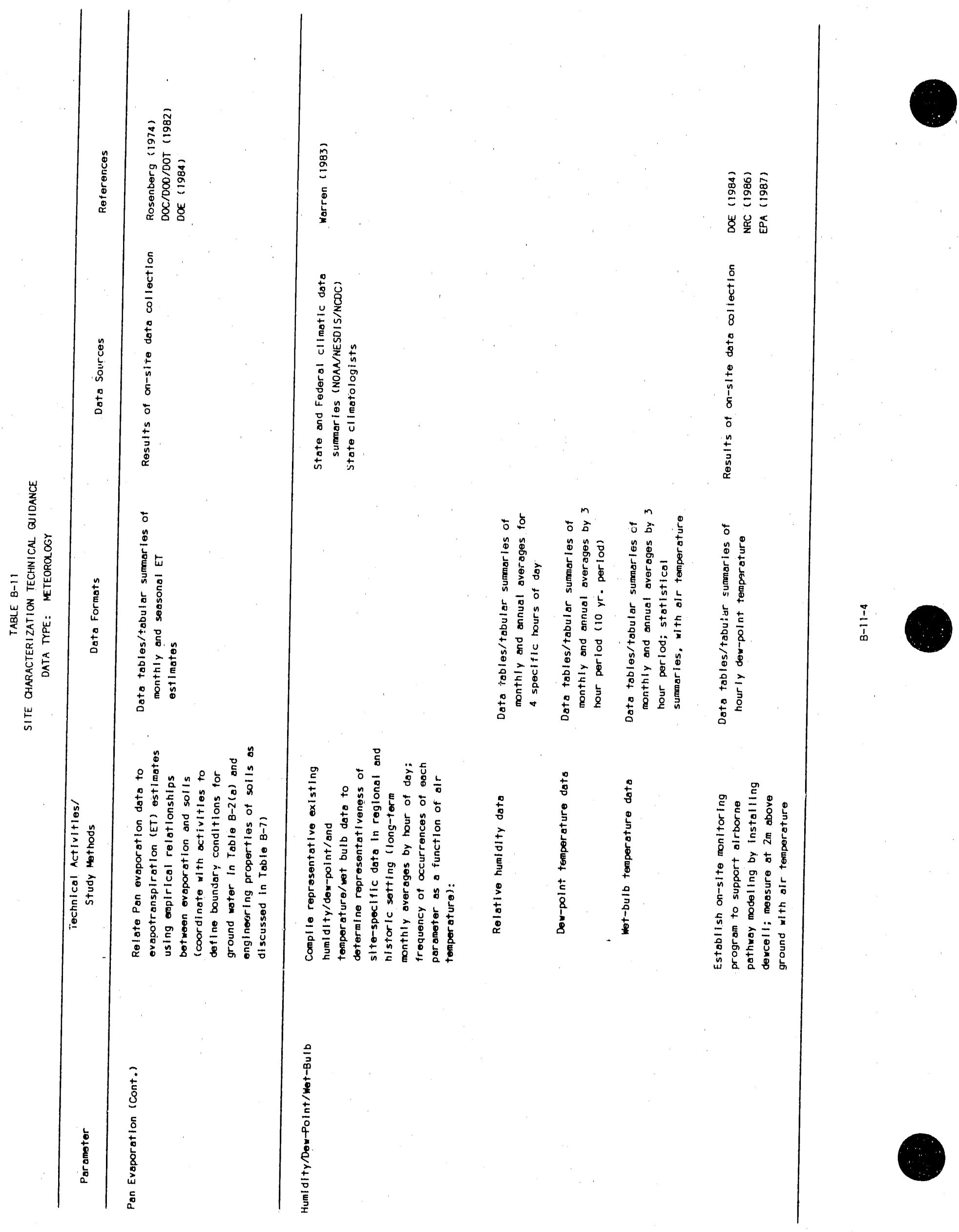


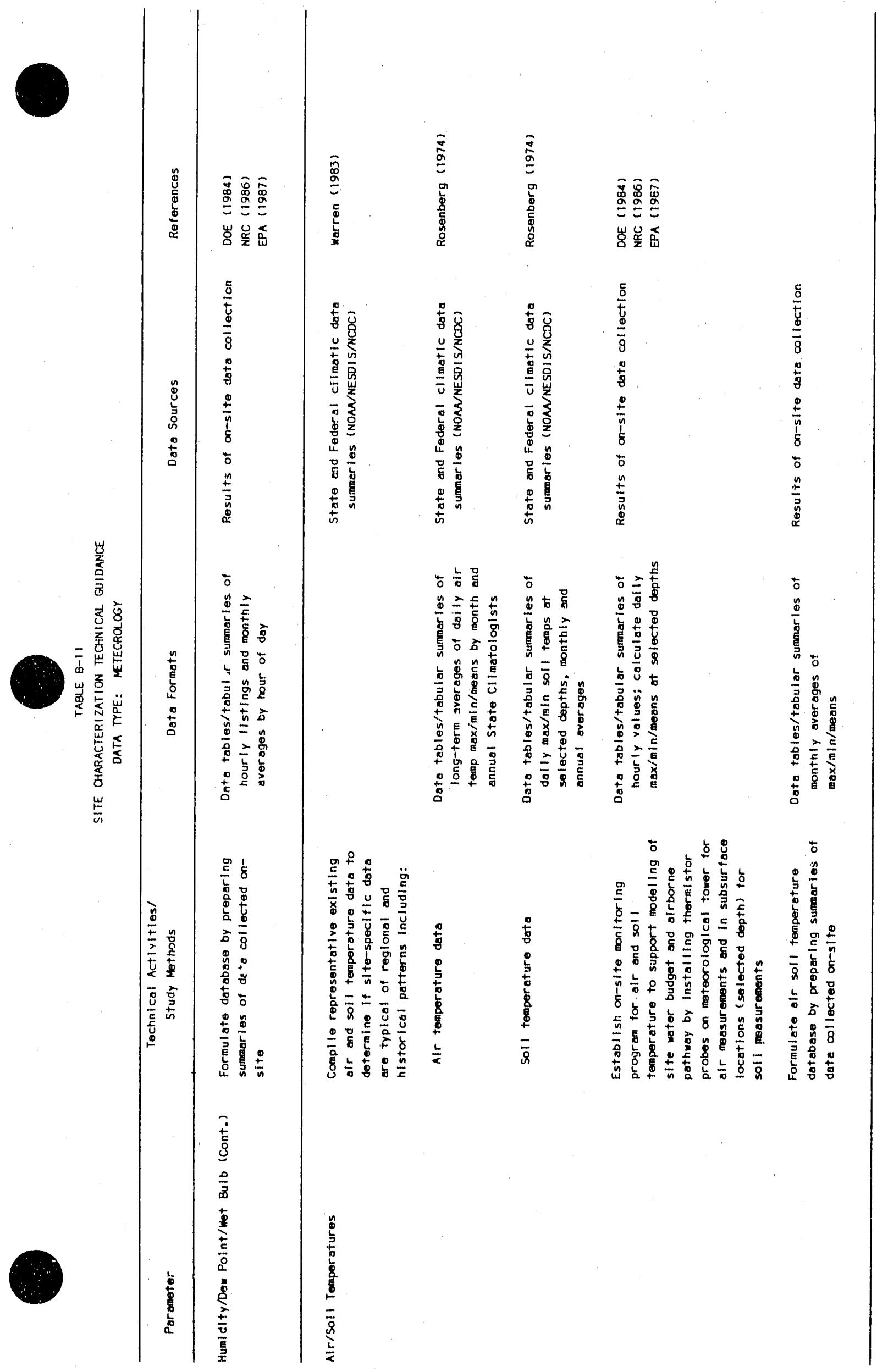




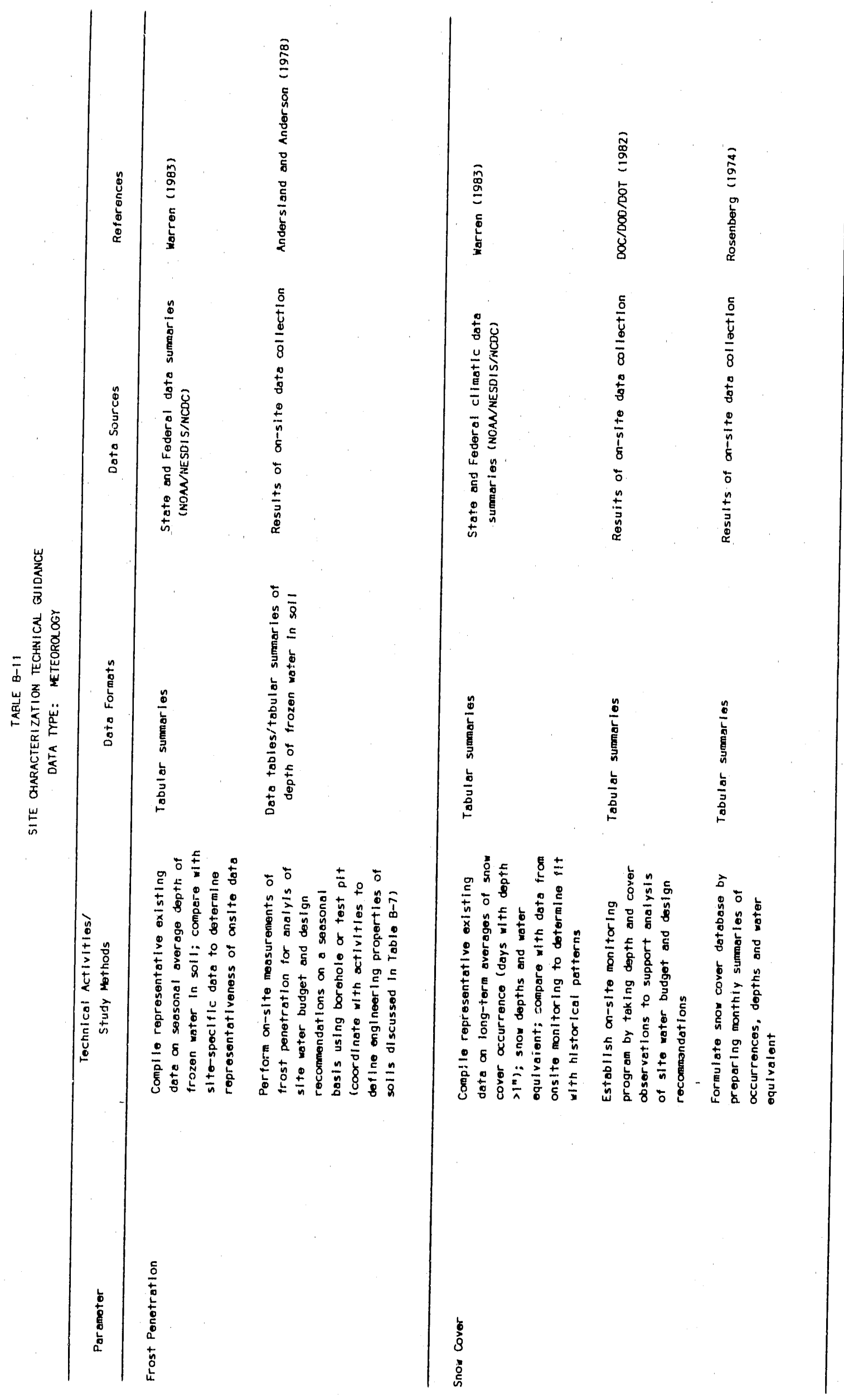




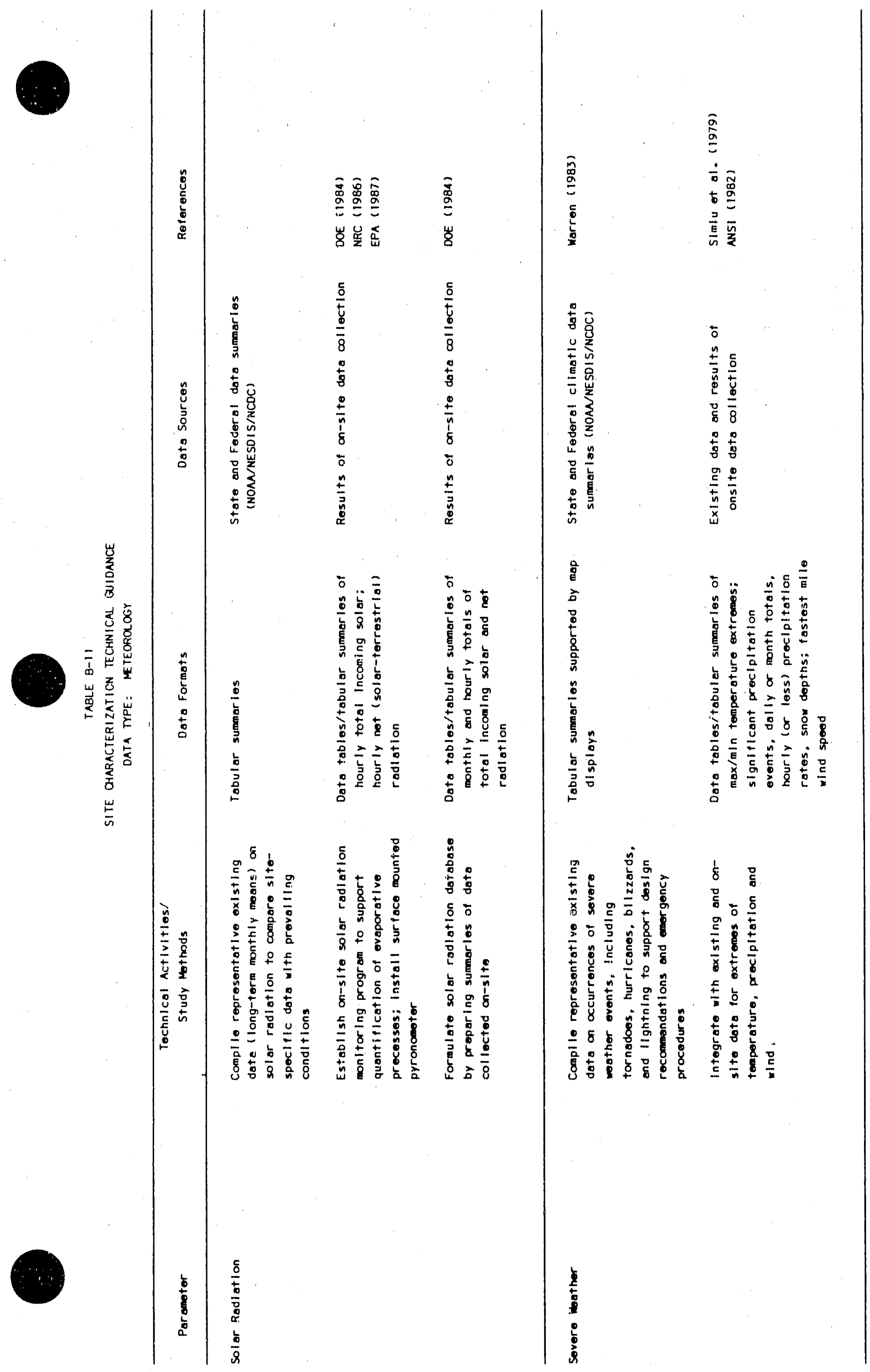

$\frac{i}{1}$ 
Pollutant Type: The classification of non-radiological, airborne, pollutants likely to be found at a proposed site as existing background or expected to be present during site development, operation, or closure; includes EPA criteria pollutants (40 CFR 50); sulfur dioxide, particulate matter, carbon monoxide, ozone, nitrogen dioxide, and lead. Also includes hydrocarbons that may cause health impacts.

Pollutant Concentrations: Measured or estimated amount of the pollutant types, based on averaging times corresponding to the ambient air quality standards.

Regional Classification: The designation given to the air quality control region through regulation or agency evaluation to denote attainment (i.e., compliance with the National Ambient Air Quality Standards) or non-attainment for each air pollutant. Special restrictions and control requirements for air pollution exist in the non-attainment areas.

Air Quality Control Region: The region of the country, as designated by U.S. EPA for control and management of air pollutants, within which the site is located.

Air Quality Cellings: Upper limits on concentrations of non-radiologic air pollutants, as set forth in 40 CFR 50 (National Primary and Secondary Ambient Air Quality Standards) and State regulations. 


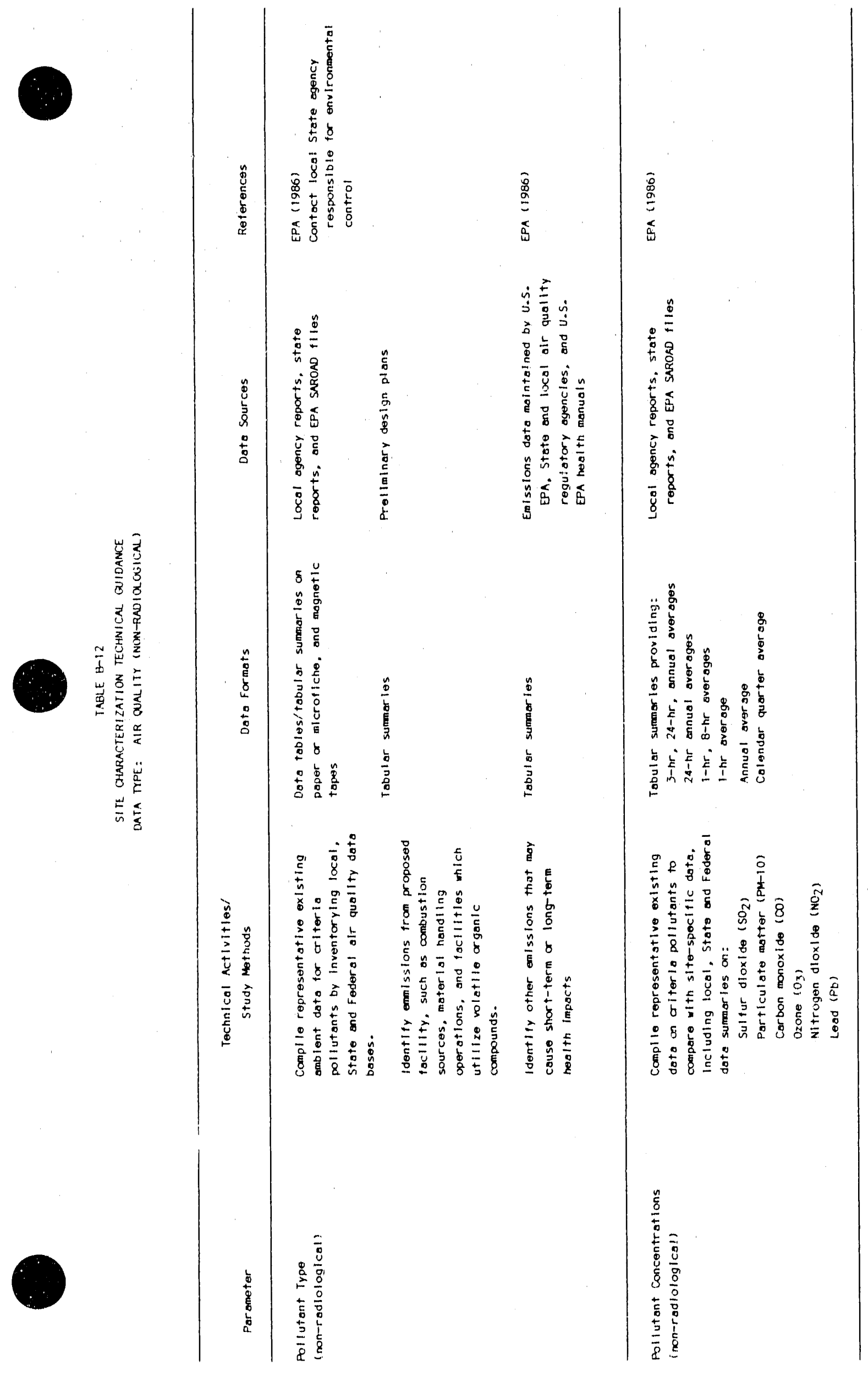




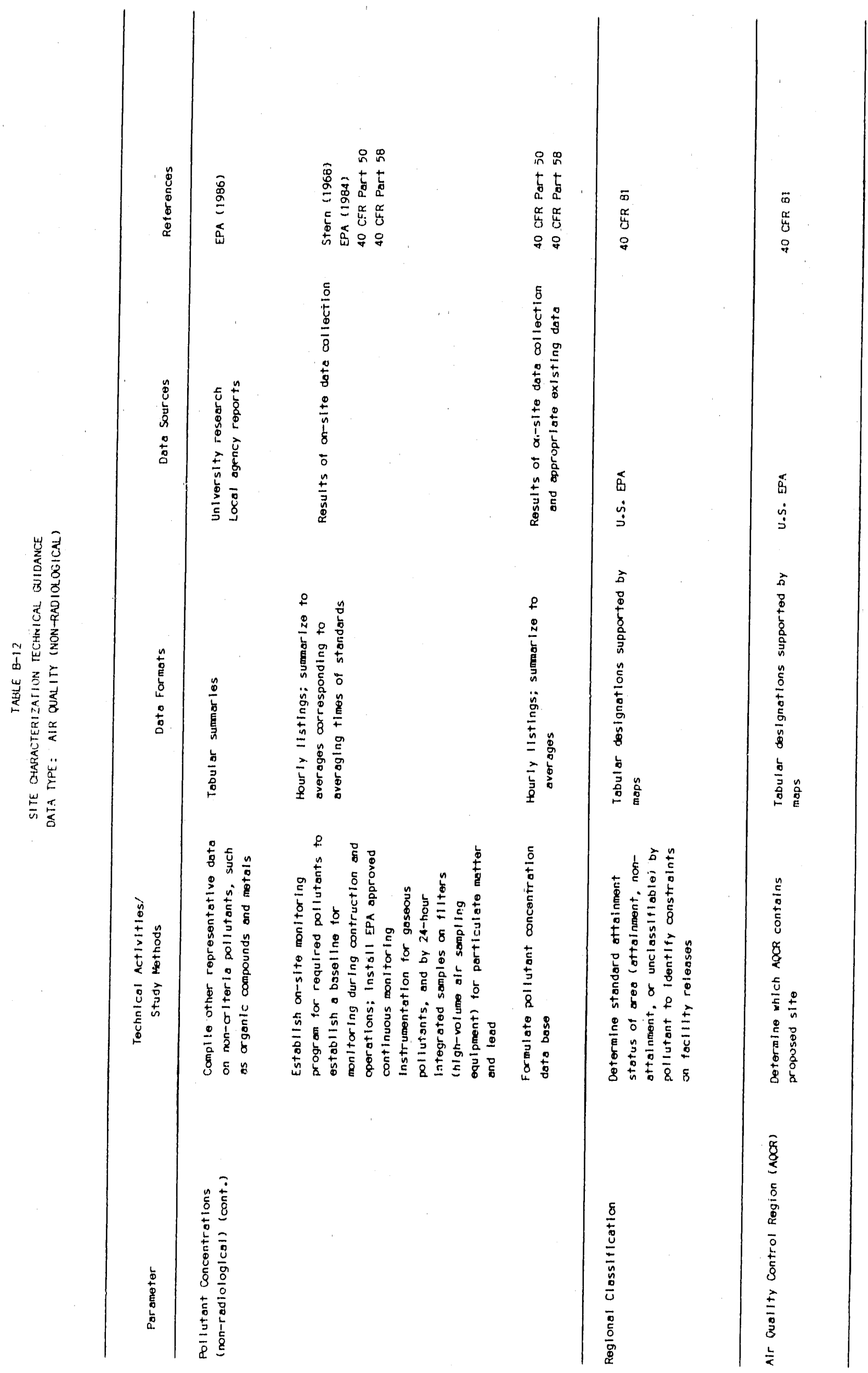




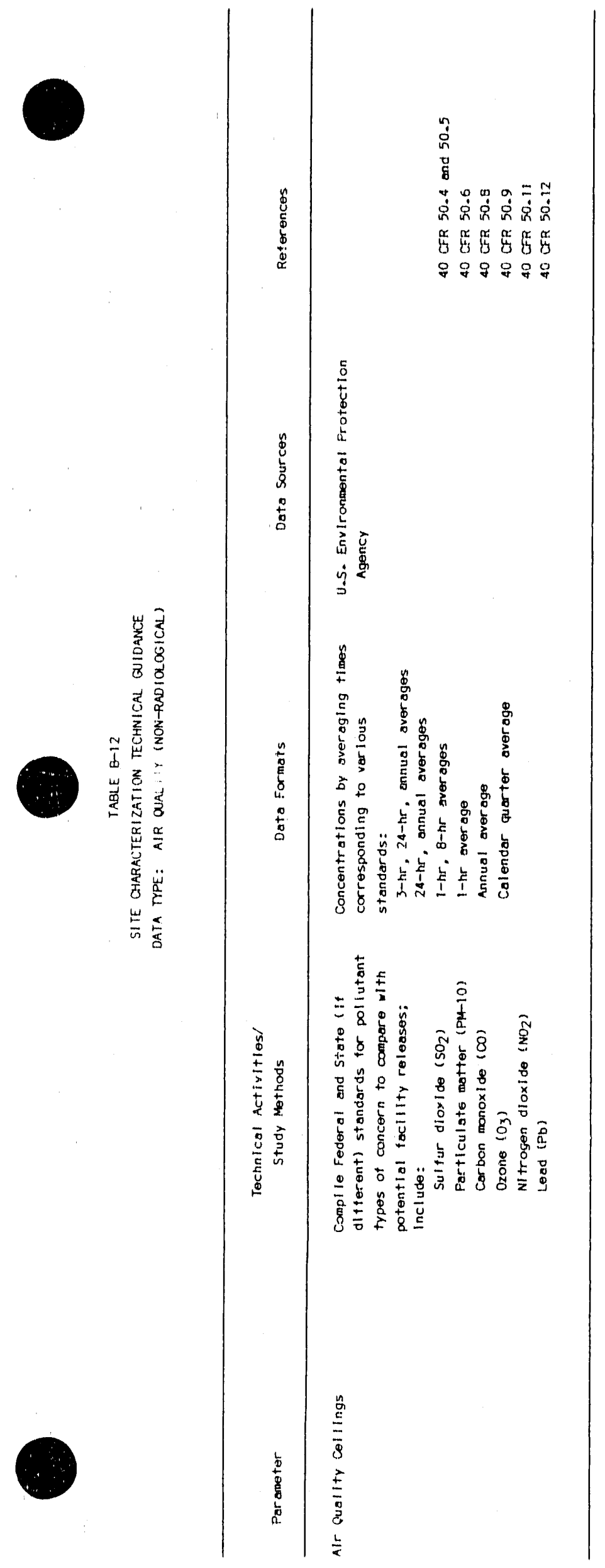


CFR; see Code of Federal Regulations.

Code of Federal Regulations, Title 40; Subchapter C-Alr Programs. Part 50 National Primary and Secondary Air quallty Standards. Part 58 - Ambient Atr Quality Survelllance, Part 81 - Designation of Areas for Atr Quality Planning Purposes.

EPA; see U.S. Environmental Protection Agency.

A.C. Stern, Air Pollution, and Ed., Vol. II; New York: Academic Press, 1968.

U.S. Environmental Protection Agency, Amtent Monttoring Guidelines for Prevention of Significant Deterioration, EPA-450/4-80-012, November 1980, a1 so Draft Revision, August 1984.

U.S. Environmental Protection Agency, Superfund Public Hea]th Evaluation Manual, EPA 540/1-86-060, October 1985. 
TABLE B-13

PARAMETER DESCRIPTIONS - RADIOLOGICAL ASSESSMENT

Direct Gamma Radiation: A measure of the fontzation produced in air by $x$ or gamma radiation. The spectal untt of exposure is the roentgen.

Atrborne Radtonuclides: The sampling of a known volume of air with subsequent identification of radionuclide and activity concentration (in picocurles per 1iter). These analyses w 111 be for both naturally occurring and man-made radionuclides.

Soll: Indentiffcation of the radfoactivity in soll. This includes direct or in vivo measurements of gamma-rays emitted from radionuclides in the surface solls (e.g., radium bearing solls) or by the collection of surface or subsurface samples with subsequent gamma-ray spectroscopy or radiochemical separation with alpha of beta counting techniques.

Surface Water: The sampling of flowing streams, ponds, lakes, and rivers with the subsequent analysis of radionuclide type and actfvity concentration in picocuries per liter recognizing the distinction between soluble specles and suspended matter.

Ground Water: The sampling and subsequent analysis of groundwater to identify radionuclides and measure the activity concentration in picocurtes per liter $(\mathrm{pc} / 1)$, recognizing the distinction between soluble spectes and suspended matter.

Sediments: Sampling of loose, unconsolidated sediments (sand, gravel, silt, mud, etc.) including the suspended fraction with the subsequent identification of radionuclide and activity concentration in picocuries per gram of solid fraction.

Flora: Radionuclides in abiotic compartments can enter plants by uptake from soil, deposition from air, or sorbtion from water in the case of aquatic plants. Uptake implies internal incorporation within tissues of the plant. Frequently radioactive materials in soll adhere to the root or shoot surface of plants but are not actually incorporated into plant tissues. Radionuclides in air or water can be deposited on or otherwise attached to plant surfaces directly without passage through soil. Analyses should be made to identify the radionuclide and determine the activity concentration in picocuries per gram.

Fauna: Passage of radioactive material to terrestrial and aquatic species occurs primarily by ingestion and inhalation. Each step of the food chain provides some form of discrimination in that radionuclides are channeled physjologically into certain tissues, depending on their physical/chemical properties. Analyses of fauna can be organ specific (e.g., I-131 in the thy.oid) depending on the radionuclide of concern, or whole body specific (e.g., Cs-137). Analyses should be made to ident ffy the radionuciide and determine the activity concentration in picocurtes per gram.

Food: Measurement of radioactivity in crops, livestock, dairy products and game animals consumed by humans including radionuclide and concentration. 


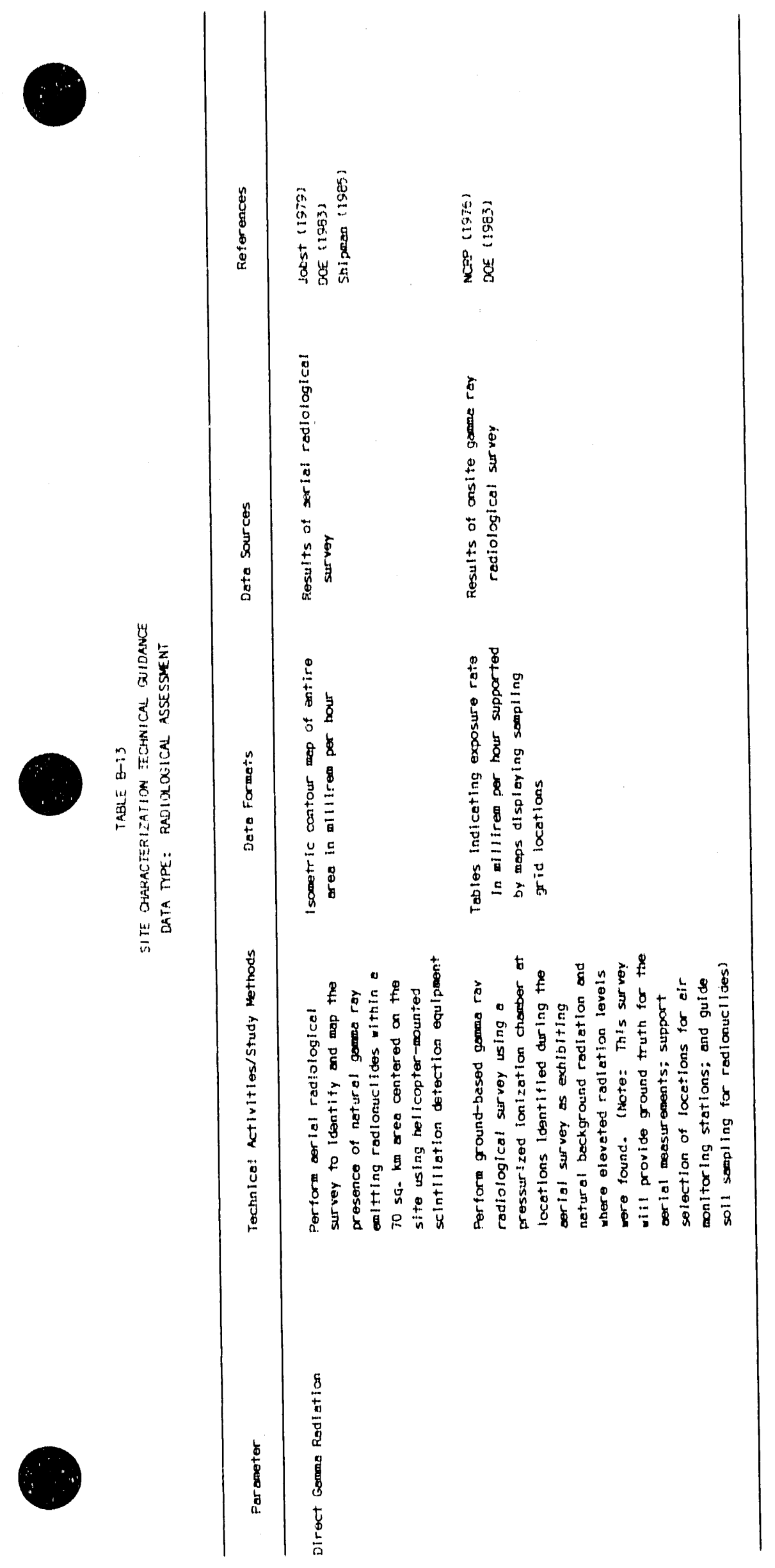



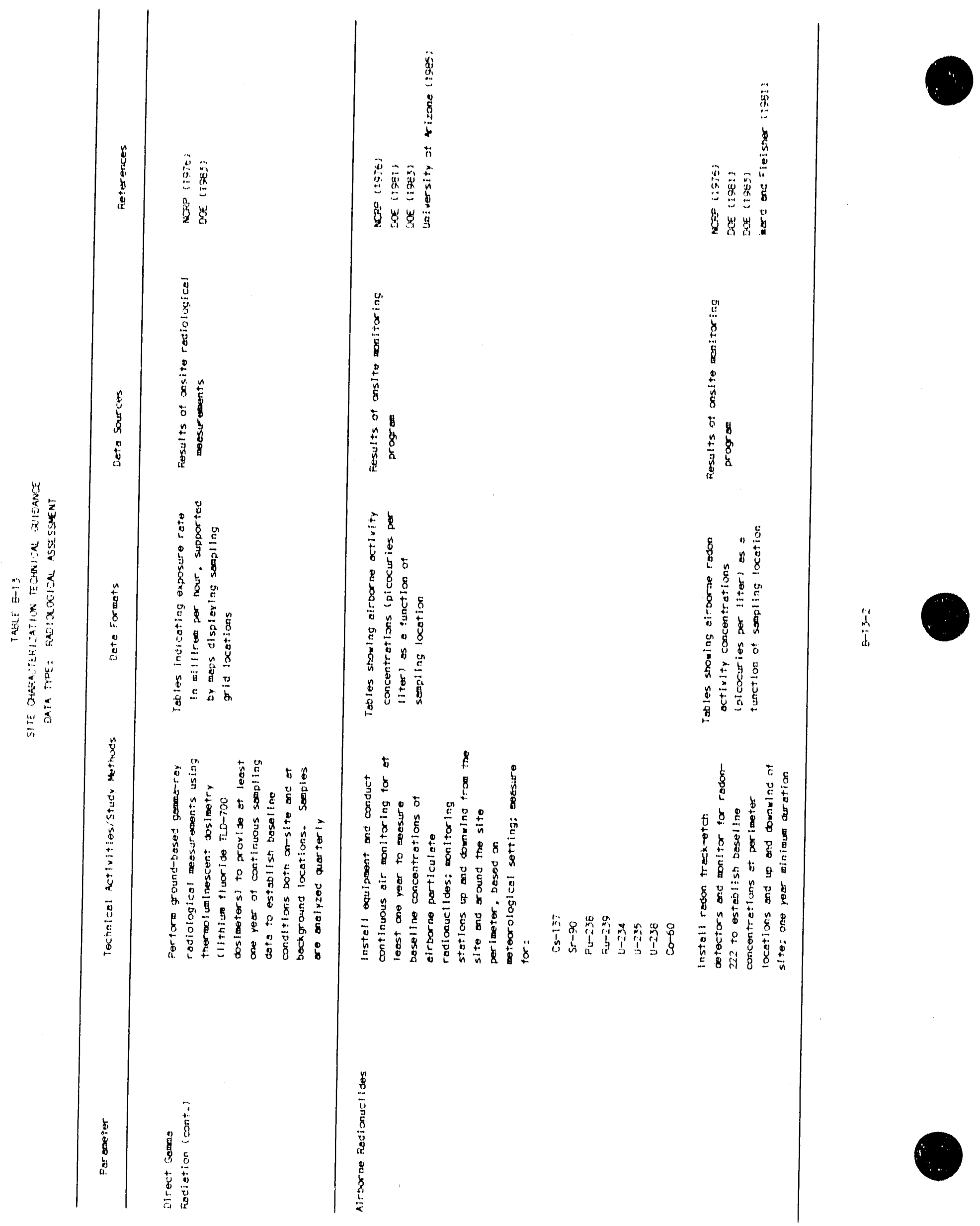


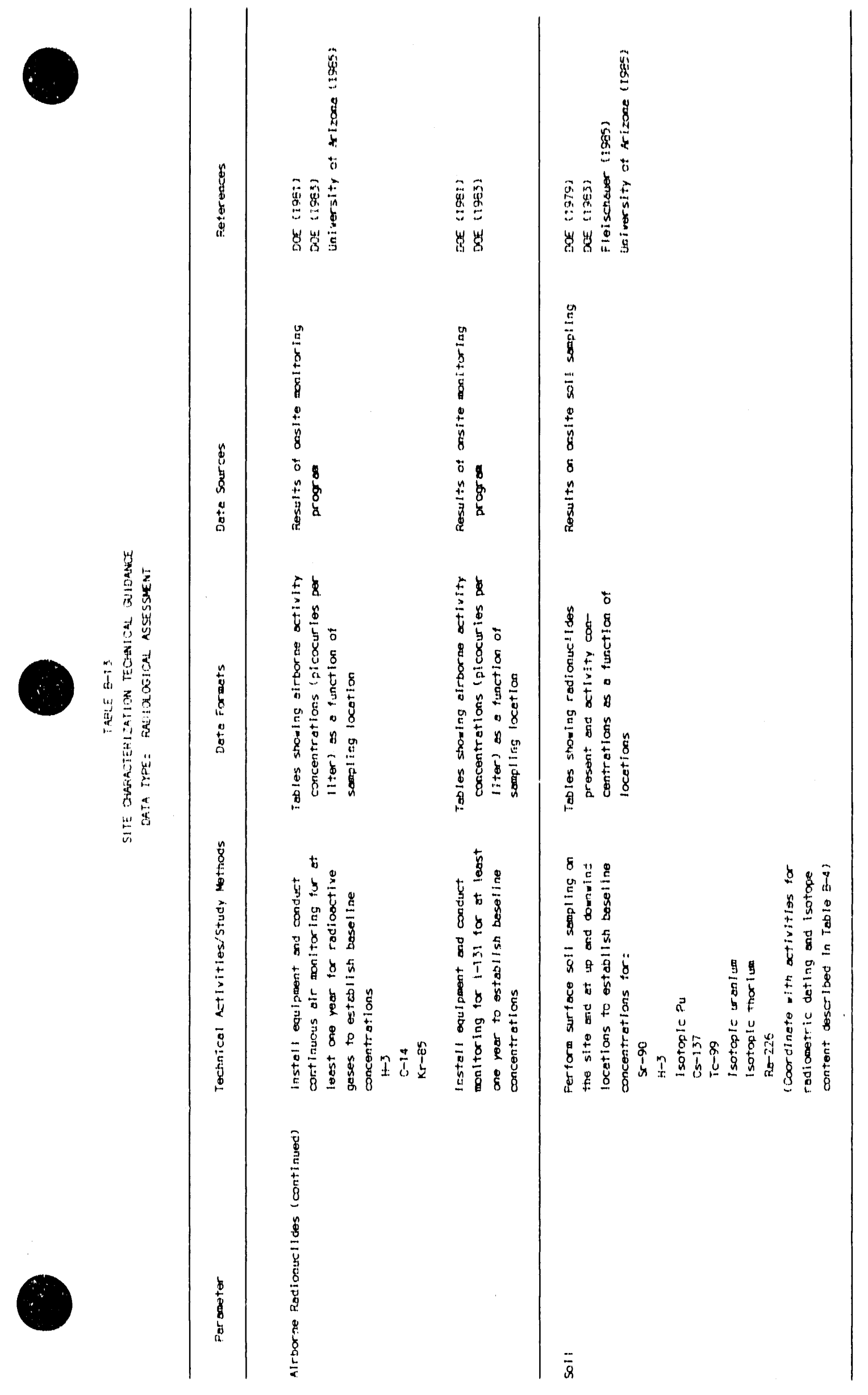

$\frac{a}{a}$ 


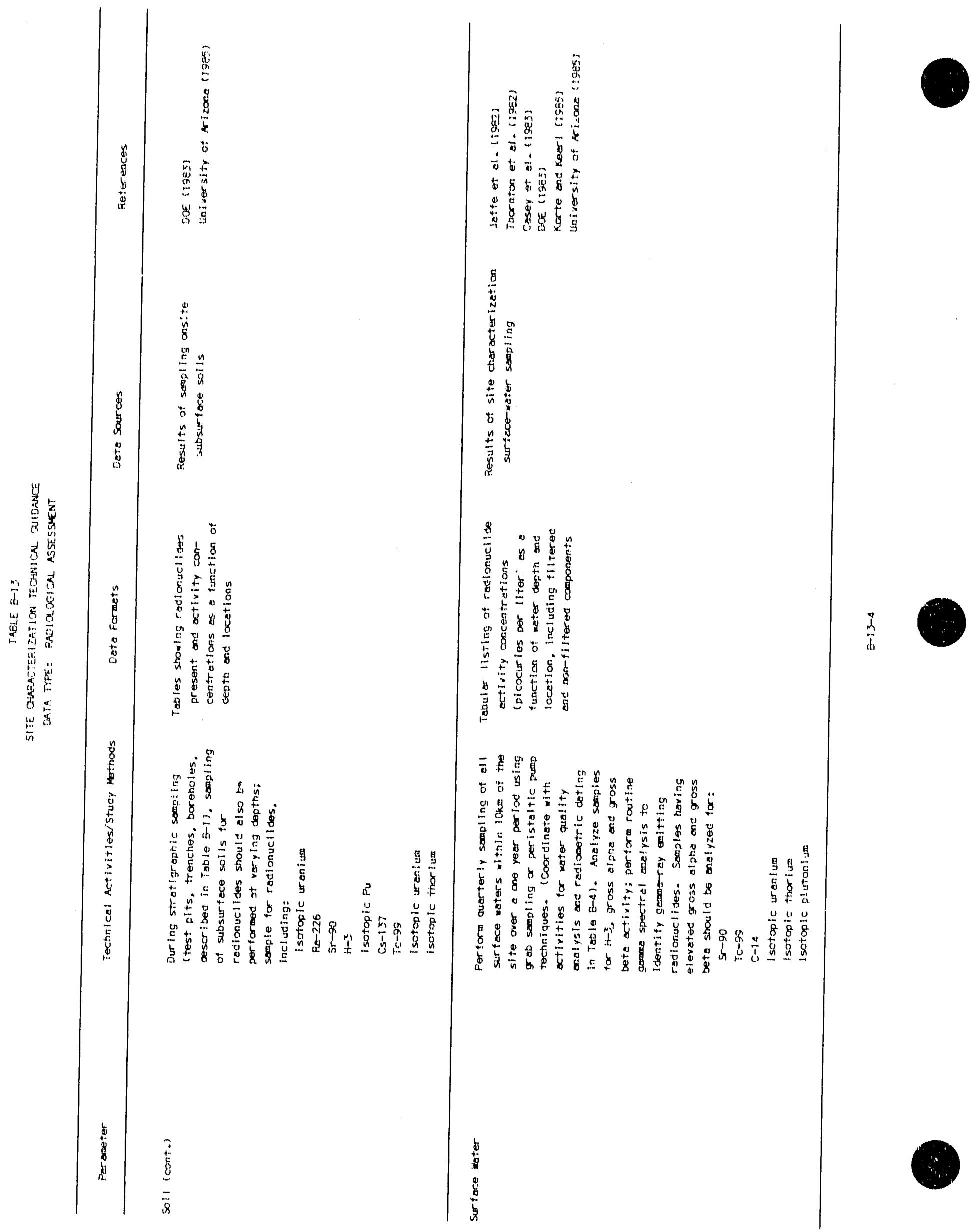




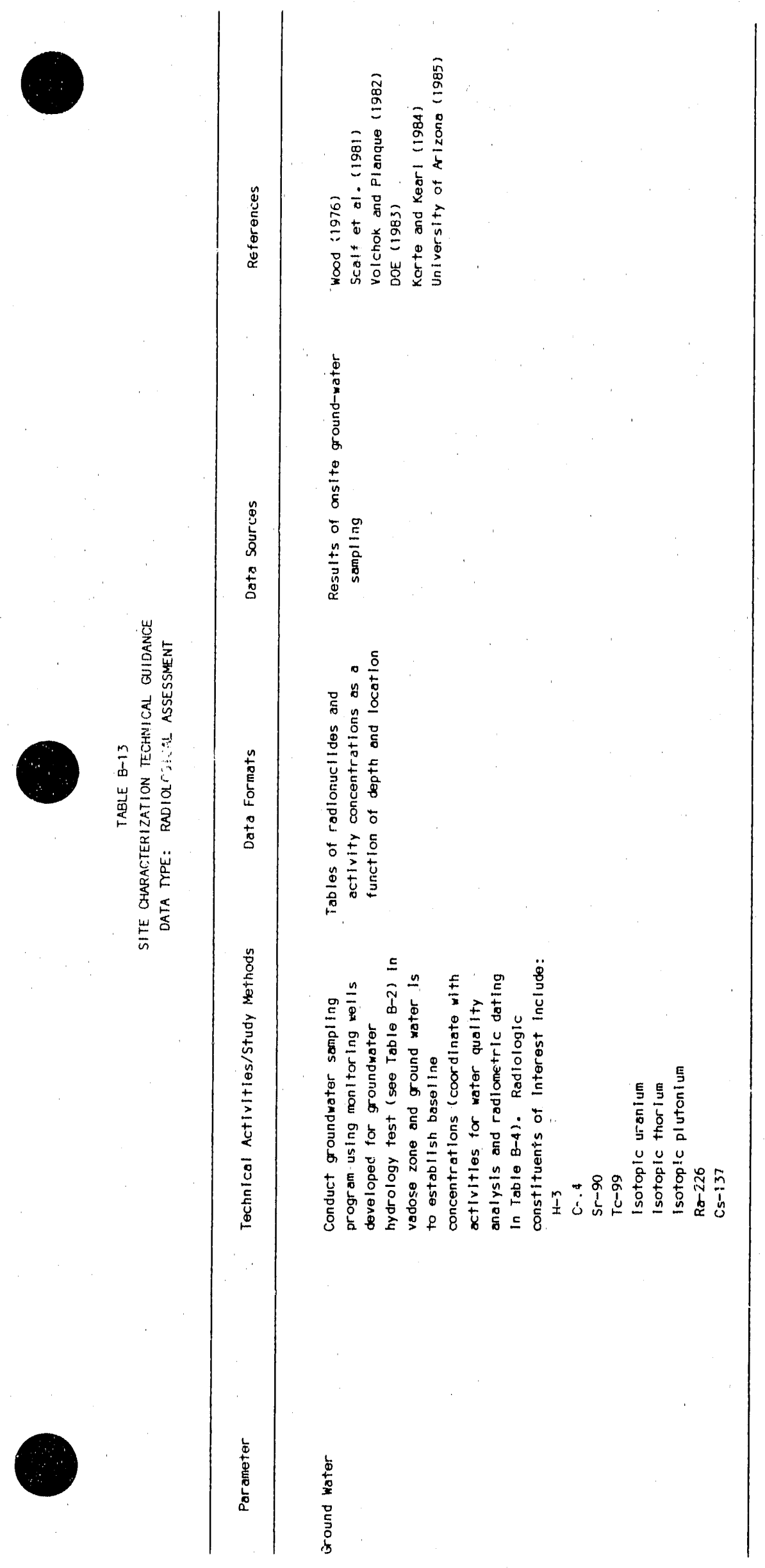




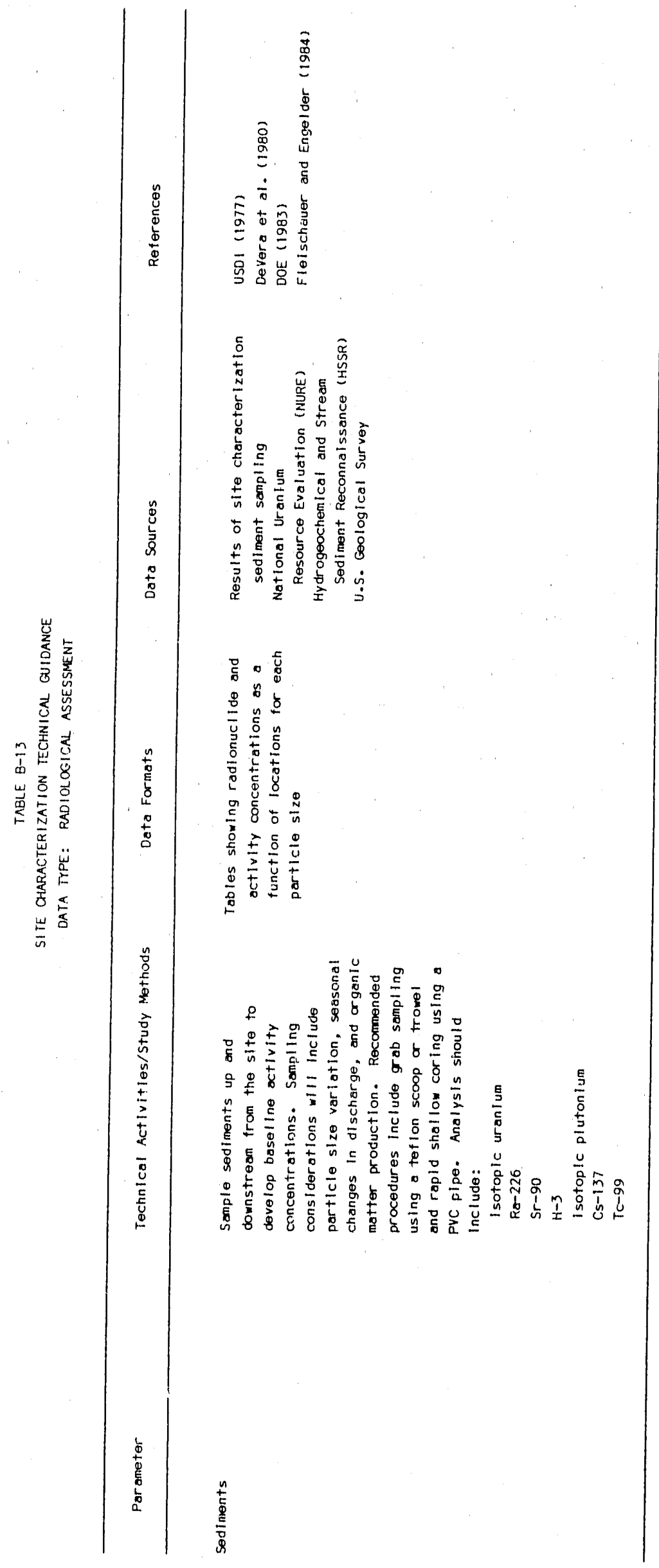

$\frac{0}{1}$

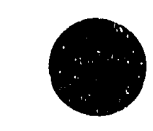




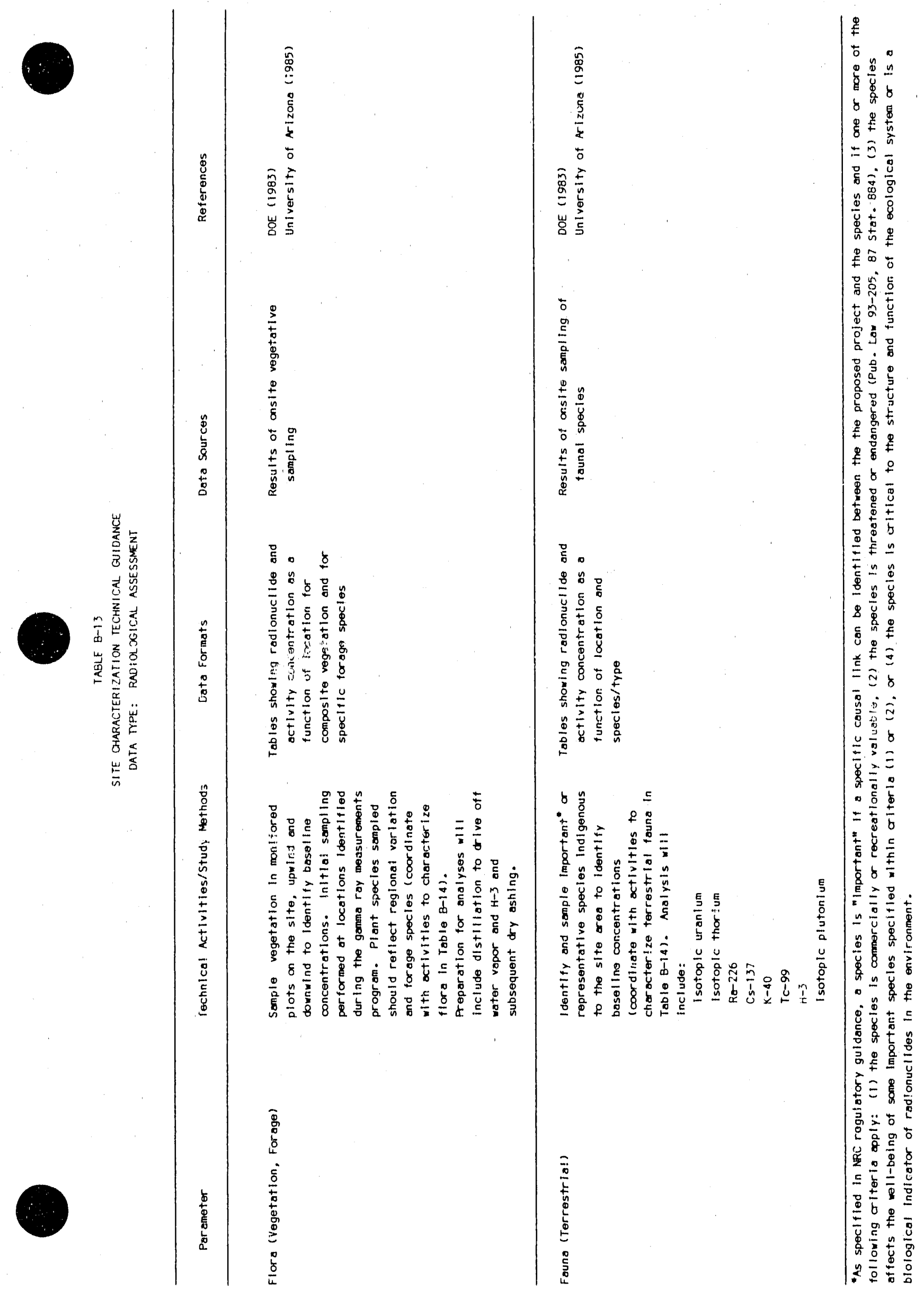



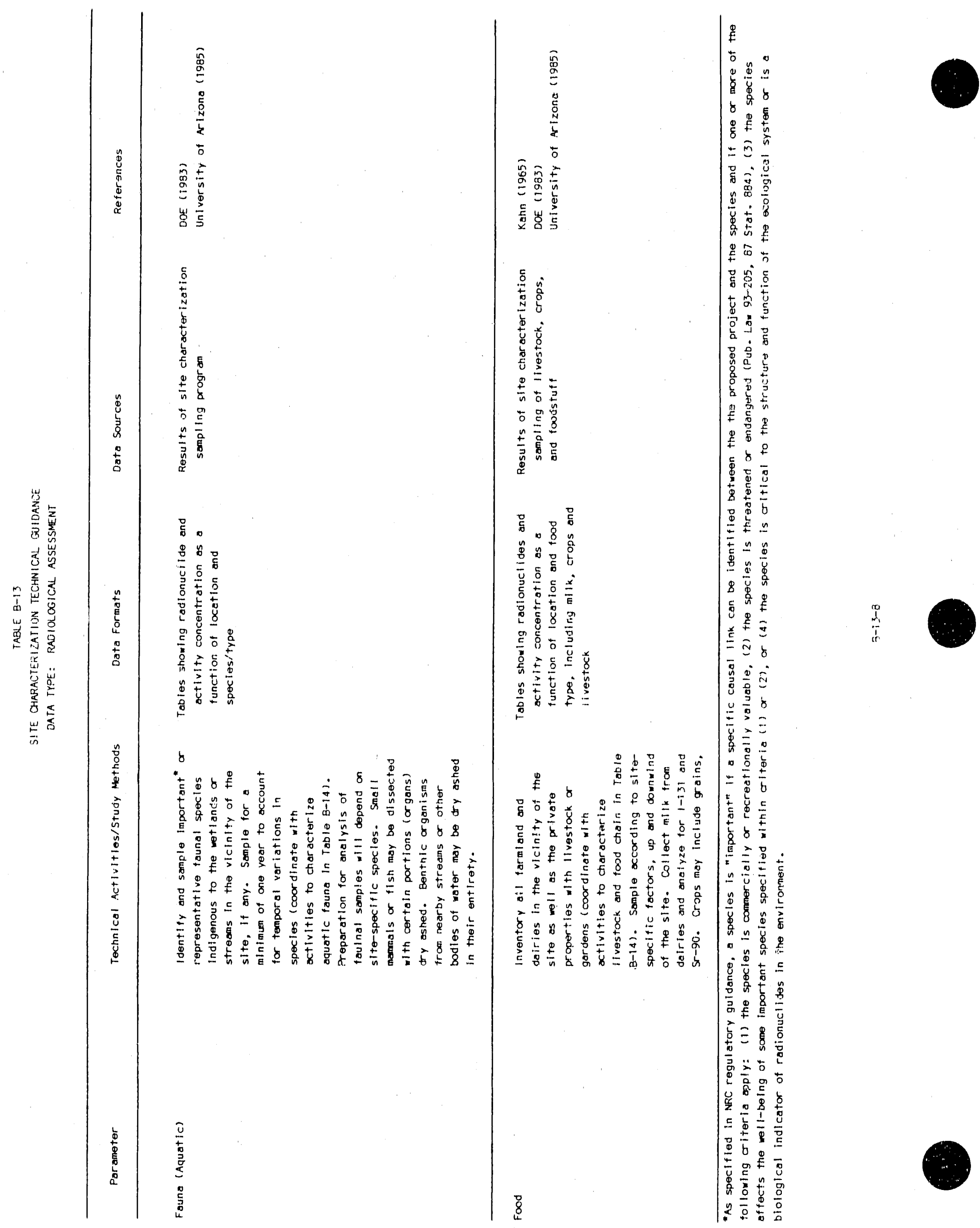


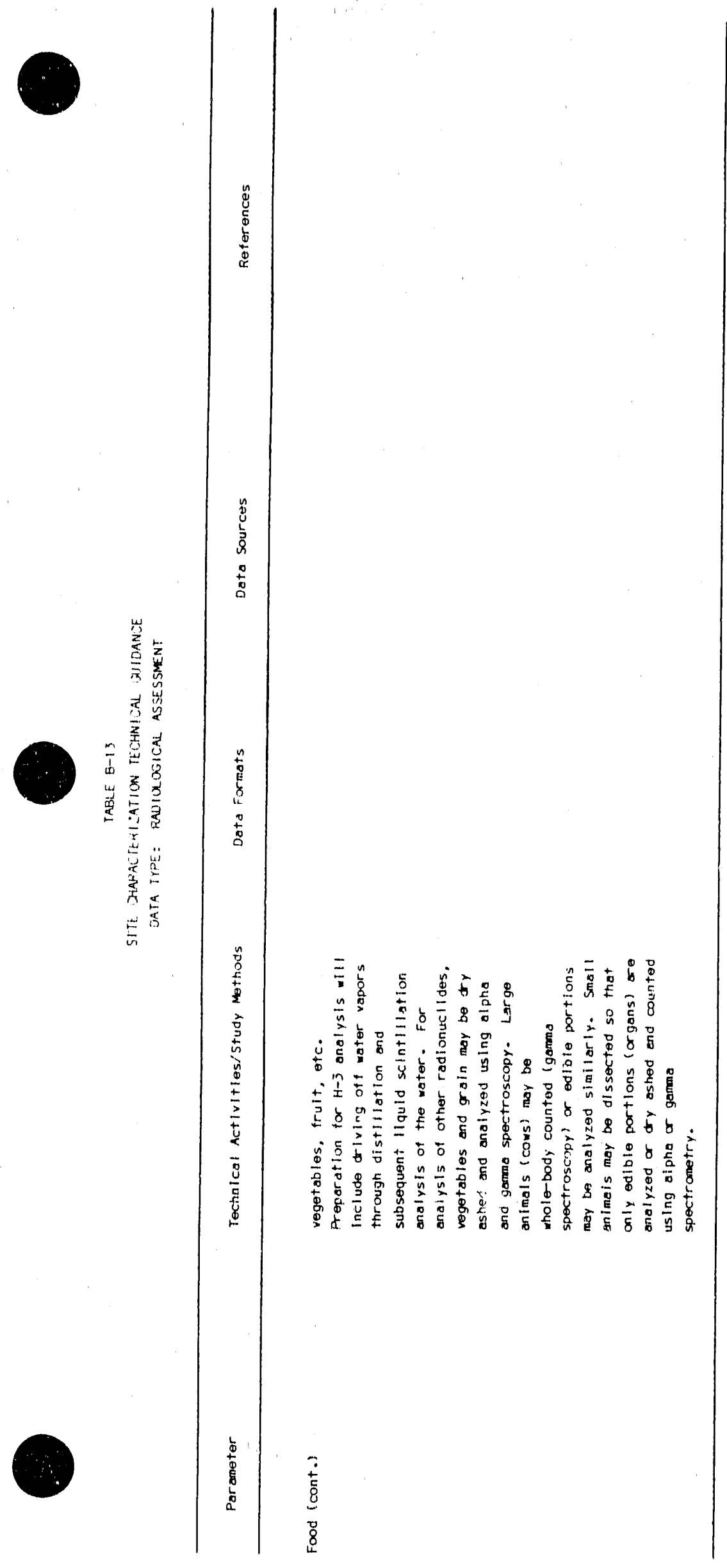


TABLE B-13

REFERENCES - RADIOLOGICAL. ASSESSMENT

D. Casey et al., "Sampling Frequency for Water Quality Monitoring: Measures of Effect iveness," Water Resources Research, 19, 5, 1983, pp. 1107-1110.

E.R. DeVera et al., Samnlers and Sampling Procedures for Hazardous Waste Streams, U.S. EPA-600/L $80-018,1980$.

DOE; See U.S. Department of Energy

H.L. Fleischaver, Procedures for Sampling Radium Contaminated Soils, USDOE Technical Measurements Center, GJ/TMC-13 UC-70A, October 1985.

H.L. Fleischauer and P.R. Engelder, Procedures for Reconnaissance Stream Sediment Sampling, GJ/TMC-14 UC-70A, 1984.

P. Jaffe et al., "Distribution of Toxic Substances in Rivers," Journal of the Environmental Engineering Diviston. ASCE, 108, No. EE 4, 1982, pp. 634-649.

J.E. Jobst, "The Aerial Measuring Systems Program," Nuclear Safety, 20, 1979.

B. Kahn, "Determination of Picocurie Concentrations of lodine-131 in Milk," Agricultural Food Chemical, 13, 1965.

N.E. Korte and P.M. Kearl, Cross Discipline Harmony Keeps Groundwater Monitoring Efforts in Tune," Water Engineering and Management, March 1984.

N.E. Korte and P. M. Kearl, Procedures for the Collection and Preservation of Groundwater and Surface Water Samples and for the Insta]lation of Monitoring Wells, U.S. DOE Technical Measurements Center, 2nd edition, GJ/TMC-08, October 1985 .

National Council on Radiation Protection and Measurements, Environmental Radiation Measurements, NCRP Report No. 47, 1976.

NCRP; See National Council on Radiation Protection and Measurements.

M.R. Scalf et a1., Manual for Groundwater Sampling Procedures, Worthington, OH: National Water Well Association, 1981.

G.R. Shipman, An Aerial Radiological Survey of the Feed Materials Production Center and Surrounding Area, EG\&G-10282-1084, 1985.

K. Thornton et a1., "Reservoir Water Quality Sampling Design," Water Resources Bulletin. American Water Resources Association, 18,3, 1982.

University of Arizona, Site Characterization Field Manual for Near Surface Geologic Disposal of Low-Level Rad oactive Waste, U.S. Department of Energy report DE FG07 $841012514,1985$.

U.S. Department of Energy, Environmental Measurements Laboratory Procedures Manual, HASL-300, 1979. 
U. S. Department of Energy, A Guide for Environmental Radiological Survetllance at USDOE Installations, DOE/EP-0023, JuTy 1981.

U.S. Department of Energy, Environmental Monitoring for Low-Level Waste Disposal Sites, DOE/LLW-13Tg, January 1983.

USDI, See U.S. Department of Interior.

U.S. Department of Interior, National Handbook of Recommended Methods for Water-Data Acquisition, U.S. Geological Survey, Reston, Virginia, 1977.

H.L Volchok and G.J. Planque (eds.), Procedures Manual, U.S. Department of Energy Environmental Measurements Laboratory, 1982.

A.H. Ward and R.L. Fleisher, "Passive Integrating Radon Monitor for Environmental Monitoring," Health Physics, 40, 1981, p. 693.

W.W. Wood, "Guidelines for Collections and Field Analysis of Groundwater Samples for Selected Unstable Constituents, "Techniques of Water Resources Investigations of the United States Geological Survey, Book 1, Chapter D2, 1976. 
Ierrestrial Species (Fauna): Important wild and domestic animal spectes, including abundance, characteristics, distribution, ecological interrelationships, and breeding grounds.

Terrestrial Species (Flora): Major spectes of vegetation, including plant communities, species composition, relative abundance, successional stage, and vegetatior types.

Aquatic Species: Aquatic spectes (flora and fauna), including composition, distribution, abundance, importance, seasonal varfability, harvest, and nutrient concentrations.

Livestock: Domestic arimals such as datry cows and goats, with food chain significance.

Food Chain: An abstract representation of the passage of energy (or possible contaminants) through populations of terrestrial and aquatic organisms in a community.

Migratory Species: Species that migrate through the site or the vicinity.

Game Animals: Wild animal spectes (on the site and in the vicinity), which are hunted and potentially consumed.

Habitat: Habitats for important terrestrial or aquatic species, including location and area occupied; wildlife sanctuaries or natural areas; special, rare, unique habitats; and site-specific habitat for any identified threatened or endangered species.

Threatened/Endangered Species: Species existing in the site area or vicinity (or potentiaily present) that are designated by the U.S. Fish and Wildlife Service or a cognizant State agency as threatened or endangered.

Disease Vectors/Pests: Vertebrate and invertebrate species of 1ocal importance or concern as disease vectors or pests that could impact workers or operations on the site. 


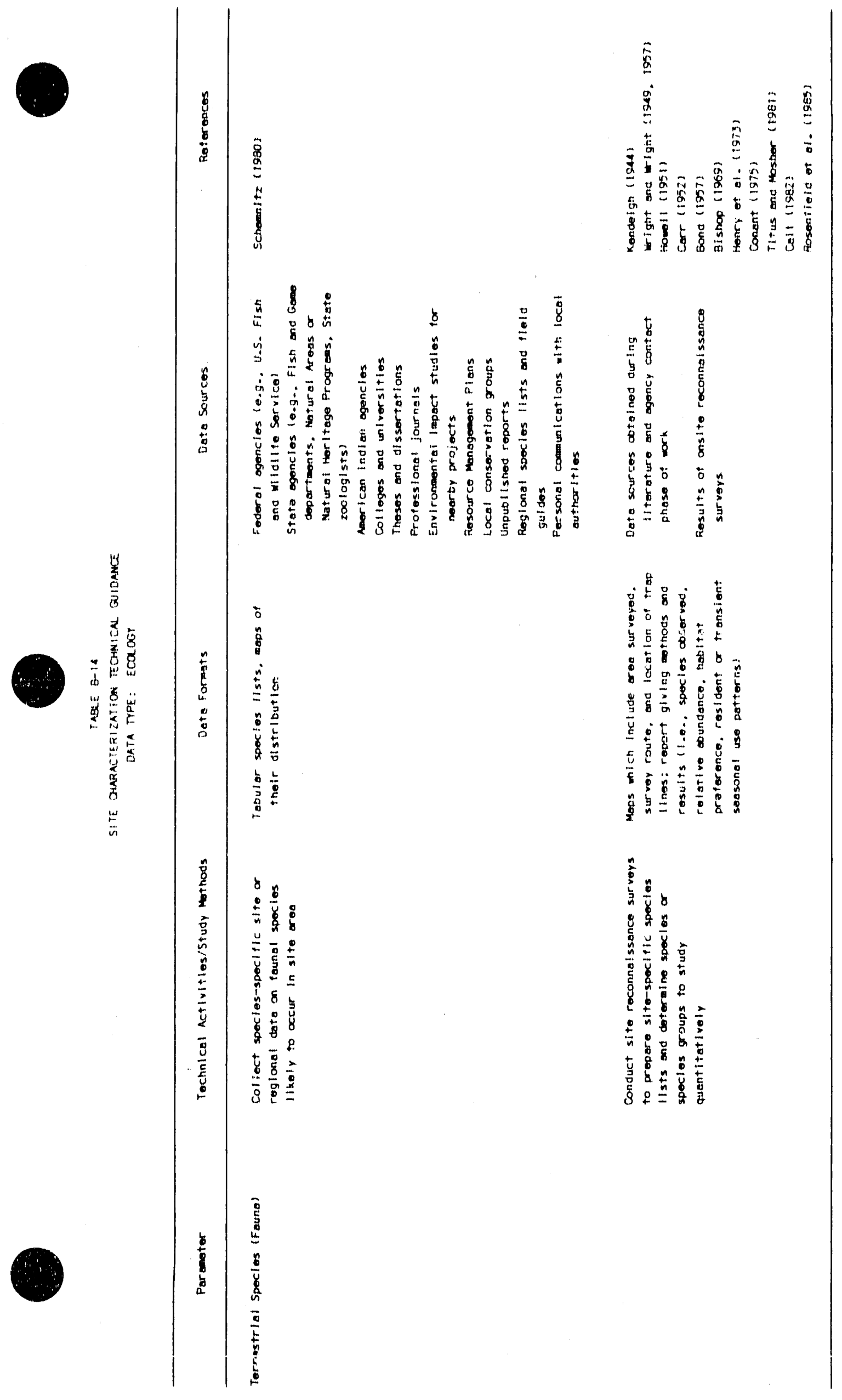



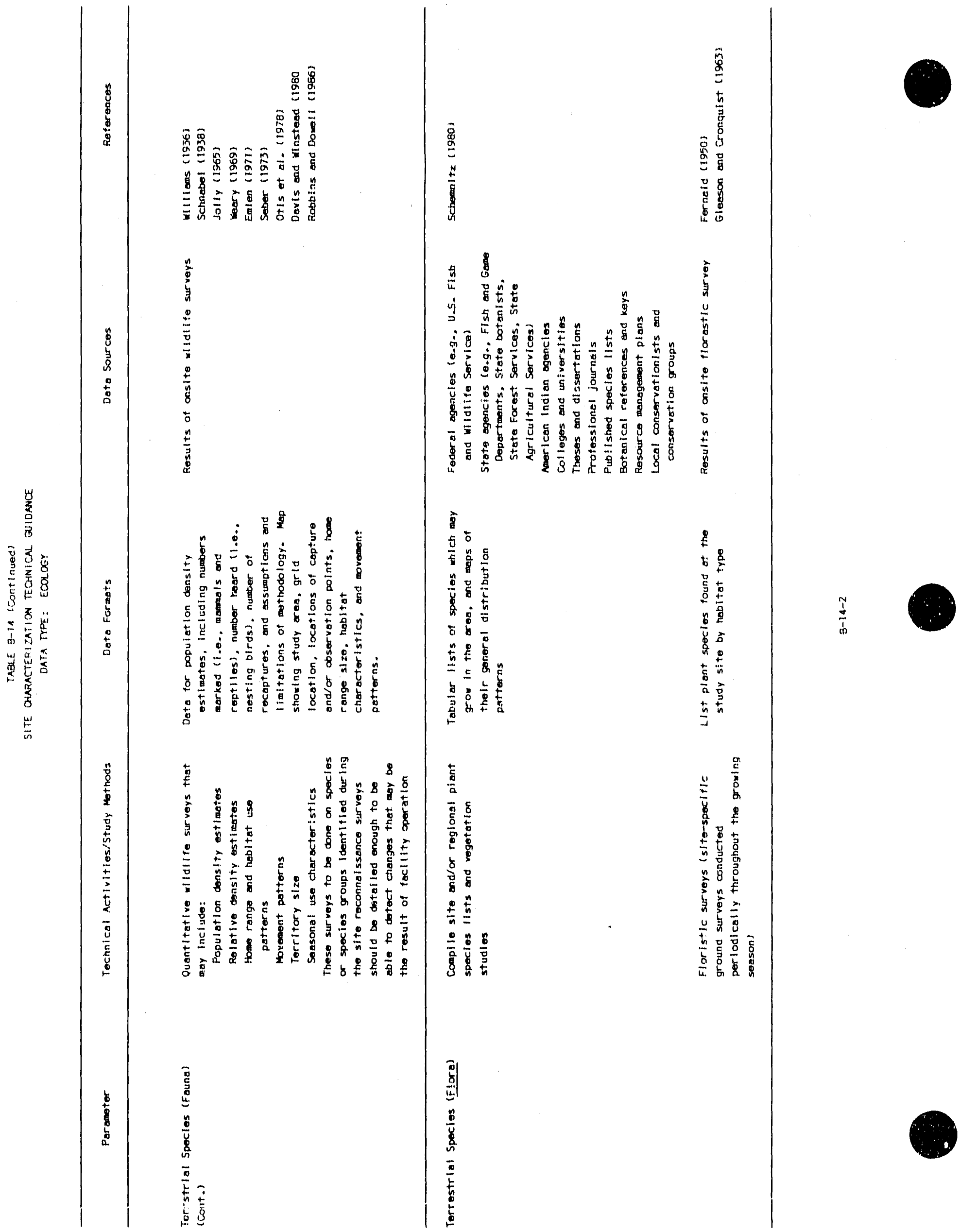


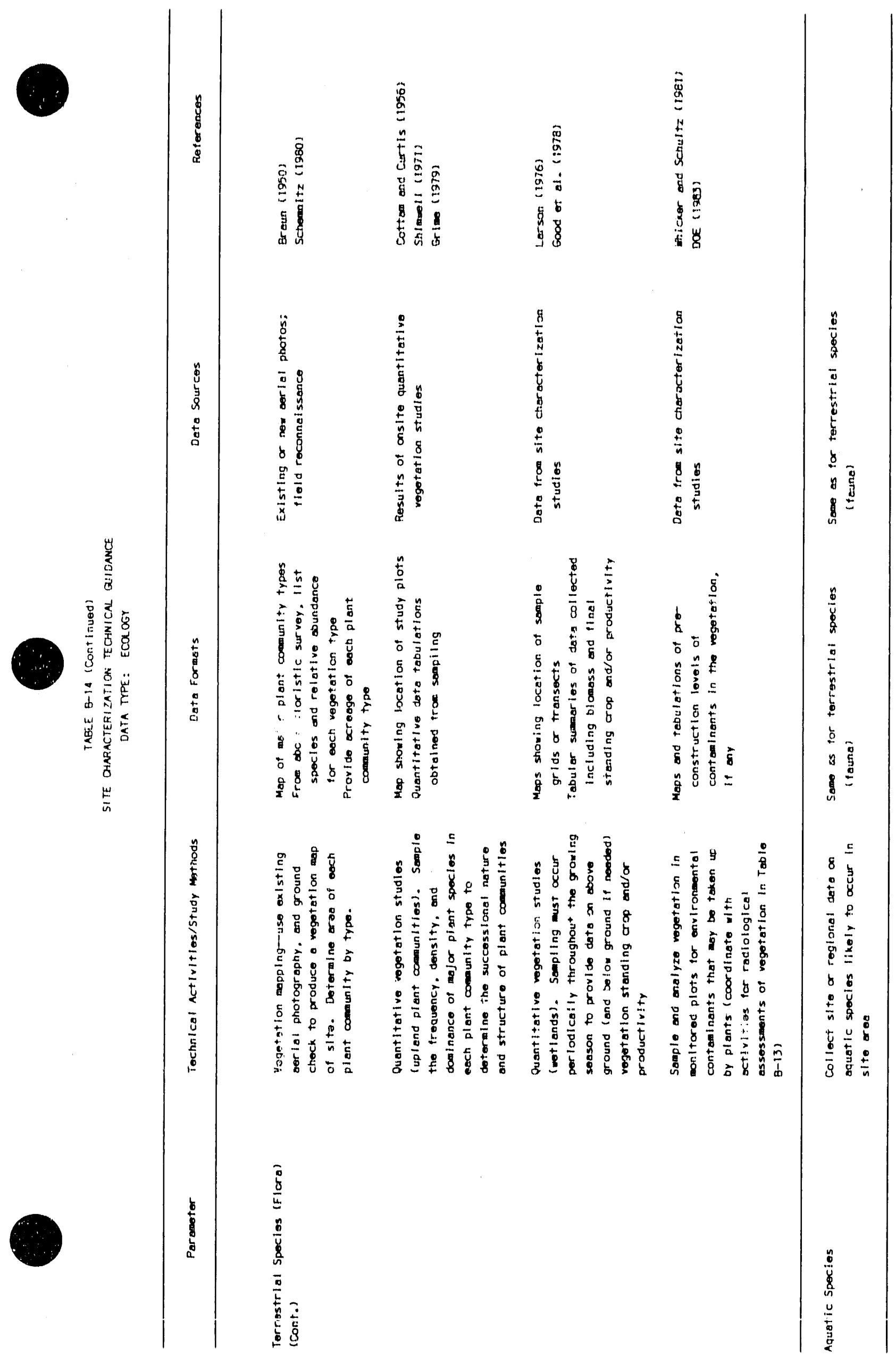




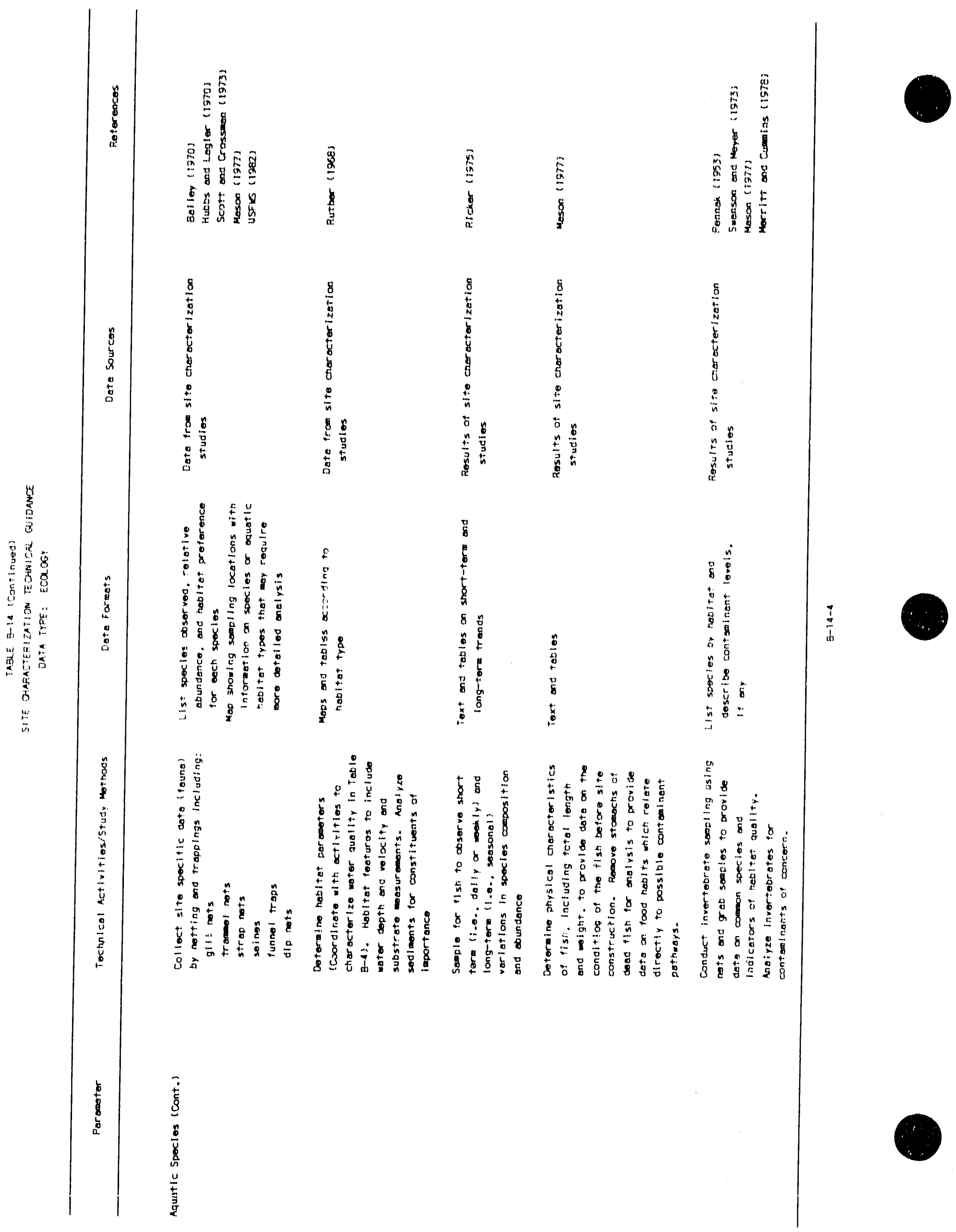




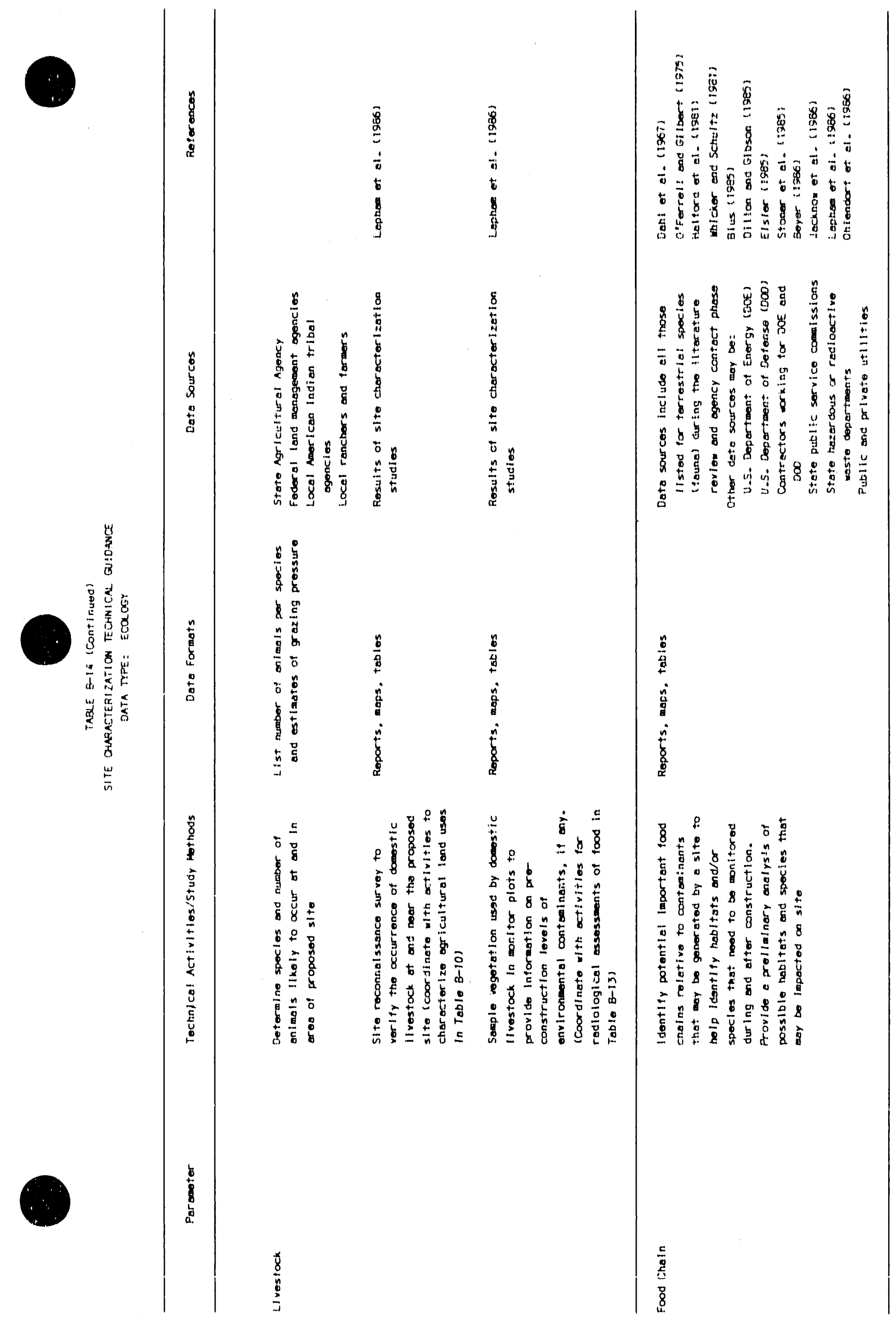

$\frac{\mathfrak{z}}{\mathrm{a}}$ 


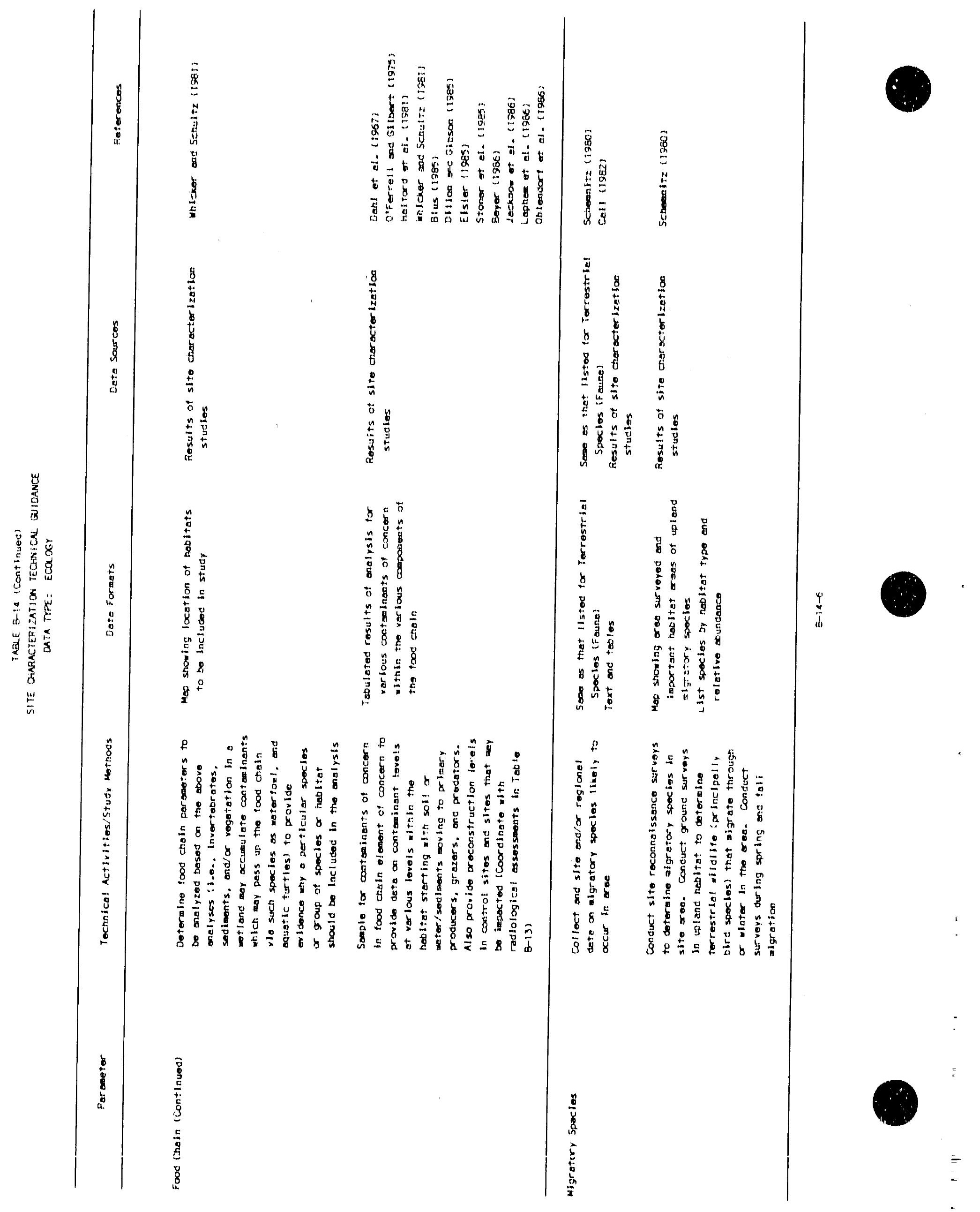




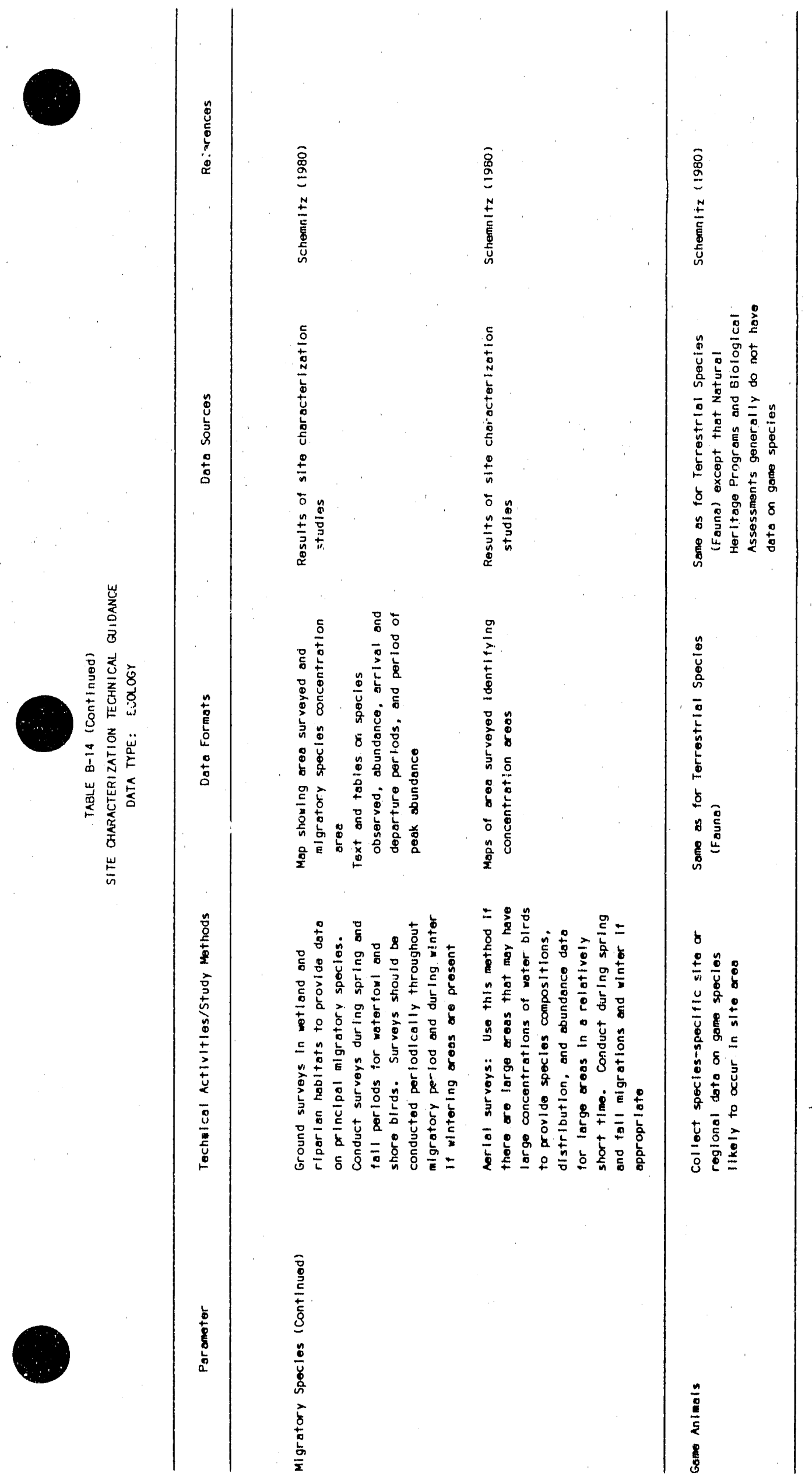

$\frac{5}{1}$ 


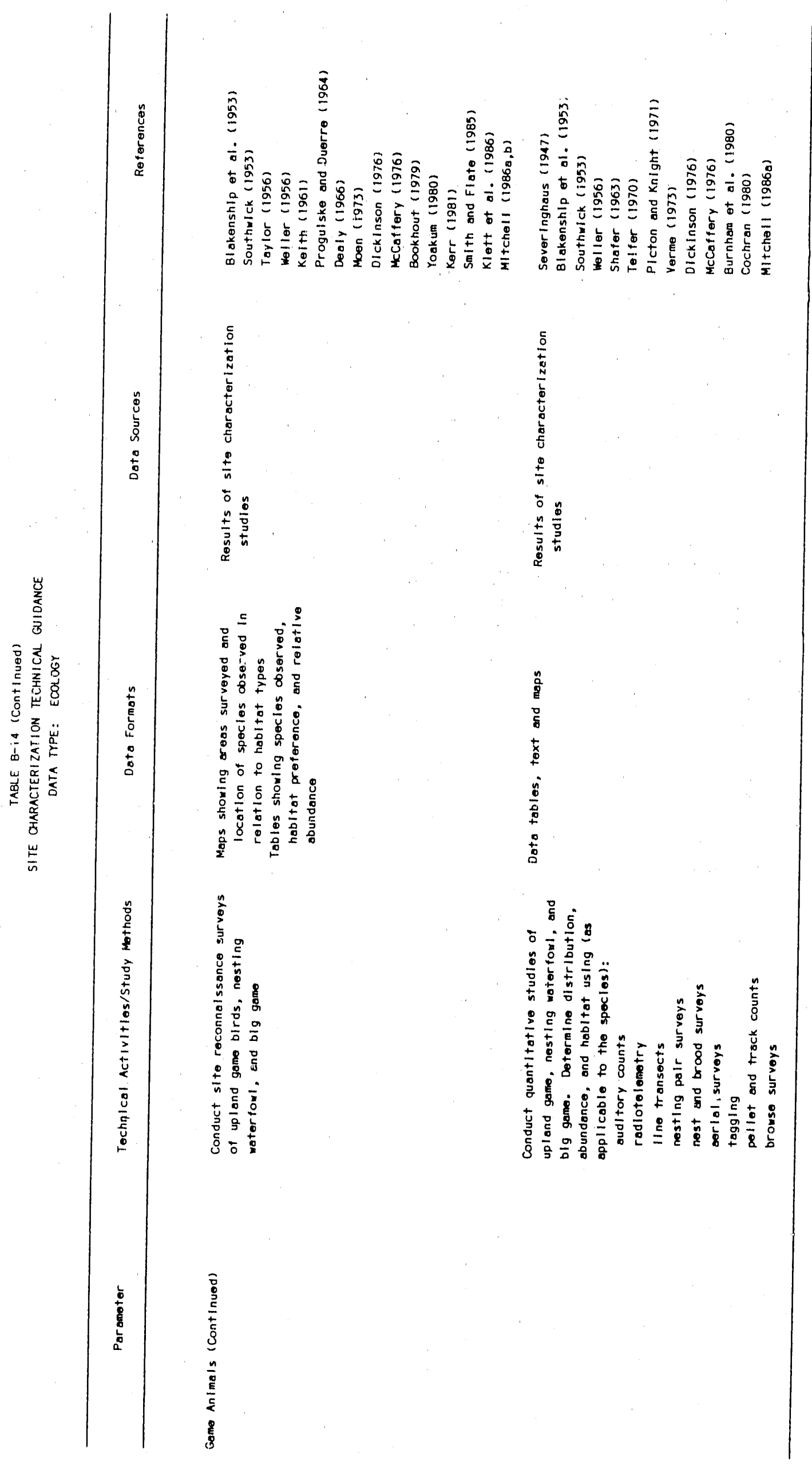




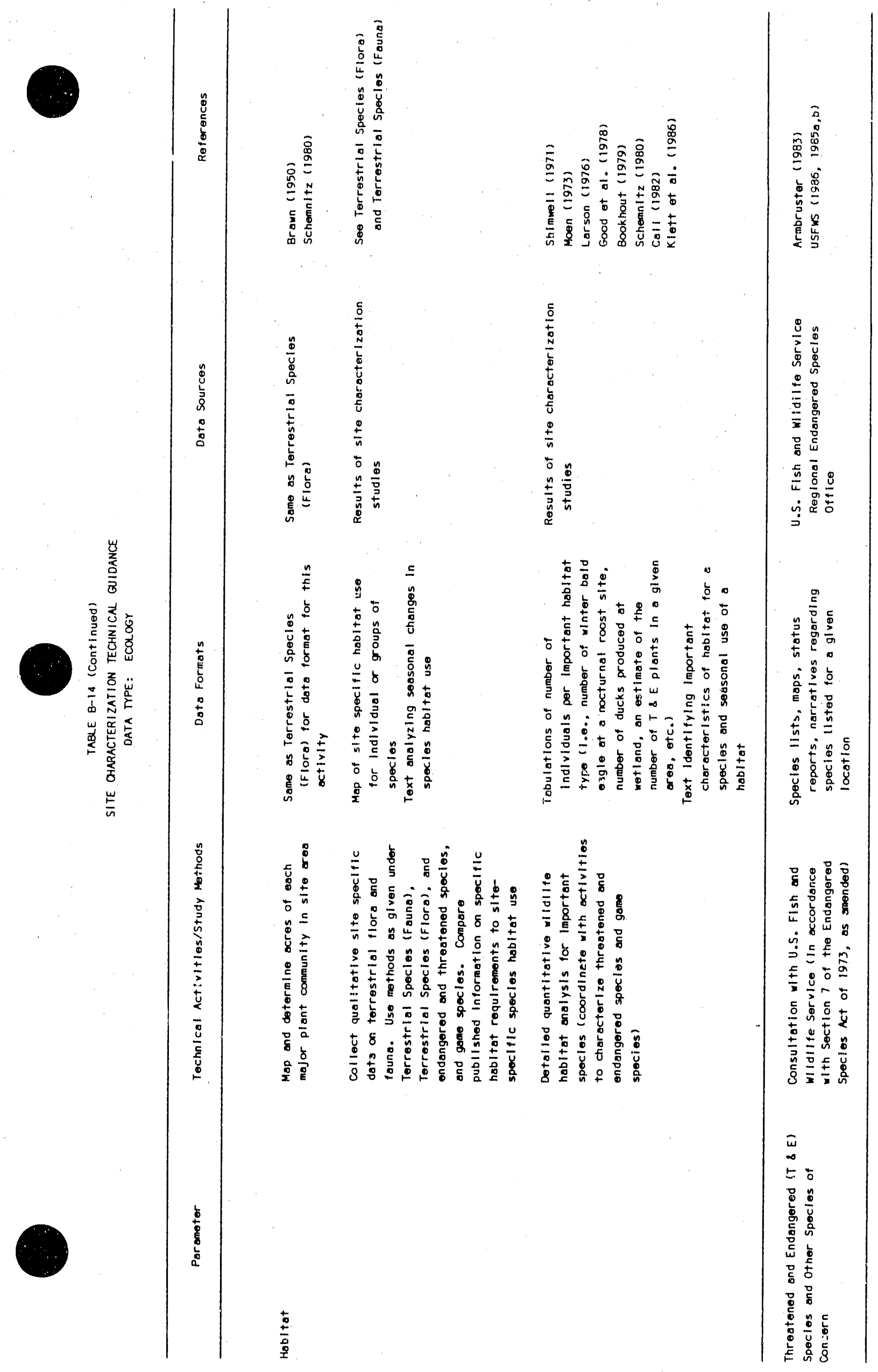




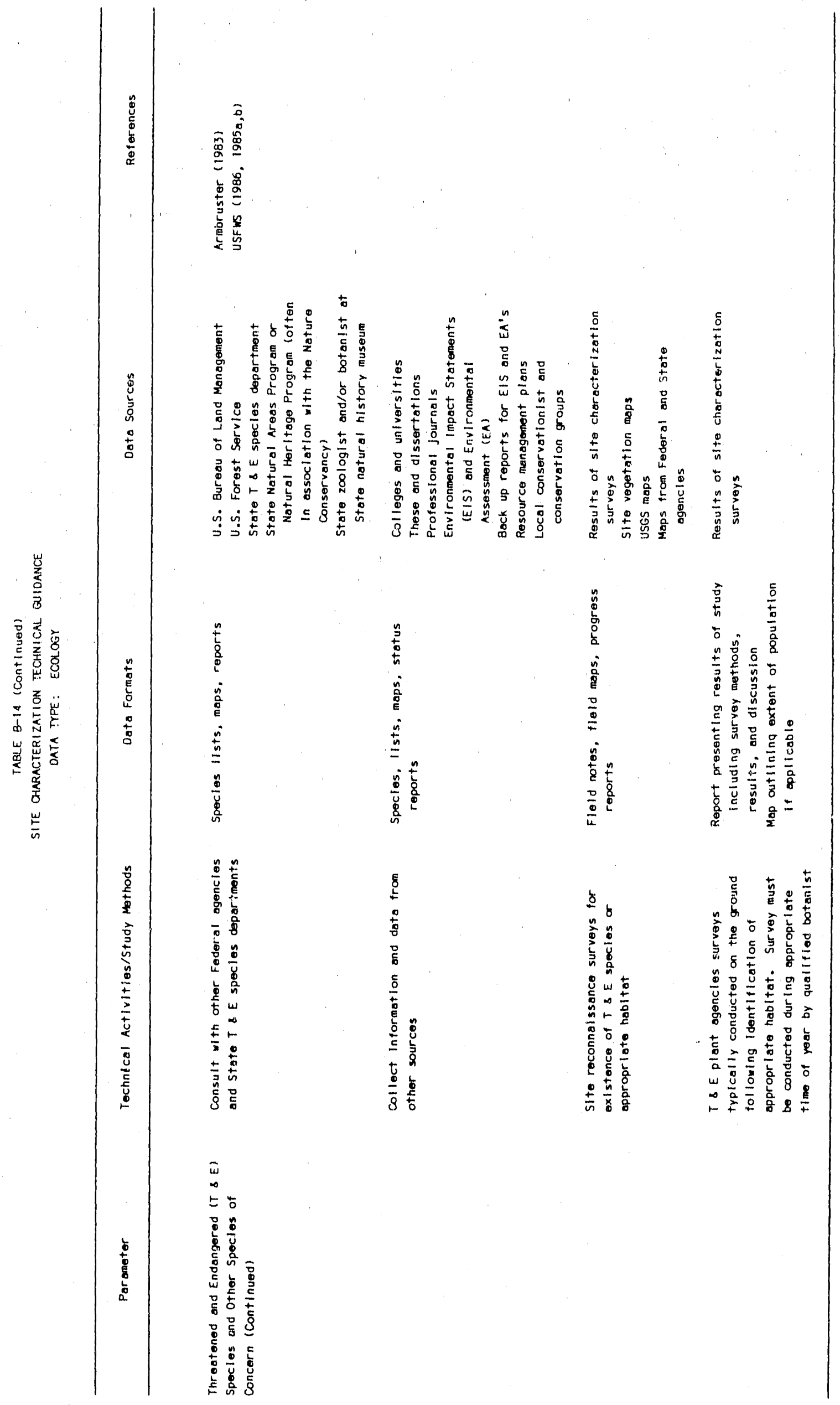




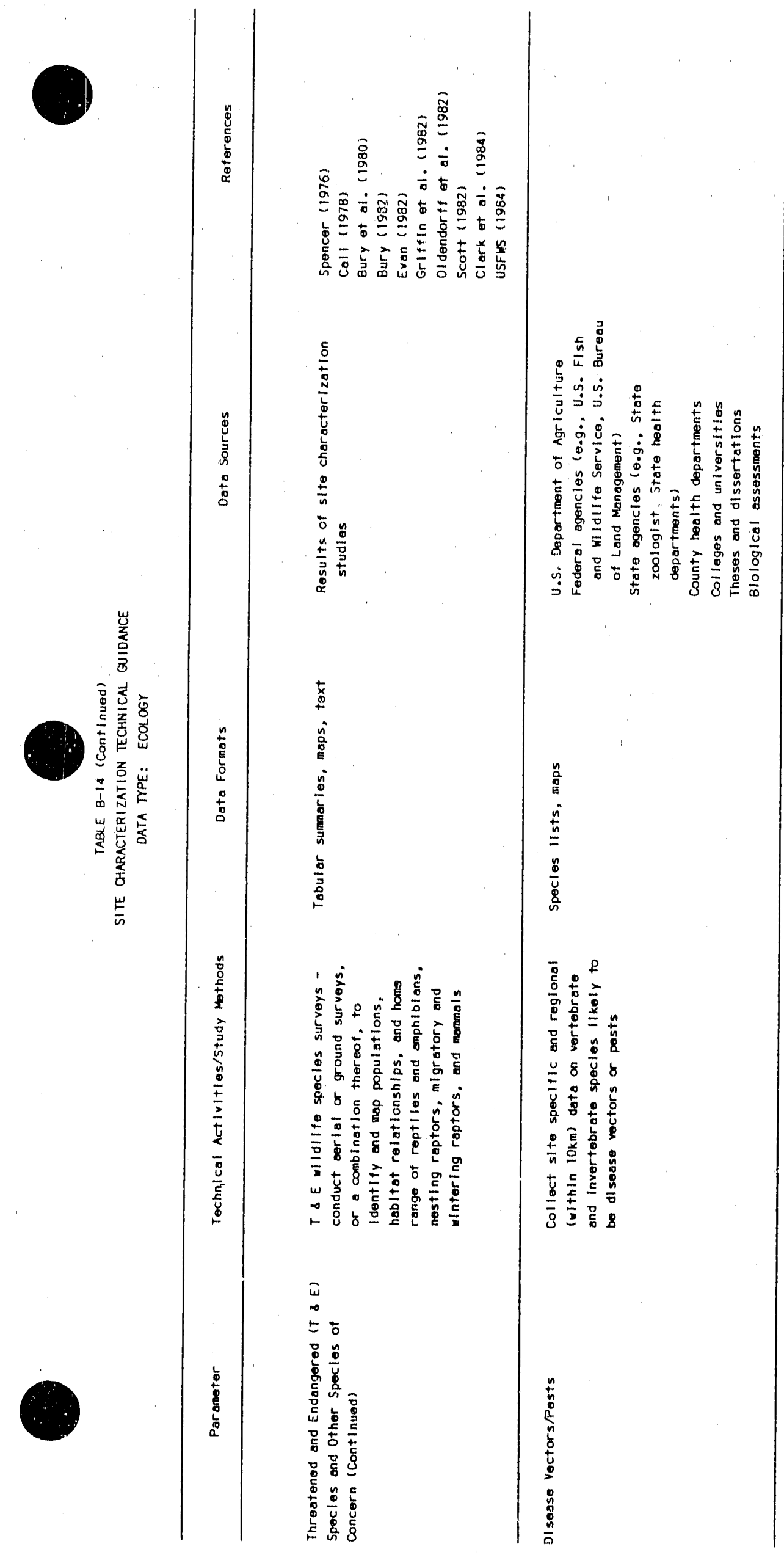

$\frac{7}{\frac{1}{5}}$ 
TABLE B-14

REFERENCES - ECOLOGY

J.S. Armbruster (ed.), Impacts of Coal Surface Mining on 25 Migratory Bird Species of High Federal Concern, U.S. Fish and Wildlife Service, FWS/OBS$83 / 35,1983$.

R.M. Bailey, A list of Common and Scientific Names of Fishes from the United States and Canada, American Fisheries Society Special Publication No. 6, 1970.

W.N. Beyer, "A Re-examination of Biomagnification of Metals in Terrestrial Food Chains," Environmental Toxicology and Chemistry, 5, 1986, pp. 863-864.

S.C. Bishop, Handbook of Salamanders, Ithaca, New York: Comstock Publishing Company, 1969.

L.H. Blankenship et a1., "Techniques for Brood Production Studies,". Miss issippi Flyway Council Technical Committee, St. Paul, Minnesota:

University Farm, 1953.

L.J. Blus, "Reproduction, Mortality, and Heavy Metal Concentrations in Great Blue Herons From Three Colonies in Washington and Idaho, "Colonial Waterbirds, 8, 1985, pp. 110-116.

R.R. Bond, "Ecological Distribution of Breeding Birds in the Upland Forests of Southern Wisconsin, Ecological Monographs, 27, 1957, pp. 351-384.

T.A. Bookhout (ed.), "Waterfowl and Wetlands - an Integrated Review," Proceedings of a Symposium held at the 39th Midwest Fish and Wildlife Conference, Madison, Wisconsin, 5 December 1977, Sponsored by the North Central Section, The Wildlife Society; 1979.

E.L. Braun, Deciduous Forests of Eastern North America, Philadelphia: Hofner Publishing Company, 1950.

K.P. Burnham, D.R. Anderson, J.L. Laake, "Estimation of Density from the Transect Sampling of Biological Populations," Wildlife Monographs, No. 72, 1980.

R.B. Bury, C.K. Dodd, G.M. Fellers, Conservation of the Amphibia of the United States: A Review, U.S. Fish and Wildlife Service, Resource Publication 134, 1980 .

R.B. Bury, North American Tortoises: Conservation and Ecology, U.S. Fish and Wildl ife Service, Wildlife Research Report 12, 1982.

M.W. Call, Nesting Habitats and Surveying Tochniques for Common Western Raptors, U.S. Bureau of Land Management, Tecrnical Note 316, 1978.

M.W. Ca11, Terrestrial Wildl ife Inventories, Some Methods and Concepts, U.S. Bureau of Land Management, Technical Note 349, 1982. 
A. Carr, Handbook of Turtles, Ithaca, New York: Comstock Publishing Company, 1952.

T.W. Clark et al., Handbook of Methods for Locating Black-Footed Ferrets, U.S. Bureau of Land Management, Cheyenne, Wyoming, Technical Bullet in No. 1, 1984.

W.W. Cochran, "Wildlife Telemetry," in S.D. Schemnitz (ed.), Wildlife

Management Techniques Manual, The Wildlife Society, Washington, DC, 1980, pp. $507-520$.

R. Conant, A Field Guide to Reptiles and Amphibians of Eastern and Central North America, 2nd edition, Boston: Houghton Mifflin Company, 1975, pp. 1621 .

G. Cottam and J.T. Curtis, "The Use of Distance Measures in Phytosociological Sampling," Ecology, 37, 1956, p. 451-460.'

A.H. Dahl et a1., A Study of the Food Chain Pattern of Strontium-90, Cesium137, and Iodine-131 in a Wild Deer Population, Colorado State University, Research Foundation, C00-1156-22, 1967.

D.F. Davis and R.L. Winstead, "Estimating the Numbers of Wildlife Populations," in S.D. Schemnitz (ed.), Wildlife Management Techniques Manual, The Wildlife Society, Washington, OC, 1980, p. 221-245.

E.J. Dealy, Spotlighting Deer: Potentials for Management in Western Oregon, U.S. Forest Service, Forest and Range Experiment Station, Research Note, 1966.

N.R. Dickinson, "Observations on Steep-Slope Deer Wintering Areas in New York and Vermont," New York Fish and Game Journal, 23, 1976, p. 51-57.

T.M. Dillon and A.B. Gibson, Bioaccumulation and Effects on Reproduction in Aquatic Organisms: An Assessment of the Current Literature, U.S. Corps of Engineers, Waterways Experiment Station, Miscellaneous Paper D-85-2, 1985.

DOE; See U.S. Department of Energy.

R. Eisler, Selenium Hazards to Fish, Wildlife, and Invertebrates: A Synoptic Review, U.S. Fish and Wildlife Service, Biological Report 85 (1.5), Contaminant Hazard Reviews Report No. 5, 1985.

J.T. Emlen, "Population Densities Derived from Transect Counts," Auk, 88, 1971 , p. 323-342.

D.L. Evan, Status Reports on Twelve Raptors, U.S. Fish and Wildlife Service, Special Scientific Report, Wildlife No. 238, 1982.

M.L. Fernald, Gray's Manual of Botany, Eighth Edition, New York: American Book Company, Inc., 1950.

H.A. Gleason and A. Cronquist, Manual of Vascular Plants of Northeastern United States and Adjacent Canada, Princeton: D. Van Nostrand Company, 1963. 
R.E. Good, D.F. Whigham, R.L. Simpson (eds.), Ereshwater Wetlands, Ecological Processes and Management Potential, New York: Academic Press, 1978.

C.R. Griffin, T.S. Baskett, R.D. Sparrowe, Ecology of Bald Eagles Wintering Near a Waterfowl Concentration, U.S. Fish and Wild life Service, Special Scientific Report, Wildlife No. 247, 1982.

J.P. Grime, Plant Strategies and Vegetation Processes, New York: John Wiley \& Sons, 1979.

D.K. Halford, J.B. Millard, O.D. Markham, "Radionuclide Concentrations in Waterfowl Using a Liquid Radioactive Waste Disposal Area and the Potential Radioaction Dose to Man," Health Physics, 40, 1981, pp. 173-181.

C.J. Henry et a1., "Territorial Behavior, Pesticifes and the Population Ecology of Red-Shouldered Hawks in Central Maryiand, "Ecology, 54, 1973, pp. $545-554$.

J.C. Howe11, "Roadside Census as a Method of Measuring Bird Populations, " Auk, 68, 1951, pp. 334-357.

C.L. Hubbs and K.F. Lagler, Fishes of the Great Lakes Region, Ann Arbor, Michigan: The University of Michigan Press, 1970.

J. Jacknow, J.L. Ludke, N.C. Coon, Monitoring Fish and Wildlife for Environmental Contaminants: The National Contaminant Biomonitoring Program, U.S. Fish and Wildlife Service, Fish and Wildlife Leaflet 4, 1986.

G.M. Jolly, "Explicit Estimates From Capture-Recapture Data with Both Death and Immigration-Stochastic Model," Biometrika, 52, 1965, pp. 225-247.

L.B. Keith, "A Study of Waterfowl Ecology on Small Impoundments in Southern Alberta," Wildl ife Monographs, 6, 1961.

S.C. Kendeigh, "Measurement of Bird Populations," Ecological Monographs, 14, 1944, pp. 67-106.

R.M. Kerr, Mule Deer Habitat Guidelines, U.S. Bureau of Land Management, Technical Note $336,1981$.

A.T. Klett et a1., Techniques for Studying Nest Success of Ducks in Upland Habitats in the Prairie Pothole Region, U.S. Fish and Wildlife Service, Resource Publication 158, 1986.

S.C. Lapham, J.B. Millard, J.M. Sanet, Radionuclide Levels in Cattle Raised Near Uranium Mines and Mills in Northwest New Mexico, New Mexico Environmental Improvement Division, Santa Fe, 1986.

T.S. Larson (ed.), Models for Assessment of Freshwater Wetlands, Water Resources Research Center, University of Massachusetts, Amherst, 1976. 
W.T. Mason (ed.), "Methods for the Assessment and Prediction of Mineral Mining Impacts on Aquatic Communities: A Review and Analysis," Workshop Proceedings, December 6-7, 1977. Harpers Ferry. West Virginia, U.S. Fish and Wild iffe Service, Harpers Ferry, 1977.

K.P. McCaffery, "Deer Trail Counts as an Index to Population and Habitat Use," The Journal of Wildlife Management, 40, 1976, pp. 308-316.

R.W. Merritt and K.W. Cummins (eds.), An Introduction to the Aquatic Insects of North America, Kendal/Hunt Publishing Co., 1978.

W.A. Mitche 11, White-tailed Deer Track Count Census, U.S. Army Corps of Engineers, Waterways Experiment Station TechnicaT Report EL-86-52, 1986a.

W.A. Mitche11, Deer Spotlight Census, U.S. Army Corps of Engineers, Waterways Experiment Station Technical Report EL-86-53, $1986 \mathrm{~b}$.

A.N. Moen, Wildlife Ecology, San Francisco: W.H. Freeman and Company, 1973.

T.P. O'Farrell and R.0. Gilbert, "Transport of Radioactive Materials by Jackrabbits on the Hanford Reservation," Health Physics, 29, 1975, pp. 9-15.

H.M. Ohlendorf et al., "Relationships Between Selenium Concentrations and Avian Reproduction, "Iransactions of the 51st North American Wildlife and Natural Resources Conference, 1986, pp. 330-342.

R.R. Oldendorff, R.S. Matroni, M.W. Ca11, Raptor Management - the State of the Art in 1980, U.S. Bureau of Land Management, Technical Note 345, 1982.

D.L. Otis et al., "Statistical Inference from Capture Data on Closed Animal Populations," Wildl ife Monographs, 62, 1978.

R.W. Pennak, Fresh-Water Invertebrates of the United States, New York: Ronald Press, 1953.

H.D. Picton and R.R. Knight, "A Numerical Index of Winter Conditions of Use in Big Game Management," Proceedings of Snow and Ice Symposium. Ames, Iowa, 1971, pp. 29-38.

D.R. Progulske and D.C. Duerre, "Factors Irifluencing Spotlighting Counts of Deer," The Journal of Wildl ife Management, 29, 1964, pp. 27-34.

W.E. Ricker, Computation and Interpretation of Biological Statistics of Fish Populations, Department of the Environment, Fisheries and Marine Service, Bulletin 191, Ottawa, Canada, 1975.

C.S. Robbins and B.A. Dowe11, "Use of Miniroutes and Breeding Bird Survey Data to Estimate Abundance," Proceedings of the Second Northeastern Breeding Bird Atlas Conference, Laboratory of Ornithology, Cornell University, Ithaca, New York, 1986, pp. 28-40. 
R.N. Rosenfield et a1., "Taped Calls as an Ald in Locating Cooper's Hawk Nests," Wildlife Society Bullettn, 13, 1985, pp. 62-63.

F. Ruther, Fundamentals of Limnology, Toronto: University of Toronto Press, 1968.

S.D. Schemnitz (ed.), Wildlife Management Techniques Manual, The Wildlife Society, Washington, D.C., 1980.

Z.E. Schnabel, "The Estimation of the Total Fish Population of a Lake," American Mathematical Monthly, 45, 1938, pp. 348-352.

N.J. Scott (ed.), Herpetological Communities, U.S. Fish and Wildl ife Service, Wildl ife Research Report 13, 1982.

W.B. Scott and E.J. Crossman, Freshwater Fishes of Canada, Fisheries Research Board of Canada Bullet in 184, 1973.

G.A.F. Seber, The Estimation of Animal Abundance and Related Parameters, New York: Hafna Press, 1973.

C.W. Severinghaus, "Relationship of Weather to Winter Mortality and Population Levels Among Deer in the Adirondack Region of New York, "Iransactions of the North American Wildl ife Conference, 1947, pp. 212-223.

E.L. Shafer, "The Twig Count Method for Measuring Hardwood Deer Browse" The Journal of Wildlife Management, 27, 1983, pp. 428-437.

D.W. Shimwe11, The Description and Classification of Vegetation, Seattle: University of Washington Press, 1971.

R.L. Smith and L.D. Flate, "Moments and Habitats of Brood-Rearing Wood Ducks on a Prairie River," The Journal of Wildlife Management, 49, 1985, pp. 437442 .

C. Southwick, "A System of Age Classification for Field Studies of Waterfowl Broods," The Journal of Wildlife Management, 17, 1953, pp. 1-8.

D.A. Spencer, Wintering Bald Eagle, National Agricultural Chemical Association, 1976.

D.A. Stoner et a1., "Mode?ing Radionuclide Concentration and Transport Downstream of the Susquehanna Steam Electric Station Using Dye Tracer Studies," Proceedings of the Eighteenth Midyear Topical symposium of the Health Physics Society, 1985, pp. 567-574.

G.A. Swanson and M.I. Meyer, "The Role of Invertebrates in the Feeding Ecology of Anatinae During the Breeding Season, "The Water Fowl Habitat Management Symposium, Moncton, Nova Scotia, 1973.

W.P. Taylor (ed.), The Deer of North America, Harrisburg, Pennsylvania: The Stackpole Company, 1956. 
E.S. Telfer, "Winter Habitat Selection by Moose and White-tafled Deer," The Journal of Wild If Ie Management, 31, 1970, pp. 553-559.

K. Titus and J.A. Mosher, "Nest-Site Habitat Selected by Woodland Hawks in the Centra1 Appalachians," Auk, 98, 1981, pp. 270-281.

U.S. Department of Energy, Environmental Monitoring of Low-Level Waste-

Disposal Sites, Low-Level Radinactive Waste Management Handbook Series, DOE/LLW-13Tg, 1983.

USFWS; See U.S. Fish and Wildlife Service.

U.S. Fish and Wildiffe Service, Colorado River Fishery Project, Final Report, Fleld Investigations, U.S. Fish and Wild life Service and Bureau of

Rec.lamation, Salt Lake City, Utah, 1982, pp. 4-18.

U.S. Fish and Wildlife Service, Draft Black-Footed Ferret Survey Guidelines

for Complitance with the Endangered Spectes Act, U.S. Fish and Wildlife

Service, Albuquerque, New Mextco, 1984.

U.S. Fish and Wildlife Service, Endangered and Threatened Wildlife and Plants: Review of Vertebrate Wildlife, 50 CFR Part 17, Department of the Interior, U.S. Fish and Wildlife Service, 1985a.

U.S. Fish and Wildlife Service, Endangered and Threatened Wildlife and Plants: Review of Plant Taxa for Listing as Endangered or Threatened Species, 50 CFR Part 17, Department of the Interior, U.S. Fish and WildTife Service, $1985 \mathrm{~b}$.

U.S. Fish and Wildlife Service, Endangered and Threatened Wildlife and Plants, 50 CFR 17.11 and 17.12, Department of the Interior, U.S. Fish and Wild if fe Service, 1986.

L.J. Verme, "An Index of Winter Weather for Northern Deer," The Journal of Wild life Management. 32, 1973, pp. 566-575.

G.C. Weary, "An Improved Method of Marking Snakes," Copeia, 1969, pp. 854-855.

C.I. Weber (ed.), Biological Field and Laboratory Methods for Measuring the Qual ity of Surface Waters and Effluents, U.S. Environmental Protection Agency, Cincinnati, Ohio, 1973.

M.W. Weller, "A Simple Field Candler for Waterfowl Eggs," The Journal of Wild ife Management, 20, 1956, pp. 111-113.

F.W. Whicker and V. Schultz, Radioecology: Nuclear Energy and the Environment, Volume 1, Boca Raton, Florida: CRC Press, Inc., 1981.

A.B. Williams, "The Composttion and Dynamics of a Beech-Maple Climax Community," Ecological Monographs, 6, 1936, pp. 317-408. 
A.H. Wright and A.A. Wright, Handbonk of Frogs and Toads of the United States and Canada, I thaca, New York: Comstock Publishing Company, 1949.

A.H. Wright and A.A. Wright, Handbook of Snakes, Volume I and II, I thaca, New York: Comstock Publishing Company, 1957.

J. Yoakum, Habitat Management Guides for the American Pronghorn Antelope, U.S. Bureau of Land Management, Technical Note 347, 1980. 
TABLE B- 15

PARAMETER DESCRIPTIONS - SOCIOECONOMICS

Later Force: The size, composition, and availability of the labor force in the region, including the county in which the site is located and those specific portions of surrounding counties and urbanized areas (up to $40 \mathrm{~km}$ from the site) from which the work force would be principally drawn.

Housing: The types, amounts, age, condition, and availability (turnover rates, vacancy rates, price) of existing housing and the location and amount of projected housing in the region from which the work force would be principally drawn or which would be affected because workers changed residence.

Health and Public Safety Systems: Capacity of utilities (e.g., solid waste disposal, water and sewer), and capabilities of police, fire, hospitals, physicians, and specialized health facilities to meet projected needs in the region from which the work force wollld be principally drawn or which would be affected because workers changed residence.

Education Systems: Capacity and availability of primary and secondary schools, junior colleges, technical schuols, and higher institutions in the region from which the work force would be principally drawn or which would be affecteci because workers changed residence.

Tax Base: The regional political jurisdictions and tax districts that will be affected by the facility, the regional tax structure, and present tax revenues.

Sociocultural Characteristics: The social structure (i.e., community composition and cohesiori), local attitudes, cultural values, life style indicators, family stability, and community problems in major communities within the region around the site. 


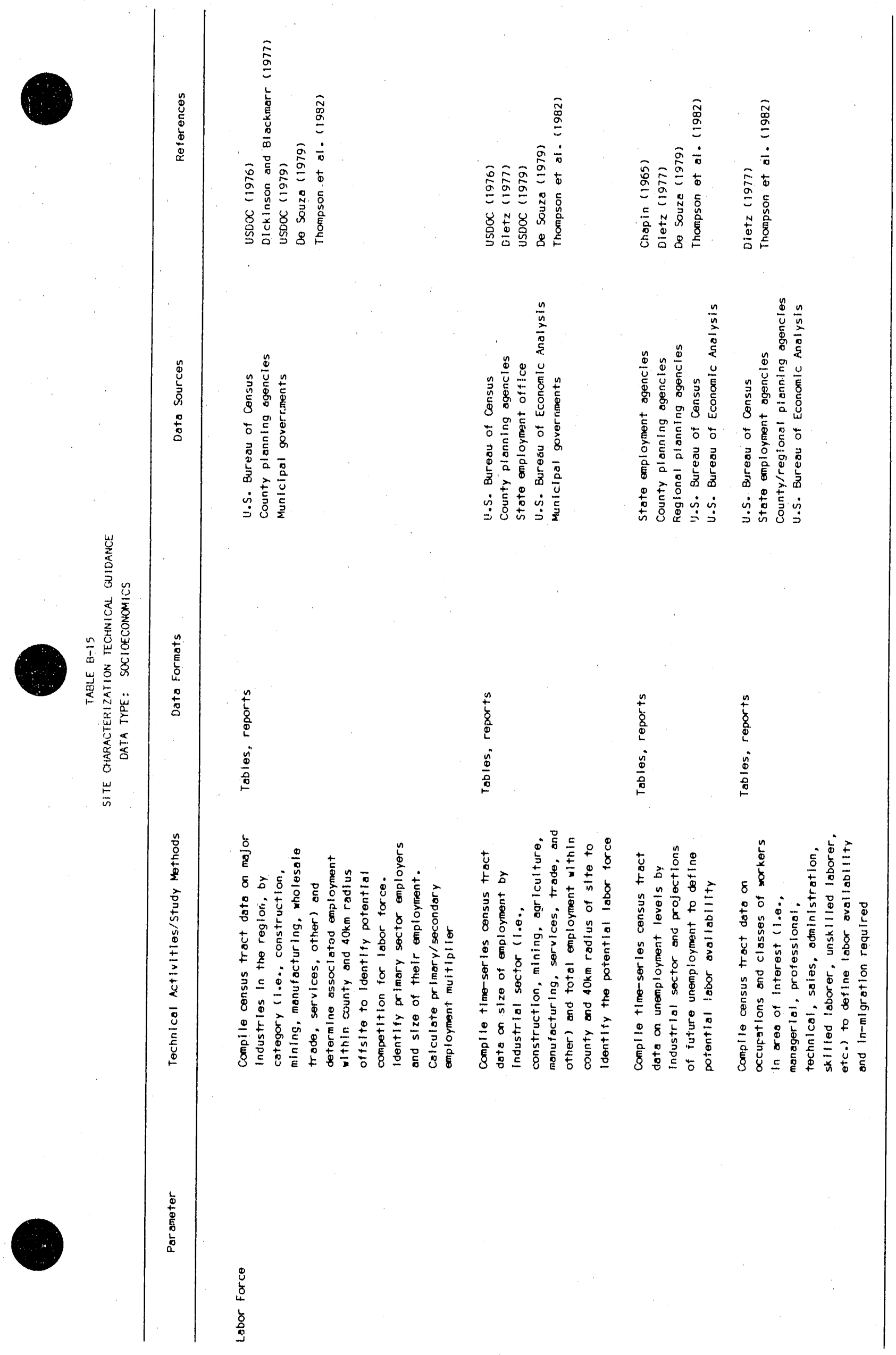

$\frac{T}{1}$ 


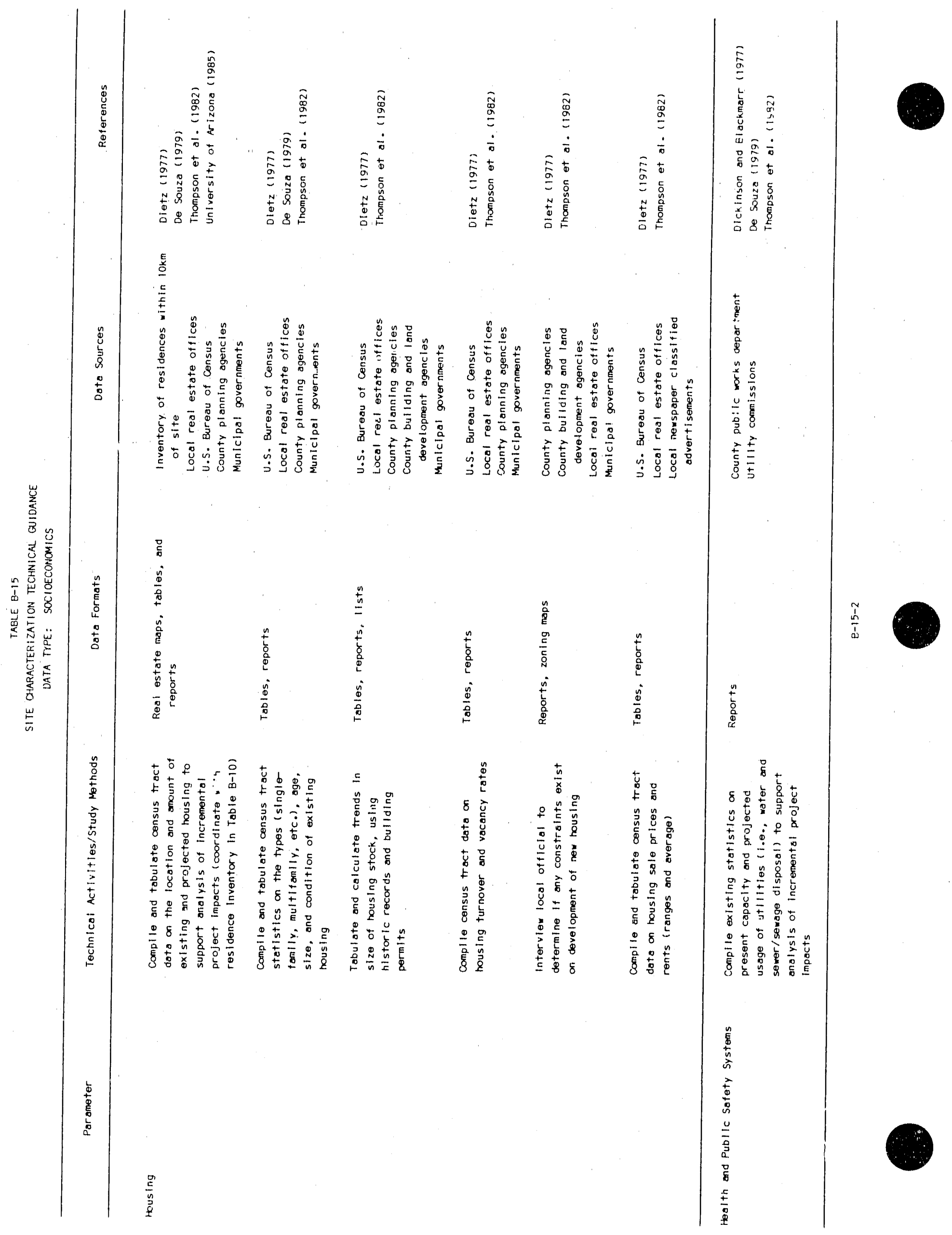




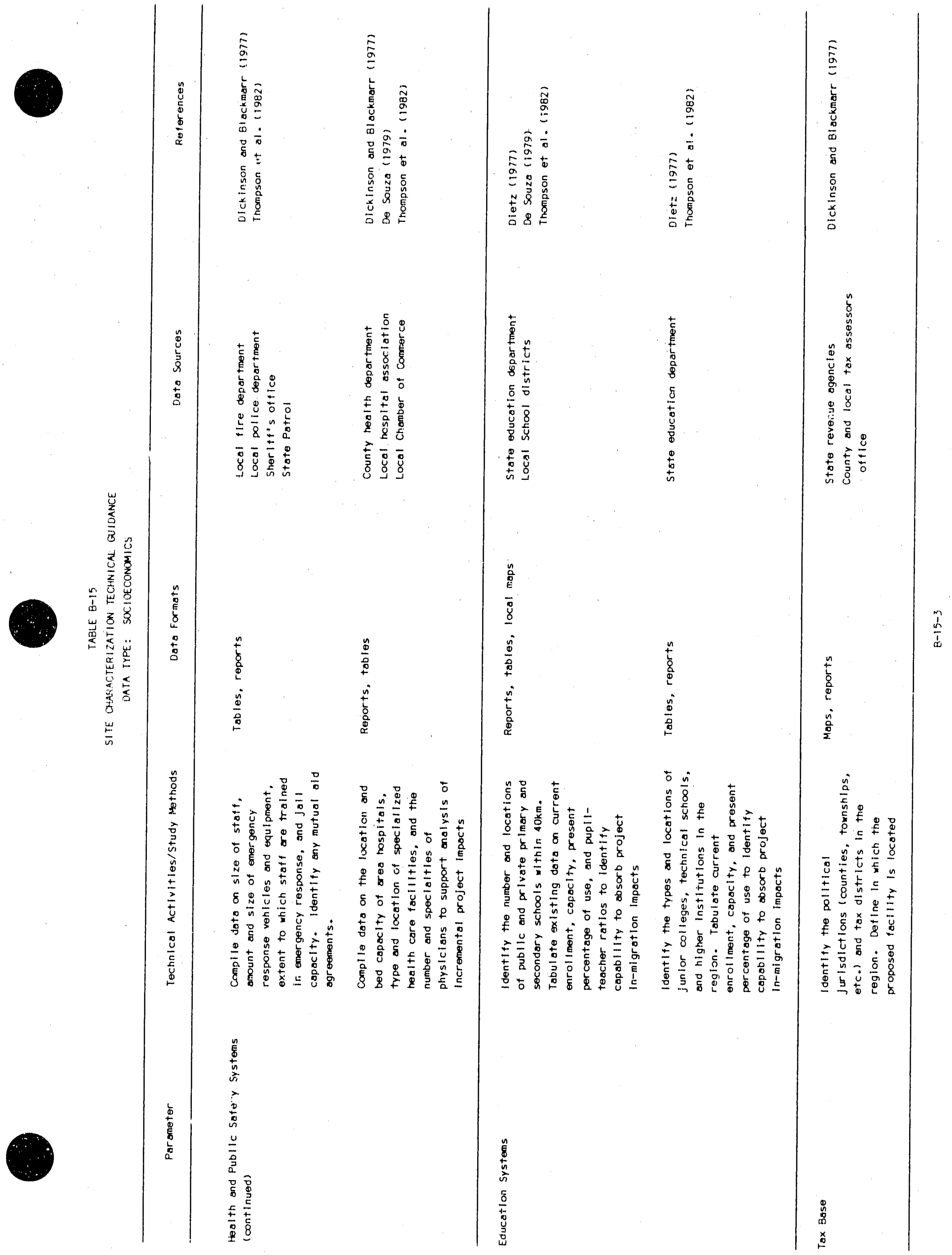



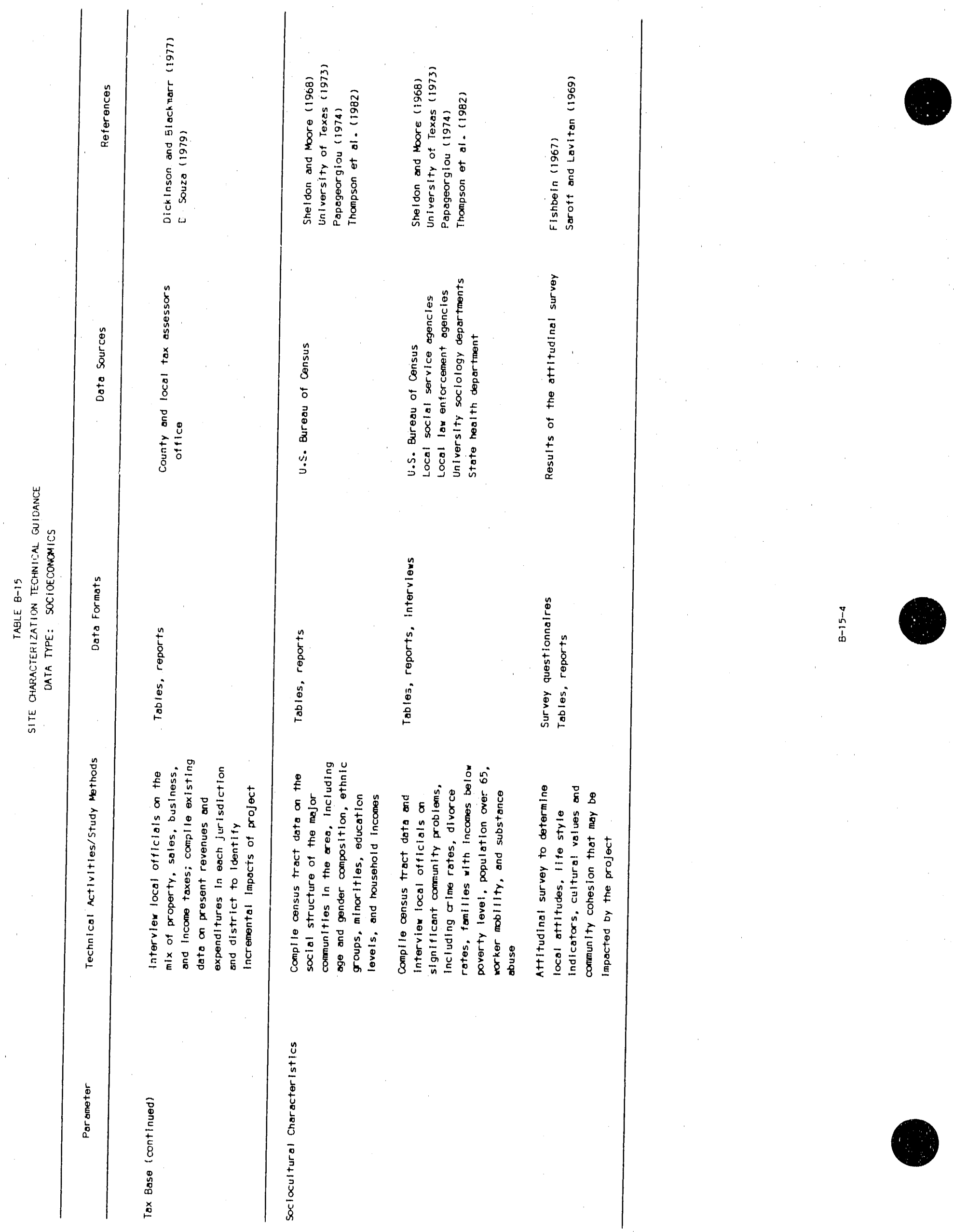
TABLE B- 15

REFERENCES - SOCIOECONOMICS

F. Chapin, Jr., Urban Land Use Planning, Urbana, IL: University of 111 inois Press, 1965.

G.R. De Souza, System Methods for Soctoeconomic and Environmental Impact Analysis, Lexington, MA: Lexington Books, 1979.

T.E. Dickinson and J.R. Blackmarr, "Evaluation of Private and Publ ic Economic Impacts Caused by Developments," Handbook on Environmental Planning - The Social Consequences of Environmental Change, New York, NY: John Wiley \& Soris, 1977.

T.M. Dietz, "Demographic Perspectives on Impact Assessment," Handbook on Environmental Planning - The Social Consequences of Environmental Change, New York, NY: John Wiley \& Sons, 1977.

M. Fishbein (ed.), Readings in Attitude Theory and Measurement, New York, NY: John Wiley \& Sons, Ltd., 1967.

J.C. Papageorgiou, "In Search of Quality of Life Indicators and Factors Affecting Their Magnitude," 1974 Earth Environment and Resources Conference Digest of Technical Papers, New York, NY: Lewis Winner, September 1974.

J.R. Saroff and A.Z. Lavitan, Survey Manual for Comprehensive Urban Planning: The Use of Opinion Surveys and Sampling Techniques in the Planning Process, SEG Report No. 19, Institute of Social, Economic, and Government Research, University of Alaska, 1969.

E. Sheldon and W.E. Moore (eds.), Indicators of Social Change, Concepts and Measurements, New York, NY: The Russell Sage Foundation, 1968.

J.G. Thompson et a1., The Bureau of Land Management Social Effects, Project Summary Research Report, U.S. Department of Interior, JuTy 1982.

USDOC; See U.S. Department of Commerce.

U.S. Department of Commerce, Environmental/Socioeconomic Data Sources, Bureau of Census, Octuber 1976.

U.S. Department of Commerce, Guide to County Census Data for Planning Economic Development, Bureau of Census, 1979.

University of Arizona, Site Characterization Field Manual for Near Surface Geologic Disposal of Low-Level Radioactive Waste, U.S. Department of Energy report DE FG07 $841012514,1985$.

University of Texas at Austin, Lyndon Baines Johnson School of Public Affairs, A Resource Handbook for Developing Community Indicators, 1973. 
TABLE B-16

PARAMETER DESCRIPTIONS - CULTURAL RESOURCES

Historic Places: Districts, sites, buildings, structures or obje:ts of historical significance listed or eligible for inclusion in the National Register of Historic Places, or of State or local significance.

Archaeologic Sites: Sites containing artifacts of the 1 ife and culture of ancient peoples.

Other Cultural Resources: Other sites, buildings, structures, or objects of historical, archaeological, architectural, scenic, cultural or landmark. significance, including traditional folklife remnants, Native American religious or sacred sites, and paleontological (i.e., fossil) resources. 


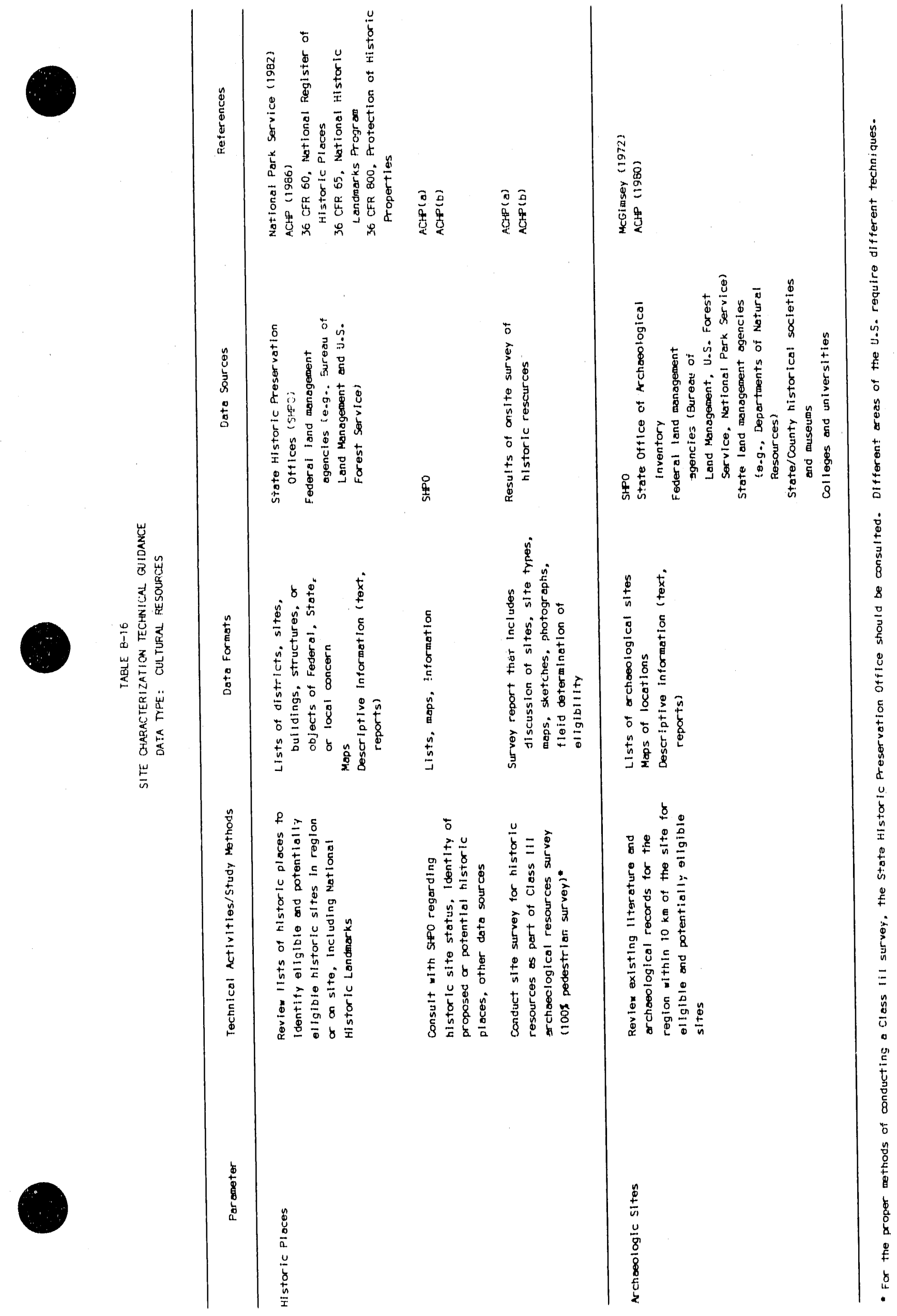




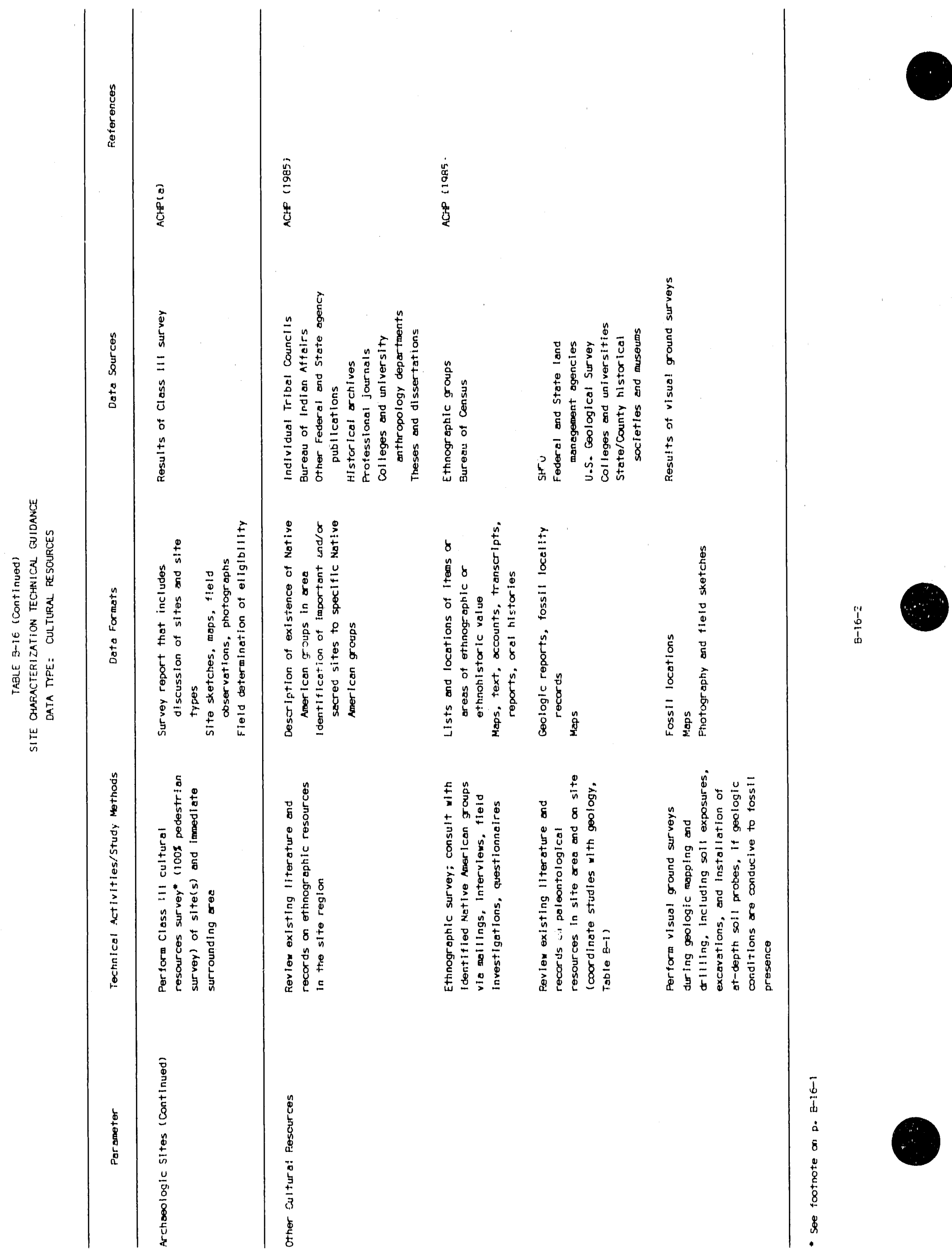


TABLE B- 16

REFERENCES - CULTURAL RESOURCES

ACHP; See Advisory Counctl on Historic Preservation.

Advisory Counctl on Historic Preservation (a), The Archeological Survey: Methods and Uses, no date.

Advisory Counctl on Histortc Preservation (b), Guldelines for Local Surveys: A Basis for Preservation Planning, no date.

Advisory Council on Historic Preservation, Ireatment of Archaeological Properties. A Handbook, 1980.

Advisory Council on Histortc Preservation, Guidelines for Consideration of Traditional Cultural Values in Historic Preservation Review, 1985.

Advisory Counctl on Histortc Preservation, Working with Section 106. 36 CFR Part 800. Protection of Histortc Properties, Requlations of the Advisory Council on Historic Preservation Governing the Section 106 Review Process, 1986.

C.R. McGimsey, Public Archeology, 3d, New York: Seminar Press, Inc., 1972.

National Park Service, How to Apply the National Register Criteria for Evaluation, Draft gutdance, Washington D.C.: National Park Service, 1982.

36 CFR Part 60, National Register of Historic Places, National Park Service 36 CFR Part 65, National Historic Landmarks Program, National Park Service. 36 CFR Part 800, Protection of Historic Properties, Advisory Council on Historic Preservation. 
Major Highways: Major interstate, U.S. and State highways enruute to the stte from centers of waste generation, statewide and/or reglonwide, and in the vicinity of the site.

Local Highways and Roads: County and local highways and roads in the vicinity of the site, especially connectors to major highways.

Navigable Waterways: Rivers, canals, and other navigable waterways, statewide and/or regionwide, and in the vicinity of the site.

Rallroads: Existing major and short line roads and classification yards enroute to the site from centers of waste generation, statewide and/or regionwide, and in the vicinity of the site.

Rights-of-way: Rights-of-way needed to provided access to the site from local transportation routes.

Public Transportation: Existing modes of public transportation (buses, trains, air service) providing access to the site. 


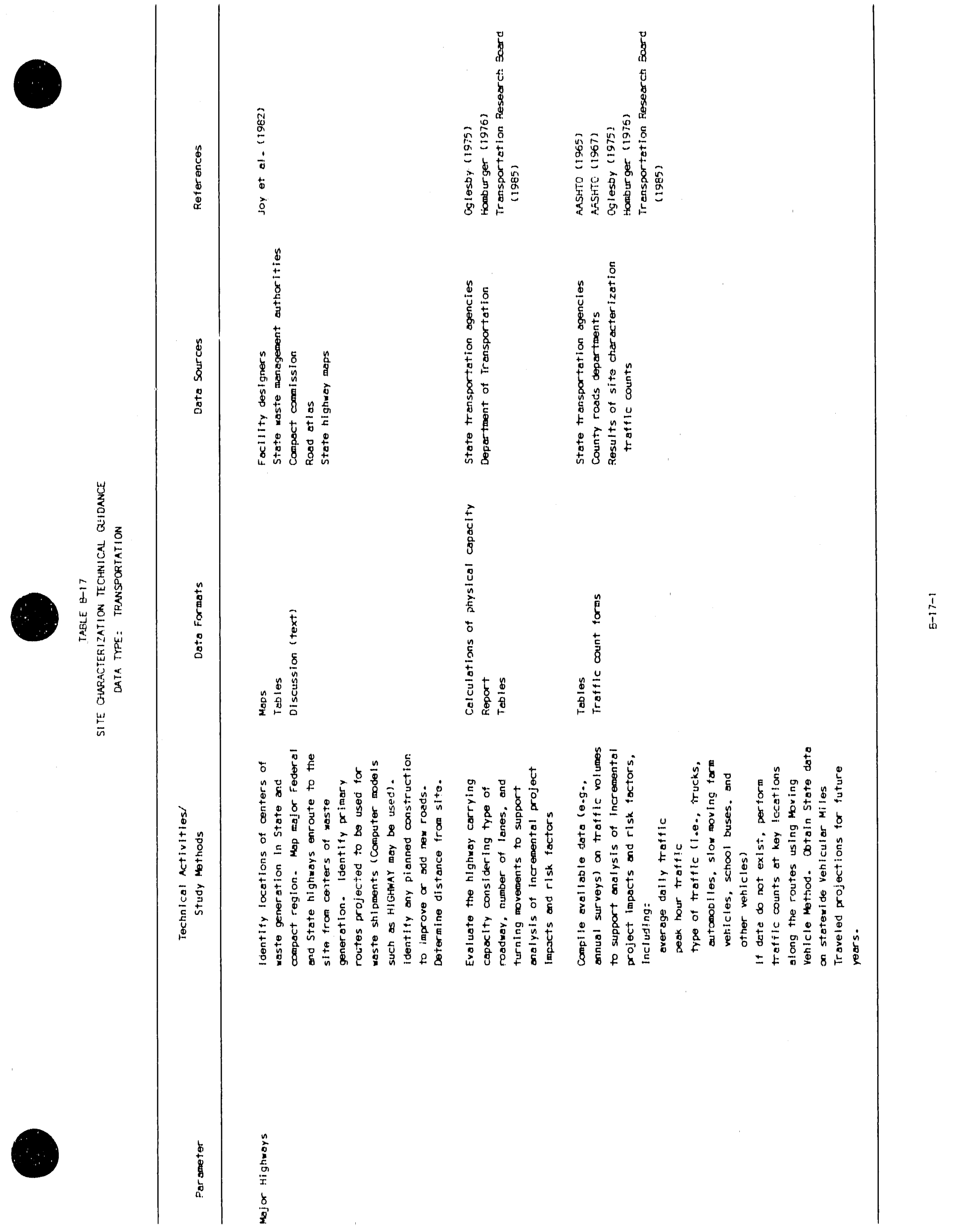




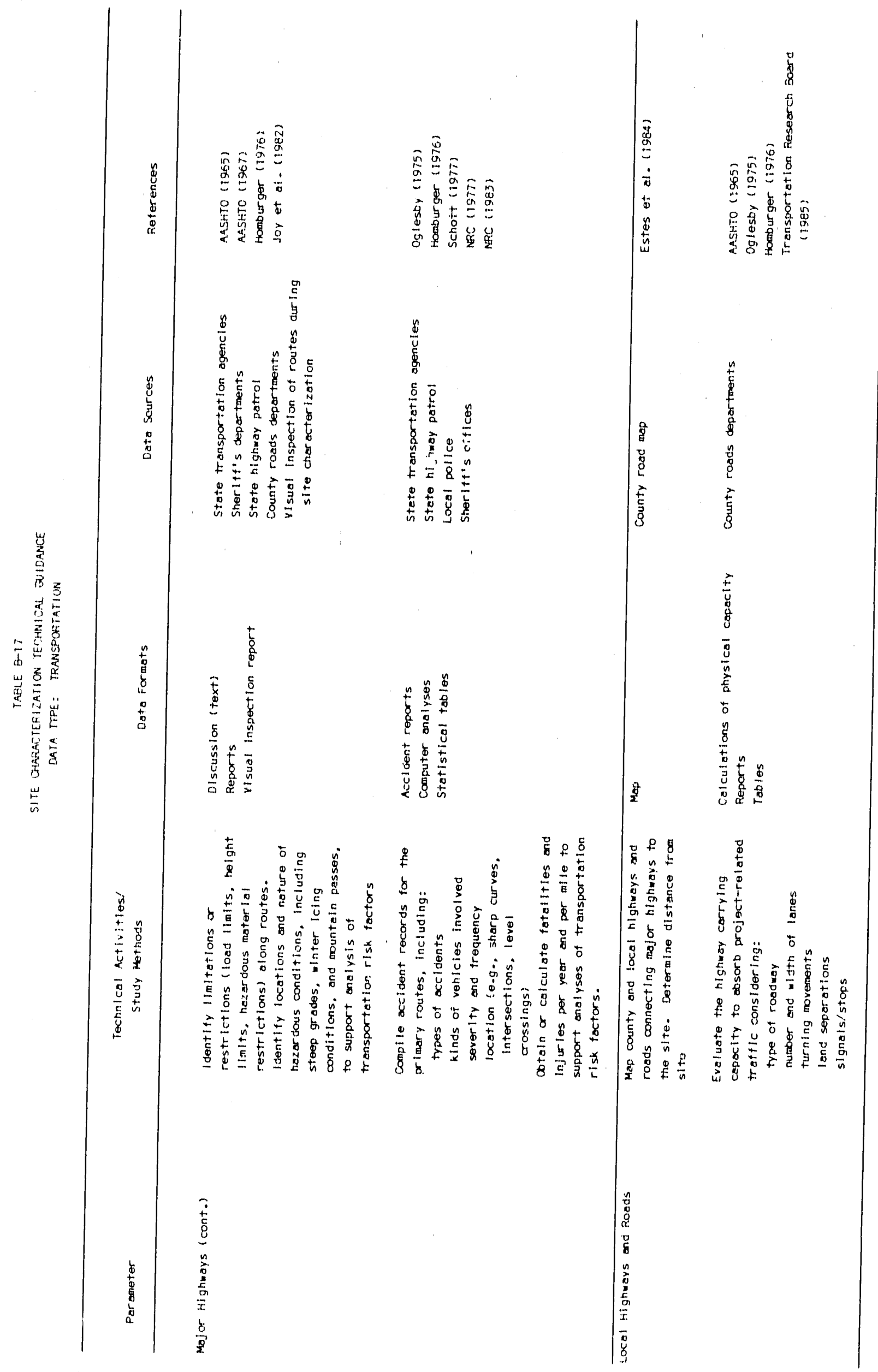

$\frac{N}{a}$

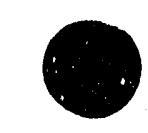




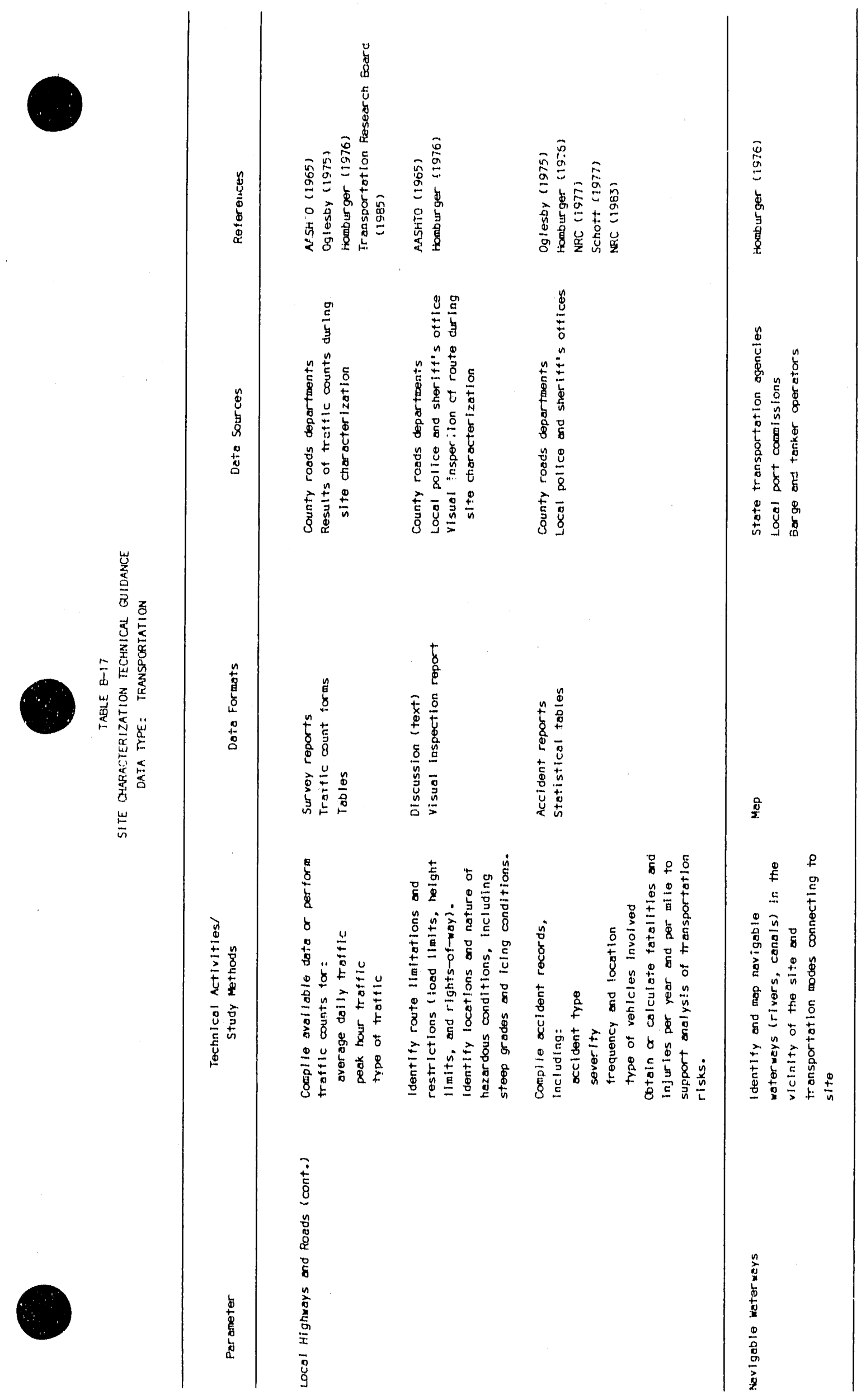




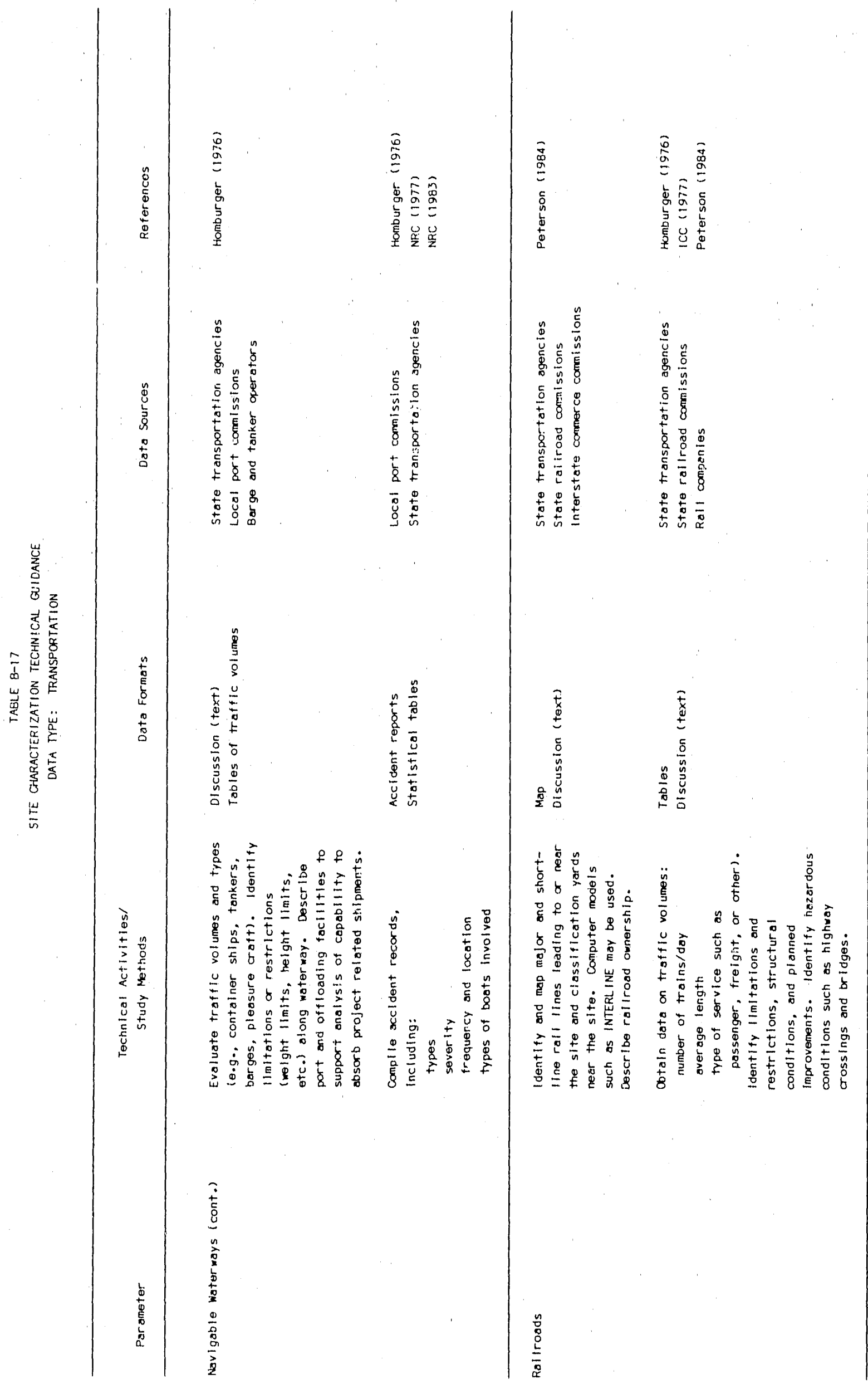

$\frac{1}{5}$ 


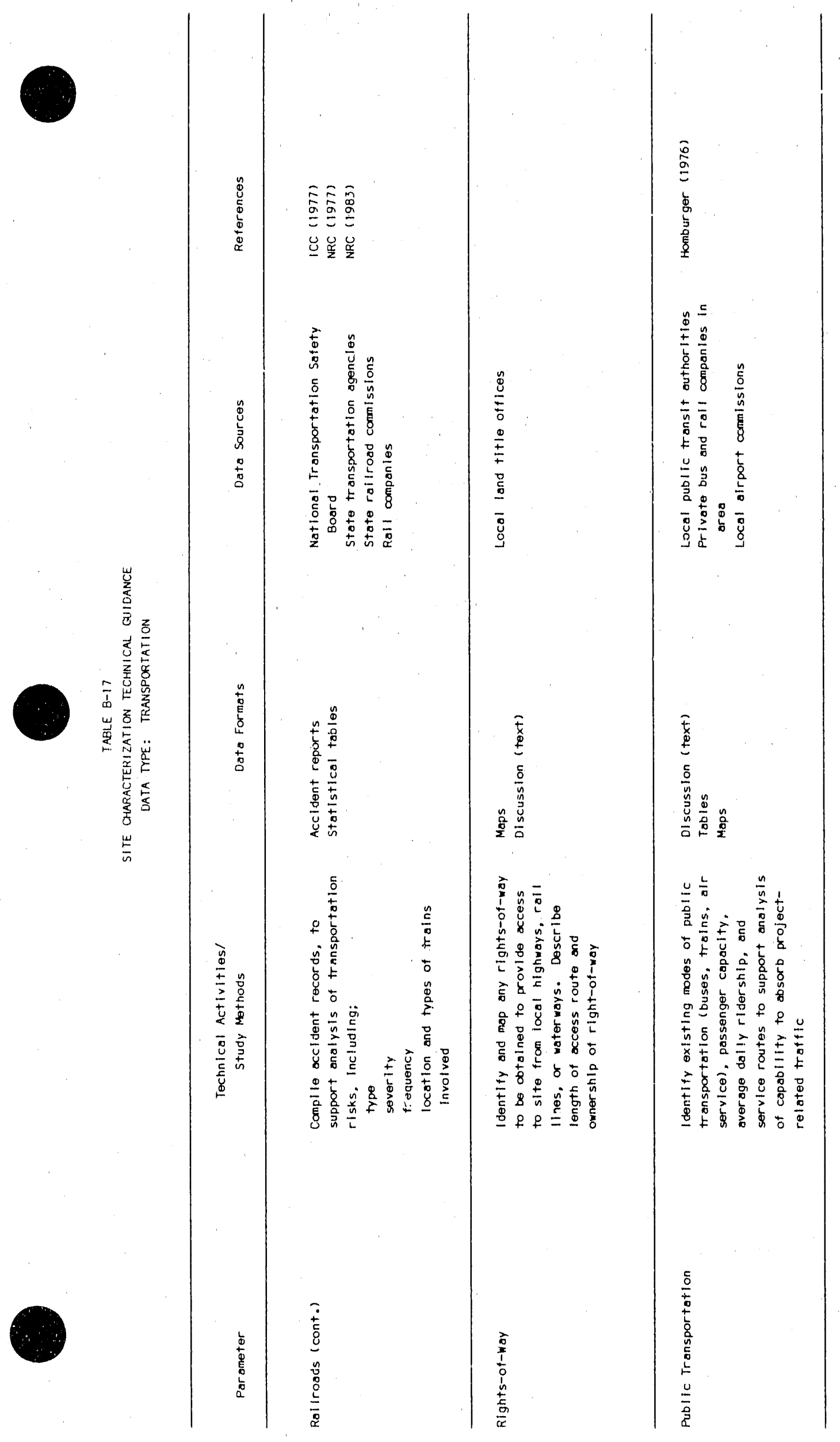

$\frac{n}{1}$ 
TABLE B-17

REFERENCES - TRANSPORTATION

AASHTO; see American Association of State Highway and Transportation Officials.

American Association of State High ay and Transportation Officials, A Policy on Geometric Design of Rural Highwdys, Washington, D.C., 1965.

American Association of State Highway and Transportation Officials, A Policy on Design Standards - Interstate System, Washington, D.C., June 1967.

J.E. Estes et al., Evaluation of Low-Altitude Remote Sensing Techniques for Obtaining Site Characteristic Information, U.S. Nuclear Regulatory Commission NUREG/CR-3583, S-7.62-R, RE, 1984.

W.S. Homburger (ed.), Transportation and Traffic Engineering Handbook, Institute of Traffic Engineers, Englewood Cliffs, NJ: Prentice-Hall, 1976.

ICC; see Interstate Commerce Commission.

Interstate Commerce Commission, Final Environmental Impact Statement Transportation of Radioactive Material by Rail, Office of Proceedings, Washington, D.C., 1977.

D.S. Joy et a1., HIGHWAY, a Transportation Routing Model: Program Description and User's Manual, ORNL/TM 84-19, 1982.

NRC; see U.S. Nuclear Regulatory Commission.

C.H. Oglesby, Highway Engineering, New York, NY: John Wiley \& Sons, 1975.

B.E. Peterson, INTERLINE - A Railway Routing Model: Program Description and Users Manual, ORNL/TM-8944, 1984.

R.D. Schott, "Social Impacts of Transportation," Handbook for Environmental Planning - The Social Consequences of Environmental Change, New York, NY: John Wiley \& Sons, 1977.

Transportation Research Board, National Research Counci1, Highway Capacity Manual, Special Report 209, Washington, D.C., 1985.

U.S Nuclear Regulatory Commiss : in, Final Environmental Impact Statement on the Transportation of Radioactive Material by Air and Dther Modes, NUREG-0170, 1977 .

U.S. Nuclear Regulatory Commission, The Transportation of Radioactive Material to and from U.S. Nuclear Power Plants - Draft Environmental Assessment, NUREG/CR-2325, 1983. 
Visual Resources: Assessment of visual quality for specific geographic areas, based on numbers and types of viewers, uniqueness of the landscape; determined through viewsheds (i.e., depiction of what is seen from selected offsite viewer locations) and resource classifications (e.g., U.S. Forest Service Visual Resource Management System).

Noise: The measurement of background noise levels to support determinations of incremental noise impacts from facility construction and operation; measured in decibels. 


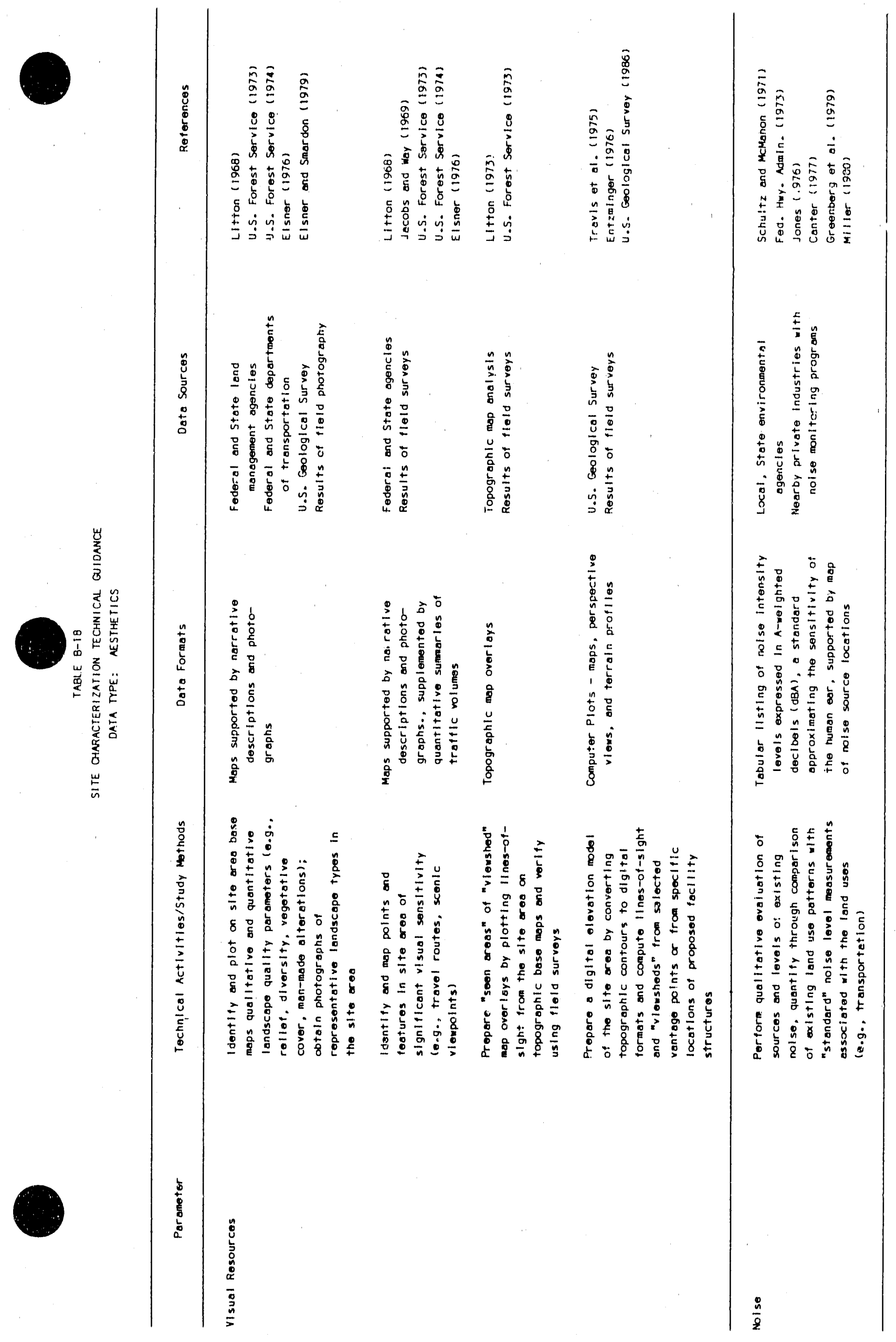

$\frac{\overline{1}}{\frac{1}{a}}$ 

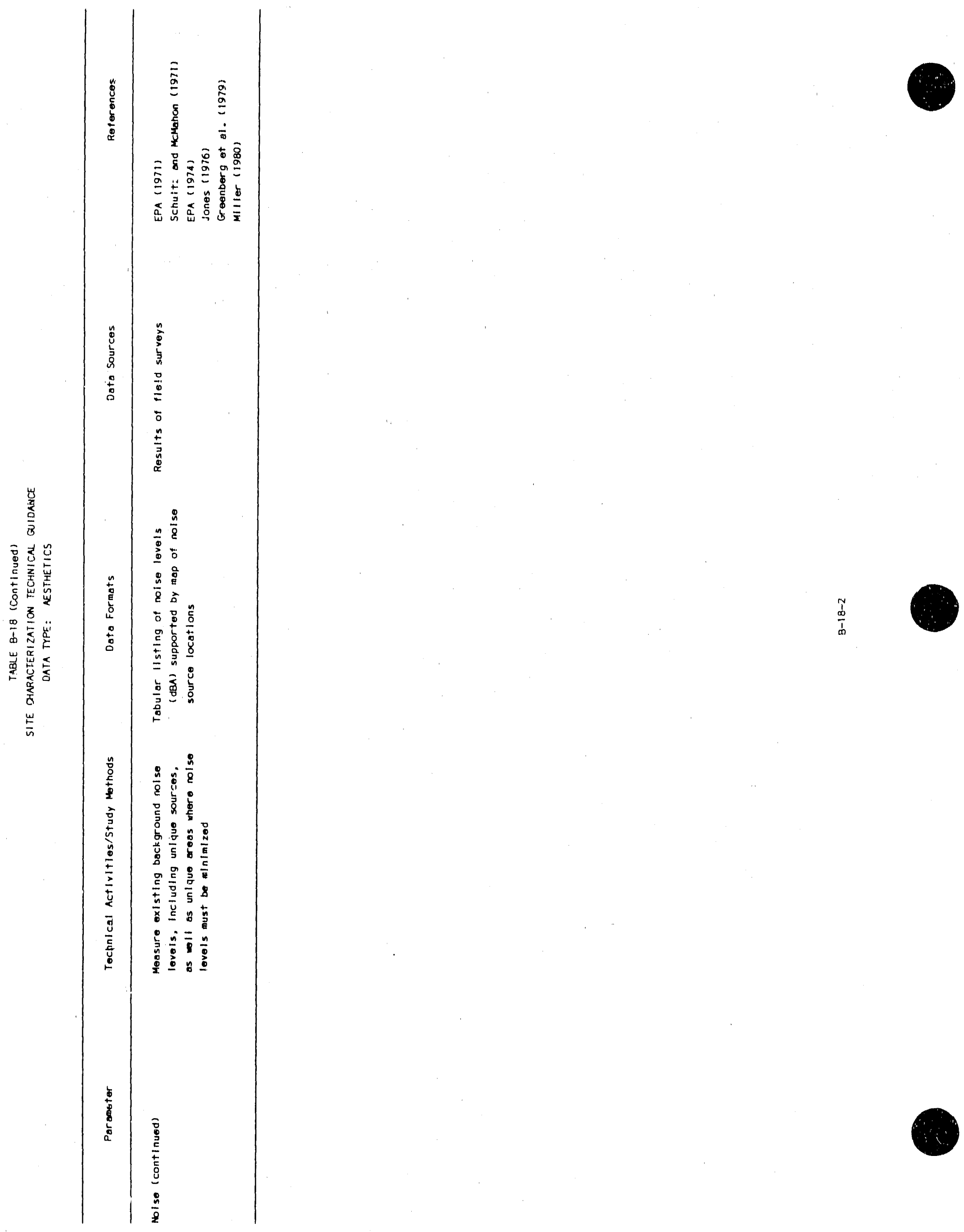
L.W. Canter, Environmenta] Impact Assessment, New York: McGraw-H 111 Book Company, 1977, pp. 120-144.

G.H. Elsner, "Quant ifying Landscape Dimensions for Land-Use Planning," XVI IUFRO World Cong. Proc. (Div. 6), 01so, 1976, pp. 28-38.

G.H. ETsner and R.C. Smardon (Eds.), Our National Landscape, Proc. of a Conference on Applied Techniques for Anlalys is and Management of the Visual Resource, USDA Forest Service General Technical Report PSW-35, 1979.

R.A. Entzminger, "MOSAIC/Photomontage: A New Concept to Help Reclamation Planning," Coal Min. and Process J., 13(6), 1976, pp. 76-78.

EPA; See U.S. Environmental Protection Agency.

Federal Highway Administration, Noise Standards and Procedures, Policy and Procedure Memorandum 90-2, U.S. Department of Transportation, Washingtion, D.C., 1973.

M.R. Greenberg et a1., A Primer on Industrial Environmental Impact, Brunswick, $\mathrm{NJ}$ : Center for Urban Policy Research, 1979, p. 19-99.

P. Jacobs and D. Way, Visual Analys is of Landscape Development, Cambridge, Mass.: Harvard University, 1969.

I.D. Jones, "Road Traffic Noise," Progress in Planning, 5, Part 3, oxford: Bergamon Press, 1976.

R.B. Litton, Jr., Forest Landscape Description and Inventories - A Bas is for Land Planning and Design, U.S.D.A. Forest Service Res. Paper PSW-49, 1968.

R.B. Litton, Jr., Landscape Control Points: A Procedure for Predicting and Monitoring Visual Impacts, U.S.D.A. Forest Service Res. Paper PSW-91, 1973.

R.K. Miller, Noise Control Solutions for the Construction Industry, At1anta: The Fairmont Press, Inc., 1980.

T.J. Schultz and N.M. McMahon, Noise Assessment Guidelines, U.S. Dept. of Housing and Urban Development, 1971.

M.R. Travis et al., VIEWIT: Computation of Seen Areas, Slope and Aspects for Land-Use Planning, U.S.D.A. Forest Service Gen. Tech. Rpt. PSW-11, 1975.

U.S. Environmental Protection Agency, Community Noise, MTID 300.3, 1971.

U.S. Environmental Protection Agency, Information on Levels of Environmental Noise Resu te to Protect Public Heal th and Welfare with an Adequate Margin of Safety, ËPA-550/9-74-004, 1974. 
U.S. Forest Service, Nat lonal Forest Landscape Management, Vo1, 1, U.S.D.A. Agriculture Handbook 434, 1973.

U.S. Forest Service, National Forest Landscape Management, Vo1, 2, U.S.D.A. Agriculture Handbook 462, 1974.

U.S. Geological Survey, Digital Elevation Models, Data Users Guide 5, 1986. 


\section{APPENDIX C \\ PHASING OF SITE CHARACTERIZATION ACTIVITIES}




\section{APPENDIX C \\ PHASING OF SITE CHARACTERIZATION ACTIVITIES}

Site characterlzation can be divided into multiple phases. The following discussion has assumed three phases to demonstrate the groupings of strateglc dectsion points prtor to completion of the program. The description of phases and the structure of the program are offered only as an example of many genertc activities and the thought processes most common to site characterization studies.

Phase 1, Reconnalssance, is designed to: 1) quickly and economically assess the site for fatal flows, 2) develop the basic parameters for the geologic models, and 3) begth the hydrologtc and meteorologic characterization and monttoring programs. Phase 1 also develops an extensive data base on the site and region from published and unpublished sources. The combined results of Phase 1 becomes the basis for planning the detalls for Phase 2 activities.

Phase 2, Exploration, will only proceed if the site has no obvious fatal flaws. Phase 2 comprises a more comprehensive subsurface investigation destgned to expand the understanding of the geologic, hydrologic, and environmental model. The activities focus on investigating any anomalous conditions revealed in phase 1, adding to the density of subsurface information in a selected area of the site (identifying and partially trvestigating a facllity location), and conducting fleld and laboratory testing.

Phase 3, Confirmation, completes the field investigation program by increasing the density of subsurface information (especially at a facility location), performing the analytical and numerlcal modeling, and completing the testing required to determine site parameters important to analyzing site performance objectives. Phase 3 also establishes the requirements for longterm monitoring for the hydrologic prograin. Phase 3 usually concludes with the preparation of technical reports for input to design and licensing documents.

Each of these phases may have an expanded or reduced scope depending on the character, size, and number of sites. In addition, each phase must remain flexible to potential changes in the investigation results and the necessity for redirecting the effort. Phase 1, Reconnaissance, may also be applied all or in part to alternate sites that require some site-specific data for general characterization.

\section{Recorinatssance Phase}

\section{Planning Access:}

Based upon review and revistons to the site Characterization plan, detalled plans for Phase 1, Reconnaissance, can include preparation of specific schedules, logistical planning, planning for obtaining access to the

$$
\text { C-1 }
$$


stte to carry out fleld activities, and application for the permits required to intitate vartous figld activities.

\section{Pre-Field Research:}

Prenfleld research can include review of background information developed during stte selection, as well as collection and review of additional regional and siterspeciftc published and unpublished data and maps on geology, hydrology, resources, meteorology, demography, ecology, and other relevant disciplines to confirm that the site has no known fatal flaws, and to provide a data base upon which to plan the subsequent fleld evaluation and monitoring programs.

\section{Pre-Monitoring Surveys:}

Activities that can be carried out in the fleld prior to the inttiation of the field studies and monltoring include: performance of a cultural resources (primartly archaeology) survey and an environmental revtew prior to any surface-disturbing activittes; performance of a general field reconnaissance to assess the general physical characteristics of the site and the access to the slte; performance of a land survey, including the establishment of permanent survey marker control points for horizontal and vertical control, and preparation of a site topographic maps; and installation of monttoring wells and meteorological/air quality stations.

\section{Field Monftoring Surveys:}

The NRC requtres a pre-operational monttoring and sampling program to establish a statistical data base for pre-existing background concentrations of radioactive and chemlcal constituents and other time variant data. This monitoring program should have at least a one-year duration to account for seasonal variations. Environmental monttoring inftiated during the preoperational phase should be continued durting the operational phase to evaluate whether background concentrations have been exceeded.

Activities carried out during the pre-operational monitoring program should include measurements of direct gamma radiation, as well as sampling to determine background concentrations of radloactive contaminants and nonradiological constituents in ground water, surface water, soll, sediments, air, and flora and fauna. The NRC recommends continuous sampling where practicable during the one-year monttoring period (e.g., air sampling), but prefers discrete sampling at selected intervals for media affected by random climatological events (e.g., surface-water quality and quantity). Specific NRC guidance for pre-operational monttoring activities can be found in the NRC (1986) "Working Draft, Technical Position Paper on Environmental Monttoring of Low-Level Waste Disposal Facilities".

Pre-operational monitoring activities include: ground-water monitoring to measure ground-water levels and fluctuations and to determine hydraulic yradients, and sampling for radiological and non-radiological constituents; collection of site-specific and regional long-erm moteorological data, measurements of meterological parameters to determirie the water budget, and 
atr qualtty monttoring; installation of soll monttoring probes to measure temperature, molsture, etc., and soll sampling for radlological and nonradiological consttuents; surface-water monitoring of flow, and sampling of surface water and stream sediments for radiological and non-radiological constituents; and environmental monttoring, including radiological monttoring of flora and fauna, and inventory and analysis of the abundance and characteristics of local spectes.

Time-varlance site characteristics requiring monitoring may include: hydrological charactertstics such as soll molsture content, ground-water levels, surface- and ground-water quality; meteorological characteristics such as temporature, wind direction, and precipitation; and ecological characteristics such as the presence of migratory spectes. The preoperational monttoring program can be ongoing with other stte characterization fleld studies, and tt should begin as early as posstble in the site characterization program to allow adequate time for the minimum one-year requirement to account for seasonal vartations.

\section{Fleld Surveys:}

For purposes of this example, fleld surveys are considered to be those activities exclustve of monttoring that are necessary to fully define that surface and subsurface characteristics of the site and surrounding area. Field exploration activities can be ongoing with or precede the preoperational monitoring program. Fleld activities that precede the monitoring program can provide input to the selection of sites for the monitoring wells and other subsurface boreholes.

Field surveys during the reconnaissance phase can include: geologic and geomorphic mapping; performance of reconnatssance surface geophysical surveys; performance of a surface-water hydrology evaluation; drilling and logging of reconnatssance boreholes supplemential to the monitoring boreholes; performance of a borehole geophysical survey; evaluation of natural resources (geologic and water); performance of a ground-water hydrology evaluation; performance of a reconnaissance-level geutechnical engineering (geoengineering) evaluation; demographic data collection and synthesis; performance of a socioeconomic evaluation; land use mapping; performance of an aesthetics evaluation; and performance of a transportation analysis. Specific components of these field activities are described further in Appendix B.

Activities for natural resources, demography, land use, aesthetics, and transportation studies under the fleld survey program can be started during the reconnaissance phase if desired, but are not necessarlly required to be carried out in this phase. Depending upon local or site-specific conditions, they could be deferred to later phases as the schedule permits. Most field activities can be carried out simultaneously during this phase, with the exception of those activities that supercede the driliting of boreholes, such as borehole geophysical logging and hydrologic testing. 
Laboratory Testing and Analys.ts:

Laboratory testing and analysis can be ongoing with all the stages of the reconnatssance fleld surveys and the pre-operational monitoring activities, and will include testing and/or analys ts of rock, soll, sediment, water, air, flora, and fauna samples. Analyses and tests should be performed by qualified laboratories that follow accepted industry and qualtty control procedures. Adequate time should be allowed in the scheduie for analysis and reporting of sample results by the laboratortes.

\section{Data Analysis:}

Data evaluation and analysis can be ongoing during each phase of the program, but should be performed in depth at the completion of each phase in order to develop models of stte characteristics, and to integrate the results among disctplines for planning the next phase of the program.

\section{Reporting/Dectston Points:}

The data evaluation will result in the identification of any fatal flaws or the determination that the site is sultable for further site characterization studies. If the site is considered sultable, recominendations can then be made for the initiation of Phase 2. If part of the overall program plan is to reduce the size of the area to be characterized after the reconnaissance phase, identification of a smaller area to be studied in greater detall in subsequent phases of the investigation could be done at this point. The Phase 1 arialyses can result in a synthesis of data collected to date, which can in turn provide input to a recornaissance interim report and various programmatic documents. The final products of the phase 1 reconnatssance program can become the basis for preparation of a refined Site Characterization Plan for the Phase 2 exploration program and the Phase 2 QA/QC Plan.

\section{Exploration Phase}

\section{Planning/Access:}

Based upon the Phase 1 program, detalled plans for Phase 2 exploration can be prepared, including preparation of schedules and logistical planning.

\section{Eield Monttoring Surveys:}

The fleld monitoring surveys in Phase 2 are a continuation of the preoperational monttoring surveys begun in Phase 1. These surveys will generally be carried out for a minimum of twelve months from the date of their initiation in Phase 1.

\section{Field Surveys:}

The field surveys carried out during the exploration phase can be used to develop more confidence about site characteristics and to investigate any 
anomalies revealed in Phase 1. This phase should be performed in greater detall than Phase 1 and should be designed to increase the derisity of data points across the site. Fleld surveys during the exploration phase of the program can include detalled: surface geophysical surveys; surface-water hydrology evaluation; exploratory drilling and logging; borehole geophysics; exploratory trenching $t_{i}$ selected areas to investigate subsurface deposits; natural resources (geologic and water) evaluation if indications of resources are present; ground-water hydrology evaluation; geoengineering evaluation for near-surface matertals; soctoeconomic evaluation; land use mapping; demographic data collection and sampling; aesthetics evaluation; and transportation analysis.

Laboratory Testing and Allalys is:

Laboratory testing and analysis can be ongoing with the exploration field surveys and the pre-operational monttoring activities, and will include testing and/or analysis of rock, soil, sediment, water, air, flora, and fauna samples.

\section{Data Analys is:}

Data analysis can be ongoing during Phase 2, but should be performed in depth at the completion of the phase in order to further refine site models and to integrate the results among disciplines for planning Phase 3 investigations.

\section{Reporting/Decision Points:}

The data evaluation will result in the identification of any fatal flaws or the determination that the site is suitable for further site characterization studies. The synthesized Phase 2 data can provide input to an exploration interim report and various programmatic documents. The final results of the Phase 2 exploration program will become the basis for preparation of a refined Site Characterization Plan for the Phase 3 confirmation program and the $Q A / Q C$ Plan.

\section{Confirmation Phase}

\section{Planning/Access:}

Based upon the Phase 2 program, detalled plans for Phase 3 confirmation can be prepared.

\section{Field Monitoring Surveys:}

The field monitoring surveys in Phase 3 are a continuation of the preoperational monitoring surveys begun in Phase 1. These surveys will generally continue for a minimum of twelve months from the dace of their initiation in phase 1. 


\section{Field Surveys:}

The field surveys carried out during the confirmation phase can be used to develop more confidence about site characteristics and to complete the testing required to evaluate site parameters important to site performance objectives. This phase should be designed to increase the density of subsurface information, particularly at the facility location. Field surveys during the confirmation phase of the program can include detailed: exploratory drilling and logging; borehole geophysics; exploratory trenching in selected areas to investigate subsurface deposits; ground-water hydrology evaluation; geoengineering evaluation of near-surface materials; socioeconomic evaluation; land use mapping; demographic data collecting and sampling; aesthetics evaluation; and transportation analysis. Among the various environmental activities, the bulk of the work may be completed in Phases 1 or 2 , but there may be some additional site-specific data that may not be available until Phase 3.

\section{Laboratory Testing and Analysis:}

Laburatory testing and analysis can be ongoing with the exploration field surveys and the pre-sperational monitoring activities, and will include testing and/or analysis of rock, soil, sediment, water, air, flora, and fauna samples.

\section{Data Analysis:}

Data analys is can be ongoing during Phase 3, but should be performed in depth at the completion of the phase in order to complete site models and performance assessment studies. The data evaluation will also result in determination of the requirements for long-term monitoring activities.

\section{Reporting/Decision Points:}

The final results of the Phase 3 monitoring program will become the basis for input to the SAR, ER, and other programmatic documents. 


\section{APPENDIX D}

FEDERAL DATA SOURCES 


\section{APPENDIX D}

FEDERAL DATA SOURCES

Federal Aviation Administration 800 Independence Avenue SW Washington, DC 20591 (202) $\quad$ 226-8058

Federal Emergency Management Agency 500 C. Street SW Washington, DC 20472 (202) $646-4600$

National Advisory Council on Historic Preservation Room 809, 1100 Pennsylvania Avenue NW Washington, DC 20004 (202) 786-0503

National Bureau of Standards Gaithersburg, MD 20899 (301) 921-1000

National Oceanic and Atmospheric Administration (NOAA) Department of Commerce Washington, DC 20230 (202) 377-2985

National Park Service

Department of the Interior P.0. Box 37127 Washington, DC 20013-7127 (202) 343-7394

National Transportation Safety Board 800 Independence Ave. SW Washington, DC 20594 (202) $382-6600$

National Weather Service National Oceanic and Atmospheric Administration Department of Commerce Washington, DC 20230 (202) $377-2985$

Office of the Chief of Engineers Department of the Army Washington, DC 20314 (202) $693-6136$ 
U.S. Army Corps of Engineers

Headquarters, Department of the Army

Washington, DC 20314

(202) 272-0001

U.S. Bureau of the Census

Washington, DC 20233

(301) $763-4640$

U.S. Bureau of Economic Arialys is

Department of Commerce

Washington, DC 20230

(202) 523-0777

U.S. Bureau of Indian Affairs

Department of the Interior

Washington, DC 20240

(202) $343-7445$

U.S. Bureau of Land Management

Department of the Interior

Washington, DC 20240

(202) 343-9435

U.S. Bureau of Mines

Department of the Interior

2401 E Street NW

Washington, DC 20241

(202) 634-1004

U.S. Bureau of Reclamation

Office of Public Affairs

Department of the Interior

Washington, DC 20240

(202) 343-4662

U.S. Department of Agriculture Stabilization and Conservation Service 14 th Street and Independence Avenue SW

Washington, DC 20250

(202) 447-2971

U.S. Department of Commerce

14 th Street and Constitution Avenue SW

Washington, DC 20230

(202) $377-2000$

U.S. Department of Defense

The Pentagon

Washington, DC 20301

(202) $545-6700$ 
U.S. Department of Energy 1000 Independence Avenue SW Washington DC 20585

(202) $252-5000$

U.S. Department of Housing and Urban Development 451 Seventh Street SW, Room 1202

Washington, DC 20410

(202 655-4000

U.S. Department of Transportation 4000 Seventh Street SW

Washington, DC 20590

(202) $426-4000$

U.S. Environmental Protection Agency

401 M Street SW

Washington, DC 20410

(202) 382-2090

U.S. Fish and Wildlife Service Department of the Interior Washington, DC 20240

(202) 343-5634

U.S. Forest Service

Aerial photographs:

U.S. Department of Agriculture

2222. West 2300 Street

Salt Lake City, UT 84119

(801) 524-5856

U. S. Geological Survey

119 National Center

Reston, VA 22092

(703) $648-4460$

Aerial photographs:

National Cartographic Information Center

U.S.G.S

507 National Center

Reston, VA 22092

Books, other publications:

Text Products Sections

Eastern Distribution Branch

U.S.G.S

604 South Pickett Street

Alexandria, VA 22304-4658

(703) $756-6141$ 
LANDSAT photographs:

User Service Unit

EROS Data Center

Sioux Falls, SD 57198

(605) 594-6151

\section{Maps:}

U.S.G.S.

Box 25286, Federal Center

Denver, Co 80225

(303) 234-3832

U.S. Nuclear Regulatory Commission Washington, DC 20555

(301) $492-7715$

U.S. Soil Conservation Service Department of Agriculture P.0. Box 2890

Washington, DC 20013

(202) $447-4543$

U.S. Water Resources Council

1025 Vermont Avenue NW

Washingto 1, DC 20025

(202) 382-6104

\section{Other National Data Sources}
American Water Works Association
Government Affairs Office
1010 Vermont Avenue NW, Suite 810
Washington, DC 20005
(202) 628-8303

Earth Observation Satellite Company (EOSAT)

1901 North Moore Street

Arlington, VA 22209

National Water Well Association

88 East Broad Street

Columbus, $\mathrm{OH} 43215$

(614) 224-6241 

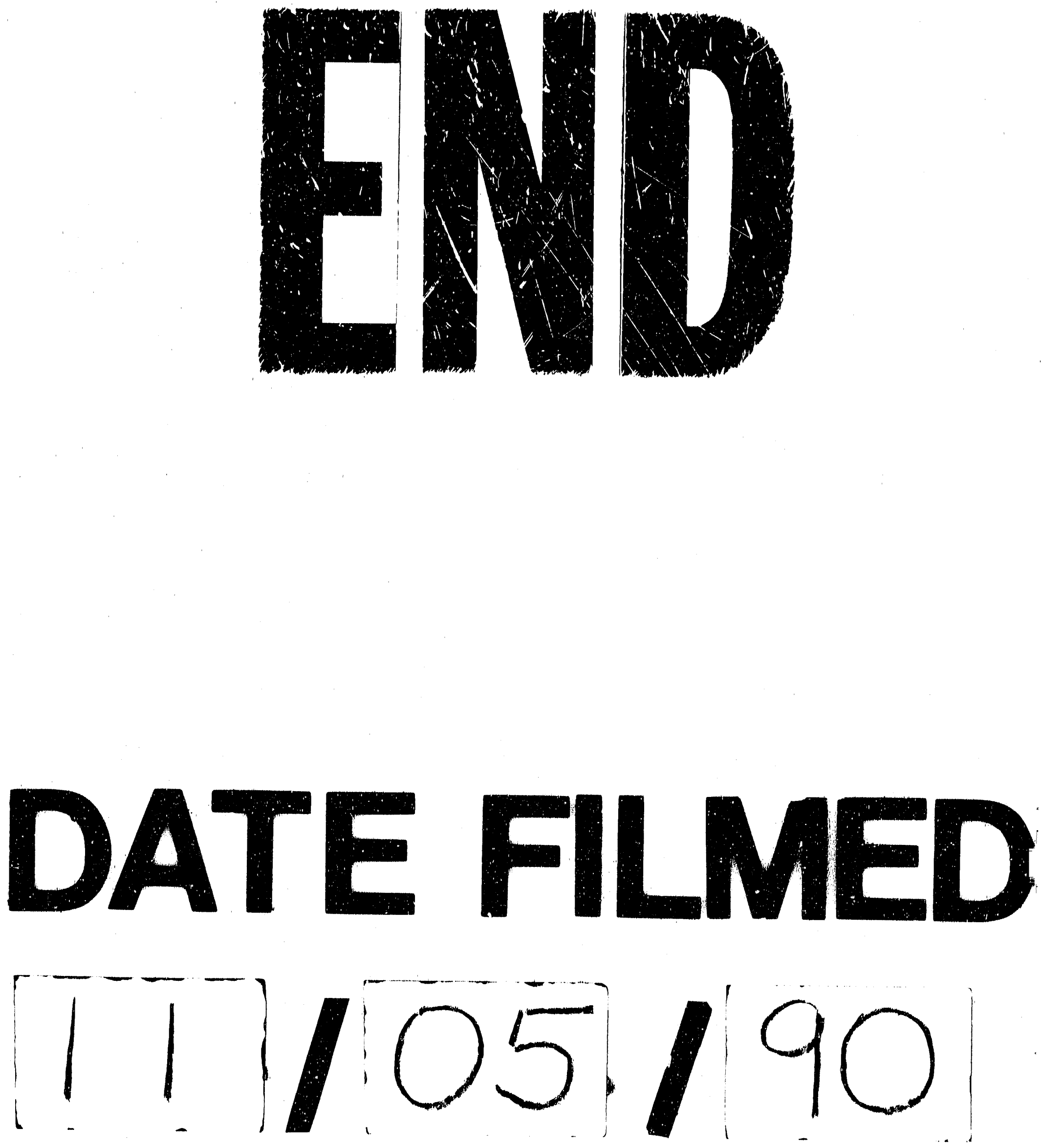
